
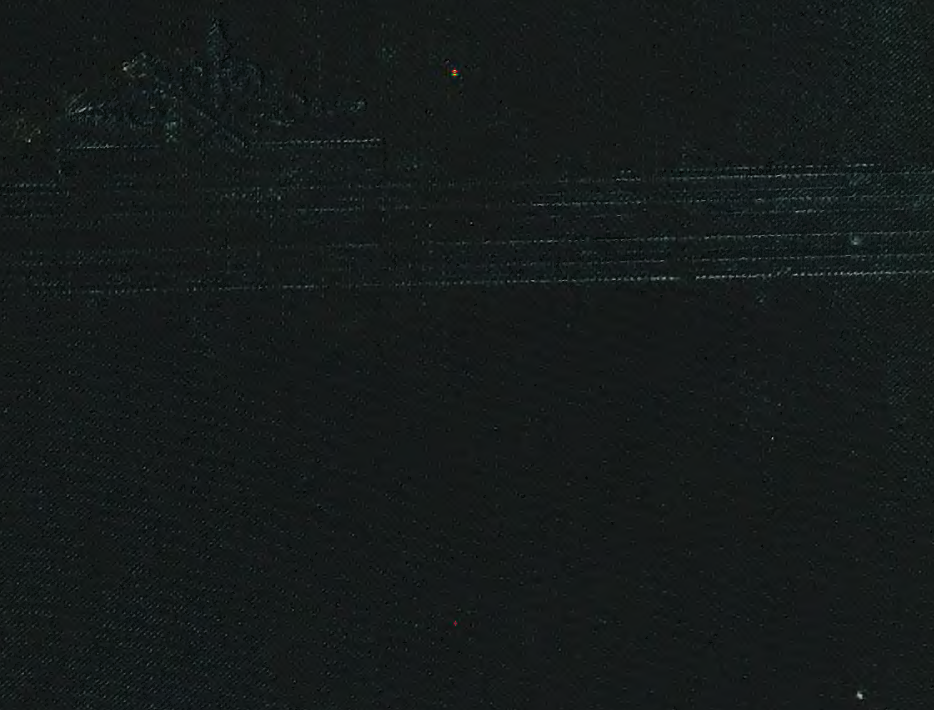


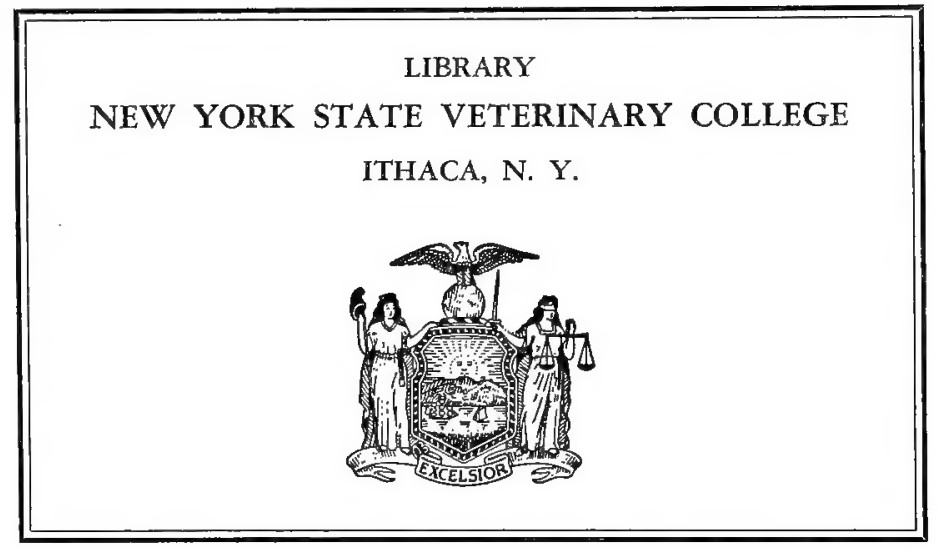




\section{SF 375 Cornell University Library}

The sheep,

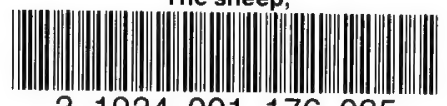

$31924001 \quad 176035$ 


\section{Cornell University Library}

The original of this book is in the Cornell University Library.

There are no known copyright restrictions in the United States on the use of the text. 





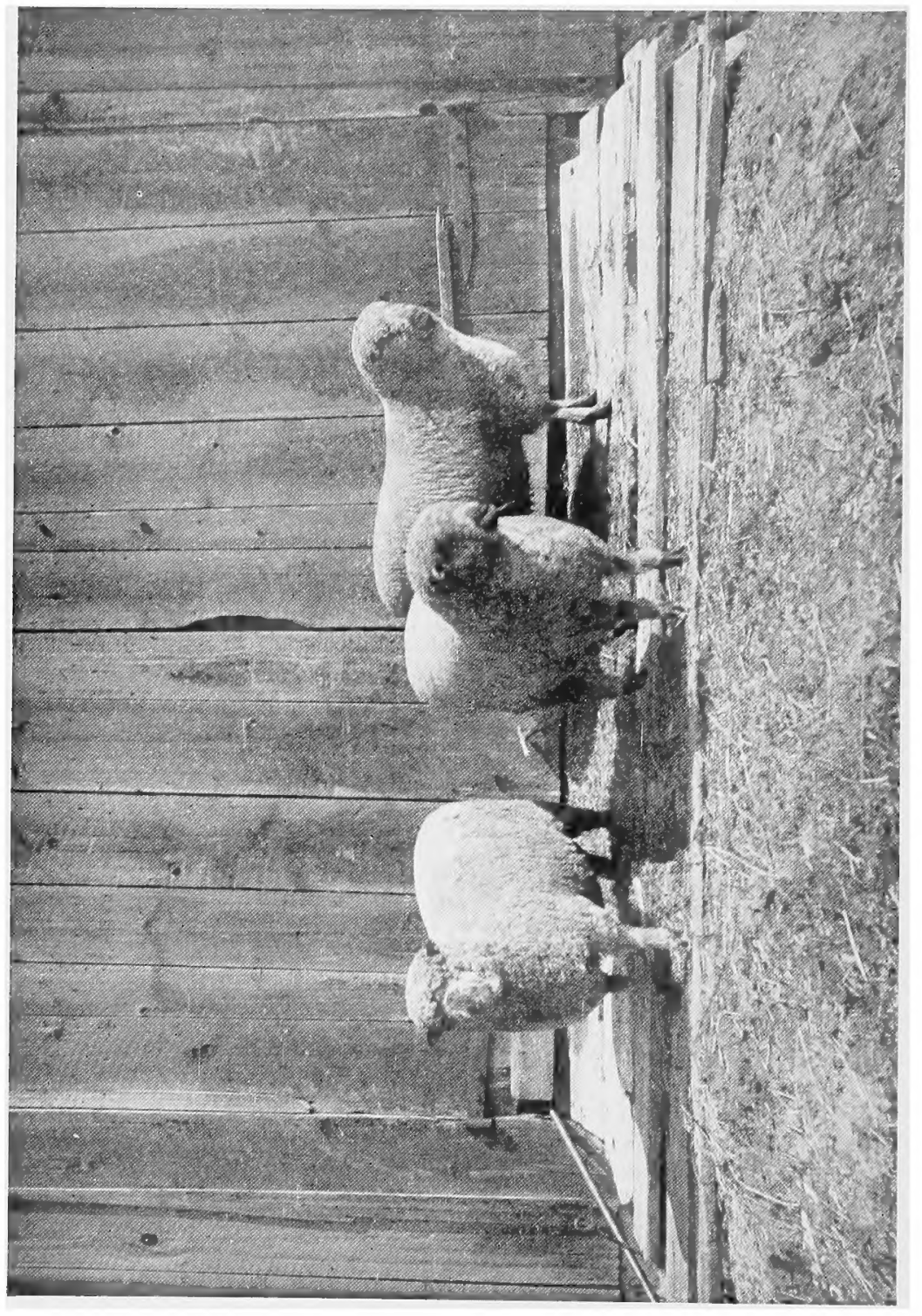

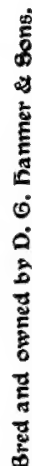

s

ธै

a.

$\div 5$

$\infty$

京

o

妾

है

흠

疍

ह

$\frac{9}{0}$

ह

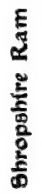




\section{THE SHEEP}

BY

\section{DR. WILLIAM A. RUSHWORTH,}

LATE SHEEP INSPECTOR, LARIMER Co., COLORADO, INSPECTOR BUREAU OF ANIMAL INDUSTRy, DEPARTMENT OF AGRICLUTURE, ETC., ETC.

A historical and statistical description of Sheep and their products. The fattening of Sheep. Their diseases, with prescriptions for scientific treatment. The respective breeds of Sheep and their fine points. Government inspection, etc., with other valuable information.

INCLUDING NUMEROUS ILLUSTRATIONS;

ALSO

AN APPENDIX CONTAINING

\section{SHEEP BREEDERS' DIRECTORY.}

THE BUFFALO REVIEW CO.,

Publishers, 1899. 
Entered according to Act of Congress, in the year 1899, by WM. A. RUSHWORTH,

In the office of the Librarian of Congress, at Washingrton. 


\section{Preface.}

The present work was undertaken by the author from the belief that at this time a short and concise treatise on the sheep in general, and more particularly the diseases of the sheep, would prove acceptable to the veterinary student, and perhaps assist the sheep-owner in combatting some of the conditions affecting his stock, especially if the same was written in plain language with the least possible use of technical terms. In the parts of the work dealing with the anatomical structure and digestive arrangement endeavor has been made to merely make mention of and explain those parts, and their uses, which are most often involved in the diseases of the system.

The author desires to express his sincere thanks to many of the secretaries of the different sheep societies of America, who furnished him data concerning their respective breeds, and to whom he is indebted for many valuable electrotypes of prizewinning animals.

In the part of the work relating to disease, the classification follows the parts involved. All specific diseases have been relegated to one chapter, and those due to parasitic invasion are also treated separately.

The laws and regulations governing the importation, exportation and inter-state shipments of live stock, sheep more especially, are given in full in a chapter devoted to that purpose; as with the exception of the Inspectors of the Department of Agriculture and those specially engaged in enforcing the laws, 
few persons are familiar with the process, or really appreciate the use and benefits which they derive from such legislation.

The author, in compiling this short treatise, has obtained much information from many noted authorities, credit to whom is given in the pages of this work; especially is he under great obligations to Dr. A. S. Alexander, Professor of Hygiene and Breeding at the Chicago Veterinary College, for much valuable information, and whose able assistance and ability used in editing this work has made it possible for it now to be presented to the general reader. 


\section{Chapters.}

CHAPTER I-Sheep. 'Their Origin and Early History.

CHAPTER II-The Prominent Breeds of Sheep.

\section{A- - Irong-Cuooled Breeds.}

1. The Leicester and Border Leicester.

2. The Cotswold.

3. The Iincoln.

4. The Rommey Marsh, or Kentish Long-wooled.

B-The Middle-clooled Breeds.

1. The Southdorn.

2. The Shropshires.

3. The Hampshire Down.

4. The Oxfordshire Down.

5. The Dorset Horned.

6. The Suffolk Down.

\section{C-Short-culooled Breeds.}

1. The Spanish Merino.

2. Rambouillet.

3. Delaine Merino.

\section{D-Mountain Breeds.}

1. The Cherint.

2. The Herdwick.

CHAPTER III-The Tool Industry.

CHAPTER IV-Feeding and Fattening.

CII.IPTER V-The Anatomical Structure. 
CHAPTER VI-The Digestive System.

CHAPTER VII-(a) Rumination, how performed.

(b) The Intestinal Organs.

(c) The Genito-Urinary System.

CHAPTER TIII-Mating and Selection.

CHAPTER IX-A Study of Disease in general.

CIIAPTER X-Diseases of the Brain and Nerrous System.

CHAPTER XI-Diseases of the Respiratory Organs.

CHAPTER XII-Diseases of the Digestive Organs.

CHAPTER XIII-Diseases of the Urinary System.

CIHAPTER XIV-Parasitic Diseases; due to Internal Parasites.

CHAPTER XV-Parasitic Diseases of the Skin.

CHAPTER XVI-Specific Diseases.

CHAPTER XVIT-Operative Surgery and Diseases of the Eye.

CHAPTER XVIII-Local Non-Contagious Diseases.

CHAPTER XIX-Parturition and Diseases incidental thereto. CHAPTER XX-Medical Treatment in General, agents used, their therapeutic actions and doses.

CHAPTER XXI-Inspection of Sheep-Federal and State. 


\section{Synopsis of Chapters.}

CHAPTER I-SHEEP. Their origin and early history. The White Sheep of Asia. Rocky Mountain Sheep. The Mrusmon of Africa. First domestication very remote and uncertain. Sheep of the Bible. Sheep the forerunners of and aid to the civilization of man. Adaption to climatic conditions. Sheep husbandry a most honorable calling among the ancients. The Sheep of Greece, Italy and Spain. Spanish Tool. First wearers of wool. Origin of English breeds of Sheep, very early. Their advent in America. The Llama. Importations to Lnited States. Growing demand. Now is the time to embark in Sheep raising.

CHAPTER II-THE PROMINENT BREEDS OF SHEEP. Long-wooled breeds. The Leicester and Border Leicester. The Cotstrold. The Lincoln. The Rommey Marsh, or Kentish Long-wooled. The middle-wooled breeds. The Southdown. The Shropshires. The Hampshire Down. The Oxfordshire Down. The Dorset Horned. The Suffolk Down. Shortwooled breeds. The Spanish Merino. Rambouillet. Delaine Merino. Mlountain breeds. The Cheviot. The Herdwick.

CHAPTER III-THE TOOL INDUSTRI. Cloth manufacture dates back to earliest Bible history. Romans first established factories in England. pinning universal under the Saxon Monarchy. History of ancient woolen factories. The Spinster. Wars of the Crusades. Wool and national wealth takes the place of money. The fine goods of Holland. Spain 
taxes the woolen industry out of the country, and it goes to England, and among her greatest industries. Nature of wool filaments. Secreting glands, the yolk, felting of wool. Discovery of the character of wool filaments. Processes of manufacture. Cloth. Worsteds. Carpet wools. Points to consider in selection of wool. Strength, fineness, curl, thickness, closure, bad qualities of. Constitutional and hereditary defects in sheep. Stripy wool, toppiness, felty wool, cloudy wool, broad-topped, break in wool. Exportation statistics and tables.

CHAPTER IV-FOOD OF THE SHEEP. Feeding large proportions of the business. Export trade. Crossing of mutton breeds. Methods of feeding. Desirability of large and small sheep for mutton. Testern customs. Colorado and Tew Mexico. Alfalfa. Corn. Oats. Changing feed. Rock salt. Hot and cold weather. Regularity in feeding. Cost of. Shipments east. Feeding in general-amount. How to keep sheep healthy. How to produce fat. Taste of tissues. Other animals. Canivora versus herbivora, carbon, etc. Proportions of flesh and blood. Analysis of mutton fat. Failure of some foods in producing. Inporfance of protein, casein, albumen. Tables showing quantities for proper feeding. The Wolff standard. Correct rations. Clean troughs. Proportions of food to fat produced. Oil meal, corn, turnips, ete. Oxen and sheep as sheep mature. Offal diminished. Intestines of sheep. Feeding for home and foreign markets. 'i'he best feeders to buy.

CHAPTER Y-ATATOMICAL STRUCTURE. Technical terms and their aroidance. Resemblance between the sheep and of. Cells. Tissues. Solids. Fluids. Epithelial cells. Musculdr tissue. Nerve tissue. Bone tissues. Bones, how jointed. Thnlons. The brain and spinal cord. Glandular structure. Stoma ch. Heart. Teins. Circulation of the blood. Lacteals. Chyle Intestines. Description of the bony structure. 
Physiological conditions. Inorganic salts. Long, hollow and flat bones. Spine. Ossification. The skull. The cranial cavity. Horned sheep. The parietal bones. Frontal, cerebrum, occipital and temporal bones.

CHAPTER VI-THE DIGESTIVE SYSTEM. How sheep feed. Conformation of the mouth, lips, "teeth, jaws, fibrous pad, tooth growth and development, incisors, molar teeth, gums, cheeks, salivary glands and ducts. Great quantity of saliva produced. Swallowing food. Rumination. Complication of the digestive organs. Their nervous energy. The eosophagus. Procession of the food. The first, second, third and fourth stomachs. How the weight of food is supported in the abdominal cavity. Compartments. Iloneycomb formation. Mucus secretion and liquids of the stomach. The object of papillae, in third stomach. Why some sheep scour habitually. Only one opening to the omasum. The true stomach, where the gastric juice is secreted. Nature of gastric juice; its specific gravity. Shape of the fourth stomach; the difference between the mucous lining of it and other stomachs. The pylorus, how constructed.

CHAPTER VII--(a) RUMINATION, how performed. Food deposited in rumen.

When rumination commences, sheep generally lies down. Change of position of food in rumen. Liquid portion of food passes to reticulum. How food is returned from the stomach to the mouth. The oesophagus has a double duty to perform. Dry condition of third stomach. The stomach proper. Stomach employed by lambs when existing solely off the ewe's milk. Derelopment of first, second and third stomachs. Food converted into chyme.

(b) THE INTESTINAL ORGANS. The pyloric opening permits passage of chyme from abomasum to intestines. 
How return of chyme from intestines to abomasum is prevented. Classification of intestines, the large and small; difference in appearance. Small intestines arbitrarily divided into three subdivisions. Glands in the duodenum. Entry of ducts from pancreas and liver. Formation of small intestines. Divisions of large intestines. Shape of caecum, valve at juncture of ileum and caecum. Lise of caecum; how important. Tarious dimensions of the colon. The facces changed into pellets. Manifold functions of the liver; importance of bile secretion. Sugar manufactured in liver gains access to the circulation. External appearance of the liver; its intimate structure. Examination of a lobule. The blood from which the bile is elaborated. Ruminants have a reservoir for the reception of the bile; anatomical difference as compared with the horse. Functions of the bile. Definition of secretion and excretion. Pancreatic juice; its activity. Specific action of pancreatic juice on fatty matter.

(c) THE GENITO-URINARY STSTEM. Trine separated from blood. Appearance of kidney. Direction of ureter; mode of effecting entrance to bladder. Important part in the animal economy played by the kidneys. Extent of mrcous membrane lining renal basin. Ninute tubes in structure of kidners; their uses. Properties of the urine. Separation of urea. What produces uraemic poisoning. Extent of urethra in the ram.

THE GENERATIVE ORGANS. Those of the male. The semen, its uses, and where elaborated. Disposition of peritoneum in scrotal sac. What constitutes congenital hernia. How the semen is expelled from the vesiculae seminales; where deposited. Wronderful procreative power of rams. How vermiform appendage is frequently injured.

THE GENERATIVE ORGANS OF THE FEMALE; where situated. Their uses. Where the germ orum is located. 
Situation of womb. Termination of uterus; its projection into vaginal cavity. Vaginal cavity lined with mucous membrane. The orum is vivified. Period of time required before birth of lamb takes place.

CHAPTER TIII-IIATING AND SELECTION. Qualities to be considered. The influence of the male. Nature's laws tend to fix external conformation by the sire. Points sought for by breeders. Signs of good qualities. What constitutes a good quality. Points sought after in breeding. Distribution of flesh. Judicious cross-breeding. Long-wooled breeds improved by Leicester cross. Cross-breeding experimental. Inand-in breeding. Objectionable in application to the human family. Advantages of in-breeding as applied to animals. Breeding with a view to improrement. Best qualities become concentrated in one family. Inheritance of the good qualitics of in-bred ancestors. Stock to be preserved pure. Sclection. Weeding undesirable ewes from the flock. Drafted ewes unfit to perpetuate their kind. Selection of rams. Breeding for wool. Breeding for mutton. Breeding for both wool and mutton. Faulty conformation of ram, evidence of weakness in chain of ancestry. Particular class desired by the breeder. Making drafts from the flock. Drafts tend to strengthen appearance and value of flock. Undesirable ewes. How bad points may be orercome in breeding. Condition of ewes before being served by the ram. The best shape to conceive. Lambing season materially shortened.

CHAPTER IX-A STUDY OF DISEASE IN GENERAL. Definition of health. What is disease? Symptoms of disease. Dry condition of the fleece. Unnatural positions. Diseases of sheep numerous and frequently fatal. Excessive derelopment of digestive organs of the sheep. Sheep unfitted for laborious exercise. Its energy and vital- 
ity tend to weaken as sheep become better bred. Small proportion of blood in the sheep as compared to other animals. Combustion depends on exertion. Tissue waste. Large amount of vascularity unneeded in the sheep. Specific diseases few as compared to some other classes of animals. Sheep slaughtered before reaching maturity. Examination of sheep. Proper methods of control. Not to be held by the wool. Huw to catch ewes. Lse of the erook. How to lift the sheep. Tarious operations. Trifling derangements liable to become serious. Diseases affecting digestive organs more numerous than any others. Ilerding in flocks facilitates spread of infectious diseases. Enzootic diseases. Blceding; how performed. Effects of purgative drenches; how assisted. Bleeding from the jugular vein. Amount of blood to be drawn. IIow to bleed from the chcek vain. The saphena vein, its location and how operated un. Ligature. Difficulty in bleeding fat sheep. Definition of the pulse. Number of pulse beats per minute. Where to take the pulse in the sheep. Temperature not a reliable sign to go by in the sheep. Effects of shearing on the temperature. The gait of the animal to be taken into consideration in diagnosing diseases. Other signs. Incorrect diet and lack of hygienic surroundings fertile canses of disease. Prevention of disease more profitable than medication.

\section{CIIAPTER X-DISEASES OF THE BRAIN AND} YERVOUS SYSTEM. Nervous system of lower animals not so sensitive as that of the human. Divisions of the nervous system, phenomena peculiar to themselves. Then the brain is inrolved in the disease. In cases of transterse paralysis. Disease of the spinal cord. Localized parts only paralized. Injury to corticle portion of the brain. Injuries to deeper portions; what they effect. Mlay be great derangement of function without perceptible alteration of structure. Frenzy, encephalitis, rr 
cerebritis its causes. Predisposing influences. Affects lambs more frequently than grown sheep. The symptoms of cerebritis, violent actions on part of affected subjects. More marked in lambs than old sheep. Treatment for Cerebritis. The postmortem appearances. Apoplexy, frequently caused from plethora; more cases among sheep than cattle; why? Symip. toms. Affected animals generally die before aid can be extended them. This condition is easier to prevent than to treat. Epilepsy, its causes, reflex irritation due to parasites; its symptoms and treatment. Hydrocephalus, the nature of. Rare disease among adult sheep. Treatment always unsatisfactory. Louping-ill, Tremblings, Mad-staggers, etc. A remarkable disease, its pathology and supposed causes. Great loss caused from louping-ill. Srmptoms and treatment. Simple Paralysis, Palsy, occurs in ewes after difficult parturition. Occurs in other sheep also. Its causes. Srmptoms and treatment. Paralysis in newlyborn lambs. Simple treatment therefor.

CHAPTER XI-DISEASES OF THE RESPIRATORY ORGANS. Less frequent and numerous than those of digestive system. Pleurisy a common affection of sheep. Sheep early shorn liable to pleurisy. Trasal catarrh frequently affects sheep. Exists in three forms. Symptoms of nasal catarrh. Its treatment. Treakness subsequent to attacks of catarrh hard to overcome. Its prevention. Sore-throat, also called laryngitis. Symptoms. Treatment. Operation of tracheotomy. Bronchitis; adult sheep suffer sererely from this affection. The atmosphere as a cause of bronchitis. Symptoms of bronchitis. Methods of detection. Treatment, hygienic surroundings a necessity. Inflammation of the lungs; of common occurrence. Symptoms and treatment. Pleurisy due often to sudden changes in temperature. It frequently follows dipping. Symptoms and treatment of pleurisy. 


\section{CH.APTER XII-DISEASES OF THE DIGESTIYE} SISTEM. Generally arise from errors of diet. Concentrated foods dangerous. Diseases of the digestive system of sheep rery numerous. A phtha, sore-mouth, frequently fatal. Affects sucking lambs. Ewes become inoculated from their young. Cause of disease unknown. Symptoms and treatment. Obstruction of the gullet may occur in the pharynx. Srmptoms dependant also on derangement of pneumogastric and sympathetic nerres. Treatment, entirely oprative. Ilethods. The trocar, and its uses. Bloat, also called Horen or Blasting, not a disease; due to fermentation of contents of rumen. Srmptoms and treatment. Loss of $\mathrm{Cud}$, not a disease, but a condition. Impaction of the $\mathrm{Om}$ asum, often due to pasture containing astringent herbs. Impaction of the Rumen, a mechanical distention of the organ. Wheat produces this condition. Fatal terminations frequent. Symptoms, dintingulshed from bloat by examining left flank. Treatment, both medicinal and operative. Intestinal obstructions, Trool-balls, Stony Concretions, Calculi, Rupture, Hernia, Strangulation, Stricture, Tolvulus, Intus-susception. Impaction of the fourth stomach of lambs, due to milk curdling. Colic, a rare affection among sheep. Inflammation of the Bowels. Not common in sheep. Diarrhoea results ustally from mismanagement. May be a symptom of some other conclition. May be due to any of many different causes. Diarrhoea of Lambs, White Skit, virtually due to constipation. The Green Skit, due to exposure and dietetic errors. Treatment for diarrhoea in adult sheep, also for white and green skit. Dysentery, frequently fatal; of a trphoid character. Pinding. Flies and maggots attack the hind quarters. Remove wool and keep parts clean. Make affected animals comfortable, gire good hygienic surroundings. Constipation, rectal injections beneficial. Imperforate Anus, a surgical operation necessary. Hemorrhoids, Piles, pile ointments. Peritonitis, a rare disease in sheep, may result in old 
sheep from debility. Diseases of the Liver, size of liver as compared with that of other animals. Only two, non-parasitic in origin, considered in this chapter. Hepatitis, Jaundice Icterus. CHAPTER XIII-DISEASES OF TIIE LRINARY SYSTEM. Surplus of nitrogen in the system. Urea. Kidneys. Ureters. Bladder. Lrethra. Acid urine. Alkaline urine. Litmus paper. Crine tests. Sabulous deposits. Nephritis, never reported as an original lesion. Renal Calculi, generally the causes of urinary diseases in sheep. Urethral Calculus, liable to cause rupture of the bladder. Treatment operative; liable in cases of rams to injure their procreative qualities.

\section{CHAPTER XIV-PARASITIC DISEASES DUE TO} INTERNAL PARASITES. Parasites, living animal orgunisms. Entozoa. Ectozoa. Parasitic disease of the brain. Sturdy. Gid. Coenurus cerebralis. Hydatid cysts. Disease resembling gid. Operation for gid not always successful. Dogs and their relation to gid. Parasitic diarrhoea, a serious complaint. Taenia expansa. Observers quoted. Description of parasite causing the discase. Parasitic gastric eatarrh. Occurs as an epizootic. Nodular disease; first recognized in Washington, D. C., by Dr. D. E. Salmon. Parasitic nasal catarrh, due to oestrus ovis. Surgical treatment for removal of larvae. Parasitic bronchitis. Hoose. Husk. Snots. A destructire affection. Strongylus filaria, strongylus refescens. Nature of the disease. Methods of introduction. How they arrive in the bronchial tubes. Treatment, both preventive and curative. The Rot has caused more loss to flock-owners than all other diseases. Virulent in Egypt. Distoma hepaticum. Wonderful life cycle of parasite. Duration of the disease. Post-mortem appearances. Description of fluke. Preventive treatment.

CHAPTER XV-PARASITIC DISEASES OF THE SKIN. Scabies causes great losses to the wool-growers. Life 
history of seab parasites. Gerlach's table of scab mite multiplication. The Common Scab. The Head Scab. Examination of sheep for scab. Methods of infection. New Mexican lambs, their liability to scabies. Dipping. Hand-dressing for scab. Dipping plant. Lime and sulphur dip. Sheep Tick. Melophagus Ovinus. Lice. Peculiar appearance of the wool of sheep affected with lice. The Fly. Lucellia Marcellaria. Cause of maggot.

CHAPTER XTI-SPECIFIC DISEASES. Germs. Classification of germs. Methods of introduction into animal econony. Germs the cause of all specific diseases. Period of incubation. Braxy. Anthrax Ferer. Treatment preventive. Tool-sorters' disease. Black-leg. Quarter-ill. Quarantine of infected pastures. Foot-and-Mouth Disease. Infectious Aphtha. Eczemả Epizootica. Tetanus-lock-jaw. As seen following parturition. Use of tetanus anti-toxin. Erysipelas. Actinomycosis-due to a fungus-occurs in the human, cattle, swine, and rarely in the dog. Sheep Pox. Variola Ovina. Tuberculosis very rare in sheep. Rabies. Hydrophobia. Postmortem appearances. Symptoms of rabies in the dog. Blood Diseases. Red Water. Sanguineous Ascites. Anaemia. Rheumatism. Pining. Tinquish.

\section{CHAPTER XVII-OPERATIVE SURGERY AND} DISEASES OF THE EYE. Castration. Methods of operation. Covered operation for scrotal hernia. Trapping. Tying or lashing. Bistournage. Docking. Spaying. Fractures. Simple. Compound. Comminuted. Wounds, incised, punctured, lacerated, or torn, contused or bruised. Bruises. Strains. Sprains. Abscess. What constitutes a tumor. Overgrowths of tissue. Homologous and heterologous tumors. Methods of growth. Tascularity. Malignant and benign tumors. Cankes of tumor formation. Cohnheim's theory. Parasitic 
origin. Cystic tumor's. Treatment of tumors. Goitre. Struma. Real, fibrous, varicose, cystic bronchocele. Treatment of goitre. Diseases of the Ere. Simple Ophthalmia. Simple. Specific Amaurosis. Gutta-serena. Glass-Eye. Fungus hematodes. Opacity of the Cornea. Wounds of the Eye.

\section{CHAPTER XYIII-LOCAL NON-CONTAGIOUS} DISEASES. Eczema, different forms of. Erythema. Cellulitis Prurigo. Impetigo larralis. Foot-Rot. Paronychia Interdigitalis. Wet pastures conducive to this condition. Differences between foot-rot and foot-and-mouth disease. Foot baths. Fungoid growths. Inflammation of Inter-Digital Canal.

CHAPTER XIX-PARTIRITION AND DISEASES INCIDENTAL THERETO. Normal Parturition. Period of Gestation. Womb contractions. Prolonged parturition, causes. Rigidity of os uteri. Obliteration of the os. Torsion of the uterus. Mal-presentations. Monstrosities. Conditions liable to occur incidental to Parturition. Retention of Foetal Membranes. Inversion of the Womb. Prolapsus Uteri. Inversion of the Vagina. Inflammation of the Vagina. Vaginitis Inflammation of the Womb. Metritis. Malignant Parturient Fever. Garget. Mammitis or Mastitis. Cracked Teats. Founder. Parturient Laminitis. Asphixia. Bleeding from the Umbilicus. Umbilical Hemorrhage. Inflammation of the Umbilical Cord. Navel-Ill. Retention of the Meconium. Imperforate Anus. Cyanosis. Abortion.

CHAPTER XX-MEDICAL TREATIENT IN GENERAL, AGENTS U'SED, THEIR THERAPEUTIC ACTIONS AND DOSES. Medicinal treatment of sheep. Singly and in flocks. Drugs haring a nauseous taste. Yriolent poisons. Vis medicatrix naturae. Medicinal agents. Definition. Therapeutic action. Astringents. Alteratives. Anti-spasmodics. 
Anaesthetics. Anthelmintics. Ant-Acids. Anodynes. Antiseptics. Cathartics. Carminatives. Cholagogues Diuretics. Diaphoretics. Hypnotics. Termifuges. Vermicides. Tonics. Doses for sheep and lamb. Fluid measure. Weight measure. Symbols. Drug tables.

\section{CHAPTER XXI-INSPECTION OF SHEEP, FED-} ERAL AND STATE. Commencement of live-stock inspection in the L'nited States dates back about twenty years. Method of inspection. Condemnation of carcasses unfit for human consumption. Sheep imported from other countries. Canada and South American republics excepted. Quarantine regulatione. Special regulations concerning Canadian imports of live stock. Official Canadian reterinarian's certificate required. Sheep for immediate slaughter do not require certificate. Duration of quarantine exacted on importations of live-stock from Europe. Sheep scab guarded against. Regulations concerning the exportation of sheep abroad, notably to England. Inter-state shipments; regulations concerning the same. Morement of Western range sheep to Eastern feeding grounds; their liability to carry the infection of scab. State Inspection. Western and Middle West States adopt legislation for their own protection. Chas. Gresswell, M. R. C. V. S., opinions on inspection of live-stock in general. Regulations of the State of Colorado concerning the transportation of sheep into or across that State. Other States adopting similar legislation. 


\section{CHAPTER I.}

\section{Sheep.}

Their Origin and Historr. It is berond question impossible to know, or eren surmise, the actual origin of the domestic sheep. It appears rery doubtful whether there exists any connection between them and the Argali, or white sheep of 1:ia, and the Musmon of South Europe and Africa or the Rocky Mountain sheep of North America; eren should this connection be believed in, they must have been domesticated in the very remote past, their habits materially changing, before any records appear in the most ancient histories we can command. We find on consulting the Bible that sheep are spoken of in its earlier passages, and that Abel chose sheep-herding as bis vocation, while Cain tilled the soil, and that the jealousy resulting from Abel's offering of a firstling of his flock for sacrifice, resulted in the first murder of which there is any record. Before agriculture was practiced to any great extent, when the population of the earth was comparatively small, sheep husbandry was universally followed, their natural disposition and constitution renclering them capable of adaptation to different climates and conditions, furnishing food and clothing to their possessors, affording a profitable investment to the shepherd, the most ancient and honorable calling of man. Te find sheep preceeding cirilization of the different parts of the world. Ancient Greece for many years was the sole possessor of this valuable animal in Europe; its introduction to Italy follotring the foundation of the Roman Empire; the Roman Conque'sts extended their use to the conquered territories, Spain especially affording them an abundance of pasture, and to Spain the honor 
belongs of developing and improving their condition, so that even in the time of the Romans, Spanish wool was celebrated for its quality, which pre-eminence it retained up to the commencement of the present century. In ancient times sheep skirs: were used for clothing, but as civilization progressed, we find manufactured cloths taking the place of skins. This necessitated the improrement of the fleece by careful breeding and selection. In Incient Rome fine wools were made a study, the fineness of the fleece was cultivated to an extraordinary extent; the sheep were clothed to insure a delicacy of the wool filaments; the fleece being combed to prevent matting of the wool, the skin being oiled and moistened with wine. Pliny, a Roman writer, states that the best wool was that of Apulia on the Adriatic Sea; the excessive care bestowed on these sheep predisposed to constitutionally weaken them, rendering them liable to disease; and with the fall of the Roman Empire these choice breeds were broken up and lost, and while a few fine-wooled sheep can still be found in Italy, they are badly formed and very inferior to their ancient progenitors.

The history of the sheep in England dates back to the earliest records. We find that the Romans considered the British wrool as an object of Inxury in the Capitol of the Empire. During the Roman occupation of Britain, a wool factory was established at Winchester, the fabrics of which became a subject of favorable comment to the historians of Rome, and while the origin of the different English breeds of sheep is altogether shrouded in mystery, we know that certain breeds have occupied stated localities as far back as the earliest records, and from these localities we are enabled to trace the different classes of English sheep, ascertaining their sources of improvement, and the evolution of the recognized mutton breeds of the present day.

The origin of sheep in North America dates back to the 
conquest of Mexico by the Spaniards in the fourteenth century. Previous to their advent in the New World, the nearest approach to the species was the llama, found in South America, when Pizarro conquered Peru, and so far as is known even this animal was not found north of Central America. After Mexico. was parcelled out among the conquerors and colonization was started, the necessity of stocking the grants caused the exportation of large numbers of live stock from Spain to North America, and as the western broncho can be traced as a lineal descendant of the fiery barb, ridden by the Spanish cavaliers, so can the Mexican sheep be traced back to the silky-fleeced Merino of Castille. The care of the converts under the supervision of the priests, and the pastoral duties of the different missions which included raising of live stock and agricultural pursuits in general, as much as the welfare of the souls of the converted Indians, was responsible for the rapid increase of the flocks and herds and their extension to other parts of the continent, notably New Mexico and Califormia. Thile Spain is to be credited with being the source from which the Southern and Western sheep in this country originated, we find also that in the rear 1600 sheep were imported by the early settlers of the New England States from England and Holland, and that prior to the Wrar of Independence many importations were made, the housewives in those days being expcrt with the spinning wheel. Imported cloth fetching a high price, sheep were bred for the wool they produced, the clip being spun and converted into cloth at home for the use of the members of the family. From the commencement of this century up to the present time the importations have been many and good, the best breeds of all foreign countries having been freely drawn from, the imports embracing all the recognized breeds from the Spanish Merino even to the Persian sheep, and increasing in number until at the present time the annual importations amount to many thou- 
sands for breeding purposes alone. Thile the importations for breeding purposes have been large, the number of sheep in the United States has decreased rather than increased in the last twenty years, which at first glance appears remarkable when the increasing consumption of mutton as a food is taken into consideration, and it can only be accounted for by the decrease in the price of wool, which made the handling of large herds of wool sheep unprofitable to the flock owner.

We find that in 1879 there were all told in the Lnited States 38,123,000 sheep, and that in 1884 the top of the ladder was reached, there being at that time $50,626,626$ in the country. From then the decline in numbers gradually progressed till in 1895 there were all told only 42,294,064 head, and at the present time, 1899, the estimates only call for $39,114,453$, a most remarkable decrease since 1884; and when the increase in population and increasing popularity of mutton as an article of diet for the home market, as well as the growing demand from abroad is taken into account, that there should be a decrease in numbers since 1879 of nearly half a million head, and from 1854 to 1898 of a decrease of $11,512,173$ head, makes the fact become all the more surprising. It would certainly appear reasonable that now is the time to embark in sheep husbandry, the demand for feeders increasing every year. Every year new feeding grounds are springing up in the Trest till at the present time the breeding and feeding of sheep has risen to be the most profitable branch of stock-raising in which the farmer can .engage. 


\section{CHAPTER II.}

\section{Che Prominent Breeds of Sheep.}

In describing the different breeds of sheep we shall classify them according to their fleece, as long, middle or short-wooled. The long-wooled breeds are white-faced, somewhat coarse in flosh and not so active as the shorter-wooled species. The longwooled breeds of sheep are English by origin. We find belonging to this class the Lincoln, Kent, Cotswold, Leicester; also the Devon long-wooled breeds. The first place on the list undoubtedly belongs to the Leicester, it being the first breed improved by skilful selection and crossing.

\section{Leicesters and Border Leicesters.}

THE LEICESTER SHEEP appears to have been a native of Leicestershire and adjoining counties. For a considerable period before it came under the genius of Bakewell, to whom belongs the honor of being the pioneer in the field of improrement of all kinds of live stock. This man, who was an English farner living at Dishley, Loughborough, Leicestershire. He recognized the fact that the properties of parents may be transmitted to their offipring until the type will finally become fixed. He was also endowed with the gift of discernment, in being able to tell by an animal's exterior and quality whether or not it possessed the properties he desired to perpetuate. About 1755 Bakewell commenced on the improvement of the Leicester sheep, the result being the formation of an animal somewhat smaller than the original type, but thicker and deeper, more symetrical and better adapted for fattening, combined with an earlier maturity. The old Leicester breed was a coarse, large sheep, with an abundant 


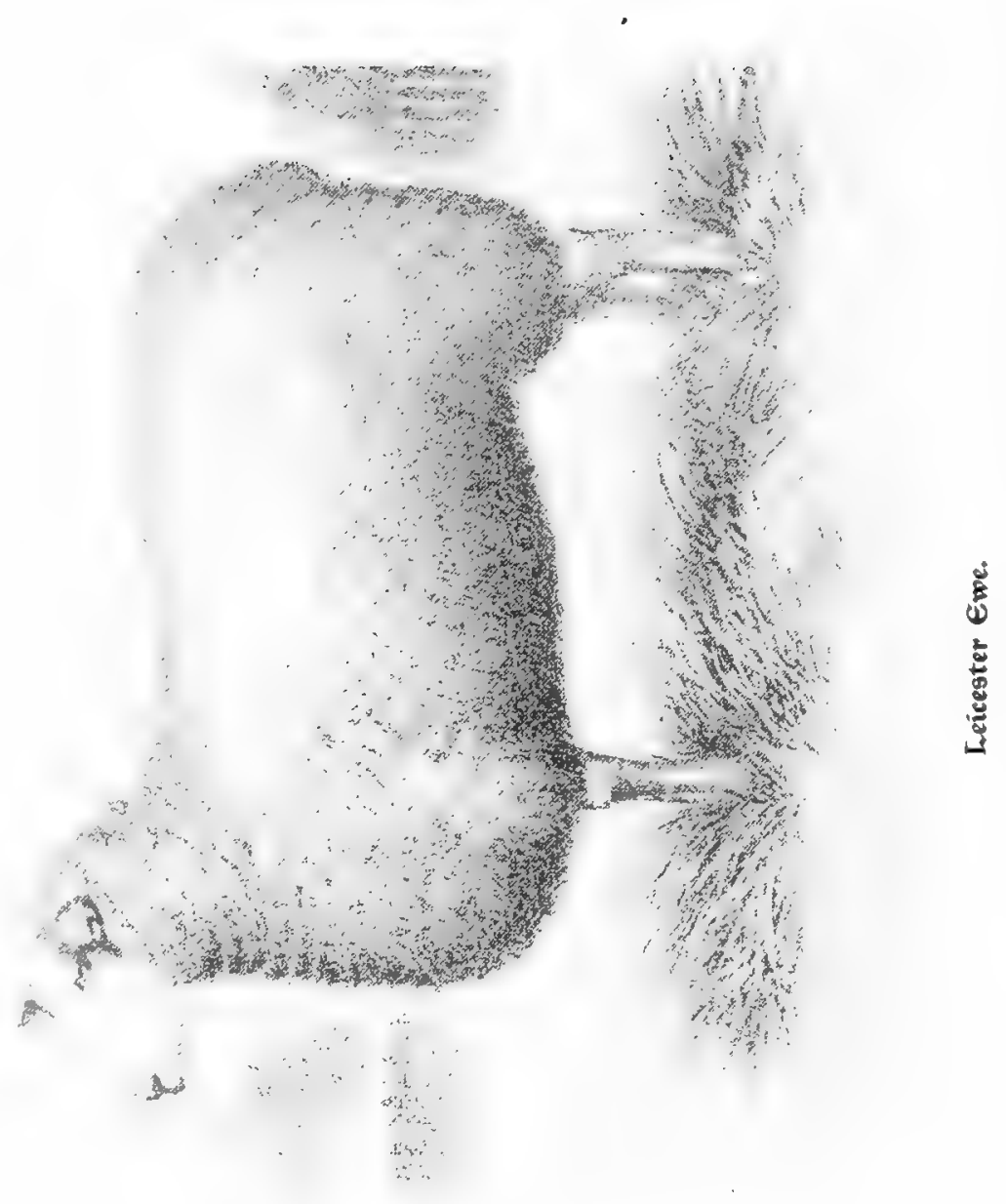


fleece, but in the selection of smaller and more compact animals, necessary for the improvement in carcass, unfortunately the fleece diminished in weight proportionately to the decrease in size of carcass. The Leicester sheep as improved by Bakewell may be described as a white-faced, hornless sheep, covered with a fleece about seven inches in length, liaving a lashy wool, terminated with a short twisted curl. The points of the Lcicester are: Head, hornless, long, small, tapering towards the muzzle; lips and nostrils black; nose slightly narrow and Roman, giving the face a wedge-shaped appearance; face is covered with thin, white hairs; forehead covered with wool; ears thin, rather long and mobile and directed backward; a black speck on face, and ears not being uncommon; eye large and prominent; neck shurt, level with the back and broad at its base where it leaves the chest, gradually tapering towards the head, being particularly fine at the articulation of the head and neck, the neck appearing to project straight from the chest, so that there is almost one continued liorizontal line from the rump to the poll. The breast is deep, broad and full; shoulders upright and wide across the tops, giving a great thickness through the heart; well filled up behind the shoulders, making the girth large; ribs are well sprung; loins wide; hips level; quarters long and straight; barrel round; ribbed well home; no irregularity on the line of the back or the belly. The bone is fine, the legs being small, standing wide apart; no looseness of the skin about them, and are comparatively free of wool; the fleece is fine and curly and free from black hairs; firm flesh; springy pelt and pink skin. In general form, the carcass is rectangular, with legs set well on, hocks straight, pasterns good and neat feet. All these various points were only obtained by paying long, continued attention to the individual pecularities, selecting the best to breed from, always bearing in mind that it is far easier to perpetuate a defect than to fix an improvement.

The LEICESTER fattens best when about a year or a year 
and a half old; the carcass then weighing about 80 to 85 pounds. They are an excellent sheep for crossing purposes, reproducing their wonderful carcasses even when crossed on very inferior stock.

The pure-bred Leicester is liable to lay on fat very thickly, which is to their disadrantage, the demand for fat mutton having ceased. There are few breeds, however, which have not been improved w an admixture of the Leicester blood. Notably have the Southdowns, Cotswolds, Lincolns and Hampshire T!owns. It may be as well to mention here the breed known as Borler Leicester. This is now recognized as an independent brcel, rivalling in its valne and distribution the original Bakewell Leicester, from which it is descended. The breed originated about 1\$63, when a Mr. George Cully visited Dishley, forming an intimate friendship with Mr. Bakewell, he obtained Leicester rams, and by crossing them on a long-wooled breed, called the Teeswaters, in time established a flock of Leicesters. The Cully stock is looked upon as the origin of the Border Leicester. Rams from their flock were hired by breeders both English and Scotch, who often paid as high as $\$ 500$ for the use of a ram for one season.

The difference between the Leicester and Border Leicester is chiefly observed in the head, that of the Border Leicester being white, nose slightly Roman, full muzzle, wide nostrils, and erect ears. The head is clean and free from wool, while the English Leicester has a tuft of wool on its head, also having wool in the shanks. The head of the English Leicester instead of being clear whitc, has a bluisl white tinge; the carcass also is not so long or large as the Border Leicester.

Fault has bcen found with the Leicester ewe on account of its predisposition to get too fat, especially when on good soil. This has been partially orercome by crossing with the Clicriot, which produces a hardier sheep, and not so liable to over-fatten. 


\section{Che Cotswold Breed.}

This is a very ancient breed. We find farorable mention is made of the Cotswolds by the very early writers. Speed, writing nearly 250 years ago, says that the wool from this breed rivalled that of Spain. It has been claimed that they even were the origin of the Spanish Merino, it being a historical fact that Edward IV. permitted the exportation of a number of this breed to Spain, where they increased and spread rapidly, but, as befure stated in the chanter on the "origin of sheep," Spanish wool was noted long before this for its fineness of fibre. The also find writcrs in the time of Queen Elizabeth speaking about the longwooled Cotswold, which would go far to prove that the breed has always been so, and that they were never originally short-woolerl. The COTSWOLD is a large, hornless sheep, with a long and abundant fleece. The ewes are good nurses and very prolific. The Cotswold of to-day contains a considerable strain of the Leicester, which has tended to rather diminish the size and shorten the fleece, but they have retained the hardihood of the Cotswold, and are good rustlers and should cross well on the native stock of this country.

\section{Description of the Cotowold.}

Legs and face white, with occasional dashes of brown or gray, showing traces of the original stock. The head is strong and massive, without horns, and having a heavy forelock of wool; the neck and fore-quarters are strong and square; the brisket fairly prominent; the hind quarters are square, full and broad; the ribs well sprung, making a round barrel; the flanks are deep; the legs close but not long; the bone fairly heavy. Their general appearance is attractive, indicating a hardy, rigorous animal. They are shaped to fatten easily, making them a prime mutton breed. The fleece is close upon the back, and 


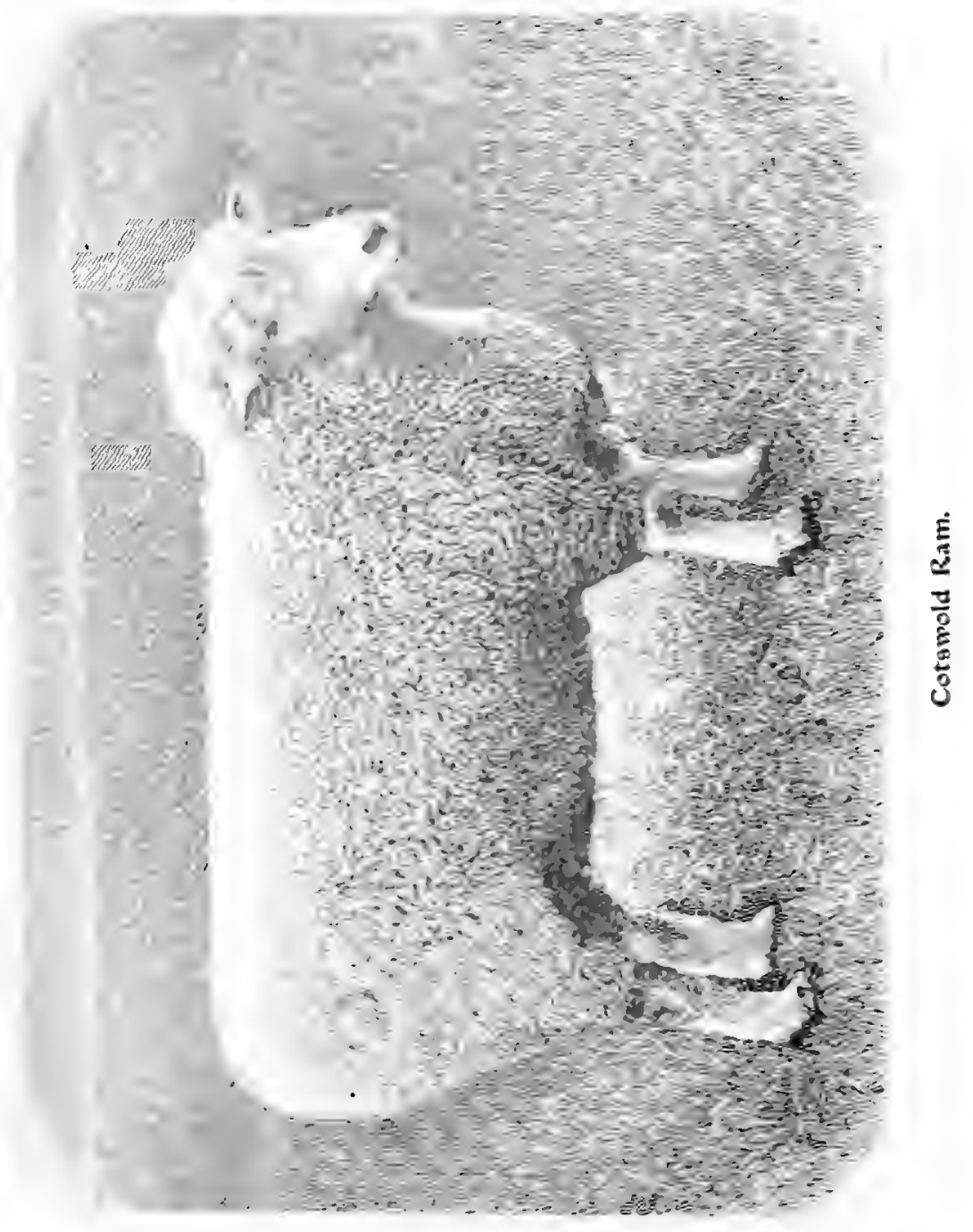


long, sometizes being nine inches in length; is well waved and soft. The Cotswold has assisted materially in establishing several of the prescnt crossbreeds, notably the Oxford Downs and Shropshires in England, and the Cotswold Merino in Germany. Its availability of adaptation to various climates and conditions and the general useful character of its fleece in woolen manufacture makes it one of the most valuable breeds we possess at the present time.

\section{Che Luincoln Sheep.}

This is another famous breed of English sheep, and may almost be said to be a manufactured breed, owing as it does its present perfection and size to systematic and judicious crossing of the old Lincoln sheep with other breeds, notably the improved Leicester. THE OLD LINCOLN was a large coarse sheep, with flat sides and hollow flanks, large legs and feet. Their fleece averaged between ten and twelve pounds, almost touching the ground, and was very oily. They fattened slowly, and made much fat internally.

THE NEW LINCOLN is, as before stated, the product of Leicester crosses upon the original breed, the result being a large sheep; in fact, the largest of any in the British Isles. The flesh is firm; wool extraordinarily long; fleece very heary, a ram's clip often weighing between twenty-five and thirty pounds; the wool is bright, and lustrous when shorn. Thile some breeders consider that the Lincolns as a mutton breed are inferior to the Downs, every one admits that for crossing on the common or native stock of the American Continent they are "second to none." H. A. Danniels, Secretary of the National Lincoln Sheep Breeders' Association, writes concerning their early importations to this country as follows: "Among the first importers of this breed to Canada were John Geary of London, William Walker of 


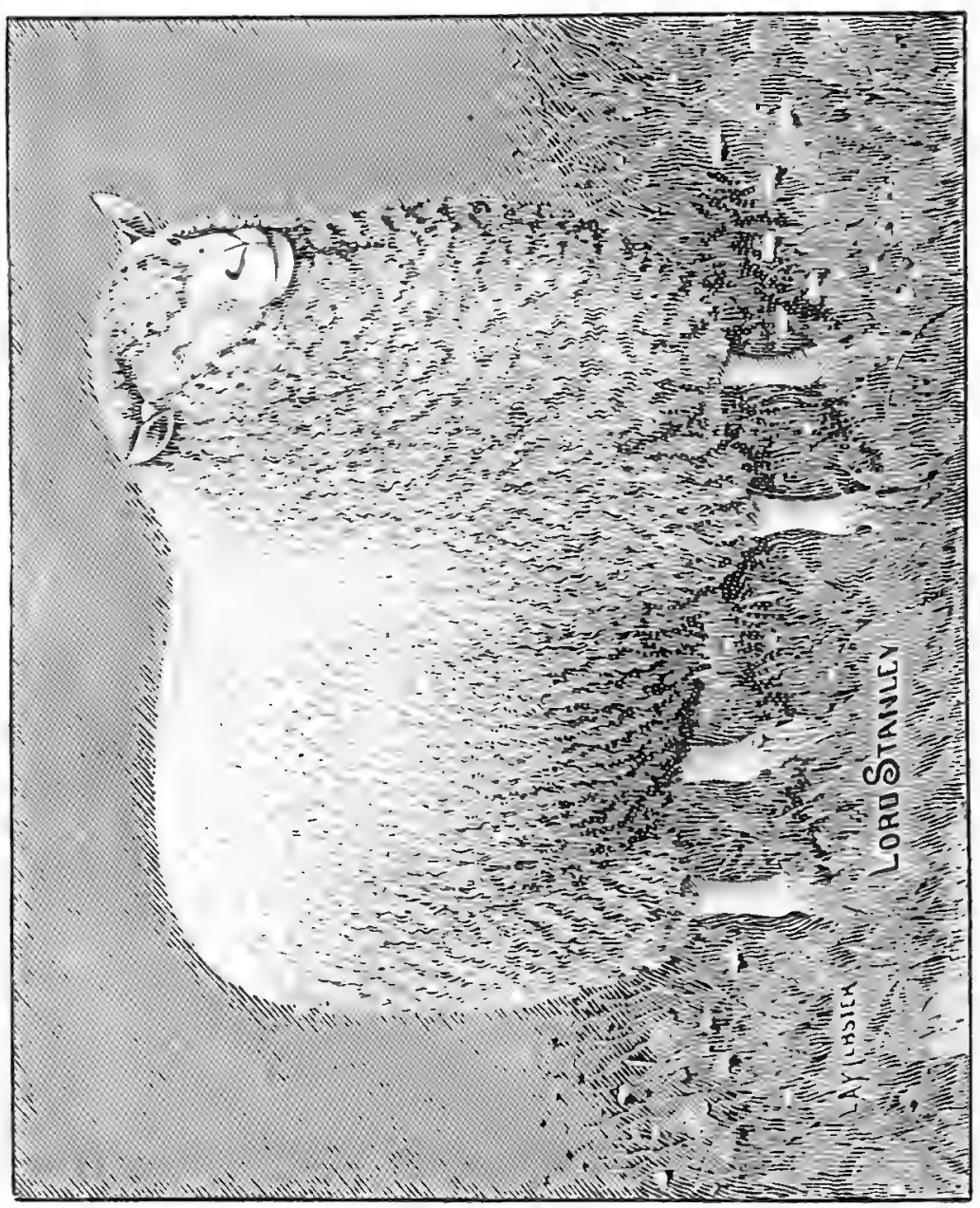




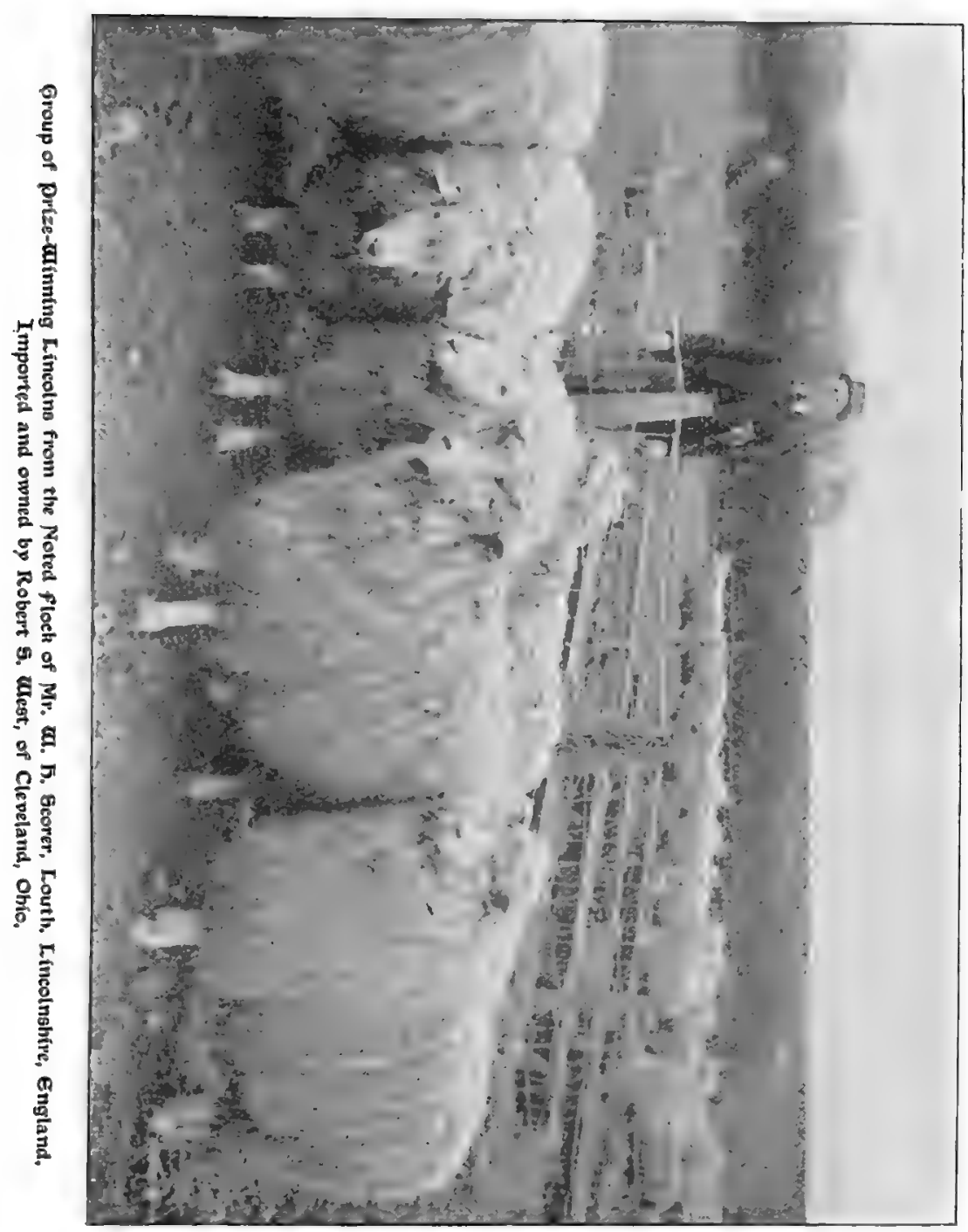


Ilderton, and J. T. Gibson of Denfield, also last, but not least, Wrilliam Oliver of Aronbank. The first Lincolns brought to the tnited States were from the above importations, and the first breeders were G. S. Allen of Portland, Mich., and Robert Tinight of Marlette, Mich. J. J. England of Cairo was one of the early breeders, buying largely in Canada, and in '94 made a

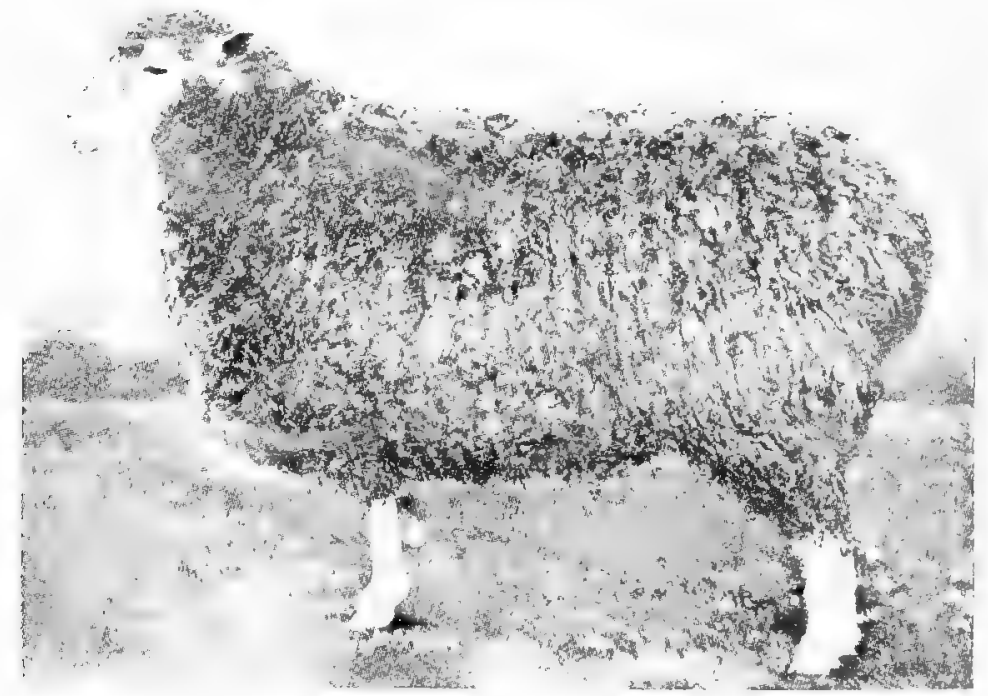

Champion. Lincolnshire $E_{w e}$, shown at New South שales, Bustralia, 1898.

direct importation from England. The writer started a flock ahout this time, viz., 1sso, lnying the tirst lot of Robert Kinight, later making purchases in Canada, having brought orer of Canadian and English bred five bunches.

"The National Association was organized in 1891 with nine members, and now is composed of 112 of the best Lincoln brecters in Torth America. The have 5,000 Lincolns regis- 
tered, the association having now attained its ninth year, and is still growing."

\section{Standard and Scale of Doints of Lincoln Sheep.}

Constitution-Body deep, back wide and straight;

wide and full in the thigh; bright, large eyes; skin

soft and of a pink color...............25 points Size-Matured rams not less than 250 pounds, when

in good condition. Matured ewes not less than

200 pounds....................10 points Appearance-Good carriage and symmetry of form. .10 points Body-Well proportioned, good bone and length;

broad hind quarters; legs standing well apart;

breast wide and deep..................15 points Head-Should be covered with wool to the ears; tuft

, on forehead; eyes expressive; ears fair length;

dotted or mottled in color..............10 points Neck-Medium length; good muscle; well set on body 5 points Legs-Broad and set well apart; good shape; color white, but some black spots do not disqualify; wooled to the knees.............10 points Fleece-Of even length and quality over body; not

less than eight inches long for one year's growth. 10 points Quality of Wool-Rather fine, long wool; strong,

lustrous fiber; no tendency to cot......... 5 points

Total.................100 points

\section{Che Romney Marsh, or Kentish Long-Clooled.}

This sheep belongs to one of the old breeds which grazed on the marsh lands of the coast of Kent, England, taking their name from the locality called Romney Marsh, a low-lying strip of land 


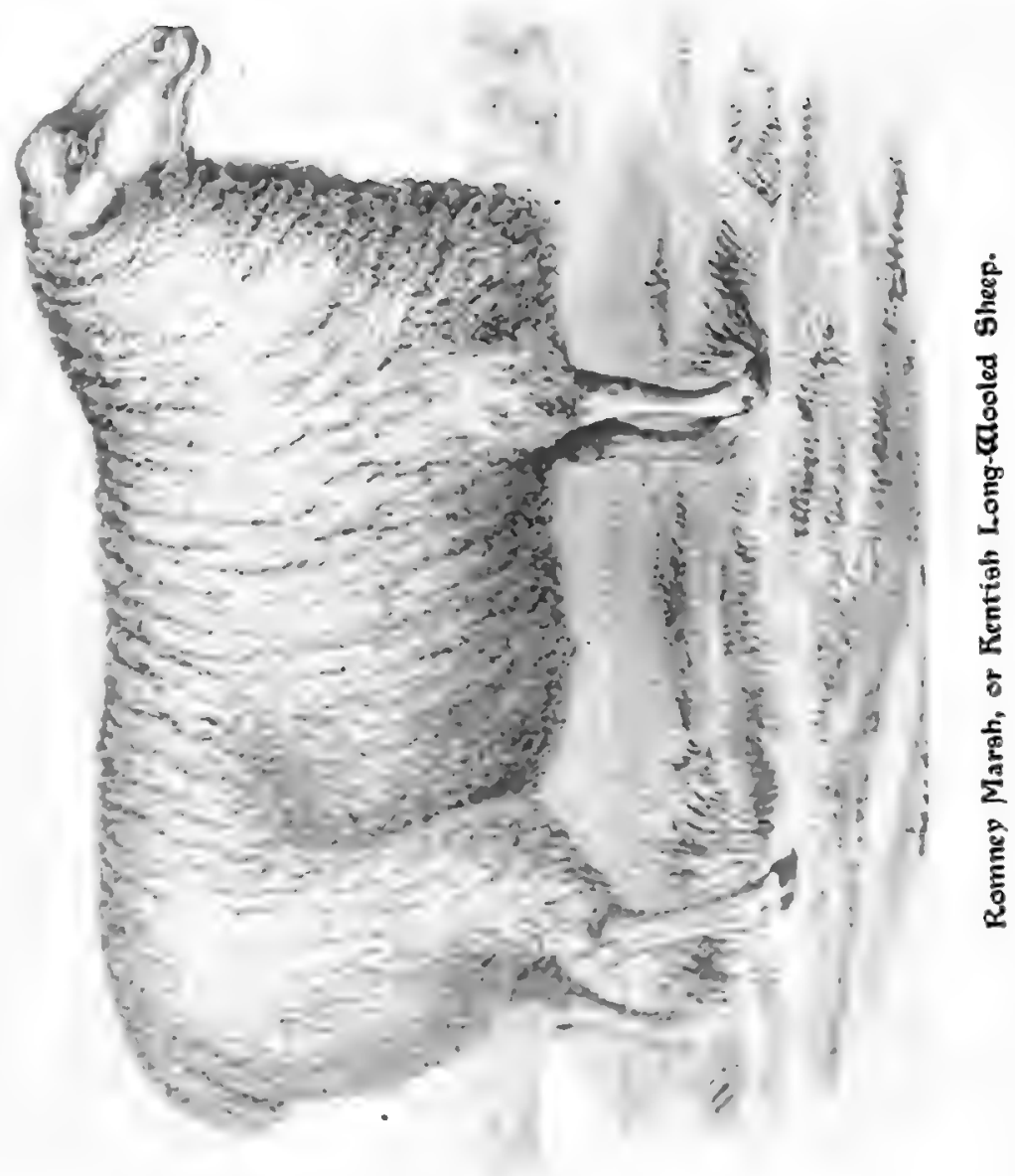


not exceeding fourteen miles in length by ten miles in breadth. The soil being a heavy rich clay, was adapted to the growth of a large breed of sheep, and we find the Romney Marsh competing with the Lincoln for weight of carcass.

The unimproved breed is described as having had flat sides, big bellies, narrow chests and large heads, and were evidently more useful than good-looking; but by the judicious infusion of improved Leicester blood, and years of careful selection, they have attained a place of favor in the estimation of sheep breeders which they certainly merit. They are especially adapted to lowlying soils.

In general appearance they resemble the Lincoln, being white-faced, hornless; the wool is of long staple and heavy. The first importations of the breed to America are supposed to have been in the early settlement of Massachusetts, evidently being the unimproved breed. Latterly the Romney Marsh are springing into favor, and doubtless in a short time an association will be formed in the United States to record correct pedigrees, etc, and establish the breed in its proper place among the others of this country.

\section{Middle-cuooled Breeds.}

\section{Che Southdown.}

Also called the Sussex. This breed of sheep trace back with a long line of pure descent to a period prior to the reign of William the Conqueror. It is beyond a doubt one of the purest and most unmixed breeds in England, holding a position in the esteem of breeders second to none. This noted breed has reached its present state of perfection by unceasing attention on the part of breeders, perpetuating the purity and perfection of 


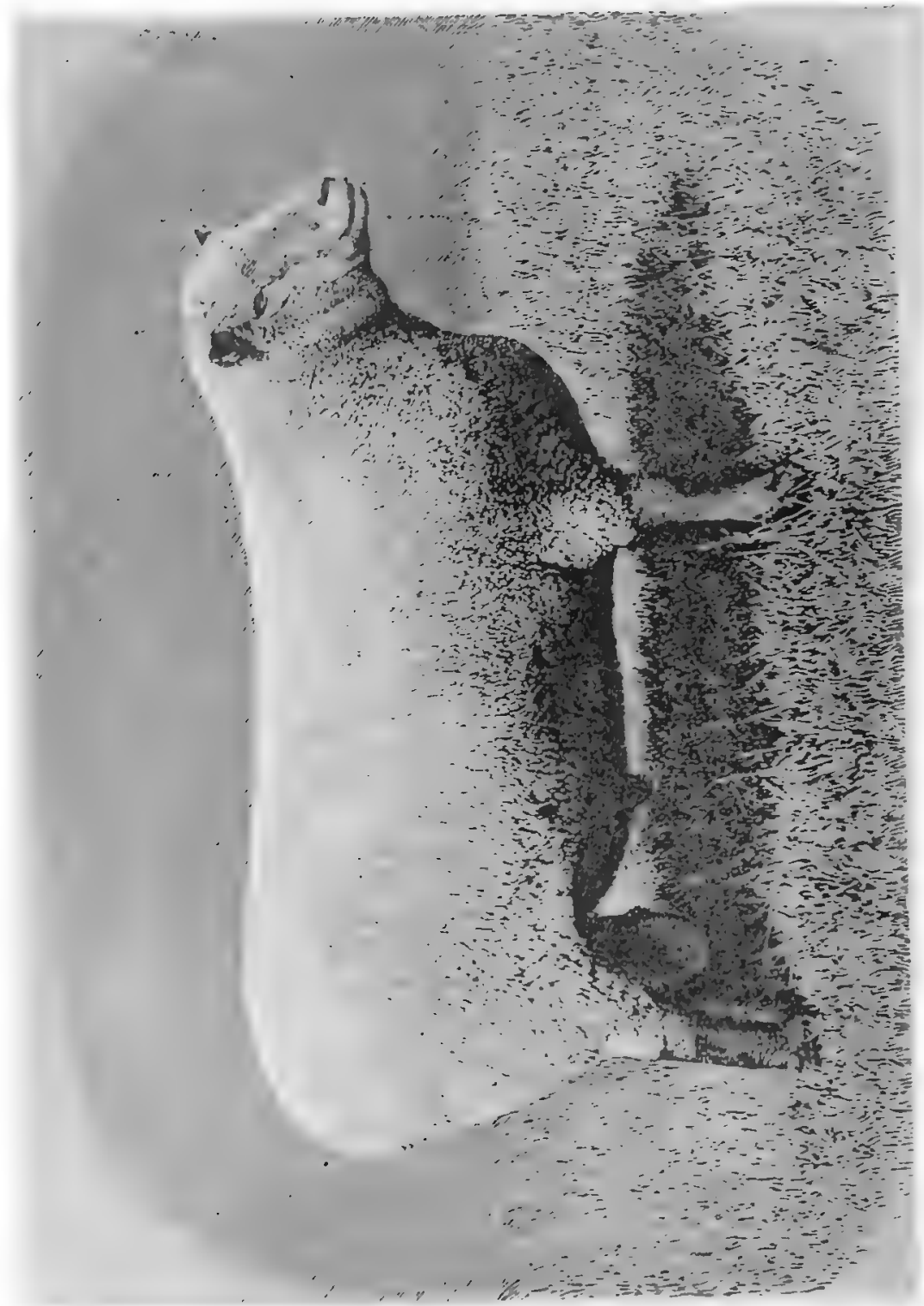


the original ancestors. As far back as 1776, a Mr. Alford Young comments on their fine coat, but criticizes the thin chine, low fore-end and rising back bones. The aim in improving this breed has been to amend these defects, and in accomplishing this the improvement has produced a readier disposition to fatten, with a heavier carcass, while they still retain their character for hardiness and good rustling qualities. One of the great points of excellence in these sheep, as compared with many others, is that they ean stand bad weather, with a correspondingly less loss of flesh, and being good travelers, are adapted for use on the Western plains. There is no reliable data concerning the first importations of this breed to America. We have, however, every reason to believe that some were brought here by the first settlers in the New England States, and as early as 1648 some ewes were bought by Gov. Winthrop; also that they were known in Virginia as remote as 1688 there is no doubt, as we find Mr. John Clayton of that period mentioning them," and praising their mutton qualities. These of course were from the old and unimproved breed, which have from time immermorial been renowned for their mutton qualities, the present improvement being due to the efforts of such men as Ellman, Drake, and Jonas Webb of England, who, like Bakewell, in breeding Leicesters, made certain points of excellence their alim in breeding. We find that in $1803 \mathrm{~A}$. D. Rose imported a small flock of Southdowns to his estate at Fayette, N. Y.

Later, in 1824-1828, John H. Powell of Philadelphia, Pa., and Francis Rotch of New York made importations, supposed to have been obtained from the Fllman flock of England. Still later we find Samuel Thorne and L. G. Morris, both of New York, made importations from the best flocks of England, and by $1863 \mathrm{Mr}$. Thorne's flock counted descendants from fourteen different importations, principally from the flock of Mr. Jonas Webb of Babraham, Cambridgeshire, Eng. In $1844 \mathrm{Mr}$. Jesse 


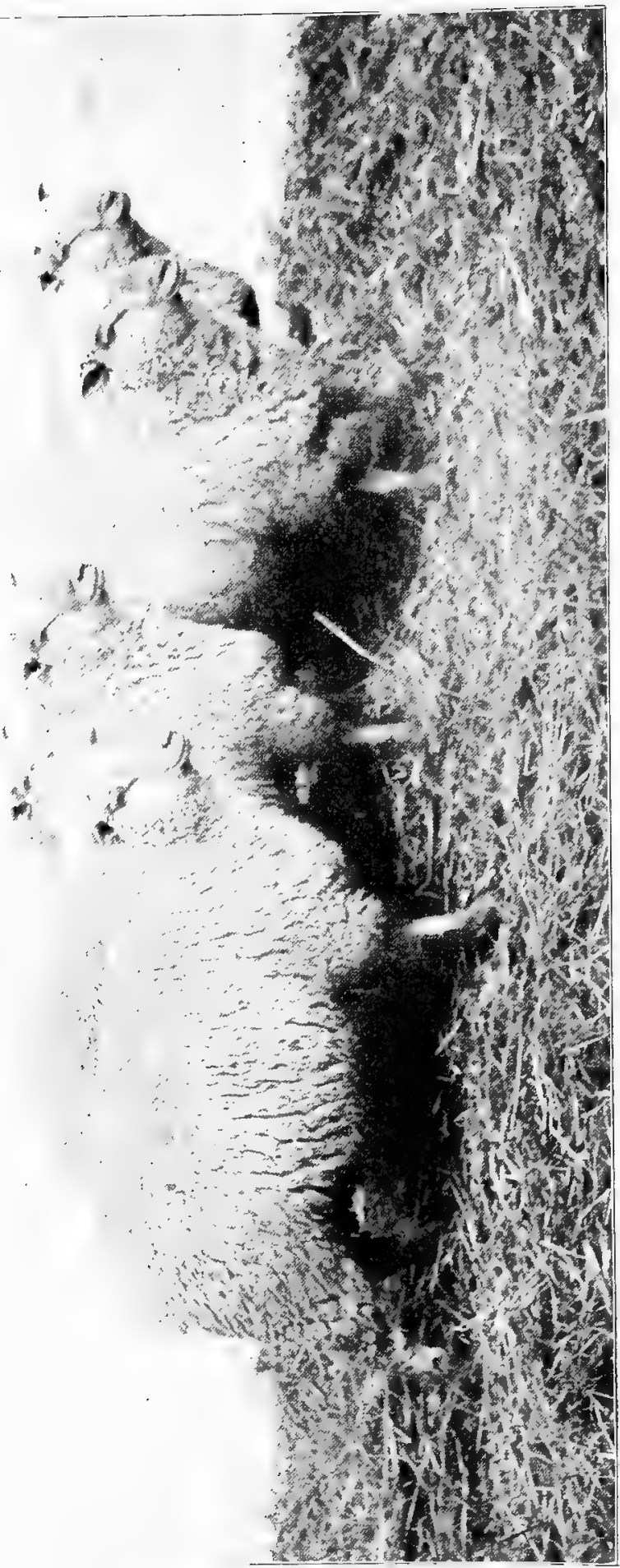

8 
A. Pickrell of Sangamon Co., Illinois, imported a ram and two ewes; and in the same year Mr. J. T. King of Warren, Ohio, began to breed Southdowns with stock imported by Mr. J. Mr. Hesless of Trumbull Co., Ohio. In the year $1848 \mathrm{Mr}$. J. C. Taylor of New Jersey commenced breeding Southdowns, and established a flock which was entirely descended from the celebrated Webb stock. Mr. R. Scott of Kentucky was also noted for his efforts in forwarding the claims of the Southdowns. Gen. C. M. Clay, White Hall, Ky., commenced breeding Southdowns in 1855, and by constantly introducing blood by the best rams obtainable, and only breeding to his own ewes, he obtained sheep of great excellence, increasing the amount of wool, and almost doubling the size of the carcass. In 1857 the Illinois Importing Co. made an importation of thirteen head from the flock of Jonas Webb. Again in $1861 \mathrm{Hon}$. John Wentworth of Chicago, Ill., made importations of Southdowns, and by intelligent selection and a long term of years so successfully improved his flock that it is hard to obtain a better foundation for a flock today than from those descended from the Summits farm. In 1875 the North Elkhorn Importing Co. of Kentucky made importations, and in 1876 sixteen rams and twenty-three ewes were imported from the Wralsingham flocks of England.

On May 1st, 1882, at Springfield, Ill., the American Southdown Breeders' Association sprung into being, its aim being the collection, revision, preservation and publication of the history and pedigrees of pure-bred Southdown sheep. The aim of the Association has been to encourage and aid breeders of Southdown sheep, taking care that none but worthy claims should be advanced to their credit, and also that none but worthy sheep should be recorded. The following is the standard of excellence adopted by the American Southdown Breeders' Association, and which is accepted both in this country and in England as a correct guidance for determining the true type of the Southdown: 


\section{Standard of Excellence for Southdown Sheep,}

\section{Hdopted by the Fimerican Southdown Hssociation.}

Head medium in size and hornless, fine, carried well up, the forehead or face well covered with wool, especially between the ears and on the cheeks, and in the ewe slightly dished..................... 5

Lips and under jaw fine and thin............... 1

Ears rather small, tolerably wide apart, covered with fine hair, and carried with a lively back and forth movement ............................. 2

Eyes full and bright..................... 3

Face a uniform tint of brown, or gray, or mouse color..... 3

Neck short, fine at the head, but nicely tapering, and broad and straight on top at the shoulders............ 4

Shoulders broad and full, smoothly joining the neck with the back .........................

Breast wide, deep, and projecting well forward, the forelegs

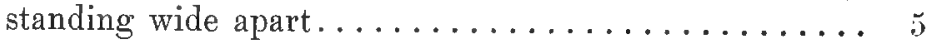

Back and loin broad and straight from shoulders to rump... 7

Ribs well arched, extending far backward, the last projecting more than the others................... 6

Rump broad, square and full, with tail well set up...... 6

Hips wide, with little space between them and last ribs.... 6

Thighs full and well let down in twist, the legs standing well

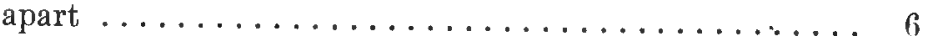

Limbs short and fine in bone, and in color to agree with face. 3

Forelegs. well wooled and carrying mutton to the knees, but free from meat below.................. 2

Hind legs well filled with mutton and wooled to the hocks, neat and clean below................... 2 
Belly straight and well covered with wool, the flank extending so as to form a line parallel with the back or top

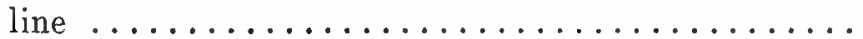

Fleece compact, the whole body well covered with moderately long and close wool, white in color, carrying some yolk. 12 Form throughout smooth and symmetrical, with no coarseness in any part................... 9 General appearance spirited and attractive, with a determined look, proud and firm step, indicating constitutional vigor and thorough breeding.............. 8

\section{Che Shropshire Breed.}

The Shropshire is undoubtedly a cross-bred animal, and evidences a striking example of the perfection that may be obtained by judicious crossing of various breeds. The original breed was horned, and it is believed that the first attempt at improvement was to abolish these useless appendages. There is good reason to believe that this was effected. by a Southdown cross. The original stock were called Morfe Common sheep, deriving their name from the locality to which they were indigenous, if such a term could be used. They were a black-faced, brown or spottedfaced sheep; horned; not subject to scab, or rot, producing only about forty-four to fifty pounds of mutton to a carcass, clipping nearly two pounds of fine wool to the fleece. These sheep were crossed with the Southdown and afterwards with the Cotswold and Leicesters, the crossing and re-crossing, combined with careful selection, yielding the uniformity sought for and obtained, thus establishing the present superior breed. Since 1874 further crossing has been considered unnecessary, the results obtained prior to that time haring produced a distinct and separate breed. The Shropsbire sheep are hardy, thrive well on moderate keep 


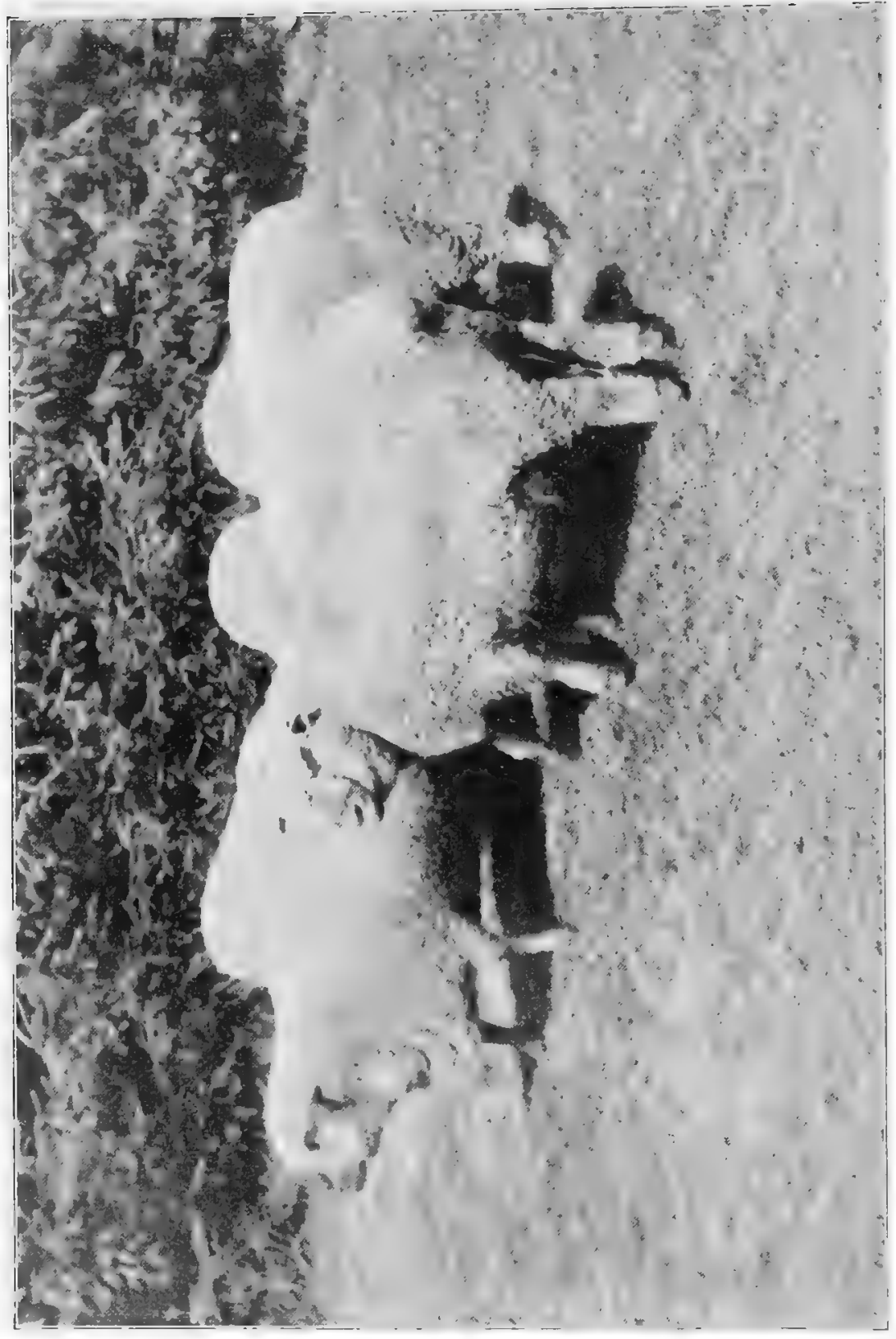


and fatten quickly, these qualities rendering them invaluable for crossing on the common native sheep.

We find that a few Shropshire sheep were imported to this country in 1833 , becoming popular wherever known. In 1875 a Mr. H. C. Chaffee of Tippecanoe City, Ohio, imported quite a number, other importations following fast. In 1883 about 4,000 were imported, and in 1884 5,000 more.

In the year 1884 the Shropshire Registry Association was established, and at the present time (1899) there are recorded in the registery of the Association over 100,000 individual purebred registered Shropshires. Shropshire sheep have gained in popularity every year, their fecundity, hardiness and ability to adapt themselves to different climates and conditions being unexcelled by any other breed.

\section{Doints of Excellence}

for Pure-Bred Shropshire Sheep, Recorded, or Eligible to Registry in the American Sbropsbire Registry Association Record.

General Appearance-Attractive, indicating breeding and quality, with stylish carriage and a symmetri-

cal form covered with a dense fleece.......25 points 'Constitution-Robust as indicated by width and depth

of chest; strength and formation of neck, and by

bold active morement.............10 points

Size-In breeding condition when fully matured.

Rams should weigh not less than 180 to 225

pounds, and ewes not less than 125 to 170 pounds. 10 points

Fleece and Skin-Fleece of good length, dense, elastic

to touch, medium fine, free from black fibre, slightly crimped, with evenness of texture throughout; scrotum of rams well covered with wool. Skin light cherry color, clear and free

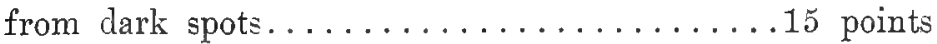




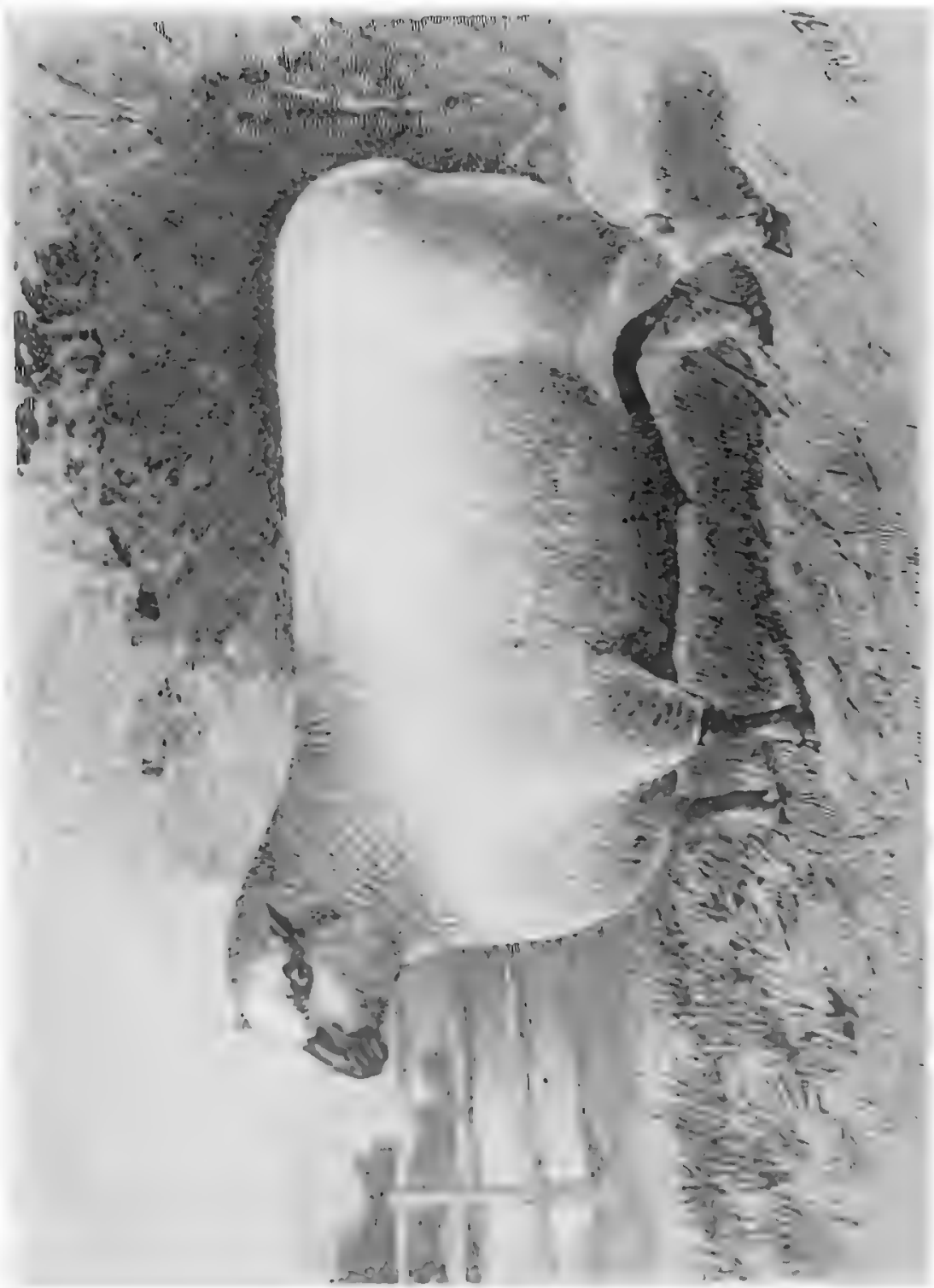


Body-Well proportioned, with shoulders well placed, fitting smoothly upon the chest, which should be deep and wide, broad and straight back, thick loins well covered with firm flesh; hind-quarters well finished; twist deep and full...........20 points IIead and Neck-Head, short, broad between the ears and eyes, bold and masculine in rams, without horns, well covered with wool, ears short and erect, eyes bright, color of face and ears darkbrown. Neck of medium length, strong and muscular (especially in rams), symmertically joined to head and shoulders.................. points Legs-Well set apart, broad, short, straight, color darkbrown and well wooled; pastern strong and upright $\ldots \ldots \ldots \ldots \ldots \ldots \ldots \ldots \ldots \ldots$

5 points

100

\section{Che Dampshire Down.}

The Hampshire Down of to-day in no manner resembles the old Hampshire from which it is supposed to be descended.

The old Hampshire had probably existed on the Downs of Hampshire in the time of the Roman occupation of Britain, and doubtless its fleece helped furnish the supply for the wool factory established by the Romans at Winchester.

They were a large, long-horned sheep, with fine, short wool. The rams were noted for their large, bony, unsightly heads.

The present improved Ilampshires are supposed to have originated from a cross between the old Wiltshire horned-sheep as well as the Berkshire Knot and the Southdown. A bout 1829 a Mr. John Twynam used improved Cotswold rams on Hampshire ewes, obtaining an animal which combined the qualities of the old Wiltshire, Southdown, and Cotswold. As we find the 


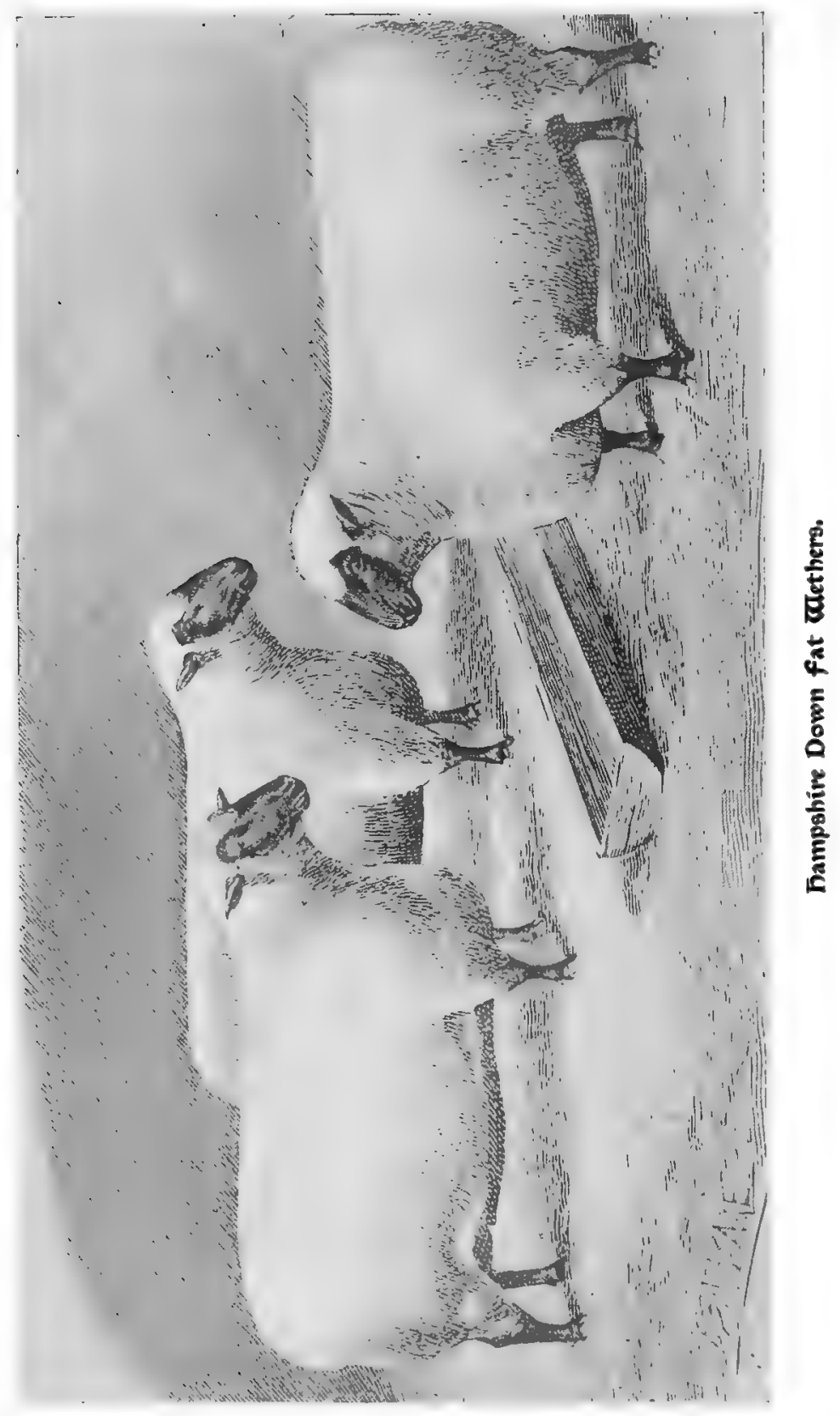


name of one man generaliy figuring in the building up of a particular breed, so we find that the Hampshire Downs owe their present excellence in a great manner to a Mr. Humphrey of Oak Ash, Wantage, Eng., who by careful crossing with the largest and best fleshed of the improved Southdowns, succeeded in producing a sheep of perfect form, with a strong constitution, and carrying a useful and valuable fleece. All the praise, however, does not belong to Mr. Humphrey, as among the careful breeders of this particular breed the names of Mr. Rawlence of Bulbridge, Mr. Stephen King, Mr. William King, Mr. Moore, Mr. Edward Waters, Mr. Frank Budd, and some others, are divided the honors of bringing this breed to its present state of perfection and excellence.

The Hampshire sheep were first imported into the United States a short time before the War of the Rebellion, the first irnportation being made to Virginia. In 1855 Thomas Messenger of Great Neck, Long Island, imported a small flock of these sheep from England. In 1881 Henry Metcalf of Canandaigua, N. Y., imported the ram "Shepherds' Pride." Since this time the importations have increased in frequency, the Hampshires obtaining their just deserts in becoming more popular year by year.

The imported Hampshire Down vies with the Oxfordshire Down for being the heaviest of the Down breeds. They mature early. The fact that the Hampshire ram lambs are sold for service at seven and eight months would go to prove this assertion.

The ram lamb should have a black face, surmounted by white fleece; a dark tinge round the poll not being desirable, and will materially reduce the value of the animal possessing it. The ears must not be mottled, but should be semi-transparent, resembling a bat's wing. The shanks should be a rich brown, almost black color, free from mottled appearance; the nose of the ram should be thick, the head being large, with a slightly Roman profile; the neck is long and well set on; shoulders sloping; deep 


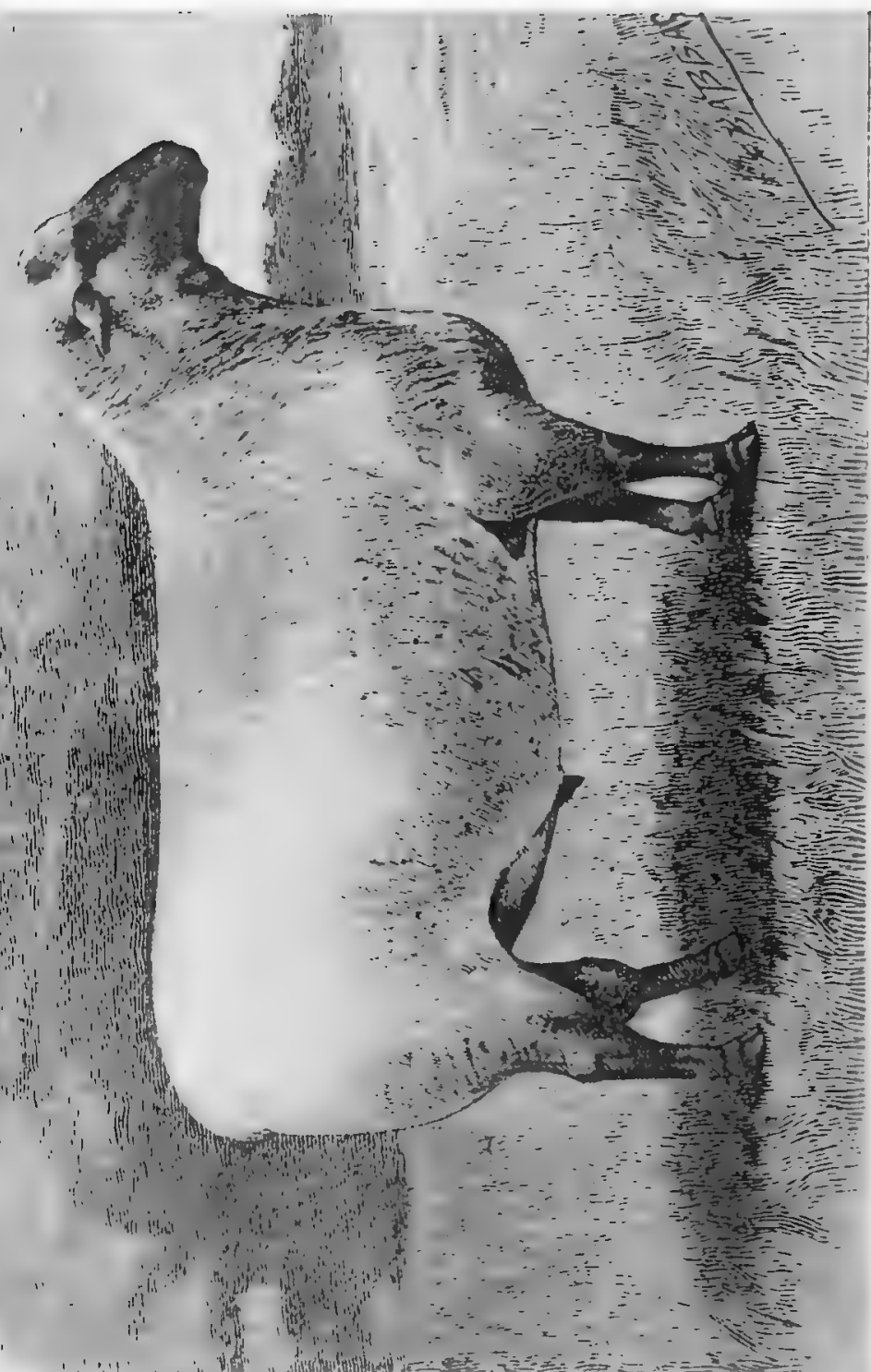

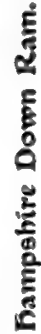


in the brisket; ribs well sprung; back straight; broad across the loin; the quarters are long and broad; the hams round and heavy. The ears are characteristic of the breed. They are thin and mobile, falling outwards slightly, giving the appearance of great width of poll. The head is well covered with wool between the ears and on the cheeks. The wool is medium length, and of strong fibre. Mature rams weigh up to 300 pounds and ewres a trifle over 200 .

As a race of sheep they possess constitutional vigor; mature early; the lambs possess excellent fattening qualities. The ram is endowed with remarkable prepotency, indelibly leaving his mark on his offspring, making him a valuable animal to cross on common ewes.

We print here the standard of excellence for Hampshire Downs as recognized by the Hampshire Down Breeders' Association of America:

\section{Standard of Excellence.}

Head-Moderately large, but not coarse; well covered with wool on forehead and cheeks.

Nostrils-Wide.

Color (head and legs)—Dark-brown or black.

Eyes-Prominent and lustrous.

Ears-Moderately long and thin, and dark-brown or black color.

Legs-Well under outside of body, straight, with good size of bone. black.

Neck-A regular taper from shoulders to head, without any hollow in front of shoulders, set high up on body.

Shoulders-Sloping, full, and not higher than the line of back and neck.

Chest-Deep and full in the heart place, with breast pronlinent and full.

Back-Straight, with full spring of rib. 
Loin-Wide and straight, without depression in front of hips.

Quarters-Long from lips to rump, without sloping, and deep in thigh. Broad in hips and rump, with full hams. Inside of thighs full.

\section{Scale of Points.}

Head-Size and shape, 5 ; ears and eyes, 3 ; color, 5 ; legs

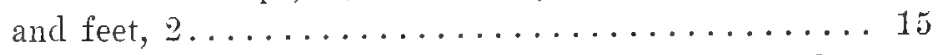
Neck, shoulders and breast-Neck, 5 ; shoulders, 10; chest

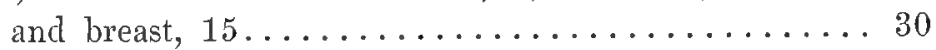
Body-Back and loin, $15 ;$ rib, $5 \ldots \ldots \ldots \ldots \ldots \ldots \ldots$ Quarters-Length, 10; width, 10; twist, $5 \ldots \ldots \ldots \ldots .25$ Wool-Forehead and cheeks, 2; belly, well covered, 3; qual-

ity, $5 \ldots \ldots \ldots \ldots \ldots \ldots \ldots \ldots \ldots \ldots \ldots \ldots \ldots \ldots \ldots \ldots \ldots \ldots$ Total............. 100

\section{Oxfordshire Down.}

This popular breed of sheep originated shortly prior to 1833 as the result of crossing Cotswold rams on Hampshire Down ewes. A Mr. Samuel Druce of Eynsham, Oxon, England, was the first to establish the new breed, his aim being to produce a sheep with the frame of the long wool and the quality of the Down. The Hampshire at this time was not that of the present improved type, but the old stock, said to be a loosely made, bigheaded sheep, which a few years afterwards underwent improvement at the hands of Mr. Humphrey. About this time a number of breeders became interested in the cross instigated by $\mathrm{Mr}$. Druce, and we find that Mr. Gillet of Southleigh, Mr. Twonham, and a Mr. Blake practising this method. As the number of breeders of this particular class increased, the opportunities 


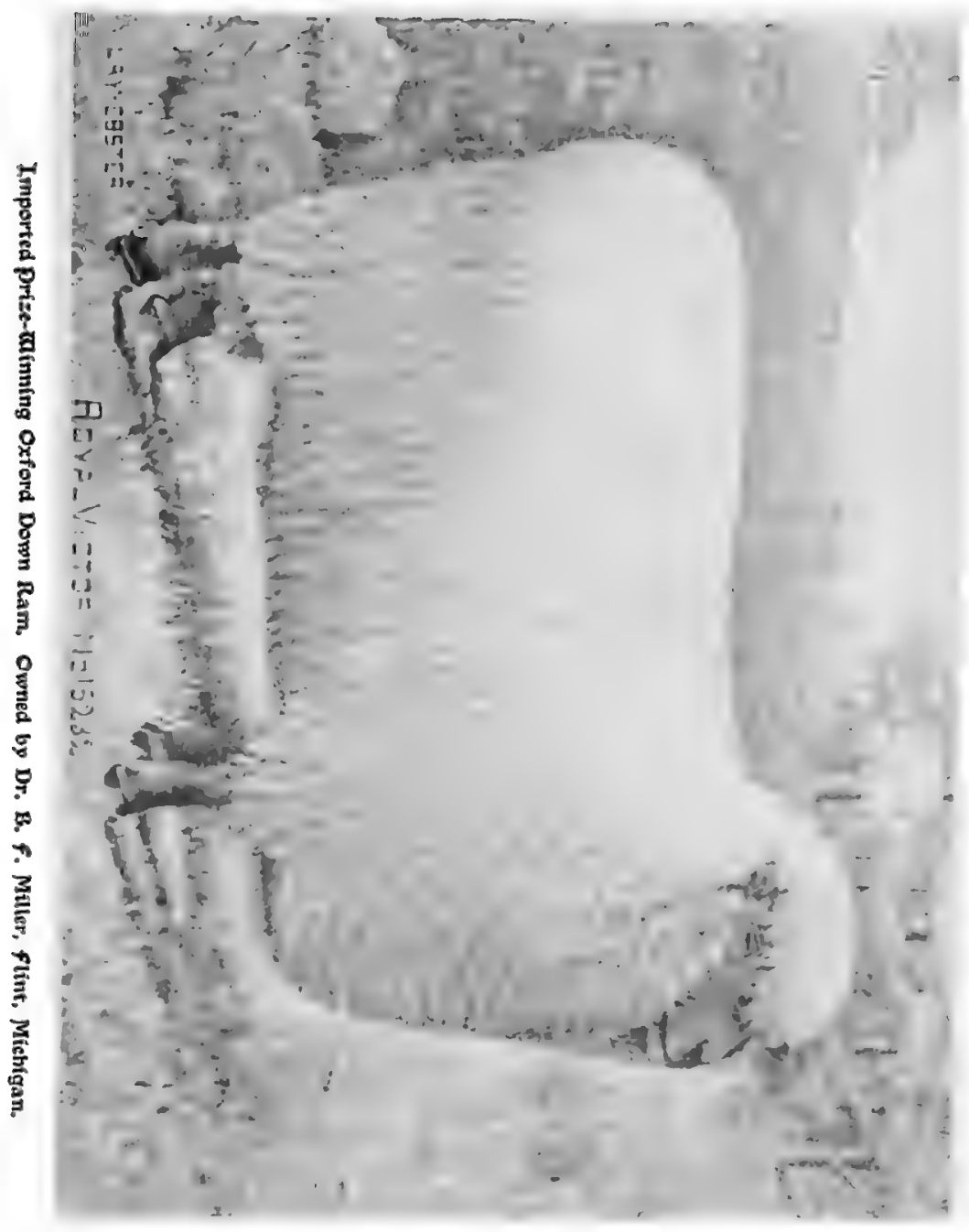


of better selection advanced. It became possible by this means to produce a distinct breed of a uniform shape and character.

Prior to 1859 they were known as Down-Cotswolds-Mr. Druce calling them his half-breeds. When the breed was still in its embryonic stage, the records show that a considerable amount of promiscuous crossing took place before a type was finally fixed.

IIr. C. T. Read states: "The owner formerly divided his flock into three parts, putting a half-breed ram to the ewes which were about right - a Cotswold to the smaller ones, and a Down to the coarser sheep," - and we also find that several breeders used Cotswold rams on Southdown ewes, thus infusing the blood of the improved Southdown in the new breed. As already stated, they were named Oxford Downs in 1859, and have undoubtedly been bred pure ever since that date. They obtained recognition as a distinct breed in 1862, the Royal Agricultural Society, at the Battersea meeting, offering prizes for Oxfordshire Downs, recognizing the fact that short-wooled sheep, not Southdowns, was not a proper classification of the middle-wooled breeds of sheep of the British Isles.

The first importation of Down-Cotswolds to America was made in 1846 by Mr. Clayton Reybold of Delaware City, Del., and in 1853 William C. Rives sent to Virginia one ram and five ewes, a Mr. Fay introducing them into Massachusetts about the same time, obtaining them from the same flock in England as those obtained by Mr. Rives. Careful breeding and selection has given them that uniformity of character, the lack of which was freely criticised in the early lifetime of the breed, till since 1870 the type has become firmly fixed, specimens of the breed being found in almost every part of Europe, South Africa, Australia, North and South America. 


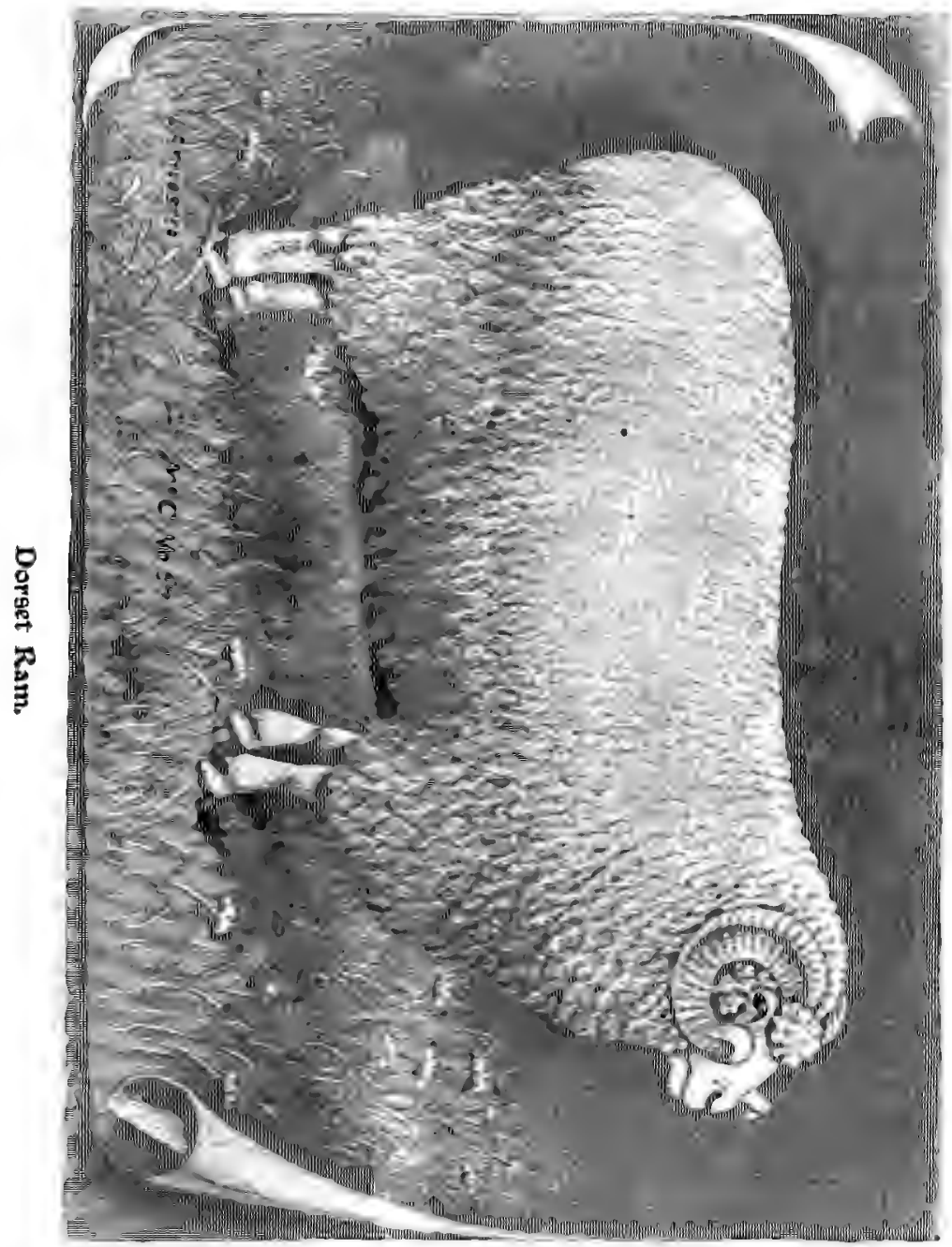




\section{Che Dorset.}

This is the oldest known breed of English sheep, having been preserved unmixed from a very remote period, and are certainly the best of all the horned breeds. The Dorset has some very valuable traits, the chief of which is fecundity and the ability to breed at an early season. Dorset ewes take the ram in April, and yean in September. The lambs are then fit for the Christmas market. The ewes make excellent nurses, frequently bearing twins, and will rear a greater number of lambs than any other breed of sheep. The Dorset horned-sheep is somewhat larger than the Southdown; longer in the legs; face and legs white, and the horns of both sexes of moderate size; their frame is more compact, the barrel rounder, and they are by no means bad feeders. Mr. M. A. Cooper, Secretary of the Dorset Horn Breeders' Association of America, writes about the breed as follows: "Dorsets were first introduced into America in 1885, but little interest being taken in the breed until about 1890 to 1891, when a few breeders in America united and formed an association. Since 1891 importations have been made every year, till at present they have been introduced into twenty-eight of the different States. Two very large importations were made in 1897. The Dorsets are popular with breeders generally, the demand exceeding the supply. The Dorset ewes are more correct in their shape than many of the improved breeds, being straight in the carcass, deep in the body, the rump large and round, the leg full and well let down toward the shank. Losses in lambing and barreness in ewes are rare; 150 to 160 lambs may usually be calculated for every 100 ewes. The rams are being extensively used in the Western States for crossing purposes. The demand for Dorsets increase every year, as their merits become known to the flock master." The Dorsets are hardy, very quiet and docile, readily adapting themselves to changes in surroundings and conditious. 


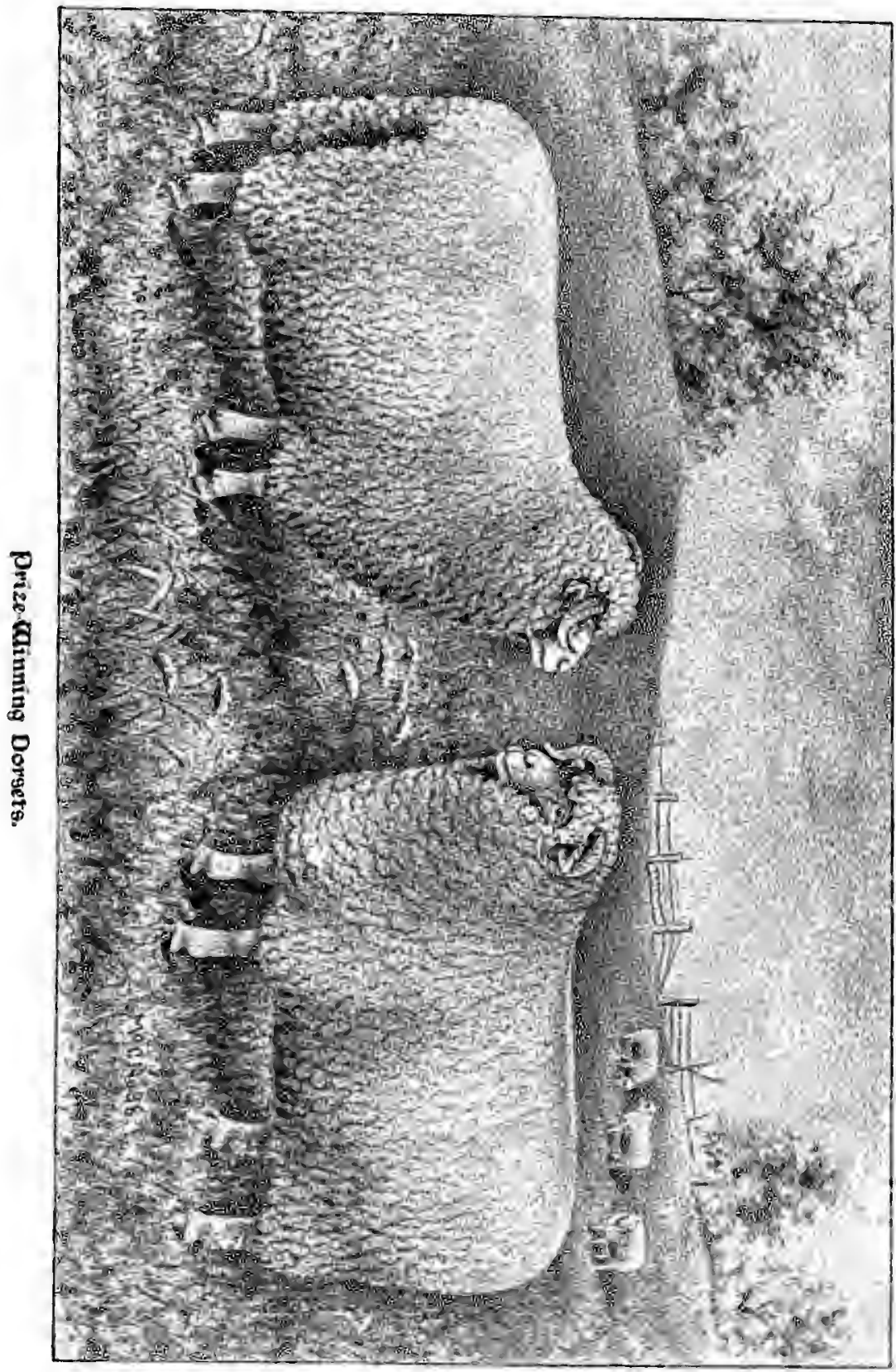




\section{Che Suffolk.}

This is one of the few remaining breeds of Down sheep which grazed on the chalk hills of England, from Norfolk and Suffolk to Kent, Sussex, Surrey, Hampshire, Bucks, Berks, Wilts and Devonshires, all of which counties possess an underlying chalk formation. The origin of this breed were the old Norfolks, of which mention is made by Arthur Young in 1797, who states that "their mutton for the table was superior in grain, flavor, quality and color of gravy." The first improvement was made by crossing improved Southdown rams. This, however, was supposedly prior to 1850 , since which time it is claimed they have been bred pure, without any. outside admixture of blood.

The Suffolk Sheep Society of England lay down the following points as necessary attributes of this breed:

Head hornless; face black and long; muzzle reasonably fine, especially in ewes (a small quantity of clear white wool on the forehead not objected to); ears medium length, black and of fine texture; eyes bright and full; neck moderately long and well set; shoulder broad and oblique; chest deep and wide; back and loin long, level and well covered; tail broad and well set up; ribs long and well sprung, with a full flank; legs and feet straight and black, with fine and flat bone; wooled to knees and hocks, clean below; fore legs set well apart; hind legs well filled with mutton; belly well covered with wool; fleece moderately short, close, fine fibre, without tendency to mat or felt together, and not shading off into dark wool or hair; the skin fine, soft and pink. The first importation of Suffolk sheep to the United States was in 1888, made by Mr. M. B. Streeter of Brooklyn, N. Y., the first President of the American Suffolk Flock Registry Association. In 1890 the Iowa Suffolk Sheep Company of Atlantic, Iowa, imported quite a number, subsequent importations both in this country and Canada following fast, till at the present writing 


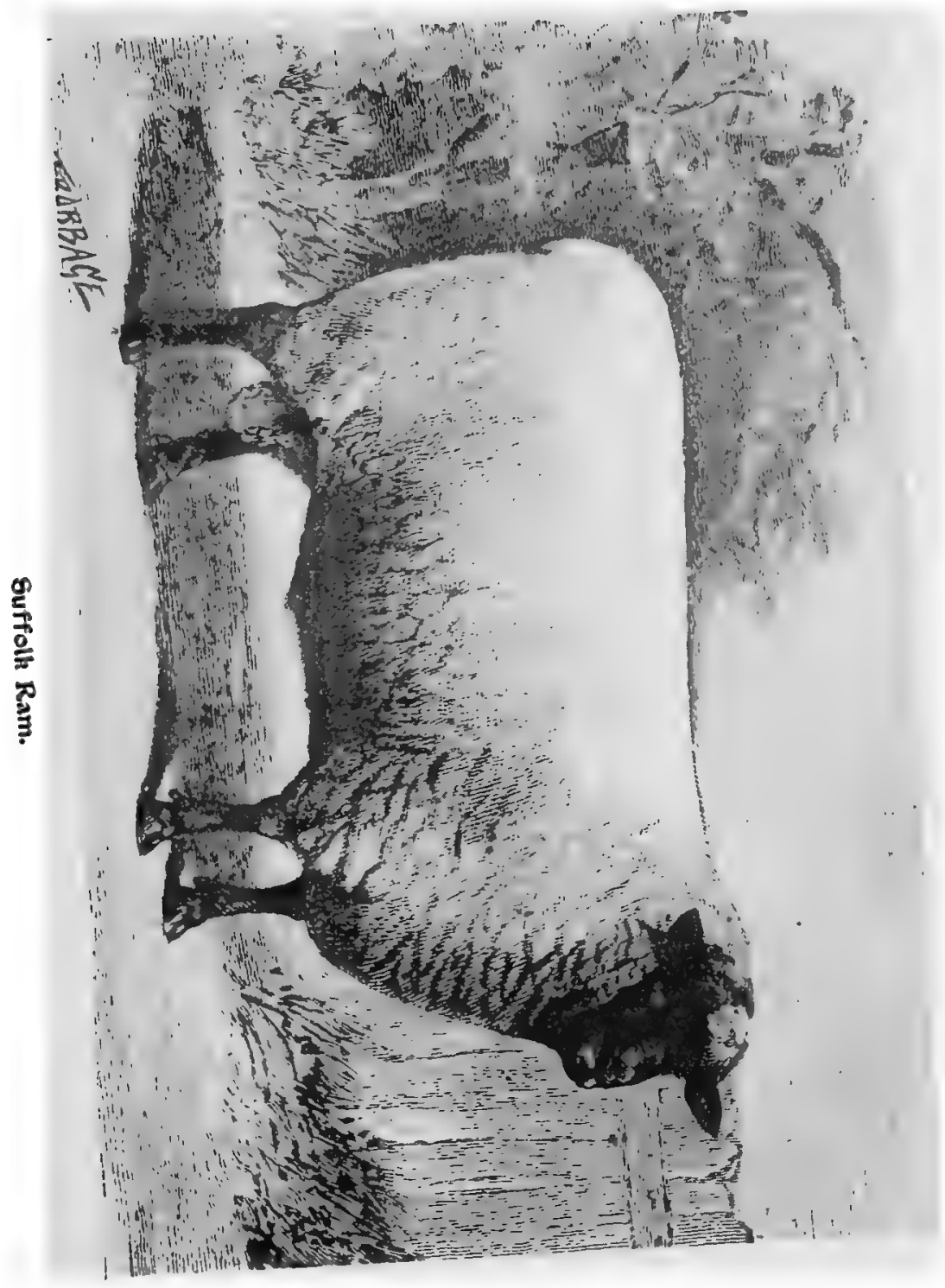


they are becoming well known, and have established themselves as an important addition to the recognized breeds of sheep on the American Continent. They are a hardy, healthy sheep, suitable for ranging on the Western prairies, and their comparative freedom from foot-rot favors their trial on some of the marshy soils of the Eastern and Middle States.

The following is the scale of points adopted by the American Suffolk Flock Registry Association:

\section{Seale of Doints for Suffolk Sheep.}

General Appearance-Pleasing outline; good carriage, and symmetry of development. Points.......... 7

General Form-Large in size; inclined to long in body; medium strength of bone; somewhat cylindrical in shape, and straight above, below and in the rear........ 15

Head-Medium in size, inclining to be long and covered with fine, short, glossy, black hair to the junction with the neck; a small quantity of clean, white wool on the forehead is not objected to, muzzle moderately fine, especially in the ewes; eyes bright and full; ears of medium length and fineness.............. 10

Neck-Moderately long and well set, and blending well with the body with some crest in the lambs.......... 5

Fore-Quarters-TTell developed; breast wide, deep and full; brisket, broad; chest, capacious with good heart girth; shoulders, broad, oblique and well filled in the neck vein and crops; withers, broad; arm, well developed...... 15

Barrel-Roomy; back, straight, broad and well fleshed throughout its entire length; ribs, well sprung and moderately deep; fore and hind flanks, full and deep.... 15

Hind Quarters-Long, deep and full; tail, broad and well set up; buttock, broad; twist, full; thigh, broad and full... 15 
Feet and Legs-Straight, of medium length with flat bone; bare of wool below the knee and hock, glossy black in color and set well apart.................. Fleece--Moderately short with close fine lustrous fibre, and without tendency to mat or felt together, or to shade off into dark or gray wool or hair, especially about the neck and tail. The fleece should cover the whole body except the head and the legs below the knee and hock; and the skin underneath it should be fair, soft and of a pink color........................ 10

Total.................... 100

\section{Che Short-Kalooled Breeds.}

\section{Che Merino.}

The home of this ancient and famous breed appears to have been in Spain, from whence they were imported into France, England, Germany, the United States of America and Australia. They are the only truly, short or fine-wooled breed, and as raised in Spain, were distinctly a wool sheep. We cannot do better here than print verbatim an article written by Mr. E. N. Ball, Secretary of the Michigan Merino Sheep Breeders' Association, which fully covers the history of the breed and its first importations to this country:

"The ancestors of the American Merino, called by some at this late date Spanish Merino, Vermont Merino, etc., were imported to the United States from Spain. The true origin of the sheep and the country from which they eminated is somewhat uncertain, but at an early day fine-wool sheep of excellent quality were transported from Syria to Greece, from Greece to Italy, and from Italy to Spain. 


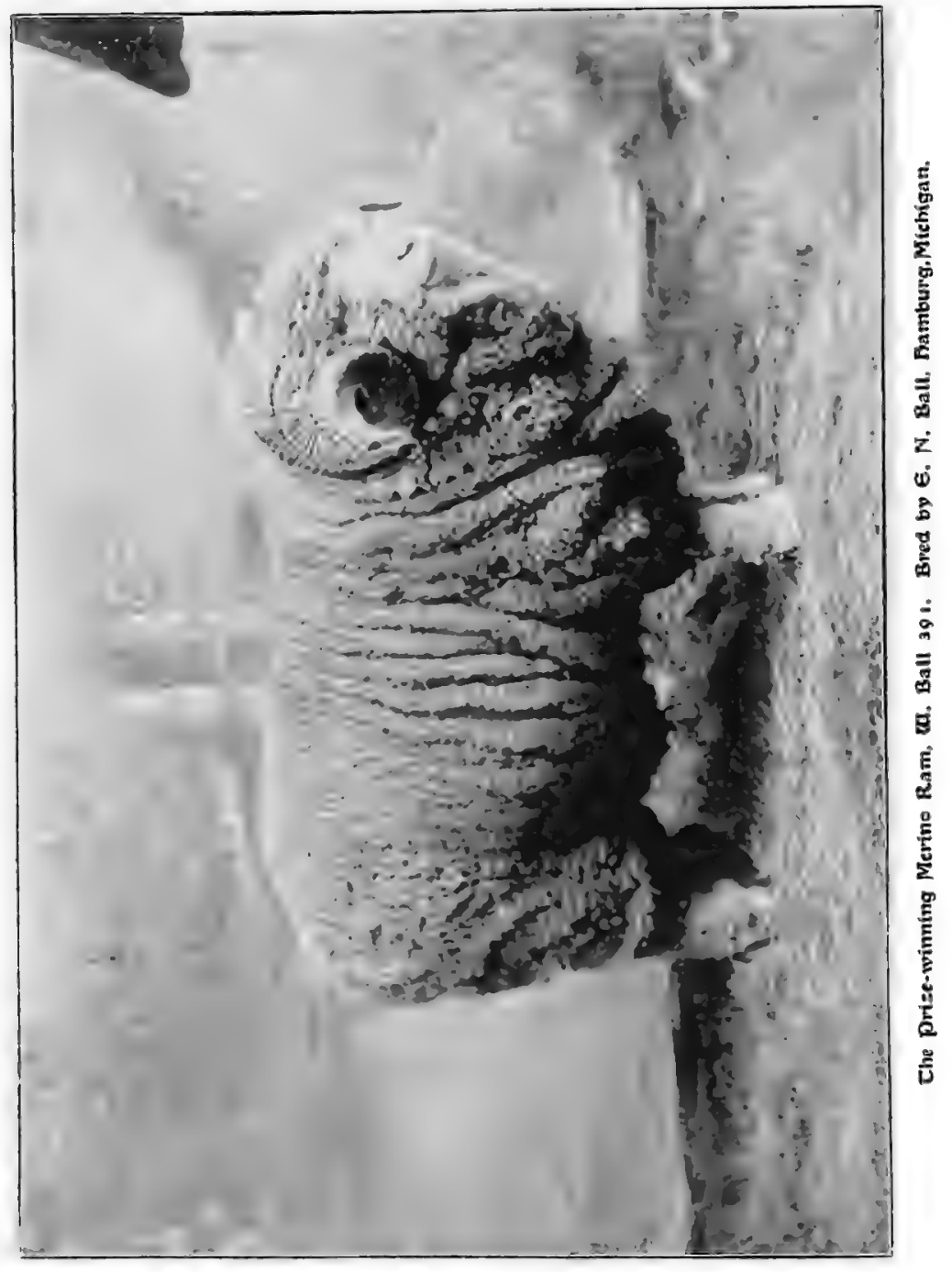


At a very early period Mliletus, a Grecian colony in Syria, was celebrated for its woolen fabrics, and listorians lead us to believe that not only the woolen goods but also the sheep that produced the wool were carried into Greece itself.

708 B. C., Tarentum, in Italy, was settled by the Greeks, and of this prosperous settlement mention is made of the production and manufacture of its excellent wool. The Tarentine sheep were unexcelled for their fine wool. Dr. Perry notes that the Spanish Merino and the ancient Italian race seem to hive certain qualities common to both. It was a marked characteristic of these sheep that the rams had horns and the ewes had none, and this is believed to be the only breed of short-wooled sheep in Europe presenting this distinguishing characteristic.

Morrell states that about the beginning of the Christian era, the sheep of Italy surpassed all others in the fineness of their fleeces, and according to Pliny 'the best wools are those of Apulia, which are of a very short staple.'

Youatt says of the sheep of Spain that they were probably imported from Italy. They were the Tarentine breed and had gradually spread to the western extremity of Europe.

These sheep once introduced and established never afterward were aliens to the country of Spain. In the eighth century the Saracens and Moors conquered a portion of Spain, which abounded in flocks and herds. These people were enterprising, and under their management the sheep increased in number and popularity, and to such an extent had grown the wool industry of Spain and so renowned her woolen fabrics that in the thirteenth century 16,000 looms were in operation in Seville alone, but later, when the Moors were expelled from Spain, the looms of Seville dwindled to sixty, and Spain was importing wool. In 1576 she exported to Bruges 40,000 sacks, each selling for no less than $\$ 45$. Others of finer quality were shipped to Italy at the price of $\$ 112.50$ per sack. For centuries the 


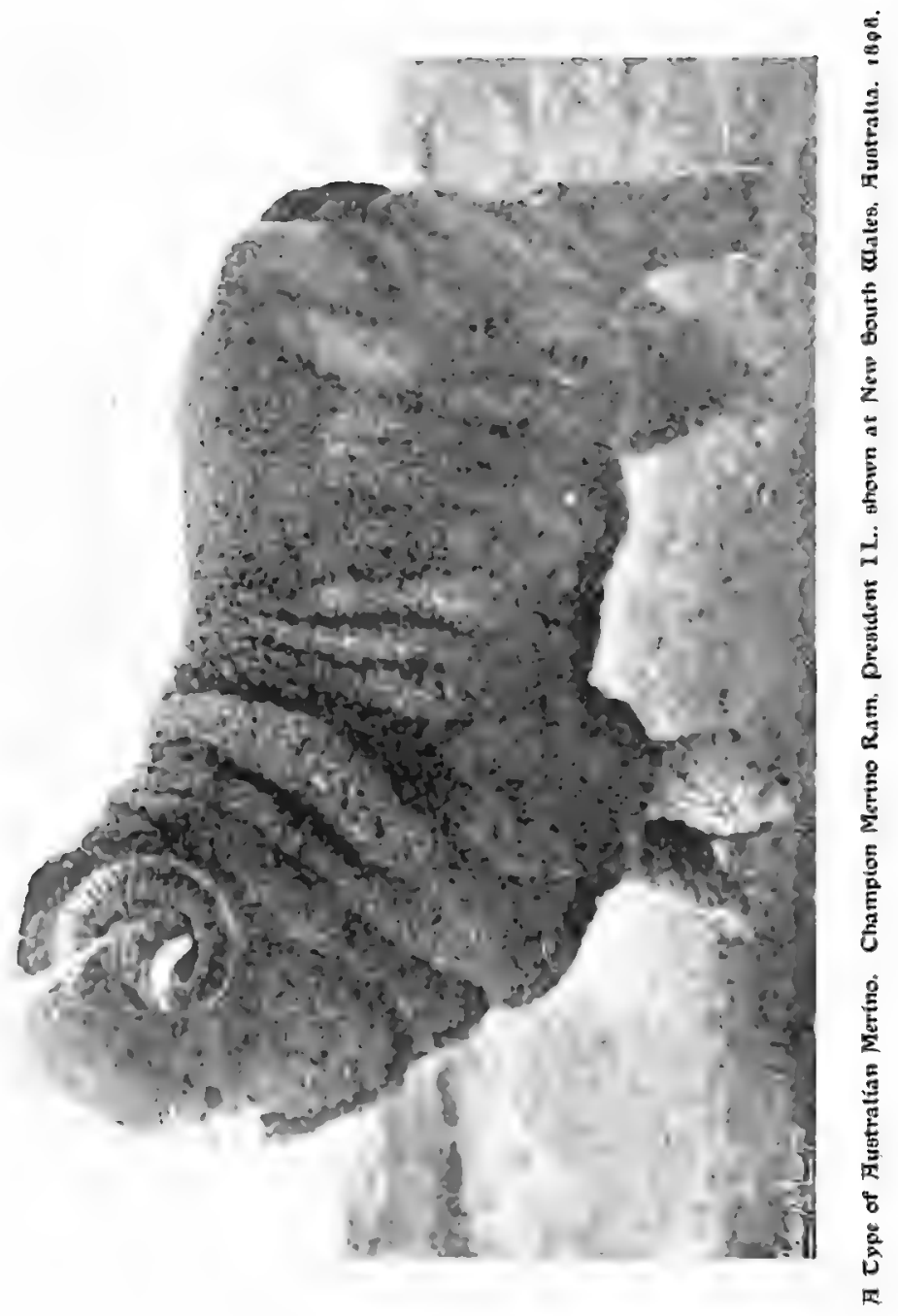


Merino sheep of Spain contributed largely to the support of the Government.

The Spanish Merino was of two divisions, transhumantes, or migratory flocks, and Estantes, or stationary flocks. The Transhumantes were divided into two classes, Leonese and Sorian. Of all the sheep of Spain those of Leon were superior in form, quantity and quality of fleece.

At the beginning of this century Dr. R. R. Livingston, many years a resident of Spain, says of this class of sheep there were about four or five million distributed as follows:

The Duke of Infantadoes' flock............ 40,000

The Countes del Compo de Alonse Negretti...... 30,000

The Paular Convent................. 30,000

The Escurial Convent................ 30,000

The Convent of Gaudaloup.............. 30,000

The Marques Perales.................. 30,000

The Duke of Bejar................ 30,000

Ten flocks belonging to sundry persons........ 200,000

All other flocks in the Kingdom........... 3,800,000

As to the very first importation from Spain to the United States there seems to be a difference of opinion. One says in 1793 Mr. William Foster of Boston, Mass., imported two ewes and a ram smuggled through the port of Cadiz. These Mr. Foster gave to Mr. Andrew Craigue of Cambridge, who, not knowing their value, killed and ate them. Another says the first importations was by William Porter of Boston in 1798 of two ewes and a ram. These he gave to $\mathrm{Mr}$. Andrew Craigue of Cambridge, who, not knowing their value, killed and ate them. One thing seems pretty certain, the first importations of Spanish Merino sheep into the United States disappeared as mutton, and were of no account from a breeding standpoint, but beyond a doubt the mutton was good. In 1801 Seth Adams imported a 
pair of Merino sheep that were taken to his farm in Zanesville, O. In 1801 a Merino ram, "Don Pedro," was imported, being one of four selected, the others having died, at the request of Mrr. Dupont de Nemones by M. Delessert of Paris, who was at the head of a commission to select in Spain on behalf of the French Government a flock of 4,000 Merino sheep.

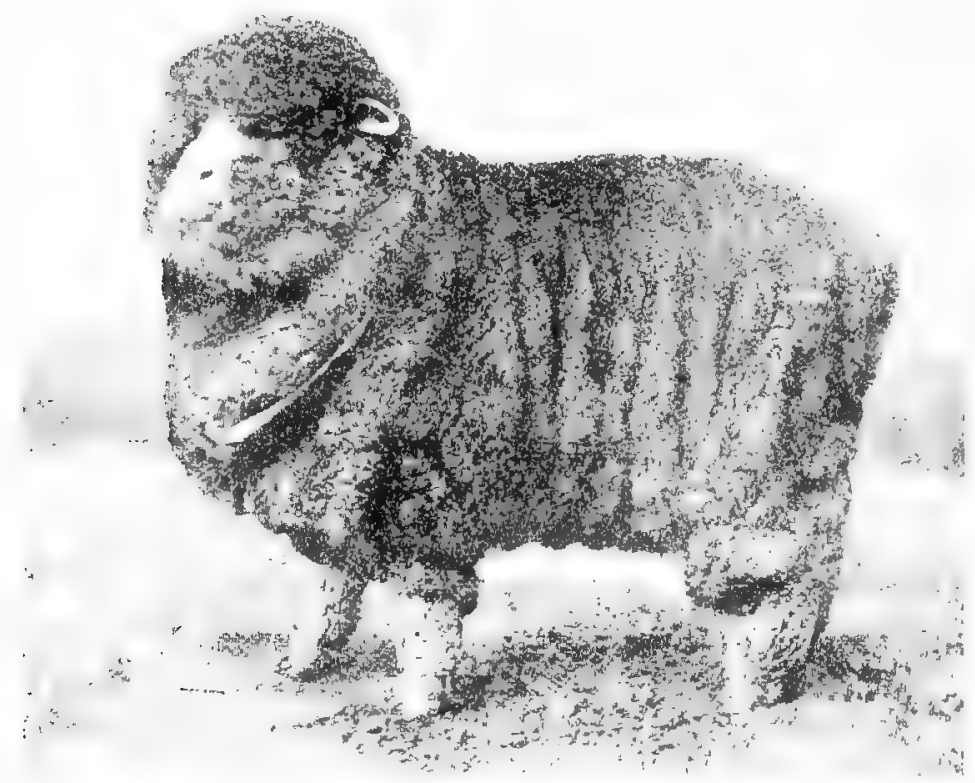

Champion Merino Ewe, Daisy. Shown at New Bouth đales, Hustralia, 1898.

The first importation of value was on the 10th of April, 1:02. Colonel David Humphreys shipped at Lisbon seventyfive ewes and twenty-five rams-pure Spanish Merinos one and two years old, and after a voyage of fifty days landed seventy ewes and twentr-one rams in the United States, which were taken to his farm at Derby, Conn. The larger portion of the ewes 
were retained in one flock, but a portion of the rams were sold to neighboring farmers for improvement of their flocks. In 1803 Dr. James Meares of Philadelphia imported two ewes and two rams.

1809 William Jarvis procured 200 Mermos of the Royal Escurial flock by special faror, and these, no doubt, were the only Escurials ever imported. In $1810 \mathrm{Mr}$. Jarvis procured 1,400 Spanish Merinos of the Paular flock. These sheep were from true Transhumantes, from the best flocks, and were undoubtedly among the best sheep imported into the United States.

Mr. Jarvis imported approximately 1,400 Paulars, 1,700 Aguirres, 200 Escurials, 130 Negrettis, and about 200 Montarcas-3,630 in all.

In 1810 Gen. E. H. Derby made a shipment which resulted in landing 300 to 400 Merinos. In the same year, 1810, Peck and Atwater of New Haven, Conn., imported a flock, and in January, 1811, Heaton \& Co. of New Haven, Conn., landed a cargo which were taken to Connecticut.

From these early importations the Spanish Merino fast became scattered throughout the Eastern portion of the United States. The improvement has been steady until the original Spanish Merino is lost sight of in the more perfected animal, known as the American Merino, reared in a large number of States from the far East to the extreme West, and there is not a State in the Union where sheep are bred that the stamp of the American Merino is not seen, and exports have reached to Australia, Africa, and South America."

In the management of Merino flocks in Spain great care is exercised to promote the growth and prevent injury to the fleece from any cause whatever. They are constantly under the care of shepherds, who house them whenever it rains, and are always stabled at night. The average amount of fibres to the square inch of skin surface is from 40,000 to 48,000 , far in excess of the 
number of any other breed. The length of the wool varies from one to four inches. As a general description we find the Merino is of fair size; head handsome; decorated with horns, the head short around ears and well covered with wool. The horns are open and wide, well turned and marked with fine transverse wrinkles. The nose is short and may be pink in color, but a darker shade is preferable. The neck is short but full and gains character from the heavy folds of skin which adorn both males and females. The shoulders should be very wide over the tops, the body long, ribs deep and well sprung. The legs are short, the hocks incline to be cat-hammed. Folds of skin are gathered round the base of the tail which, from their disposition, are called the rose. The wool must grow over the whole body down to the claws, and wool fibres are often seen growing out of the clefts of the hoof.

\section{Che Rambouillet.}

The origin of the French Merino dates back to 1721, when some ewes were imported from Spain into France. This importation was followed by another about 1750 , and in $1776 \mathrm{M}$. Trudaine, the French Ilinister, imported another flock. In 1785 Louis XVI., King of France, who owned an estate called Rambouillet, established there an experimental farm and obtained permission to purchase and export from Spain a flock of purebred Merinos, which he placed on this estate. This importation was made from the finest flocks of Spain, being selected from the flocks known as the Serales, Paular, Negretti, Escurial, Alcola, San Juan, Portaga Iranda and Salezar. Of this importation 366 head, composed of forty-one rams, 318 ewes and seven wethere, arrived safely at Rambonillet, although thirty-five of the ewer and sixty lambs succumbed to foot-rot soon after their arrival. 


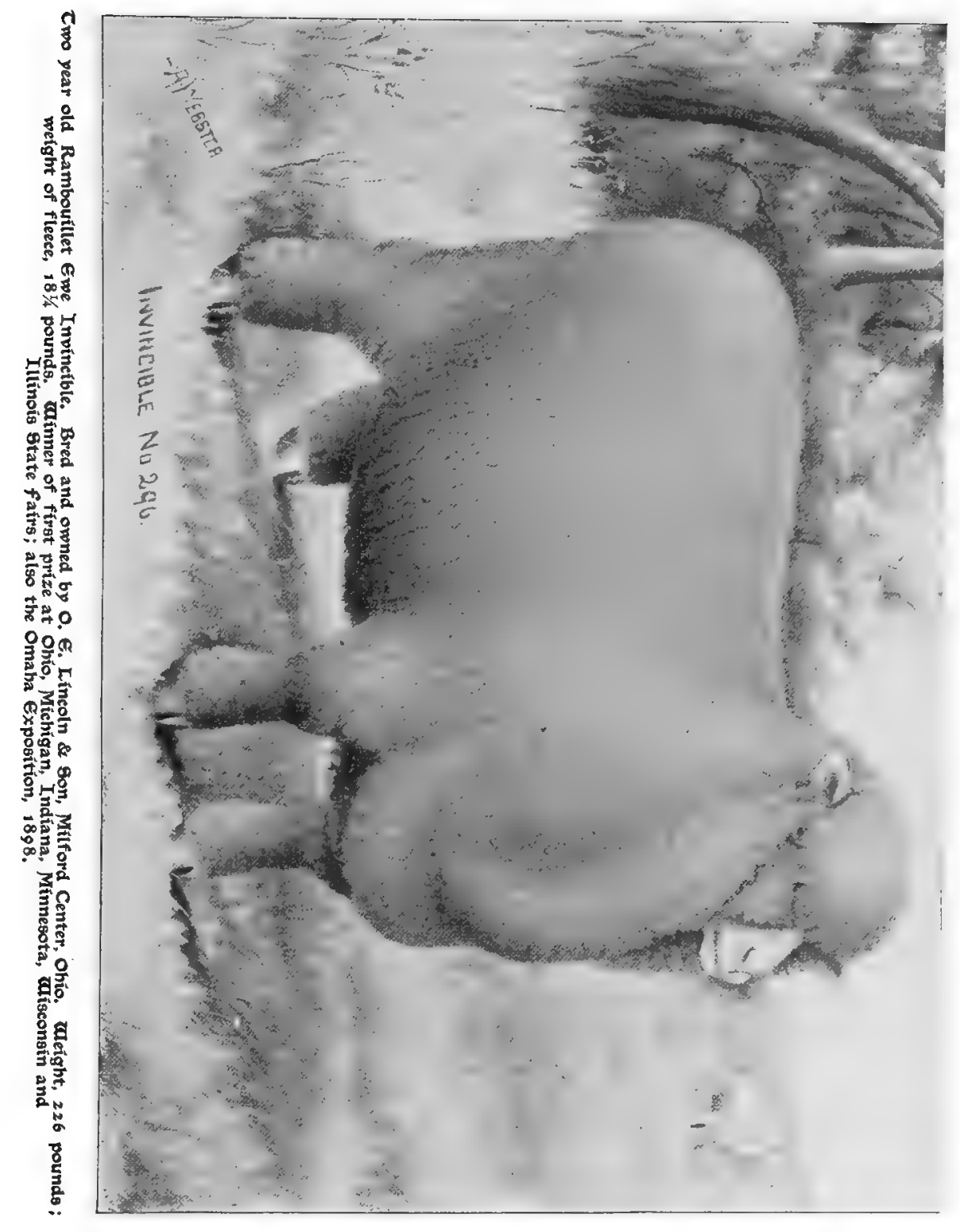


The Rambouillet flock, after surviving many vicissitudes during the French Revolution and subsequent reconstruction period, was the subject of close attention and care on the part of the French authorities, an exact record being kept and every means taken to insure its well-being. About 1834 several of the English mutton breeds were imported into France. The cross of those on Merinos being favorably thought of by the French agriculturists induced the management of the Rambouillet flock to increase the size of their sheep, the increase being obtained solely by selection and feeding, thus maintaining the purity of the breed. In 1850, continuing these methods, the Rambouillets had become large in carcass, but less robust in constitution, accompanied also with a diminution of the fleece. To overcome the last two defects a return to original conditions became necessary, the Negretti type becoming the favorite, till in 1867, the flock improved in regard to the production of wool, and became able to support itself exclusively on pasture, and endure the hardships incidental to weather changes and dry seasons, for which the high feeding and long continued pampering had almost ruined it.

The first importation of Rambouillets to the United States was made by D. C. Collins of Hartford, Conn., in 1840, who succeeded in obtaining two rams and twenty ewes. Later, in 1846, a Mr. John A. Taintor secured two rams and seven ewes from the Gilbert flock; these were also brought to Connecticut, subsequently being purchased by A. L. Bingham of Cornwall, Vt. These first importations did not prove popular, however, and it was not till some years later that this particular class of Merino found favor among the flock-owners of this country.

The Rambouillet Association was organized in March, 1890, the list of members and number of animals recorded inereasing year by year. 


\section{Delaine Merino.}

Is supposed to have sprung from an importation of Infantados, imported about 1810 by R. W. Meade, part of which in 1820 or 1821 passed into the hands of a Mr. Alexander Reed. Later several parties purchased sheep from Mr. Reed, and these then became the base for that particular type called the Delaine.

These were a small sheep originally, but by good feeding and careful selection they soon developed into large-framed, black-topped sheep, with an abundant fleece.

The mating of the Dickinson Merino with the Meade sheep appears to have been the origin of the new Delaine, and while no one or two individuals can claim to have been the ancestor of this particular class, as the breeders made selection from all the best Merino flocks which had been imported from Spain, there appears to be no doubt that to the Meade or Dickinson stock the chief credit is due.

In 1882 an association was formed to record all such animals as were eligible to registry in the Register of the Association, only sheep designated as belonging to the Victor-Beale Delaine Merino were to be admitted to registration.

Mature rams should weigh not less than 150 pounds and the ewes not less than 100 pounds.

Scale of points as given by the Delaine Merino Sheep Breeders Association is as follows:

Constitution ...................... 10 points Heavy round the heart................. 6 points Short heavy neck..................... 6 points Good dewlap..................... 5 points Broad back....................... 8 points Well sprung ribs.................... 5 points Short legs...................... 6 points 
Heavy bone.................... 8 points

Small, sharp foot.................. 10 points

Length of staple, one year's growth three inches... 8 points

Density of fleece.................... 8 points

Darkish coat on top................. 5 points

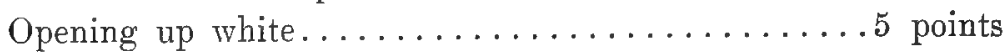

Good flow of white oil............... 5 points

Good crimp in staple................. 5 points

Perfection.............100 points

\section{Mountain Breeds.}

Of these breeds we shall only take special notice of two, viz., the Cheviot and the Herdwick, - the first named breed claiming more particular notice, importations of them having been freely made to the United States. The Herdwick can be taken as a type of other mountain breeds, of which there-are quite a number, differing only one from the other in name, possessing, all more or less, the same general characteristics.

\section{Che Cheviot.}

Takes its name from the hills which it has grazed over for a period of centuries. They are a hardy sheep, fitted to thrive on scanty pastures, and contend with the climatic changes so prevalent in their native hills. Beyond a doubt their present existence has largely been due to the law of "survival of the fittest," they being the one brced out of many others which frequented the same district which withstood the test of time, not only having held their own, but spreading out, obtaining foothold in many localities other than their native hills. 


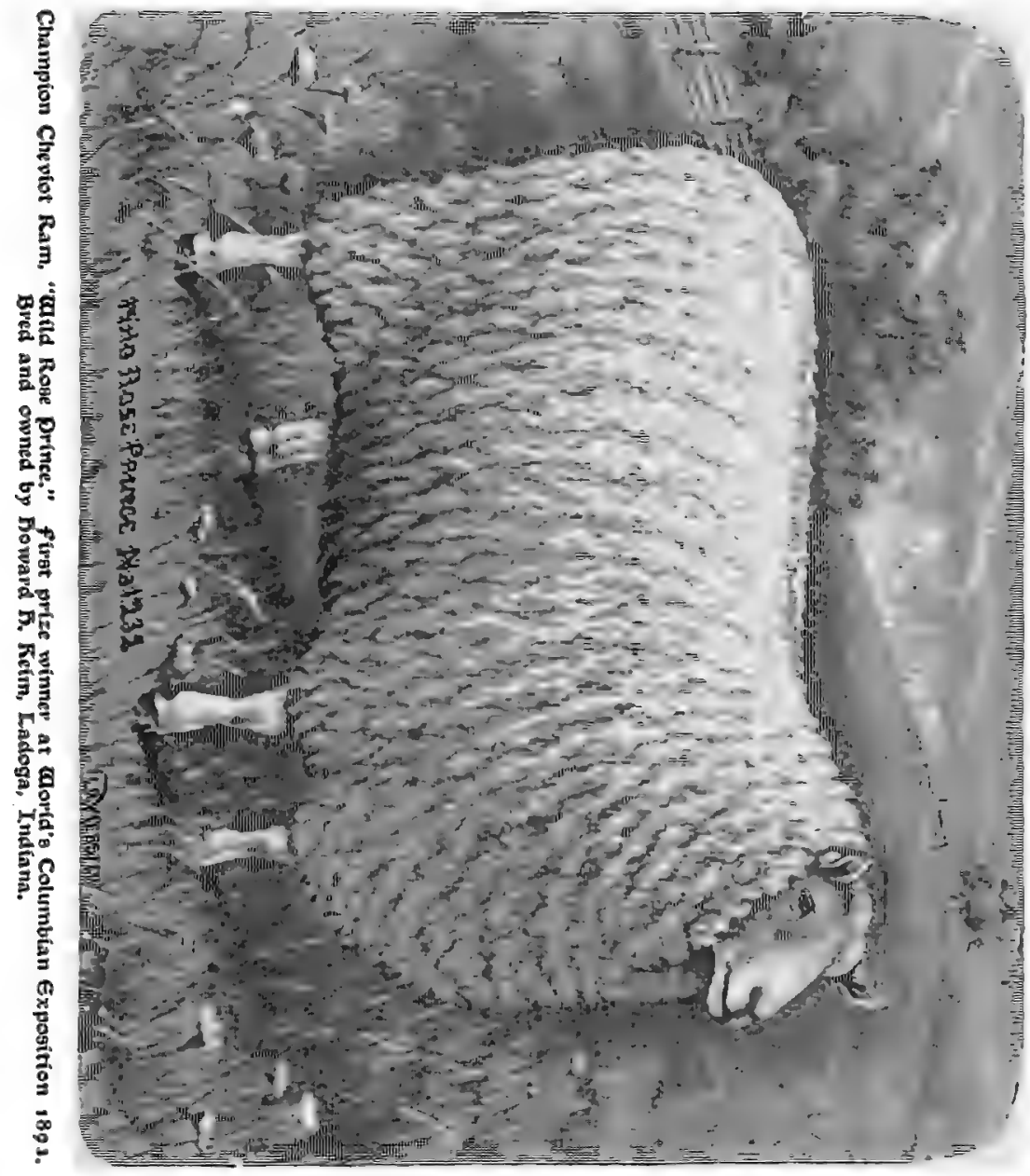


They are a white-faced, hornless sheep, carrying a fine, short fleece. Like the majority of mountain sheep, they are liable to be light in the fore-quarter.

Their designation as Cheviots appears to have been given them in 1792 by Sir John Sinclair. They were termed long sheep (meaning length of body) in contradistinction to the blackfaced or short sheep - a breed more especially to be met with in the North of Scotland, the stronghold of the Cheviot being in the South. The first improvement of the original stock appears to have been about 1755 or 1756 , by the judicious admixture of Lineoln blood; they have also been greatly benefited, as have many other of the prominent breeds of to-day, by crossing with the improved Leicester However, experience has proven. that to maintain the characteristic hardiness of the race, it is necessary to breed them pure. As a mountain sheep they are unexcelled, and should prove valuable to withstand the hardships of the Western mountain ranges.

\section{Che Бerdwick.}

Is a native of the North of England Lake Region, grazing over the beautiful mountain districts of Westmoreland and Cumberland. It has become famous throughout the North of England more on account of the delicate flavor of its mutton than for its wool-growing qualities.

Tradition places the origin of this breed at the time of the defeat of the Spanish Armada in 1588, stating that a Spanish vessel, in trying to escape, ran aground on the coast of Cumberland, and that "forty small sheep managed to save themselves from the wreck, swimming ashore at Drigg, and were claimed as jetsam and flotsam by the lord of the manor." For the last 300 years they have held their own in the district, being peculiarly adapted to their mountain ranges. 
In general appearance the Herdwick is a small sheep, carrying a heavy fleece, which is disposed to be heavy on the top of the shoulder; the wool grows well down to the knees and hocks, the poll and belly being well covered. The head is broad, nose Roman, the nostrils are wide, jaws deep; the eyes are prominent and lively; the ears are fine and white. The faces and legs of lambs when first dropped are black, a few white hairs, however, being visible at the tips of the ears, and also in some cases round the feet. The white hairs gradually increase till at three years of age the white predominate, some being perfectly white, otluers a steelish grey.

The rams generally are horned, the horns starting weil at the back of the head, and curled. The hoofs should be white.

There are no records to show that any of this breed have been imported to America, and it is doubtful whether ther would prove a useful addition to the stock of the country, being small in size, and carrying a poor quality of wool. Their only recommendation is their inherent hardy constitution to overcome the above mentioned disadvantages. 


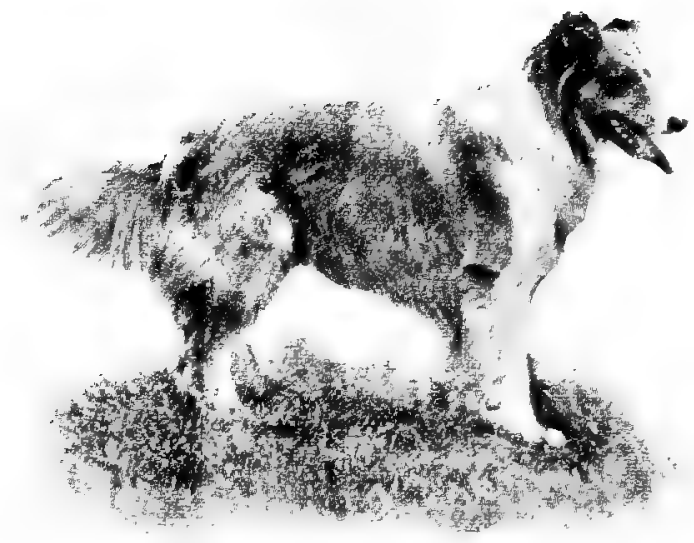

famous Imported Collie, Cleveland Derfection, sired by Southport Derfection. Imported and owned by Robert 5. Clest, Cleveland, Ohio. 


\section{CHAPTER III.}

\section{Che ralool Industry.}

The manufacture of woolen goods dates back to Bible history. As stated in the introductory chapter of this work, the Romans introduced the arts of weaving and spinning wool and established a factory for the same at Winchester, England, soon after their conquest of that country. Under the Saxon monarchy following the Roman exodus from Britain, we find that wool spinning became universally followed in all households, and so high was the art esteemed that princesses and noble ladies learned to spin, and from the habit being universally followed by the female members of the families the word spinster for unmarried ladies has been handed down to the present time. In the time of the Wars of the Crusades, and even later, we find that wool reprsented the national wealth, frequently being used to supplement the limited coinage of those times. It was accepted in payment of ransoms and as collateral security for the sinews of war. Later Holland excelled all other countries in the manufacture of woolen goods up to the time of its conquest by Spain. Then the industry suffered from the tyrannical imposts of the governing power, which finally drove the artizans to seek other lands. England afforded many of these exiles protection, and to this source is directly traceable her superiority in the art of woolen manufactures, which to a certain extent she retains up to the present day.

Wool, unlike hair, grows in a spiral form, is softer and more pliable, due to a fatty secretion issuing from the glands situated in the cutis vera or true skin, which supplies the rolk of the 
fleece, preventing injury to the wool fibres from cotting or felting from the constant friction while upon the sheep's back.

Wool resembles hair, in that each filament is a minute tube flled with pulp, covered externally by a scaly covering formed by flat cells, the edges of which over-lapping each other, give the filament a serrated appearance when examined under a high magnifying power, to which also the wool owes its felting properties and its adaptation for clothing purposes. The felting property and other qualities of different wools have long been known by practical experience, but that felting was due to the serrated edges of the individual wool filaments is a comparatively recent discovery which was made in 1795 by a Mr. Monge in France, and later, but independently, by a Mr. Youatt in England. Different wools were found to possess a greater or a less number of serrations to the inch in length, the felting property depending on the increase or decrease of the serrations. It was found that in Merino wool (Saxony) the serrations ran as high as 2,700 to the inch, in the English Southdown 2,050, and in the Leicester 1,850 .

Fine wool, possessing a greater number of serrations and growing in a spiral form, being superior in its felting properties to the coarser goods.

Wool when it is to be manufactured first undergoes the process termed carding. The card is an instrument which breaks the wool, dividing it into a multitude of fragments, which from its spiral form are left in a curved state. When pressure and moisture are applied the serrated and curved filaments intertwine and lock together. This is termed felting. After wool is carded it is spun and woven into cloth, being oiled during this process. Following this it is treated with Fuller's earth to extract the oil, the moisture and pressure which are now applied calling out its felting properties and giving the cloth a close and dense appearance. 
Wool for worsteds is treated very differently. Instead of being carded, it is combed. This consists in combing it out smooth and then spinning it, giving it a looser appearance, thus accounting for the more open texture which carpets possess as compared to cloth or carded goods. Raw wool passes through eleven different stages before the manufacture is completed, viz: Sorting, washing, drying, plucking, combing, breaking, drawing, roving, spinning, reeling and weaving.

Wool is generally classed as long or short, being graded as superfine, fine, medium and coarse. The same fleece will be made up of wool of the various degrees of fineness, it being the business of the wool stapler or sorter to separate these varions qualities and prepare them for manufacture. The fleece is unrolled; the wool sorter then selects the fine locks from the coarse; the finest wool is selected from the neck, shoulders and sides; the next best from the upper part of the legs and thighs, extending to the haunch and tail; the inferior wool being distributed on the upper part of the neck, throat, belly, breast and part of the legs. The stapler then divides the finest wool into ten lots, classed according to the degree of fineness, commencing with the pick lock, then the prime, the choice, the super, the head, the downrights, the seconds, the abb, the liver, and lastly the breech wool. These are the divisions which are found to exist in a single fleece. On the sheep's back the following points are taken into consideration:

1. Strength of fibre.

2. Fineness.

3. Curl.

4. Thickness.

5. Closure of the fleece. 
1: TIIE STRENGTH OF FIBRE. This is indicated by the amount of rolk in the fleece. When this is small in quantity the fibre becomes dre and brittle in character.

2. FINENESS. The wool should be fine in quality all over the carcass, the diameter of the filaments ${ }_{1000}^{\frac{1}{0}}$ to ${ }_{12 \delta}$ of an inch in thickness.

3. ('LRL. This is the raved appearance of the wool fibres. These wares should be uniform and numerous throughout the length of the fibre.

4. TIIICKNESS. This means the closeness of the fibres upon the skin, which raries according to the breed, those of the pure-breil Merino being as many as 48,000 to the square inch of skin surface.

5. CLOSTRE OF FLEECE. This is important. A well-closed fleece renders the wool impervious to dust and dirt, which would be injurious to the quality of the staple. The closure is formed by the matting together of the frec ends of the wool fibres through the riscid properties of the volk. This g'ummy sulstance gathers the dust, which forms a black coating to the fleece, making a crusty covering, which when lightly pressed upon feels elastic to the touch. The bad qualities of a fleece may be enmmerated as follows:

1. Stripr or watery wool.

2. Toppiness.

3. Felty wool.

4. Hemp.

5. ('loudy wool.

6. Broad-topped wool.

ヶ. Break.

1. STRIPY OR WATERT WOOL is generally fuund in cr near the shoulder, where the best wool should be. This wool 
is called stripy on account of the straightness of the fibres, the natural wares or curres being absent, when pressed between the fingers it appears lifeless; devoid of elasticity; more like cotton than wool. This staple is only fit for very inferior goods, and sheep with this defect should not be bred from.

2. TOPPINESS. This is where the tops of the wocl fibres do not join together evenly to effect a perfect closure of the fleece. This defect frequently causes a matting together of the ends of the points of the wool, making when the wool is worked, a quantity of noils, causing waste. This may be due to uneven growth in the early life of the lamb, in which case, after the first shearing, it will not be liable to recur. When present in old sheep it indicates a defect in the animal's breeding.

3. FELTY WOOL. This is caused by an absence of yolk in the wool, which allows the wool fibres to felt on the sheep's back. It may be due to exposure to wet weather long continued or more frequently to a low condition from poor feed, or chronic ill health. Sheep possessing felty wool as a constitutional defect should not be bred from.

4. HEMP consists of hairs interspersed among the wool fibres. It may be detected on the face and forearm, and in rams on the scrotum. Whenever it is found in these localities it will be present throughout the whole fleece. These hairs being white and not taking the dye, injure the fleece for the manufacture of dress goods and fine cloth to such an extent that a fleece so affected is reduced by value one-half. Sheep with this defect should be sold to the butcher, as they are worthless for breeding for wool, the defect being hereditary.

5. CLOUDY WOOL is a condition where the fibres adhere together from the skin to the points of the wool, but not to such an extent as to be termed felty. A flossiness is apparent at the bottom of the staple which, in combing, is removed, while in 
carding wools this is not so objectionable; in combing wools the floss is thrown out, and becomes waste. This defect is also hereditary. Sheep so affected should not be bred from.

6. BROAD-TOPPED WOOL is a very serious defect. It consists of an interlacing of the fibres, which are split, the top appearing even; but the surface is divided into broad masses, or, as they are commonly termed, "tops," and on endeavoring to part the wool, it will be found felted together, tearing apart with difficulty. Broad-topped wool is dead, deficient in yolk, breaking off in the process of manufacture, causing a very great loss of material. This affection is also hereditary, and should preclude the animal from breeding.

7. BREAK IN WOOL renders the fleece worthless as far as combing is concerned, and no matter how fine the staple may be as regards quality it can only be used to manufacture the class of goods which are made from inferior wool. A breachy staple when stretched out for examination will be found to part with great ease down the middle or in some other part, showing a weak place in the wool. On examining the fibres microscopically at this spot they will be found of a dead, stripy appearance. This defect being present in the staple, makes it impossible to sort, and causes the entire fleece to be classed as inferior in quality. This is a common defect, and is generally due to mismanagement in feeding or exposure or any other cause affecting the condition or health of the sheep. The weak spot in the fibre is carried forward as the wool grows. If the cause is removed, however, the wool may regain its normal condition. To avoid this trouble the flock should be fed and watered regularly, and shielded from undue exposure, as a check for a short time is a frequent cause of this serious trouble.

Another cause, and the most general one for break in the wool, is the use of caustic solutions in sheep dips, especially the 
lime and sulphur preparation. It is a fact that the majority of the wool clip from the Western States, namely, Colorado, New Mexico, Arizona, Wyoming and Utah, is seriously depreciated in value from the fleece containing this defect, and it has been argued more particularly at Farmers' Society meetings in the East by certain local authorities that it was due to the alkali dust robbing the fleece of its natural yolk. This idea is erroneous, however, a properly topped fleece containing the normal amount - of yolk will not permit the entry of foreign substances, whether it be dirt, sand or alkali dust; but the mere fact of dipping sheep in the solution above mentioned, which robs it of its power of . self-protection, is almost wholly responsible for this defect in Wrestern fleeces. This is easily shown. Sheepmen who use standard preparations which contain mineral or vegetable vils and which do not exert caustic properties on the wool fibres, do not experience this difficulty in the fleece.

Mr. H. W. Smart of Ogden, Utah, who runs between 50,000 and 55,000 sheep on the range annually, in talking to the writer on the subject of dips made this statement: "We have had to fight the scab year after year, and have used lime and sulphur because it was cheap. There is no doubt that it is injurious to the sheep, causing break in the wool, besides exerting a cauterising effect of the skin, and we are continually experimenting with and are on the lookout for something to take its place which will not be too expensive." If Mr. Smart was to take into consideration the amount of money which he loses annually from this defect in his wool clip from the use of the abore named solution, he could well afford to use some preparations which are known to be effective, and which do not cause this defect in the fleece, even though it cost him five cents per head to dip his sheep.

While the production of wool in the United States has steadily increased from vear to year, the supply has never been suffi- 
cient for the home demand. We find in 1850 there were, all told, 21, 223,220 head of sheep in the Cnited States, according to statistics of the Agricultural Department. In January, 1897, the total number amounted to $36,818,643$ - an increase since 1850 of $15,095,423$. But when the corresponding increase in the population of the country is taken into account, we find that the sheep supply falls far short of keeping pace with the growth of the population.

On next page we print a table showing the amount of wool imports into the United States from 1893 to 1898, inclusive, as compared with 1838.

The exportation of wool from this country being of such small amount it is only necessary to state that the total exportation for the year ending June 30,1896 , amounts to only 855,950 pounds. The above figures being correct, it becomes apparent that so far as wool is concerned, there is no probability for some rears to come to fear an orer-production. The sheep industry is steadily on the rise, with prospects of higher prices for wonl, and an increasing yearly demand for feeders. 


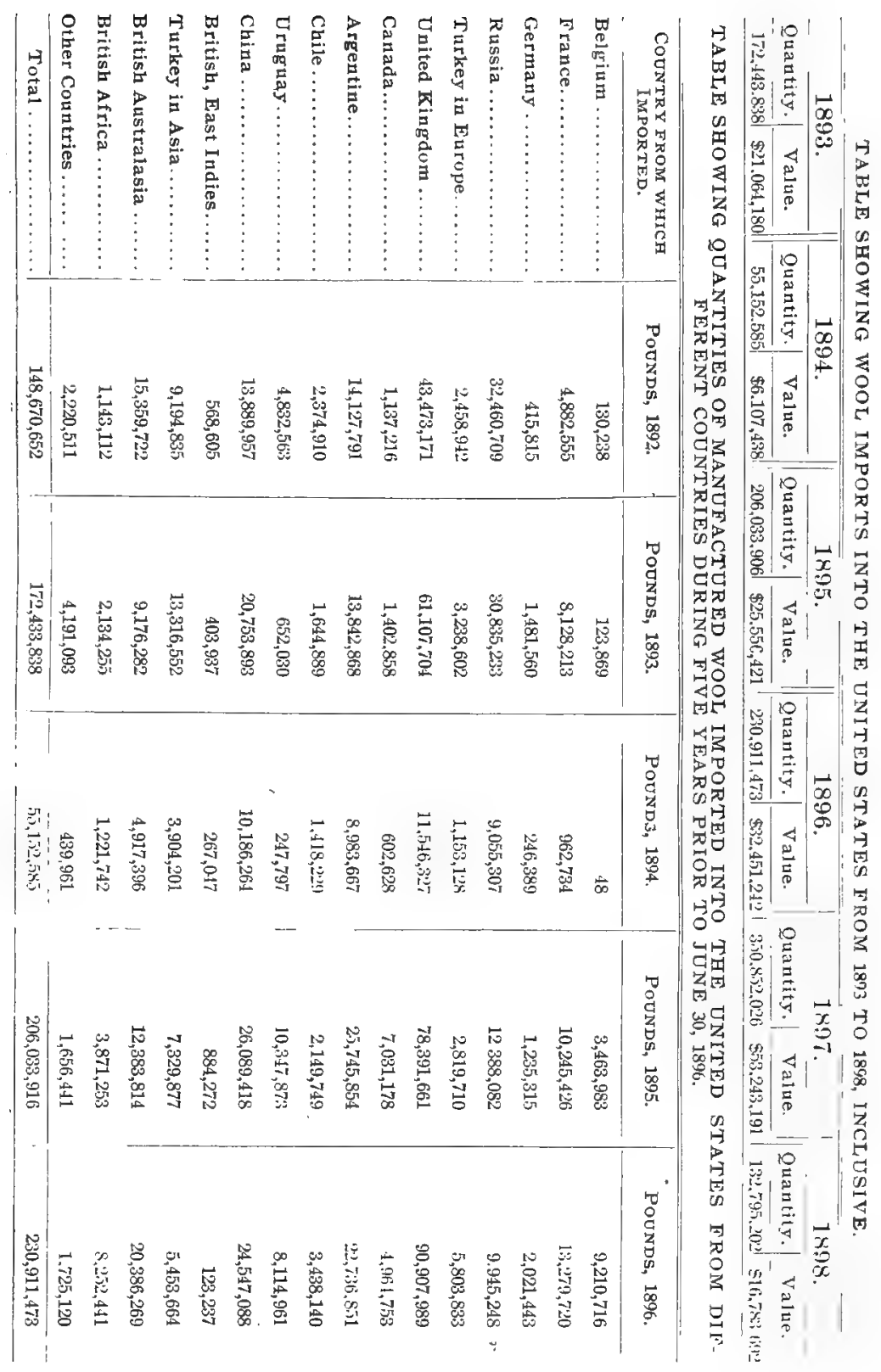




\section{CHAPTER IV.}

\section{feeding and fattening.}

It is only of recent year's that the industry of feeding sheep in this country for the home and export trade has assumed large. proportions. Formerly the sheep were valued more for the wool they produced than their mutton qualities, but as wool depreciated in value and the people at large became educated to the value of mutton as an article of diet, chiefly through the crossing of valuable foreign mutton breeds on the native stock, the matter of feeding sheep to meet the demand clained the attention of the flock-owncrs, until at the present time sheep feeding has become of almost as much importance as wool growing. It is our aim here to show the various methods in feeding adopted in different parts of the country, which, necessarily, have to vary to suit different localities and conditions. Naturally the attontion of feeders is called to consider what particular breed has the most aptitude to make flesh and fat, also what particular class will fetch the highest price on the market he is feeding for. For instance, a feeder expecting to supply the export trade will feed only such animals that have a large carcass, the demand abroad being for large mutton, while that which brings the top. price at home is the medium size to small of frame when prime.

Again the majority of feeders in this country are not breeders, but rely chiefly on the supply from the Western States and territories for their stock to feed. That being the case, it remains to be seen what is considered the best class of sheep to feed.

Of late years the common lambs from New Mexico and Southern Colorado have sprung much into favor, their points of 
adrantage being their ability to fatten quickly, adapt themselves to different climates, and being small in carcass, rarely weighing over ninety-five pounds when prime, they fetch the top market price, being eagerly bought by the butcher on account of the small amount of rvaste in killing, white fat and finely flavored inutton.

These sheep are generally bought by a commission buyer, who distributes them around to his customers. As soon as they arrive at the feeding pens they are given all the hay (alfalfa if obtainable) they will eat. Then after the first week they are put on ration of oats, commencing with a small quantity, which is gradually increased until at the end of the fourth week they are eating about a pound per day to the head. Corn then is gradually introduced with the oats, the feed of oats being cut down as the corn is substituted until the sheep are on corn only, eating about one-half pound a head per day at the end of the sixth week. From now on the corn is slowly increased till full feed is reached, which means just what they will clean up without leaving any in the feeding troughs. It is a good plan once a week, every Saturday for instance, to substitute oats for the corn. The sheep will be found to relish the change and come back to their corn next day with a renewed desire for it.

Rock salt should be kept in the pens at all times. They should be watered twice a day, excepting in very cold weather, when once will be sufficient. This should always be prior to feeding. The feeding should be done at regular hours. For instance, if a pen is fed at 4 o'clock P. M. one day, it should be fed at the same time or as near that time as possible every day. Regularity in feeding will be found rery essential to success. This is the general method of feeding Mexican lambs in the IVestern States, where no sheds are required, where the air is. dry and climate uniform. During the last year a number of Mexican lambs have been imported into the Eastern States to. 
feed, especially in Ohio and Michigan and even as far East as New York, and it is a question whether the same success will crown the efforts of the Eastern feeders, the climate being diametrically opposite to that of the Western States, sheds being a necessity and higher priced feed having to be taken into consideration.

\section{On the feeding of Sheep in General.}

A certain amount of food is required to enable an animal to live and remain in health. This is termed the necessary ration of food. Should this be diminished the animal will fail in flesh, and in time die; vice versa, if more than the necessary ration be fed than is requisite to repair the natural waste of the animal body it will gain flesh, or give an increase, if a female, in the milk supply or wool.

A full-grown sheep takes 2 1-3 per cent. of its weight in hay per day to kcep in ordinary condition. Growing animals should be given all they will eat readily. Quietude and warmth greatly facilitate the process of fattening; that this is a fact is easily shown. Ilotion increases waste of tissue, causing an increased respiration to supply the extra amount of oxygen needed; the excess of oxygen requires an increased amount of carbon, which is virtually wasted, whereas it should be expended in producing fat. Cold operates in a like manner, an extra supply of oxygen and carbon being required to produce extra combustion to restore the loss in temperature. Among herbivorous animals, to which class of course the sheep belong, the carbon required for the warmth of the system and respiratory process is in greater part supplied by the food the animal consumes, while in carnivorous or meat-eating animals it is chiefly supplied from the waste of the tissues of the animal economy. With carnirora, the whole of the food consumed can be converted into flesh, while with herbivora, only a portion is capable of being assim- 
ilated. $\Lambda$ simple analysis of the blood and flesh can be estimated as follows: For simplicity, we will take 10,000 parts instead of 100 , which will avoid the use of decimals, making it more intelligible to the general reader.

In 10.000 parts of flesh and blood we find:

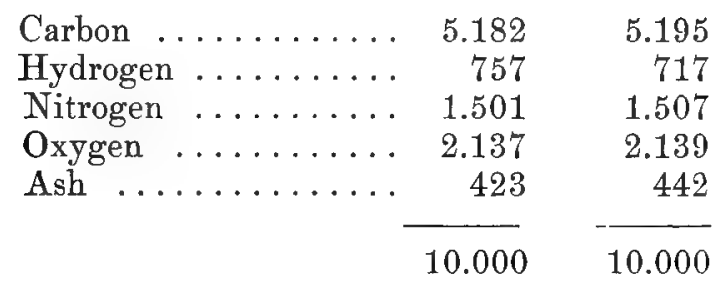

It will be apparent by comparing these figures that but a slight difference between the two exists, and that the proportion of carbon and nitrogen in both is practically the same. These are the proportions in which these two elements unite in the tissues of the body.

Nitrogen always will be found in the elements composing muscle structure, commonly ealled flesh. Any food deroil of nitrogen being valuless in nutritious properties. The difference between flesh and.fat can be said to consist in the absence of nitrogen in the latter.

An analysis of mutton fat, taking 10.000 parts again, can be estimated as follows:

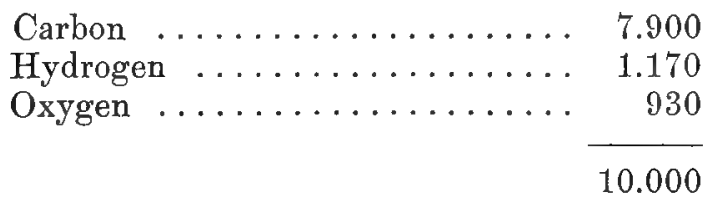

So it will be apparent that articles of food, such as oil, butter, starch, "sugar, etc., which are devoid of nitrogen, while they increase the development of fat, fail entirely to nourish the tissues, and so would in time fail to support life. 
Before giving a table of feeding stuffs, it will be as well to briefly explain the terms used. For instance, our analysis of the blood and tissues was found to contain carbon, hydrogen, nitrogen, oxygen and ash, and the value of a foodstuff will depend on the proportion of the above elements which it may contain. The oxygen and hydrogen will be taken into the animal body in the form of water. Wrater (all feeding-stuffs contain water), the amount varying from eight to fifteen pounds per 100 pounds of dry materials such as hay, straw, or grain to sixty to eighty pounds in ensilage, and ninety pounds in such roots as turnips, etc.

Materials containing nitrogen are classed as

Protein. These furnish materials for the creation of muscle-fibre, blood, skin, tendons, nerves, hair, horn, wool and the constituents of milk, known as casein and albumen, thus conclusively showing that protein is one of the most important constituents of feeding-stuffs.

Ash is the residue from the combustible part of any feeding-stuff, and is found chiefly to consist of potash, soda, iron, lime, magnesia, chlorine and carbonic, sulphuric and phosphoric acids. It is largely responsible for the formation and building up of the bones of the body, the excess of ash being voided in the manure.

Carbo-hydrates are free from nitrogen and are classed under the head of nitrogen-free, extract. They include fat producers, such as starch, sugar, gums, oils, etc., and form an important part of all feeding stuffs. Carbo-hydrates form the larger part of all regetable foods. They are either stored up as fat or consumed in the body to produce heat and energy.

A certain quantity of food being required to repair the waste of the animal economy, as has been stated heretofore, is termed the necessary ration. An excess of this ration means a 
corresponding gain in flesh, or fat, milk or wool, etc., while a diminution would mean a wasting or starving of the constituent parts of the body and finally death. In trying to ascertain the food-requirements of the sheep we cannot do better than print Wolff's tables for the same:

Per Day and per Бead.

\begin{tabular}{|c|c|c|c|c|c|c|}
\hline \multirow[b]{2}{*}{$\begin{array}{c}\text { Growing } \\
\text { Sheep. } \\
\text { Age. }\end{array}$} & \multirow{2}{*}{$\mid$\begin{tabular}{c|} 
Average \\
Live \\
Weight \\
per Head, \\
Pounds.
\end{tabular}} & \multicolumn{3}{|c|}{ Digestible Food Materials. } & \multirow[b]{2}{*}{$\begin{array}{c}\text { Total Or- } \\
\text { ganic Matter } \\
\text { Pounds. }\end{array}$} & \multirow[b]{2}{*}{$\begin{array}{l}\text { Fuel Value, } \\
\text { Calorics. }\end{array}$} \\
\hline & & Protein. & \begin{tabular}{|c|} 
Carbo- \\
Hydrates \\
Pounds.
\end{tabular} & $\begin{array}{c}\text { Fat, } \\
\text { Pounds, }\end{array}$ & & \\
\hline $\begin{array}{l}5 \text { to } 6 \text { mo. } \\
6 \text { " } 8 \text { " } \\
8 \text { " } 11 \text { " } \\
11 \text { " } 15 \text { “" } \\
15 \text { " } 20 \text { " }\end{array}$ & $\begin{array}{l}56 \\
67 \\
75 \\
82 \\
85 \\
\end{array}$ & $\begin{array}{l}.18 \\
.17 \\
.16 \\
.14 \\
.12 \\
\end{array}$ & $\begin{array}{l}.87 \\
.85 \\
.85 \\
.89 \\
.88 \\
\end{array}$ & $\begin{array}{l}.045 \\
.040 \\
.037 \\
.032 \\
.025 \\
\end{array}$ & $\begin{array}{l}1.6 \\
1.7 \\
1.7 \\
1.8 \\
1.9\end{array}$ & $\begin{array}{l}2143 \\
2066 \\
2035 \\
2067 \\
1966\end{array}$ \\
\hline
\end{tabular}

By calculating the daily ration of the sheep, assuming that the food consists of clover, hay, corn-silage, wheat bran, whole corn, barley or oats.

We find that the Wolff standard for growing sheep between the ages of six to eight months calls for protein .17, carbohydrates .85 of lb. and .040 of a pound or $40-1000$ of a pound of fat, which would produce 2,066 . calories of heat.

In 100 lbs. of clover hay, corn-silage, wheat bran, whole corn, barley and oats, etc., the following proportion of dry matter and digestible food ingredients will be found:

\begin{tabular}{|c|c|c|c|c|c|}
\hline Food Stuff & $\begin{array}{c}\text { Dry } \\
\text { Matter }\end{array}$ & Protein & $\begin{array}{c}\text { Carbo } \\
\text { Hydrates }\end{array}$ & Fat & $\begin{array}{c}\text { Fuel } \\
\text { Value. }\end{array}$ \\
\hline Red clover. & 84.7 & 6.58 & & 1.66 & 84,995 \\
\hline silage & 20 & 0.5 & & 0.6 & 714 \\
\hline Alfalfa ........... & 91.6 & 10.58 & & 1.3 & 94,936 \\
\hline Corn grains... & 89.1 & 7.92 & 66.69 & 4.28 & 156,836 \\
\hline Barley ........... & 89.1 & $8.6 \overline{9}$ & 64.8 & 1.60 & 143,490 \\
\hline Oats........ & 89.0 & 9.25 & & 4.18 & 124,757 \\
\hline Wheat bran...... & 88.5 & 12.01 & 41.23 & 2.87 & 111,138 \\
\hline Turnips ........................... & 9.5 & .81 & 6.46 & .11 & $\mathbf{1 3}, 986$ \\
\hline Ruta-bagas ..................... & 11.4 & .88 & 7.74 & .11 & 16,497 \\
\hline Linseed meal..................... & 90.8 & 28.76 & 32.81 & 7.08 & 144,313 \\
\hline
\end{tabular}


The foregoing table gives an analysis of the food values per $100 \mathrm{lbs}$. of the common stuffs used for fattening sheep in this country. The method to obtain the necessary ration of corn and hay or alfalfa, oats, corn and linseed meal or any other mixture to compare with Wolff's table is as follows:

for Eight to Eleven Months old Lamb, Cbree Months feeding.

\begin{tabular}{r|c|c|c|c|c}
\hline \multicolumn{1}{c|}{ Ration. } & $\begin{array}{c}\text { Total } \\
\text { Dry } \\
\text { Matter. }\end{array}$ & $\begin{array}{c}\text { Digestible } \\
\text { Portein. }\end{array}$ & $\begin{array}{c}\text { Digestible } \\
\text { Carbon- } \\
\text { Hydrates. }\end{array}$ & $\begin{array}{c}\text { Digestible } \\
\text { Fat. }\end{array}$ & $\begin{array}{c}\text { Fuel } \\
\text { Value. }\end{array}$ \\
\hline 3 lbs. alfalfa hay.... & 2.7480 & .317 & 1.110 & .041 & 2848.08 \\
1.2 lb. corn.......... & .4405 & .039 & .333 & .021 & 784.18 \\
1-4 lb. oats .......... & .2225 & .020 & .120 & .0104 & $\mathbf{3 1 1 . 1 1}$ \\
$\mathbf{1}$-4lb. linseed meal. & .2270 & .071 & .032 & .017 & 360.77 \\
\hline Total .............. & 3.680 & .447 & 1.595 & .0894 & 4304.14 \\
Wolff standard, & $\mathbf{1 . 7}$ & .16 & .85 & .037 & 2035. \\
\hline
\end{tabular}

The above ration is not given as a correct ration, but as a comparison in food values, as taken with Wolff's feeding standard. It will be readily seen that there is an excess in total of dry matter of almost two-thirds, an excess of proteids of nearly the same amount, an excess of carbo-hydrates by one-half, a practical similarity in digestible fats, and twice the amount of fuel value. Taking Wolff's standard as correct, the ration should be changed by reducing the amount of alfalfa hay, and corn till the amount of digestible proteids and carbo-hydrates compare as near as possible with the standard. It is, however, impossible to give any exact ration which would be suitable to any and all feeding sheep or lambs. The amount consumed is governed by the individual idiosyncrasy of the animal, the main point in feeding all animals being regularity as regards time for feeding grain, giving just what the sheep can clean up readily, dry quarters, and quietude.

The value of a feeding table is that it shows intelligent feeders the relative difference between oertain foodstuffs as fat 
and flesh producers, enabling them to intelligently increase the feed as needed, so as to ensure desired results.

\section{food and Increase.}

Sheep fattening on corn with good hay, or alfalfa, combined with some roots or other succulent food, will consume on an average of fifteen pounds of the dry substance of the mixed food per 100 pounds of the live weight per week, and should yield over a considerable period of time one part of increase in live weight for about nine parts of the dry substance of their food. The food being of extra good quality, sheep may give a maximum amount of increase for a given amount of total dry substance of food, provided the latter contain as much as five. parts of total non-nitrogenous to one of the nitrogenous compounds. Cereals contain on an average rather more than six parts of total non-nitrogenous to one of nitrogenous compounds -the leguminous seeds, such as peas and beans, often not more than two parts to one.

Oil meal and corn contain rather more than six-sevenths of their weight of dry substance. Turnips and ruta-bagas contain from one-twelfth to one-ninth, and potatoes about one-fourth of their weight of dry substance. With as much as five or six parts of total non-nitrogenous to one of nitrogenous compounds in the dry substance of the fattening food for sheep the increase will probably be very fat. In the earlier stages of feeding it is desirable to have a lower proportion of total non-nitrogenous to nitrogenous compounds.

\section{Che Proportion of Parts.}

In proportion to their weight, sheep yield rather more internal ioose fat than oxen. In relation to their weight oxen contain considerably more of stomachs and contents than sheep. Oxen and sheep are proportionately equal in the other internal 
organs, such as the heart, aorta, lungs, windpipe, liver, gallbladder and contents; they also are proportionately equal so far as blood is concerned.

As sheep mature and fatten, the internal offal parts increase in actual weight, but decrease in proportion to the weight of the animal. The loose fat alone of the internal offal parts increases in actual weight in proportion to the weight of the body. As sheep mature and fatten the total "offal" increases in actual weight but diminishes in proportion to the weight of the body.

Fattened sheep (shorn) should yield about 58 per cent. carcass in fatted live weight; excessively fat sheep may yield 64 per cent. or more. When the fattening food of sheep contains less than about five parts of non-nitrogenous to one of nitrogenous compounds, the proportion of gross increase for a given amount of dry substance of the food, will not increase with the increased proportion of nitrogenous compounds, whilst the proportion of the carcass to the live weight will be somewhat less, the carcass being more fleshy and containing less fat. Sheep should store up about ten parts of fat for every 100 parts of non-nitrogenous substance consimerl. Sheep on a mixed fattening diet should give about nine parts dry increase, made up of about eight parts fat, eight-tenths to nine-tenths of a part nitrogenous substance, and about one-fifth of a part mineral matter for 100 parts dry substance consumed, demonstrating that nearly ninety parts of the consumed dry substance are expired, perspired, or voided from the system. The stomachs and their contents constitute about seven and one-half per cent. of the entire weight of the body; the intestines and other contents amounting to about three and one-half per cent.

Taking collectively the stomachs, small and large intestines and their respective contents, we find that the entire bodies of sheep yield an average of rather more than eleven per cent. 
The rate of increase in actual weight as the sheep fattens is rather greater for the heart, aorta, lungs and widpipe, liver and gall-bladder, pancreas, spleen and blood than it is for the collective stomachs, intestines and their contents. A fat sheep or lamb fit to kill should contain about thirty per cent. of fat--a very fat sheep might contain considerably more. It must be thoroughly understood that in fattening sheep, the same as in fattening other animals, that heat is a food saver. Little exercise and warm quarters will effect a saving of a third in the cost of feeding. 


\section{CHAPTER V.}

\section{Anatomical Structure of the Sheep.}

We shall not enter deeply into a consideration of the anatomy of the sheep, believing that the technical terms, while very necessary for the use of scientific men, would only tend to confuse the general reader. We will endeavor to simply explain the general structure and internal crgans and their uses, so that when describing symptoms of diseases, and after-death appearences, the parts mentioned can be readily understood.

We find that the sheep, so far as its general make-up is concerned, resembles the ox very closely. The animal body is an aggregation of separate cells, each endowed with life and haring a certain function to perform. The general make up of an animal is called tissue. Tissue of an animal body is a collestion of cells, together with their formed material, which is characterized by a special function. The formed material is that which surrounds the cells and is not vital in its properties.

The animal body is corrposed of solids and fluids. The solids are the muscular, nervous, epithelial and connective tissues. They may be said to enter into the conformation of the solids. There are, however, a few special tissues which it will not be worth our while to consider in this work.

Epithclial cells are those having the special function of protecting the organs underlving them, they also have the function of secretion and enter into nerve construction. They are always found covering the surface of the body, and the interior of all cavities having communication with th.e exterior of the system. Connective tissue is a collection of cells with their 
formed material controlling the shape and framework of the body. Connective tissue is divided into three classes, 1 fibrout. 2 cartilaginous, 3 bone.

Muscular tissue is composed of a collection of cells with their formed material, having the function of contraction. Of muscular tissue we have two varieties, namely, the voluntary and the involuntary. The voluntary muscular tissue is that which is under the control of the will, such as the muscle tissue of the legs, neck, tail, etc. Involuntary muscle tissue is that which is not under the control of the will of the animal, for instance, the muscle structure of the heart, stomach, etc. Fat is formed in the animal body by the degeneration of the cells themsel res. Adipose, or fatty tissue, is formed by the aggregation of masses of degenerated cells held together by the formed material of those cells.

Nervous tissue is composed of a collection of cells, endowed with the function of irritability. To support the various tissues and afford shape and support for them, we find the class of connective tissue called bone, being arranged to form a framework, or skeleton, to which all the various tissues are attached. In the sheep we find that the skeleton is composed of nearly two lundred separate bones of rarious sizes and shapes. The bones in order to permit morement, one over the other, are joined together ly strong bands called ligaments, the motion of the limbs, head, and neek and other parts of the body being effected by the contraction of the various muscle structures, which are connected to the bones. The insertion of the muscle to the bone being by means of a tough fibrous structure, intimately connected with the muscle substance, and called the tendon.

Muscles as a rule have two separate points of attachment, which are generally bones, the contraction of the muscles brings: these points nearer together, so effecting motion. 
Muscles are supplied with vessels of various kinds, such as arteries, to bring them blood for their nourishment; veins to carry away the worn out material, nerves to furnish sensation to the parts and communicate the mandates of the will.

The nerves pass from the brain or spinal cord, and resemble a system of telegraph wires; one set of which receives sensation and transmits it to the brain, the other which transmits the will from the brain to the muscles. The brain is a whitish, pulpy substance situated in a large cavity in the skeleton of the head, which extends from the forehead, above the eyes, to the base and back of the skull. The spinal cord is situated in the hollow found in the center of the bones of the back, generally called the vertebrae, and extends from the base of the skull, where it connects with the brain, to the center of the first bone of the tail. The body, viewed as a whole, can be divided into two cavities, that of the chest, in which the heart and lungs and various gland structures are situated, and that of the abdomen, where the stomachs, intestines and other organs neecssary for the digestion of foods are located.

The heart is the pump of the system, the lungs may be said to be the filter and sterilizer. The blood as it leaves the heart is forced by the heart's contraction to all the various parts of the body, carrying to those parts nourishment and material to repair their continual waste. Having performed these functions it passes into minute vessels called capillaries, from thence into large ones called veins, and from there it is returned to the heart, only entering into a different cavity in that organ than that from which it started. From this cavity the blood is again expelled by the heart's contraction, passing to the lungs, there it is exposed to the air and takes up oxygen, throwing off the carbonic acid gas and effete matter which it had collected in its journey through the animal body; from the lungs it passes back to the heart, finally entering into the same cavity from 
which it was first expelled, only to be again pumped out and sent on its mission through the system. The abdomen contains, as has been mentioned, the stomachs, liver, intestines, kidncys, bladder, and other organs, where the functions of digestion are carried on, and where various fluids are manufactured for or excreted from the system. We find that the internal organs are not firmly fixed in the different cavities, but are suspended as it were from the roof of these chambers by a membrane, endowed with nerres and blood vessels, called respectively: the pericardium, as it envelopes the heart; the pleura, as it invests the lungs, and the peritoneum as it suspends and covers the stomachs, liver, intestines, and other parts in the abdomen. The part of the peritoneum suspending the large and small intestines is called the mesentery, and contains within its folds nerves, blood vessels, and glands, connecting with the circulation of the blood supply of the absorbent glands of the bowels, called villi. These glands in the mesentery are called lacteals, they absorb the products of digestion, called the chyle, and convey it away to a duct or canal called the thoracic duct, which enters the circulation near the point of entrance of the venous blood to the heart. It is the chyle in the blood which furnishes nutriment to the various tissues, and is of vital importance in repairing the incessant waste of the tissues. We shall consider the functions of the liver and other organs of the body when describing the respiratory and digestive organs of the body.

The Skeleton of the Sheep is an aggregation of bones possessing stability and firmness for the attachment of muscles, and the protection of the vital organs situated in the chest and abdominal carities.

Bones are composed of inorganic salts deposited in a basis of animal matter; to the former it owes its hardness and density, to the latter its elasticity and tenacity, the combination of the two rendering the tissue solid and elastic enough to prevent 
breaking from any ordinary cause. The external surface of every bone is covered by a dense, tough, inelastic membrane called the periosteum, except where a tendon plays over the bone, or where one bone articulates with another, in which places will be found a layer of cartilage.

The periosteum is firmly adherent to the bone, and is the bed in which the blond ressels and nerves supplying the bone

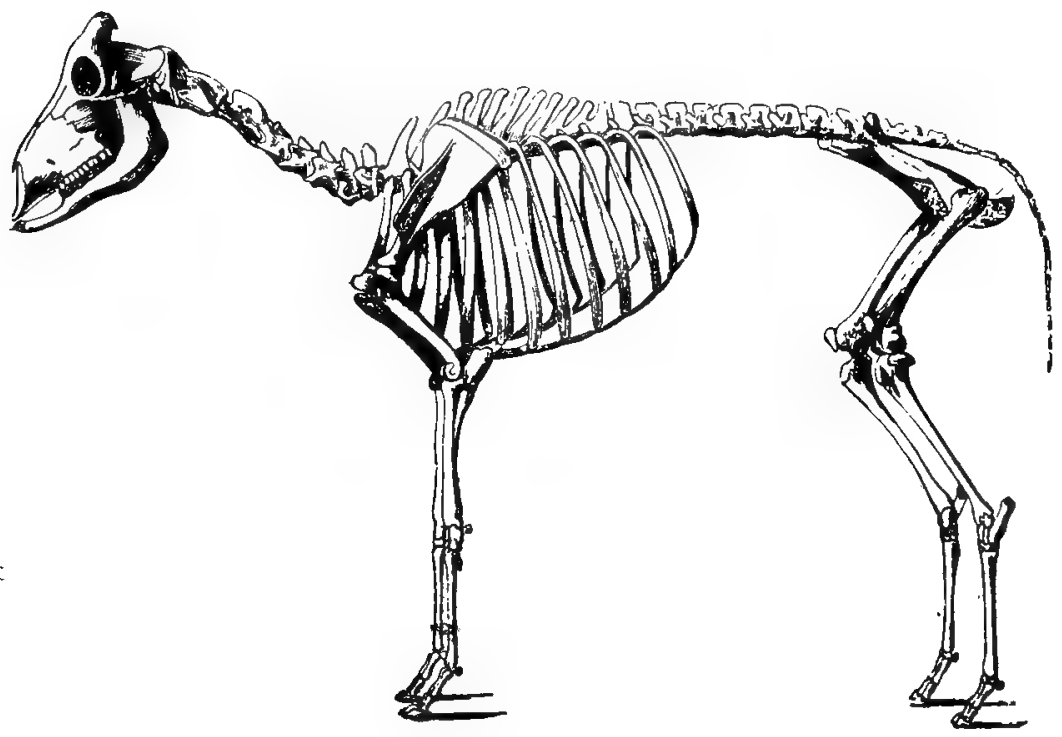

Skeleton of the Sheep.

are distributed. It becomes very painful when inflamed, on account of the pressure on the nerves, due to its inelasticity. It is the protecting life membrane of the bone it covers; any bone denuded of this covering will in all probability die, exfoliate and decay.

The long bones of the limbs contain a hollow cavity extending from one end of the bone to the other. This carity contains a substance called the marrow, which is a soft 
yellow fat, deposited in fibres of connective tissue. It nourishes the bone, preventing brittleness and dryness. Bones are classed as long, flat or irregular. Under the head of long bones are classed the bones of the limbs, which support and act as levers for the bony framework. Flat bones are found where the least possible motion is desired. They help to enclose cavitics containing important organs, such as the brain; or the bones enclosing the cavity of the chest, where the heart and lungs are situated. Irregular bones include all not classed with the long and flat varieties. They are found in the spinal column, skull, and also in the limbs. They possess as a rule many angles, with surfaces for attachment of tendons and articulating surface. In proportion to their size they present a much greater mechanical strength than those of the other classes.

\section{Che Bones of the head.}

The skull of the sheep articulates with the first cervical vertebrae from which it is suspended by its base. It is composed of a number of distinct and separate bones, which, as the animal becomes advanced in age, ossify into one solid mass. The first object of the bones of the skull is to protect the brain from injury. For this purpose the skull surrounding the brain consists of two plates or tables, the outer tough and thick, the inner hard and brittle. The outer, being tough, yields slightly to resistance, diminishing concussion, while the latter, by its hardness, prevents the entrance of sharp bodies into the brain. The cranial cavitycontaining the brain is about one-third the size of the other parts of the skull, the other cavities being the mouth, for the entrance and mastication of food, and the nasal, for breathing and smelling purposes.

The cranial cavity is formed by the union of nine distinct 'bones, called respectively 2 frontal, 2 parietal, 2 temporal, 
sphenoid, ethmoid, occipital. The frontal bones form the anterior part between the eyes, called the forehead. The inner plate of these bones is separated from the outer, forming a carity between them called the frontal sinus, which sinus is divided by a septum or ridge to afford support and strength to the part.

The internal plate corers the anterior portion of the part of the brain called the cerebrum. In horned sheep this froutal sinus or cavity is considerably deeper than in others, affording greater protection for the brain, the horned sheep being naturally more pugnacious than its hornless brother, and with greater adrantages to do harm. In horned sheep the horns proceed on each side from the frontal bone, appearing to be prolongations of that bone. The two parietal bones are placed at the upper and middle part of the cranium, covering the middle parts, or lobes of the cerebellum, their internal surfaces closely corresponding to the external conformation of the cerebellum.

The accipital bone is situated at the back or base of the skull. It is a single bone possessed of great strength. Its internal surface covers the base of the brain called the cerebrum, the medulla oblongata, which may be classed as the connection between the brain and spinal cord, resting on its floor; the posterior part of the bone is smooth and round, to articulate with the first bone of the cervical vertebrae or neck, called the atlas. It has many external projections for the attachment of muscle tendons, giving motion of the head on the neck.

The temporal bones forming the sides of the cranium are composed of two parts, one the squamous temporal and the other the pctrous temporal, which in the sheep are distinct and separate from each other.

The squamous temporal is externally a convex plate, with a hooked projection arising from it. This projection assists in forming what is called the zygomatic arch. The squamous 
portion in its posterior part has a shallow cavity for the articulation of the lower jaw-bone. This carity is shallow in herbivorous animals, such as sheep, when compared with that in meat cating, or carnivorous animals. This is due to the different modes of mastication of the two classes, that of herbivora being a grinding lateral motion, only a shallow articulation is required, while in carnivora, which require to tear and rend their food necessitating opening the jaws very wide, the articulation is necessarily deep.

The petrous portion of the bone is hard, flinty, apparently a solid convex figure. It is the receptacle, howerer, for the organ of hearing, and contains on its internal face orifices for the passage of the auditory nerve, with a corresponding larger one on its external face for the passage of sound.

The inferior and middle parts of the cranium are formed principally by the sphenoid bone. This supports the middle lobes of the cerebrum, and has many holes in it for the passage of nerves and blood ressels.

Anterior to and inferior to the cranial cavity we find another called the nasal, which is separated from the cranial by a bone called the ethmoid. This bone supports the anterion lobes of the cerebrum, and has passages through it for the exit of the olfactory nerves, which are those conveying the sense of smell to the brain. This is the bone which is punctured when operating on "sturdy" or "giddy sheep," by passing a wire up the nasal cavity through the ethmoid and puncturing the sack containing the parasite in the cerebral part of the brain substance.

The other bones of the head are those composing the part called the face, viz., the frontal, nasal, superior maxillarr, Inchrymal, anterior maxillary, palate bones, malar, and inferior maxillary. These bones are of various sizes and shapes, intimately joined together, becoming blended almost into one solid inass as the animal progresses in age. 


\section{Che Bones of the Body.}

The backbone, or vertebrae, extends from the articulation of the first bone of the neck, called the atlas, to the last bone of the tail, termed the coccyx.

The bones of the neck, or cervical vertebrae as they are termed, are very irregular in shape, with a large channel in the center passing through all of them, and protected on all sides by the bodies of the separate rertebrae. It is in this channel that the spinal cord is situated, and through holes in the bodies of the vertebrae, called foramen, the spinal nerres pass to the different parts of the body. These bones all have large projections from their superior surfaces and sides, which are respectively termed the superior and transverse processes. The superior increase in size become very large in the region of the shoulder, and then decrease as they approach the tail, while the transverse processes are small in the region of the neck and shoulder, increasing in length as they approach the loin, finally disappearing at the coccyx.

These processes or spines are for the attachment of the rarious muscles, and from those of the neck we also find a yellow elastic ligament passing forward from the withers to the poll, which is mainly instrumental in supporting the head and neck. Attached to the side of the bodies of the vertebrae of the -houlders and loin are long, flat bones, termed the ribs, 13 on each side, eight of which being attached directly to the chestbone, called the sternum, are termed the true ribs, the other five are attached by a cartilage to the former, and are termed the false. The ribs should spring horizontally from the backbone describing an arch as they descend downward and slightly forward, increasing the rotundity of the frame, which gives the animal a greater surface for the deposition of flesh. The loins are formed by the strongest of the vertebrae, the transverse pro- 
cesses at this point being long and broad, they afford protection to the roof of the abdominal cavity. On their length depends the breadth of loin and ability for the animal to put on flesh at that part.

Behind the loin we find that five of the vertebrae become ossified into one single bone of great strength, and perforated by numerous holes for the passage of spinal nerves. The spinal cord diminishes in size on entering this bone, terminating at its hind extremity in several nerves, which pass to the muscles of the tail. The bones of the tail, called the coccyx, are not perforated in their middle, are irregular in shape, and numerous. They simply give attachment to the tail muscles.

\section{Che Bones of the fore Extremities.}

The shoulder-blade, called the scapula, is a triangularshaped bone, the base being situated uppermost. It has a spine or ridge running down its middle for muscle attachment. It is not very long in proportion to its width, being flat and slightly hollowed out on its inner face, where it is attached to the ribs by means of muscles. The forepart of the body being slung, as it were, between the fore extremities, concussion and injury is materially diminished and an additional flexibility is given to the body, wheh could not be obtained by a bony articulation.

Articulating with the lower end of the shoulder blade we find a thick, irregularly-shaped long bone, termed the humerus, or upper arm bone. It projects downward and backwards, and articulates with the lower arm bone or radius. This bone in the sheep is short and strong. Back of the radius and running parallel to it and articulating with the knee-joint below and humerus above is situated the elbow-bone or ulna; below these the bones of the knee-joint are situated, and below these again is the shank or metacarpus, composed of two bones, one of which 
is rudimentary. The principal metacarpal bone is furrowed throughout its entire length by a deep fissure, a trace of primitive separation of the bone in two pieces, the posterior face being also similarly marked. Below the metacarpus we find four bones or digits, two of which are perfect. Behind the articulation of the metacarpus and digits are two small bones called sesamoids, which serve as levers, over which tendons pass. The bone of the foot or os pedis is also double, and articulating; superiorly with pasterns, gives the conformity of cloven foot. The foot is formed by the coffin bones and navicular, two of each, surrounded by a horny box, as an outside protection to the sensitive parts overlying these bones.

The lower and back part of the coffin bone is attached to an elastic pad of a fibrous nature, which by its elasticity minimizes the concussion consequent to the weight of the animal being suddenly thrown on the foot. This pad, resting on the horny heels, supports the principal part of the animal's weight, very little being communicated to the toe of the foot. In sheep the crust of the foot is secreted by a vascular structure, the coronary substance which in the horse secretes the greater part of the crust, being absent in the sheep. The sole of the foot is secreted from the vascular membrane situated immediately above it, called the sensitive sole, there being a considerable thickness of this dense substance between the coffin bone and horny sole. This explains why, in sheep with foot rot, the foot can be so quickly restored, as when the horn is lost it is immediately replaced from the structure under it, and there is not the delay as in the horse, where the secretion is mainly formed from the coronary substance.

The inside of the crust, between the toes or cleft of the foot, is much thinner than that portion on the outer side, and it is here that foot rot most frequently commences. The horny part of the foot consists of the crust, or outer shell, and sole. The crust 
surrounds the sides and front of the foot, turning inwards at the toe, passing straight back to the heels. It is thin on its inner sides, getting thick at toe and outside of foot. The sole covers the bottom of the foot, the heels being jointly formed by the crust and sole.

The heels are springy and soft. They support the principal part of the animal's weight, and are the part which suffer most when the sheep are compelled to travel far over hard ground. At the pastern joint where the foot becomes cleft a small opening can be detected, which is the entrance to what is termed the

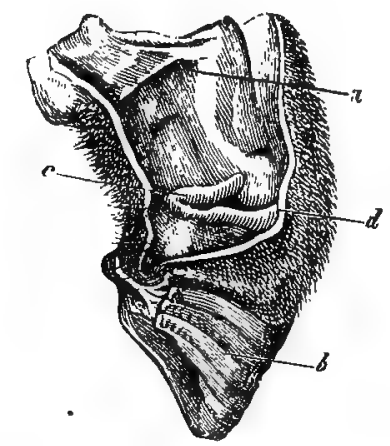

\section{Interungulate Sinus of Sheep.}

a-Inner aspect of first phalanx. b-Hoof or claw. c-Interungulate gland. d-Orifice of its duct.

interdigital canal. This enlarges, passing downwards and wiuding around in a circular direction, terminating in a closed pouch, called a cul-de-sac. The internal surface of this canal is lined with hair covered with a sebaceous secretion from glands opening into the canal. The use of this hair-lined canal is to prevent friction in the movements of the pastern joint, which is so great in sheep that without some such provision of nature the skin would be continually chafed, and it happens that when this part becomes drr from a lessening of normal secretion, or 
through accumulations of dry sand, that an ulceration is set up, which often proves very difficult to cure.

\section{Che Find Extremeties.}

The pelvis is composed of six separate bones in the young animal, which become ossified into a single one as the sheep advances in age. The pelvis has two sides and a floor, and affords protection to the bladder and organs of generation; it lies in an inclined plane, projecting downwards and backwards, the inner surface of its superior projections articulating with the first transverse processes of the sacrum, passing backwards and downwards they converge inwards, forming an imperfect circle, their union forming a flat surface, called the floor of the pelvis. The posterior projections of the bones are called the ischiatio spines; the superior and interior projections forming the hips of the animal, these in well formed sheep being short and covered with flesh and fat. Just anterior to the ischatic spines will be noticed a deep cavity in which the head of the thigh bone, or femur, articulates. This bone has a round head, the form of articulation and depth of cavity in which its rests permitting a backward and forward motion, and to a certain extent rotary. We find that the femur extends downwards and forwards, that it is proportionately heavier in the sheep than in the horse, and it is thickly surrounded with flesh, which, when cut off the carcass for sale, is termed the leg of mutton.

Its lower end forms with the bone below and one placed in front of their union, the stifle joint, the bone in front of the joint being called the patella, so situated as to act as a lever for the muscles of the anterior part of the hind limb. The bone below the femur is termed the lower thigh bone, or tibia, extending lownwards and backwards from its articulation with the patella and femur. Tre find that in proportion to the horse it is not 
so long; it corresponds to the lower arm bone or radius of the fore extremities, and its inferior part forms with the bones immediately underneath the liock joint.

The hock joint is composed of six bones arranged in layers, forming three distinct joints, the motion being confined to the upper layer the bones below, serving as buffers to minimize concussion, with the exception of the bone projecting upwards from the back of the joint, which is called the calcis, and acts is a lever for the powerful extensor muscles of the hind leg.

The bones below the hock correspond with those below the knee joint in the fore extremitr, and the description of them also applies to these.

\section{Che Nerpous and Muscular System.}

The brain is a softish grey body, situated in the cranial cavity. It is the seat of the mind and sensation. Its size in the sheep as compared with man is small. The outer surface is covered 'with ridges, called convolutions, with a dividing furrow from before backwards, separating it into two halves called the right and left hemispheres. The anterior larger part of the brain is called the cerebrum, the middle and small part the cerebellum, while the underlying posterior portion is called the medulla oblongata. Between the brain substance proper and the bones forming the cranial carity we find a strong dense membrane closely attached to the bony structure, called the dura mater, immediately underlying which and attached to the brain substance, is another called the pia-mater, the space between these two membranes being called the arachnoid space. The spinal cord is virtually a continuation of the brain extending from the medulla oblongata through the vertebrae anil terminating in the sacrum at the root of the tail. It is enveloped by the same membranes disposed in the same manner as 
those of the brain. In form the spinal cord is cylindrical, composed of bundles of nerve fibres, with a fissure or canal passing through its center.

We find that in sheep forty pair of nerves originate from the brain and spinal cord, ten arising from the brain, the balance being from the cord, are hence called spinal nerves.

Nerves are an aggregation of nerve tubes, the tubes being composed of sections of nerve cells enveloped by a membrane called the sheath of Schwann.

Of the cranial nerves the first pair are the olfactory, which conduct the sense of smell to the cerebrum, arising in the cerebrum they pass out of the cranial cavity through the ethmoid bone, to be distributed throughout the mucous membrane lining the nostrils.

The second pair are termed the optic. They also originate in the cerebrum from opposite hemispheres, joining before leaving the skull, when the right nerve passes to the left eye, and the left to the right eye by a process termed decussation, taking an oblique course, they pierce the outer coats of the eye and spread out over the retina, from whence impressions of objects are conveyed to the brain. The sense of taste is supplied by the fifth pair of nerves, that of hearing by the auditory, a portion of the seventh pair; the other cranial nerves conveying motion and sensation to the various parts of the head.

Another nerve of the cranium which deserres special mention, being the most important of them all, is the tenth pair, or pneumogastric, remarkable for its extent and for the multiplicity of the physiological uses ascribed to it, being distributed to the gullet, throat, lungs, bronchial tubes, windpipe, and stomach. It controls the motions and secretions of the organs to which it is distributed, having special power over the heart's action. Special nerves are termed compound nerves with a double function and twofold origin, convering both sensation and motion. 
They arise by numerous filaments from both the superior and inferior surfaces of the spinal cord, the filaments intertwine, and before they emerge through the dura mater, they join together just anterior to their union, a sort of knot being formed on the upper nerve, which is termed a ganglion. This upper nerve is the one conveying sensation, while the lower is the nerve of motion, so these nerves, originating as they do, form different portions of the spinal cord, even after they join together. The intimate fibres convey, or rather own, different attributes, although all are bound together in one sheath. Lastly we shall mention the sympathetic nerve, it rivalling in importance the pneumogastric, which has already been deseribed.

The great sympathetic nerve is the nervous apparatus of the organs of vegetative life. It extends in the form of two long cords from the head to the tail, the two cords being situated immediately under the vertebral column to the tail, appearing to arise from a ganglion at the base of the brain, anterior to the commencement of the spinal cord. By its numerous branches it is connected with all the other nerves, and distributes branches to all the glands, blood vessels and lymphatics of the system, also the heart, lungs and digestive organs. It is the virtual life of the organic system, influencing all functions of nutrition and secretion.

The brain of the sheep is small when compared with that of other animals, the whole make-up of its nervous system being comparatively feebly dereloped. This fact has a considerable influence over the diseases which affect the animal, accounting for the fact that in so many debility quickly follows sickness; the sheep speedily succumbing to what at first appear to be slight ailments. 


\section{Che Muscular System.}

II uscles are fibrous organs, possessing the property of contraction under the influence of a stimulus. While the shape of the body depends to a great extent on the bony framework, there is a vast difference between the appearance of the skeleton and the body itself.

The muscles are the fiesh of the animal, attached to ancl covering erery part of the skeleton.

The motion of any and all parts of the body is dependant on the contraction of the muscles attached to those parts. Muscles are attached to different bones. Their contraction drawing the parts together causes motion, thus limbs are bent, the head raised and lowered, and the slightest movement even of an eyelash controlled.

Those which bend or flex the limbs are called flexor muscles, those extending the same being called extensor muscles

Muscles vary in size from the large muscles of the loin and shoulder to those almost microscopical in size of the internal ear. Some are thick and bulky, others extremely short, others cylindrical and of great length. Muscles are supplied with nerves, blood ressels and absorbents. The nerres in muscle tissue are those of motion and sensation; those of motion convey the mandates of the will, thus cansing motion; those of sensation communicate the sense of feeling, being the medium both of pain and pleasure. Mnscles are composed of bundles of muscle fibres, bound together by a cellular membrane. In sheep we find they are for the most part clothed in fat, and also that fat is deposited among the fibres. It is the ability of the animal to contain this fat and the abundancy of the adipose membrane surrounding it, which distinguishes a good sheep from one of an inferior breed, giving to the former the soft and elastic feel to the hand, even when the animal is in poor flesh. 
A sheep of good breeding has large muscles, especially in the region of the loins, buttock and shoulders, while the head should be lean and small. The flexor and extensor muscles are interlaced with tendonous fibres, and are not so palatable as those from the loins and buttocks. It will be unnecessary to make individual mention of any particular muscle or group of muscle:, the subject would be too vast for a work of this kind, and unintelligible to the general reader. 


\section{CHAPTER VI.}

\section{Che Digestive System.}

We find that the slieep can, oring to the conformation of its mouth and appendages, the lips, thrive on scanty pasture, where an ox or other animal would have to struggle for existence. The lips being covered by hair, are protected from injury against the ground, in which they come in close contact when the animal is feeding. We find on examination that the upper lip is cleft, and that the two when together tend to forn a point, enabling the animal to virtually crop the grass on a level with the surface of the ground.

\section{The $\tau_{\text {eeth. }}$}

These are the agents by which matication of the foor is carried on. They are hard organs, bony in appearance, firmly implanted in the jaws, and projecting into the interior of the mouth.

The incisor teeth, or nippers, are in the sheep as well as in other ruminating animals situated upon the lower jaw, the upper jaw with which they come in contact during mastication being covered ly a dense fibrous pad. Tre find that the incisors, unlike the back or molar teeth, are not firmly embedded in the lower jaw, but possess a certain degree of mobility (sometimes being mistaken for a diseased condition); this, howerer, is necessary in order to prevent their injuring the fibrous pad of the upper jaw, against which they press.

The Incisor Teeth are eight in number when the mouth is perfect, or full, as it is termed. Tre find that the lamb when 
first dropped has two incisor teeth, and that two more are shortly in evidence. In fourteen days time after birth two more are erupted, making six then in all, and by three weeks after birth two more become visible, giving the lamb eight incisor teeth. This is not by any means without exception, as frequently lambs are dropped with all eight incisors in evidence. These are the temporary or nillk teeth, and as the animal progresses in age they drop out, and are replaced by the permanent teeth. For instance, when the lamb gets to be between one year and one year and a half old the two central incisors are replaced by two larger and stronger teeth, the lamb then being called a yearling.

By two years the tooth on either side of the centrals undergoes the same transformation, and are succeeded the following year or year and a half by those adjoining; so that in three and a half years the sheep has six permanent teeth, and between four and four and one-half years the last two temporary incisors disappear to be replaced by permanent ones, the sheep then being said to be full mouthed. While the above is substantially correct and can be counted on as a general rule, yet sometimes permanent teeth appear much earlier, and at others their appearance may be protracted to a later period. After the sheep possesses a full mouth the teeth rarely remain perfect for any length of time, some of them becoming broken or lost. They are then said to be broken mouthed. In appearance the incisor teeth are chisel shaped, rather resembling the human incisors, they are curved, being convex in front and concave behind, the whole of the crown being covered with enamel.

The Molar Teeth are twenty-four in number, twelve on cach jaw. They are firmly implanted in the jaw bones, being alsu covered with enamel on their face. These faces are very irregular, to enable them to grind tough and unrielding substances, such as corn and dry grass. On the sides of the base of the risible 
portion of the molars the gums are situated, which, in common with the other parts of the mouth, are covered by mucous membrane, in some parts a firm dense material being interposed bctween this membrane and the bone.

The sides of the mouth carity are formed by the cheeks, made up of powerful muscles, covered internally by mucous menbrane and externally by the skin, they form the greater part of the bulk of the face and are the agents which control the grinding motion of the lower jaw. The lips serve for the prehension or gathering of both the solid and liquid food, retaining it in the mouth after its introduction therein, and preventing the cocape of the saliva; they are furnished with nerres of feeling, and are composed of muscles externally covered by the skin, the inside surface being covered by mucous membrane, they possess the powers of motion and sensation to a considerable degree. The mouth is plentifully supplied with a watery, slightly alkaline fluid termed the saliva. This is secreted by three pairs of glands, collectively termed the salivary glands. There is a slight flow of saliva from these glands in to the mouth at all times, which is considerably increased during mastication.

The largest pair of these glands is known as the parotid, situated at the base of each ear, extending downward in a line with the jugular rein, they connect with the mouth cavity by means of a duct, which opens into the mouth about the level of the fourth molar. This is known as Steno's duct, and sonetimes becomes enlarged, forming a fluctuating tumor at the side of the face, due to obstruction from inflammation and obliteration of it, from injury, where it lies close to the surface in the meshes of the masseter muscle, passing upwards over the lower jaw. The next largest pair is known as the submaxillary. They are situated under the jaws, their ducts opening into the mouth by projecting elevated points or barbs placed near the fraenum 
of the tongue. The other pair of glands is called the sublingual, placed under the tongue, they communicate with the mouth close to the opening duct from the submaxillary. In addition to these we find other small glands connected with the cheek and floor of the mouth, all of which assist in secreting fluid to lubricate the bolus of food and perform the first stage of digestion. Iferbirorous animals secrete considerably more saliva than the carnirora, which is rendered necessary by the hard and woody nature of the food the animal is called upon to consume. Situated on the floor of the mouth, and principally filling that caritr, a pointed, rough, elongated body is found, termed the tongue. This is principally muscular in structure and very flexible. It is the special organ of taste, and alsi materially assists in mastication and swallowing. In the sheep it is a prehensile organ, assisting the lips in gathering the food into the mouth. A decided difference in the back part of a horse's and sheep's mouth is noticeable. Thile in the horse the soft palate, situated in the entrance of the gullet, is sufficiently long to fall down and completely close the back part of the mouth, excepting when food is being swallowed, prolibiting a horse from breathing otherwise than through the nose, and also preventing vomition, whereas in the sheep, being a ruminating animal, such a structure would be inapplicable, as it would prevent the return of the contents of the first stomach to the mouth, consequently the soft palate is considerably shorter and narrower, not reaching the tongue. At the base of the tongue we find the larynx and pharynx connected to the tongue and to the upper jaw bone, or rather the bones of the head, by means of a bone called the os hyoides. Adjoining the pharynx are two spaces called the eustachian tubes, sitnated one on each side, and communicating by means of a tube with the internal car. At the superior extremity of the trachea, between the first and fourth rings of that tube, are found two round, ovid bodies, one 
on eacl side of the tube, joined together by a narrow band, or isthmus. These glands are termed the thymus or thyroid bodies. They are large in foctal life, but tend to diminish in size as the animal matures in age; they are well supplicd with blood ressels, nerves and lymphatics, and although their use is not fully determined upon by anotomists, they doubtless exert an important influence, especially in young animals. It is these glands which become enlarged in goitre, a condition which we shall consider later on in this work.

\section{The Digestive Organs in General.}

These are more extensive and complicated than the corresponding parts of the canivorous animals, as they have a more oncrous task to perform, the food heing crude and wholly unprepared as compared to the flesh consumed by the carnirora, which virtually is composed of the constituents of the blond itself, and has not to be transformed into the material like the grains and grasses forming the natural diet of the sheep.

So to comply with these extra requirements the digestive organs of the sheep have to be more spacious to afford means to retain the food until the nourishment can be cxtracted therefrom. To perfom these extra functions the digestive track of herbirora is endowed with greater nervous energy, causing a larger amount of rital and chemical force to be manufactured, thus enabling a greater digestive force to be exerted.

Tre find that herbirorous animals in a state of nature are almost continually fecding, a greater amount of the crude material having to be taken into the system to support life, so to enable the animal to retain this food, the alimentary canal has to be of enormous bulk, digestion being almost continually carried on. Sheep when grazing tear the grass off by a jerking action of the muscles of the liead and neck, the grass being held 
between the incisor teeth and the cartilaginous pad in the mouth, is moderately chewed by the molar teeth, being replaced between them by the action of the tongue and cheeks, it is then formed into a bolus, thoronghly saturated with the saliva, and conveyed by the tongue back into a pouch situated at the superior extremity of the gullet, called the pharynx.

The pharrnx is lined with mucous membrane the same as the moutls. It is virtually a nucous lined muscular box, the contraction of the sides being the means by which the food is forced into the gullet, which scientifically is termed the oesoplag'us, and is the tube connecting the mouth with the stomach. Immediately under the pharynx we find a cartilaginous box, termed the larynx, forming the entrance to the windpipe, or trachea. The food passes into the gullet, orer the larynx, from which, lowerer, it is prevented from entering by a triangular lid composed of cartilage and termed the epiglottis, which is forced dorn, effectually closing the entrance to the larynx. Directly the food has passed over the larynx, the epiglottis assumes an upright position, freeing the entrance to the larynx and permitting the entrance of air for the purpose of respiration. The food after learing the pharyux passes into the gullet. This is composed of involuntary muscular fibres, and the bolus, acting as an irritant, causes these muscles to contract, the fibres running lengthwise with the tube, draw it up, shortening the distance between the stomach and the mouth, while the contraction of the circular fibres forces the food down the tube, finally lodging it in the first stomach. Tracing the course of the gullet we find that on leaving the pharynx it passes down the neck, at first behind the windpipe, then inclines to the left of it, entering the chest carity in company with it; it then passes to the upper side of the trachea over the base of the heart, through the muscle dividing the chest from the abdominal cavity, and which is called the diaphragm, and entering the stomach by a funnel- 
shaped opening. The oesophagus, on leaving the pharynx and entering the chest cavity, diminishes in calibre, expanding again as soon as it has passed through the diaphragm or midriff. It does not actually terminate in either of the stomachs, but ends in a pouch called the oesophageal canal. This is about 4 to $4 \frac{1}{2}$ inches in length, formed superiorly by the oesophagus and inferiorly by muscular pillars or duplicatures of the upper portions of the first and second stomachs. So it will be apparent that the oesophageal canal or furrow is a sort of passage, having connections with the different stomachs, and which, with the exieption of the second and fourth, are the only openings these stomachs are endowed with. The food passing from the oesophagus enters the first stomach, called the rumen, the entrance to which is close to the termination of the oesophagus and the entrance of the canal. The rumen is of enormous extent, occupying when full of food nearly three-quarters of the whole of the abdominal carity.

By reference to the illustration on opposite page it will be seen that the oesophageal furrow or food duct commences at the entrance to the rumen, its floor being composed of muscular pillars formed by the upper part of the second stomach, the entrance to which is between these groores. The pillars are continned within the cavity of the second stomiach for nearly an inch and a half to the entrance to the carity of the third, which, being situated above, forms the roof of the oesophageal furrow. The entrance to the fourth stomach is $2 \frac{1}{2}$ inches in length, formed by the turning back of the mucons and muscular coats of the riscus, which at times are in close apposition one with the other, as the necessity of nature may require. The food on passing through the oesophagus usually falls into the rumen or first stomach. This stomach, the largest of the four, occupies the left flank; by a constriction across its middle it is almost divided into two compartments. Externally lining it is the 


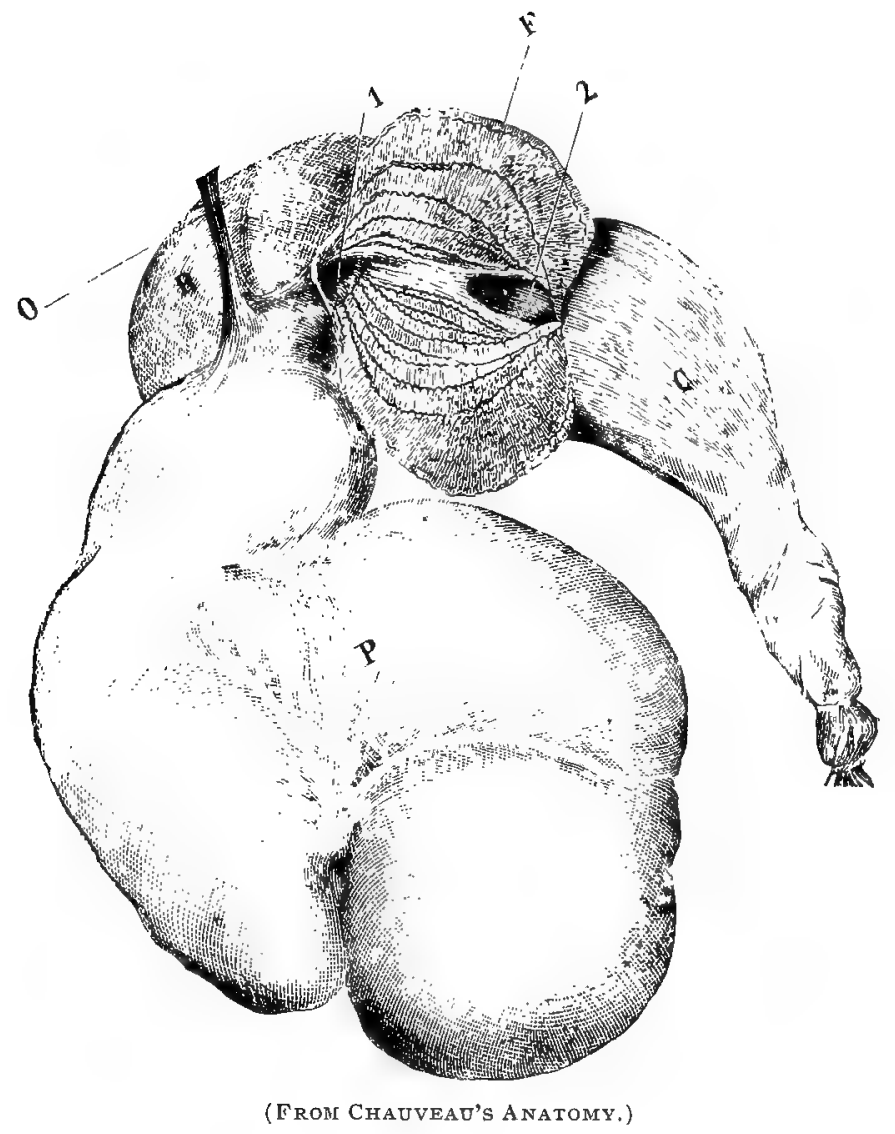

\section{Stomach of the Sheep. Seen from Interior of the Omasum.}

O-Esophagus. P-Rumen. R-Reticulum. C-A bon1asum. F-Omasum, opened at its large curvature, the two portions being reversed forward and backward. 1-Opening between the rumen and reticulum, surrounded by the extremity of the lips of the osophageal furrow. 2-Opening between the omasum and abomasum. I-Commencenent of the smail intestine. 
nembrane termed the peritoneum, which covers all organs in and virtually suspends all intestinal organs from the roof of the abdominal carity. The internal surface of the rumen is covered by a multitude of papillary prolongations, which are dependencies from the mucous membrane. These papillae are very large (foliated or leaf like in shape), and numerous on the right side of the stomach, being more rare on the left and absent on the muscular bands or columns running on the inside and, as before stated, partially dividing the organ. While we have said that the stomach is partially divided into two compartments, it will be more correct to say that there are four or five of these divisions, the utility of which is to prevent any one portion of the stomach being compelled to bear all the weight of the food at any one time. By their arrangement they afford depositories for food which has partially undergone maceration, the upper compartment being the one into which the food is raised previous to the process of rumination. While the rumen is partially attached to the second stomach, it only communicates with it through the common opening of the two stomachs with the oesophageal canal. The second stomach is called the reticulum. The reticulum or honevcomb is the smallest of the four. It is elongated from side to side, slightly curved on itself, placed between the midriff and the forward extremity of the left sac of the rumen.

It is globular in shape and is the part of the animal which is eaten as tripe. The internal structure consists of a rast number of shallow cells, resembling lionercomb; the cells near the entrance to the stomach are small, increasing in size as they leave this point. The sides of the eclls are formed by ridges from the mucous and cuticular conts, and across within these cells smaller ridgeswill be olserved. They are in slape five or six sided, and on their surfaces are an immense number of papillae, more pointed but much smaller in size than the corresponding papillae in the 
rumen. These papillae secrete a mucous fluid which assists in the process of digestion. Externally corering the second stomach we find the peritoneum, under which is situated the muscular coat, composed of two separate layers of strong muscle fibres criss-crossing each other. The opening into this stomach is of some extent, the grooves forming it are the floor of the greater portion of the oesophageal canal. The contents of this stomach are more liquid than those in the others. Just before the end of the entrance to the sècond stomach the oesophageal furrow virtually ends in the third stomach, called the Omasum or Many Plies, so called from its peculiar internal make up, which is formed by a number of unequally developed leaves of mucous membrane filling and running the length of the cavity. These leaves increase the internal surface of the organ ten fold; they are studded with numbers of small papillae, which are harder than those in the reticulum. Some of the papiliae on the edges of the leares are in the shape of a bent cone pointing towards the entrance of the stomach, the object of these being to retain food for a certain period of time, and it has been found that in certain sheep, which were subject to scours and unable to retain their food, that these cones were abnormally short. The omasum has but one opening, which is in direct communication both with the oesophageal furrow and the fourth stomach. In appearance the third stomach is globular in form, possessing muscular and mucous coats the same as the first two. Its contents will generally be found to be hard, and much more so than the contents of the other stomachs. The fourth stomach, or Abomasum, is in fact the true stomach, corresponding to the stomach of man, being that which secretes the gastric juice, which, by its action on the food, converts it into chyme. This juice is by nature acid. It is a clear watery yellowish liquid having a specific gravity of 1005, as compared to water at 1000 . It contains solids to more or less extent, the main part of which 
is pepsin, hydrochloric acid being present in the watery part in the strength of about 2 parts to the 1000 of water. Externally this stomach is somewhat conical in shape, the apex being the part joining the intestines. It possesses three coats. The internal surface, however, differs in appearance from that of the other stomachs, being red and shining, the mucous membrane being very vascular, the glands secreting the gastric juice, being embedded in its folds. By its internal surface being in the form of plaits arranged lengthwise, the digestive capacity of the organ is considerably increased. The entrance to this stomach is close to the entrance of the omasum, the exit being situated at the apex, which is closed by the valve called the pylorus, which is a duplicature of the mucous lining of the viscus. 


\section{CHAPTER VII.}

\section{Rumination.}

The rumen is the first receptacle in which the food is deposited after it has been sufficiently masticated and corered with saliva to permit the act of deglutition; being received in the stomach mouthful by mouthful, until the riscus is comparatively full, the animal feels repletion, at which time rumination generally commences, the sheep usually assuming a recumbent position.

The food to be re-chewed is not that which was last swallowed, but that which has been in the rumen for twelve to sixteen hours previously.

The food in the rumen is constantly being changed to a different location by the action of the muscular walls of that organ, being mixed with the juices secreted by the mucous glands of the internal surface. Entering the superior portion it passes to the inferior, again passing to the superior before rumination commences. For the act of rumination to be performed it is necessary that the rumen be at least three-quarters full to enable the food to occupy the upper part of the organ to enter the o'sophageal groove. The liquid portion then passes on to the reticulum, which is only a kind of offshoot or diverticulum, acting as a reservoir to dilute the solid substances which may pass into it.

All the food which is taken into the rumen does not go through the process of rumination, but only the hard, indigestible substances. These are supposed to be separated at the juncture of the oesophagus with the rumen and reticulum, the hard 
substances being returned through the oesophagus to the mouth by the contraction of the muscle fibres of the tube, assisted by the action of the midriff or diaphragm, which presses on the rumen, contracting its size and forcing the contents into the oesophageal groore to the gullet. The other portion passes on to the reticulum, some even entering the third stomach or omasum, without passing through the second stomach. In the reticulum the contents are subjected to pressure, extracting the liquid portion, which passes on to the third and fourth stomachs,

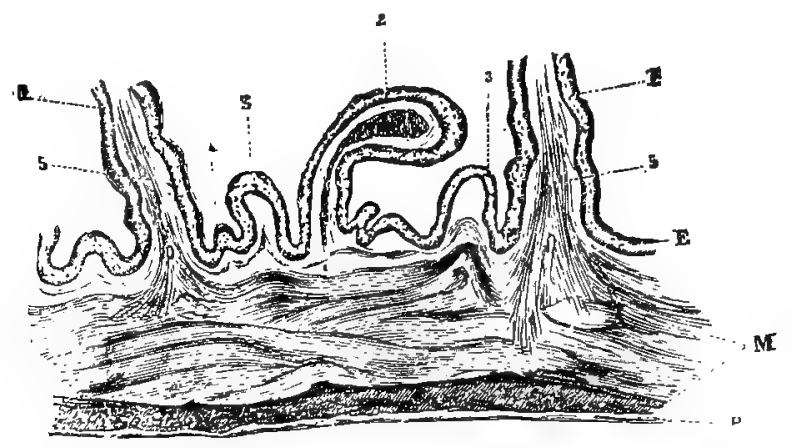

(From Chauveau's Anatomy.)

"section of the xall of the Omasum of the Sheep. from the Great Curvature, Shopring the Origin of the Leaves.

P-Peritonehm. M-The two muscular layers. E-Epithelium, 1, 1-Principal Jeaves at their origin. 2-Secondary leaf. 3,3-Leaves of the third order. 4-Denticulated lamina. 5,5-Two piailes of $\mathrm{m}$ is scular flbres ascending into the principal Jeaves, some issuing from the muscular layer of the organ.

the solid, dry residue leing taken up by the oesophagus and returned to the mouth to be re-masticated, proving that it is not only the contents of the rumen which enter into rumination, but those of the reticulum as well. The oesophagus in ruminating animals having a double duty to perform, is proportionately supplied with muscles. Especially is this the case around its lower portion, where the bolus is first seized to be returned to the 
mouth. Beyond a doubt some portions of the tood undergo remastication sereral times. The liquid portion of the food after passing through the reticulum most likely goes direct to the fourth stomach. This is inferred from the dry condition of the contents of the third stomach, eren when the animal is in the best of health, that riscus being the organ which triturates and breaks up into small fragments, the matter which passes into it thus rendering them more susceptible to the action of the gastric juices of the abomasum or stomach proper. Where the leaves in the omasum are imperfectly formed it has been observed that the animal so affected will not thrive, although it may consume a large amount of food. The fourth stomach, called the abomasum, is the stomach proper, where the virtual act of digestion is carried on, the contents being subjected to the action of the gastric juice. Young animals existing on their mother's milk employ only the fourth stomach for the digestion of the same. The other stomachs, not being in use, are practically undeveloped, but as it commences to feed on other substances requiring a more extensive and intricate process to extract their nutritive properties the other stomach develop in size to accommodate the new conditions. By the time the food arrives in the fourth stomach it has been well macerated and mixed with fluid, forming. a pulpy mass, ready to be submitted to the action of the pepsin and acid secreted from the mucous glands of the organ. The food in this viscus is converted into a mixture called chyme, rendering it fit for further processes of digestion in the intestinal canal. On leaving the fourth stomach the food passes through a valvular orifice called the pyloric opening, the passage through which is guarded by valves opening towards the intestines, affording entrance to them, at the same time rendering a return of the contents of the intestines to the stomach impossible. 


\section{Che Integtinal Organs.}

The intestines are sub-divided into two classes, the small and the large; the small being narrow and uniform in diameter and of considerable length, the large being irregularly rilated and sacculated. The small intestines are arbitrarily

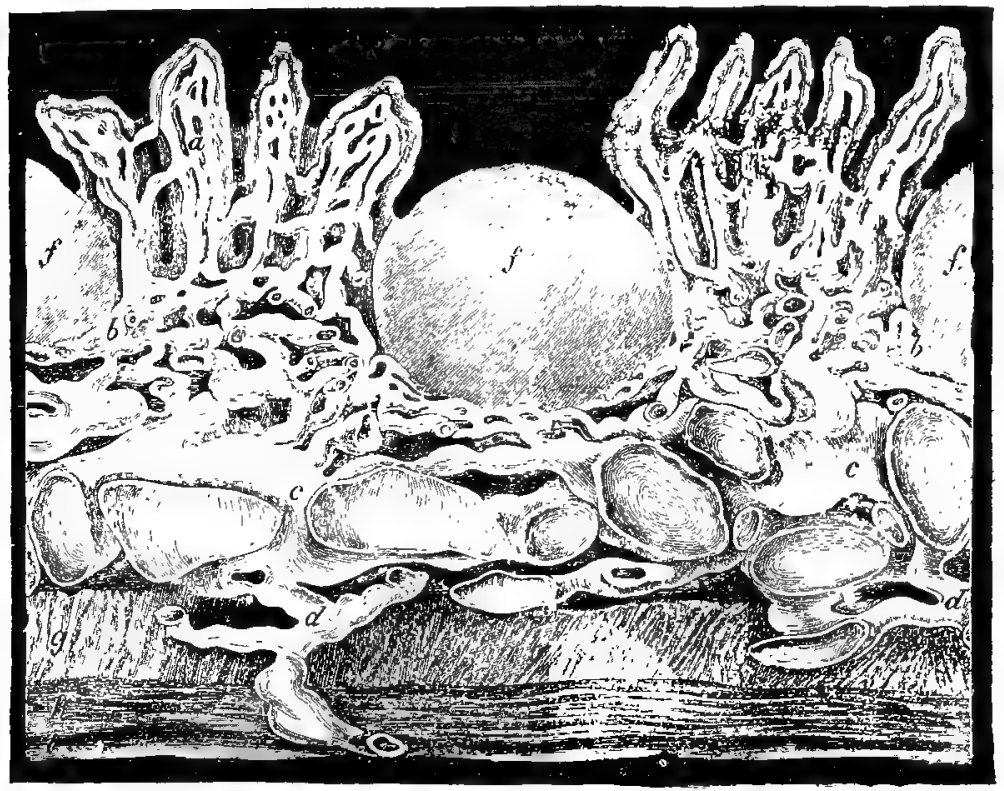

(FroM ChaUVEAU S ANATOMY)

$a, a$-Lacteal vessels in the villi. $b, b$-Superficial layer of the lacteal vessels (rete angustum). c, c-Deep layer of the lacteals (rete amplum.) d, $d$-Efferent vessels prorided with valves. e-Lieberkühn's glands. $f$-Peyer's glands. $g$-Circular muscular layer of the wall of the intestine. h-Longitudinal layer. i-Peritoneal layer.

divided into three sub-divisions, that joining the abomasum being called the duodenum, which is a short curved portion containing glands called Peyers patches, and receiving ducts from the pancreas and liver. This is succeeded by a short portion 
descending downward and backward to the left flank, where it becomes the jejunum, the ileum being the portion suspended in the left flank which terminates at its junction with the large gut called the caecum.

\section{Che Large Intestines}

Are divided into three divisions. 1. The Caecum. 2. The Colon. 3. The Rectum.

The caecum is a vast reserroir in the form of a cul-de-sac. It is nearly aylindrical in form without bulgings or longitudinal bands; its extremity is rounded and globular, floating freely in the cavity of the abdomen and directed backwards. The ileum joins the caecum by piercing the latter at right angles at its superior extremity, the internal mucous membrane of the ileum forming a valve permitting the passage of material to the caecum, but effectually preventing its return. The caecum serves as a reservoir for the enormous quantity of fluid ingested by herbivorous animals, which in its rapid course through tho stomachs and small intestines is not absorbed by the villi or mucous projections in the bowels. The fluids accumulate is this gut, and by their solvent properties on the matter contained in it favor their entrance into the circulation through the large expanse of absorbing surface which the mucous membrane of the gut presents. It is in this riscus that digestion is virtually completed in herbivorous animals. The colon commences from an opening situated above the entrance of the ileum to the crecum. In calibre it at first equals the caecum, but soon becomes constricted, maintaining a uniform diameter, which, for about eight feet in length, is nearly treble the diameter of the small intestines; then the gut decreases in size to the same calibre as that of the small intestines, continuing so for about nine feet in length, when it again increases in size about one foot prior to its termination, this latter part being termed the rectum. 


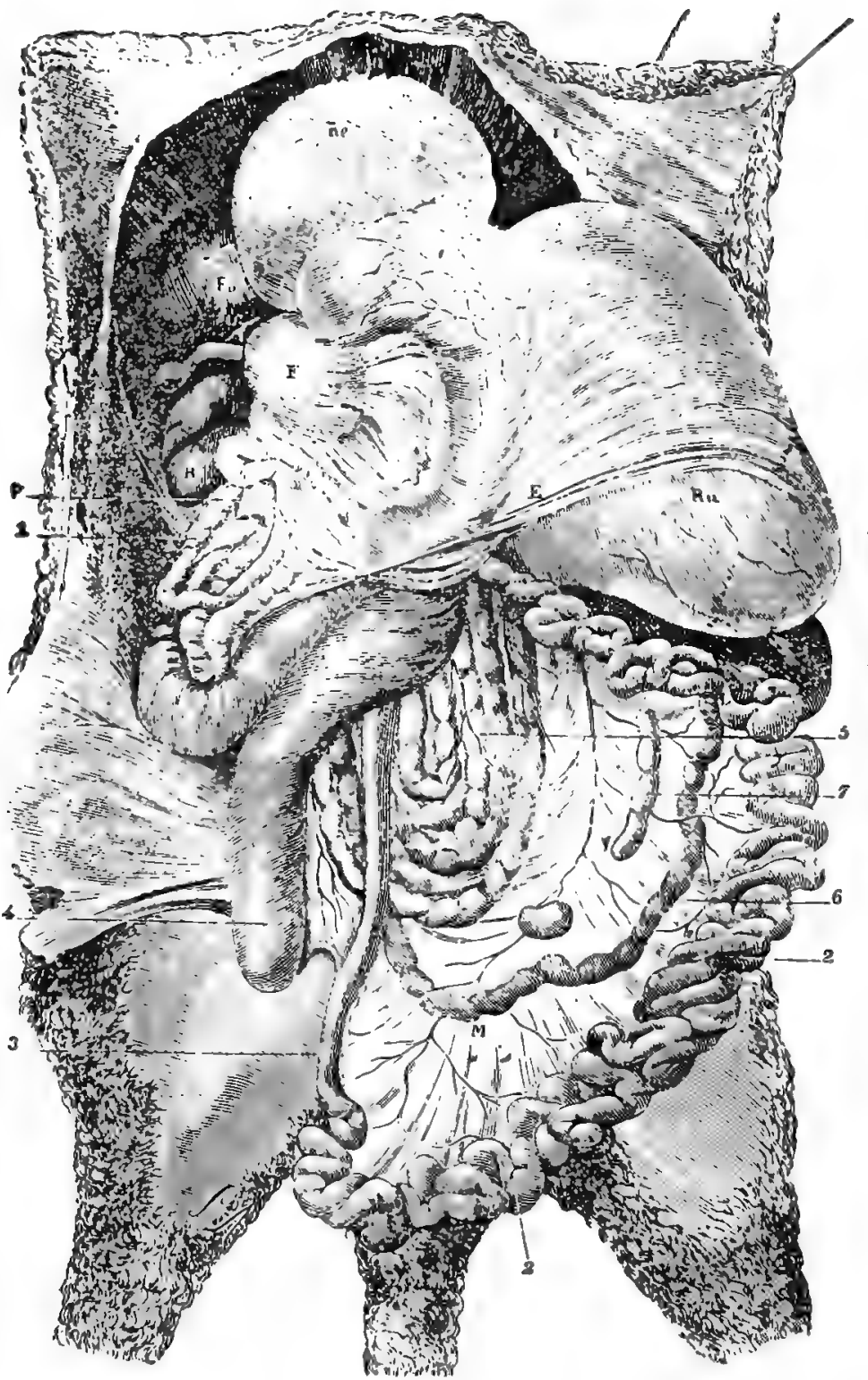

我总 퐁는

튜료

里。

눙효

舵

를

픙

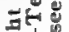

페

월

党粃

\&

난

古实

Q

- 5 둥

훙

을 훈뭉

電

$<$ б 0

क ส

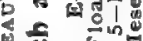

过

ह

क्ष

के हैं

\% 응

은 4 퐁

난 0

-

\% 붕

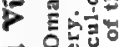

돌

हैँ

Ez

를

$\because$.

果的

比

近

a

욜

E

证

$1=$

政 
At the point of diminution of calibre of the large intestines the faeces gradually become hard, acquiring the form of small black pellets, being voided in this condition when the animal is in good health.

T'e shall now consider the organs secreting fluids which have entrance to the intestinal canal, for the purpose of aiding digestion. Of these we find two, the liver and pancreas. The liver is the largest and most useful solid organ of the body. Having manifold functions, it secretes the bile which.is of rast importance for the digestion of food; and furthermore, it manufactures sugar, the bile is thrown into the ducts, while the sugar finds immediate access to the blood vessels, to be conveyed on through the system. In the sheep the weight of the liver averages about 1-50th part of that of the carcass, with a slightly greater specific gravity than water. The structure of this organ is peculiar, owing to the diversity of the functions it is called upon to perform. Externally it is found to present a mottled appearance due to small polygonal spaces of a rounded appearance, in the center of which redish spots will be observed.

These circular bodies are the lobules about 1-20th of an inch in diameter, separated one from the other by the polygonal spaces, which are really a network of blood vessels. To explain the structure of this important organ it will be only necessary to examine one of the lobules. The lobule itself is separated from the others and held in place by a network of blood vessels, which permeate its substance, joining together in the center of the lobule. An artery called the hepatic artery and a vein called the portal vein convey blood to the liver, both entering the organ side by side through a fissure called the transverse.

\section{Che Bille.}

The bile is elaborated from the blood brought to the liver by the portal vein, which comes direct from the intestinal mucous surfaces, charged with assimilable substances absorbed by the veins of the intestinal papillae called the villi. 
The bile being separated from the blood is conveyed into a receptacle called the gall bladder, from which a duct issues, opening into the small intestines about eighteen inches from the junction of the stomach and intestines. Ruminants are all furnished with this reservoir or gall bladder, so also is man, and the majority of carnivorous animals, the exception being the horse, in which case the bile is thrown out into the bowel as soon as it is manufactured, causing at all times a constant flow into the intestines of this liquid.

\section{Che functions of the Bile.}

Bile is both a secretion and an excretion. To better understand the meaning of these terns: it may be well to define them as follows:

A secretion is a fluid manufactured in the animal body for further use.

An excretion is a waste material to be eliminated from the system.

Bile contains both secretory and excretory ingredients. It is a natural purgative, stimulating the action of the intestinal juices and the peristaltic motion of the bowels. Besides being an antiseptic, it assists in the digestion of fats. Entering the intestines close to where the chyme flows from the stomach it precipitates certain ingredients in that fluid, rendering them susceptible to the action of the juice from the pancreas.

The quantity of bile secreted from a sheep's liver in 24 hours by weight amounts to between three and five pounds.

The liver then may be considered as the regulator of the amount of sugar and fatty matter in the blood, any excessive amount which is not required to support combustion accumulating in the various tissues of the body.

\section{Che Pancreas.}

The Pancreas is an organ composed of glandular tissue entirely, making a fleshy mass, hence the name pancreas, 
which means "all flesh." The fluid secreted from this urgan empties into the intestines through the same duct conveying the bile. It is cxceedingiy active, possessing in its varied functiuns more powers than any other juice. In herbivorous animals the How of pancreatic juice is continuous, never ceasing entirely. It contains five different ingredients, which exert changes on various kinds of foodstuffs, having a specific action in emulsifying fatty matters, rendering them capable of absorption.

\section{Che Genito-Arinary System.}

Urine is an excretion, separated from the blood by the kidneys, which are two solid organs situated in the abdominal cavity, firmly attached to its roof in the part called the sub-lumbar region, or loin.

The kidney in appearance is bean-shaped, with a tube leaving its concave portion called the ureter. This tube proceeds backwards and downward, reaching the pelvic cavity, where immediately below the terminal end of the intestine we find a large fluctuating sac, the size of which depends on the amount of its contents-this is called the bladder. The ureter passes back to the neck of the bladder, to which it gains access by penetrating first its muscular coat, between which and the mucous membrane it passes for a short distance, then piercing the mucous membrane it gains access to the interior of the bladder, this peculiar manner of penetrating the coats of the bladder being an arrangement of nature by which the flow of the urine from the bladder back into the ureter is prevented. The kidneys play a most important part in the animal economy, as they eliminate from the blood not only the superfluous water and other accessory substances, but the excremential nitrogenous products resulting from tissue waste. Comprising the urinary apparatus we find the 
(1) Kidneys. (2) The ureters. (3) The bladder. the urethral canal leading from the bladder and communicating with the outside of the animal body either by passing through the penis, or, as in the female, by an opening on the floor of the vaginal eavity.

If a horizontal section is made of a kidney it will be found to possess a cavity called the renal basin, which receives the urine as it is secreted by the gland. It is here that the ureter commences. The internal surface of the renal basin is covered with a mucous membrane, which extends continuously through the ureters to the bladder, which organ it entirely lines, extending from it down the urethral canal to the end of the penis, or, in thar female, the vulva.

The intimate structure of the kidney is composed of fininute tubes which arise from tufts of blood ressels. The excrementitious matters are separated from the blood in these tufts and conveyed down the tubes to the renal basin, from which they are conveyed by the ureters to the bladder, being voided from that organ in accordance with the will of the animal.

The urine is a peculiar fluid. Its solids represent the waste from tissue change. It is the sewage of the system, and contains among its solid ingredients a substance termed urea, which if separated and purified appears in the shape of needle-like crystals, which are soluble in hot or cold water. Urea is supposed to arise from excess of nitrogenous food, and from nitrogenous changes constantly taking place in the body. Its elimination from the system is very important. Should urea remain in the blood, or be re-absorbed, uraemic poisoning is produced, a condition frequently seen in cases where the functional properties of the kidneys are impaired by disease. In the ram the urethra is of considerable length, extending as it does the whole length of the penis; just below the anal opening it forms an acute angle to conform with the downward and forward direction of the penis. 


\section{Che Generative Organs.}

Individuals in the organic kingdom possess the faculty of reproduction in order to perpetuate the species to which they belong. Milk-giving animals, to reproduce their kind, need the concurrence of two individuals, a male and a female, who under certain circumstances have intercourse, the male furnishing the fertilizing fluid for the germ, which is supplied by the female. The fluid from the male is called the semen. This rivifies the ovum, rendering it capable of development.

\section{The Genital Organs of the Male.}

The semen, or vitalizing fluid, is elaborated in two glands called the testes or testicles. These are oval in shape and situated in a cutaneous sack placed between the hind legs, which is called the scrotum. In this sack they are separated one from the other by means of a dividing septa, a prolongation from the peritoneum lining the abdominal cavity. The testicles in the foetus are formed in the abdominal cavity, descending into the scrotum a few days prior to or after birth. In descending they carry their peritoneal covering down with them into the scrotum, giving them three coats as it were, one of skin and two of folds of peritoneum. Frequently the testicles in leaving the abdominal cavity are accompanied by a portion of the intestines, which also occupy the scrotal sac, forming what is termed a congential hernia. Arising from the testicle is a thin whitish cord, which connects it with the glands or reservoirs placed on the superior surface of the neck of the bladder. This is called the spermatic cord. It is composed of nerves and blood vessels and a portion of peritoneal covering, enclosing also the duct called the ras deferens, which conveys the semen from the testicle to the glands on the bladder, termed the vesiculae seminales. Connecting the resiculae seminales to the urethra are two short tubes termed 
the ejaculatory ducts. The semen being thrown through the ejaculatory ducts into the urethra, by the contraction of the walls of the resiculae seminales at the time of copulation, passes down the urethra and is deposited in the vagina of the female. The testicles in sheep are very large in proportion to the animal's size, which accounts for the wonderful procreative powers possessed by rams, that are able, when full grown, to serve from 75 to 100 ewes in the course of a month. The penis of the ram has at its extremity a rermiform appendage, which is a prolongation of the urethra. This is very sensitive, and is the part frequently injured in the removal of calculi from the penis. When injured this appendage is rery apt to slough off, seriously affecting the usefulness of the ram for breeding purposes.

\section{The Generative Organs of the female.}

Situated in the abdomen, close to the borders of the pelvic cavity, are found two oroid shaped glands, one on each side, resting in the folds of a ligamentous structure called the broad ligament. These are the oraries, and are to the female what the testicles are to the male. In these bodies the germ orum is generated. Passing downwards and backwards from the ovary we find a very short convoluted tube, which connects the ovary with the womb. This tube is called the fallopian tube. It is at tached to the ovary at the time of germination of the ovum by means of a fimbriated umbrella-like opening called the pavilion of the tube. The womb is a membranous sac to which the crum is carried, and in which it develops. It is situated at the entrance of the pelvic cavity, immediately under the rectum, being held in position by the broad ligament. It possesses a body and two arms, or horns as they are termed, the extremities of which are twisted upwards and outwards, and are also held in place by folds of the broad ligament. The posterior end of the uterus terminates in a muscular neck, called the cervix uteri, 
which projects into the vaginal cavity. The cervix uteri is always tightly closed, excepting in the period of oestrum and during parturition. The ragina is a muscular carity, lined with mucous membrane, situated immediately under the rectum and communicating with the outside by means of a slit-like opening called the vulva. The orum being generated in the orart, is

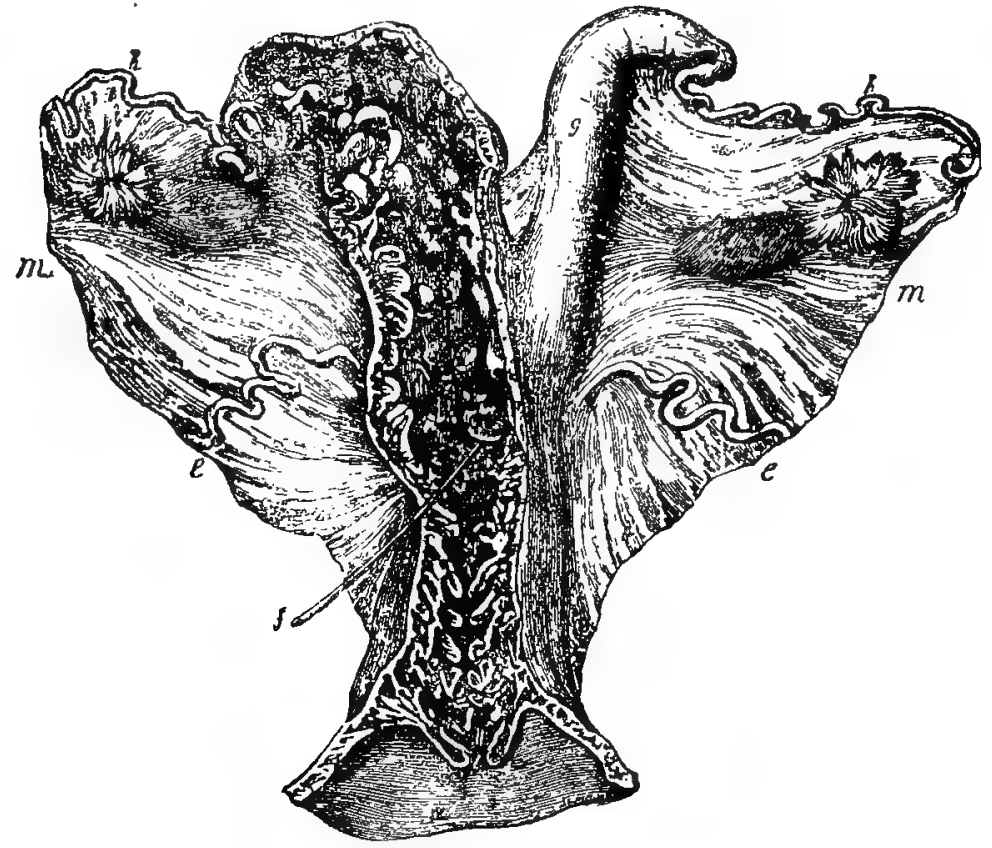

\section{Uterus, Oviducts and Ovaries of Sheep.}

$f-$ Confuence of cornua. e-Round ligament. $g$-Cornua. $h-$ Fallopian tube. $m$-Broad ligament (Owen).

vivified by the semen from the male, either in the fallopian tube on its passage to the womb or in the womb itself. As soon as fertilized, the egg locates in one of the horns of the womb and there develops into the foetus, the process of derelopment lasting over a period of about fire months before birth of the mature lamb takes place. 


\section{CHAPTER VIII.}

\section{Mating and Selection.}

In mating sheep the qualities of both parents must be considered, aiming to correct the bad ones and at the same time perpetuate those which are desirable. In the greater number of cases the influence of the male on the offspring is found to exceed that of the female. This is seen in other animals as well as sheep. A mule, for instance, simulates its sire, the ass, in general conformation and habits; a small mare bred to a large stallion produces an offspring half as large again as itself; a Lincoln ram on a Down ewe will produce offspring resembling the former more than the latter. Nature's laws seeming to be that the sire shall to the greater extent fix the conformation of the offipring, the disposition being frequently governed by that of the dam, the exceptions to this being few, and only tend to prove the rule. In mating and selecting sheep, breeders seek for various points, not so much on account of their particular value. when taken singly, but because they are evidence of other valuable qualities, such as an ability to quickly take on flesh or mature early. Thus we find that in the Southdown breed small heads and legs and small bones are sought after, as these qualities are found to be accompanied with exceptional fattening properties. Again black legs and muzzles are desirable, generally insuring a hardy constitution. These then are only the signs of good qualities, the qualities themselves consisting in the different points tending to make up the general conformation of the animal; for instance, a straight back is a quality in itself, as also is breadth of loin and rotundity of frame. A straight back 
gives a large surface for putting on flesh, and also affords more space for the abdominal organs beneath it. For mutton breeds small bone is desirable; large bone takes a correspondingly greater supply of nutriment in the form of blood, ete., which would otherwise be employed in building up the fleshy tissues, hence it is a superfluous quantity, and for a like reason horny appendages can be dispensed with. Rotundity of frame is an excellent attribute, supplying as it does an extended surface for the attachment of the muscles of the back and loins. A soft mellow feeling to the skin is another good quality to be sought after, showing as it does that the cellular tissue underlying it is in a healthy condition, and that fatty cells are being formed in its meshes. The point sought after in breeding is a well formed animal, its frame plentifully supplied with flesh, with as little bone and gristle as possible. The flesh should be distributed largely on the loins and quarters, correspondingly less on the head and neck. Where a large development of flesh exists a disposition to fatten will also be found, and for this to be profitable the animal must be capable of quick maturity. A number of the prominent breeds, especially those of mutton qualities, have been improved and owe their present state of excellence to judicious cross-breeding, and while this is a fact, it has been demonstrated that no more difficult task in breeding animals than successful crossing can be attempted, calling for not only the application of correct principles, but a degree of practical judgment and shrewdness, which in some persons secms to be inherent with their nature, while others may strive a lifetime and never acquire the science. Time and time again useful breeds have deteriorated by the injudicious application of cross-breeding, some fatal defect having been overlooked only to appear exaggerated in the progeny.

Again there is hardly a breed of long-wooled sheep which has not been improved by the admixture of Leicester blood, 
but where this has been tried on the middle-wooled breeds results were moderate, not effecting any permanent improvement, and often, as in the case of the Southdown breed, were far from successful or virtually failures. So it must be borne in mind that crossing in the main is experimental, at times succeeding beyond the breeder's most sanguine expectations, at others failing entirely for no risible reason. Where judgment assists in the process is in selecting the successful results, perpetuating them and rejecting the failures. In this manner after a few generations a breed of sheep is sometimes produced which, as in the case of the improred Oxford Downs, Shropshires, and some others we could mention, are desirable to perpetuate without the further admixture of foreign blood.

Another subject of great importance to breeders is "in-andin breeding". This process as applied to the human family would be found highly objectionable, for the reason that among people marriages are contracted with little if any regard to the health of the individuals concerned, and certainly without an extensive knowledge of each other's family history. For instance, we find a healthy man marrying a consumptive female to perpetuate the faults of her constitution to his offspring, or a healthy young woman marrying a stphilitic man to hand down a curse to four generations of their descendants. Now should the offspring of these ill-sorted couples inter-marry the predisposition to the disease already inherited would be increased twofold. A scrofulous brother and sister, from sexual intercourse, could only beget diseased progeny; but supposing that a family had been bred by careful selection, if for generations the ancestors on the male side had been always healthy and well formed, and the same could be said of the ancestors on the female side, what danger could be apprehended from a cross in, as breeders term it, riz: the intercourse of brother and sister, or son with parent, where there were no defects to be transmitted, none 
would be possible, and the unnatural mating would only tend to increase the strength of the already present good qualities. While this would be an impossibility as applied to the human family on account of the promiscuous intermingling and indelible stamping of inherent defects for generations and generations, when applied to animals its rationality becomes apparerit. Where due attention has been paid to the breeding only from healthy, well formed subjects, in time the disposition for health and form become inherent, and as a sound constitution and perfect conformation are essential to successful breeding, it is the development of these points which we most desire. For this reason the objection to breeding from close relationship, which is insurmountable in the human family, is untenable when applied to animals. The advantages of in-breeding as applied to animsils are as follows: Supposing that the qualities of both parents are good, the more likelihood of the progeny inheriting them by breeding with a riew to improvement, the best qualities become concentrated in one family. Should the members of this family not breed one with the other, they would most likely hare to be crossed with inferior animals of either sex. This process instead of furthering rould retard improvement. It is for this reason, therefore, that the most eminent and successful breeder: have built up and perpetuated indiridual families of sheep by the process of in-brecling, and the stock from these pure-bred sheep have proved the strength of heredity by the inheritance of the good qualities of their in-bred ancestors.

Where in-breeding fails is in neglect of proper selection, not culling the weak and badly formed from the flock, the breeding of these only tending to perpetuate defects, or where two animals possessing the same bad quality are allorred to breed. Notwithstanding their own good qualities, the tendencr to perpetuate the bad becomes increased trofold and is hard to get rid of, a defect seemingly being handed down with greater 
ease than a good point can be introduced. Should, however, proper care be employed, and only those animals possessing good forms and sound conilitions be allowed to breed, then beyond question the stock will be preserved pure, the proper form and qualifications will be handed down to the offspring.

\section{Selection.}

This consists in the proper weeding out of the undesirable ewes from the flock and the selection of rams specially fitted to propagate the type of breed and form sought after by the breeder. The drafted ewes, consisting not only of those with broken mouths, but such of the younger stock whose faulty conformation renders them unfit to perpetuate their kind. The breeder selects every year one or more rams to place with the ewe flock, and naturally selects those whose points and breeding are in line with his desires. Should he be breeding for wool more than mutton the selection will be of a ram of the Merino type, taking care that in all respects it is a typical representative of the breed. If breeding for mutton, or for both wool and mutton, those selected will be from such breeds as are noted for these particular points and qualities, but in no case does the breeder select a ram of faulty conformation, even though he be descended from a long line of noted ancestors, the mere fact of his imperfections bcing evidence of a weakness in his chain of ancestry.

The same applies to the selection of ewes. The breeder having decided on the particular class which he desires, always bears the same in mind when buying ewes to add to his flock. He will also make annual drafts from the flock, all undesirable animals being sold as feeders, or if fat disposed of to the butcher. Every draft made on a flock tends to strengthen the general appearance and enhances the value of the remainder. Ewes with weak necks, imperfect form or fleece, flat ribs or slanting quarters, are undesirable, their progeny being certain to inherit 
some of their faulty features. If the breeder will cull out all such animals it will only be a short time before the results will more than pay for the sacrifice. At the same time it must be admitted that a weak fore-end can be crercome by crossing with a ram with an exceptionally strong one; that a weakness on the part of one parent may be surmounted by the selection of one of the opposite sex which evidences a proportionate amount of strength where the other shows weakness.

Ewes before being put to the ram should be in good condition. They will then be in the best shape to conceive, and the lambing season will be materially shortened thereby. 


\section{CHAPTER IX.}

\section{A Study of Disease in General.}

Before defining the word disease it would be as well to understand what constitutes health. Prof. A. H. Baker of the Chicago Veterinary College defines health as follows: "When the lungs, heart and abdominal vestments, with their functions, attendants, and adjuncts, causing respiration, circulation and digestion, all presided over by the brain and nervous system, working harmoniously together are each performing their function rythmically, one with the other, the condition is known as health."

Disease is the opposite to health, or a deriation from the healthy condition, some organ or organs failing to perform its proper functions.

The general symptoms of disease in a sheep are the want of sprightliness, acting in a dull manner, an inability or indifference to remain with the flock, a rough, dirty, dry condition of the fleece, assuming unnatural recumbent positions, a desire for its own company, leaving the herd, and moping by itself. The diseases of sheep are numerous, and frequently fatal, being influenced by the nature and habits of the animal as well as by its constitution. As stated previously, when considering the digestive system, the organs of digestion are excessively developed in the sheep to permit it to extract nutrition from coarse and seemingly innutritious foods; to supply this complicated digestive machinery an excessive nervous development is required, and hence it will be found that the brain is small and the intellect poorly developed, the nervous energy being expended on the stomachs and intestines. 
The muscular system is also weak, the sheep being unfitted for laborious excrcise, even in its free state, and still more so among the better bred and pampered varieties, where the nature of the food and enforced inactivity tend still further to weaken its energy and vitality.

In comparison with the weak muscular development we find that the vascular system is also feeble, the amount of blood circulating in the system being considerably less in proportion to the body weight than in the horse.

Exertion requires extra combustion, greater waste of tissues, and a correspondingly greater circulation of blood to supply the tissue and repair its waste. The horse being required to exert muscular force frequently needs a large blood supply, whereas in the sheep these exertions are not necessary, hence the waste of tissue is also less, and a large amount of vascularity is unneeded; and while the sheep consumes a greater amount of food, as compared in size with the horse, we find that it is quickly conrerted into flesh, only a small portion remaining as blood in the system. It will be noticed that the number of specific diseases of sheep as compared to the horse and ox are few, seemingly due to the animal's inherent constitution, which resists certain diseases affecting other herbivora, as pleuro-pneumonia contagiosa, glanders, etc., but it is found that the diffusion of races of sheep to other localities has tended to increase the number of contagious sheep diseases. Again a large proportion of sheep are sold to be slaughtered before reaching maturity, and the majority before reaching old age, virtually redneing the number of diseases to which they would be liable had they been allowed to reach adult state. For this reason we have few chronic diseases to deal with, such as produce serious changes in the skeletal, circulatory, and digestive system-of the horse for an exampleresulting from orerwork and old age. 
The small size of the sheep, combined with its docile nature, render its handling for examination and treatment in disease an easy matter, but it may be as well to state here the proper manner to catch them to avoid injuring the animal or the staple. Sheep should not be held or lifted by the wool, as it not only produces unnecessary pain, but the struggles on the part of the animal cause the skin to be bruised. Ewes heavy in lamb should never be caught by the hind leg for self-evident reasons. To catch sheep, especially large heavy ones, seize the animal by the neck with both hands, pass one hand around the body, grasp the brisket, and lift the sheep clear from the ground, setting it on its rump. When using a crook apply it quickly to the hind leg above the hock, drawing the animal back sharply to prevent it from springing sidewise and wrenching the leg; when the sheep is within reach seize the leg, releasing the crook. The simplest manner to lift a sheep without inflicting injury is to grasp it around the body with the arms immediately behind the forelegs, raising it and laying it on its side or setting it on its rump. The domestication of the sheep calls for various operations, such as shearing, washing, castration, etc., any of which when not properly carried out being liable to cause disease; exposure to cold storms, errors in hygienic surroundings, even if apparently trifling, grazing on unsuitable pastures are all fertile causes of disease. Even domestication predisposes to disease, especially among the highly improved breeds, from the artificial nature of the animal's existence, which renders the system more complicated and susceptible to trifling derangements, which very quickly become serious. Owing to the complex arrangement of the digestive system it is frequently the seat of disease, which is as often caused by an excess of aliment as a deficiency, or a superabundance of dry matter, or from the germs of parasites, which mature and exist in the internal economy at the expense of the health of the animal, and it will be observed that the diseases 
which affect the digestive organs are more numerous and frequent than all others to which sheep are liable. By their exposure to the vicissitudes of the weather, although greatly protected by their woolly covering, also from being grazed on cold and wet soil, mnsuitable to their natural habits, diseases are frequently induced, especially those of the feet, such as foot-rot. The herding together in flocks facilitates the spread of infectious diseases through the herd, and the attacks of flies and other vermin during the summer months are a source of annoyance and care to the sheep owner. Parasites are the most serious and fatal causes of sheep diseases, producing a large proportion of the losses. They affect the animal internally and externally, causing debility and wasting, but at the same time they are easily recognized, and yield readily to properly applied agents. Diseases which affect limited areas or districts, due to some local cause, are called enzootic. Sheep from their conditions of life and management are frequently subject to enzootic diseases, a number of a flock being affected simultaneously, causing the necessary treatment to be applied in a wholesale or general manner. In the treatment of large numbers of a flock it would be impraticable to catch each individual member and dose it separately. To overcome this difficulty it is necessary to supply such agents in the food, which, being consumed by the flock, will do the most good, and for this reason such medicines as sulphate of iron and salt are given in the feeding troughs; for foot-rot foot baths (consisting of shallow troughs containing the desired medicinal agents) through which the sheep are driven; dipping or washing with agents to destroy parasites and salves of different kinds have been found useful, the healthy as well as the diseased being submitted to the treatment. In the treatment of plethoric diseases, such as apoplexy, phrenitis, and some congestive disorders and blood derangements, bleeding is uscful and frequently resorted to. Purgatives are specially valuable on account of 
their quick action on the digestive system; of these we find oily dowes more useful than the Glauber and Epsom salts. Pills or boli so frequently used in the treatment of the horse are unsuitable for the sheep or ox, and should not be used. The effects of purgative drenches are greatly assisted by the addition of stomachics and stimulating agents, which by their action on the nerrous system give tone to the mucous lining of the stomachs, expecially the maniplies. When bleeding is resorted to the reins under the ear and eye are nsually selected for the operation, but should a considerable blood letting be desirable opening the jugular will be found the quickest and best. The amount of blood to be drawn should not exceed eight ounces. It is useless to take less than one ounce, as the effect of the loss of such a small quantity on the stratem would be nil. A rough method of bleeding frequently applied is the amputation of the ear or tail. This is, howerer, a crude method of obtaining the result desired, and inflicts disfigurment on the animal.

To bleed from the cheek rein stand astride the sheep, pressing its body between the knees, pass the left hand under the jaw, drawing the head upwards and backwards slightly. When in this position the animal can neither struggle nor escape, then press the fingers of the left hand beneath the angle of the right jaw, just in front of the swallow or gullet. This will stop the circulation of the rein, causing it to enlarge; with the right hand trace the swelled rein in its course orer the cheek, and at a point about equidistant from the eye and angle of the mouth insert the lancet, making the incision from below, upward:, being careful not to cut through the imner side of the roin, but only its outer border. Ifter sufficient blood has been extracted discontinue the pressure caused by the left hand and the bleeding generally will cease. Should it not, howerer, insert a pin through the lips of the incision and wind some thread round, it. It is sometimes adrisable to bleed from the saphena rein. 
This is located on the inside of the hind leg, and is operated on about two inches above the hock joint. To operate lay the sheep broadside on the ground, tie three legs together, leaving the one to be operated on free, have an assistant draw it out straight and hold firmly. Shave off any hair or fleece over the part to be operated on, and by compression or ligature above the part distend the vein, then make incision through its external coats with the lancet, remove desired amount of blood, release the pressure, and secure lips of incision with a pin, as above described. In bleeding from the jugular the animal is controlled in the same manner as when operating on the cheek vein; the neck is then compressed by passing a string around it tightly; this is termed ligating, the string being called the ligature; the wool is then cut array from the course of the rein and the lancet inserted. After sufficient blood is drawn the wound is closed by pin suture. Bleeding from the jugular, in fat sheep, is a difficult matter on account of the adipose tissue placed immediately under the skin, making it hard to satisfactorily locate the rein. In such cases bleeding from the saphena or cheek veins is advisable.

The pulse is clefined as the impulse given to the blood through the action of the heart, representing, as it does the actual heart beats, which in healthy subjects average a certain number per minute. It acts as a register of the condition and number of heart beats, which when they exceed the normal or fall below the same to any amount would show a derangement of the animal economy, viz: disease.

The normal pulse of a sheep ranges from 90 per minute in the lamb to $60 \mathrm{in}$ the adult, averaging $\tau 5$. It can readily be taken at the femoral artery on the inside of the thigh by pressing it firmly with the fingers against the thighbone. The pulse in sheep, however, cannot altogether be relied on as an indicator of disease, as in all animals when subjected to excitement it is 
liable to run up considerably above the normal, and the sheep being very timid and excitable when caught is liable to be found with an abnomally high pulse, although in a state of perfect health. So also the temperature, which while in most animals is a sure index to the condition, in the sheep varies considerably even in health, different observers having arrived at rarious results in forming estimates of the arerage, running all the way from 101 degrees to 104 degrees Fahr.

Shearing has also been found to cause a slight fall, the temperature of unshorn sheep exceeding those shorn.

An experienced flock-master is generally able to determine with comparative ease the nature of any particular affection which may be of frequent occurrence in a flock, the finer methods of diagnosis only being necessary as a rule in obscure sporadic cases. The gait of the animal and its behavior are special guides to many affections, such as lock-jaw, sturdy, rabies, ete., the color of the mucous membranes of the eye, state of the tongue, condition of the urine or faeces, all are guides governing the animal's condition. The condition of the tongue is an extremely valuable sign. Youatt states that in inflammations affecting serous membranes, such as peritonitis, pericarditis, etc., the tongue will be found red, and that previous to an attack of dysentery the edges become red, showing a marked contrast to the body of the organ. It becomes yellow-brown in disease of the liver, purple or black in blood and respiratory diseases, pale and soft in atonic maladies and anaemia.

The condition of the faeces, their character, color and composition, and amount of urine voided, its color, ctc., are all valuable guides to the animal's health. The shedding of wool, or slipping the fleece, wool-slip as it is termed, is frequently observed after severe diseases, where the internal body temperature has been high, or may be caused by drinking an excessive amount of cold water when fatigued, or through sudden changes of diet. 
Frequent causes of disease among sheep are unsuitable pastures, containing an excess of laxative or perhaps astringent herbs; the excessive feeding of roots, such as turnips, grazing on rye or old dead grass, even salt in some cases causes plethora, and many such simple causes are all fertile disease-breeders to sheep, showing that what at one time may constitute a healthful article of diet, at others becomes a menace to the animal's exist- once. When studying the cause of obscure maladies all the above causes must be taken into consideration, as also the nature of the soil and composition of drinking water, and everything with which the animals have come in contact. Overcrowding in feeding lots, or overstocking of pastures, want of exercise, all are prejudicial to a normal, healthy condition.

Disease in many instances can be prevented by a proper regard to sanitation, only exhibiting healthy diet, taking into consideration all the common causes of disease, and removing the same where possible, in fact the judicious use of common sense as applied to sheep raising will be found generally more profitable than medication. 


\section{CHAPTER $\mathbf{X}$.}

\section{Diseases of the Brain and Nerpous System.}

While the nerrous system of the lower order of aninals possibly is not quite so sensitive as that of the human, it is found that the finer bred the animal is the more sensitive the nervous arrangment becomes. Each of the divisions of the nervous system have phenomena peculiar to themselves, enabling the observer to ascertain which becomes involved in disease. The different classes of disease being divided according to the parts involved, those of the brain being called cerebral, of the spinal cord the spinal, and of the nerres the peripheral. When the brain is involved in disease there is a loss of perception, rolition and special sensation. In paralysis of one side of the body, either motor or sensory, the brain is affected, but in cases of transverse paralywis, where the hind limbs are affected or a posterior portion of the carcass, then it is due to disease of the spinal cord, also in cares of incontinence of urine or retention, we conclude the cord to be affected. Where certain localized parts only are paralized, such as a muscle or set of muscles of one portion of the leg, it is due to an affection of the nerres supplying the part, and is termed peripheral.

Injury to the outer or corticle portion of the brain will affect the roluntary motions of the animal, while injuries to the deeper portions affect the involuntary or automatic motion, and serere injury to the rital parts produces instant death by (allsing paralysis or suspension of the vital functions. All injuries embracing the whole system produce either excitation and increased nerrous excitability or paralysis. One of the greatest 
peculiarities of this system is that there may be a great derangement of function without perceptible alteration of structure.

\section{frenzy, Encephalitis, or Cerebritis.}

This is inflammation of the brain substance. It is frequently seen occurring as a sequela to the operation for gid, or following an attack of apoplexy or fractures of the cranium. It is also caused by exhaustion and exposure or as the result of some specific ferer from the blood becoming poisoned. Food of too stimulating a nature, or an excess of coarse, innutritious foodstuffs. Rye-grass tops are apt to cause the disease, especially when overripe. Plethora and exposure to the hot rays of the sun in the summer season are predisposing influences. Lambs are more often afflicted with this disease than grown sheep.

\section{Symptoms.}

The primary symptoms are stupor, the animal being dull and unwilling to move. This stage is rapidly suceeeded by more active symptoms. The animal becomes frantic, throwing itsclf -about with great riolence, the mucons linings of the eyelids become red and congested, the eyes appear to bulge from their sockets, the pupils of the eves contract, respirations become irregular and bowels constipated. In lambs the riolent toms are most marked. They jump about continually, their motions appearing ridiculous. A few generations ago when thus affected they were said to be bewitehed, and burned alive by good churchmen to exorcise the fiends. Grown sheep when attacked may suddenly spring from the ground and fall clead, or should the attack be prolonged the periods of excitability are alternated with intervals of exhaustion and quiet. During the acute periods the sheep breathes hard and runs about in all directions with its tail carried upwards. It will butt in its delirimu at men or other sheep or anything which comes in its way. 


\section{Crèatment.}

This in such a severe affection must be prompt. It is advisable to bleed from the jugular rein, as directed in a preceeding chapter, taking about eight ounces of blood from a full-grown sheep. This should be followed by a cathartic. In this case Epsom salts are useful; give four ounces in half pint of warm water, to which one drachm of Jamaica ginger should be added. When the animal affected is of sufficient value to warrant particular care, it should be confined so as not to injure itself during delirium and given one drachm doses of bromide of potassium every two or three hours.

\section{Post-Mortem Bppearances.}

The lungs will be found congested, the blood vessels in the brain much distended, in some cases being ruptured, the blood oozing into the brain substance.

\section{Apoplexy.}

This is an intense congestion of the blood vessels of the brain, with rupture and more or less hemorrhage. This disease is most frequently caused from the plethoric condition. It gencrally occurs in hot weather and where sheep are grazed on rich pastures. It is more frequently met with in the sheep than the ox, Youatt explaining this as being due to the less perfect heat regulating power of the former animal and its being more forced in feeding.

\section{Symptoms.}

The attack is always sudden. The sheep falls to the ground in an unconscious condition, sometimes froths at the mouth, the eyes are dilated and prominent, the animal often seeming to be blind. In the commencement of the attack, instead of falling down, the sheep may stand still in one spot, apparently oblivious to its surroundings, and on being compelled to move falls over 
and dies suddenly. Owing to the causes producing this trouble, the first precaution should be to move the balance of the flock to poorer pasture, supplement this with a wholesale purge of Epsom salts and gradually reduce all artificial food, such as linseed meal, oil cake, etc.

The affected animals as a rule die before aid can be extended them, and should they recover from the apoplexy they are very liable to be attacked with inflammation of the brain. This is a disease which can better be prevented than treated, and if the sheep has been carefully watched some premonitory signs may be detected, such as a refusal to feed, the animal does not chew the cud, appears listless and dull, the linings of the eyelids are congested, and the respirations rapid. As soon as these signs are noticed the sheep should be bled at once, taking at least eight ounces of blood, making the incision in the jugular. The animal should be removed to different quarters, the feed reduced, and four ounces of Epsom salts, combined with $\frac{1}{2}$ ounce of liquor ammon. acetatis and $\frac{1}{2}$ pint of warm water administered as a drench. In the majority of cases this will ward off the threatenèd attack, and is always worthy of a trial.

\section{Epilepsy, fits and Convulsions.}

Epilepsy, fits, convulsions with delirium, the sheep becoming insensible, and at times comatose, is a disease caused by anything which tends to irritate the nervous system, such as tumors in the cavity of the cranium, fractures and depression of the cranial bones, or reflected irritation to the brain from other parts of the body, caused by the presence of worms in the intestines; indigestion, especially such as occurs in lambs due to sudden changes of pasture, neglect or mismanagement. Grazing the flock early in the morning while hoar-frost is still on the ground is also a cause, and accounts for epilepsy frequently breaking out 
among sheep in the early spring and late fall, when they are thriving well and in good condition.

\section{Symptoms.}

The sheep being apparently in good health suddenly throws up its head, staggers, looks wild, champs its jaws, and froths at the mouth, runs round a few times, then falls, convulsions ensue, the movements of the limbs become rigid, the sheep becoming totally insensible. The fit may last a minute or two, then consciousness returns. The animal rises with a dazed look, oradually getting all right and commencing again to feed, as if nothing had occurred.

\section{Creatment.}

If due to hoar-frost on the grass, keep animals confined till it has disappeared before allowing them to graze. If due to worms, treat for the same as prescribed in the chapter on worm diseases.

General treatment consists in affording hygenic surroundings, paying particular attention to the feeding, seeing that stimulating and fattening foods are fed sparingly. Mark the animals in the flock subject to epilepsy and sell them for slaughter. Do not breed from animals subject to the disease. Never in any case set a dog on a sheep suffering from an epileptic fit to drive the fit away, as is sometimes brutally cione.

\section{Бydrocephalus, or Clater on the Brain.}

Hydrocephalus, water on the brain, dropsy of the brain, usually due, always in the adult, to a serous collection in the ventricles of the brain. The lamb is particularly subject to this complaint, and as it sometimes exists prior to birth, the size of the head prevents delivery. When found occurring in the foetus (unborn lamb) it is due to some congenital taint, which interferes with the proper development of the foetus. 
This disease in the adult sheep is rare. When occurring, the symptoms are similar to those of inflammation of the brain, commencing with drowsiness withont delirium. As the serum collects, consciousness diminishes, the pressure on the brain finally causing paralysis, death usually taking place during convulsions.

\section{Treatment.}

Treatment is always unsatisfactory. When the first symptoms become noticeable the sheep should be slaughtered, and if in fair condition, and in the commencement of the disease, could with safety be used for human consumption.

As seen in the foetus, to save the life of the ewe, it becomes necessary to destroy the lamb by puncturing its skull to permit escape of the fluid and allow the bones to collapse. Prudence teaches us not to use the ewe again for breeding, and if many cases occur in a flock, the ram must be looked upon with suspicion, and had better be changed.

\section{Louping-Ill.}

Louping-ill, also called Tremblings, Thorter-ill, Mlad Staggers, etc. This is a remarkable disease, seemingly caused by a deranged sensibility of the nerves of the hind parts, probably due to a sub-acute inflammation of the spinal cord, more particularly in the region of the loins.

The inflammation of the spinal cord is followed by a serous effusion, which in mild cases coagulates, becoming transformecl into a sort of fibrous tissue. This produces permanent pressure on the cord; not sufficient to produce paralysis, but enough to cause derangement of sensibility. Great losses have resulted from this disease, and notwithstanding the large amount of practical and theoretical investigation instituted as to its nature and cause, much remains shrouded in darkness. Gamgee, Rich- 
thofer, Roll, Hamilton, Profs. Williams, Dick and Young have conducted careful studies and experiments as to the origin of this disease without any definite results. The history of louping-ill shows that it has existed in epidemic form many times in Scotland-notably on the Silurean strata, extending from the Hebrides to the Southern extremity of Dumfriesshire. Waldie of Jedburg long ago suggested that louping-ill was due to liming the soil, and that it disappeared 'when the lime became exhausted.-Steele. Dr. Hamilton suggester that the disease was inflammation of the brain and spinal cord. Profs. Dick and Robertson both considered that smut on grasses caused the disease; coarse withered grasses for food are also generally associated with this disorder. Ticks have also been considered to be the cause, supposedly carrying some specific poison and infecting the sheep, but this theory seems untenable, as the disease has been known to appear in pigs, where the idea of tick infection would have to be discarded, it being more probable that it originated in them from eating sheep offal from animals which had suffered from the malady. Overstocking, poverty, dry easterly frosty winds in April and May are also said to be productive of louping-ill to a great extent-in fact, almost everything has been claimed to be a cause, showing certainly a great diversity of opinion as to the origin of this obscure complaint.

\section{Symptoms.}

Trembling of the hind parts, twitching of the muscles. In acute cases, the pulse is accelerated, skin dry and hard, catarrh is often present, emaciation sets in, the sheep grinds its tecth, commences to pine, and finally death supervenes. Richthofer claims that the disease has only dereloped and become hereditary since the introduction of Merinos, and Roll also classes it as a disease of high-bred, fine-wooled sheep. In the early stages of the disease the sheep are in poor condition and going lock, the 
fleece is dry and dead to the touch, the nervous symptoms soon setting in, generally evidenced by a loss of power in one or more limbs, sometimes the whole side being inrolved, or even the whole body of the sheep may be affected, appearing to be palsied or attacked with tetanus, both of which diseases it simulates to a considerable extent. The head and neck are attacked with periodic spasms, which contract or draw them backwards with a violent jerk, tending to constrict the oesophagus and threaten strangulation on attempting to swallow liquids. A frothy saliva is emitted from the mouth, especially during the convulsive fits, which may occur every five minutes, and are accompanied by a very laborious and quick respiration, which subsides on the termination of the spasm. A sheep may exist for days in this condition, and should it not rally, death sooner or later ensues; even of those which eventually recover, many will lose the use of a hind leg for a considerable time, drawing it behind when moving, the leg feeling dead and cold to the touch. Not infrequently tumors appear around a joint or on the forelegs and brisket, which on being opened are found full of pus.

\section{Creatment.}

Treatment is entirely preventive, and consists in removing the flock to new and fresher pastures, feeding commercial foods, as oil cake, etc. Give the lambs a sufficient dose of Epsom salts to act as a purge, about four ounces for adult sheep. In fact, stimulating, nourishing diet and good hygienic surroundings are all we can prescribe for this condition, owing to the lack of knowledge as yet existing in reference to the cause of this most destructive complaint.

\section{Simple Daralysís-Dalsy.}

Simple Paralysis-Palsy, is a loss of power either sensory or motor, or both. It is a frequent disease in lambs, caused by 
exposing the ewe at weaning time to inclement-weather, combined with want of proper nutriment. This affection is also seen occurring in ewes as a sequela to abortion or prolonged difficult labor. It frequently attacks newly-dropped lambs, often prov-ing fatal in a night. Indigestion caused from gorging on roots, poisons ingested with grasses from the pastures, or obstinate constipation are frequent causes of paralysis.

\section{Symptoms.}

When not very sererc the lamb will be found standing still, with the hind parts powerless. In bad cases the subject will be found down, unable to rise, all power orer the hind limbs being lost. Where the motor functions are generally affected, a severe and persistent diarrhoea frequently results, the animal seldom thoroughly recovering.

\section{Creatment.}

For adult sheep, purgatives, tonics, and stimulating liniunents are best calculated to remove the cause and restore tone to the system. Take

Gentian fluid extract......... drachm

Ginger tincture............ drachm

Sweet spirits of nitre........2 drachms

Mix and give as one dose in two ounces of water twice daily.

For lambs give one-quarter to one-half of the above amount, according to age. In persistent cases nux vomica may be tried, administered in gruel; of this give five to ten drops in the gruel, commencing at five drops and gradually increasing the dose till ten is reached, then scale down to five again. Where the loins are badly affected and the animal is valuable, the owner wishing to save it, should clip the fleece off over the loins for a space of three inches each way and paint the back with a solution of linar caustic one drachm to one ounce of distilled water.

Apply some of the above with a brush to part; use it once 
daily for a period of two or three days. Repeat in a week if necessary. Where the animals are in good condition and fit for slaughter, they should be sold to the butcher, unless, as above stated, the owner is particularly desirous of keeping them.

As seen occurring in newly-born lambs, the young animal should be rubbed and warmed gradually; a teaspoonful of sweet spirits of nitre should be administered in a little warm water, and the lamb returned to the ewe, both being made as comfortable as possible and protected from cold winds. 


\section{CHAPTER XI.}

\section{Diseases of the Respiratory Organs.}

These include all diseases of the lungs, bronchial tubes, larynx, nostrils, etc., and while they occur less frequently and are not so numerous as those of the digestive system, yet they will be found occurring both in the milder forms of influenza and catarrh and the severer forms of inflammation of the lungs, or their serous coverings in the form of pleurisy, or attacking the bronchial tubes, as in bronchitis. In fact it is asserted that pleurisy is a common affliction of sheep, numerous cases of the same having been recorded following shearing and dipping, ete. Sheep shorn early in the season are very liable to pleurisy, and fatal terminations are not uncommon.

\section{Nasal Catarrh.}

Nasal Catarrh, commonly termed "snuffles," very frequently affects sheep which have been exposed to stormy weather, especially in the winter season. Sheep which have been shipped a long way to market frequently arrive at their destination with a severe attack of snuffles. Nasal catarrh is an inflammation of the lining membrane of the nose, and may exist in either of the three forms of inflammation, viz: acute, sub-acute or chronic.

\section{Symptoms.}

In the acute form considerable fever will be present, denoted by rapid breathing, a high color of the visible mucous membranes. The head is held out straight, the appetite is affected to a certain extent and there seems to be a tendency for the inflammation to pass downwards to the lungs. A cough is gener- 
ally present, caused by the accumulation of mucus from the inflamed surfaces. In the first stage the sheep sneezes frequently, shaking its head, evincing pain, and in the course of a few hours a mucus discharge from the nostrils commences. The linucus discharge soon becomes thick, but is odorless. After a few days pus is formed and emitted with the discharge, which in consequence becomes thicker and yellow, with a heary specific. grarity, - sinking in water. This disease will often, if not treated, continue in this state for several weeks, till nature effects a cure, or it may be followed by an extension of the inflammation to the lung tissue, causing pneumonia or bronchitis, which are very liable to prove fatal.

\section{Creatment.}

The removal of affected sheep from exposed places and administration of tonics and stimulants will in the majority of cases effect a speedy cure. Give one teaspoonful of sweet spirits of nitre three times daily in a little water, or Dunn's tonic drench, made as follows:

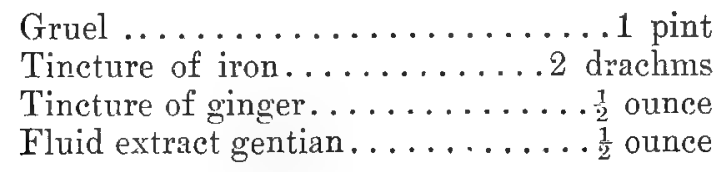

Mix and divide into three doses; give one dose daily.

Another excellent tonic is Elixir calisaya bark, iron and strychnine, dose one teaspoonful four times daily in a little water.

On account of this disease affecting a number of a flock simultaneously, it has been held to be contagious. This, however, is erroneous, the multiplicity of cases being due to all of the sheep having been exposed to the same errors of hygiene contemporaneously.

Catarrh causes a weakening and prostration of the affected sheep, which is very hard to overeome, making them unprofitable 
feeders; so it should be guarded against by not unduly exposing the flock in the fall and winter to serere storms or grazing them on damp unsuitable pastures. Randall says: "T early found that depletion in catarrh in our severe winter months rapidly produced that fatal prostration from which it is next to impossible to recorer the sheep-entirely impossible without bestowing an amount of time and care on it costing far more than the price of an ordinary sheep. The next course is to prevent the disease by judicious precautions."

\section{Sore Chroat, Laryngitis.}

This is inflammation of the mucous membrane lining the larynx - the cartilaginous box situated at the superior extremity of the windpipe or trachea. We find in acute cases the swelling is oedematous (spongy), the blood-vessels of the throat becoming engorged with blood, while gangrenous patches may form on the mucous membrane which may extend orer the whole of the throat, causing diphtheritic sore throat.

\section{Symptoms.}

Some fever, indicated by rapid respirations, the head projected in as straight a line as possible, the mouth is held open, a frequent painful dry cough is present, the sheep evidences difficulty in swallowing, especially liquids, which return through the nostrils, the eyes protrude more or less, and saliva forms in the mouth, which dribbles from it in the animal's repeated efforts at swallowing.

\section{Creatment.}

Apply the following stimulating liniment to the throat once or twice daily for two or three days, rubbing it well in:

Take. Oil of turpentine.............. ounce

Strong aqua ammonia.......... ounce

Linseed oil.............6 ounces

Mix, shake well before using. 
Internally give:

Chlorate of potash..........4 drachms

Tincture of iron...........6 drachms

Water ................ 8 ounce

Give one tablespoonful three times daily. This is a dose for an adult sheep. For lambs give one-quarter of above. Yearling sheep one teaspoonful. Give affected animals warm quarters and good nursing. This disease in the sheep as a rule yields to treatment, whereas in the horse it is a serious affection, frequently proving fatal. Youatt, in his work, mentions two cases of oedematous sore throat in sheep in which he performed tracheotomy (an operation in which the windpipe is opened and a tube inserted) with satisfactory results. This is evidence that severe cases may occur which require heroic treatment. It is a good policy where a valuable animal becomes attacked with laryngitis to commence treatment early to avoid any such difficulty.

\section{Bronchitis.}

Is inflammation of the mucous lining of the bronchial tubes. In its nature it is catarrhal, and is frequently found occurring as a sequela to nasal catarrh and laryngitis. Adult sheep, according to Gangee, suffer severely from this affection, and lambs are very liable to it, due to too early exposure to the elements or continued wet, stormy weather and overcrowding in sheds. Having to breathe a vitiated atmosphere also is a fertile cause of this disease.

\section{Symptoms.}

Are the same as those of nasal catarrh, but the cough is moist in character, a wheezing sound being audible, considerable fever is present, the throat and belly are tender to the touch, the respirations are quick, increasing in rapidity as the disease progresses, the appetite is lost from the start, the thirst, which at 
the commencoment of the attack is not excessire, soon becomes sı. By placing the ear to the sides of the chest peculiar murmurs called "rales," will be heard; these are caused by the expired air passing through secretions of liquid mucus in the bronchial tubes. As the disease progresses the sheep rapidly becomes weak, the urine is scanty and high-colored, and the droppings are coated with slime, but try and hard on the inside.

\section{Creatment.}

Hygienic treatment for this affection is most desirable. Remove the sheep to a roony shed where it can obtain plenty of fresh air and at the same time be protected from draught.

Stimulants especially are needed in the treatment of this complaint.

Take. Fluid extract of belladonna leaves..1 drachm Fluid extract liquorice root.....2 ounces

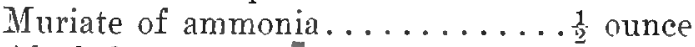

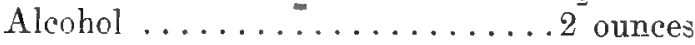
Water ................ ounces

Mix. Give one tablespoonful twice daily. This is a dose for an adult sheep. Combined with this treatment give two drachms of sweet spirits of nitre twice daily in half pint of oatmeal gruel. Purgatives are not safe to use in this affection and all darugs which tend to debilitate or deplete the animal's svistem should on no account be used.

\section{Inflammation of the Lungs-Dneumonia.}

This discase is of common occurrence where sheep have been subjected to exposure, particularly if the climate is damp and subject to sudden changes of temperature. It is also found following the inhalation of noxions gases or the extension of the inflammation of nasal catarrh or laryngitis. 


\section{Symptoms.}

It is usually ushered in by a shivering fit, which, however, is seldom noticed on account of its short duration. About the first warning symptom will be a persistent and troublesome cough, the breathing becomes labored, the elbows are generally turned outwards, there is increased motion of the ribs, and the flanks heave rapidly, the pulse becomes quick and strong. This however is only during the primary stages of the disease, as later on it becomes soft and very weak. The appetite is partially and oftentimes wholly lost, the sheep ceases to chew the cud, thirst is considerable, there is a foetid discharge from the nose, the animal grinds its teeth as though in pain. Woakness now becomes very evident, the eye has a peculiar glazed appearance; on passing the hands over the loins a crepitating noise is noticeable, the sheep has fits of delirium, and shortly succumbs from exhaustion.

\section{Treatment.}

As pneumonia in sheep has a tendency to assume a gangrennus character the need of administering only remedies which lave a tonic and stimulating effect is indicated. Counterirritation, such as the application of a stimulating ammoniacal liniment, applied behind the elbows, will prove of some benefit. As a prescription the following will be found useful:

Take. Sulphate of quinine........40 grains Tincture of iron............. Whiskey $\ldots \ldots \ldots \ldots \ldots \ldots .71_{2}^{2}$ ounces

Mix. Give two tablespoonfuls every four hours in half pint of oatmeal gruel. This is the dose for an adult sheep, others in proportion.

When sheep suffer from chronic pneumonia the animal is not worth the treatment, never being likely to breed, and useless for fattening. 


\section{Pleurisy.}

This is inflammation of the serous coverings of the lungs and chest cavity. It is produced by the same causes which result in inflammation of the lungs, more particularly in sudden changes in temperature, which tend to thoroughly chill the whole system. It is frequently seen following dipping in the late fall or sheep-washing in the spring, or may arise from the extension of inflammation from parts contiguous to the pleural surface or from direct injury, or adventitious growths involving the pleura, such as cancer, etc.

\section{Symptoms.}

Spasmodic pains will be observed, causing the sheep to grunt, grind its teeth and appear anxious and uneasy. The other symptoms resemble closely those of inflammation of the lungs, except that the pulse is hard and strong, the ears and leg's become cold, the flanks heave, while the ribs appear fixed. This stage of the disease may last two or three clays, recovery taking place by a cessation of the inflammation and a return of the parts to their normal condition. Should this not occur, however, it is very liable to terminate fatally, but death may be deferred for a week or even ten days. Prior to this second stage the appetite is lost, but as the effusion from the inflamed pleural surfaces takes place, resulting from the inflammation, the sheep commences to fced, the extremities get warm and an apparent change for the better takes place. This, however, is only the forerumner of the third stage of the disease. The effusion increases till the chest cavity becomes filled with a watery serous liquid, the respirations once more become labored, the eyes become glassy, and the sheep soon dies, virtually from suffocation. The effusion in the chest cavity is termed in scientific works hydrothorax, which may at the commencement terminate favorably through a cessation of the effusion and its absorption by the 
system. This, however, seldom happens in the sheep. Following attacks of pleurisy the lungs frequently adhere to the chest walls from the adhesive action of the inflammation. Sheep in this condition are very unsatisfactory feeders, generally losing flesh instead of fattening, and are not liable to breed.

\section{Treatment.}

For pleurisy, when noticed in the first stages, bleeding is useful-the extraction of not less than eight ounces of bluod from an adult sheep is advisable. It should not be repeated. Give the animal good hygienic treatment, and in the commencement of the attack, if noticed when shivering, a close of whiskey, about one ounce in four ounces of gruel, will effect much good. In the second or painful stage of the disease give as follows:

Fluid extract belladonna.......2 drachms

Sweet spirits of nitre.........2 ounces

Muriate of ammonia...........

Water ................6 ounces

Mix. Give one tablespoonful every two hours in one-third pint of gruel. Apply the ammonia liniment, previously prescribed in this chapter, behind the elbows and lower part of chest. 


\section{CHAPTER XII.}

\section{Diseases of the Digestive System.}

These generally arise from errors in diet, the food being either too bulky or too concentrated, too rich or too poor, not sufficient food or over-feeding an excess of indigestible foodstuff, or a deficiency of the same, to which may also be added irregular feeding. A concentrated food, if fed in large quantities, produces indigestion, the effect being felt in the stomach. Food should not enter the stomach in a wholly digestible state, as that organ needs a stimulus to make it work, the stimulus resulting from the irritation caused by the indigestible matter in the food. It will be found that of all the classes of diseases affecting sheep those of the digestive system are the most numerous, more losses probably occurring from them than from all the other classes combined.

\section{Hphtha; Sore Mouth.}

This is a very troublesome and at times even fatal affection. It is generally seen occurring among lambs in the early spring, those still sucking the ewes being most frequently affected. Older sheep sometimes are severely affected by it. Stock over two years old, however, is rarely attacked by this disease. There seems to be some ground for the belief that feeding sheep turnips has a tendency to cause this condition; errors in diet are also supposed causes, improper sanitary conditions, the spores of certain fungi, low vitality, and in aged sheep carious teeth, etc, have all been set down as causes of aphtha. The fact, however, that even in simple aphtha the teats of the ewe be- 
come affected from the lips of the lambs would tend to prove its cortagious nature. Nocard claims that it is due to a microorganism which he has found not only in the milk but also in the watery effusions present in the abdominal cavity after death. Apparently the lambs first become attacked, the ewes being inoculated by their young, but as to the actual cause or source from which the lambs receive infection but very little is known.

\section{Symptoms.}

The first apparent symptoms :re on the part of the lambs a disposition to drag behind, not keeping up with the ewes, reluctance or inability to grasp or suck the teat, taking it into the mouth and letting it go quickly, the mouth when the lamb is endeavoring to suck becomes filled with foam, which coats the udder of the ewe, a desire to lay down and not frisk about is observed, the lambs get weak, evidences of cachexia or wasting away becoming apparent, they appear listless, the ears hanging pendulous and the head drooping forwards. Small pimples will now be observed round the mouth. These enlarge and ulcerate, become confluent, forming sores which become covered with scabs. Inside the mouth these pimples and sores will also be found attacking the tongue, gums and lips; in severe cases the gums ulcerate, the teeth even become loose, and may fall out, the lower jaw bone in such cases generally being diseased. When existing in this form death frequently occurs from an inability on the part of the affected animal to obtain food. In these severe cases there seems to arise a systemic blood-poisoning, which induces inflammation of the lungs, abscesses on the course of lymphatic vessels, causing prostration, rapid breathing, coughing and inability to move.

When the udder of the ewe is attacked the eruption is similar to that found in and around the mouth of the lamb. The teats are covered with sores, which become crusted over witl 
thick black scabs, and as the lamb is unable to extract the milk from the udder, both on account of its condition and the soreness of it, the gland becomes inflamed from retention of milk and extension of the disease on the course of the milk ducts, resulting frequently in a gangrenous condition, the whole or a large portion of the udder sloughing off.

\section{Creatment.}

Immediately separdte the healthy stock from the sick; take the healthy to an entirely new locality. The others, being affected, may as well remain where they are till cured, so as not to spread the disease. Change the feed of the ewes, and so long as the udders are not affected the lambs may be allowed to remain with them. Should the udder be attacked, wean the lamb, and raise it by hand. To the sore udder apply the following lotion:

Tannic acid.............. drachm

Acetic acid.............1 ounce

Water ............... pint

IIandle the gland carefully. It should be milked out twice daily, using great care not to bruise the part. This is a troublesome procedure, but very necessary, as it will prevent the loss of the ewe. Internally, at the commencement of the attack, a dose of Epsom salts is indicated. Give four ounces in half pint of warm gruel. In the feed-trough mix with the food and give as follows:

Powdered liquorice root........4 ounces

Sulphate of iron..........5 drachms

Powdered gentian.........4 ounces

Wood charcoal.............2 ounces

Linseed, ground..........5 ounces

Nix. A tablespoonful should be given in the food twice daily. To the above a small quantity of common salt might be added with benefit. The mouth of the lamb should be washed 
several times daily with a solution of chlorate of potash, applying both inside and externally over the sores.

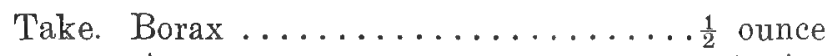

Aqua ................ pint

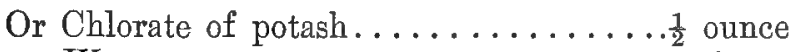

Water .................... pint

Swab out the mouth with onc of these mixtures, being careful that very little if any is swallowed; also apply the lotion externally to the affected parts. If the mouth is foetid, the ulcers appearing gangrenous, use as follows:

$$
\begin{aligned}
& \text { Potassium permanganate....... grains } \mathrm{X} \text {. } \\
& \text { Wrater } \ldots \ldots \ldots \ldots \ldots \ldots \ldots \ldots \ldots \text { pint }
\end{aligned}
$$

Mix, and apply as directed with the other. Should proud flesh appear on the lips or gums, touch it with caustic potash, or better still, nitrate of silver; if the teeth become loose and carious, they should be removed.

\section{Obstruction of the Gullet-Choking.}

This may occur in the pharynx, but generally in the oesophagus or gullet. It is usualy caused by the lodgment of food. It is rarely seen in sheep as compared with the ox, but may occur where roots are being fed.

\section{Symptoms.}

The sheep stops feeding, the breathing appears difficult, the animal commences to bloat, the swelling appearing greater in the region of the left flank than in the right. Death frequently occurs, due to suffocation from pressure of the distended stomachs on the diaphragm or midriff, which diminishes the capacity of the chest cavity, preventing free expansion of the lungs, the derangement of the pneumogastric and sympathetic nerves from the irritation also helping to cause a cessation of the rital functions. 


\section{Creatment.}

This is entirely operative, and for the speedy relief of the animal a probang is needed. This is a thin flexible tube, with a small knob or protuberance on the end which is inserted in the mouth.

To operate, set the sheep on its rump, the shoulders resting between the knees of an assistant, who also takes hold of the fore-feet to keep the animal steady; then by the use of a gag or the hand of the operator the sheep's mouth is kept open, and the probang, smeared with lard or vaseline, is gently passed over the back of the tongue and down the gullet. When the obstruction is reached only gentle pressure must be exerted. as violent efforts are liable to rupture or lacerate the coats of the oesophagus, in which case the animal would most likely have to be destroyed. When the obstruction is moved by the probang and passes into the rumen, relief is instantaneous.

Where bloating is considerable, the rumen should be punctured prior to passing probang, with an instrument termed a trocar-this is a very necessary article for all stock-owners to possess; its use permits the escape of gases arising from fermentation in the stomach or bowels, and secures time for the administration and action of medicinal agents.

The trocar is a pointed stillet, about 1-16 of an inch in diameter and fire inches in length, which fits in a closely fitting tube. The part to be operated on is selected and the instrument inserted. The stillet is withdrawn, leaving the tube in position, through which the escape of gases is perfected. In bloat from choke in both oxen and sheep the place to be operated on is the left flank, the operator selecting the location by careful examination, taking the soft and most bulging point for a guide, so as not to strike the last ribs, or transverse processes of the lumbar vertehrae with the instrument. Should the probang not be successful in removing the obstruction, the animal, unless very valu- 
able, had better be slaughtered. If, however, extreme measures are to be tried, select the bulging portion of the gullet caused by the choke for the point to be operated on, clip the wool off from the part, wash the skin with soap and waterr, and apply a 5 per cent. solution of carbolic acid; then make a bold incision with a sharp knife (which must be clean, and should have been dipped previous to use in the carbolic solution) through the skin and underlying tissues to the gullet, lay the gullet open by another stroke of the linife, remore the obstruction, take a surgeon's needle, threaded with sterilized silk or catgut, and bring the edges of the gullet together, being certain that the inside mucous linings are in apposition, wash the wound out with carbolic solution and sew up the skin, using three or four stitches. After the operation the animal whould be kept perfectly quiet and fed on a liquid diet till the wound in the gullet has perfectly healed, the best food being linseed jelly or oatmeal gruel, to which a little whiskey has been added, or anything which can be swallowed without exerting the muscular coats of the gullet. If in two or three days after the operation the swallowed liquids continue to exude from the wound the animal had better be slaughtered, as the chances are that the operation has been a failure.

\section{Bloat, Бoven, also Called Blasting.}

This is not in itself a disease, but rather a condition arising from the mal-assimilation of food, it being due to the collection and formation of gases in the rumen or first stomach, due to the fermentation of its contents. It arises from various causes, such as the eating of grasses still wet with dew-especially should they belong to the clover family-frosted roots, or root tops, and a diet containing a surplus of moisture, especially if suddenly forced on the sheep, or it may arise as a sequel to choke, as stated in descriptions of preceding disease. 


\section{Symptoms.}

The sheep is dull, breathes hard, exhibits abdominal pain, the body back of the ribs commences to enlarge, especially in the region of the left flank where the rumen is situated, the swelling on this side being more bulging and projecting higher than it does on the other.

\section{Treatment.}

This may be both medicinal and operative. In many cases agents which, when swallowed, arrest the process of fermentation, will be all that is necessary to effect a speedy cure. The writer has found the following one of the most effective agents to remedy this condition, and it is always worthy of trial before using the trocar. Take tincture of colchicum seeds and place 20 to 30 drops on the sheep's tongue, repeating in 20 minutes if necessary. This is in the line of homeopathic treatment, but experience has proved its success, and being simple to administer, is a desirable remedy to use. Bi-carbonate of soda is also administered for this trouble, and if the colchicum is not obtainable is a good article to use, as all households have a supply of cooking soda on hand. The dose should be one tablespoonful dissolved in half pint of warm water and given as a drench. If the bloating is rery severe, the trocar should be used without delay. Plunge it into the highest bulging portion of the left flank. This will permit the escape of the gases. Then administer the colchicum or soda treatment to arrest the fermentative changes taking place in the viscus.

If this trouble arises from eating reet grasses in the early morning or from the ingestion of too succulent a diet, correct the same, seeing that dry hay is fed or the animals kept in the pens in the early morning till the dew has disappeared from the grass.

\section{Los9 of the Cud.}

This is not a disease, but an effect of derangement of some part of the system. An animal suffering from any serious sick- 
ness naturally does not desire food. When the trouble is removed, the animal will soon commence to chew the cud again. IThen this happens without any appreciable cause, the administration of a cathartic such as Epsom salts 4 ounces, hyposulphite of soda 1 ounce, dissolved in one pint of warm water, will generally give satisfactory results. If it is due to indigestion, evidenced by the sheep pulling and eating its wool, prepared chalk mixed with common salt sprinkled over the fodder will effect a cure.

\section{Impaction of the Rumen.}

This is a mechanical distension of the rumen with food. It is practically a filling up of the rumen with solid food, more particularly grain; it may also be seen where sheep are grazed on new grass in stubble fields, the sudden changing from poor to rich pastures; new wheat also has been known to produce very fatal effects. The walls of the rumen become paralyzed, their natural motions cease, and the food remains in the viscus as an inert indigestible mass.

\section{Symptoms.}

It will be distinguished from bloat in that pressure on the left flank reveals a doughy, pitting feeling, the rumen, as felt under the skin, not being a yielding buoyant tumor as in bloat. The sheep appears dull and stupid, naturally does not chew the cud, grunts occasionally from pain, has an anxious look, and, as before stated, a diagnostic symptom is the inelastic, doughr, feeling of the left flank.

\section{Creatment.}

A cathartic should be administered, combined with which stimulants are indicated, both nervous and systemic.

Take. Fluid extract nux vomica......5 minims

Barbadoes aloes............. $\frac{1}{2}$ ounce

Aromatic spirits ammonia.....2 drachms

Warm water................ pint 
Mix. Give as one dose. Should this not prove effective, and the owner wishing to save the sheep for breeding purposes, clip the fleece off the region of the flank, then take a clean sharp knife, make an incision downwards and inwards through the skin from a point about two inches from the protuberance of the hip bone, making it about three inches in length to permit entrance of the hand of the operator; break through the tissues underlying the skin with the fingers, exposing the external coats of the first stomach, make a bold incision through this, insert the hand (first taking a napkin or clean cloth and placing it so that it covers the dependent part of the wound in the skin and also stomach-this to prevent the contents from falling down between the walls of the stomach and abdominal cavity, in which case peritonitis would most likely result), remove at least onethird of its contents, and then pour into the stomach a purgative such as:

Take, Common salt.............2 ounces

Solution of ammonium acetate.... $\frac{1}{2}$ ounse

Water .................... pint

Then sew up the walls of the rumen (stomach), being careful to bring the inside surfaces together, making the stitches with a fine surgeon's needle about half an inch apart, using sterilized cat gut or silk for the sutures. Then take silk and sew up the skin. Do not take the stitches through the tissues underlying it between it and the walls of the rumen. Dress the external surface of the wound with pine tar. This is a very effectual operation, and if properly performed is not liable to produce any serious results.

\section{Impaction of the Chird Stomach.}

Impaction the Third Stomach, or Omasum, also termed "grass staggers," "drying up" or "fardel bound," occurs in the same way as impaction of the first stomach or rumen. Prof. Williams says that it is always accompanied with inflammation 
of the fourth stomach, which, he claims, is the original lesion. Sudden changes of food, changing the sheep from a grass to a dryer and less nutritious ration, astringent herbs in the pasture, especially when the season is dry, also cause this condition.

The omasum becoming filled with dry food, the leares of mucous membrane, of which its interior is composed, become partially paralyzed, their movements and mucous secretions cease, this being immediately followed by inflammation of the organ, due to the irritation caused by the retention of its contents. As a result of the inflammation, the contents become dryer and the mucous membrane exfoliated from the folds, causing a highly dangerous condition.

\section{Symptoms.}

The bowels may be natural or eren loose in the first stages of the disease. This is soon followed, however, by obstinate constipation and fever. The sheep stands with a straightened neck, the nose is hot and dry, the eyeballs stand out prominently, the mouth is covered with a frothy, slimy discharge, the animal will grunt frequently, cough is rarely present, which will assist in not confounding this complaint with lung trouble, the respirations become quickened, evidences of cerebral derangement appear, such as delirium and erratic violent motions, followed by stupor. Exhaustion takes place rapidly and unless relieved the sheep quickly succumbs.

\section{Creatment.}

Endeavor to soften the contents of the omasum. For this purpose an oleaginous purge as indicated.

Take. Barbadoes aloes..............

Fluid extract belladonna leaves... $\frac{1}{2}$ drachm

Linseed oil................ pint

Mix and give as a drench. When drenching ruminants, and it is desired to have the medicines reach the third and fourth 
stomachs without passing into the rumen, pour the drench into the animal's mouth slowly. In this case the drench being intended for the omasum, it should be administered as directed above. Give frequent drenches of oatmeal gruel or linseed jelly in warm water, to which should be added some such stimulant: as aromatic spirits of ammonia, whiskey, ete. The following prescription will be found useful:

Take. Aromatic spirits of ammonia.. ..1 $1 \frac{1}{2}$ ounces

Fluid extract, nux vomica....... $\frac{1}{2}$ drachm

Alcohol ...............2 $\frac{1}{2}$ ounces

Mlix and administer two tablespoonfuls twice daily in half pint of oatmeal gruel. It will be found advisable in obstinate cases to give rectal injections (enemas), composed of warm water and soap, to which a small quantity of common salt, about half teaspoonful, has been added. These should be used twice daily. Powerful purgatives, such as croton oil and mercury, or calabar bean, are absolutely useless and exceedingly dangerous.

This disease is always serious and demands the best of care and attention, in spite of which fatalities frequently occur.

\section{Intestinal Obstructions.}

First under this head we recognize accumulations of wonl, or wool ball, stony concretions, etc., all called calculi.

Secondly, rupture, or hernia, with strangulation.

Thirdly, stricture.

Fourthly, volvulus and intus-susception.

\section{đalool Balls.}

Wool balls, the results of felting wool and food materials, are frequently found in post mortem examinations of the first stomach of the sheep. These appear to cause the animal but little inconvenience and deserve but passing notice, excepting when occurring in lambs, just after the ewes have been shorn, 
and the ticks migrate to the lambs, cansing them to bite, and tear out the wool, which they swallow in large quantities, it is liable then to produce conditions which are apt to terminate fatally. Calculi, composed of stony or mineral material, formed round some object, which acts as a nuclcus, such as a nail-head or piece of gravel, are frequently found in the bowcls, where they also effect little harm, forming pouches or depressions in the buwels, where they rest, and it is only when through some cause or other they become ejected from these pouches that they are liable to cause colicky symptoms, which may terminate fatally through inflammation of the bowel.

\section{Бernia, Rupture.}

Of this we have several different kinds, depending on their location. Ilernia in general is a protrusion of a part of an intestine, through an opening in the peritoneal covering of the abdominal cavity. Hernia is recognized as a fluctuating tumor; when occurring in the middle of the belly near or at the navel it is termed umbilical hernia. When in the serotum, as is sometimes seen in rams, it is called scrotal hernia. When above the scrotum, high up on the inside of the flank it is termed inguinal. Should an intestine protrude through the midriff or diaphragm, or should that muscle become ruptured from any cause it is termed diaphragmatic hernia. Should the aperture through which the bowel exudes be small so that the bowel becomes constricted and the free passage of the faeces becomes interferred with, strangulation takes place, in which event the bowel outside the opening becomes congested and swollen, gangrene sets in, the bowel sloughs and the animal quickly dies from the effects.

\section{Diaphragmatic Бernia.}

Always results from flatulence, due to accumulation of gases in the stomachs, which, through pressure on the midriff, cause it to rupture; this condition is always fatal. 


\section{Ambilical Бernia.}

T'mbilical Trernia is very common in the sheep, and rarely if ever causes any inconvenience.

\section{Creatment.}

Where rupture threatens the life of the animal through strangulation it had better be sold to the butcher. Umbilical hernia as seen in sheep, while unsightly, is seldom serious and in no case would an operation for this trouble in sheep be justified.

\section{Stricture.}

In the bowel occurs as a result of changes in the tissues of the bowel, resulting from acute inflammation, chronic thickening and degeneration of its walls, which by constricting the tube, acts as a mechanical obstruction to the passage of faecal material. This complaint is rare, and when occurring in sheep has no differential symptoms to distinguish it from inflammation of the bowels, which it virtually causes.

It is alwavs fatal. To treatment.

\section{Volvulus.}

Is a twist or alteration from natural position of part of the bowel, generally the ileum twisting round the colon. No treatment or diagnostic symptoms. Always fatal.

\section{Intus-Susception.}

Is when one part of the bowel slips into the part posterior to it. It may be likened to the finger of a glove, half turned inside out. This is supposed to occur from violently increased bowel motion, (peristalsis). This also is a fatal affection, with no particular diagnostic symptoms. In all the above enumerated troubles the symptoms simulate those of inflammation of the bowels, there being intense nervous prostration and nausea, with an absence of bowel sounds or murmurs, scientifically called borborygmus. To treatment. 


\section{Impaction of the fourth Stomach of Lambs.}

Due io milk curdling. This is a very fatal and frequent disease, being due to forcing lambs for the early spring market, where cow's milk is given in addition to what the lamb obtains from its mother.

\section{Symptoms.}

The lamb is dull, stupid, unwilling to move, breathes hurriedly, is constipated, the belly is swollen and tender.

\section{Creatment.}

Freely administer thin gruel to which has been added bicarbonate of soda. Give about 10 grains by weight of the soda in every dose of gruel, administering two or three ounces of gruel every two hours. Follow this treatment with linseed oil as follows:

Aromatic spirits of ammonia. . $\frac{1}{2}$ teaspoonful Linseed oil..............4 ounces

Shake well and give as one dose.

\section{Colic.}

This is rather a rare affection so far as sheep are concerned, due no doubt to the fact that the food having been so thoroughly worked over in the stomachs, indigestible materials rarely enter the bowel.

\section{Symptoms.}

Colicky pains, grinding the teeth, frequently getting up and lying down, striking the belly with the hind feet, the pain not constant, there being intervals of ease between the spasms of pain. This condition is more frequently seen occurring in lambs than sheep, resulting from errors in diet, such as over-feeding from the bottle, when cows milk is used, or from obtaining a surfeit of milk even from its own dam. 


\section{Creatment.}

A ntispasmodics and carminative agents are indicated, sucls as peppermint, ginger, and sulphuric ether. Counter-irritation, such as the application of a stimulating liniment to the belly, the ammonia liniment preseribed in this work being useful. Cathartics should also be given.

Take. Tincture of ginger........... drachm .

Sulphurie ether............ drachm

Trarm water............4 ounces

Mix. Give as one dose. This is the dose for a lamb about three months of age; others in proportion to age. This will be found in the majority of cases to speedily give relief. A rectal injection of soap and warm water may also be administered with beneficial results.

\section{Inflammation of the Bowels, Enteritis.}

This is a rare condition in the sheep, and whether it really exists as a disease or is the effect of other diseased conditions yet remains to be proven, it being considered doubtful by a number of authorities whether true enteritis ever occurs in the sheep. "Youatt mentions strangulation, intussusception, volvulus, hernia, rupture and ascites, as found in post mortem cases where from the caecum to the abomasum, after including it and other stomachs, there was distinct inflammation and sometimes gangrene."-Steele.

\section{Symptoms.}

In addition to those found in cases of colic, the sheep lies down most of the time, the pain is continuous instead of intermittent, the temperature is elevated and continues so, till towards the termination of the attack. A frothy saliva will be observed round the mouth, the belly is tender to the touch. 


\section{Creatment.}

A stimulating application to the belly is indicated. For this use the ammoniacal liniment, or the fleece may be clipped close and a mustard plaster applied. Purgatives in this discase should never be used. Opium, combined with quinine, and perhaps belladonna and camphor, will often afford relief. Give mucilaginous fluids instead of clear water to drink; during cunvalescence administer mild diffusible stimulants, such as solution of ammonia acetate in drachm doses, and should constipation be present use rectal injections to counteract it. On no account use purgatives. A prescription for enteritis may be written as follows:

Take. Laudanum ...............1 $\frac{1}{2}$ ounces

Spirits of eamphor.........6 drachms

Fluid extract belladonna leares...2 drachms Alcohol ..............6.61 ounces

Mix. Give one tablespoonful cvery three hours in quarter pint of warm gruel. The counter-irritation in the form of external applications to the belly should not be neglected in these cases, and, as stated above, the application of mustard will afford much relief

\section{Diarrhoea, or Super-Purgation.}

This is an unnaturally fluid condition of the faeces, resulting from mismanagement and neglect. It exists either as a functional disturbance or a symptom of some other condition. It is caused by some irritant in the stomach or borrels, which produces an increase in their peristaltic motions, an excessive amount of water being extracted from the capillary blood vessels in the mesentery, and thrown out into the bowel. This gives rise to an increased thirst, which unless controlled will only increase the trouble. Abundant and watery diet, unripe grasses, sudden changes in the food, exposure to inclement climatic con- 
ditions, or after such operations as dipping, shearing or washing, are all common causes in adult sheep. Mechanical and chemical irritants, local tissue changes, functional changes of the abdominal glands as seen in tuberculosis, diseases of the liver, where an over-secretion of bile is present, are also fertile causes of diarrhoea. This disease is frequently complicated with dysentery, often terminating in an attack of that affection.

\section{Symptoms.}

A thin, watery condition of the faeces, frequent, painless, odorless, and free from slime or blood. At the commencement of the trouble there will not be any constitutional disturbance, but should the trouble persist, the lining of the borvels becomes injected, causing colicky pains, increased pulse beats, which get weaker and weaker. A rapid lowering of the temperature takes place, in all cases an excessive thirst will be exhibited, the animal loses flesh rapidly, the face has an anxious, haggard look, the tongue becomes furred, the extremities, as death approaches, get cold, the visible mucous membranes turn a pale color instead of the normal pink, these latter symptoms being those of extreme and protracted cases of diarrhoea, which if existing would clearly go to prove neglect on the part of the sheep-owner.

\section{Diamboea of Lambs.}

Diarrhoea of Lambs, also called the White Skit, from the profuse white-colored evacuations. This is caused by the ingested milk curdling in the lamb's stomach. It is a dangerous disease, and is virtually due to constipation and not diarrhoea, the watery discharge being the whey from the mass of curdled milk in the fourth stomach. The fourth stomach of runinants, as has been stated in a prior chapter in this work, is the digestive stomach, and normally possesses the property of curdling milk to better facilitate its digestion. This disease being due to 
an excess of the natural functions of the stomach, the milk either being too rich in quality, or partaken of in excess, coagulates too quickly from the increased powers of the gastric juice, which increase takes place when the lamb commences to pick other nourishment.

\section{Symptoms.}

In addition to the characteristic white color of the discharges will be found dullness, heaving of the flanks, a tense, enlarged condition of the abdomen and at times costiveness.

\section{Che Green Skit.}

Also a disease of lambs, in which the watery evacuations are of a greenish color. This is due to exposure and errors of diet at the time of. weaning. It is often quickly fatal, sometimes terminating unfavorably in twenty-four hours.

\section{Treatment for Diarrboea in Bdult Sheep.}

Make the patient as warm and comfortable as possible. Ascertain the cause of the trouble and if possible remove it. In all cases withhold the water, only allowing the sheep to drink bland fluids, such as linseed or rice tea, flour gruel, etc.

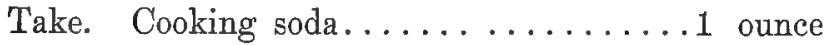

Water ................. gallon

Allow the sheep to quench its thirst with the above. It will be found useful to correct any excess of acidity in the stomach and bowels, and may go far towards relieving the trouble. Take

Prepared chalk............1 ounce

Laudanum ............4 ounces

Tincture of ginger.........1 ounce

Peppermint water.........8 ounces

Mix. Shake before using, giving the affected sheep two to three tablespoonfuls night and morning. For lambs just weaned 
give half the abore dose. In all cases of diarrhoea the diet demands particular attention, and if the purging persists orer twenty-four hours, the sheep should be moved to dryer pastures or fed dry food, such as hay and bran. In cases of diarrhoea it is not considered good practice to try and stop the evacuations suddenly with astringent mixtures, but rather to aid nature in getting rid of the irritant. For this purpose it is as well to commence treatment with linseed oil, and if pain is a marked symptom, opium in any of its forms, preferably laudanum, can be added, as for instance

Take. Linseed oil.............4 ounces

Laudanum ...........2 drachms

Give as one dose for an adult sheep; younger animals in proportion to age. Then a few hours after, if the sheep does not appear better, commence the use of the prior prescription.

\section{Creatment for the albite Scours or Skit.}

In this instance we must endeavor to dissolve the hardened mass in the fourth stomach, the proper method being the administration of alkalies.

Take. Sulphate of magnesia.........1 ounce

Conking soda...............

Tincture of ginger.......... drachn!

Warm thin gruel.........4 ounces

Mix and give as one dose. Following this a cordial mixture may be used, such as

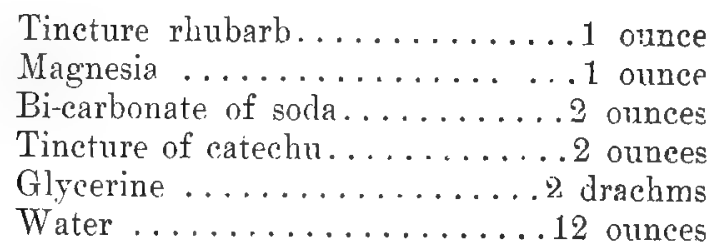


Mix. Give from one-half to two tablespoonfuls three times claily according to the lamb's age. In all cases where the young animais are still dependent on their mother's milk for their nourishment it is advisable to treat the dam, especially is this the case in diarrhoea attacking lambs. To do this the preceding mixtures can be administered to the ewe twice daily in doses of three to four tablespoonfuls, the direct treatment of the lamb being reduced to a minimum.

For green skit as seen in lambs just weaned, the animals should be made as warm as possible, and the above cordial mixture prescribed for the white skit should be given in tablespoonful doses every three hours. Combined with which it will be well to use small doses of whiskey, as a quick stimulant is urgently needed in this complaint.

\section{Dysentery, Bloody flux, also called Cling.}

Is an inflammatory disease, affecting the mucous membrane of the large intestines, and is frequently fatal. It appears to be attended by a form of fever typhoid in character, accompanied by fluid discharges from the bowels, large quantities of mucus and some blood. It is often caused by the continual feeding of coarse and unwholesome food, or from grazing on low lands which have been submerged by water, the sand and grit deposited on the grasses setting up an irritation, followed by inflammation of the botvels. Hay cut from such pastures will also produce this disease.

\section{Symptoms.}

The sheep has an exhaustive diarrhoea, fever quickly develops, the animal showing evidences of extreme weakness. The fever in these cases marks the difference between them and diarrhoea, as in that disease the temperature is lowered instead of elevated. The evacuations are thin, but adhesive, painful, laden with mucus and often accompanied with blood, the belly is 
tender to the touch and swollen, the watery faeces adhere to the wool of the tail and thighs, causing soreness and sometimes ulceration of the parts. Flies invade the sore surfaces, maggots developing as a result of their attacks. The sheep has an excessive thirst, the appetite is unnaturally good, the animal still eating, notwithstanding its weakened and diseased condition. Death may result in a few days, or the attack may be prolonged up to five or eight weeks, the animal finally succumbing from exhuustion. The wool may become so matted over the rump as to prevent the expulsion of the faeces. This condition is called "pinding," and should it not be removed it will eventually cause death from retention of the faecal matter. Mistakes are also liable to occur. A cursory examination might result in this condition being taken for constipation, and purgatives administered, which would produce fatal effects. Youatt makes special mention of this condition, and states that it is frequently found affecting ewes when suckling lambs. To avoid this condition in cases of dysentery the wool on the rump and thighs should be removed and the parts kept clean. The following powder dusted on the part will be soothing and prevent the attacks of flies.

Take. Iodoform .............. I drachm

Calomel ................ drachm

Sub-nitrate of bismuth........2 ounces

Mix. Or a solution of oil of tar and turpentine can be employed, which is less expensive and equally effective, as

Oil of $\operatorname{tar} . \ldots \ldots \ldots \ldots \ldots \ldots$ ounce

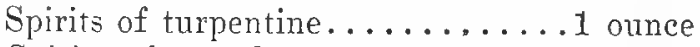

Spirits of camphor.........2 ounces

Neatsfoot oil ............4 ounces

The affected animals should be comfortably housed. The diet must be of the best. Dry feed, such as a ration of oats and bran, with good har, with small allowance of linseed meal. In the commencement of the disease give the sheep four ounces of 
linseed oil. This will tend by its laxative action to remure any irritant from the bowels, and at the same time has a soothing effect on the mucous surfaces. Small doses of linseed oil should be persisted in all through the treatment. This is best giren combined with rhubarb, ipecacuanha and laudanum.

Take. Laudanum ................2 ounces

Wine of ipecac............. ounce

Tincture of rhubarb..........1 ounce

Linseed oil..............9 ounces

Mix. Give two tablespoonfuls twice daily. Combined with this, administer Dover's powder, 30 grains, once daily for three days. Where the discharges are offensive Dr. Alexander recommends administering as an adjunct to other remedies, pure beech-wood creasote in drop doses. Convalescents from this disease need careful feeding and should receive tonic treatment for some time, as recovery is slow in all these cases.

Take. Powdered nux vomica.........3 drachms Powdered sulphate of iron.......3 ounces Powdered gentiar root.........4 ounces Powdered saltpeter............. 1 ounce Linseed meal.............8 ounces

Mix. The above prescription, on account of containing nux romica, must be thoroughly mixed to insure the even distribution of that ingredient through the balance of the prescription. Gire the sheep recovering from dysentery one tablespoonful in the feed twice daily. All sheep in the spring of the year should be "tagged," which consists in the removal of the tags of wool around the breech, so that should they scour the evil effects from flies will not take place.

\section{Constipation}

in adult sheep. This is a condition arising from a surfeit of dry feed. When occurring in lambs it may be due to gastric trouble. 
In adults it may be due to defective peristaltic motion, caused by impaired nerve force, the result being a deficiency of mucus in the bowels, so retarding the onward passage of the faeces.

\section{Creatment.}

For adult sheep administer at once a rectal injection of soap and water or warm linseed oil, or better still glycerine, and internally give:

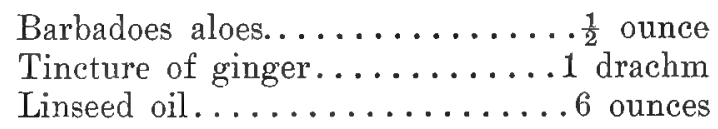

Mix. Give as one dose. For lambs the best agent to administer is an animal fat, such as lard, three or four tablespoonfuls of warm hog's lard is to be highly recommended, and should this be slow in acting, give a rectal injection of warm milk, to which sufficient molasses has been added to make it a chocolate color. The best way to give this is to suspend the lamb by the hind legs, the syringe is then inserted, the animal held up for a brief period, and then set free-the results should be prompt. The newly born lamb is best treated through the medium of its dam. To effect this give the ewe the cathartic drench above prescribed. In cases where the rectum of the young animal is obstructed with hardened faecal matter, it should be removed with the fingers and a small injection of oil given. This will soften the mucous surface which might be injured during the extraction of the mass.

\section{Imperforate Fnus.}

Is a condition sometimes seen affecting the newly born, the rectum having no communication with the outside. Sometimes the rectum can be felt underneath the skin, in which event a surgical operation may be successful. In any event, should this condition not be righted, death would soon take place from the absorption of effete material. 


\section{நemorrhoids, Piles.}

These may project externally or be situated within the rectum. Internal piles cause a bloody appearance of the freces, and the animal appears stiff behind. The external project from the anus sometimes to the extraordinary length of six to eight inches, being an eversion of the rectum. The writer has seen quite a number of these cases, the mucous membrane surface being congested and ulcerated, the best treatment for which is slaughter, for if the animal has not been suffering from irritative fever due to the trouble, the flesh may with safety be consumed by the public. This trouble generally occurs from constipation, or may follow an attack of diarrhoea, and is due then to an atonic condition of the bowel. We have classed it here under the head of hemorrhoids. It is scientifically termed prolapsus of the rectum, and only differs from protruding piles in the large amount of surface exposed.

\section{Treatment.}

Laxative diet, the application of an ointment composed of equal parts of sulphur and lard will be found of service, or

Take. Acetate of lead............20 grains

Tannic acid..............2 drachms

Calomel ...............2 drachms

Sulphate of morphia.........4 grains

Glycerine ............... ounces

Mix. Apply to the hemorrhoids. Where the piles protrude, smear them with the ointment, and pass them back through the anus,

\section{Deritonitis.}

Is inflammation of the peritoneum or covering of the bowels, which also invests the walls of the abdominal cavity. This is a very rare disease in sheep. The omentum or that part of the peritoneum investing the bowels is remarkable for its large size. 
It is frequently the seat of parasitic diseases, notably the nodular disease caused by the oesophagostoma columbianum, which we shall treat of in the chapter on parasitic diseases. Steele says "that simple peritonitis is common in old sheep, resulting from debility, the evidences of which are dropsical swellings, etc." In these cases the destruction of the animals is the best method of procedure, very old sheep not being worth the time and trouble necessary to effect a cure.

\section{Diseases of the Liver.}

The liver of the sheep is one-twenty-fifth part of the weight of the animal, exceeding in weight the liver of the human being, being proportionately twice as large. Of the diseases affecting the liver of sheep non-parasitic in origin, we shall only describe two as being of sufficient importance, viz., inflammation of the liver, called "Hepatitis", and jaundice or "Icterus". Diseases affecting the liver, which necessarily interfere with its functions, are recognized by the yellow appearance they produce on the visible mucous membranes, especially the lining of the eyelids (conjunctiva).

\section{Heute Inflammation of the Liver, Depatitis.}

This is supposed to arise in the investing membrane of the organ, called the capsule, being virtually its peritoneal covering, originating generally as a result of inflammation in some contiguous organ.

It is most frequently caused by grazing sheep on low-lying pastures, where the growth of grass is high and rank, and is supposed to be due to over-nutrition.

\section{Symptoms.}

'The sheep is feverish, the respirations hurried, the visible mucous membranes are of yellowish appearance, due to the pres- 
ence of bile in the fine capillary blood-vessels. That pain is evidenced when pressure is exerted behind the right shoulder we believe to be doubtful, unless abscesses already exist, in the liver, although this has been claimed by authorities, notably Williams, to be a diagnostic symptom; lameness of the right foreleg has also been stated as a prominent symptom.

\section{Creatment.}

The sheep should be bled. This is best accomplished by opening the jugular, as has already been described in this work. The diet should be reduced and the following cathartic administered.

Take. Glauber salts.............4 ounces

Bi-carbonate of soda.......... drachm

Common salt..............1 ounce

Dissolve in a sufficiency of warm gruel and give as a drench, administering it slowly. After the purgative has operated, the following preseription will be found useful.

Take. Fluid extract gentian.......... $\frac{1}{2}$ ounce

Alcohol ..................2 ounces

Sulphuric acid........... $\frac{1}{2}$ drachm

Water ................. o ounces

Mix. Give one tablespoonful twice daily half an hour before feeding grain.

Sheep suffering from hepatitis should be fed grain sparingly, the best ration being a small feed twice daily of bran and oats mixed, half lb. of each.

\section{Jaundice, Icterus.}

Is a yellow condition of the system, and may be due to either a non-secretion of the bile from the blood, or a re-absorption of the bile into the blood, through some obstruction in the bile ducts of the liver. Prof. Dick claimed that jaundice was 
more frequently observed in the sheep and dog than in the other domesticated animals, but this assertion no doubt included cases of liver-fluke, of which we shall treat separately. Where sheep are highly bred, and especially where they are pampered for exhibition purposes, the liver is very liable to acute or chronic degeneration of a fatty character, and according to Steele, "this seems to be the nature of the fatality which often occurs among highly-bred sheep, more especially ewes in lamb." Sheep, however, die in great numbers from liver diseases about the period of parturition; sometimes without presenting any symptoms of disease of that particular organ, or of any disease whatever; sometimes anaemic, and occasionally with well marked symptoms of jaundice."-Williams, Vet. Med.

\section{Spmptoms.}

Will be recognized by a general yellowish appearance of the eyes and mucous membranes, the faeces are offensive, the mouth lias a sour smell, the skin is itchy, dry and yellow in color instead of normal pink. In acute attacks the condition may resemble anthrax, death occurring in from sixteen to twenty-four hours. Should the trouble persist, blood-poisoning is likely to sct in, in which case the evacuations become black, then green, and finally bloody in character, the temperature being elevated and the respirations hurried.

\section{Creatment.}

This is in the main preventative; the disease being caused by errors in diet, the first procedure is to correct the same, certainly so far as the balance of the flock not yet diseased are concerned. In the sheep this affection arises from feeding materials rich in saccharine products and lacking in nitrogenous elements, and is frequently seen arising where turnips have been fed in large quantities to the exclusion of other foodstuffs. So in 
order to change the diet to rectify this error, nitrogenous foods should be supplied mixed with the roots, such as hay, or straw, bran, oats, etc.

The affected sheep should be given a liver stimulant, specially if the disease is due to non-secretion of the liver.

Take. Aloes ...............2 drachms

Fluid extract of rhubarb root.....1 drachm

Warm water.................... pint

Give as one dose. Follow this daily with one ounce of Glauber salts.

Dissolve one ounce of cooking soda in one gallon of watcr for the animal to drink.

All medicinal treatment in this trouble, however, is rery liable to be unsatisfactory when applied to sheep. 


\section{CHAPTER XIII.}

\section{Diseases of the Arinary System.}

The surplus of nitrogen in the system is formed into urea and voided through the organs composing the urinary system, viz., the kidneys, ureters, bladder and urethra. Should, however, this through some cause be retained, its effects would produce blood-poisoning from the altered condition of the blood supply, being evidenced by delirium, terminating in coma and death. In herbivorous animals the urine has what is termed an alkaline reaction and is tested by dipping in it a piece of red litmus paper; this (when the fluid is normal in character) will immediately turn blue in color and vice versa; should the urine be acid, blue litmus paper will be turned red. It is not necessary in this work to enter into any extended description of urine tests to diagnose the diseases which affect the urinary system of the sheep, as these animals rarely suffer from such complaints, those occurring generally being due to sabulous deposits in the bladder, or calculi in the kidneys and ureters, due to an excess of phosphates, cansed by high-feeding, unnatural conditions, ete.

\section{Nephritis, Inflammation of the Kidneys.}

This disease has never been reported as an original lesion in adult sheep. Steele gives an account of it occurring in lambs newly born, recapitulating an address delivered on the subject by Mr. Roger Wrilliams at a meeting of the Pathological Society of London, April 6th, 1886, who states as follows: "The disease began soon after being 'wet born,' with difficulty in 'walking, the new-born falling down and lying down on one side, some- 
times with choreoid movements, without loss of consciousness, without difficulty in breathing or cough. They may linger on for two or three weeks, but in the end always die. Sucking was not impaired nor the appetite. The disease may terminate in joint evil, with pus in the joints and all along the spine. The disease occurred on heavy clay soil, and in the lambing season the east wind was cold and nipping. At all events, it was found that if a ram served only ten ewes, the progeny was vigorous and did not become affected with the disease.

"The urine was albuminous and acid; there were no renal casts, crystals, pus or blood. The eapsules of the kidneys stripped off easily, exposing a surface studded with congested stellate reins. The cortex was swollen and soft, pale and yellowish in color, whilst the pyramids were firm and deep red in color. The disease was acute tubal nephritis. The interstitial tissue was normal-nothing abnormal was detected in any of the organs, and the spinal cord was healthy. Some of the lambs were born with the disease and soon succumbed."

\section{Renal Calculi.}

- Stony deposits in the pelvis of the kidneys and in the ureters. These deposits are generally the cause of urinary diseases in sheep. They are mostly composed of phosphate of lime, and seem to be due to an excess of dry food, as sheep at pasture are seldom affected with this complaint. When these calculi occur in the kidneys they seldom cause any appreciable disturbance, but their lodgment in the ureters, which would tend to cause a retention of urine, would be followed by grave results. These cases are very rare, howerer. As seen in the bladder, they appear harmless, their effects being marked when they cause a stoppage of the urethra, in which case an excessive inflammation of tissue and extravasation of urine results, which speedily proves fatal. 


\section{Uretbral Calculí.}

Are deposits of stony materials which by their presence obstruct the passage of the urine through the urethra, causing its accumulation in the bladder, with distension and perhaps rupture of that organ or a filtering through its walls into the adjoining tissues, causing pyaemia, eventually septicaemia and death.

\section{Symptoms.}

The sheep is unable to void its urine, prefers the recumbent position, on being forced to rise the back is suddenly curved, after which a few drops of urine are passed. The respirations are hurried, the sheep grunts frequently, is restless and uneasy, refuses to feed. As the urine accumulates the animal becomes stupid, symptoms of abdominal pain are evidenced, the temperature is elevated, the mucous membranes becoming red and congested, uraemic poisoning results, quickly followed by death unless previous to the uraemia the calculus is forced through the penis above the vermiform appendage, leaving a free passage for the accumulated urine.

\section{Creatment.}

This is necessarily operative. If the sheep is turned up on its rump and an examination made of the skin covering the end of the penis, called the prepuce, it will be found enlarged and inflamed; a dropsical condition of the tissues of the belly will also be frequently noticed, especially in cases where the trouble has existed for some time. Push back the prepuce and draw out the penis; an examination of the worm-like extremity will generally reveal the presence of sediment, obstructing the end of the urethra. This deposit may be in the form of gravel or fine sand, and unless it is removed little can be done to afford relief. Where the deposit is of a gravelly nature, the best method is to remove the appendix entirely. When the deposit is very fine in character 
a careful manipulation of the part will almost always effect its removal. This should always be preceded by the application of warm water to relax the tissues, so facilitating the removal of the deposit and reducing the liability of lacerating or bruising the sensitive vermiform appendage. If the obstruction is caused by sabulous material deposited on the lining membrane of the urethra, extending some distance from the appendage, it may be necessary to cut down and remove the deposit, making a longitudinal incision in the penis, through the urethra, laying it open from above downwards to the vermiform process. This operation on wethers is simple and efficacious, but when performed on rams is liable to seriously impair their breeding qualities, although there is considerable difference of opinion on this point, many breeders claiming to have lambs got by rams which have been so mutilated as to have lost the vermiform process entirely. Should the operation on the penis prove of little benefit it must be taken as evidence that the accumulations are so abundant that they occupy not only the urethra but the bladder, ureters and kidneys, in which event no treatment could prove of any service and the animal should be destroyed. In these cases the meat is unfit for human consumption, the tissues of the belly being impregnated with urine, the presence of which taints the whole system.

Where several animals in a flock show symptoms of strangury, it is well to inspect their diet, which should be changed and carbonate of potash administered. A frequent cause for urethral calculi in sheep is feeding excessive quantities of mangolds or beets. Where this is the case, change to other rations.

The following will be found useful in these conditions. Take

Fluid extract of belladonna......1 ounce

Potassium carbonate..........3 ounces

Water ................. pint 
Mix. Give one tablespoonful three times daily-dose for adult sheep. Sanmetto in teaspoonful doses three times daily is. also a most effective remedy in all diseases of the urinary organs of sheep. As a dressing to the penis, where gravel has been removed by operation, the following will be found useful:

Fluid hydrastis (Merrill's).....2 drachms

Distilled extract witch hazel.......1 ounce

Water .................. 3 ounces

This can also be injected into the urethra, and will prove beneficial. 


\section{CHAPTER XIV.}

\section{Parasitic Diseases, Due to Internal parasites.}

Parasites are living animal-organisms, which extract nourishment for their existence from the tissues of their host. Of these we shall recognize two general classes.

Entozoa, those which live on the natural cavities or solid tissues of the animal.

And Ectozoa, those infesting the outer surface, or skin, existing on the effusion created by the irritation caused by their presence.

In this chapter we shall consider only the diseases due to the presence of the entozoa, or internal parasites. In sheep we find that parasites are the cause of many of the most serious diseases -they invade all the organs of the body, from the brain to the rectum, their multiplication and resultant damage being in direct proportion to the neglect and bad management on the part of the flock owner.

\section{Parasitic Disease of the Brain.}

\section{Sturdy, Gid, Curnsick.}

This is a condition due to the presence of a larval tapeworm or hydatid in the brain substance, the parasite as seen in its cystic state imbedded in the brain being termed the coenurus cerebralis. It is caused from the ingestion by the sheep of the eggs of the taenia coenurus-a species of tapeworm, which have been dis- 
tributed on the ground or in the drinking water by other animals, such as wolves, foxes, coyotes, etc., but more especially is the dog responsible for sowing the germs of this disease. The prevalence of this disorder depends to a great extent on the use of sheep dogs, it being noticeable that where the sheep run in enclosed pastures where dogs are not required to assist the herders, the liability to infection is reduced to a minimum.

The eggs of the tapeworm on being swallowed by the sheep hatch within its stomach, immediately pierce the walls of that organ and gain entrance to the circulation. They are then car-

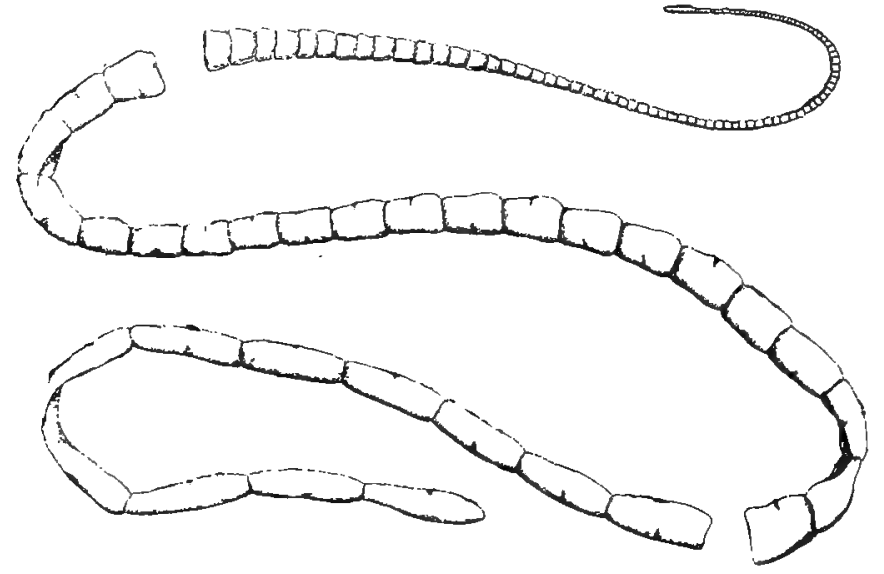

Caenia Coenurus. Hdult, Natural Size.

(RAILlET.)

ried to the different parts of the body, those which reach the brain and spinal cord remaining in those organs, developing into cystic bodies, which continue to thrive and grow at the expense of the tissues. The others which fail to reach the brain and spinal cord may locate temporarily in the heart, lungs, diaphragm, etc., where they seem to grow for a time and then disappear. On reaching the brain substance the young parasites pierce the tissue, lodging in it and commence to develop. 
In the course of two or three months time they may have attained the size of a hazel nut, their presence at that stage seriously interferring with the general health of the sheep. Should the head of a sheep infested with these hydatids be fed to dogs these organisms in the brain tissue develop into adult tapeworms, the eggs of which being passed by the dogs on the grasses, etc., and being eaten by the sheep, develop again into hydatids, so completing the life cycle.

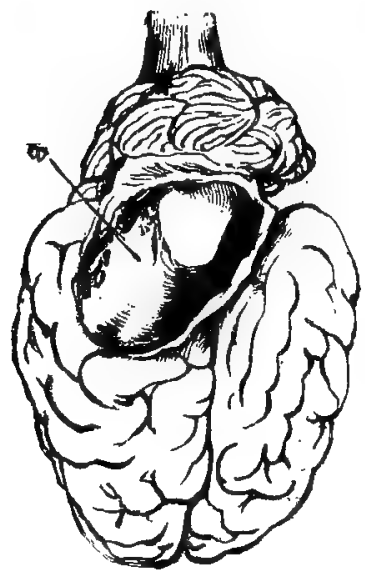

Brain of Sheep with Coenurus in posterior part of Right 5emisphere.

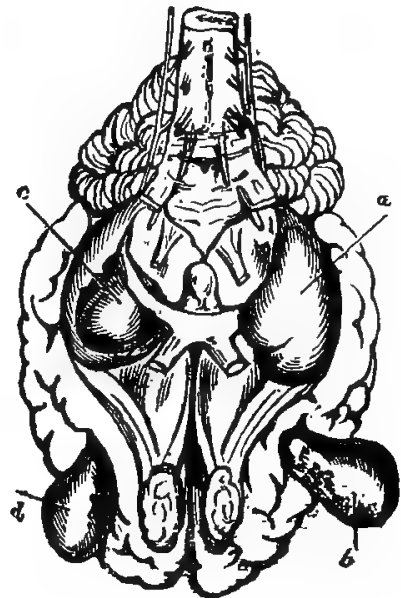

Brain of Sheep with four Coenuri símultaneously.

(CовBоLD.)

\section{Symptoms.}

The sheep appears dull, out of sorts, grazes in a listless manner, rumination is imperfectly performed, the animal seeks seclusion, its morements are erratic, staggers as it walks, becomes giddy and falls down frequently. Again it may be grazing quietly, suddenly jumps as if frightened, and runs away at full speed. The primary symptoms of dullness and stupor seemingly are due to congestion and inflammation of the brain caused by the invasion of the young parasites, and should the sheep re- 
cover from this stage there will be an apparent improvement in its health for a few weeks time, till the gradual enlargement of the cyst or cysts so press upon the brain substance as to interfere with its blood supply, causing absorption of brain tissue, at the same time numerous heads are protruded from the cyst, which also tend to produce irritation of the brain. At the commencement of the second stage the animal is weak and fallen away in flesh, due to the first attack. This condition speedily becones aggravated, the sheep stops feeding, the appetite is lost and rumination suspended. The animal has a haggard appearance, due to blindness, which may affect one or both eyes, caused from pressure on the optic nerve. The sheep continually moves in a circle, assuming peculiar gaits and positions, depending on the part of brain in which the hydatid is located. Spooner states that if the head is held constantly on one side, and the animal always moves in a circle, corresponding to the way the head is held, that the coenurus is located in the depressed side, probably in the lateral ventricle of the brain. Should the sheep move in a circle sometimes in one direction, and again in another, it may be concluded that a parasite is present in both hemispheres, and if the animal depresses its head, moving forward in a straight line, stumbling over and running into everything in its path, the hydatid is probably located in the division of the brain between the hemispheres. Again should the sheep throw up its head, moving forward with a reeling motion, the conclusion is drawn that the cyst is in the cerebellum or fourth ventricle of the brain. When more than one cyst is present, the symptoms are a combination of the above, and cannot be relied on as a guide for operation, of which we shall treat later. When the coenurus invades the spinal cord or medulla oblongata it causes paralysis, and should this symptom be combined with blindness, the probability is that the cyst is located at the base of the brain. When the spinal cord is invaded the sheep stagger and walk without 
control of the posterior limbs, or an intense itchiness may be present along the backbone, and complete paralysis of the posterior portion of the body involving the bladder and rectum frequently takes place.

A disease which resembles gid to a certain extent is caused by grubs in the nasal and frontal cavities, produced from the larvae of the gad-fly. It will be récognized, however, by the symptoms of catarrh and sneezing, and lack of the riolent morements seen in gid.

\section{Creatment.}

This is preventive to a great extent and consists in administering vermicides to the dogs which inhabit the farm where the sheep are kept, especially the sheep-dogs, and keeping the sheep where they are not so liable to pick up the eggs voided by dogs belonging to other parties. The heads of affected sheep should on no account be fed to dogs, but should be burnt or otherwise effectually destroyed. These precautions, while they would not entirely stamp out the gid on account of other animals, such as foxes, wolves and coyotes being bearers, they will lessen the trouble to a great extent. Experience shows that with a better general care of sheep, gid is less frequently observed attacking them. Gid attacks appear to be more frequent in animals which have been exposed to inclement weather, which has a tendency to weaken the nervous system, the resulting debility making them more prone to attack. When one or more cases occur in a flock, it is permissible to suppose that a number have been invaded at the same time, in which event any animal which is fat, and shows the slightest indication of gid, should be sold to the butcher. Where treatment is to be tried, the operation of trephining the skull and puncturing the sack is performed. This allows the escape of the contents of the cyst, and in some cases where only one cyst is present it has been known to be successful. 


\section{Co Operate.}

It is necessary to make a careful examination of the skull, and where the cyst is located close to the surface a softening of the bone will be noticeable. By trephining the skull at this point the parasite can be discovered and removed, also an operation termed wiring has been performed. This was the method first employed by a Scottish shepherd by the name of Hogg, and in his hands was oftentimes successful. It consists in feeling for the soft spot in the skull and placing the thumb of one hand firmly on it, while with the other hand a thin wire or knitting needle is pushed up the nostril nearest the affected part till the point of the wire is felt under the thumb, so perforating the cyst and permitting the escape of its contents. Should this not cause inflammation of the brain, and no more cysts be present, the sheep will have a good chance to entirely recorer.

To treat the sheep-dogs and to ensure their freedom from the canse of all this tronble it is necessary to administer vermicides to them about every four months.

The dog to be treated should not be fed for at least twelve hours before receiving the medicine, but it can be allowed all the water it desires. The erening before administering the worm medicine a dose of castor oil is advisable-for large dogs the dose is three tablespoonfuls. Medium sizes one to two tablespoonfuls. Then in the morning

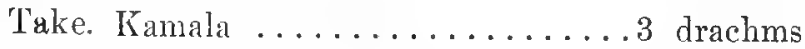
Gruel ................ ounce

Mix. Give as one dose. Where the dog is medium sized, two drachms of kamala will be sufficient. This is a very effectual taeniacide. It is not necessary to follow up its administration with a cathartic on account of its laxative properties. 
Finlay Dun prescribes for tapeworm as follows.

Take. Oil of male shield fern........20 drops

Oil of turpentine............30 drops

Sulphuric ether...........60 drops

Beat all together witlı one egg and administer to the dog in a small quantity of soup. This should be followed in twelve hours' time by a dose of castor oil. This disease occurs more frequently in lambs than in old sheep, presumably due to the tissues of the young animal being softer and more easily penetrated by the parasites. $\Lambda$ s dogs are the most fruitful source of distribution of this pest, and the sheep being the source from which they obtain the same, it is advisable that all viscera and heads from slaughtered sheep should be withheld from them, unless thoroughly cooked. If this was universally carried out the losses from gid would materially decrease.

\section{Parasitic Nasal Catarth.}

This disease is directly attributable to the invasion of the nasal cavities by a fly called the gad-fly (oestrus ovis), which deposits its larvae on the inside of the nostrils. The embryos proceed to crawl up the nostrils, producing intense irritation of the mucous membranes, investing the frontal and maxillary sinuses. In appearance the gad-fly resembles an overgrown house fly. When flying it is so quick as to be almost invisible. It is a dull-colored insect, the head and thorax being about as long as its abdomen, the back is brown, with small points and patches of darker color, its under surface is dark brown, with yellow spots at the center of each abdominal segment. The wings are transparent, mottled with spots and stripes, they are almost as long as the body, which they completely entelop. The head is large, containing two large greenish eyes, the under surface of the head has white markings. The antennae are short 
and bulbous at their bases. There are a few hairs on the head and quite a number on the body, sides and limbs. It has no mouth, or appreciable proboscis, its object in life seeming to be the propagation of its species, which when the male has impregnated two or three females, marks the end of his existence. The male gad-fly in size is as large as the female, but its head is narrow. They do not attack the sheep, and, as above stated, only exist to impregnate the female. The female gad-fly is supposed to deposit not the eggs, but live larvae within the nostrils of the sheep, few only being placed on any one animal owing to the agitation and riolent morements exhibited by the sheep on the approach of the fly. These larvae are exceedingly small in size when first deposited. Their bodies are elongated and white. On examination with a lens they show that the body consists of eleven segments, with two hooks at its anterior end to be used to attach itself to the tissues and also to draw its body upwards and forwards; the posterior end is furnished with two stigmata, or breathing pores. The under surface is covered with minute spines. The bodies are transparent, close examination revealing the respiratory and digestive apparatus. The larvae as it matures changes in appearance, attaining a considerable size (about three-quarters of an inch), the body becomes dark and striped with black bands, the spines also turn black. When this condition is reached the grub escapes from the nostrils of the sheep, and falling on the ground immediately bores into it. It remaine in the ground for a period of from one to two months (the length of time depending on the wcather conditions). When the fly is matured within the chrysalis, it pushes up the upper end of the case and reaches the surface of the ground by the same hole the larvae made in the first instance. On arriving at the surface the fly appears at first sluggish and dull, the body and wings needing exposure to the air to cause them to harden. When this has taken place and the right time comes-that is when the 
fly is fully matured-it darts off with remarkable swiftness to find a flock of sheep and single out its victim.

\section{Symptoms.}

On the fly touching the nostrils of the sheep the latter inmediately shakes its head, at the same time striking the ground with its fore-feet. The sheep commences to run, holding its nose close to the ground, endeavoring to escape its pursuer. The animal runs into the middle of the flock. The whole flock becomes alarmed even if only one fly is in evidence. They place their noses close to the ground and huddle together as closely as possible to make it difficult for the fly to attain its object. The young larvae deposited on the mucous membranes create an intense irritation from the insertion of their hooks and spines, drawing themselves up the nasal chamber by means of these projections, leaving dark points of hemorrhage on the mucous surface wherever the points have been inserted. On proceeding upward they reach the turbinated bones, entering the frontal and even superior maxillary sinuses. Those that reach the superior maxillary sinuses grow in size, but never escape from their location, finally dying and undergoing degeneration. Those which reach the frontal sinuses, however, on reaching maturity find their way backward to the nasal chambers, and are voided to the ground. As the larvae grow in size in the sheep's head the animal becomes affected with a catarrhal discharge. This is at first clear, but later becomes thick with mucus. The sheep frequently sneezes, these efforts resulting in the expulsion of mucus and oftentimes matured larvae. The animal will lie down and hold the nose pointed in the air, gradually turning its head round and backwards. The eyes become red and watery, the sheep moves with the nose close to the ground, stepping high with the hind legs, frequently raising the head to the wind and bending it sharply backwards. They may be seized with giddi- 
ness, and stagger, but they do not turn in a circle or show evidences of any acute brain disturbance, all signs tending to show an obstruction and irritation of the nasal chambers.

The duration of the attack may be from sixty days to ten months, all depending on the time the larvae remain in the nasal chambers. A sheep may be re-infected at different times, and so contain larrae of different sizes and various stages of development. The fly is liable to attack the sheep whenever the temperature is not too low for its existence, the months of June and July being those in which its depredations are most to be feared.

\section{Creatment.}

This is of two kinds, preventive and surgical. A practical method of prevention consists in smearing the noses with a mixture composed of tar and grease in equal parts, rubbing it on with a brush. Where the owner has only a few sheep to take care of this individual dressing of the animals may be feasible, and to be effective should be applied at least once a week throughout the fly season. Where large flocks are kept it becomes an exceedingly difficult matter to secure them from the attacks of this pest. It is a good plan to herd them during the hot part of the day (when the fly is most active) on dusty ground, the dust raised by the sheep tending to prevent the onslanght of the flies.

\section{Surgical Creatment.}

This is only resorted to where the removal of the larvae is absolutely necessary, the owner desiring to keep the animal for breeding purposes, and its life being threatened by the attack. It consists in trephining the skull at the frontal sinus, the opening being made, according' to Turn, as follows: "Cut off the wool which covers the forehead. Trace with colored chalk a transverse line uniting the middle of the two eyebrows and livide it by another line passing at the middle of the forehead. 
The point of choice for trephining will be in each of the two upper angles thus obtained, without engaging the lines which limit them. The operation is performed according to the ordinary rules of surgery. From the opening made one often sees the larvae, which are extracted by forceps. To kill others, benzine moderately diluted with water is injected. The flap of skin is then cleaned, applied to the opening and sewed to the adjoining skin. The whole is then covered with a turpentine-coated leather plaster. The patient is separated for a few days from other sheep. Sheep bear the operation with the same impunity as they do marking the ears or other minor operations." This operation would not be advisable in the hands of every flock owner, and when all is said and done, it only relieves the trouble for the time being, as the next fly which comes along and deposits its larvae will create the same trouble. Perhaps the actvice given by Neumann, in his work on parasites, is the best ani easiest carried out (except where the sheep are raluable and desired for breeding purposes). He says: "At all times, if the number of animals affected is considerable, the malady should be left to follow its course, and those which present the gravest symptoms should be sent to the shambles."

As a preventive in large herds the following might be tried: Take a squared log and bore holes in it with a large augur; in these place salt, and dress the edges of the holes with tar. Sheep then will apply tar to their noses every time ther eat the salt.

\section{Parasitic Bronchitis; Бoose, Бusk.}

Also vulgarly called "Snots." This destructive affection is due to the invasion of the bronchial tubes and lung tissue by worms scientifically called the strongylus filaria and strongylus rufescens, the former, however, is the one most frequently present, and is found attacking other ruminants, notably the eamel and goat. 
The strongylus filaria in length is from one to two and a half inches long, in color the male is a brownish yellow, and the female white, their bodies are uniform throughout their entire length, except at the ends, which are tapering. "The head is short, stumpy, rather angular, but not tuberculated as in other strongyles. Extending from the mouth is a short oesophagus, entering the stomach, from which a straight intestine is continued nearly to the extreme end of the tail. The tail of the female is pointed; the oriducts filled with eggs and live young extend into the vulva, which is situated close to the anus."Tilliams.

In aged sheep these parasites do not always cause inconvenience, as an examination of the lungs of fat sheep has shown them to be loaded with these worms; but in lambs the parasites pierce the softer lung-tissue, gaining entrance to the bronchial tubes, where they set up an intense irritation, frequently causing death. While aged sheep are not so liable to show the effects of attacks from these parasites, sometimes they become anaemic and debilitated, especially is this noticeable in lambing ewes, many of which succumb to the trouble. These parasites in sheep are the cause of bronchitis and sometimes pneumonia, and very often a combination of the two called broncho-pneumonia.

The method of their introduction appears to be through the medium of the water supply, or from grasses, especially those of low-lying lands having an insufficient drainage. On gaining access to the alimentary canal (stomachs and intestines) they pierce the walls of these riscera and obtain entrance to the circulation, by which they are carried to the lung tissue, where they remain till mature, when they pierce the tissues and pass into the bronchial tubes. Their presence then sets up the irritation characteristic of the disease, the parasites remaining in the lung tissue outside of the tubes, appearing to cause little if any inconvenience. Williams states that he has observed these parasites 
in the cavities of the heart and in the blood-ressels, and this goes to prove the correctness of the above theory of migration. I very large number of worms may be present in the lungs of a single sheep and are also found infesting the intestines. This would account for the amount of infection and source of danger a single diseased sheep may be to a pasture.

\section{Symptoms.}

These depend to a great extent as to whether the lungs only are attacked, or whether the parasites are also present in the intestinal canal. In the majority of cases the parasites are present only in the lungs; in some cases both the lungs and. alimentary canal contain the worms, and in a few exceptional cases they are only present in the stomachs and intestinal canal. As seen attacking the lung-tissue of lambs, they cause distressing fits of coughing, difficulty in breathing, the affected animal frequently rubbing its head against the ground. Symptoms of anaemia (bloodlessness) soon become apparent. This is evidenced by a paleness of the mucous linings of the eye-lids, the skin becomes dry and papery, the wool has a tendency to fall out, the breathing becomes hurried, the animal loses strength and sinks rapidly. When the parasites are present in the intestinal canal as well as the lungs, purging is associated with the other symptoms above mentioned. The animal has colicky pains, intense thirst, and a tendency to dropsy.

An examination of the mucus discharges of the nose and of the faecal matter will frequently reveal the live parasites.

The disease runs a course extending all the way from one to four months, depending on the strength of the sheep and the number of parasites gaining access to the system. If the symptoms are well marked at the outset, the disease is almost sure to prove fatal unless the worms are few in number and the animal 
has sufficient strength to cough them up. This disease appears to be more prevalent some seasons than others, its ravages being more serious after prolonged damp spells, when it is liable to be epizootic, and canse very large losses to the flock-owner.

\section{Creatment.}

This must be both preventive and curative. As a preventive the sheep, lambs especially, should be moved to fresh pastures. If the season is wet they should be herded on the hill sides, aviding all low-lying lands as much as possible. Salt seems to exert destructive influence on the parasite; rock salt should be plentifully supplied for the sheep to lick, and dry fodder should be fed if obtainable in which salt has been plentifully sprinkled. The curative treatment, which will be found most practicable, is to confine the sheep in sheds, which are as air-tight as possible, then by burning sulphur in an iron kettle suspended from the roof of the shed just above the heads of the sheep sulphurous acid gas is formed. The inhalation of the fumes will cause violent expectoration on the part of the sheep, the parasites being expelled in the mucus discharges. These fumigations should be repeated three or four times. The safest plan is for an attendant to stand in the shed, and when he finds that the fumes are as strong as he can possibly bear them, to come outside, bringing out the burning sulphur with him. The sheep should then remain in the shed for a period of ten minutes. This procéclure shonld be repeated the next day, the sheep being compelled to inhale the fumes for a longer period, say twenty minutes. On the third day the fumigations should again be carried out, which should prove sufficient to greatly relieve if not entirely cure the sheep. When the flock is few in number, so that individual treatment can be instituted, injections of medicinal 
agents into the trachea (windpipe) will often prove of great benefit.

Take. Iodine ................ drachm Iodide of potassium........2 $\frac{1}{2}$ drachms Distilled water..............3 ounces

This solution is mixed with two ounces of oil of turpentine to which must be added six ounces of olive oil. Of this mixturc. after it has been thoroughly shaken, one to two drachms should be injected into the trachea by means of a hypodermic syringe. The injection may be repeated in two or three days time, the number of injections depending on the seriousness of the attack. Where the parasites are suspected in the alimentary canal, it becomes necessary to administer such agents as have a tendency to destroy the pests.

Take. Oil of cloves...............5 drops Tincture of ginger........... $\frac{1}{2}$ drachm

Oil of turpentine..........2 drachms Linseed oil...............1 ounce

Mix. Give as one dose in oatmeal or linseed gruel, which may be repeated after an interval of two to four days.

The viscera, lungs, etc., of sheep and lambs which have been destroyed by this disease should be burnt or otherwise disposed of so as not to spread the infection. Pastures which have become infected should receive a thorough dressing of salt. Care should be taken in introducing strange sheep into the flock to provide. against their carrying the contagium of the disease.

\section{Daragitic Diarrhoca.}

This disease is now recognized as one of the serious complaints affecting sheep. It is extensively distributed, occurring wherever sheep are to be found, and is the source of great concern to the sheep owner on account of its frequent fatalities. It 
is caused by irritation of the mucous membranes of the alimentary canal, owing to the presence of the tapeworm, scientifically termed the taenia expansa. Many writers report having observed cases of diarrhoea in sheep and lambs where segments of tapeworm were found in the faecal discharges. In 1877 an outbreak occurred in Central Park, New York, in which the intestines of lambs were filled with taeniae ranging from one to fifteen feet in length. The animals were unwell for two or three days, then, becoming affected with convulsions, would turn round in a circle and drop dead. Cross of Shrewsbury, Eng., the same year reports a case of scouring in lambs, in which innumerable segments, with double sexual organs and unarmed heads, were found in the alvine discharges. Cobbold also reports large losses in Australia, due to the same pests, and Gamgee also states that in Australia an enzooty, due to taeniae in lambs, is of frequent occurrence, especially on land which is overstocked. Where tapeworm is suspected in a flock of sheep, an examination of the soil (after a heary rain) on which they have been folded will often reveal the segments, washed free from the faecal matter. Cooper Curtice in the Government report of 1890 states that "no section of the United States seems to be entirely free from it," and further says: "It was introduced into this country from Europe along with the imported flocks, which harbored it."

\section{- Description of the Parasite.}

Length variable, the largest measure from five to six yards in length and from one-twenty-fifth of an inch in breadth at the head to one-half an inch at the tail. The head is generally small and pointed, the neck very short, if discernible at all, the first segments are very short, the others as they proceed backwards to the tail becoming longer and broader. The head is small at the end, and is furnished with four suckers. The body of the 
worm is made up of segments, very wide and flat, which vary in length in the different portions of its extent. In appearance the worm is a dull white, but becomes transparent on being submerged for a few hours in water. Each segment is endowed with an independent set of genital organs, and contains eggs or young embryos, so it will be observed that each segment is capable of reproducing its kind without the assistance of outside agencies. The segments become mature as the embryos develop within them, and are separated from the others to be ejected with the excreta on the ground, there to fulfill their life cycle. The segments nearest the tail maturing first, are the first to be shed, the remainder following in their turn till the head only remains. It is owing to this process that lambs are able to recover after being attacked by this species of taenia.

\section{Symptoms.}

A paleness of the skin will be noticeable, the visible mucous membranes, such as the lining of the eyelids, will also have a bloodless appearance, the fleece is dry and brittle, the animal becomes poor in flesh, and, should it be a lamb, it ceases to develop. The appetite will still remain good, being increased if anything, the desire for liquids is also increased, the animal at times drinking greedily. The digestive functions soon become deranged, rumination is imperfectly performed, the breath becomes foetid, signs of colic will be observed at irregular intervals, the evacuations are varied in character, at times the animal is constipated. again it suffers from exhaustive diarrhoea, the belly becomes distended owing to accumulations of faecal matter or gas. The evacuations have a mucus character and are yellowish in color, an examination frequently revealing segments of the taenia expansa. In severe cases the sheep becomes so weak that it with difficulty keeps with the flock when grazing. They are attacked with convulsions, finally a malignant diarrhoea which refuses to 
yield to treatment sets in, the effect of which is to su increase the debility and wasting that the animal falls down unable to rise, quickly succumbing from exhaustion.

\section{Creatment.}

This is also both curative and preventive. Where taenia expansa is suspected in a flock all the animals should be dosed, as the well ones if allowed to graze in the same pasture as those already affected are sure to pick up the eggs of the parasite, and in turn become mediums for its distribution. Before administering vermifuges to the sheep they should be prepared for the same by being kept without food and water for at least twelve hours. They should be all dosed at one time and kept confined for at least twenty-four hours after receiving the medicine, so that the segments and eggs, which will be voided, are not distributed over the pastures. When the owner or foreman is satisfied that the medicine has had the desired result, the sheep should be allowed access to the pasture, and the yard in which they were confined should be thoroughly covered with quick lime to destroy all evidences of the disease. One of the best and simplest taeniacides to use is kamala. This is obtained in the form of a coarse red powder, its effects on the sheep for the expulsion of tapeworm being very satisfactory. Take

\section{Kamala ................ drachms}

Mix thoroughly in three ounces of linseed gruel; this is the dose for adult sheep, lambs take from one to two drachms, according to their age. This should be administered very slowly to the animal to insure its passing into the fourth stomach and so on into the intestines, as, if it should be hastily given, it is liable to enter the rumen, where its effects would in all probability be nil. Should the kamala not prove efficacious the follow.. ing can be tried.

Take. Ethereal extract, male shield fern.1 drachm Castor oil..............4 ounces 
Mix and give as one dose to adult sheep; lambs can be given from one to three-fourths of the above with safety. Following this treatment a tonic should be used to stimulate the appetite and assist nature in restoring health.

Take. Salt .................. lbs.

Epsom salts.............. lb.

Sulphate of iron.............

Powdered gentian........... $\frac{1}{2} \mathrm{lb}$.

Nitrate of potash..........4 ounces

Mix thoroughly. This can be given by mixing it in the feed, and will make a sufficient quantity for 100 sheep. It should be repeated two or three times a week till the animals show signs of marked improvement.

\section{Preventive Creatment.}

Consists in not over-stocking the pastures. The lambs should be kept in fields which have not been used for some months previously". Attention must be paid to the water supply, as this appears frequently to be a source of infection. It must be borne in mind that this disease is more prevalent during the summer months and that the majority of fatalities take place in lambs under six months of age. Lambs recovering from the attacks of taeniae or those which have been treated and rid of the same, should receive the best of care and attention, as the system is run down, the animals are weakened and emaciated, making them more liable to attacks from other ailments.

\section{Paragitic Gastric Catarrh.}

This disease is generally found occurring as an epizootic. It is due to the presence of round worms, scientifically termed twisted strongyles (strongylus contortus) in the abomasum! (fourth stomach). As seen attacking lambs it is particularly fatal. It is found occurring in all countries where sheep are 

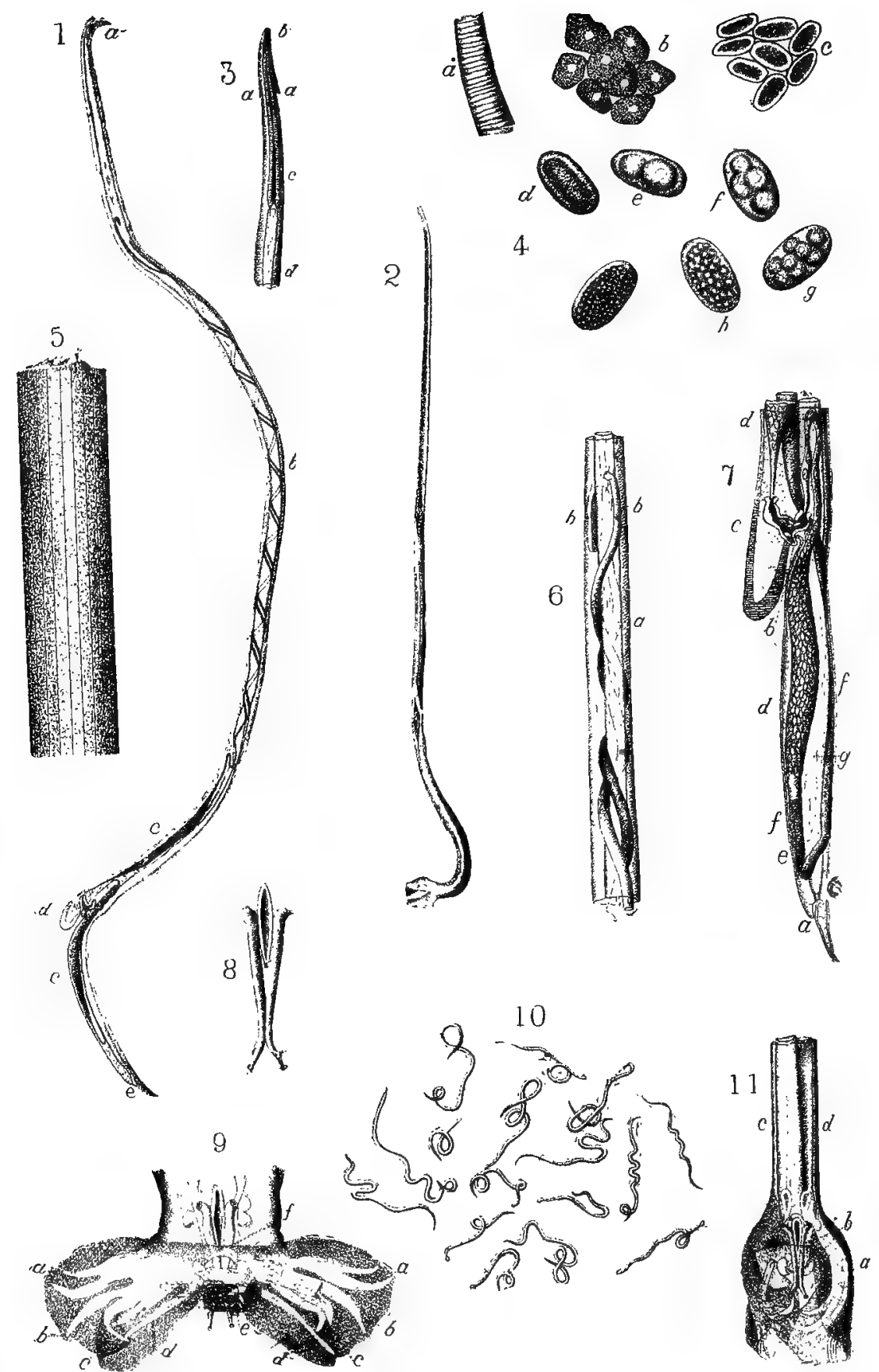

Strongylus Contortus, Rud. 


\section{Description of Illustrations on Opposite Page.}

Fig. 1. Adult female, $\times 6, a$, head; $b$, ovaries wound around the intestines; $c, c$, uteri ; $d$, a large papilla, just in front of and covering the vulva; $e$, anus.

Fig. 2. Adult male, $\times 6$.

Fig. 3. Head-a, two barb-like papillæ; $b$, mouth; $c$, csophagus; $d$, intestine.

Fig. 4. Eggs, highly magnified-a, eggs before they have left the ovaries; $b$, eggs showing nuclei; $c$, egge after they have passed through the oviduct; $d$, egg with one cell; $e$, with two; $f$, with four; $g$, with eight; $h$, with many; $i$, egg as it is laid.

Fig. 5. Skin, showing nine of the eighteen longitudinal lines.

Fig. 6. Portion of female- $a$, the intestine; $b, b$, the ends of the ovaries.

Fig. 7. Caudal end of female- $a$, the anus; $b$, the vulva; $c$, vagina; $d, d$, uteri filled with eggs; $e$, oviduct; $f, f$, ovary; $g$, intestine.

Fig. 8. Spicula, enlarged.

Fig. 9. Bursa, expanded to show costæ: $a$, ventral; $b$, ventro-lateral; $c$, lateral; $d$, dorso-lateral; $e$, dorsal; $f$, spicula.

Fig. 10. Group of adult males ant females, natural size.

Fig. 11. Caudal end of male- $a$, bursa ; $b$, spicula; $c$, seminal reservoir; $d$, intestine. 
kept. It is frequently complicated with verminous bronchitis, and is generally prevalent during the spring and summer months.. No portions of the United States appear to be free from its ravages. Throughout Arizona, New Mexico and Mexico proper, it is known under the name of lombriz, a derivation from the Spanish "lombrici," meaning worms; its attacks being of frequent occurrence in those districts.

\section{Hppearance of calorms.}

Body red or white according as its intestine is full of blood sucked from the mucous membrane of the stomach, the extremities are pointed, just behind its anterior extremity two small lateral projections (papillae) are noticeable. These are shaped in the form of teeth, projecting backward. Fine lines or striae mark its integument (skin) transversely, in addition to which are longitudinal ridges forty or fifty in number. The male worm is from one-half to one inch in length, the female from one to one and one-half inches, its body terminating in a pointed tail. Its vulva is situated a short distance from the tail in a depression covered by a powerful tongue-like appendage, which points backward; its eggs are ovoid and infinitesimally small in size.

The probable source of infection of sheep by these pests is through the medium of the water supply. Lenkart reports that he has seen them grow rapidly in muddy water, reaching such a state of growth as to be able to mature after gaining access to ruminants. Such. being the case, it is necessary to guard against the water supply being contaminated with the excrements of animals which are themselves suffering from these worms.

\section{Spmptoms.}

These so far as being characteristic of this particular order of worms are not well marked. The affected animal is dull, 
suffers from a depraved appetite, intense thirst, becomes poor in flesh and dropsical, the belly becoming enlarged and tense. It will suffer frequently from attacks of colic, and is affected with a black diarrhoea, which generally terminates in death.

\section{Post-Mortem.}

Examination of the fourth stomach of sheep which have been attacked by these worms will find it containing hundreds and perhaps thousands of twisted round worms elosely packed together, their heads buried in the mucous membrane, which is thickened and has a blocdless or pale appearance.

\section{Creatment.}

Where the sheep are suspected to be suffering from worms they should be dosed individually, unless the flock is so large as to make it impracticable.

Take. Kamala ................. drachms

Linseed gruel............6 ounces

Mix this is a sufficient dose for one large sheep. Lambs can be given from one-half to two drachms of kamala according to their age and size. Finlay Dunn in his work on veterinary medicine, prescribes as follows.

Take. Common salt..............

Powdered ginger.............

Powdered salt petre............

Dissolve in three gallons of warm water, to which when nearly cold add twenty-four ounces of turpentine. The dose for lambs of from four to six months old is two ounces, the full prescription being a sufficient quantity for 160 head of lambs. Zurn recommends picrate of potash, claiming that it will be found less irritating, and at the same time as efficient a vermicide as kamala. The dose for a lamb is from three to five grains, and for grown sheep twenty grains. It should be administered dis- 
solved in water. Where large numbers of sheep have to be treated pumpkin seeds have been used, and in many cases with satisfactory results. These can be given in unlimited quantities, mixed with dry feed, such as shorts, the great drawback in using this simple remedy being the difficulty to get the sheep to eat a sufficient quantity. After treatment the flock should be moved to fresh and uninfected pastures. The ground from which they have been moved should not be used to graze sheep on for at least two seasons, and where practicable the pasture should be given a dressing of lime or salt.

A new method, and apparently, from all data which can be gathered on the subject a most successful one, is the use of benzine, or to make it more plain to the reader, gasoline, in a treatment of this affection. This is used as follows: For lambs weighing about 75 pounds administer one tablespoonful of gasoline in half a pint of linseed tea or oat-meal gruel; repeat daily for three or four days. Adult sheep take from two to three tablespoonfuls. This treatment is simple, and from all accounts. would certainly warrant a trial. It was first used in France, and the reports from that country were most gratifying, leading to the adoption of this agent by many prominent sheep men in this country, notably Jos. E. Wing of Mechaniesburg, Ohio, who reports favorably.

\section{Nodular Disease of the Intestines.}

This is a diseased condition of the intestines, due to a parasite called the oesophagostoma columbianum, the last word signifying that it was first found in the District of Columbia. The investigations leading to and determining this particular species of worm were successfully carried out by Dr. D. E. Salmon, Chief of the Bureau of Animal Industry, assisted by Dr. Cooper Curtice, also a member of the Department of Agriculture. Its presence can only be detected by post mortem ex- 
amination, when it will be found that the intestines of the sheep, more particularly the large guts (colon and caecum), are studded with whitish tumors, ranging in size from that of a millet sced to as large as a hickory nut, giving the external coat of the bowels a knotty appearance, so injuring the gut as to make it worthless for sausage casings, inflicting serious monetary loss to the butcher. "The adult worm is found in the large intestines of sheep in considerable numbers, and in the same animal may also be found the tumors. The parasite is usually found below the narrowing of the large intestines, where the latter change from a sac-like receptacle to a large tube, and below the mass of tumors. The tumors may, however, extend the entire length of the intestines. It is evident that the distribution of the eggs of this adult would be favorable for sheep becoming again infected by them."-Department of Agriculture Report 1890, Cooper C'urtice.

There are no special symptoms characteristic of this particular species of worm. The writer has seen hundreds of sheep killed at the abattoirs, the intestines of which were studded with tumors, the animals in life showing no particular signs of verminours trouble. In fact, it was frequently noticeable affecting the intestines in fat, prime sheep, but there is no doubt that serious trouble results to sheep harboring this parasite for any extended length of time, its effects appearing to be more disastrous in the Southern and South Eastern States of America than in the more northern latitudes.

The white tumors or cysts being situated under the peritoneal correring and external to the mucous lining of the intestine, are not susceptible to the action of medicinal agents. The mature worms which are found in the intestines will rield to the same treatment as that prescribed for tapeworms causing parasitic diarrhoea. 
The fact of this particular oesophagostome being so universally distributed over large portions of the United States renders the problem of possible infection a hard one to solve. As a matter of economics this disease is worthy of grave consideration; large importations of sausage casings being necessary to supply the home demand.

\section{The Rot.}

This disease has been the cause of greater loss to the flock owners than almost all the others combined, with the exception, perhaps, of sheep scab. Records dating back hundreds of years show that in Egypt the discase was most virulent, appearing there annually following the inundation of the banks of the Nile. Beyond a doubt, all cases of rot have arisen from keeping sheep on a wet, swampy soil, they being naturally an inhabitant of dry and lofty situations, and while they have been made to thrive on unsuitable grounds, the perversion of their natural habits exposes them to attacks by this most disastrous disease.

The parasite causing this disease is known as the distoma hepaticum or liver-fluke; and while it is very common and has caused immense losses on the European continent and Great Britain, it has rarely been found affecting American sheep, although a few cases have been recorded in the East, on Long Island, also in Louisiana, Texas and California. As a matter of listory, it may be stated here that the liver-fluke in Great Britain alone was, until recently, responsible for the loss of $1,000,000$ sheep and lambs annually, and that in 1830 to 1831 this number was more than doubled, many farmers losing all their flocks, one farmer in the County of Kent losing $\$ 15,000$ worth of sheep in the course of three months.

On the continent of Europe its ravages have been fully as great. Its presence has also been felt in Australia, and to a 
certain extent throughout the different parts of the world where the land is swampy and subject to floods.

M. M. Hamont, in an essay on this subject, states that "it assumes its most serious character after heavy rains and extensive floods, and in wet countries covered with aquatic plants. It affects animals of different ages and in all seasons. It appear: every year in Egypt after the fall of the Nile, and it follows and keeps pace with the subsidence of the waters. In the superior parts of Upper Egypt it commences about the end of July, near Cairo in August, in the environs of the capital in October and November, and during the months of December, January anit February in the Delta. It is most obstinate and continues longest in the neighborhood of the confluence of the waters. In Lower Egypt it lasts about 120 to 130 days, and it disappears soonest and is least fatal when the rise of the Nile has not been considerable. Desolation and death accompany it whererer it passes. The Arabs say that this pest annually destroys 16,000 sheep in Egypt. Its victims usually perish on the twenty-fifth, thirtieth, thirty-fifth or fortieth day after the apparent attack." From this extract we can readily understand that it is a particularly fatal disease, and that it being of so rare an occurrence in the United States of America is a cause for self-congratulation among the flock owners of this country.

\section{Symptoms.}

The primary symptoms are slight. Instead of the animal losing flesh it appears to increase in weight, the appetite remain= good, the tendency to fatten being due to the better assimilation of the food products, owing to the increased secretion of bile caused from the irritation due to the young liver-flukes in the bile-ducts and liver, and this very tendency to fatten in the first stages of the disease has led feeders, notably the celebrated Bakewell, to purposely expose the sheep intended for early 
market to the infection, so that the period of feeding would be shortened, and the profits correspondingly increased. Among the first noticeable symptoms will be a dullness and a pale appearance of the mucous membranes of the eyelids, nasal carity and mouth; the membrana nictitans, or winking eyelid, situated at the corner of the eyes nearest the nose, becomes yellow.

As the disease progresses the affected sheep become flaccid about the loins, and commence to shrink; by passing the hand over the hips a crackling sound is produced, caused by the presence of gases in the sub-cutaneous connective tissue; the countenance becomes pale, the skin changes color from the normal healthy pink hue to a pale red, the wool parts easily from the skin, which as the disease progresses becomes covered with yellow and black spots; in a short time the dullness increases, the animal continues to lose flesh, the paleness of the mucous membranes increases until they become almost white, at which stage they commence to become yellow, showing the presence of bile in the blood; the yellow appearance extends to the skin, which now becomes loose and flabby, a watery fluid collecting under it, dropsical swellings being noticeable under the belly between the fore-legs and under the jaw. This last appears in the form of a large watery swelling, giving the sheep the appearance termed "chockered." Then this stage is reached the sheep quickly succumbs.

\section{Duration of the Disease.}

Some authorities state that the flukes remain nine months, others claim fifteen months in the affected sheep, and that after this time they gain access to the intestinal canal and are voided with the droppings.

Thomas says he has seen the sickness last six years, Neumann claiming, as does Perroncito, that the flukes rarely quit their hosts, and the question of re-infection of the same animal 
creates a doubt whether such a long period of infection was all due to the same parasites or to renewed generations of them.

The disease ordinarily lasts from three to six inonths, but this is very uncertain, affected animals having been known to succumb in a few days after infection, the death in such cases being caused by acute inflammation of the liver, due to the irritation caused by the presence of the parasites. Sheep suffering from the rot, owing to their weakened condition, become susceptible to other maladies which are liable to cause death, eren before the liver disease has had time to run its course.

\section{Post-Mortem.}

Post mortem appearances depend entirely on the stage in which the sheep is destroyed. Shortly after infection the thin edge of the small lobe of the liver, termed the quadrate lobe, becomes a whitish-blue color, which spreads along the upper and lower sides.

When the disease has run a more protracted course, the flesh is found pale, and in the dependant parts of the body infiltrated with a yellowish serous fluid. In far advanced cases few parts of the body are found which do not present evidences of disease, the heart is soft and pale, the lungs often being studded with tubercles; in all cases the liver is found extensively affected, generally pale in color and friable or mottled, with hard scirrhons spots with a fluid jelly-like deposit on different parts of its surface, particularly so around the bile-ducts. It will also appear puckered in places with cicatricial markings, caused by the reparative process and contraction of the newly formed tissue. Channels are formed in the substance of the organ under the serous membranes covering it. These are visible to the naked eye. The biliary ducts are irregularly enlarged and thickened, the sacculations frequently being as large as a hickory nut, and on making a transverse section of these they will be found to 
contain flukes of various sizes in a greenish black, stjcky mas, the inside surfaces of pouches being lined with a gritty calcareous deposit. When the flukes leare the liver for the intestinal canal the structure of the organ will partially heal, but the liver never returns to the normal healthy condition.

Neumann describes the appearance of the liver-fluke as follows: "Description.-Body flattened, leaf-like, pale brown, irregular, the adult from eighteen to thirty-one $\mathrm{mm}$. long and

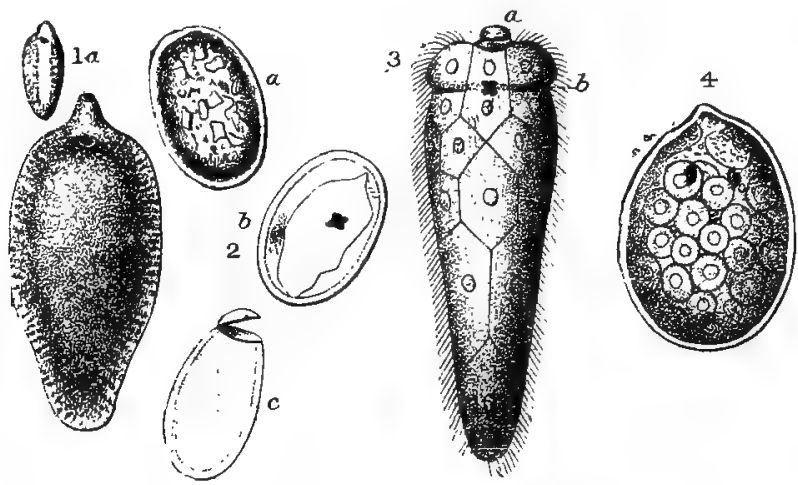

\section{Distoma hepaticum, Linn.}

Fig. 1. Adult flulse, natural size-la, young fluke, natura1 size. (Raillet).

Fig. 2. Eggs-a, egg with developing embryo; $b$, egg with embryo; $c$, egg-shell. (Raillet.)

Fig. 3. Ciliated and free embryo-a, perforating apparatus; $b$, ocular spot. (Leuckart). Fig. 4. Encysted embryo found in suails. (A. P. Thomas).

from four to thirteen $\mathrm{mm}$. wide, oblong, oval or lanceolate, larger and rounder in front, where it is abruptly contracted in such a way as to present a conical neck, attenuate and obtuse behind, skin bristling with numerous little points directed backward. Oval sucker terminal, rounded. Ventral sucker, large, projecting with a triangular opening, situated about three min. behind the first. Intestine with two ramified branches visible through the skin, and of a deep shade. Penis projecting in front 
of the abdominal sucker, always recurved. T'ulva small, sitnated at the side of the male orifice or a little behind. Eggs brown or greenish, oroid, length from 0.130 to $0.145 \mathrm{~mm}$., width 0.070 to $0.090 \mathrm{~mm} . "$

The parasite has been found in the livers of the sheep, goats, cattle, camels, and a number of wild ruminants, also in the horse, ass, pig, elephant, rabbit, and man. Its habitat is in the biliary ducts of the liver where, according to Kuchenmeister, it feeds on the blood from the mucous membranes of those passages.

Its life history was first determined by Leuckart, and later, but independently, by Thomas, an English scientist.

It was called the fasciola hepaticum by Linnaens, the naturalist, the name of distoma hepaticum being bestowed on it by Retzius, the word hepaticum being used in conjunction with either of the others to designate that the fluke is found in the liver.

The flukes deposit their eggs in the biliary ducts, from which they pass into the intestines, and are voided from the srstem, dropping on the ground, where those falling in suitable places, under farorable conditions, hatch and escape by the raising of a lid-like contrivance on the small end of the egg. These newly-hatched parasites are not young flukes; on the contrary, they are small ciliated embryos, which are enabled by the fine cilia (hair) covering them to strim about in water. These embryos immediately seek out the small water snail, it being necessary for the completion of the life cycle of this remarkable parasite that this snail act as an intermediary host for it during the completion of this stage. Should the embryo fail to become attached to the water snail in two days time it will die without completing its life cycle. On the other hand, should it become attached to the snail, it immediately bores through the shell. 
lodging in the respiratory cavity of that mollusk. Here it becomes encysted, contracting into an oval mass, which grows rapidly. It this stage it is called a sporocyst. This sporocyst splits up into from five to eight bodies, called rediae, which are about $2 \mathrm{~mm}$. in length, these leaving the cyst one by one. These rediae each one of them develop within themselves fifteen to twenty cercariae, which are thrust out in turn through an orifice under the neck of the rediae.

These cercariae are what escape from the snail, being scattered broadcast in its wanderings. After a short time they lose their tails, and again become encysted, the contents of these cysts being attached to blades of grass, etc., are swallowed by the sheep or other animal, the gastric juices acting on it break the covering, setting free the young flukes in the stomach and duodeneum, from which they gain the biliary ducts, and pass up them to the liver, where they grow into adult hermaphroditic parasites able to give origin to other generations of young.

The life cycle of this parasite is as wonderful as any occurring in nature, at least seventy-five young flukes under suitable circumstances being able to develop from a single egg.

\section{Preventive Creatment.}

We cannot do better than print verbatim Thomas' formulated rules of prevention against this parasite, founded on its lifehistory, as follows:

"1. All eggs of the liver-fluke must be vigorously destroyed. Manure from rotten sheep or other infected animals. must not be put on wet ground. As the liver and intestines contain the eggs, those too must be destroyed or put in the compost heap. The manure of affected animals should not be stored where there is a drainage from it to the neighboring grass. It should be mixed with lime and salt before being spread on meadows or cultivated fields.

"2. If sheep are infected, let them be sent to the butcher 
at once, unless they are specially valuable and are not bally affected. If kept they must not be put on wet ground.

"3. Care must be taken to avoid introducing egg" of the fluke, either with manure or fluked sheep or in any other way. Rabbits and hares must not be allowed to introduce the eggs.

"4. All heavy and wet ground must be thoroughly drained.

"5. Dressing of lime and salt (or both) should be spread over the ground at the proper season to destroy the embryos, the cysts of the fluke and also the snail, which acts as host.

"6. Sheep must not be allowed to graze closely, for the more closely they graze the more fluke germs they will pick up.

"7. When sheep are allowed to graze on dangerous ground they should have a daily allowance of salt and a little dry food."

\section{Medicinal Creatment.}

A perfect cure is almost hopeless. After the period of migration of the flukes to the intestines, a spontaneous cure sometimes results, which, however, is very rare. So far as medicinal treatment is concerned, Mojkowski reports, according to Neumann, satisfactory results by giving the sheep napthol twice daily for a week, in ten to fifteen grain doses, alone or mixed with gentian. Another old English recipe calls for

Sulphate of iron........... drachm

Salt ................ d drachm

Anise seed............. d drachm

Mixed with half a pound each of linseed meal, peas and locust beans, and given daily to each sheep. The fact that salt is fatal to the fluke and that sheep may be grazed with impunity on salt marshes, is evidence that salt should be freely offered to sheep. This is best accomplished by keeping quantities of rock salt within easy access. Combined with medicinal treatment a proper stimulating and nourishing diet is of great importance. Corn, barley, peas, oats, oil-meal, cake, any dry grains, should be fed in judicious proportions. Wratery foods such as turnips, Swedes, etc., are to be avoided. 


\section{CHAPTER XV.}

\section{Parasitic Diseases of the Skin.}

While the diseases of this particular class are not so dangerous to the animal's existence as those occurring from internal parasites, yet we must place great importance on diseases of this nature, as to one of them at least, viz., scabies, the greatest loss of the wool-grower is directly attributable. The yearly shrinkage of the wool crop due to its attacks amounting throughout the world to millions of dollars. All discases of the skin tend to produce bodily discomfort, the sheep after feeding instead of being able to rest quietly, is called upon to resist the attacks of pests, the excessive itching always present in these complaints causing the animal to rub itself violently and pull the fleece from the diseased surfaces with its mouth. Animals suffering from these attacks do not fatten readily. Should they be neglected, no treatment being used, the diseases become virulent, the animal perceptibly loses flesh, and is virtually eaten alive by ever-increasing multitudes of parasites.

\section{Scabies, Scab.}

Is a disease due to the presence of an animal parasite, which exists on the effusion arising from the irritation to the tissur: cansed by its presence. Of the scab insect infesting sheep wr find three kinds, namely, the sarcoptes oris, which burrow in the skin; the dermatodectes, also called the psoroptes communis, the cause of common scab, which simply bite and hold on to the skin, and which is the parasite we shall mostly have to deal with in this chapter, and thirdly the symbiotes, or chorioptes ovis, the 
cause of foot scab. In studying the life-history of these parasites we find they are virtually alike, in that they attack the skin of the sheep, and live on the fluid arising from the irritation from their bites. The scabs form orer the irritated surfaces; and beneath these crusts the insects deposit their eggs. In the course of from two to three days the eggs hatch, the newly born parasite becoming adult in fifteen days. Each female parasite,

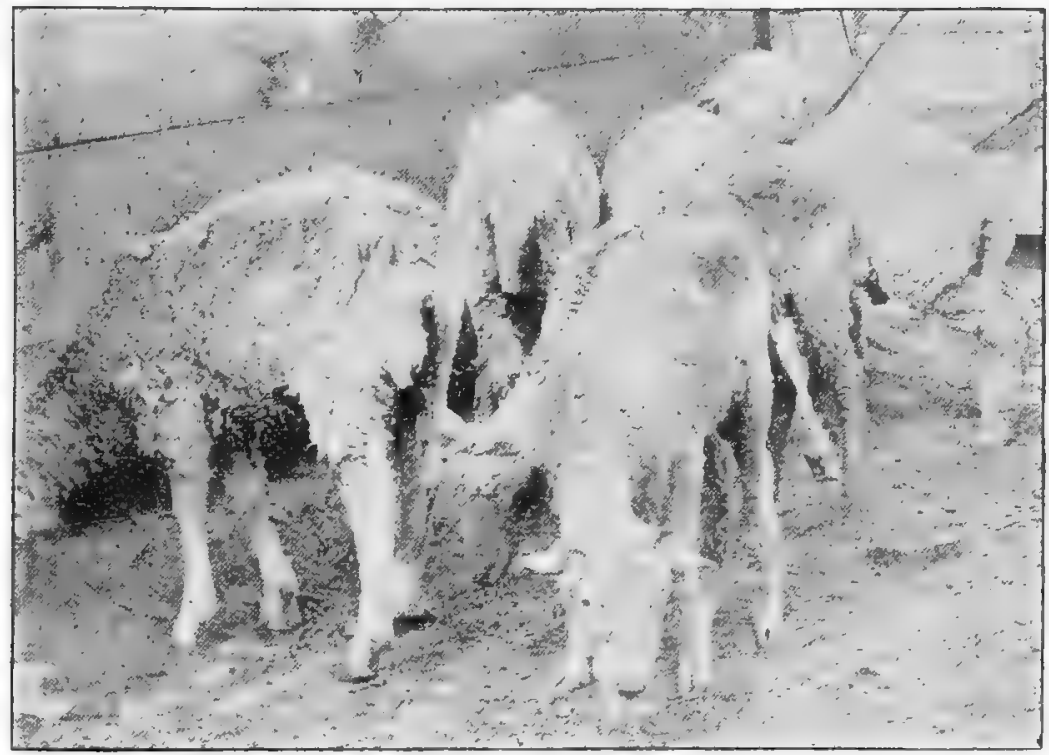

\section{Grcup of Emaciated and Scabby Sheep.}

according to Gerlach, will lay fifteen eggs, ten of which will bring forth females, the balance males. The young parasites as soon as they hatch spread and invade new territory, which gives the affected part the appearance of spreading by a constant adrance of its circumference. The eggs being embedded in these crusts or scabs, are deposited on posts, feeding troughs, or hedding, etc., and become fresh centers of infection, it only 
being necessary that they become deposited on the skin of the sheep for them to develop into live and aggressive parasites.

Gerlach, the German authority mentioned previously, computed that in three months time a single female would be re-ponsible for the existence of $1,500,000$ progeny, as is shown in the following table:

Females. Males.

First generation after 15 days produces... 10

Second generation after 30 days produces.

Third generation after 45 days produces. .

Fourth generation after 60 days produces.

Fifth generation after 75 days produces. .

Sixth generation after 90 days produces. . 1,000,000 500,000

Unless the affected sheep is submitted to proper treatment to destroy these pests they will increase indefinitely in numbers until cleath to the patient ensues. The form of scabies commonly affecting the sheep in the United States from the Atlantic seaboard to the Pacific Ocean is that caused by the psoroptes communis, which attacks the parts of the sheep covered by the heavy fleece, causing the animal to rub and pull the fleece, so effecting a shrinkage in the wool clip, which, when the large number of affected animals are taken into account, will be found to annually mount up to millions of dollars, all of which could be prevented by intelligently carrying out the Federal and State regulations governing the same, subjecting all affected animals to a rigid quarantine and effective treatment, and heavily punishing the owner of a lot of infected sheep if he should wittingly allow them to run at large.

The common scab attacks the backs, flanks, sides, shoulders, necks, bellies, and rumps of the sheep, the spot infected appearing ragged, the sheep frequently biting the part as if it was trying to tear the wool, or striking the spot with a hind foot; in 
aggravated cases tearing the skin with the hoof, causing ulceration and thickening of the cuticle.

\section{Che head Scab.}

This disease, as has already been stated, is caused by parasites called the sarcoptes scabiei. They are the smallest of the scabforming parasites, being almost invisible to the naked eye. In appearance they are rounded, ovoid bodies, with small pointed proboscis, the full grown parasite having eight legs, four to a side, supplied with suckers or feelers, while the newly-hatched insect posisesses only three pair of legs, the other pair appearing about thirty-six hours after birth.

\section{Location and Symptoms.}

This disease first makes its appearance around the nostrils, rarely on the eyelids, and around the ears. From these locations the scab extends over the whole face, cheeks and eyelids, eren to the lower portion of the limbs, under the belly, and especially in the flexures of the knee, hock and pastern joints, wherever the wool is scarce, as this species does not attack the parts covered by the heary fleece. The first symptom noticeable will be that the sheep rubs and scratches its head violently. On examination at this period, a very small whitish yellow pimple will be found, which, on being rubbed, ruptures, allowing the escape of a yellowish serosity. This in drying forms minute crusts, the aggregation of which tend to form a thick and hard scab. The vesicles themselves are formed by the parasites burrowing into the skin, where they find the necessary nourishment for their growth and the propagation of the species. The young as soon as they hatch out migrate to a fresh location, where they immediately bury themselves in the skin in the same manner as their progenitors. In this manner the disease spreads, slowly at first, but after the first thirty days by leaps and bounds. As the dis- 
ease progresses the scabby patches become confluent, thicker and harder and white in appearance, extending over the lips, cheeks, nostrils, face, forehead, eyes and ears in one hard, thick scabby mass, causing an incessant, unbearable itching, in trying to allay which, by rubbing and striking the part with its feet, the animal tears through scab and skin, causing bleeding, soreness and ulceration of the part. As these patches increase round the edges, the centers tend to heal, leaving scars and cicatrices to show the ravages of the disease. When the scabs cover the eyelids, the animal is in danger of starving to death, being unable to sce where or how to obtain food. To find this insect it is necessary to raise the scab and examine the moist underlying exudate by the aid of a microscope. They are not to be found on the hard and dry portions of the scab.

Head scab is not a common form of the disease in Torth America, although cases of it are occasionally found.' It is the most susceptible to treatment of the three kinds of scab, and while, unlike the common scab, it does not work direct injury to the fleece If neglected, the patient becomes poor in flesh, and indirectly by its effect on the general health, the normal growth of the fleece is prevented, so curtailing the clip.

\section{Creatment.}

The application of a good sheep dip or wash will effectnally cure this trouble.

\section{Common Scab, Dsoroptes Communis.}

The parasite cansing this disease is much larger than the sarcoptes, being easily discernible with the naked eye, especially if placed on a black surface. It has caused more monetary Ins: to sheep breeders of all countries than any other condition $01^{\circ}$ disease, not excepting the ravages caused by the liver-fluke; so rapidly does it run through a flock, and so destructive are its 
effects on the wool industry, that nearly all governments have enacted legislation aiming to control and eradicate the disease.

\section{Symptoms.}

When scab first breaks out in a flock of sheep the affected ones will be noticed scratching, biting, rubbing themselves, taking hold of the wool and pulling it from the skin, causing the fleece to have a rough uneven look, the wool fibres being stuck together and wet where the animal has been biting the part.

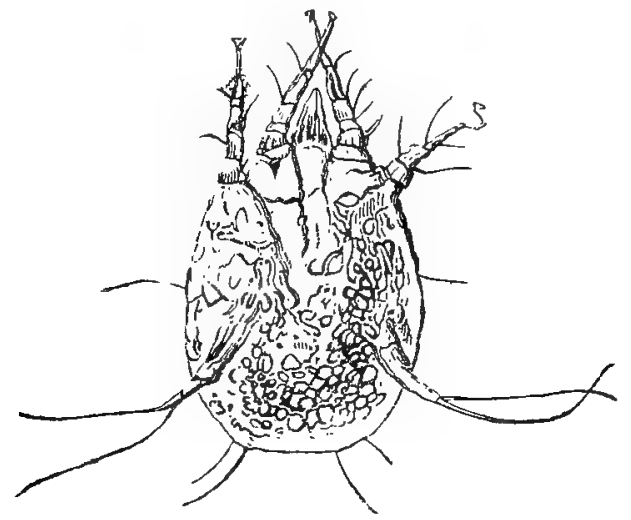

A Young gix-legged Hcarus $\times 100$, (Brown.)

Sheep badly affected will be uneasy at all times, constantly pulling and scratching, especially is this the case if they are driven around and over-heated, the itching then becoming very severe.

\section{To Examine a Sheep for Scab.}

Part the wool over the spot where the animal has been biting, and by closely examining the skin small whitish-yellow clevations will be observed which present a marked contrast to the normal pink skin. These elevations are caused from the bites of the scab mites, which will be found on the wool fibres in close proximity. As the mites increase in numbers, 


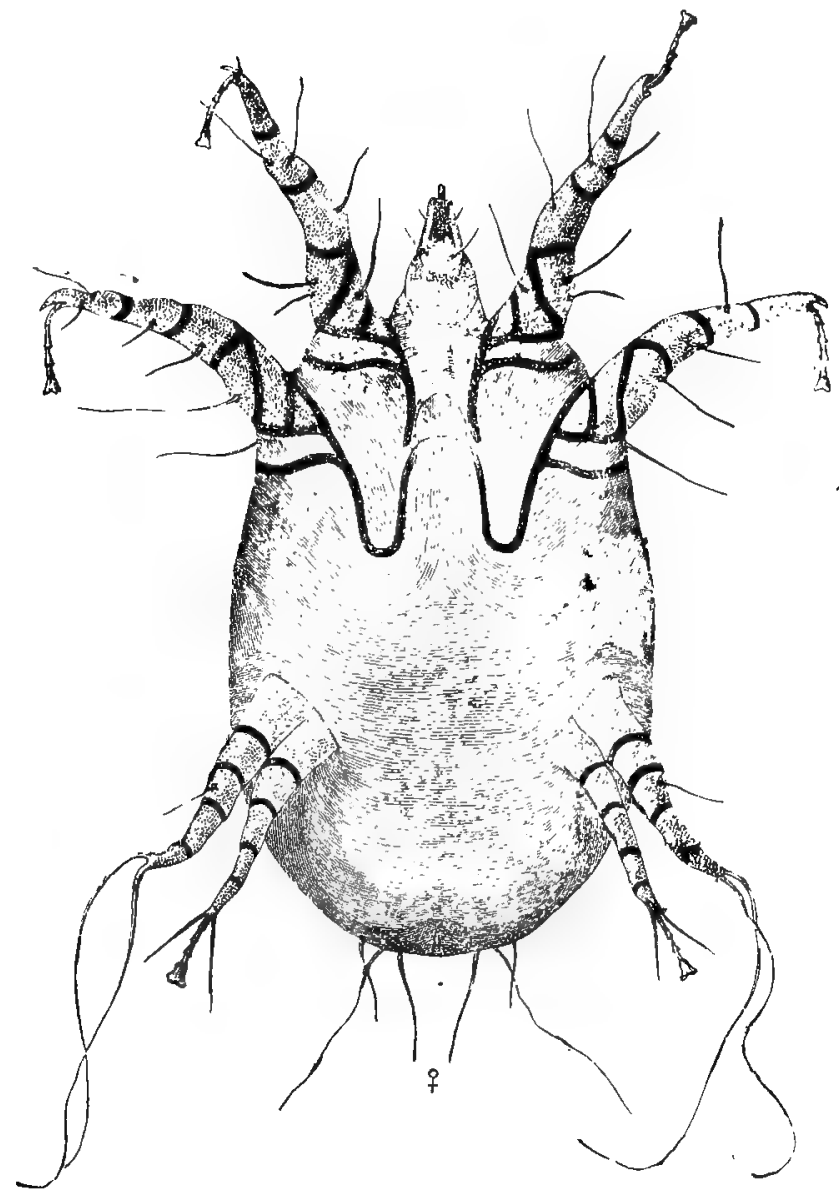

Psoroptes Communis $\forall e l$ Dermatodectes Ovis. (Gerlach.) 
the elevations do likewise, becoming closer together, finally uniting. The vesicles, on being rubbed, exude a watery seros- ity, which accumulates and in drying forms a thin crust, called a

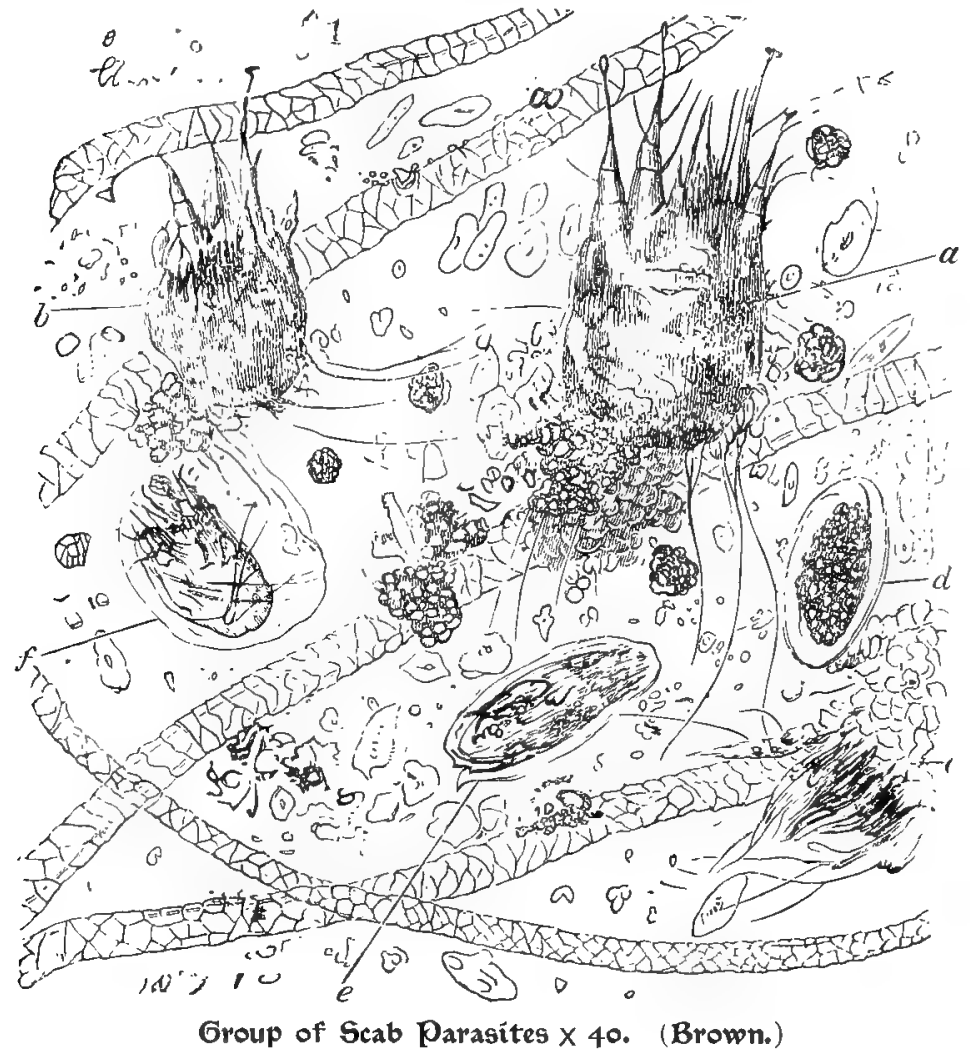

$a$, nuature female acarus in a mass of scab. $b$, young acarus after change of shin. , cast-off slrin of an acarus. $d$, drum with yolk contracted. $e$, drum containing a young acarus. $f$, orum with young acarus in iuterior about to be hatched.

scab. The scab appears as a yellowish, thin, greasy layer. This as the disease progresses becomes thick and hard, spreading wider as the parasites invade fresh tissue around the edges of the scal). These crusts in being rubed off or torn out by the 
frenzied motions of the sheep carry with them tags of wool, leaving the affected surfaces denuded and sore. These become again covered by scabs, which are thicker than the former, these being still further increased in circumference by the outward migration of the parasites. As the affected surfaces enlarge their centers tend to heal, but the skin remains thick and wrinkled for a long time, the growth of the fleece being retarded and sometimes destroyed from the injury to the hair follicles.

\section{Modes of Infection.}

Since seab is caused by insects which are being continually distributed by the sheep rubbing on posts or dropping tags of wool containing pieces of scab, which on coming in contact with other sheep soon cause an outbreak on them also, it can readily be seen that the sources of infection are many, among which can be enumerated the shipping of infected sheep in railroarl cars as one of the commonest methods of distribution, or permitting healthy sheep to graze on a range on which scabby sheep have been kept, or the exposure in any way of healthy shcep to the eggs of the parasite, which are more to be dreaded than the mite itself. The parasite itself cannot live for any length of time away from the body of its host, and experiments have shown that it will succumb after a period of from ten to fifteen days, but its eggs, being almost indestructible orring to their dense fibrous covering, will last indefinitely, and should the sheep pick up any particle of wool or pieces of acab containing these eggs it is only necessary for them to remain in contact with the skin for a short period for them to hatch and beeome the foci for new and disastrous outbreaks. Ranges when once infected are not considered safe grazing grounds for the space of one year. Pens when infected need to be thoroughly gone orer with slaked lime wash, with some parasiticide added to it, before they are 
safe to hold sheep again. All railroad cars should be thoroughly cleaned and disinfected after having been used for the transportation of sheep, especially is this necessary in the West, where cars frequently are kept in use till the manure has accumulated to such an extent that it becomes almost impossible to load sheep in them. These manure beds teem with the eggs of the parasites, which are picked up by the sheep's fleece, causing a wholesale infection of all exposed, thus carrying the disease from one district to another or from State to State, and in many instances from the far West to the Atlantic seaboard. There are few if any counties in the Western States and territories in which scabies is not constantly present, and it is from these districts that the lambs are sold to be fitted by the Eastern feeder for the spring market, which accounts for the general distribution of this disease every fall and spring. While at the time of sale and up to their arrival at the feeding grounds they may appear perfectly clean and healthy, experience has taught those who make a business of handling feeders that it is a waste of time and feed to neglect dipping the lambs at once on their arrival, and if possible before they go into the feeding pens, as when this is delayed, as soon as the animal begins to get on feed the scab is sure to break out, the disease then being almost impossible to cure on account of the infection of the pens. The writer, when sheep inspector at Fort Collins, Col., can remember one season in particular when the lambs from New Mexico appeared healthy on their arrival from that territory, but in a short ime scab developed in every flock of feeders in Larimer County, and as there were 150,000 head on feed in fifty-five separate flocks the reader can well understand the loss sustained by the owners, some of whom were compelled to dip their flocks five times in as many months, and then were only able to keep the disease under control, but not eradicated. Had these sheep 


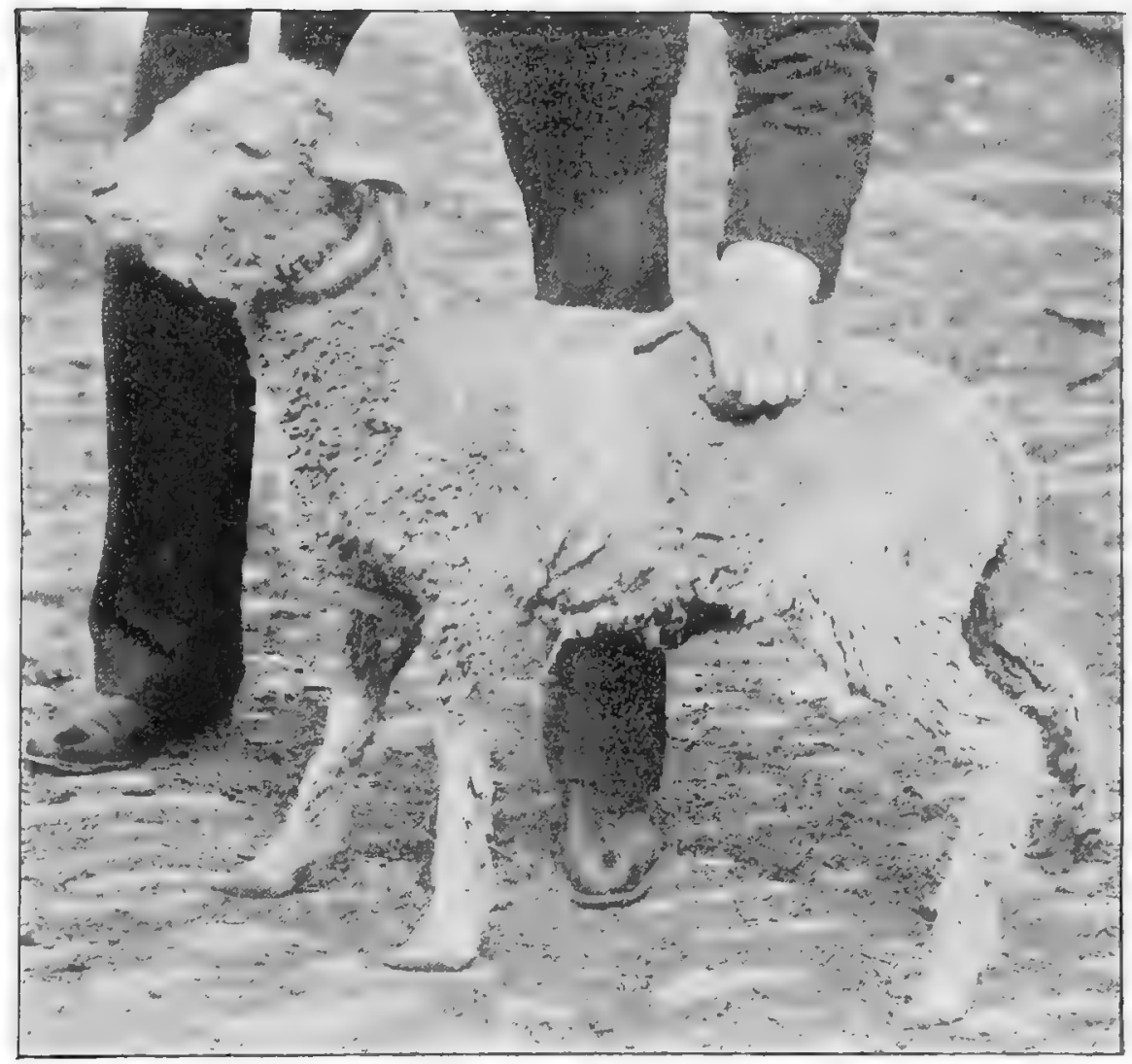

म Bad Case of Scabies, the affected area extending from the Crooh around the Fnimal's Neck to the thumb of the Examiner. Che Cuticte is much thichened and raw with pus in the Gub-cutaneous Cissues. 
been thoroughly dipped before shipping and then loaded on clean and disinfected railroad cars, this trouble would have been arerted to a great extent, and one more dipping on their arrival at the feed yards would have been all that was necessary to carry them through till spring.

The mite causing common scab can easily be found at the edges of the scabs, and can be studied by means of a low porrer microscope, and so numerous are these parasites that one slide will often reveal the adult mites, the six-legged young and many eggs. Fall and winter are the seasons most farorable for the spread of this disease, owing to the animals being congregated together under sheds or in feeding lots, and the fleece at those seasons being long, facilitates the propagation and vitality of the parasites. In summer the change from dry food to green grass appears to effect a certain influence antagnostic to the spread of the scab, especially is this so after spring shearing. Scab if not treated will eventually cause extreme debility and perhaps death, owing to impoverishment of the blood and fatigue from loss of rest and sleep, caused by the intense itching due to the presence of these pests. Where breeding cwes become affected with scabies, there is great danger of abortion, and should this not occur, the newly born lamb will be weak and feeble, predisposed to sickness, and rery hard to rear. Ewes not in lamb will seldom conceive when affected with this disease, and when this fact is taken into consideration, together with the depreciation of the value of the wool clip, from double ended wool, and a light fleece, it will readily be understood that the damages to flock owners from this disease which is spread so universally over the country, especially in the Wrestern States, is enormous, and that without exaggeration it must amount to several millions of dollars yearly. 


\section{Creatment.}

Treatment for common scab is of two kinds:

(1). Dipping; where the animal is immersed in a watery solution containing parasiticides, which while they destroy the pests, are supposedly harmless to the sheep.

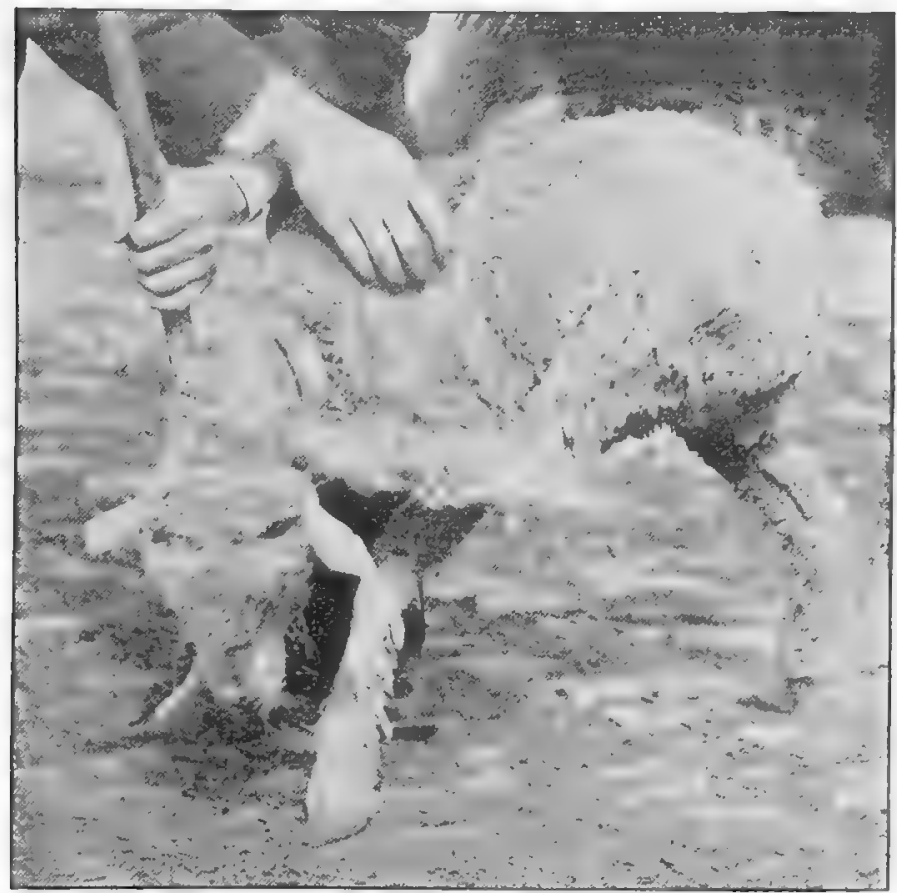

In Hggrapated Case of Bcabies, showing the Subject Kicking with its foot and kaophing its Mouth in Response to a Little Additional Irritation from the Examiner.

(2). Hand dressing; which consists in the application of some such substance as the mercury stone or turpentine and lard, etc., which is rubbed on the affected parts. This method is only practicable where few animals are to be treated. In all cases 
where large flocks are infected, thorough dippings of all the sheep is the only practicable method of combatting the disease.

\section{Dipping.}

Under this head we cannot do better than quote verbatim some of the instructions given out by the Department of Agriculture in a bulletin lately issued dealing with the subject.

"(1). Select a dip containing sulphur. If a prepared 'dip' is used, which does not contain sulphur, it is always safer to add about sixteen and one-half pounds of the sifted flour of sulphur to every 100 gallons of water, especially if after dipping the sheep have to be returned to their old pastures.

"(2). Shear all the sheep at one time, and immediately after shearing confine them to one-half the farm for two to four weeks. Many persons prefor to dip immediately after shearing.

"(3). At the end of this time dip every sheep (and every goat also, if there is any on the farm).

"(4). Ten days later dip the entire flock the second time.

"(5). After the second dipping place the flock on the purtion of the farm from which they have been excluded during the previous four or fire weeks.

"(6). Keep each sheep in the dip for two minutes by the watch, do not guess at the time, and duck its head at least once.

"(7). Be careful in dipping rams, as they are more likely to be overcome in the dip than are the ewes."

Be careful in making your choice of a dip. In these day, when manufactured non-poisonous preparations are obtainable there is no excuse for endangering the lives of the sheep, and not them only, but those of the other live stock of the farm by using poisonous compounds, especially those heavily charged with arsenic. In regard to arsenical dips, the United States Department of Agriculture, in the bulletin already quoted from, says:

There are both home-made arsenic dips and secret proprie- 
tary arsenical dips. It is well to use special precautions with both, because of the danger connected with them. One of the prominent manufacturers of dips, a firm which places on the market both a powder arsenical dip and a liquid non-poisonous dip, recently summarized the evils of arsenical dips in the following remarkable manner:

"The drawbacks to the use of arsenic may be summed up somewhat as follows:

“(a) Its danger as a deadly poison.

"(b) Its clrying effect on the wool.

"(c) Its weakening of the fibre of the wool in one particular part near the skin where it comes in contact with the tender wool roots at the time of dipping.

"(d) Its not feeding the wool or stimulating the growth or increasing the weight of the fleece as good oleaginous dips do. "(e) The danger arising from the sheep pasturing, after coming out of the bath where the wash may possibly have dropped from the fleece, or where showers of rain, after the dipping, have washed the dip out of the fleece on to the pasture.

"(f) Its occasionally throwing sheep off their feed for a few days after dipping, and so prejudicing the condition of the sheep.

"(g) Its frequent effect upon the skin of the sheep causing excoriation, blistering and hardness, which stiffen and injure the animal, sometimes resulting in death."

"Although this manufacturer has gone farther in his attack upon arsenic than this Bureau would have been inclined to do, it must be remarked that when a manufacturer of such a dip can not speak more highly of the chief ingredient of this compound than this one has done in the above quotation, his remarks tend to discredit dips based upon that ingredient." 
The extracts from the Bureau of Animal Industry concerning the use of arsenic are fully endorsed by the majority of flock owners.

Among the most popular agents used for dipping purposes we find tobacco and carbolic acid; these two enter largely into the composition of the most extensively used prepared dips.

\section{Cobacto.}

Is a very efficient agent for the destruction of the acari. Its effects appear to last longer than those of the carbolic acid or coal tar preparations. We find it as the base of some of the most popular sheep dips. Home-made tobacco infusions, prepared by boiling a certain quantity of the natural leaf in a given amount of water, were formerly very popular with sheep owners, but since manufactured extracts have been placed on the market their extended use has largely been superceded by the prepared article, which possesses the advantage of always being uniform in strength and requiring only the admixture of warm water to be ready for use.

\section{Carbolic Acid.}

Carbolic acid is also a reliable parasiticide. Many of the cold water preparations are largely composed of this article mixed with other ingredients, and presented to the public in such a form as to make a perfect emulsion when mixed with water.

\section{Che Dipping Plant.}

This consists of a trough or vat and catching and draining pens. The vat is made either circular or straight. It should be at least five and one-half feet deep, and not to excecd six inches in width inside measure at the bottom, and twenty inchers in the clear at the top. Its length will depend on the number of sheep intended to be dipped in it at any one time. For a dipping plant with a capacity for 5,000 sheep per day the following dimensions will be found satisfactory: 


\section{Che Catching Den.}

This should connect with a large pen, made to hold 1,000 head of sheep, from which they are driven into the catching pen, which is built as follows:

Its floor is raised eighteen inches above the ground, to be on a lerel with the sides of the dipping vat, which project about that distance above the ground; its size, to be convenient for catching sheep, should not exceed twelve feet by twelve feet. A gate is placed at the end communicating with the large pen, the sides are boarded up for about three feet in height, an opening two and one-half feet wide being left where the vat and pen join.

\section{The Vat.}

The vat should be at least fifty feet long, the other dimensions the same as those previously given. It should be built of two-inch grooved pine lumber, well leaded in the seams when put together, to make it absolutely water-tight. It is sunk in the ground to a depth of four feet, so that it projects not to exceed eighteen inches above the ground; the sides should be tied to beams sunk in the earth, level with the bottom of the rat, to prevent the outside pressure causing the sides to bulge in and make it too narrow. The end of the vat next to the catching pen is made perpendicular, while the end leading to the draining pens is made to slant at an angle of forty-five degrees, with strips nailed across to form a ladder for the sheep to climb out on. length of vat on surface fifty feet. Length at bottom forty feet.

The draining pens are of great importance, as they effect a large saving in dip. They should be built as per the illustra. tion, the plan being to build one large pen twenty feet by twenty feet square, haring a slope of one foot from back of floor to end of vat, the sides sloping towards the center, with about six inch pitch from side of pen to center. In the center is a gutter 


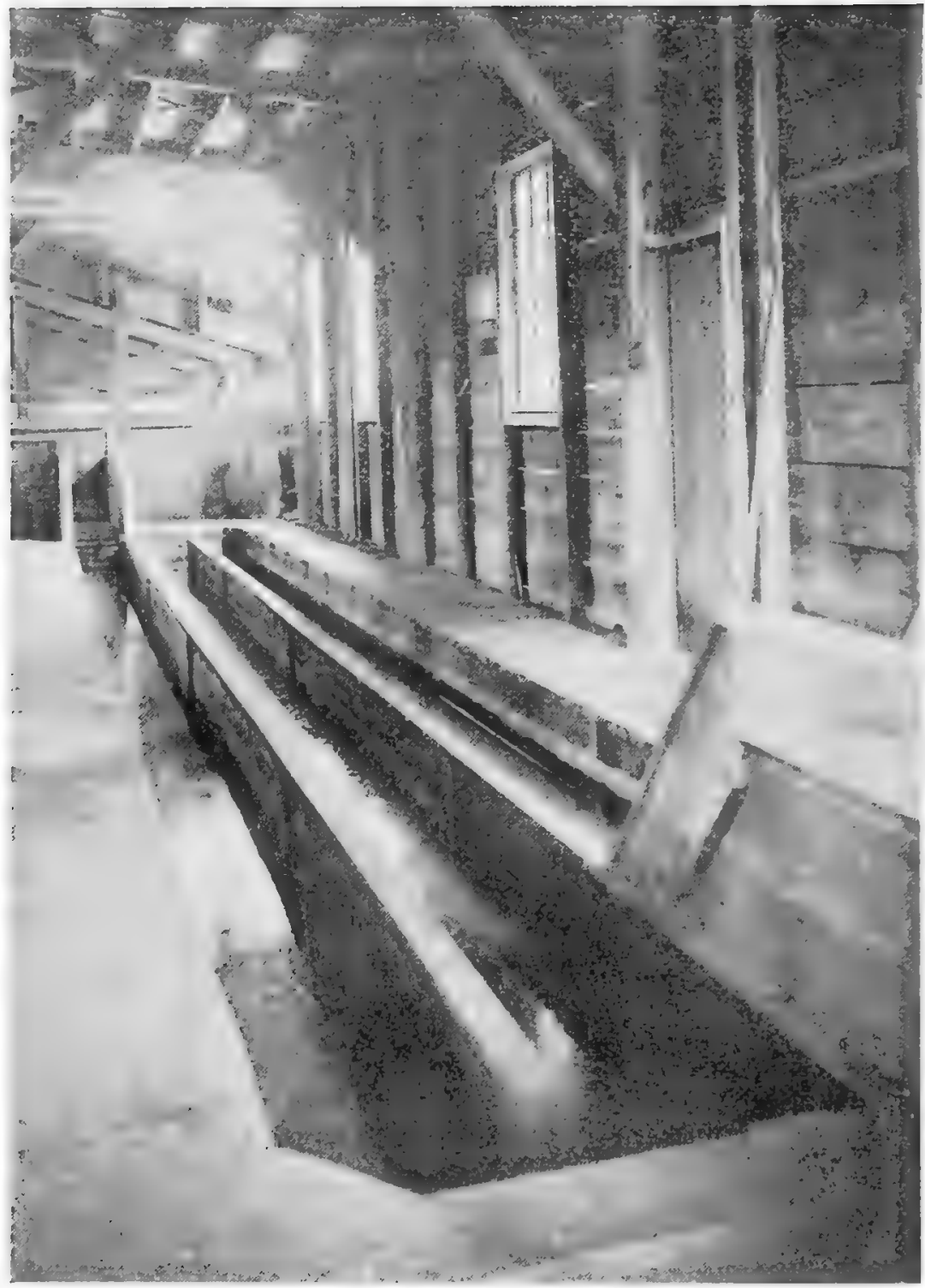

Mammoth Sheep-Dipping Vat at the New Yorh Central Stoch Zarde, Buffato, N. Y. Length of Swim in the elear 136 Peet. Capacity 100 sheep at a time. Feated by steam and with all the lateot improvements, making it by far the largest and best appointed Dipping plant in the United Brates. 
eight inches wide running the whole length from back of pen to vat. The floor is made of matched flooring laid on rough twoinch lumber. In center of pen, in a line with gutter, a division fence is run, which forms two pens ten feet by twenty feet, a swing gate being placed at end next vat, which when closing one

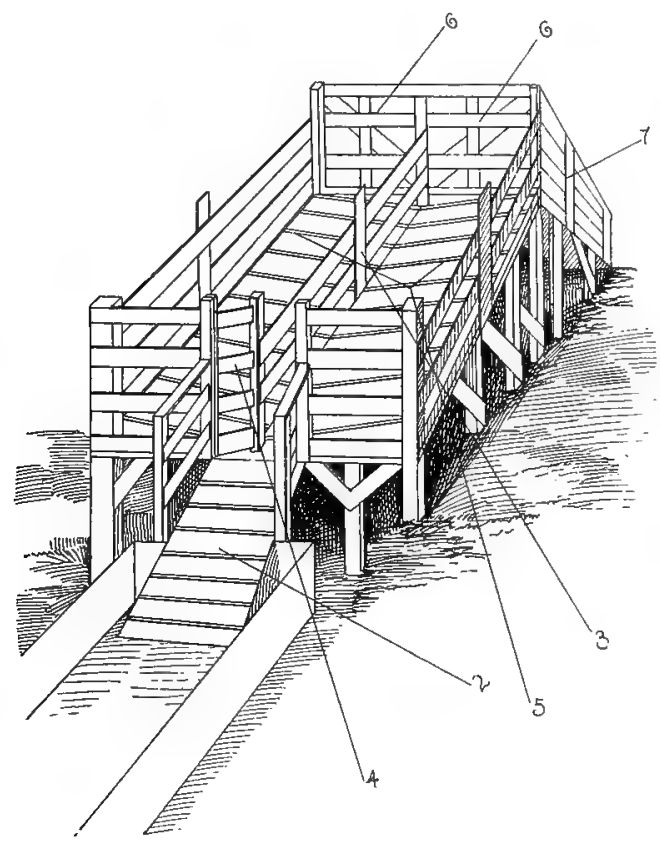

1. Draining pens, 2. Steps leading from vat to draining pen, 3. Showing division of draining pen. 4. Swing gate at entrance to pens. 5. Slats of bottom of pens, leading from sides of peus to gutter in center. 6. Gates at exit of draining pens. 7. Ranway back to ground.

pen leaves the other open, so that when one pen becomes filled with sheep the gate is brought over, leaving the other opening free. When this pen is filled, the sheep in first pen will have been drained sufficiently, and the gate at rear of pen can be opened to give them exit. By this means a continual stream of sheep is kept passing through the pens. 
The entire cost of a dipping plant of this size should not exceed $\$ 150$, and is a very necessary investment for the successful raising of sheep. In the Western States, where thousands of sheep are fed for the Eastern markets, erery feeder has a dipping plant close to or adjoining his feeding pens, so that on the first sign of scab the affected sheep can be immediately treated before the disease obtains much headway; and even where a few sheep only are kert, and those mostly for breeding purposes, a dipping vat is an indispensable necessity. The flock should be dipped at least once a year and better twice to rid them of vermin, which are the natural enemies of the sheep in its domesticated state. Ticks, lice, etc., of which we shall treat later, are common pests of sheep, and are best reached by thoroughly dipping the animals harboring them.

\section{Fand Dressing for Scab.}

This can only be satisfactorily carried out when the flock is composed of a few animals. It consists in catching the affected ones and pouring a strong solution of a prepared dip along the middle of the back, first parting the fleece into a furrow, and also in the arm pits and flanks, any affected part is also thoroughly saturated with the mixture. A mixture of lard and turpentine, or coal oil and lard is frequently used for an application to the affected patches. This, however, while effectual in killing the parasites, leaves a dirty black mark in the fleece, which remains for months, besides frequently so cauterizing the skin as to caise it to slough, and in no way are the effects superior or cheaper to an application of some standard preparation which by reason of its mixing properties with water is easily applied and does not leare any mark to show that it has been necessary to use such an agent. It should be borne in mind that the pens in which affected sheep have been kept are sources of contagion for future outbreaks. When dipping sheep in feeding lots, the pens 
should be thoroughly cleaned out, and the woodwork gone orer with a solution of lime, or the ooze from the rat may be used instead, so that the pens are thoroughly disinfected before returning the sheep to them. Should this not be done, the dipping of the sheep is only palliative at the best, for as soon as the effects of the dip leave the fleece the sheep will become re-infected from their own surroundings.

Lime and sulphur has not been recommended lere as a dip for general use, als, in order for it to be serriceable it has to be properly made, requiring much experience to be able to mix it so that the effects will not be deleterious to the fleece. The presence of lime in the mixture tends to harden the wool fibres, making them brittle and dry, appearing to rob the fleece of its natural yelk. While expcrimenters on a few head of shcep at agricultural colleges claim that its use does not set the sheep back or interfere greatly with their well being, it has been the experience of large feeders that hot lime and sulphur dips cause great damage, in some cases blinding the animals, and in all cases putting them off their feed for fourteen day: or longer, which does not seem to be the case where some of the standard preparations have been used.

\section{Sheep Cick." (Melophagus Ovinus.) Linn.}

A rery common parasite of the sheep found g'enerally throughout the whole extent of the Lnited States and C'anadi. This parasite, while not nearly so destructive as that cansing the scab, produces sufficient damage to merit a study of its habits and life-history. In appearance the sheep tick may be sail to represent a greatly enlarged scab mite, with the exception of its being minus suckers and feelers, and also only possesses six legs, whereas the adult scab mite has eight. In length they are about one-quarter of an inch, the body is short, broad, and tough. In color it is ferruginous, its abdonsen being a greyish brown, 
irregularly mottled. The head is small and resembles that of the common house fly in being disengaged from the thorax. The legs and body are covered with minute fine hair. Its legs are strong, each one being furnished with two strong, sharp claws. The abdomen of the tick when filled with blood from its host is immensely distended and transparent, the blood being plainly risible through its texture. The male and female differ from each other, the former being a little smaller than the

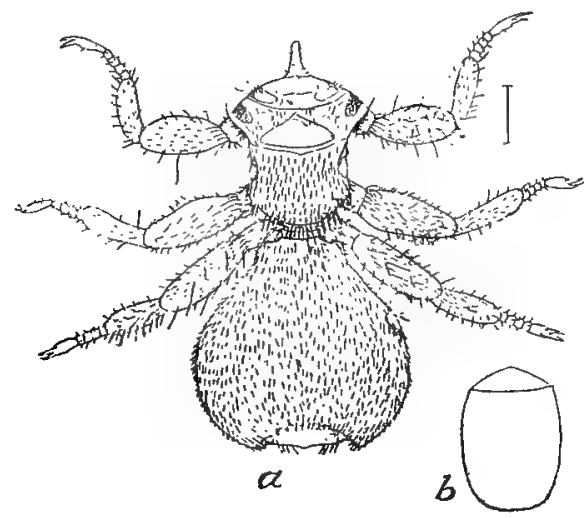

Hdult Sheep Cick, $a$; and puparium, $b$. (Melophagus.) Enlarged, after Osborn, 1896.

latter. The eggs laid by the female are flat, oroid in appearance and of a brownish color. They are nearly one-third the size of the abdomen of the parent. The eggs arc laid one at a time, and are corered with a sticky dark material, securely fastening them to the wool fibres. When mature the embryo emerges through an opening in one end of the shell made by the splitting outwards of a portion of it, resembling a lid to a box, the young insect being an exact counterpart of its progenitors, and not having to pass through any intermediate stage of development, so generally the case in the reproduction of parasitic life. The life of the parasite is wholly spent on the body of its host. A 
sheep infested with ticks, is a source of infection for the whole flock. A sheep freed from ticks can only again become infected with them by contact with other sheep harboring the parasite.

\section{Symptoms.}

The severity of the symptoms depends to a great extent on the number of parasites infesting the sheep. While a few will cause the animal but a trifling annoyance, in a short time they increase to such numbers that they cause an intense irritation and restlessness, interferring greatly with the well-being of the sheep. Lambs particularly (owing to their tender skin) suffer from these pests, being especially noticeable after shearing. Animals harboring a large number of ticks will scratch and pull the wool, the condition being easily differentiated from scab, however, as a casual examination will reveal the ticks.

\section{Treatment.}

The best method is to dip the whole flock, and the best time is directly after shearing. One thorough dipping in any preparation used for scabies will be sufficient to destroy all the live ticks, but as some of the nits are sure to be left in the fleece, it is good policy to repeat the dipping in two or three weeks time.

Sheep should not be turned into the old pastures until two or three weeks after dipping. This allows a sufficient time for the death of whatever ticks may have been dropped on the ground. In fact it is a good plan to disinfect and clean out the sheep-pens on the farm at least once 5 year. Many ticks will be destroyed if this is carried out. Before introducing fresh members to the flock they should always be dipped. This is a useful precaution, and if taken will often prevent the spread of this class of parasitic diseases. These parasites being easily destroyed, the flock-owner should experience but slight diffeulty in keeping his sheep free of the same. 


\section{Lice.}

These parasites are frequently found atracking sheep. In appearance the sheep-louse resembles closely the common doglouse. In length it is about one twenty-fifth of an inch, the female being slightly larger than the male; its general color is white, with the exception of the head, which is a reddish-brown.
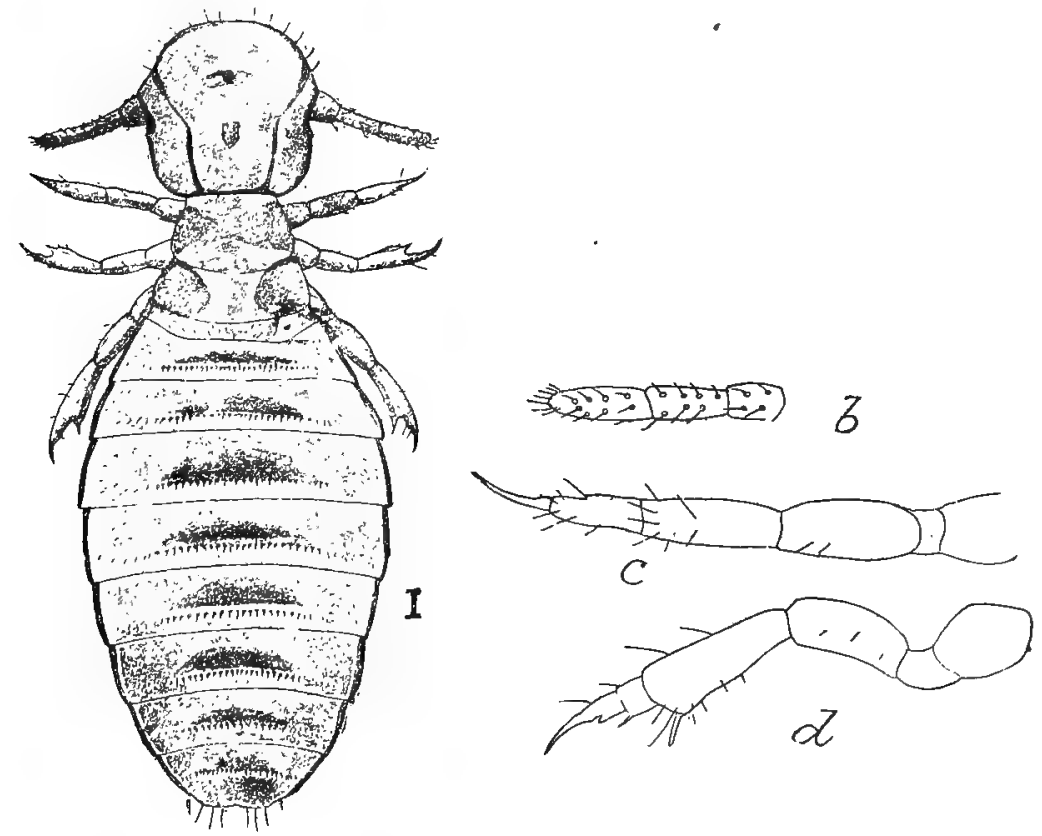

Sheep Irouse-female. (Crichocephalus Sphoerocephalus.)

$b$, attentua. $c, d$, dorsal and side view of leg, enlarged.

(After Osborn, 1896.)

Their life-history resembles that of the sheep-tick; the adults lay their eggs at the base of the wool fibres, to which they are adherent by a sticky glutinous material. The eggs hatch out in the wool, the young louse emerging by pushing up a lid-like contrivance of the shell. They are often found in large numbers 
associated with scab. Their favored locations appear to be the inner part of the thigh and sides of the neck.

Their presence on the sheep produces considerable discomfort, a thickening of the skin, which becomes rough and covered with dry blackened scales, the wool becoming dry, brittle, and lifeless, giving the sheep an appearance of being out of condition generally. Sheep harboring lice will rub against posts and nibble at their flanks, frequently scratching the elbows with the hind feet. When affected sheep lic in the sun, the parasites strike for the outside of the fleece, a careful examination revealing multitudes of small brown parasites.

\section{Creatment.}

A thorough dipping or a dressing with a preparation of sulphur will quickly rid the sheep of this form of parasite.

\section{Che fly. (I ucellia Mareellaria.)}

This insect is the chief cause of maggot in sheep in the United States. It, according to Neumann, "measures from onethird of an inch to half an inch in length, and is recognized by its blue thorax, streaked with the darker blue bands of a purple tint; the pads are black, and the wings brown at the base. The larva measure from one-half to five-eighths of an inch in length. This fly is met with over a great portion of America, from the North of the United States to the Argentine Republic." The fly deposits its eggs on the wool, the larvae living on the yolk, the most favored location being the base of the tail, especially should the animal be suffering from diarrhoea or dysentery, then all parts contaminated with the discharge are attacked by the fly. Any sores, such as those caused from fighting in rams or wounds and abrasions of any kind, are liable to attack during the fly season. As soon as the eggs hatch the larvae or maggots, as they are termed, begin to burrow into the tissues, causing 
great pain and distress. The sheep shakes its tail, will bite itself, is very restless; or the reverse may be the case; it may stand with its head down, leave the rest of the flock, and have a listless, dejected appearance; the wool at the parts attacked by maggots is raised and rough. An examination of the affected sheep will reveal numbers of whitish maggots attacking the sore spots. Should the animal not receive any treatment, diarrhoea sets in as a complication, due to the enfeebled state of the animal's system, followed by marasmus and death.

\section{Treatment.}

Take flowers of sulphur and benzoated lard, equal parts, and apply to the sore surfaces. Oil of tar applied to the diseased parts will quickly destroy the maggots and prevent fresh attacks from the fly. The fleece should be cut away exposing the whole surface of the sore before applying the tar. A few drops of fish oil sprinkled on the fleece will protect the sheep against the fly for a whole season, but owing to its very unpleasant smell and its injury to the fleece, due to its lasting properties, it is not advisable to use this agent. 


\section{CHAPTER XVI.}

\section{Specific Díseases.}

Are those which arise from a certain germ or poison, which being introduced into the system produces the same disease as that affecting the subject from which the germ or poison originated. For instance, tuberculosis (consumption) was proven by Koch to be due to the presence in the tissues of the body of a rod-shaped micro-organism, termed by him the bacillus tuberculosis. He also proved that tuberculosis did not exist without the presence of this special bacillus, and that the introduction of these baccilli into healthy subjects produced tuberculosis and no other disease. This also holds good for all specific discaises. Every specific disease has its specific germ, which if introduced into the animal economy through some channel (by the mouth, inoculation, respired air, etc.,) and finding suitable surroundings to develop in, quickly reproduces itself and poisons the blood either by direct destruction of the red blood corpuscles or by producing an alteration of the normal blood constituents, which soon causes the death of the affected subject; and vice versa, should the system be strong enough to overcome the freshly introduced germs, the surroundings not being suitable for their reproduction and development, they soon perish, in many cases without affecting any constitutional disturbance.

Germs, then, are the cause of all specific diseases, and the question arises, what are germs? They are vegetable microorganisms, rounded, ovoid, or spiral in shape, which possess the property of reproducing themselves in the animal economy. Their waste products termed the ptomaines being chiefly responsible for the damage and destruction they cause. They are 
divided into many classes and sub-classes, which it would be impossible to enumerate in this work, it being sufficient to say that the rod-shaped germs are called bacilli (rods), the oroid ones are called cocci, generally termed micro-cocci, on account of their being microscopical in size, and the corkscrew-shaped ones are termed spirilla. Rod-shaped germs (bacilli) possess the property of reproducing themselves by fission, which is a breaking in two of the rod, each rod forming then two germs, and also by the formation of spores. These are roundish, clear bodies, which appear in the centers of the bacilli, and which also possess the property of forming bacilli, should they find suitable media and conditions for growth. It can be readily understood that these minute organisms are capable of indefinite and rapid multiplication, which accounts for the short and virulent course of many diseases of this particular class.

\section{Anthrax fever. Braxy.}

This is one of the most widespread diseases, its presence being recorded in all parts of the world occupied by animal life, and at the same time it is a rery dangerous affection and highly contagious. With few exceptions all warm-blooded animals are subject to its attacks and the poison from dead carcasses, contaminating rivers and streams has been asserted to be a prolific cause for the mysterious deaths of numbers of fish.

We find that it is strictly a specific disease due to a specific germ, and that although in different countries and kinds of animals it is known under different names, still it is one and the same affection, due to one and the same cause. For instance, in the human family we find it occurring as wool-sorters' disease, or malignant pustule. In cattle it is termed anthrax fever, splenic apoplexy, also milzbrand in Germany and charbon in France. In the horse it has various names, depending on the locality in which it occurs. In East India it is known as loodiana disease, 
and in Africa as horse sickness. While in the sheep it is generally called braxy, but is also known as Cumberland disease (Australia), or great head (North England), or typhus, etc., etc.

But as occurring in all animals it is strictly correct to term it anthrax, as in all cases it is due to the presence in the system of a rod-shaped, spore-bearing bacillus, termed the Bacillus Anthracis. The history of anthrax is very interesting, dating back as it does to the remote past. A reference is supposed to be made to this disease in the Bible, Exodus, Chap. ix: "Boils which came forth as blains, upon man and upon beast throughout Egypt," one of the plagues of Egypt. Ancient Latin and Greek records describe its appearance about the time of the seige of Troy, and in 1617 at Naples, in Italy, 60,000 persons are supposed to have perished from eating the flesh of anthracoid animals.

In France its ravages have been severely felt. In the latter part of the century, it assumed a most virulent form, all kinds of domesticated animals succumbing to its attacks, and to the investigation of a Frenchman, the celebrated Pasteur, is due the recognized preventive treatment, namely, the insculation of healthy animals with an attenuated virus of the disease, which renders them forever after immune to its attacks.

In the sheep as well as in cattle a condition is met with which simulates anthrax. This is called black-leg, quarter-ill, etc., and while this is a very serious affection, its virulence is not to be compared with anthrax proper; in fact it is not due to the "bacillus anthracis," but to another form of micro-organism.

Diseases which are specific in character and similar to anthrax, are classed generally as anthracoid. They are not due to the anthrax bacillus and must not be confounded with that disease. 


\section{Cause of Anthrax.}

Certain influences seern to favor the development of the disease. It is found to be more prevalent in the early fall when the days are hot and the nights cold. Sudden changes in the weather are frequently attended by an outbreak of anthrax; humid weather, if associated with fogs, being especially liable to cause its development. Pastures bordering on rivers and streams, which are submerged at certain seasons of the year, frequently abound with anthrax infection, presumed to be carried there by the floods, which bring the germ from other localities where animals have succumbed to the disease. Hay from infected fields is liable to produce the disease, the spores having become attached to the blades of grass, only wait a suitable time and media for their development. Flies also spread the contagiurn by carrying the bacteria in their systems, and while resisting the influence of the virus themselves, they inoculate other animals with the germs, with disastrous effects. Dietetic errors seem to predispose the system to attacks from this disease, particularly is this noticeable in changing from poor to highly nutritious foodstuffs, especially if the same contain a high percentage of nitrogen. A plethoric condition is extremely favorable to the development of the anthrax bacillus, which would account for the fattest sheep in the flock generally being the first to suffer, especially those which have been thriving rapidly. It is also noticeable that the disease is very liable to break out after moving the flock from a poor to a rich pasture. Sheep on high feed preparatory to slaughter also frequently succumb to this complaint. Grazing animals on pastures or ranges, where deaths have previously occurred from anthrax, is also a prolific cause of the trouble.

\section{Symptoms.}

Anthrax fever is more particularly marked by its lack of diagnostic ante-mortem symptoms, deductions being drawn from 
the circumstances surrounding the affected sheep. Sudden and inexplicable deaths of several sheep of a flock, which have suddenly been attacked by convulsions, rapidly terminating in death, the animals, prior to the seizure having been in a healthy condition, should cause the sheep-owner to at once suspect anthrax as the cause. Then if a careful watch is kept on the flock, some premonitory symptoms may be observed. A sheep here and there will be noticed to be off its feed. On examining the same, the mucous membranes will be found congested; the animal appears stiff, especially about the head and neck; it mores with a sort of stiff gait, or it may be dull, and refuses to keep up with the flock, and if made to move will stagger and appear dizzy. Where the disease runs a comparatively slow course the patient will be feverish, appetite lost, appears dull, leaves the flock, the head hangs down, and the ears cold to touch and pendulous; the sheep is stupid and at times delirious, frequently tries to urinate, the material passed being scanty and brown-colored, the animal lies down almost all the time, is constipated, apoplectic symptoms supervene, speedily followed by death. Associated with the above symptoms will frequently be noticed a discharge of mucus streaked with blood from one or both nostrils, the faecal matter also containing quantities of a blood-colored fluid; the carcass may swell, more especially the head and legs; the swellings emit a crackling sound when pressed by the hand, due to the presence of gases under the skin (a sign of mortification of the tissues). On the inside of the mouth patches on the mucous membrane are often present. These exhibit a light riolet color. Twitching of the muscles and effusions of a bloody serum between the skin and carcass, more particularly in the region of the shoulders and neck, generally take place just prior to death. When anthrax attacks a flock of sheep it will be noticeable that a very few, possibly 1 per cent. of those contracting the disease, make a recovery. This fact 
alone should cause an observer to suspect anthrax in an outbreak of the above character. It will also be noticed that the fat sheep are the first ones to succumb and are also the first to be attacked by the disease. The sheep-owner must be a careful observer of conditions leading to sickness in his flock to be able to satisfactorily diagnose and differentiate disease, and in cases where his intelligence appears to him to be at fault before the majority of the animals are destroyed, a professional man of known ability should be called in who can readily tell by microscopical examination of the blood from the dead animals whether or not anthrax is the disease affecting the flock. As in almost all cases an outbreak of anthrax be checked by moving the whole flock to an entirely new locality and vaccinating the healthy members with Pasteur's Anthrax Vaccine.

\section{Creatment.}

In all cases of anthrax is only preventive, the disease running such a rapid course, the subject frequently dying before even showing signs of sickness, medisinal agents cannot be used with any hope of success. The matter of first importance is to find out whether the complaint causing destruction to the flock is anthrax or not. Should it be this disease, the sheep should immediately be moved to different pastures or ranges, and Pasteur's method of inoculation used on all the healthy members of the flock. This consists in the injection under the skin of the hind leg of an attenuated virus of the disease, which has to be specially prepared, and is obtained from the Pasteur laboratory in Paris, France, agencies for which exist all over the civilized world. Sheep when once treated with the anthrax virus are immune to the disease for the balance of their lives. This process is extensively carried on in European countries, and has been introduced in America with good results.

In Europe thousands of cattle as well as sheep are sub- 
jected to vaccination, with the result that the losses in those countries practicing this method have been steadily reduced year by year. The sheep-owner must exhibit great caution in the handling of animals which have died or are suffering from this disease, as malignant pustule in man results from the inoculation of anthrax blood into his system by the slightest wound or abrasion of the skin, a pin scratch having been known to produce the disease. Steele says: "A case is recorded of a shepherd, in bleeding a braxy sheep, getting a drop of blood in his eye, not washing it out, and dying from anthrax in three days."

Then again woolsorters' disease is caused by the inhalation of powdered anthrax material from the wool of diseased sheep. The flesh of animals which have succumbed to this disease is extremely dangerous, and has proven fatal to pigs and dogs. So in all cases the carcasses should be burned without skinning, or buried to a depth of at least six feet, the carcass being thickly covered with quick lime.

The after-death appearances of an anthrax carcass will reveal the following: Liquid bloody effusions directly under the skin, the blood in the arteries and veins is black and does not coagulate, red spots will be noticeable on the peritoneum covering the bowels, and on the kidney capsules, effusions of blood will be found in the stomachs and bowels, the spleen is greatly enlarged, and the trabeculae (partitions) on its inside are broken down, so that by holding it up by one end its contents will gravitate to the other. This condition is not present in any other disease, and is of itself diagnostic of the complaint. The liver is also enlarged, and the urine in the bladder appears to be mixed with blood.

\section{Black-Leg; Quarter-IIl.}

Scientifically termed emphysema infectuosum and haematosepsis. This is an anthracoid disease, due to a germ which, 
while being distinctly different to the anthrax bacillus, causes symptoms which simulate those of that disease. It is a very fatal affection, but does not spread so rapidly throughout a flock as anthrax fever. Like anthrax, it generally selects the fattest and best feeders in the flock for its victims. The disease runs a rapid course, and a very small percentage of the affected animals make a recovery. It is due to the introduction in the system of a vegetable micro-organism, which in size is slightly larger than the bacillus anthracis. It appears to localize itself in certain parts of the system, being present in the effusion of the affected quarter, but is absent in the spleen. Its methods of infection are very similar to those of anthrax. Low-lying pastures and grounds bordering on streams seem to be fertile localities for harboring the germs. The soil on which black-leg patients have died abounds with the bacilli, the grass on these spots generally growing very rank from the fertilizing effect of the carcass, and is eaten by the best feeders of the flock, which are not so particular about their diet as those which do not feed so heartily, the consequence being that they become inoculated with the germs of the disease, which develop with fatal effect. This in part accounts for the fact that the fattest animals generally are the first to be attacked, their plethoric condition also faroring the rapid multiplication of the germs. It is a common disease of both cattle and sheep, generaly seeming to prefer the young, immature members of the herd or flock, but older animals are not immune.

\section{Symptoms.}

The sheep is noticed to be dull, off its feed, found lying down. If the disease has not progressd so far as to prevent the animal from getting up, it will be slow in its movements and very lame, either in front or behind, depending as to whether the fore or hind quarters are attacked. If the animal is down and unable to rise, an examination will reveal swelling of a fore 
or hind quarter, generally the latter. The swelling is emphysematous (air in tissues under the skin), and on passing the hand over it emits a crackling sound; it feels bloated to the touch, which is due to the rapid mortification and death of the part, taking place even before the death of the animal. The skin is bluish in color. The symptoms resemble so closely those of anthrax that it is only of late years the difference has becu recognized, it being satisfactorily proven by comparing the bacilli of the two diseases and noting their different characteristics.

\section{Treatment.}

Like anthrax, the medicinal treatment of black-leg animals does not recommend itself to our notice, the germs having gained access to the system, produce such grave and rapid tissue changes that no amount of dosing could be expected to restore normal conditions. Such being the case preventive trcatment is relied on, and can be as satisfactorily administered as that used for anthrax fever. The Pasteur method of raccination is used to this end, and has proved itself remarkably successful. It has been in vogue many years on the continent of Europe, and has been extensively used in large cattle herds throughout the Western States. It offers the same advantages for use in sheep, and is a subject well worthy of the attention of the flock-owner. Carcasses of black-leg subjects should be burned or buried with quick lime. Infected pastures should be quarantined and thoroughly dressed with lime. When the members of a flock commence to die from black-leg, the rest should immediately be moved to fresh grazing grounds. Should this be done and the healthy members of the flock raccinated in the majority of cases the death-rate will cease as suddenly as it commeneed. 


\section{foot and Mouth Disease; also called Infectious Bphtha, or Eczema Epizootica.}

This is a specific eruptive fever, which not only affects sheep but cattle, pigs, dogs, poultry and occasionally the human family. There have been repeated outbreals of this disease in Europe, its history being almost as ancient as that of anthrax. England first experienced its attack in 1839, the first appearance on the American Continent being about ten years later. It is a highly contagious affection, evidenced by pustules in the mouth, mostly on the dental pad, and around the coronets just above the hoofs, and in the clefts of the digits, these pustules rapidly forming angry sores which extend their circumferences and tend to coalesce.

It is supposedly caused by a micro-coccus, although the germ of this particular malady has never been isolated, but that such a germ exists is beyond a matter of doubt, all the characteristics tending to prove that the disease is specific in origin. The infection is contained in the saliva and excretions. It can be carried from animal to animal by the attendant. The excretions from the sores, also containing the contagium, accounts for the wholesale infection of pastures and the wide distribution of this disease. Dogs may carry the virus on their feet from one district to another, as also beyond a doubt do rabbits and other animals. An instance is recorded by Williams where the virus was evidently distributed by a shepherd, whose clothes had become infected a year prior to the outbreak of the disease. This appears doubtful, however. The period of inoculation is short -from twenty-four hours to six days. The disease usually runs a benign course, the mortality being light. One attack does not confer immunity against subsequent ones.

\section{Symptoms.}

The course of this disease is divided into four stages. 
(1) In which fever, alternated with shivering fits, will be noticed; the pulse is rapid and the temperature high. The sheep appears dull; its nose is dry; the head feels hot; and in ewes suckling lambs, the milk secretion ceases. The urine is scanty, and sometimes slavering from the mouth is noticeable. This stage may last two or three days, then the second commences.

(2) Vesicular eruptions appear on different parts of the body; the feet become swollen, the sheep being very lame. (This is often mistaken for foot-rot.) The vesicles are noticeable around the coronets, between the digits (toes), on the rulva if a female, and also on the teats, and in some instances, rarely however in sheep, in the mouth on the dental pad. When the mouth is affected, the saliva flows from it freely, the appetite is good, the inability to eat being due to the sore mouth and not to constitutional disturbance.

(3) The vesicles break and discharge; ulceration commences, the ulcerous patches having a tendency to extend and coalesce. Extensive sloughing of the skin above the hoofs frequently takes place, the sheep kneeling to eat, and also moving on its knees. In severe cases the sloughing extends into the joints, causing open-joint-a very serious and dangerous condition. The duration of this stage is from a few days to perhaps two weeks, then being followed by the fourth.

(4) The ulcers dry up, desication tàking place; the soreness leaves the mouth, the animal eats well, exhibiting a good appetite, recovery being rapid and satisfactory.

\section{Creatment.}

Medicinal treatment is of little avail, the disease running a regular course. Foot baths are, however, especially beneficial to sheep, as they suffer more in this complaint from foot soreness than other animals. 
To administer this shallow troughs are made with fences at the side, and the sheep compelled to walk through them, the medicinal agents being mixed with water in the troughs. For this the following will be wseful:

Take. Sulphate of zinc.............2 lbs.

Acetate of lead............. $2 \frac{1}{2}$ lbs.

Carbolic acid crystals ........8 ounces

Water ................ 10 gallons

Mix thoroughly, pour into trough and compel the affected animals to walk throngh it once or twice daily, and care should be taken that lame sheep immerse each foot, as they are apt to hop through on three legs. This mixture must be stirred thoroughly before passing sheep through it.

\section{Cuberculosis-Consumption.}

This is a rare affection of sheep, and while tabies mesenterica has frequently been reported as present in postmortem, we must believe that it has been confounded with nodular disease of the intestines, due to the oesophagostoma Columbianum, a very prevalent condition, which is described in the chapter on internal parasites.

Walley, in his work, "The Four Bovine Scourges," writing concerning tubercle, says as follows:

"Species of animal: The bovine tribe is pre-eminently disposed, equally so indeed with man. Next in order comes the common rabbit, which animals in some districts are almost annihilated by the disease; the pig is very prone to tubercle, as are also poultry, our feathered household pets, and under certain circumstances, game birds. I have even seen it in the rook, though it is curious that the palmapedes are exempt from it. Tubercle is rarely seen in the sheep, cat or dog." 
Many conditions have been asserted to be due to tubercular infection, and are sadly lacking in procf.

Where the disease is suspected, a subcutaneous injection of tuberculin would readily facilitate a correct diagnosis.

\section{Sheep Dox. Variola Ovina.}

This is a very destructive and dangerous disease which froquently breaks out among sheep on the European Continent, but which has up to the present time been unknown in the hemispheres of the New World. The reason for this is due to its short period of incubation. Even should infected sheep be shipped across the Atlantic, the disease would break out while they were on shipboard, which would, orring to the excellent methods of inspection and quarantine of imported animals, debar them from becoming a source of danger to the flocks of this country. Should, however, the time'ever arise when cattle-boats would make the trip at the same rate of speed made by the present liners the dangers of introduction of this disease would be increased considerably and would call for extraordinary efforts on the part of the authorities to overcome the same.

\section{Causes.}

Beyond a doubt this is a specific disease, although the special contagium or germ responsible for its appearance has not yet been satisfactorily demonstrated. It is a highly contagious affection, and all conditions, such as orercrowding, cold, damp spells of weather, or any such causes which facilitate the spread of other contagious affections, hold good for this disease also. The stage of incubation when arising from natural infection and not experimental inoculation is computed by Prof. Simonds to be from nine to tweIre days. The disease may be carried from one locality to another on the clothes of persons who have been in contact with diseased sheep. The contagium contained in the 
discharge of the sores on becoming dried and powdered up is carried by the wind and distributed over large areas, the virus of this disease appearing many times more volatile than that of the majority of the contagious affections to which the sheep are liable.

\section{Symptoms.}

The first apparent symptom is the presence of nodules which seem to be deeply imbedded in the skin. These are reddish in color and are more particularly noticeable on those parts not thickly corered with fleece, as the inside of the thighs and armpits, the prepuce of the ram, lips of the ragina in the ewe, and the under surface of the tail. The papillae enlarge and coalesce, and the animal is feverish from the first commencement of the attack. The red elerations enlarge in size, rising considerably higher than the surrounding skin; liquid forms under them; their centers become transparent and finally turbid; the liquid in the vesicles dries up, forming scabs which are desquamated, the under-lying part healing and gradually assuming its normal condition.

In the malignant form it frequently does not produce typical vesicles, but destroys the sheep from blood-poisoning. In this case the skin cracks in fissures, the nostrils become filled with foetid pus, and the animal soon succumbs to the disease.

\section{Treatment.}

Consists in separating the healthy sheep from the sick and establishing a rigid quarantine. Keep sick animals in as cleanly condition as possible; the nostrils should be frequently syringed out to prevent the accumulation of pus, which would be liable to cause suffocation. Give the sheep good shelter and keep them warm, and should ther desire to eat, feed nourishing, easilydigestible foods. Medicines do not effect much benefit, the 
disease running a regular course, and should only be used to combat special conditions, such as diarrhoea or excessive rises in temperature.

\section{Rabies, Madness, Бydrophobia.}

The earliest writers described this most fatal affection. Regarding it MIr. George Fleming, in his work dealing on the subject, states as follows:

"Its great antiquity is undoubted. Plutarch asserts that according to Athenodorus, it was first observed in mankind in the days of the Asclepiadae, the descendants of the god of medicine, Aesculapius, by his sons Podalirius and Mechaon who spread through Greece and Asia Minor, as an order of priests, prophets and physicians, preserving the results of the medicine experience acquired in the temples as a hereditary sect. They were the earliest physicians known to us, and it is not unlikely that they may have been the first to observe the madness of dogs transmitted to man." The contagion seems to chiefly reside in the saliva, the infection being transmitted from animal to animal and also to man by a bite from an affected subject. It is undoubtedly a specific disease due to a specific germ, althongh up to the present time, notwithstanding careful investigation, the germ has not yet been isolated. It is important, so far as sheep are concerned, on account of their association with dogs, these animals seeming to be more susceptible to this particular trouble than any other species.

Rabies is only transmissible by direct inoculation with the saliva from an affected patient. The deposition of the rirulent saliva on an abraded surface will as readily produce the disease as a bite from an affected animal. This should be borne in mind when handling sheep which may have been bitten by a supposedly rabid animal. 
The period of incubation varies considerably in the different species of animal, the shortest recorded in the dog being seven days, the longest 155 days, while in sheep the disease is liable to develop any time between fourteen days to eight months.

\section{Symptoms.}

The sheep will appear restless, evidencus a desire for sexual intercourse, is off its feed and rapidly runs down in flesh, soon becoming dull, a state of stupor developing. This is followed by a state of great excitement. The sheep shows a desire to attack whatever comes in its way, butting with its head to such an extent and with such violence as to produce severe injury, being oblivious, however, to any pain. A frothy saliva dribbles from the mouth, the appetite is depraved, and rumination is suspended from the commencement of the disease.

The sheep now manifests a desire to nibble and bite both animate and inanimate objects; does not appear to dread water, but is unable to swallow liquids. Muscular tremblings will be observed, accompanied by rapid and shallow breathing; the seat of inoculation appears to cause pain, evidenced by the sheep biting and pulling the wool from the part. The violent symptoms are quickly followed by paralysis of the hind extremities; coma sets in, death usually taking place between the sixth and eighth day after the first apparent symptoms of disease were noticeable.

\section{Creatment.}

After the disease has once manifested itself medicinal treatment will be deroid of beneficial results. Where several sheep in a flock have been known to be bitten by a dog, supposed to be rabid, they should be separated from the flock and kept apart from all the other animals for at least three months. If rabies does not develop in that time it would be safe to infer that they had not been inoculated. 
As a preventive, bitten animals should have the wourds cauterized, actual cautery being preferable to the application of nitrate of silver or caustic potash. Where a rabid dog has run amuck in a flock of sheep the only safe procedure is to shear the whole flock, carefully examining each animal and cauterizing all the wounds which may have been inflicted.

\section{Post-Mortem Appearance.}

The fourth stomach contains a dark brown colored slime; portions of the brain and spinal cord are congested; there appears to be a breaking down or softening of the brain substance and meninges, particularly at the base of the brain. The bladder is usually empty, its mucous lining being covered with petechiae (spots). The lungs are congested, the capillary blood ressels being distended with a tarry, imperfectly coagulated blood. The spleen, liver, and kidneys coated with red spots, due to the capillary extravasation.

\section{Symptoms of Rabies in the Dog.}

As the dog is generally the agent in disseminating the rirus of the disease, itwill be appropriate here to describe the symptoms as they appear in that animal; which will act as a guide for the flock-owner in determining as to whether his flock has been exposed to the infection of rabies, or subjected to the bites of a naturally vicious animal.

The first noticeable symptoms of rabies in the $\mathrm{dog}$ is a scared appearance; the animal is inclined to hide and will howl frequently; it appears to be very thirsty and endeavors to lap water, but is unable to swallow it, probably due to muscular paralysis of the throat; it will exhibit a depraved appetite, devouring excreta, sticks, earth and small stones; delirium sets in; a desire to gnaw is noticeable; the dog will bite frequently, often sitting up and snapping at the air. A ropy saliva flows from the mouth; the animal attacks everything in its path. Where a 
dog attacks a flock of sheep, inflicting bites on a number without trying to kill outright any of them, it at once becomes an object of suspicion, such an animal should not be destroyed, (that is to say, if it can be caught and confined without anyone being exposed to its attack), as, if rabid, the disease will run its course in a short time, four to eight days, after which there is still time to apply preventative treatment to the sheep, rabies not being liable to make its appearance among them for twenty days after inoculation. Where a dog has been found annoying sheep and is killed, a post mortem examination of its stomach will materially facilitate a diagnosis. If rabid, the stomach will contain rubbish, such as sticks, stones, etc. This can be relied on as diagnostic.

Dogs which foam at the mouth and have fits are not rabid, and no danger is to be apprehended from them, even though they should inflict bites during the period of the fit.

\section{Tetanus-Lock Jaw.}

Is a condition caused by the direct inoculation with a germ called the bacillus tetani. It is decidedly a specific disease, and in no manner can it be said ever to arise spontaneously. Wounds and abrasions of the skin are very liable to be the channel through which the contagion gains access to the system. The germ of tetanus is of the character called anaerobic, meaning that it develops only in media free from oxygen; hence we find that slight wounds, especially punctures wich tend to heal and close up immdiately after infliction, so excluding the oxygen of the air, are the most prone to be followed by tetanus. The germ appears to be present very generally in the soil, and only awaits the opportunity to gain entrance into the animal economy to develop and multiply with the most disastrous results to its host. Where cases are noticed arising without any apparent cause, it would be possible for the subject to have become inoculated 
through an abrasion in the mucous membrane of the alimentary canal, the germ having been taken into the system with the food. That form of nervous affection, arising after exposure to cold storms or the hot sun, in which many sheep become affected simultaneously, cannot be said to be tetanus proper, but rather a condition of innervation, accompanied with tetanic spasms, as a result of the perverted nervous functions. This condition is not nearly so fatal as tetanus proper, and will frequently yield to treatment.

Rams, when castrated, are liable to develop tetanus; sheep, after shearing, have also been known to suffer from this disease. It is also met with as a sequel to parturition, in which event metritis, (inflammation of the womb), is always present.

\section{Symptoms.}

First signs of this disorder are a stiffness of the head and neck, involuntary twitchings of the superficial muscles of the face; the animal grinds its teeth; the jaws in a short time become rigid; the whole carcass becomes affected, the muscles of the neck especially become hard and knotty; the neck is curved, drawing the nose out straight, pointing, if anything, slightly upwards; the limbs become stiff. The condition of rigidity is subject to periods of excitability, during which the patient is thrown into convulsions, the rigidity being more marked and severe following each period of convulsion. The disease in sheep tends to run a rapid course, generally terminating fatally in from ten to twenty-four hours after the seizure.

\section{Treatment.}

If due to wound infection or following castration, wash out the wound with a strong antiseptic wash-five per cent. watery solution of carbolic acid, or a one to 1000 solution of corrosive sublimate. In all these cases give the wound plenty of air enlarging the cut if necessary. 
The sick animal should be kept in warm quarters, and if the disease has been detected in the early stages, a full dose of Epsom salts is to be recommended, followed by such drugs as have a sedative action on the nervous system, such as potassium bromide, chloral hydrate, etc.

As seen in ewes following parturition it is almost always fatal-in fact this disease is a most intractable and unsatisfactory one to treat-a small percentage of cases making a perfect recorery. Where sheep have suffered from tetanus and have been destroyed, they should not be used for human consumption. Injections of tetanus anti-toxin are reported as being very successful in treating this disease in the human subject, and in case of a valuable animal becoming stricken, its use on sheep would be justifiable.

\section{Erysipelas.}

This is a contagious and malignant affection of the skin, due to the introduction of a germ known as the streptococcus erysipelatis, which on gaining access to wounds and abrasions of the cuticle is responsible for a deep-seated inflammation, which not only attacks the epidermis, but is prone to penetrate and involve the sub-cutaneous structures.

Sheep frequently suffer from this disease, it being often observel after shearing, where the cuticle has been injured, or following any and all classes of wounds. Malignant metritis of ewes, following lambing, is frequently due to inoculation with erysipelas streptococci. The period of incubation is from fifteen to sixty hours.

\section{Symptoms.}

First recognize a tense, hard swelling of the skin, which is very painful to the touch; the sheep exhibits symptoms of fever. In parting the fleece, and carefully examining the skin, numerous small blisters will be found, which contain a reddish, watery 
serosity The affected part may at first be small in diameter, but exhibits a tendency to enlarge by constantly increasing its circumference. The line of demarkation between the healthy and affected part is well defined, the affected portion being of such a deep red, inflamed appearance, and spreading so quickly as to have merited the popular name of "wild-fire," especially appropriate when occurring in the epizootic form, when it attacks numbers of sheep in a flock or district almost simultaneously, these cases appearing to arise spontaneously in the form of a violent skin inflammation.

\section{Treatment.}

The affected animal, if in good condition, should receive a full dose of Epsom salts; mineral tonics, especially iron, are indicated in this disease. These are the best administered in the feed.

Take. Sulphate of iron............2 ounces Gentian ...............4 ounces

Quinine sulphate..........4 drachms Licorice root powd..........6 ounces Linseed meal.............4 ounces

Mix thoroughly. Administer one tablespoonful in dry chopped feed twice daily, or where the patient refuses to eat its feed give it as a drench, mixed with half pint of water.

To the inflamed surface apply an antiseptic wash, such as the White lotion, the formula for which will be found in the chapter on "Medicinal Agents," or camphorated oil, or any other soothing antiseptic application will be all that is required.

\section{Hctinomycosis.}

Is a condition caused by the presence in the tissues of the animal economy (most generally those of the mouth or lungs) of a vegetable fungus termed the actinomyces or ray fungus.

Every stock-owner is familiar with this disease, as it occurs 
in cattle under the name of "lump-jaw," but in sheep its presence is very rare, and when occurring in them is generally found located in the soft tissues of the mouth; the writer remembers one case, however, where the lungs were affected.

The presence of the fungus in the tissues of the body acts as an irritant, causing excessive cell proliferation in the immediate surroundings, resulting in a tumor formation, the swelling being composed of fibrous tissue, which exhibits a tendency to granulate, and finally break down, forming a large firm mass with one or more centers of suppuration. The liquid pus from the tumor contains small, yellowish, cheesey granules, which, if properly treated under the microscope, will prove to be colonies of actinomyces.

While actinomycosis generally locates itself in the tissues of the upper or lower jaw, still the tumors may be found in any part of the animal economy. The fungus being a common parasite of certain grasses and grains, on being taken into the animal's mouth along with the fodder, causes actinomycosis principally by direct inoculation; should the sheep have a hollow tooth or abrasion of the mucous membrane of the mouth, its localization in that part of the system can readily be understood, and this accounts for those parts being more frequently the seat of the tumor than the internal organs. The internal organs, such as the liver, spleen, etc., must evidently, when affected, become so through the media of the blood supply, and the fact that these organs at times are the seat of this disease would go to prove the danger attendant to actinomycotic infection.

Actinomycosis occurs in the human family, cattle, sheep, swine, etc. This being the case, the flesh of animals suffering from the disease should be viewed with suspicion. When once the disease has obtained a firm foothold, medicinal treatment is (if no avail, and the subject had better be destroyed. 


\section{Blood Diseases.}

\section{Red rater. Sanguíneous Hocites.}

This disease is frequently seen occurring in lambs, in those still sucking, as well as those already weaned. It also occurs in adult sheep. It is a very fatal affection, running a rapid course, death frequently taking place in six hours or less, after the first symptoms have been manifested.

The cause of this condition appears to be in the nature of the food,- - turnips and other foods containing an excess of water, and a lack of flesh and fat-forming materials, are especially responsible for this disease. Spooner states: "It usually attacks both sheep and lambs when feeding on turnips, and particularly when there is a hoar-frost, and the sheep are folded on them during the night." It is a condition which all herbivora appear to be liable to, even the deer and other of the wild ruminants when kept in captivity, are liable to contract the disease. The writer was so fortunate as to be present at a post mortem on a young moose at the Park Zoo, Buffalo, N. Y., which evidenced every symptom of this interesting and obscure complaint. This animal had been running in a paddock containing suceulent grasses, notably clover, which in the mornings would be heavily coated with dew; that, and the fact, perhaps, that the food supplied lacked some essential characteristic contained in the material eaten by the moose when roving wild, was evidently, partly, if not wholly, responsible for its death.

\section{Symptoms.}

The first noticeable symptoms will be a refusal to feed on the part of the sheep; rumination is suspended; the animal appears dull; the eyes have a staring look; the breathing is labored; belly enlarged; the bowels may be very loose, with foetid discharges, or the subject may be constipated. Swellings will fre- 
quently be noticeable under the jaws and lower part of the neck. In some cases the animal falls dead suddenly, without having evidenced any marked symptoms of sickness, or they may be suddenly seized with giddiness, fall down on one side, become delirious, and succumb very quickly.

Lambs, when attacked, appear to lag behind the flock; are dull and listless; succumbing suddenly. without previously shuwing signs of acute pain.

\section{Treatment.}

Consists in a change of diet; internally iron and mineral tonics are indicated. If the stock have been grazed on rape or turnips, they should be given plenty of dry food to compensate for the watery qualities of the other.

Where the symptoms have once manifested themselves, the sheep is almost sure to perish, medical treatment being of no avail. The other members of the flock, however, should at once be moved to drycr pastures, and receive the tonic treatment already mentioned before greater losses ensue.

\section{Post-Mortem Appearances.}

The abdomen will be found to contain a red, watery fluid; the tissues of the body are anaemic, and present a glistening appearance, being pale in color; the blood vessels, and cavities of the heart, are comparatively empty; the kidneys are pale, the tubules containing a viscid fluid; the liver is cnlarged and soft('ned, appearing as if it had been boiled; the peritoneum shows evidences of inflammation, frequently being covered with petechiae (spots).

All conditions on post-mortem point toward anaemia with great debility, and extravasation of blood from the capillaries, the blood itself being altered in character. 


\section{Anaemia-Bloodlessness.}

This is a term used to designate a condition of the system, where a poverty, or deficiency of the normal constituents of the blood exists, arising from various causes, mismanagement being directly responsible.

It is a condition frequently seen accompanying debilitating diseases, or where the system has been subjected to hardships which have overtaxed its strength. Ewes suckling lambs, when not supplied with sufficient nourishing diet, frequently become anaemic. The ravages of both internal and external parasites tend to produce this condition, owing to their ability to extract nourishment from the blood supply at the expense of the subject harboring them. Loss of blood, diarrhoea, insufficient food, exposure to sudden changes of temperature, foods containing an excess of water in proportion to the flesh-forming materials, wet grasses, and all such causes are prolific of this trouble in sheep as well as other animals.

Williams states that "During the winter of $1872-3$ this condition was exceedingly prevalent, owing to the inferiority of the grasses, the moist condition of the turnips, and the humidity of the atmosphere, for in many instances no organic disease or parasitic invasion were present."

\section{Symptome.}

When not caused by some parasitic invasion, or, as resulting from some other diseased condition, can be summed up as follows:

The visible mucous membranes are very pale in color, almost white; the pulse is feeble; the subject is easily tirea; the bowels are very irregular, frequently being constipated, owing to lack of tone in their muscular coats; dropsical swellings frequently appear round the joints, or dependant parts, especially beneath and between the rami of the lower jaw, giving the sheep 
a puffy appearance of the head, termed by some "chockered" or "poked." The tongue is cool, moist, and very pale in color. Steele, writing on this condition, gives the following as having appeared in a report on diseases among the sheep of Oregon: "The lambs were weaned in 1872, on the 20th of July, on timothy aftermath; four weeks afterwards they looked miserable and died fast. Last year the lambs died rapidly shortly after weaning. This season they gave way while sucking. The symptoms both in young and old were 'tucked-up' appearance; cough, wool rough and dry, with fleeces partially cast, and wool on faces carried longer than usual; the lambs do not gambol. Some of the animals droop their heads; rum at the nose; hare gatherings under the chin, which occasionally dispel and at other times break out into running sores; a marked bloodless appearance of the mucous membranes and skin. The above animals were long-wooled sheep which for six months in the year were continually wet; the Merinos, being comparatively healthy, their thick, close, greasy wool seeming to prevent the moisture from penetrating to the skin."

Ewes in lamb are very subject to a fatal form of anaemia; the wool is dry and hard; they become feeble, and fall away in flesh, becoming very weak just prior to parturition.

\section{Creatment.}

In all cases of anaemia it is necessary to seek for the cause and, if possible, remove it. When due to parasitic invasion, this must first be attended to before a change for the better can be expected. If due to faulty management, not sufficient nourishing diet, or a superabundance of moisture, these conditions must first be changed and then the proper medicinal agents applied in order to effect a cure. In all cases of anaemia iron and vegetable tonics are indicated, such as the following: 
Take. Sulphate of iron...........2 ounces

Common salt.............4 ounces

Gentian powd............4 ounces

Licorice root powd...........8 ounces

Mix thoroughly, and administer one tablespoonful twice daily in ground dry feed.

Where ewes heavy in lamb show signs of anaemia, great care must be observed in their treatment. 'They should immediately be moved to high, dry ground, and supplied with a different diet to that which they had been having. Ground grain fed dry, with the addition of warm quarters for the very weak ones to sleep in will be found necessary to effect improvement. Particular attention should be given to the pastures, to be certain that no causes exist there which are responsible for the trouble.

\section{Rheumatism}

appears to be particularly a blood disease dependent upon some unascertained alteration of the blood. It may exist in one of three forms-acute, sub-acute, and chronic. The mature sheep are easily affected with this condition; it seems, however, to frequently attack lambs, generally in the acute form. The predisposition for this disease has always been looked upon as hereditary, and in every case where mal-nutrition of the body is present rheumatism is frequently observed. As it occurs in mature animals it is supposed to follow some debilitating disease. The exciting cause in sheep and lambs, in most cases, seems to be exposure to cold and damp.

\section{Symptoms.}

First notice lameness. The animal is feverish; the affected joint or part feels hot to the touch and frequently commences to swell; the pulse is hard and rapid; the swelling feels firm and tense; if the joints become involved, inflammation of the periosteum and synovial membranes frequently follows, accompanied 
by the deposition of porcelaineous deposits between the heads of the bones constituting the joint, in which event the lameness becomes permanent.

In sheep the neck and loins are frequently attacked, making the animal stiff and weak in its back; if the trouble locates in the neck, it will be carried bent to one side, or the disease may suddenly leave the reck or other parts and locate in a limb, the ability to leave one part of the body only to at once re-appear in another being termed metastasis.

Affected sheep generally assume the recumbent position. The acute form of rheumatism may terminate fatally. In such an event, a metastasis to the heart is generally the cause. This is not frequent, however, as the disease has a tendency to become chronic, the animal remaining stiff, with a liability to relapse to the acute condition during cold weather.

\section{Treatment.}

Acute cases of rheurnatism require good hygienic surroundings if a cure is to be expected. The affected sheep should have warm, dry quarters and nourishing food. Internally salicylate of soda in fifteen grain doses should be administered twice daily, or potassium iodide can also be given with good results. Externally to the inflamed parts a stimulating liniment should be applied, such as

Strong water of ammonia......2 ounces
Spirits of turpentine........2 ounces
Linseed oil............. ounces

Chronic rheumatism incapacitates a sheep for further usefulness in the flock. Animals so affected should be destroyed, or, if in good condition, should be sold to the butcher. 


\section{Dining-Vinquish.}

Is a disease due to grazing sheep on pastures containing a large amount of astringent plants, which by their action on the system, cause a fatal constipation of the bowels. This condition is not reported as having caused any serious losses in this country, but it has occurred frequently, accompanied with great fatality, in the North of England, being said to be mostly met with in the region of the Cheviot Hills.

\section{Symptoms.}

The affected sheep are dull, languid, lying down most of the time, the ears droop, eyes run, the hair on the face becomes dry, the wool having a bluish cast. Death usually takes place in a month's time after the first symptoms of ailing were noticeable. A whole flock may be affected simultaneously, or only a few sheep at a time. Change of pasture to good succulent herbage generally affects a cure. 


\section{CHAPTER XVII.}

\section{Operative Surgery and Diseases of the Eye.}

\section{Operative Surgery.}

In the management of sheep, surgery as a part of the medical treatment is, with the exception of such operations as castration, docking and possibly at times spaying, very seldom called for. Sheep, with the exception possibly of valuable purebred animals, should they meet with such accidents as fractured limbs or other severe injuries are, as a rule, at once turned over to the butcher, the carcass being valuable as mutton, whereas surgical skill in such cases besides being costly might not at all times prove successful, and if unsuccessful, would result in a total loss to the owner. We shall treat more particularly in this chapter of the surgical operations necessary to the proper management of the flock, describing also methods of setting fractures and treatment of wounds, etc.

\section{Castration.}

Is an operation for the removal of the testicles of lambs, by which they become deprived of sexual desire, and their ability to fatten becomes materially increased, the subject maturing earlier, the quality of the mutton being improved, as also is that of the fleece. Opinions differ considerably as to the best age at which this operation should be performed, many experienced flock-masters preferring to operate as soon as possible after the lamb is dropped, from twelve to twenty days of age, provided the weather is favorable, and claim that when thus early operated upon there is less danger of loss, the young animals 
hardly appearing to notice the absence of their male appendages, while others prefer to let the lambs run until three or four months of age, or even longer, claiming that the carcass is increased in size, and the animals grow stronger and thrive better by the delay. However it is a mere matter of choice on the part of the owner as to what age to operate. All that is necessary is to perform the operation properly and in seasonable weather.

\section{Co Operate.}

Set the lamb on its rump, and make a careful digital examination of the scrotal sac to be sure that hernia is not present. If the parts are in the normal condition, with the fingers and thumb of the left hand draw up the lower end of the scrotum (bag) and make a clean cut right across the end, severing it entirely. This is far preferable to slitting the sac, as such a wound is liable to heal prematurely and be the cause of serious trouble; whereas if the end of the sac is entirely removed the aperture will be forced to close gradually, thereby insuring good drainage, which is very essential for the ultimate success of this operation. After removing the end of the sac, grasp the upper end of the scrotum, forcing the testicles covered by their investing tunics to project from the opening, with the scalpel or knife now cut a longitudinal incision across each testicle, severing the tunies but not necessarily cutting the testicles; then take the testicles one at a time and draw downwards gradually, twisting the cord and scraping it with the knife, until it finally becomes severed. If this is properly performed and the cord slowly drawn out until it resembles a fine string, there will be little if any bleeding; whereas if the cord is directly cut across there is danger of excessive bleeding from the severed spermatic artery. The after-treatment, should the operation have been performed in fly-season, consists in dressing the parts with a carbolic salve to prevent the wound becoming maggoty. If 
the operator will be careful in performing this operation in a cleanly manner, taking care that not only his hands and knife are clean, but that the dirt from the soil does not gain entrance into the wound, unfavorable results are not to be feared. In cases where tetanus follows castration, it is always due to a want of the above mentioned precautionary measures, the wound being infected by the germs of that disease. (See tetanus.)

Many operators, especially in Europe, use elaborate methods in performing this very simple operation, all of which, however, with the exception of clams for scrotal hernia, of which we shall treat later, are quite uncalled for and liable to produce the very results which they are supposed to guard against. For instance, the method of searing the cord with a red hot iron, while the operation is necessarily antiseptically performed, the wound sloughs from the cauterization, requiring a longer time to heal without acquiring any material benefit to the subject.

\section{Crapping.}

Which consists in tightly binding the scrotum between two pieces of wood, until it sloughs off, is a slow, tedious process and decidedly antiquated and cruel.

\section{Cying and Lashing.}

Is rirtually the same as trapping with the exception that a cord takes the place of the wooden clams. It has nothing but its antiquity to recommend it. The French method, termed Bistournage, is exceedingly severe and cruel to the subject. It consists in so manipulating and dislocating the testicles that their blood supply is shut off, the organs gradually withering away; a ligature is necessary, tightly tied around the scrotum below the testicles, which are forced upward into the inguinal canal. This process is mentioned here simply as an illustration of a simple operation made complex and painful by ignorance, or an inborn desire to produce unnecessary suffering on dumb brutes. 


\section{The Covered Operation for Scrotal Lernia.}

Where the small intestines descend the inguinal canal and occupy the scrotal sac in company with the testicles, the condition is termed scrotal hernia. It is necessary when performing castration on subjects with this condition to use a special method to prevent prolapse of the intestines, which would inevitably take place if the scrotum was opened in the manner used where the parts present normally. Where scrotal hernia exists the subject must be laid on its back and the intestines returned to the abdominal cavity. An incision is then carefully made in the sac exposing the testicle covered by the tunica vaginalis (investing membrane), wooden clams are then applied to the cord. These are two short, flat-sided pieces of wood which are placed one on each side of the cord above the testicle and firmly tied together by pieces of string at each end of the clams. These are then left on until the compression by arresting the circulation of the parts causes them to slough and finally drop off, the parts above the clams becoming adherent, preventing egress of the intestines. In fact the inflammation which this process as a rule sets up is generally so extensive as to obliterate the inguinal canal, effectually preventing a future descent of the intestines.

\section{Docking.}

This very simple operation is generally performed on lambs at an early age as a rule, and properly so at the time of castration. A sheep's tail is, to say the best of it, a useless appendage. It cannot be used to brush off flies or anything else, and while most likely it had its use in prehistoric sheep, domestication by relieving it of whatever use it may have been put to, failed to prevent its appearance, atavism being stronger than years of domestication. Should the tail be left intact it collects mud and dung, giving the animal an uncleanly appearance. The 
accumulation of filth is also liable to cause fissures in the skin, which become attacked by the fly. The tail may be severed by the knife without any after treatment, or should it be preferable, after'cutting, the parts are seared with a red hot iron, which instantly checks the hemorrhage.

Ewes for self-evident reasons should always be docked even if the wether lambs are allowed to go without.

\section{Spaying.}

This is the removal of the ovaries of the female, a counterpart of the operation of castration of the male, and while it is rarely performed on ewes, owing to the fact that their breeding qualities are more to be valued than the slight improvement in the mutton and facility to fatten which this operation is supposed to confer, still as it is a common operation on other classes of she stock, notably swine and cattle, and as beyond a doubt a spayed female will take on flesh quicker and do better as a feeder than one which is entire, which would be an advantage in fitting ewes for exhibition in the fat stock class, we shall briefly describe here the modus operandi of the operation.

Place the ewe on its back on an inclined plank, having assistants to hold the subject securely in position; make an incision directly back of the umbilicus (navel) extending backwards towards the mammae about two inches in length, cutting directly through the skin and sub-cutaneous structures, exposing the lining of the abdominal cavity (peritoneum); pierce this by inserting the knife at right angles to the body of the subject, and widen the opening sufficiently to permit the insertion of the two first fingers of the hand, by reaching backwards and slightly to one side the horn of the uterus will be felt. This can be traced forward until the ovary manifests itself, situated at the extremity of the cornua; bring the ovary to the surface and hold it with one hand, employing the fingers of the other to trace and 
secure the other ovary, the possession of the first materially assisting in finding its fellow. The ovaries are twisted off to prevent hemorrhage, which would be liable to occur if the parts were directly cut with the knife. The horns of the uterus are then returned to the abdominal carity and the lips of the incision brought together by sutures. It is well to take one deep suture through the skin, abdominal walls and peritoneum, and two superficial ones through the skin, just bringing the edges of the cuticle in apposition. The sutures should not bring the edges of the wound tightly together, as the inflammation which always results would tend to tear out the stitches, which would be followed by serious if not fatal results.

The after-treatment consists in dressing the seat of the operation with pine tar or some such agent to keep the wound in an aseptic condition and prevent attacks of the fly.

\section{fractures.}

A fracture of a bone is the solution of its continuity. A simple fracture is where the bone is broken without injury to the soft tissues covering it.

A compound fracture is where an open wound exists which connects with the broken bone.

Where the bone is shattered into fine fragments, the fracture is said to be comminuted, and complicated, when together with the broken bone, severe injury to the adjacent tissues, or deep-seated bruising of the parts also exists.

\section{Symptoms.}

Great lameness, inability to bear weight on the limb, which hangs limp, the animal being unable to exert any control over the affected member. Manipulation of the part reveals crepitus, the sound made by the broken ends of the bones coming in contact with each other. The animal exhibits great pain when the parts are being handled. 


\section{Creatment.}

Consists in bringing the ends of the fractured bones together and holding them in place by putting the parts in splints or a plaster of Paris cast.

A sheep will, as a rule, nurse a broken leg and make a good recovery if the parts have been properly dressed, but unless the animal be a valuable ram or ewe, especially desired for breeding purposes, it is best not to try treatment, but to turn the animal at once over to the butcher.

\section{alounds.}

These may be divided into four classes:

1. Incised or clean-cut wounds.

2. Punctured.

3. Lacerated or torn.

4. Contused or bruised.

\section{Incised or Clean-cut ælounds.}

A clean-cut wound will as a rule unite by what is termed first intention, that is the parts when brought in apposition, adliere and heal without any visible process of granulation. The proper treatment for incised wounds is to wash them with a four per cent. solution of carbolic acid to remove any foreign matter which may have gained access, and at the same time destroy bacteria, rendering the parts aseptic; bring the lips of the wound together by sutures and apply to the surface some drying antiseptic powder, such as:

$$
\begin{aligned}
& \text { Calomel ................ drachm } \\
& \text { Sub-nitrate of bismuth.........1 ounce }
\end{aligned}
$$

Mix. Dust over affected parts once or twice daily. This as a rule will be all that is necessary.

\section{Punctured Kalounds.}

Punctured wounds require frequently to be enlarged to permit drainage. As this class of wound heals by granulation and suppuration, the healing process to be satisfactory should com- 
mence at the bottom, extending outwards; the parts must be kept clean, and daily injections with some mild antiseptic solution will be found to promote the process of healing and prevent langer of septic infection, to which this class of wound is especially liable.

\section{Iacerated or Corn calounds.}

Remove all the torn, hanging shreds of tissue and wash out the parts with some antiseptic solution, then dress daily with some powder such as calomel and bismuth, or

Take. Boracic acid..............1 ounce Iodoform .............. drachm

Powdered chalk...........2 ounces

Mix and dust over the parts once or twice daily.

A lacerated wound heals by granulation. At times these become excessive, projecting above the surface and bleeding very readily. These should be reduced by touching lightly with lunar caustic or sprinkled over with burnt alum.

\section{Contused or Bruised calounds.}

A bruised or contused wound is rarely met with in sheep, - excepting those which have been shipped to the market in overloaded cars and getting down are trampled upon. The treatment when applied consists in removing the inflammation by means of hot fomentations and dressing the parts with some cooling agent, such as the White lotion.

\section{Bruises.}

The sheep in the pasture or feeding lot rarely becomes bruised owing to the protection afforded by its fleece. Sheep which are shipped on railroad cars, from overcrowding, are often trampled on and bruised, the treatment for which is the same as that prescribed for contused wounds. 


\section{Straing or Spraing.}

A sudden stretching of a soft structure, accompanied by rupture of the muscle fibres or extension of the tendons, is often followed by acute inflammation, swelling and fever. The affected parts are then said to be strained or sprained.

The sheep, owing to its naturally slow and careful movements, rarely becomes affected with this condition. The sudden frightening of sheep by dogs or other causes might, however, result in the sprain of a limb from a sudden mis-step.

\section{Creatment.}

Consists in bathing the affected part with either hot or cold water to reduce the inflammation, and then applying some cooling lotion such as:

Distilled extract of witch hazel....4 ounces

Tincture of arnica..........1 ounce

Soap liniment............ I ounce

Alcohol ..............2 ounces

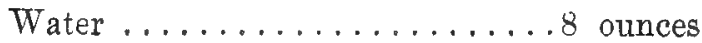

\section{Absce99.}

Is the collection of pus under the skin or in the deeper seated tissues. It may follow the infliction of a bruise or result from some constitutional ailment.

When an abscess is in process of formation the affected part feels hot to the touch; is painful and as a rule the animal shows signs of constitutional derangement, such as high fever.

When the abscess is formed, by pressing the part, the fluid contained in it is felt to fluctuate, but the part does not pit on pressure like dropsical swellings. When the part feels soft to the touch the abscess is said to point. It is then ready to open and if left to itself would burst. This, however, leaves a gaping wound which takes time to heal. The knife should always be. 
used before this stage is reached. Insert the knife in the most dependent part of the abscess, making a wide opening to permit free drainage, after the contents have been evacuated the injection of an antiseptic solution will be all that is necessary.

\section{Cumors.}

Any unnatural swelling or protuberance of the tissues of the animal body is termed a tumor. Tumors are virtually hypertrophies or orergrowths of tissue. A tumor may be composed of tissue similar to that surrounding it, in which event it is termed a homologous tumor; or it may be entirely different from the contiguous tissue, and is then termed heterologous. Tumors grow in size, either by central or peripheral growth; both, however, depend on cell proliferation, the growth being formed in the same manner as normal tissue. The blood-vessels leading to the tumor usually become enlarged; to supply nutrition to the growth, new blood ressels form among the meshes of the tumor cells. Consequently, as a rule, we find overgrowths of tissue to be very vascular, and bleed extensirely when excised. Tumors are said to be malignant when they tend to destroy the tissues in which they are situated, and have a tendency to recur after removal. $A$ benign tumor is that which does not differ materially in structure from the tissue surrounding it, and does not show a tendency to degeneration and uleeration, as do the malignant variety, neither does it as a rule recur after removal.

Tumors are classified generally according to the structure composing them. We shall not here, however, enter into this subject, as the sheep rarely, with the exception perhaps of goitre, is affected with overgrowths of tissue, and malignant cancerous swellings in this species of animal are exceedingly rare.

The etiology or cause of tumor formation has never been vere satisfactorily demonstrated. Beyond a doubt a blow or 
injury to a part may be followed by tumor formation, not merely a simple swelling of the tissue resulting from inflammation consequent to the injury, but by the formation of new adventition: tissue growth; but in the human family, and also in some of the herbivora we find heredity undoubtedly is a rital point in the situation. Then again, Cohnhein's theory of the misplacement of embryonal cells undoubtedly is frequently correct. And of late years parasitic origin appears to be receiving much sonsicteration at the hands of investigators.

Cystic tumors are enlargements containing a fluid-like scrum, and, according to Paget, originate by three different methods: Either by enlargement and fusion of the spaces of the connective or other tissues, the fluids accumulating in these spaces, causing the tissues to become rarefied, the dividing septa of the spaces becoming broken down till a sac or cyst is formerl, the outside boundaries of which continue to secrete fluid which accumulates in and press out the walls of the sac, so enlarging it; or ly dilatation and growth of natural ducts; or by rapid growth of new elementary structures, which is the form occurring as goitre, in the thyroid bodies of young animals, lambs frequently being so affected.

\section{Creatment.}

Treatment of tumors consists in their early extirpation by means of the knife or destruction of the cell elements with strong caustics, etc. The ram is at times affected with a tumor of the penis, which appears to belong to the carcinomata, and which necessitates early removal by knife or ligature.

For the removal of a malignant growth to be successful every particle of the foreign tissue must be removed, it being a safe plan to dissect out some of the normal tissue contiguous to the growth, and so guard against the possibility of leaving behind any of the adventitious tissue. Yet even in many instances where the growtl is malignant, it tends after removal, to recur 
in other parts of the system by a process termed metastasis, making such growths one of the most dangerous and unsatisfactory conditions to deal with which affect animal life. Further mention will not be made of any special class of tumor liable to affect the sheep, with the exception of goitre, which will now be considered.

\section{Goitre. Struma.}

This is an affection of the thyroid glands, in which they become enlarged, sometimes to such an extent that the functions of the trachea and oesophagus become interfered with, so as to threaten the subject's existence. It may exist in any one of four forms, riz:

(1) Real Goitre, when the swelling is due to enlargement of the gland follicles, the whole gland or only part of it being involved.

(2) Fibrous Goitre, where the connective tissue of the gland is increased, the follicles remaining normal or nearly so, portions of the gland as a rule only being affected.

(3) Dilatation of the reins, or varicose goitre.

(4) Cystic Goitre-or bronchocele. This last form is that generally found affecting sheep, lambs more especially, and is supposed to be due to the presence of magnesia in the drinking water.

Goitre is a common affection of the human family as well as animals, and up to the present time the causes do not appear to be very well understood. The locality appears to have a predisposing effect. Williams states that animals grazing on soil rich in magnesian lime are prone to this affection. $\lambda$ is it attacks animals, sheep especially, lambs appear to be more subject to the condition than mature sheep. Meredity appears to have a strongrelation to the transmissibility of the disease, instances having 
been recorded where a number of affected lambs in a flock were all got by one ram which had the disease. Lambs from flocks in certain localities have been attacked enzootically at various seasons. Low situations or a damp atmosphere upon elevated situations, according to Williams, will act as a cause of bronchocele.

\section{Symptoms.}

Swelling immediately under the larynx, at one or both sides of the trachea. This may not increase in size rery rapidly, and in some instances tends to diminish and disappear of its awn accord. Where the gland increases in size so as to compress the trachea and interfere with deglutition as well, an operation for removal of the gland might be permissible.

\section{Creatment.}

Consists in the administration internally of iodide of potassium in full doses, also giving once a week a cathartic dose of Epsom or Glauber salts. The wool should be clipped from affected surface, and the parts painted with iodine, or the compound ointment of iodine applied. Goitre, due to cancerous invasion, such as carcinomatous goitre, should be sufficient cause for slaughter of the animal. The meat on no account should in this instance be offered for human consumption. Removal of the affected gland or glands is not liable to result satisfactorily, in that the subject will become checked in its growth, and is liable to anaemia with marked debility. There would be nothing to recommend this operation so far as sheep are concerned.

\section{Diseases of the Eye.}

The sheep frequently suffers from eye affections, as do other of the lower order of animals. Many of these disorders are liable to produce permanent blindness, which is less noticeable in sheep than in other animals from the fact that their hearing 
being unimpaired they are enabled to keep with the flock and experience but slight difficulty in grazing.

\section{Simple Ophthalmía.}

Inflammation of the conjunctivae or mucous membranes lining the eyelids. It may be caused from foreign matter such as hayseed or dirt gaining access to the eyes, or bites from insects. It arises also as the result of exposure or as a complication of nasal catarrh.

\section{Symptoms.}

The eye is partly closed, the eyelids are swelled, the eye is retracted into the orbit, there is a copious secretion of tears which flow down over the cheeks. On turning back the eyelid the conjunctiva is found to be congested, with red streaks running across it.

When occurring as a complication in nasal catarrh it invades the eye through the lachrymal duct. Should it attack the cornea, exudation often takes place infiltrating the tissues of that organ. The organization of this exudate produces a condition known as opacity of the cornea.

\section{Creatment.}

If due to the presence of foreign material this must be removed, this in some cases is a matter of great difficulty, especially when the object becomes embedded in the tissues of the eyeball, and in many cases it may be necessary to transfix the membrana nictitans (winking eyelid) by means of a suture before the particle can be abstracted. After-treatment consists in bathing the eye with cold water and using some simple lotion, such as:

Sulphate of zinc..........2 grains

Sulphate of morphia.........2 grains

Distilled water............. 1 ounce 
Drop a few drops into the ere two or three times daily. Where the mucous membrane of the eyelids has been cauterized by some such agent as lime, (this is frequently seen following the use of lime and sulphur as a dip for scab), introduce something into the eye which will lubricate and have a soothing effect, such as a drop or two of linseed tea, or a kernel of flaxseed may be inserted under the lids.

\section{Ophthalmia Proper, also called the Blinds.}

This is a condition of inflammation of the conjunctiva simulating in symptoms simple opthalmia, with the difference while that is due to foreign matter, or the extension of inflammation from other diseases, such as nasal catarrh, this appears often as an epizootic; is recurrent in character, each successive attack being more severe, the result being total blindness in the majority of cases. This disease appears to be closely allied to the disease known as specific ophthalmia to which the equine is liable, which is also a recurrent disease apt to terminate in cataract and blindness. The cause of this affection so far has not been determined, but that it is infectious in character is extremely doubtful. The symptoms are the same as those noticed in simple ophthalmia, but that there appears to be a certain amount of constitutional derangement and a tendency for the complaint to run a malignant course. The treatment would be the same as for simple ophthalmia. It is a good plan, however, to commence with a mild physic, such as four ounces of Epsom salts; use cold applications to the eye and the zinc sulphate lotion. In extreme cases blceding from the angular vein appears to afford relief.

\section{Amauresis, Gutta Serena, Glass Eye,}

Is a condition in which there is paralysis of the optic nerve, rendering the ere useless. It mar be caused from injuries, such as a blow orer the head with a crook, or may be due to tumors in 
the cranium which interfere with the functions of the optic norve. This condition is incurable.

\section{fungus Гaematodes.}

This is a malignant, cancerous disease attacking the carily of the orbit. It is most commonly seen attacking cattle, but sheep are by no means exempt. It makes its first appearance as a small red spot at the side of the orbit, which enlarges rapidly, involving not only the ere itself but the bones ard tissues surrounding it.

\section{Creatment.}

C'onsists on its early removal, to accomplish which the eye must also be extirpated. If the bones are already attacked they must be scraped and the parts cauterized. The actual cautery being preferred, the removal to be successful must be complete, otherwise the growth will quickly recur. Unless the sheep be a very valuable animal and it is desired to keep it for breeding purposes no treatment should be attempted, but as soon as the condition manifests itself the patient should be turned over to the butcher.

\section{Opacity of the Comea.}

Is a sequel to inflammatory conditions of the eye, such as ophthalmia. It is due to the organization of the exudates which follow inflammation. This is of rere common occurrence in sheep, due to the fact that unless the animal is raluable or is a member of a very small flock, ophthalmia rould pass unnoticed by the flock-owner, and if observed would not as a rule be thought worthy of treatment, in which event the disease running its course uninterrupted would in the majority of cases terminatc with this condition.

\section{aloundo in the Eye.}

These, when occurring in the conjunctiva, would be accompanied by all the symptoms of simple ophthalmia. When the cor- 
nea is injured, as may oceur from a sharp instrument penetrating the eye, and the aqueous humor is evacuated, the lens is liable to fall out, in which event of course the usefulness of the eye is lost. In the treatment of all wounds of the eye try to keep down the inflammation and endeavor to maintain an aseptic condition. Always use weak solutions to drop into the eye, and in many cases the addition of one drachm of a four per cent. solution of cocaine added to one ounce of the lotion will give excellent results by relieving the pain. In all cases of inflammation in and around the eye, it is a good plan to use atropine directly to the organ. This by dilating the pupil prevents the organization of the inflammatory exudates, or, better still, use the atropine solution in the following manner:

Sulphate of atropia.........2 grains

Cocaine hydrochlorate sol. 4 per

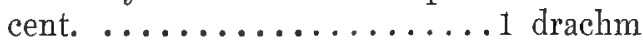

Distilled water............1 ounce

Use for two or three days, applying a few drops to the eye several times a day. And then

Take. Eserine............... grains

Distilled water.............1 ounce

and use this for two or three days.

The atropia solution dilates the pupil while the eserine solution has the opposite effect. In this manner the pupil is kept moving, lessening the possibility of organization of the products of inflammation. An opaque cornea, when of recent occurrence, can often be corrected by stimulation. To effect this apply with a feather or camel's hair brush a solution of the nitrate of silver, such as

Nitrate of silver............ grains

Distilled water.............. ounce

Apply this directly to the opacity once or twice a day. It is a gnod plan to administer internally saline diuretics, such as nitrate of potash indrachm doses, and a full dose of Epsom salts. 


\section{CHAPTER XVIII.}

\section{Local Non-Contagious Diseases.}

In the arrangement of this work a few diseases which did not especially belong with those already classified have been inserted under the above heading. Among such are several of those affecting the integument and glands of the skin and also certain conditions affecting the feet. We shall now consider such diseases of the skin as are dependent on constitutional derangement either from errors in diet or from faulty excretion of effete materials, due to an abnormal condition of the glands.

\section{Eczema.}

This is a common affection among sheep, especially with young immature animals which are highly fed to prepare them for exhibition purposes.

While eczema is recognized in several different forms, we find that the resicular is that to which sheep are more generally liable.

The attack comes on suddenly, the parts attacked generally being the face and lips, but it also may attack any of the parts of the skin, especially those where the fleece is lightest, such as the belly, inside of thighs and armpits.

The visible symptoms are intense itching, the animal rubs itself violently, small vesicles appear on the affected parts. These rupture, discharge a watery fluid, and, on drying up, a small nodule remains in the place of each resicle, which might be mistaken for scab, from which, however, it is easily differentiated, as an examination of the parts will rereal the alsence of parasites. 


\section{Creatment.}

This condition is invariably due to dietetic errors, from over-feeding, or feeding certain grains and grasses in excess, -uch as clover or buckwheat. An entire change of diet will as a rule effect a speedy cure, especially if it is possible to put the sheep on fresh grass. When show sheep are attacked with this condition it is well to decrease their rations and give a saline cathartic such as Epsom salts. Combined with the food such medicines also may be given as exert a special action on the skin, as Fowler's solution of arsenic, which can be administered in from one-half to one drachm doses twice daily. As a local application to relieve the itching and prevent the animal tearing its fleece and thereby becoming ragged, a cooling lotion will be found beneficial.

Take. Acetate of lead............. drachms

Water .................. pint

Apply to affected parts once or trrice daily, or, if preferred, finely powdered boracic acid may be dusted over the parts.

\section{Erythema.}

This is simply inflammation of the skin and may arise from one of several caulies, such as stings of insects, frost bites, etc.; chapped teats in ewes, due to lying on wet ground, is also erythematous in character.

It is characterized by a redness of the affected portion. Accompanring the abnormal redness, the parts feel hot to the touch; appear swelled and are sore

Anything interfering with the normal functions of the skin is liable to produce erythema, cold and wet being very common causes. It is also seen following debilitating diseases, where the srstem is weakened and the functions of the skin interfered with. The ndder of the ewe just previous to or following par- 
turition is very liable to this condition. Sore teats in ewes when not due to infection of aphtha maligna must be classed as errythema.

\section{Creatment.}

It is always good practice to administer a saline cathartic in these cases. The parts can be dressed with a cooling dressing, such as the White lotion, the prescription for which is to be found in the last chapter but one of this work. Nitrate of potash in one-half drachm doses can be given with advantage twice daily in the feed. For chapped teats in ewes dressing with some astringent mixture, such as

Tannic acid...........40 grains

Glycerine .............2 ounces

will quickly effect a cure.

\section{Cellulitis.}

This is inflammation of the cellular tissue underlying the skin, which it also involves. It appears to be due to a derangement of the circulation or may occur from blood-poisoning; italso occurs as an extension of erysipelas; in which case, however, its origin would be specific. Abscesses form in the cellular tissue, producing mortification and gangrene of the skin above them, which sloughs off. This condition is very rare in sheep.

\section{Creatment.}

Consists in administering tonics, such as iron and arsenic, or regetable tonics, such as gentian and quinine, feeding stimulating, easily digestible food, and adopting good hygienic measures generally.

\section{Drurigo.}

This is a condition of the skin characterized by intense itching, but not accompanied by any eruption. It appears to be due to an altered sensory condition of the periphery of the 
nerves and seems to arise as a sequela to indigestion, probably - from some peculiar effect which indigestion produces on the system generally. Overfeeding is also liable to produce this condition, especially where the diet has lacked a change. Associated with prurigo is generally a plethoric condition.

\section{Creatment.}

When due to indigestion, such agents must be administered as will tend to correct that condition, as charcoal and vegetable and mineral tonics.

Take. Sulphate of iron............1 ounce

Gentian .............4 ounces

Powdered willow charcoal.....4 ounces

Fenugreek .............1 ounce

Nitrate of potash powdered...... $\frac{1}{2}$ ounce

Linseed meal............4 ounces

Mix. Give one tablespoonful in feed once or twice daily.

When accompanied by a plethoric condition, commence treatment with saline eathartics, Glauber or Epsom salts, and feed green food, such as fresh grass, etc, when possible. When sheep on high feed are attacked with this condition it becomes necessary to reduce the ration if a cure is to be expected.

\section{Impetigo Labialis.}

Is a pustular condition found affecting the faces and lips of lambs. Some fever and other constitutional symptoms accompany the breaking out of the eruptions, but these, however, soon disappear, a change of diet being as a rule all that will be necessary to effect a cure.

\section{foot-rot, Daronychia Interdigitalis.}

We shall consider this disease under the head of noncontagious affections because its contagious character has not, up to the present time, been properly established. Not that it is desired to take issue with any of the noted authorities, who have 
expressed themselves as satisfied with its contagiousness, but that it is necessary when claiming a specific character for a disease to be able to show incontrovertible proof that such is the case, and

Fig. 1.
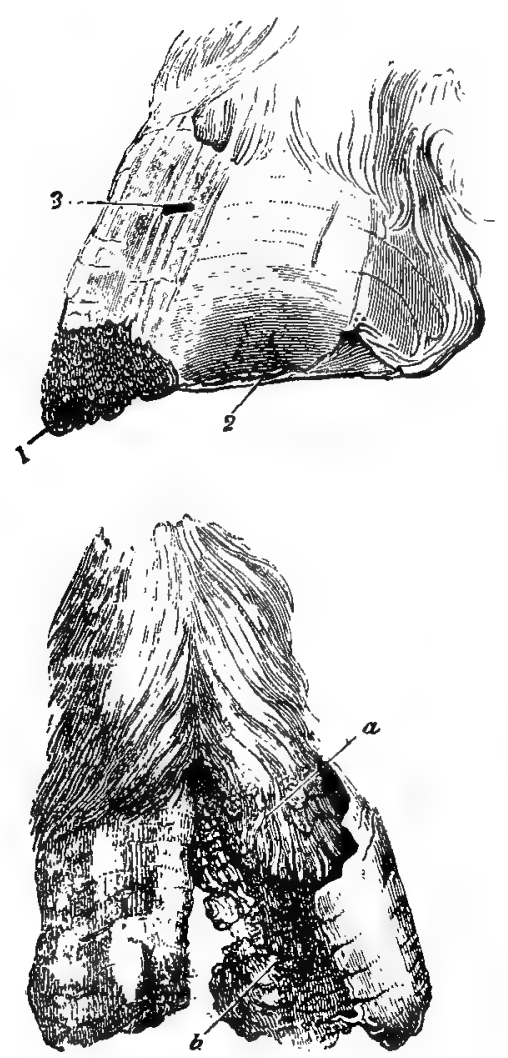

Fig. 3.
Fig. 2.
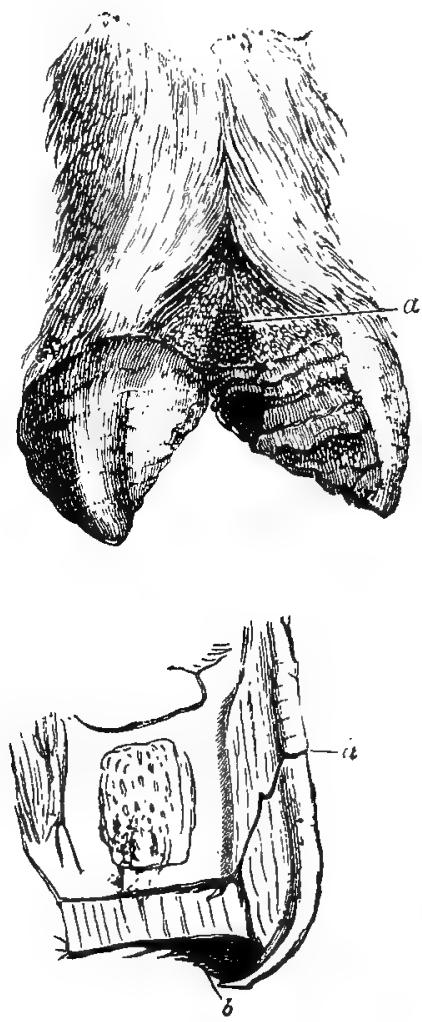

Fig. 4.

Fig. 1.-1. Shrivelled or decayed horn. 2. Dark spot indicating a carits. 3. Minute fissure, at $a$.

Fig. 2.-Early stage of foot-rot induced by rubbing matter on interdigital cuticle

Fig. 3.-Advanced foot-rot. Boof-horn overgrown to a degree highly abuormal; undz:-8urface broken and rotten at $b$. From one digit the hoof-horn is nearly detached, exposing inflamed foot at $a$. covered with fibres of soft horn.

(These three illustrations are from originals of Prof. Brown.)

Fig. 4.- Section of foot through horn-fissure $(a)$, showing extension of the crack to the interior; (b) edge of hoof bent under, permitivg collection of dirt. (Brown.) 
while certain experiments have been carried out by different noted veterinarians to that end, they have only been attended with success in very few instances, and then under such circumstances that it is reasonable to believe that the methods employed would have caused the condition without the introduction of the discharge from affected feet.

Foot-rot is the cause of very severe monetary losses to flock-owners, not that it is liable to terminate fatally, but that the irritation and fever it produces so interfere with the animal's well-being as to make it unthrifty, causing it to lose flesh, and thereby inflicting serious injury on its owner. The fact that a large number of animals in a flock often become affected simultaneously, has led many sheep-owners and also veterinarians to believe it to be a contagious affection. The question of its contagiousness has been affirmatively answered by many noted European authorities, among whom may be mentioned Gohier, Gasparin, Girard, Reynal, Mr. George Fleming and many others, and as directly denied by such eminent authorities as the late Prof. Dick of Edinburgh, and Profs. Brown and Williams. The late Mr. Read of Crediton, Eng., after making exhaustive investigations on the subject, concluded against its contagious character, and stated that it was caused from the soil not being adapted to graze sheep over, and that the mere moving of infected sheep to healthy land was sufficient in itself to perfect a cure.

Before considering the causes of this disease it may be als well to consider briefly the anatomy of the foot, a knowledge of which will materially assist in determining the cause of the trouble. The hoof of the sheep is composed of two separate digits, each enclosed in a horny box or framework, the passage between the digits being termed the cleft. We find under the horn or wall of the foot a membrane termed the subcornens membrane, which is composed of a number of leaf-like band: 
running parallel one with the other. This laminal tissue covers the digits in the same fashion as a sock does the foot, the horny covering outside of everything being similar to the boot. The outer surfaces of the claws are convex, while the inner surfaces are slightly concave, which permits them to come in contact one with the other only at their extremities. Situated between the pasterns we find a glaud known as the interungulate gland, its opening being protected by a few long projecting hairs. This gland secretes a yellow viscid fluid, intended to lubricate and prevent friction in the cleft of the foot, and were it not present the continual movements of the claws and their constant contact with grit and other foreign matter would set up a chronic state of in-

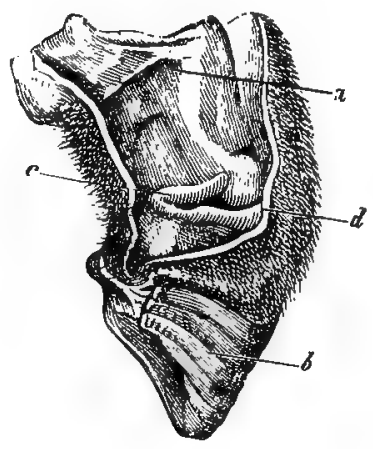

\section{Interungulate Sinus of Sheep.}

$a-I n n e r$ aspect of first phalanx. b-Hoof or claw, c-Interungulate gland. $d-$ Orifice of its duct.

flammation. This canal at times becomes diseased. Inflammation and disorganization of the structures of the hoof then develops, which if permitted to exist will eventually terminate in a condition simulating foot-rot. The hoof-horn is secreted from the coronary band, situated at the juncture of the skin and hoof. This structure is very vascular, and anything which would interfere with its normal functions would necessarily affect the secretion of the hoof-horn, either to decrease such secretion or through 
some false stimulation abnormally increase its formation, although its character would be changed and degenerated.

Now it would appear plausible that if sheep are grazed on wet pastures, the continual maceration the horny covering receives would eventually affect its structure, and that the coronary cushion would also from the same cause secrete a softened abnormal horn, the oily covering of which being washed off, especially in the cleft, would render the parts liable to not only soreness and inflammation from friction and contact with dirt and foreign matter, but would render them liable to absorb material, the presence of which would tend to set up inflammation and disintegration of the horn substance, and if that state is permitted to endure for any length of time the bones or soft structures of the foot would perforce of eircumstances also become involved in the process of degeneration.

In considering the causes liable to induce foot-rot we must then lay great stress on the grazing of sheep in wet, low-lying pastures, and every authority, even those who advocate the theory of its contagiousness, admit that for the disease to exist it is necessary that the sheep should have been grazed on wet land. Mr. Read in an essay upon the subject, which has been frequently mentioned by different authorities, says:

"Low situations conjoined with moisture are the fruitful and primary causes of foot-rot. Sheep in these situations have their hoofs and the integument above, to which they are united, and the highly elastic tissue situated between the claws constantly in a wet and humid state. Go into any of these pastures after the sheep have been placed there for only a short period and look at their feet. Will there not be an increased growth of the hoof? Will not the skin around the coronet and highly sensitive membrane be blanched? Will not the vascularity of the parts be weakened from its circulation being enfeebled? Now 
this is all produced by wet. In a few days, perhaps, we have a change of temperature; evaporation is produced from the surface of the land and from animal bodies as well, and the ground becomes drier. A reaction takes place; the circulation is quickened; the hoof swells or rather is pushed from the parts beneath; the skin between the claws inflames; the heels bulge; the coronet enlarges; abscesses form; matter penetrates between the horn and the substance beneath, and disunites the sensitive from the horny laminae, and, in the worst forms of the disease, the hoof falls off."

This description by Mr. Read very properly and accurately covers the subject, given the cause, namely, prolonged unnatural surroundings, and it is not necessary to have any specific germ to assist in producing the changes in the hoof-horn. The fact that so many members of a flock appear to become affected simultaneously, is easily explained, they all having been subjected to the same cause. The hoof to maintain its normal healthy condition must be submitted to a certain amount of wear and tear, otherwise the horn being continually under the process of formation, unless worn off and kept to its proper proportions, would grow abnormally long and favor changes in the horn substance. For this reason foot-rot is at times met with on dry, sandy soils, the softness of the soil not furnishing sufficient wearing properties to the feet. The mere fact of healthy sheep contracting foot-rot from being placed with those already diseased, in no manner proves that the disease is contagious, as the sheep are submitted to the same causes which produced the condition in the former. The form of the disease met with on high, gravelly soil is produced from an excessive wearing away of the claws from contact with sharp, gritty particles, and while they go lame and at times abscesses form with fungoid growths of horn, it cannot be said to be malignant foot-rot, meaning the kind which arises from moist- 
ure, as by moving the sheep to less gravelly surroundings and employing simple treatment, such as an application of pine tar, a cure is speedily effected, the horny secretion in this instance not being perverted and changed, as is the case where the parts have been kept in a super-moist condition.

\section{Symptoms.}

The sheep is noticed to walk with difficulty, appearing to rest frequently after progressing for a short distance. Distinct lameness will be observed in a day or two, the animal then lags bchind the flock and soon assumes a lank appearance.

On examination a moist foetid discharge will be noticeable between the claws of the affected feet. The feet are hot, the animal exhibiting signs of pain when they are pressed, and the coronet is swollen. In the commencement of the attack only one foot may be affected, or both fore-feet, or both hind, rarely all four feet are affected. At first the disease appears located in the foot, but it is liable to extend, involving the soft tissues of the coronet, forming abscesses above the hoof, and at times invading the bones and tendons of the knee. This, however, is very rare. The hoof-horn, as the disease progresses, takes on a species of dry-rot; falls away piece by piece, exposing the delicate sensitive laminae situated underneath. These sprout outwards, forming fungous growths resembling excessive granulating tissue, in that they bleed easily when touched. The discharge from the affected surface is extremely offensire, and so strong in character that if only a few sheep in a flock are affected the disease can be recognized at some little distance from where the diseased flock is grazing.

The horny sole becomes attacked and peels off, exposing the sensitive parts covering the pedal bone. The subject is then quite lame and should the fore-legs be the ones affected, it will move around on its knees, crawling on its belly if its hind feet 
arc diseased. The affected sheep lie down frequently; fall away in flesh, becoming eyesores to their owners. In extreme cases the claws are shed and the animal is liable to succumb to the disease from the pain and inability to procure food. In the summer season the odor from the affected feet appears to act as an attraction to the fly; the sores become infected with maggots, producing a most deplorable condition. In a prize essay by $\mathrm{Hogg}$, the Ettrick shepherd, we find the following:

"On examining the foot in the first stage of the disease, the coronary edge, while no external injury can be traced, is sometimes found a little swollen and inflamed; at other times the hoof is eroded, but whether it be shattered or entire, an intense heat is always perceptible in the feet, with a strong pulsation in the arteries where they are inserted in the coronary edges of the hoof, and, however sound the hoof may appear externally, the connection between it and the interior of the foot is always dissolved, though the separation is not evident until the hoof is pared away. A peculiar smell is perceptible, especially in the advanced stages or when the ulcerous part is newly opened, yet even in the worst cases a large quantity of ichor is never discharged, there being little more than will wet the finger and that only when pressed out."

This extract from Mr. Hogg's essay places the first symptoms of this disease very plainly before the reader, and it only remains to describe the differences betwreen foot-rot and a disease which it, to a certain extent, simulates and for which it has been mistaken namely, aphthous fever. (Foot and mouth disease.)

\section{foot-rot in its Primary Stages.}

Is not associated with constitutional fever. The appetite remains good and the milk-supply of ewes suckling lambs is not materially diminished, hardly at all in the first stage of the disease. 
In foot-rot, as a general rule, one or two feet only are attacked at first, generally the two fore-feet. In foot and mouth disease all four feet generally are affected, vesicles extending over the front of the digits, and almost always around the heels. In foot-rot vesicles do not appear in other parts of the body, as on the udder, skin, or in the mouth, which is the case in foot and mouth disease.

In foot-rot the separation of the wall of the hoof from the digit proceeds from below upwards, the reverse being the case in foot and mouth disease.

Lastly, foot and mouth disease is highly contagious. By annointing a wisp of hay with the discharge and drawing it through the mouth of a healthy sheep, a definite diagnosis can be arrived at, as this is always in case of foot and mouth disease sufficient to inoculate and produce the condition in the healthy subject; whereas in foot-rot the effects would be nil, it being impossible to propagate it in such a manner.

\section{Treatment.}

This must be prompt and in many cases heroic if a speedy cure is to be expected. When a large number of a flock become affected, the daily turning of each diseased sheep would be a mattter requiring a large expenditure of time and trouble. To overcome this, various foot baths have been adopted through which the flock is driven once a week or oftener, if desired, and it is highly proper here to describe this method before taking up the individual treatment of the members of the flock.

A shallow trough about two feet in width and eighteen inches deep, the length being a matter of convenience, depending upon the number of sheep to be treated, is set in the ground. A low fence is made to run the entire length and on each side of the vat, so that the sheep will be compelled to stand in it. A solution of arsenic made as follows: 
Take. Arsenious acid ............ 3 lbs.

Carbonate of potash.......... 2 lbs.

Water ................... 14 gals.

The arsenic and potash must be boiled for at least half an hour in the fourteen gallons of water in order that the arsenic may be well dissolved. A sufficient quantity of this solution is then poured into the trough so that the liquid will be about three inches deep, to permit it to thoroughly cover the feet and prasterns of the sheep.

Affected sheep before being stood in the bath, should have their feet pared; all fungoid growths should be removed. It is not necessary to stand the sheep in the bath for any length of time if the trough is over ten feet in length, the mere passing of the sheep through it will be sufficient. After leaving the bath care must be taken that the sheep are not allowed to graze until the liquid has drained from their feet, otherwise the drippings on the grass being eaten by themselves or other animals would cause arsenical poisoning.

It is a good plan to place the trough on some bare place as far away from the farm buildings as possible, having a pen at each extremity of the trough, so that the sheep can be driven through without difficulty. The pen at the outlet to be used as a draining pen, the sheep to be held there until the feet have drained dry. The trough also should be provided with a water tight lid and kept locked, otherwise it would be dangerous to the live-stock of the farm. In mild cases of foot-rot, sulphate of copper (blue stone) may be used in the place of the arsenic, this should be used in the strength of one pound to the gallon of water.

After the sheep have passed through the bath, it is found very beneficial to apply quick lime to their feet. The easicst method being to sprinkle the floor of a barn with the quicklime and compel the sheep to walk on it. It must be borne in mind, 
however, that treating the disease without bettering the surroundings which led to, and are responsible for the condition, will be a very unsatisfactory undertaking. If the disease has arisen from the excessive moisture, this must be changed before a cure can be expected; the same holds good when the soil is gravelly and liable to make the animals foot-sore. If possible rum the sheep on ground which is suitable and accords with their habits. Where it is impossible to do so, it becomes necessary tohouse the sheep at night on dry ground or in sawdust-floored pens, and to adopt all such measures as will tend to counteract the drawbacks of the locality.

Where a few sheep only in a flock are affected, those which show signs of lameness should be caught and turned. The affected feet should be pared down, all shreds of horn or fungus being removed. The ulcerated surfaces should be cauterized to stimulate the secretion of healthy horn. Many different agents have been used for this purpose with more or less success, such as butyr of antimony, nitric acid, sulphuric acid, creosote, chromic acid, terebene, and many others. Perhaps that which gives as good if not better results without danger of excessive cauterization is butyr of antimony. After applying this or any of the other agents to the sore surfaces, the parts should be dressed with Stockholm tar or carbolized tar, which makes an antiseptic and healing dressing having the tendency to stimulate the growth of healthy horn.

When the granulations are very profuse, it will be found good practice to apply the actual cautery, the red-hot iron in these cases appearing to exert a special action not to be obtained by the use of any chemical astringent and caustic agents. Ewes in lamb require careful handling, and unless the disease is far advanced they should not be turned for dressing; it will be found safer to stand them in the arsenical or copper solution. Quick- 
lime is highly recommended by many experienced flock-owners for this condition. It can be applied as already stated, and, as its cost is comparatively small, it certainly justifies a trial.

Bear in mind that foot-rot generally prevails on moist land in wet weather, and on dry land in rery dry weather (the ground then being hard on the feet). During such seasons special vigilance mist be used by the flock-owner and measures adopted to prevent the occurrence of this troublesome affection.

\section{Inflammation of the Interdigital Canal.}

On the anterior of the pasterns superior to the claws, midway between the coronet and the upper pastern joint, is situated a small aperture from which project three or four hairs abuut one fourth of an inch in length. This aperture is the opening of the canal leading to the gland known as the interungulate gland, the uses of which have already been described.

At times this canal becomes inflamed from irritation caused by the entrance into it of foreign bodies, such as pieces of grit or dirt, etc. Should these not be removed ulceration of the parts is liable to occur and abscesses form. The pus burrows through the walls of the canal between the digits, setting up intense inflammation of the foot, which may, if not speedily relieved, prove fatal. This condition is readily separated from foot-rot in that the disease only attacks one foot and commences at the interdigital canal, the orifice of which is swollen; in the same manner it will not be mistaken for foot-and-mouth disease, as only one member is affected, whereas in that complaint the likelihood would be that all four feet would be involved in the inflammatory process.

\section{Symptoms.}

Great lameness, an examination reveals the orifice of the interwsitul canal swollen, the surrounding parts being swolleu 
and the skin very red. The sheep is feverish and off it: feed; exhibits symptoms of intense pain. It carries the affected leg off the ground, limping around on three legs while grazing.

\section{Treatment.}

Consists in remoring whaterer may have entered into or blocked the outlet of the gland. The foot should be washed in warm water, the canal syringed out with a carbolized solution and the foot then placed in a poultice. After-treatment consists in applying some astringent application, such as a tincture of myrrh.

Where the inflammation has been excessire, sinuses and abscesses already having formed, the canal must be laid open and the parts dressed with a strong antiseptic solution.

When it is necessary to operate in this manner the application of a four per cent. solution of cocaine hrdrochlorate will make the operation painless to the subject. 


\section{CHAPTER XIX.}

\section{Parturition and the Diseases Incidental Chereto.}

Normal parturition is the act of expulsion of the foetus from the womb of its mother after the completion of its full period of development within that organ.

The period elapsing from the time of its first conception and its final expulsion from the uterus is called the term or period of gestation. This, as it occurs in sheep, extends over a period of nearly five months, or, to be more exact, from 142 to 150 days.

The act of parturition, while a natural physiological process, is attended in all mammalia with more or less pain and risk to the existence of the subject. The foetus, being fully developed, acts as an irritant to the organ in which it has been elaborated, inducing a marked disturbance of the nervous system, accompanied with violent contractions of the womb, aiming to expel that which has now become a foreign body.

Expulsion is not effected by one effort, but by successive, slow and progressive contractions, becoming more severe and exhausting as the labor becomes prolonged. At first the pains are of short duration, increasing gradually in force. Normal contractions take place at the fundus, (center of the body of the womb); the cornua (horns) shorten towards the fundus; the womb towards the neck, and the neck towards the opening into the vaginal cavity called the os. The water-bag enveloping the foetus acts as a mechanical dilator to the neck of the womb, which, as the pressure increases, becomes thinner and shorter. permitting the water-bag to dilate its opening or os. The limbs and head of the foetus acting as a wedge maintain the dilatatiom of the parts, which, as the pains increase in severity, finally $\in \Pi^{-}$ 
large, obliterating the os entirely, making the vagina and uterus one large distended cavity. When this stage is reached delivery takes place very rapidly.

Sheep frequently bring forth twins, and these may be born one directly after the other, or, after the birth of one lamb, a period sometimes of two or three days may elapse before the delivery of the other takes place.

Ewes, during the period of gestation, should be kept quiet and free from such disturbances as would be liable to result in premature delivery. Chasing of pregnant erres by dogs, sudden changes in diet, improper hygienic surroundings, are all liable to result in abortion, and endanger the lives of the ewes themselves.

The act of parturition is liable to be prolonged, owing to a number of causes which may arise, many of which are of such a serious nature as to result in the death of the ewe. As causes resulting in protracted labor we find: (1) Exhaustion from gensral debility. (2) Cold weather at time delivery is due. Premature rupture of the envelopes (water-bag), permitting the escape of the liquor amnii (water); the uterus then becomes exhausted from contracting on the foetus, the neck of the womb not being dilated. (4) Obstructions in the genital passages, such as tumors in the neck of the womb or ragina. (5) Rigidity of the neck of the womb, frequently due to some injury inflicted in a previous delivery. (6) A complete obliteration of the os, which condition, however, is rare. (7) Torsion of the uterus, in which event the womb has become twisted on its neck-a condition caused by violent motions on the part of a pregnant subject, and which has to be rectified before delivery can take place.

The first set of causes, such as exhaustion from general debility, exposure, etc., are due wholly to mismanagement on the part of the flock-owner, and are not to be overcome at the last moment, but should be guarded against and prevented by proper 
care of the ewes from the time of intercourse with the ram till delivery is due to take place. Where labor is prolonged from premature rupture of the water-bag, injections of warm water, or warm infusions of slippery-elm bark will facilitate the delivery.

Where obstructions, such as tumors in the genital organs, exist, their removal must take place before parturition can proceed.

In cases of rigidity of the os, whether due to previous injury or perverted nervous function, applications of warm water douches, or smearing the os with the extract of belladonna will often overcome the difficulty; should this not prove successful, however, it becomes necessary to operate, the proper procedure being as follows:

Pass the hand in the ragina. This is a matter of some diffculty, as the passage is rery small as compared with that of the cow or mare, but br diligent manipulation, using vaseline to protect the mucous membranes, it can be acemplished; pass a probepointed bistoury into the os, and make three slight incisions, as

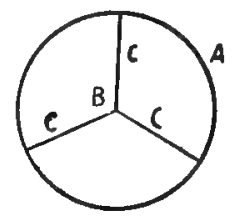

Theoretical Drawing, showing Method of Incision of Os Ateri.

$A$-Outer circumference of os uteri. $B$-Supposed centre of same. CCC-Incisions starting from $B$ to circumference s.

shown in illustration. This will permit the os to dilate and delivery to take place. Where ewes have been delivered in this manner they should not be bred from again on account of cicatricial tissue forming in the os. After the lamb is weaned, the ewe should be fattened for the butcher.

Where obliteration of the os uteri exists, the above operation 
can be performed, but it is then a matter of great difficulty to locate the proper point for making the incision. A great deal will depend on the experience and skill of the operator.

Torsion of the uterus is a very difficult matter to overcome, especially in the ewe, where the passage is of such limited size. The proper method is to introduce the hand into the vagina and up into the uterus, where the spiral turn can be felt. After deciding as to whether the twist is to the right or left side, have an assistant turn the body of the ewe in the opposite direction, the operator leaving his hand in the cavity, endeavoring to exert his force in the clirection opposite to that in which the assistant is turning. When the womb regains its natural position, delivery will be able to take place in its normal manner.

Parturition is frequently interfered with by malposition on the part of the foetus, its presentation not being suitable for its expulsion through the genital passages, or deformities of the foetus, termed monstrosities, may interfere with its delivery. These are to a certain extent common in sheep, and when present the skill of the operator will be required if the life of the ewe is to be saved.

The various mal-presentations may be summed up as follows:

(1) Where head and one fore-leg is presented, the other being retained. To overcome this condition, gently repel the foetus back into the womb, ard endeavor to obtain possession of the retained leg; bring it up into position, and allow parturition to proceed naturally.

(2) Where the head alone is presented-both fore-legs being retained-push the head back, bring up the fore-legs, sa permitting delivery to take place.

(3) Where the two fore-legs are presenting, but the head is turned back-in this instance the head may be directly turned backwards, or may be dwopped either between the legs or to one 
side of them. It will be necessary here to obtain possession of the head: Introduce a finger into the mouth of the foetus, or get the hand round the mouth, using force sufficient to bring the head up into the passage, and deliver the lamb.

(4) Where the side of the foetus only can be felt, it must be turned to its natural position. This requires judgment, patience, and skill on the part of the operator. No iron-clad rule of procedure can be laid down. The operator must manipulate the parts until he can obtain possession of a limb, which should be brought up into position and another one sought for, which, when obtained, the foetus can be extracted. Either hindlegs or fore-legs are sufficient, - of course, if the fore-legs are brought into position the head must present properly, as in paragraph three.

(5) Where the back of the foetus presents itself the same procedure recommended in paragraph four must be employed.

(6) Where the breech presents, the hind-legs being retained, repel the foetus, standing it on its head in the uterus; reach for a hind-leg, bring it up into the canal, then bring up the other, and extract the lamb by pulling it out backwards.

(7) Where the foetus is too large for delivery. These cases call for embryotomy, the foetus having to be extracted piece at a time. Frequently, in these cases, if the operator can disembowel the foetus the carcass will collapse sufficiently to permit its being extracted. Where the head is enlarged (hydrocephalic), it must be punctured to allow the fluid to escape; the head can then be crushed and delivery take place. Monstrosities also come under this class. They frequently necessitate the use of the knife on the foetus if the ewe is to be saved.

In all cases where it is necessary to offer assistance to the ewe in lambing, care must be exercised to see that no dirt or foreign substances are introduced into the womb, which would be liable to result later in septic poisoning and death to the subject. 
Force, when used, should be exerted gradually, in order that the soft parts are not injured or torn.

It is always proper to thoroughly wash the hand and arm before inserting it in the ragina, also using vaseline or carbolized sweet oil to lubricate the passage and prevent abrasion of its mucous lining. Assistance should only be offered when it becomes apparent that the ewe is unable to lamb without it; even where labor has been protracted, if the presentation is right, and the ewe still possesses good strength, it is better to let nature. take its course than to try to hurry matters along.

Conditions liable to occur incidental to parturition are as follows: Retention of the foetal membranes. These should be expelled from the uterus shortly after the lamb has been born. Where they are retained for over twenty-four hours their presence is very liable to cause septic poisoning. Take the projecting portions, twist them round a stick, and pull gently and steadily. This is generally all that will be required. After removal, give the ewe four ounces of Epsom salts, or better still,

Táke. Epsom salts..............2 ounces

Carbonate of ammonia.......20 grains

Nitrate of potash.......... d drachm

Ginger, powdered.......... drachm

Dissolve in eight ounces of water, and give as a drench.

This is a very useful prescription to give ewes a week before lambing is due. It assists in preparing the subject for the supreme act in nature and prerents, to a great extent, such conditions as are apt to follow parturition in well-bred pampered animals.

\section{Bleeding, flooding, Dost-partem Бemornage.}

May occur as a result of the retention of the foetal membranes, or from their being too suddenly severed from their attachments, or from exhaustion following protracted labor, which interferes with the natural contractions of the womb. 


\section{Creatment.}

Administer a quick stimulant, such as the following:

Take. Sulphuric ether.............. drachms

Aromatic spirits of ammonia....2 drachms

Alcohol ...............2 drachms

Add one half pint of water and gire as a drench.

Then make an examination, and if the womb is distended, filled with clots of blood, syringe it out with warm water. When cleaned out, inject a solution of iron:

Take. Tincture of iron...........4 drachms

Warm water $\ldots \ldots \ldots \ldots \ldots \ldots .1$ pint

Inject it into the uterus, apply cold water to the vulva, and internally administer the following:

Fluid extract ergot.........2 drachms

\section{Inversion of the alomb.-Prolapsus Ateri.}

This may be partial or complete. In partial inversion the fundus of the womb only is inverted into the vagina, or the whole may be inverted, projecting outside of the vaginal cavity, resembling a glove turned inside out. Where the condition has not existed for any length of time, it can readily be remedied. Wash the inverted portion with carbolized warm water, and beginning at the most dependent part, commence to turn it in by pressing the part forward and inward, turning it back into itself, as it were.

Where the condition has existed for some time, the parts may need scarification-this is done by lightly criss-crossing the organ with a knife, not cutting deeply, then apply common salt or a mixture of equal parts of powdered allspice, salt, and ginger; then turn the part back as before.

Where gangrene has set in, amputation of the uterus will be necessary if the life of the ewe is to be saved. This can be done by taking a needle with a double thread and passing it directly 
through the neck of the organ as far up as possible. Cut the ends of thread next the needle, leaving four separate ends; then take the ends of one thread and tie a simple knot, bringing it tight. This will enclose and effectually stop the circulation of half the stem. Do the same with the other thread, and then sever the parts outside of the suture with a sharp knife. After the uterus has been amputated, place the ewe in such a position as to raise the hind parts. Administer also an opiate, such as four drachms of laudanum or one grain of sulphate of morphia.

In cases of inversion of the uterus, if the womb tends to prolapse after it has been returned to position, it may be necessary to take a deep suture with sterilized silk through the lips of the vagina, or a pessary can be inserted in the vagina, a simple and efficient method being the introduction of a pig's bladder, previously softened by soaking in warm water; its external surface is well oiled, and after it has been placed in position, is blown up through a tube inserted in the neck; the neck of the bladder is then secured to prevent the escape of the air and is left inside till all danger of prolapse is over.

\section{Inversion of the Vagina.}

This is a condition very similar to prolapse of the uterus, and may be accompanied by that condition. When occurring, it is generally as a sequela to premature rupture of the foetal membranes and escape of the "waters."

The young animal, on being extracted in a rough manner, so lacerating and bruising the delicate mucous lining of the vagina, and also the underlying connective tissues, causes a flaccidity or lack of firmness in the tissues, leading to inversion, which may take place immediately following the delivery, or at a later period, caused by straining due to after-pains, or it may take place any time during several days subsequent to parturition. It is also met with following abortion or retention of the foetal 
membranes. It is an accident which may occur in other than pregnant females, due then to lack of tone in the parts, or some injury, and also can occur during pregnancy in the latter period of gestation, caused then by pressure from the gravid uterus.

\section{Symptoms.}

Notice a circular redilis mass projecting from and between the lips of the rulra. Its surface is smooth unless lacerated and covered with particles of foreign matter from contact with the soil. The tumor appears larger when the ewe is lying down. An examination of the mass will be necessary to differentiate between this condition and inversion of the uterus. In that condition the cotyledons or placental papillae are easily discernible. In inversion of the vagina, the mass is perfectly smooth and marked on its under surface with a furrow, leading to the urethra, and in some cases the cervix uteri can be seen situated in the middle of the mass.

\section{Creatment.}

Trash off with a warm antiseptic solution, and commencing from each side, at the lips of the vulva, turn the edges invards. gradually manipulating the mass till it has regained its normal position. Where the parts have become lacerated it is necessary to apply topically some astring'ent an'odyne agent.

Take. Lead acetate............... 1 ounce

Dissolve in one pint of water, to which may be added two ounces of laudanim. This can be injected into the vagina, and if necessary a deep suture can be taken through the vulva, the same as advised in inversion of the womb.

\section{Inflammation of the Vagina.-Vaginitis.}

This follows generally as the result of injury inflicted to the vagina during parturition. It is as a mle accompanied with inflammation of the womb (metritis), in which case it is a very grave affection. 


\section{Symptoms.}

In appearance the lips of the vagina are very much swollen, the mucous lining of the carity being of a deep red or livid color, frequently corered with patches of congestion; the parts feel hot and dry; the natural secretion having ceased. Pain is evidenced by the ewe when urinating; the vulva itches intensely; the ewe will rub against posts, etc., and in so doing is liable to lacerate the * parts. As the inflammation progresses, the mucus secretion which was at first suppressed becomes abnormally increased, flowing as a serous liquid, streaked with blood, changing into a purulent discharge, which in passing over the thighs exerts a caustic and excoriating effect on the skin. Where the inflammation is excessive it has a tendency to terminate in gangrene, in which event the ewe is liable to succumb from septic poisoning; this termination, however, is rare.

\section{Creatment.}

Wash the parts in warm water, and use astringent injections; that suggested in "Inversion of the Vagina" can also be used in these cases with good effect. Should there be danger of gangrene, iron and quinine can be administered internally and the parts dresied with carbolized oil.

\section{Inflammation of the calomb-Metritis.}

Parturient fever is a serious condition, due to one of several causes, such as injuries to the genital canal during parturition, retention of the foetal membranes (after birth), or the introduction of septic material, and exposure to cold during lambing has also been claimed as a cause of this condition.

\section{Symptoms.}

The ewe evidences symptoms of distress; the pulse is full and bounding: the respirations are hurried; the visible mucous membranes are congested; the lining of the vagina is inflamed, 
and the rulva swollen; the bowels are constipated, and the natural secretion of milk is suppressed. The ewe lies down, and if foreed to rise does so reluctantly. A discharge from the ragina is noticeable-at first transparent, soon becoming reddish in color and thick. The rumen is liable to become distended with gas, and in cases which terminate fatally the temperature will remain persistently high. Where the inflammation extends to the peritoneum dropsy of the abdomen frequently follows as a sequelain these cases the abdomen becomes enlarged, giving the subject a full appearance.

\section{Treatment.}

In these cases it is always advisable to commence treatment with a full dose of Epsom salts. The following is a useful prescription:

Take. Epsom salts..............2 ounces

Common salt............2 ounces

Ginger ............... 1 drachm

Molasses ............... 8 ounces

Mix and give as one dose.

Place the ewe in warm comfortable quarters, and where the temperature appears high, give full doses of quinine and aconite combined. If the udder is swollen, bathe frequently with hot water, and after each fomentation apply some soothing ointment, such as

Poke root powdered......... $\frac{1}{2}$ oz.

- Benzoated lard ............. 2 oz.

\section{Malignant Parturient fever.}

This is a very grave condition indeed, due in all cases to septic infection, complicated frequently with erysipelas. It is virtually a blood-poisoning, and must not be confounded with simple parturient fever. It can be carried from ewe to ewe by the lamber making examinations of ewes which are in the act of parturition, after having handled an affected subject. 


\section{Symptoms.}

All the symptoms of parturient fever are present in an aggravated form; the bowels at first are generally constipated, but as the disease progresses they become relaxed, diarrhoea setting in, the discharges being foetid, and in many cases accompanied by or streaked with blood. The ndder is very much swollen, and shows symptoms of erysipelas infection. When this occurs the patient rarely, if ever, recovers. The ewe shows signs of abdominal pain, and strains frequently, a sanious foetid discharge being ejected from the ragina during these efforts. The disease runs a rapid course, the animal becoming delirious, coma setting in just prior to fatal terminations.

\section{Post-Mortem Appearances.}

The womb is enlarged and thickened; the mucous membrane lining it is of a darkish brown color, darker patches being noticeable in places. In the carity of the womb, a chocolatecolored fluid is present, in which remnants of the foetal membranes are often found; the whole organ presents the appearance of rapid decomposition, and has a very foetid odor. The ragina frequently has ulcerous patches on its mucous surfaces, particularly round the vulva and meatus urinarius (opening of the urethra into the vagina). The abdominal cavity contains a reddish liquid, the whole peritoneal surface showing signs of intense infiammation; this is particularly noticeable in that part covering and supporting the womb. The muscular tissues are dark, at times almost black. The udder is sometimes spotted with gangrenous patches, resulting from a previous erysipelatous condition of that organ. Plain signs of general septic infection are also noticeable.

\section{Creatment.}

Should be on the same lines as that prescribed in "Metritis." A laxative drench is always to be recommended in these cases, especially at the conmencement of the trouble. 
The womb should be thoroughly syringed out with warm antiseptic douches. Permanganate of potash, one half drachm, in one pint of water, or injections of carbolic solutions in strength of one to forty will be found bencficial. Internally, quinine and iron are indicated, or salycilic acid combined with carbolic, and administered frequently but in very small doses. The strength of the ewe must be maintained by such stimulants as aromatic spirits of ammonia, alcohol, etc.

Take. Salicylic acid............. grs. $x$

Carbolic acid 90 per cent sol....... m. iii

Dissolve in one ounce of gruel and give as one dose, repeating every two hours, or

Take. Sulphate of quinine........... drachm

Tincture chloride of iron...... $\frac{1}{2}$ unnce

Water ............... 12 ounces

Mix and give one ounce as a dose, repeating every two hours. As a stimulant, the following is useful:

Take. Sulphuric ether............. cz.

A romatic -pirits of ammonia...... 3 oz.

Alcohol ................ 3 oz.

Dose one ounce in four ounces of water, repeated every three hours. To the inflamed udder apply warm fomentations frequently. Between these the gland should be dressed with the ointment of poke-root and lard previously mentioned, or envered all over with a thick coating of raseline. In all these cases the lamb should be taken away at the commencement of the attack. This disease is very liable to terminate fatally, to prevent which careful nursing is very necessary.

\section{Garget-Mammitis, or Mastitis.}

Is a congested condition of the udder, which may be due to several causes, among which may he mentioned exposure to coll or wet, or the udder bccoming loruised from contact with hast 
ground when the ewe lies down, or when the ewe has only one lamb to suckle, which is unable to take the full supply of milk; or it may arise as a sequela to diseases of parturition, such as parturient fever, or puerperal septicaemia. This is a very frequent condition with ewes, attacking them more often than it does other species of mammalia. It is a troublesome and dangerous affection, sometimes proving fatal from mortification of the parts taking place, and very often learing the udder in an enlarged, indurated condition, ruining the ewe for breeding purposes, necessitating her being fattened and sold for slaughter.

\section{Symptoms.}

As seen occurring following injuries or exposure, swelling of the gland or part of it, appears suddenly. This swelling is hard and tense; the secretion of milk is impaired, that which is secreted being frequently streaked with blood; in mild cases, the ewe suffers rery little pain, and there is no perceptible fever. These conditions tend to make a favorable recovery, but in cases of septic infection, the symptoms are aggrarated, the disease being prone to run a malignant course. The swelling generally commences at one of the teats, rapidly spreading to other portions of the gland. The swelled portion pits on pressure, having a doughy feeling; symptoms of ferer are well marked; the ewe appears dull and off its feed; rumination is suspended; the pulse is quick and hard, all signs of systemic derangement being present. The skin of the udder is rery red and, in severe cases, turns black, mortification setting in. The gangrenous portion of the gland commences to slough; the disease has a tendency to extend to the skin of the abdomen, simulating erysipelas; the affected ewe loses flesh rapidly; death may ensue from blood-poisoning. This malignant form of inflammation of the udder is generally considered to be contagious. Serere cases run a very rapid course, sometimes fatal terminations taking place in twenty-four hours after manifestation of the first signs of the trouble. 
Where recovery takes place, the part of the udder which was affected is liable to remain in an indurated, scirrhus condition, and even should this not be the case, the condition is liable to recur, making the ewe of little value to breed from.

\section{Creatment.}

In all cases of garget, the lamb must be taken away and put to another ewe or raised on the bottle. The ndder must be frequently bathed in warm water, using about two ounces of cooking soda in every quart of water. Between the fomentations dress the part with camphorated oil. Internally, in all cases accompanied with high ferer, aconite can be given with good results. A full dose of Epsom salts should be given at commencement of treatment.

Where blood-poisoning is to be anticipated, quinine and iron will be found useful, and also fluid extract of poke-root, internally, given in half-teaspoonful doses every three hours, which often contributes materially in controlling the inflammation of the gland.

If abscesses form, they must be opened and the contents evacuated, the after-treatment consisting in washing out the pockets with some antiseptic fluid and seeing that the parts are kept clean. Where gangrene sets in, the affected portion must be amputated. This can be done withont danger of excessive hemorrhage if the parts are incised inside of the line of demarkation. The edges of the wound should be dressed daily with oil of turpentine.

Recovery from malignant attacks is a slow process. The ewe will generally "slip its fleece." This is of frequent occurrence, however, following febrile conditions in sheep.

\section{Cracked Ceats.}

This is quite a common condition, which may be caused by the lamb pulling on an empty teat, or mas be the result of infec- 
tion, as in aphtha, where the disease is transmitted from the mouth of the lamb to the ewe's udder, or may arise from a number of simple causes which it is unnecessary to enumerate here.

Cracked teats, when not due to contagious affections and where the fissures are superficial, will, as a rule, readily yicld to treatment. But where the fissures are deep and bleed readily they are extremely sensitive, and the ewe will not permit the lamb to suckle. This condition then is liable to result in obliteration of the duct, and may finally terminate in inflammation of the udder from the retention of it: contents.

\section{Treatment.}

Consists in drawing off the milk with milk tubes, and dressing the fissures with flexible collodion or glycerine and tannic acid.

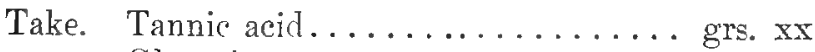

Glycerine . ............ 1 oz.

Mix and apply to -opre with a brush or feather.

\section{founder, following Lambing-Parturient Iraminitis.}

The causes leading up to this condition are not very well understood. The rmptoms are lameness due to inflammation between the claws, extending up to the coronets and heels. Cold applications appear to gire more atisfactory results than loot. Internally aconite in small frequent doses combined with quinine, to which, if the pain seems excessive, opium may be added. A moderate dose of Epcom salts should be administeled; the eve should be kept in comfortable quarters, and giren light, laxativa food. The secretion of milk is suppressed from the commencement of the attack, and the return of milk can be regarded as a sign for quick recorery. 


\section{Diseases of the Newly-Born.}

\section{Hephixia.}

This is generally due to interrupted circulation in the umbilical cord, from pressure on it in the passing of the foctus through the pelvis.

Clean any secretion from round the nustrils; close the mouth and blow in to the nostrils; shoulul respiration be established, give a stimulant, or pour a few drupe of brandy into the nostrils, place the lamb where it will be kept warm.

\section{Bleeding from the Umbilicus- - Ambilical Kaemorrbage.}

This comes, as a rule, from the cord being serered too close to the body. The application of -typtics or astringent, such as nitrate of silver, or tannic acid, will as a rule, correct this condition.

\section{Inflammation of the Ambilical Cord-Navel Ill.}

This is a very serions and fatal affection, appearing to be of specific origin. It fir t appears a inflammation of the umbilical vein, but rapidly spreads to the adjoining ti-ues, tarminating in systemic blook-poisoning.

This disease generally runs a malignant course, the inflarnmation rarely being confined to the umbilical vein. A clot forms at the umbilicus, which causes suppuration and the forming of a pervious opening or fistula. The inflammation ascend the unbilical rein, as the clot enlarges and ascend; until the whole course of the vein as high up as the liver becomes affected, the trouble extending frequently to the portal and hepatic veins.

\section{Symptoms.}

The umbilical cord, instear of drying and withering up after birth of the lamb, remains moist and enmmences to swell, projecting from the navel slightly. feeling hard and unyielding, 
and in size about the thickness of a common lead pencil. From the center of the projection flows a thin, viscid fluid, which does not possess any particular odor. The nere fact of the umbilicus presenting this appearance is evidence of the disease.

The general symptoms are as follows: First notice the lamb to appear dull, assuming a recumbent position, rising with reluctance, and when made to rise, stands with the back arched, all four feet drawn together. The lamb will not care for the teat; appears to be suffering from a dull pain; the respirations are hurried, particularly so when septicaemia ensues.

As the trouble progresses all the symptoms become aggravated; the region around the navel commences to swell, and is painful to the touch; the bowels which at first may have been constipated, become very loose, the discharges being offensive, which is nearly always the case in systemic blood-poisoning; the urine is scanty and at times verr red in color; the visible mucous membranes become yellowish-an evidence of liver complication; swellings take place in various portions of the body, particular? around the hock joints. When these appear the subject shortly succumbs.

\section{Creatment.}

This is mainly preventive, and as the cause is fairly well determined, and the preventive treatment being simple to use as well as effectire, there is hardly any excuse for the occurrence of this fatal complaint.

Cleanliness is the main preventive agent, adopting measures to prevent the freshly-severed umbilical cord of the newly-born lamb from coming in contact with filth or other material liable to harbor the germs of this disease.

Directly, or as soon as possible after birth, anoint the fresh$1 y$-severed cord with a solution of carbolic acid, or some other powerful antiseptic agent. If this is carefully followed out during the lambing season, there will be very few deaths from "navel-ill." 
But when the disease has once obtained a foothold, its treatment will be found very difficult and unsatisfactory. Even when successful, recovery is tardy, the lamb taking a long time to mature and proving an unprofitable feeder.

Syringe out the opening of the umbilical veir with an antiseptic solution:

Take. Acid salicylic............20 grains

Acid carbolic 90 per cent. (sol.)... $\frac{1}{2}$ drachm

Water................2 ounces

Mix. Use as an injection several times daily.

Internally, those agents should be given which have a tendency to counteract blood-poisoning and support the system. Give the salicylate of soda in ten-grain doses every hour, alternated with fifteen minims of the tincture of iron (med). Feed skimmed milk warm, or fresh cow's milk diluted one-third with warm water. If the lamb will suck, give the teat. See that the ewe gets plenty of nourishing diet to eat.

Where navel-ill breaks out as an epidemic, the flock should be mored to fresh pastures or lots, and care taken to treat each lamb as fast as it is dropped.

\section{Retention of the Meconium.}

The contents of the intestines of the foetus are called the meconium. They are as a rule voided immediately after the lamb is born. Should this not take place, however, means must be taken to insure the removal before ill-results appear. This is effected by oiling the anus with sweet oil, injecting a small quantity, or inserting therein a small piece of soap. If removal does not take place the lamb will show signs of pain, refuse to suck, and after a few days of suffering will suceumb from inflammation of the bowels.

\section{Imperforate Anus.}

Is a malformation, the rectum not being communicable with the 
outside of the body. Sometimes the termination of the gut can be felt under the skin where the anus should be. In these cases an incision can be made and the end of the gut fished up and sewed to the edges of the incision. Success is doubtful, however. The cheapest and best method is the destruction of the lamb, as it otherwise would have to linger and suffer, only ultimately to succumb. The same condition may exist in connection with the vagina, or the prepuce of the male. They are simply mentioned here as malformations, and not to advise any special treatment.

\section{Cyanosis.}

Is also another mal-formation of young animals. It $i$ s caused by the non-closure of the foramen orale at the time of birth, which produces a mixed venous and arterial circulation-hence the name of "Cyanosis"-(blue disease), from the blue color of the mucous membranes. kirth.

No cure. Death nsually takes place in a short while after

\section{Skin Dryness.}

This is a condition when the lamb after being dropped, through neglect or inability of the ewe to reach it, becomes dry, the result being that the ewe does not recognize it as her offspring, from its lacking some peculiarity which it seems to possess when wet with the amniotic fluid.

This is frequently met with in young ewes with their first lambs, and it is a fact that smearing the lamb with the foetal membranes will cause the ewe to recognize and care for it.

To make a ewe care for a strange lamb, something which is very frequently necessary in the lambing season, select a ewe which has just been delivered of a single lamb, rub the strange lamb against the fleece of the other while it is still wet and smear it freely with the amnintis fluid which flows from the uterus of 
the ewe. Then present the lamb to the ewe, she will at once take care of it, bestowing the same amount of affection on the stranger as it accords to its own offspring.

\section{Hbortion.}

Is the expulsion of the foetus before it is sufficiently deve'oped to exist external to its parent.

Where the lamb is not carried the full term, but is sufficiently developed to exist for any length of time in the external world, it is said to be born prematurely.

When the foetus is dropped twenty days previons to its proper time or anywhere between the period of its first conception and that time, the ewe is. said to have aborted.

Abortion may occur from several canses, such as climatic influences, cold rains, sudden changes in temperature, or from injurious ingredients in the food-supply, orer-feeding on stimillating and easily digestible food, excessive drinking of cold water, partaking of certain herbs or eating corn-fodder which is mouldy or covered with smut.

Toses of purgative medicine: often are responsible for abortion, as are injuries, sudden back slips, ete. Excitement or fear, such as the chasing of pregnant ewes by dogs; the forcible tup. ping of a pregnant ewe by a ram, neglect, starvation, and many similar causes, but last and the most serious of all, bacteria, which, on gaining access to the ragina of a pregnant animal, quickly cause this condition, and which we shall consider here under the head of

\section{Infectious Abortion.}

This is now recognized as a separate and distinct affection, being due to the introduction of certain germs into the genital passages of the pregnant female, and while experiments and investigations have all been conducted with a view to fix the specificity of this disease as occurring in cattle, without a doubt 
the causes producing the condition in dairy cows are identical with those inducing the same affection in sheep.

It has been conclusively provell that the introduction of a cow to a herd will often be followed by abortion of a number of the members composing the herd, that is to say, if the new-comer is from a herd where abortion has frequently taken place.

It was also found that a bull which served cows that had aborted was liable to carry the infection to other previously healthy cows, with the consequence that while they would conceive and carry the foetus for a certain length of time, the majority would abort, or be prematurely delivered about the seventh month of gestation.

A Scotch commission, selected to enquire into the causes and devise methods for the prevention of abortion among dairy cows in Scotland, made a voluminous report in which the conclusion was drawn that it was virtually a contagious affection, although they were unable to isolate the particular germ responsible for the trouble, but it was shown that the introduction of small quantities of the vaginal discharge from an aborting subject into the vagina of a healthy pregnant cow would be invariably followed by abortion on the part of that animal. In fact it was only necessary to soil the posterior parts and tail of a healthy pregnant subject with the foetal membranes from an affected animal to shortly produce the same condition in the former. It was also apparent that the coniagium was very active in the foetal membranes and tissues of the prematurely delivered calf, and that these being allowed to remain in the field or on compost heaps were a constant source of danger to pregnant animals. As has previously been stated, so far all experiments have been conducted to determine the nature of this affection among cattledairy cows in particular. The loss to the dairyman having assumed large proportions, the production of milk was seriously curtailed by its ravages. While this condition among erres has 
not called for or been made the subject of special investigation, it must not be construed that the trouble does not affect them, but rather that the damage to the ewe flock from this disease has not yet been properly recognized, or assumed such proportions as it has among dairy cows. Abortion resulting from whatever causes manifests certain premonitory symptoms which will at once be noticed by the careful shepherd and place him on his guard to prevent the trouble if possible.

\section{Symptoms.}

The first noticeable symptom will be dullness and refusal to feed; the ewe bleats frequently and appears very uneasy. Should these first premonitory symptoms pass unnoticed, no effort being made to alleviate them by proper treatment, all the signs become aggravated, labor pains set in; and in the course of from six to twelve hours abortion takes place. Cares of abortion arising from accident, fear or improper food, etc., are nsually manifested by the premonitory signs already described; while in cases due to infection there is apparently little if any warning. The ewe is suddenly seized with labor pains, delivery shortly following.

Abortion in ewes is rerr liable to be followed by inversion of the uterus or vagina, or both. Where the foetus is dead before delivery, the placenta is very liable to precede its expulsion, and in these cases inversion of the uterus is frequently net with. In cases of abortion due to infection from septic material, the foetus is generally born dead, the foetal membranes showing mr rked evidence of being diseased.

\section{Creatment.}

'This is both preventive and curative. Then abortion occurs in a flock of ewes and several are affected, it is always prope: to move the flock to fresh pastures, being carcful to separate the ewes which have already aborted from the balance of the fluck. 
The callse must diligently be sought for and remuved if possible. For instance, if the season has heen wet and cold it is well to substitute at once dry food and to move the flock to high ground where the herbage is shorter and less succulent. Ewes which have been subjected to excitement and fear, and show signs of abortion, should be placed in quiet quarters and giren some nerve sedative, such as chloroform, opium, or viburnum prunifolium (the black cohosh which is given with very satisfactory results in these conditions), and can be given in teaspoonful doses in the form of the fluid extract, or an infusion of the crude drug can be made and two ounces given to such of the ewes as manifest symptoms of abortion.

In all cases of abortion, whether due to infection or other causes, the dead foetus and its membranes should at once be destroyed, and not left in the pasture where other pregnant females may come in contact with them. The flock-owner must exhibit great caution and should on no account handle any other healthy nembers of the flock after attending to an ewe during abortion, as he can readily carry the infection, which is liable to spread like wild-fire through the whole ewe flock.

Following abortion in ewes where the foetal membranes are retained the following will, as a rule, cause their expulsion.

Take. Laurel berries, powdered.......2 ounces

Fennel, powdered............1 ounce

Bi-carbonate of soda.........2 ounces

Infuse in two quarts of water, giving eight ounces as one dose, repeating in six hours time if necessary. This mixture is highly recommended by Zundel, who claims that it proves cfficaciots in nearly every instance.

In small flocks of ewes where infectious abortion is to ho feared wash the rulva and base of the tail with an antiseptic solution such as a five per cent. watery solution of carbolic acid. This is an effectual preventive. In these cases it is well to in- 
ject a small portion of the solution into the vagina. This treatment, however, would only be practicable in small flocks, where the value of the animals would warrant individual treatment. In all cases of threatened abortion the ewe should,at once be removed from the flock and should be isolated therefrom for a period of at least ten days. Abortion frequently takes place where the ram has been overworked, having too many ewes to serve, in which event there seems to be a disposition to weakness on the part of the foetus, which prohibits its being carried the full term. This can be rectified by limiting the number of ewes to the ram-a matter which every careful shepherd gives attention to. Ewes in lamb should not be fed on excessive quantities of watery foodstuffs Roots, such as turnips, especially should be fed sparingly. The management of pregnant ewes calls for close attention and care on the part of the flock-owner, which will be more than compensated for in percentage of lambs, besides materially reducing the amount of losses to the ewes themselves during the lambing season. 


\section{CHAPTER XX.}

\section{Medicinal Creatment in General.}

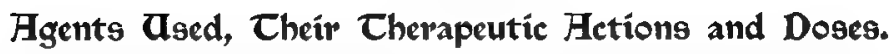

The medicinal treatment of sheep, when applied to a whole flock, differs to a certain extent from that used in the treatment of the individnal members of a flock, in that when a disease breaks out in a herd, requiring that all the members or a large number of then be subjected to the actions of remedial agents, we find it impracticable to use drug-, which, howerer much they may be indicated, possess a nauseous taste, or properties preventing thein from being exhibited in the food. To overcome this difficulty the practitioner or flock-owner has to chiefly rely on hygiene, combined with the presence of simple tonic agents administered in the food or drinking water, several such prescriptions heing innerted for their guidance in the part of this work describing liseasc. However, in the treatment of small numbers, where each animal can be caught separately and the agents administered, by far the most satisfactory results will be obtained, as the animal then will receive just the required amount of the drin or drugs to obtain the desired srstemic effect. Medicines which when taken in quantity (as would have to be the case in wholesale prescribing) are riolent poisons, become invaluable aids to restore normal healthy conditions when given in correct doses. So in prescribing for large numbers of animals, where we have to rely on what each indiridual member will consume along with its food and water, we are at once placed at a disadvantage, as the only medicines suitable for such prescrip- 
tions are necessarily not of the kind suitable for wrise systemic derangements. To combat this disadvantage, as above stated, lyygiene must be relied on. This cannot be too strongly enforced on the minds of the flock-ornner. For instance, in cases of footrot, remove the flock to high, well-ilrained ground, where the surroundings are dry. This, in connection with the treatment prescribed in this work, will effect a speedy cure, but to give footbaths, etc., and leave the animals in the same locality will not be attended with the degree of success sought after. In medicinal treatment it is well to remember that in the animal economy there resides to a great extent what is termed "vis medicatrix naturae," (power of nature to cure itself), and that medicinal agents are only useful in so far as they assist that power, and that animals are frequently injured or recovery retarled or perhaps the sheep are killed outright by the promiscuous administration of drugs. No agent should be giren without the party administering the same knowing just what he is giving, what results he expects to obtain from the rlug and in what manner it is supposed to act, and finally, the correct dose for the subject to which it is to be given. This is a fundamental rule in prescribing medicine. If you would be snceessful in treating vour flock in disease, study their wants and desires when in health. Remember for sick animals no dosing is far and away preferable to the ignorant use of powerful drugs or nauseous concoctions compounded by ignorant and bigoted quacks, who consider that the filthier the agent is which they prescribe the more salutary will be its effects. When in doubt what to use, call in someone who is qualified by his education and experience to prescribe. Tse what he tells you, and don't follow the advice of every loudmouthed empiric, who is generally talking for effect, but when put to trial lacks knowledge of eren the simple necessaries pertaining to the treatment of disease. 


\section{Medicinal Agents.}

Are substances liquirl, solid or gaseonn, which are administered with a view to their exerting some particular effect on the animal ceonomy by which changes incidental to a perversion of normal conditions arising from any cause whatsoever may be overcome and the subject restored to healih.

By the therapeutic action of a medicine, we mean the result obtained on the system from the amount of a certain drug necessary to alleviate or cure disease. By the physiological action of a drug, we mean that action obtained on the system by a drug which is the same both in health and disease.

The following columns describing the therapeutics of the common drug: used, doses and also a certain number of prescriptions, are not written so much for the use of the veterinarian, who by his education is specially fitted to know what agents are indicated and how to combinc them to meet certain conditions, but for the sheep-owner, who can refer to them for guidance, the matter being written in plain language without Latin terms, or abbreriations, so that it can readily be understood, a slight lefinition of certain terms describing the medicinal actions of the drugs being all that will be necessary.

\section{Astringents.}

Agents which cause a contraction of the tissues.

\section{Hiteratives.}

Drugs which by their modification of the nutrition overcome certain pathological conditions, permitting the parts to return to a healthy condition.

\section{Anti-Spasmodies,}

Are feeble cerebral stimulants, which by their action on the nerve-centers increase their tone, thus overcoming minor spasms and nervous conditions. 


\section{Anaesthetics.}

Agents which cause a temporary loss of sensation. There are two classes of anaesthetics: (1) Local; ( 2 ) General.

(1) Local, where the agent being applied to the body produces anaesthesia only at the seat of application.

(2) General. These produce a general condition of anaesthesia to the whole system. They are administered by inhalation.

\section{Anthelminties.}

Drugs which either destroy or expel intestinal worms.

\section{Ant-Hcids.}

Alkalies which, by their chemical action in the system, counteract excessive gastro-intestinal acidity.

\section{Anodynes.}

Drugs which by their power to diminish excitability of nerves or nerve centers, overcome the sensation called pain.

\section{Antiseptics.}

Agents which prevent the develonment of bacilli or spores, causing a condition of septic decomposition.

\section{Catbartics.}

Are agents which stimulate the action of the bowels, causing an increased flow of fluids to the parts. Of these there are three classes.

(1) Laxatives.

(2) Purgatives.

(3) Drastics.

A laxative, causes a mild action. Purgative, a slightly stronger. While a drastic canses a severe purgation.

(Sulphur.

Iaxatives........... (Epsom salts. (Cascara segrada. 
(Senna.

(Castor oil.

Purgatives........... (Epsom salts.

(Jalap.

(Aloes.

(Croton oil.

Drastics........... (Gamboge.

(Colocynth.

\section{Carminatives.}

Are agents which facilitate the expulsion of gases from the stomach or bowels.

\section{Cholagogueg.}

Agents which cause a removal of bile from the intestinal canal, by exciting the bowel movements.

\section{Diuretics.}

Medicines which increase the secretion of urine.

\section{Diaphoretícs.}

Are drugs which by their action on the glands of the skin, increase its secretory functions, producing perspiration.

\section{5ypnotics.}

Agents which, by their action on the system, induce sleep without causing previous cerebral excitement.

\section{Vermífuges.}

Are agents which remove parasites from the bowels by mechanical action, the parasites not necessarily being killed in the process of removal.

\section{Vermicides.}

Agents which destroy intestinal parasites. 


\section{Conies.}

Are medicines which produce a permanent though scarcely perceptible excitement of all the vital functions.

\section{Dose for the Sheep and Lamb.}

Has been arbitrarily set down in the following pages. That of the sheep being close to the maximum amount to be administered in any one dose.

That for the lamb being the amount safe to administer to the young animal of three to four months of age. However the flock-owner must use judgment and grade his dose in accordance with the age and size of the individual animal to which the medicine is to be given, as no hard and fast rule can be laid down in this regard. All the doses given, except when otherwise stated, are for the amount called for of the crude drug. The more convenient form in which to administer medicine is that of the fluid extract, the doses for which being exactly the same as those of the crude drug, prevents mistakes being made as regards the required amounts.

Fluid measure:

60 minims .............. drachm.

8 drachms ..............

16 ounces ................

2 pints $\ldots \ldots \ldots \ldots \ldots \ldots \ldots 1$ quart.

4 quarts $\ldots \ldots \ldots \ldots \ldots \ldots 1$ gallon.

Weight measure:

20 grains..............

3 scruples, 60 grains......... 1 drachım.

8 drachms ...............

12 ounces................ 1 pound.

Symbols:

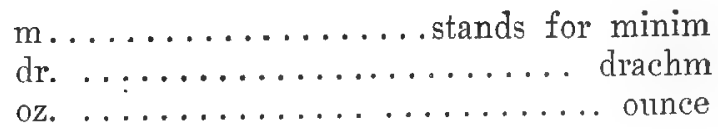




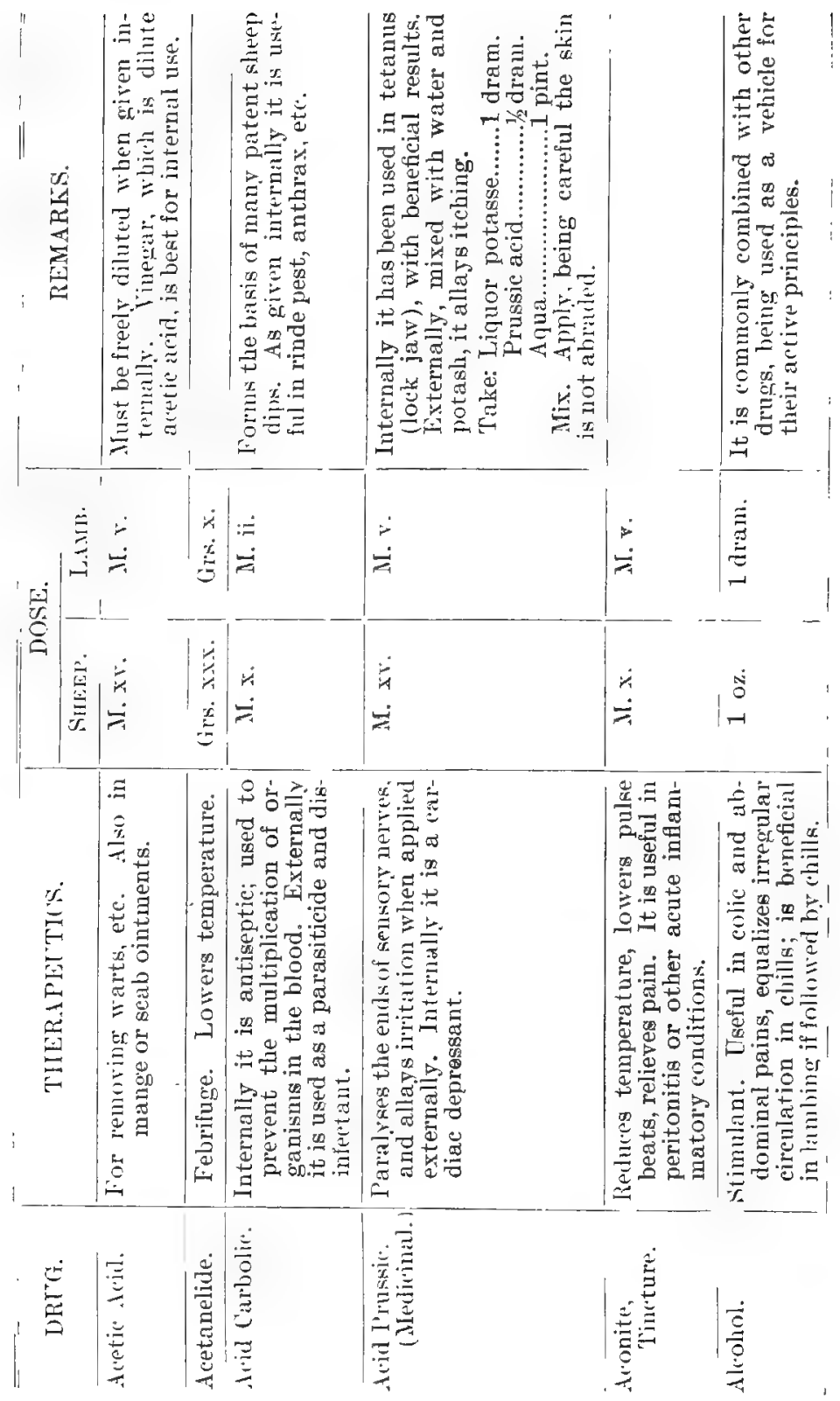




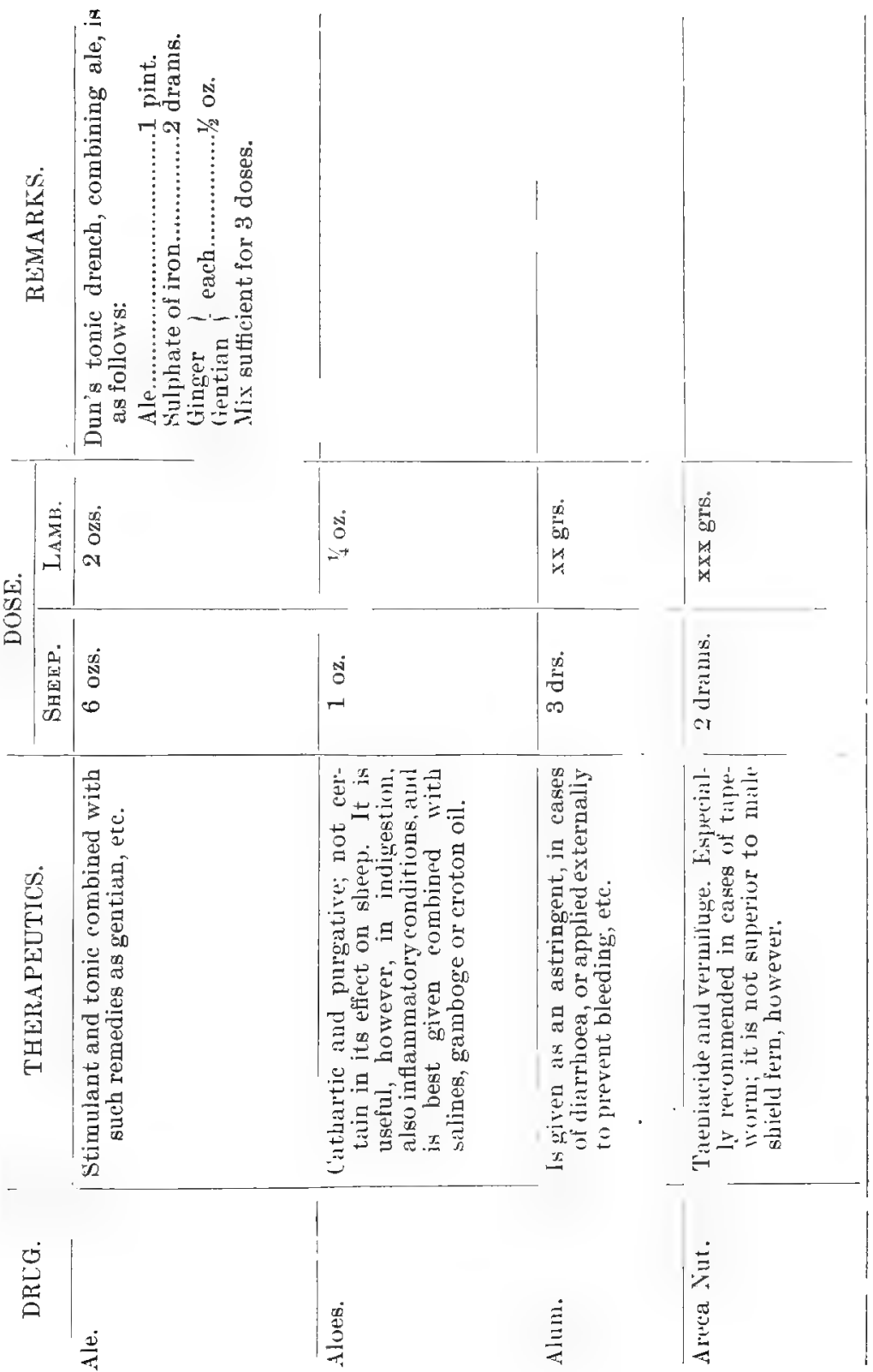




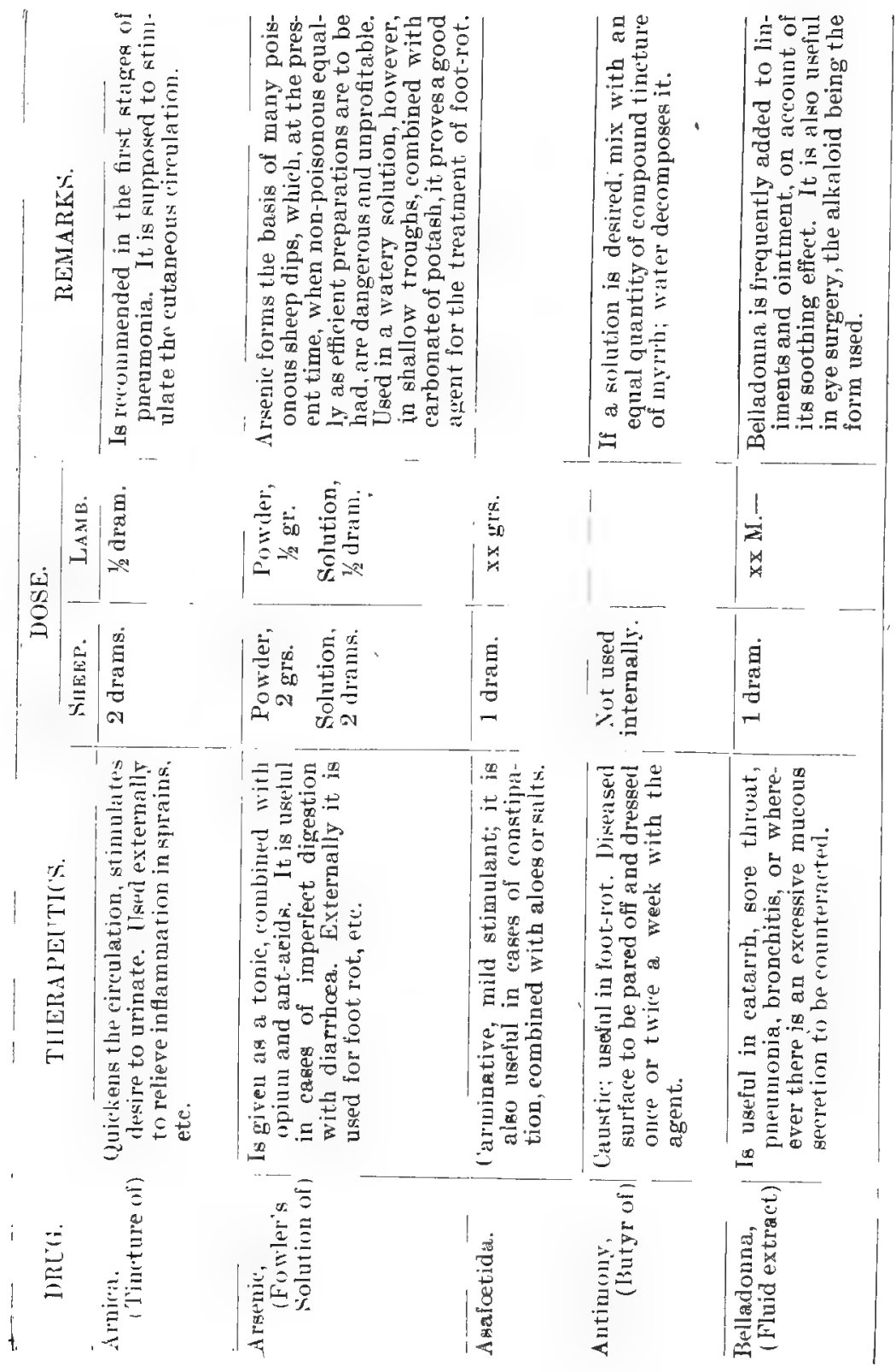




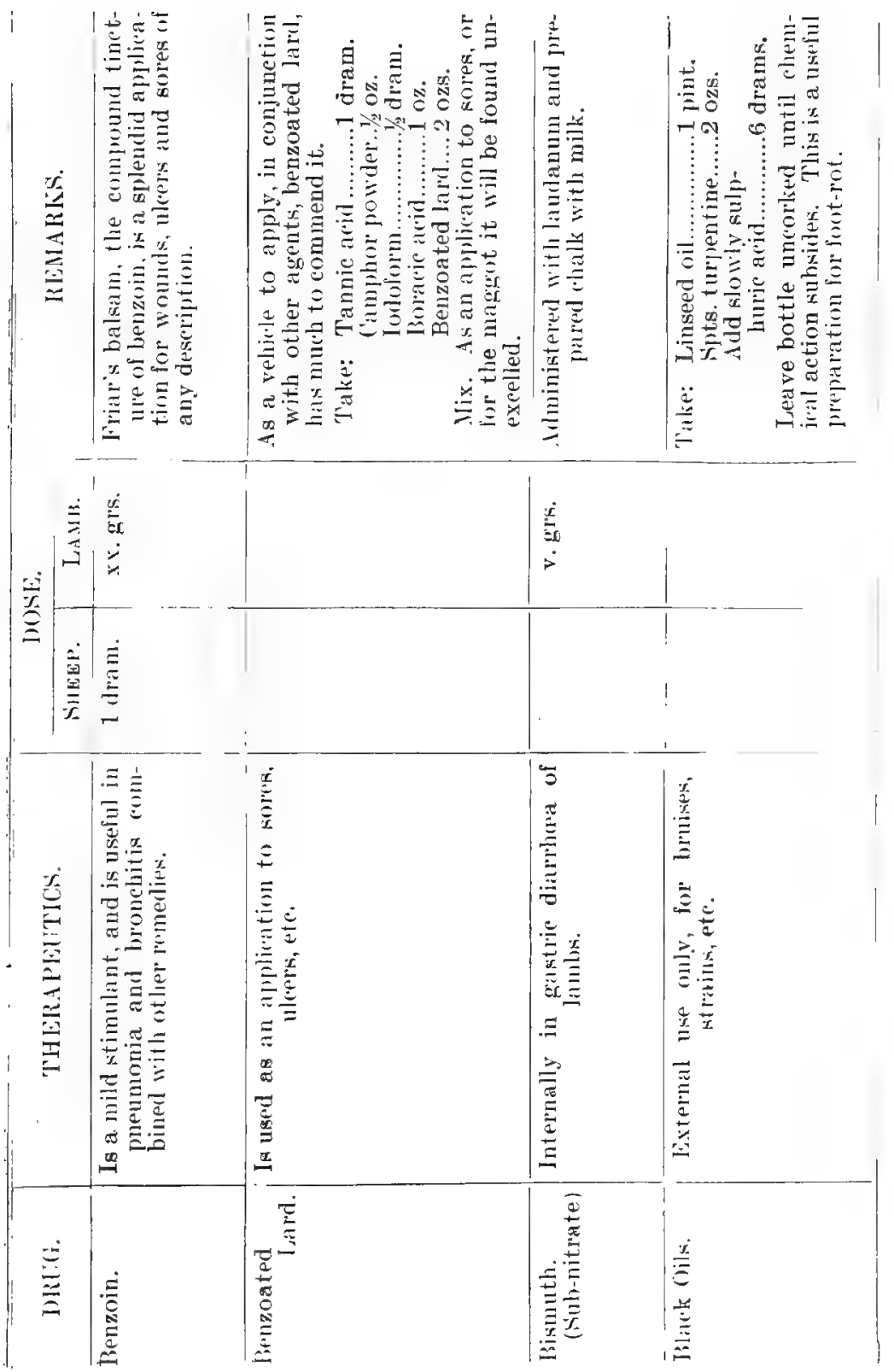




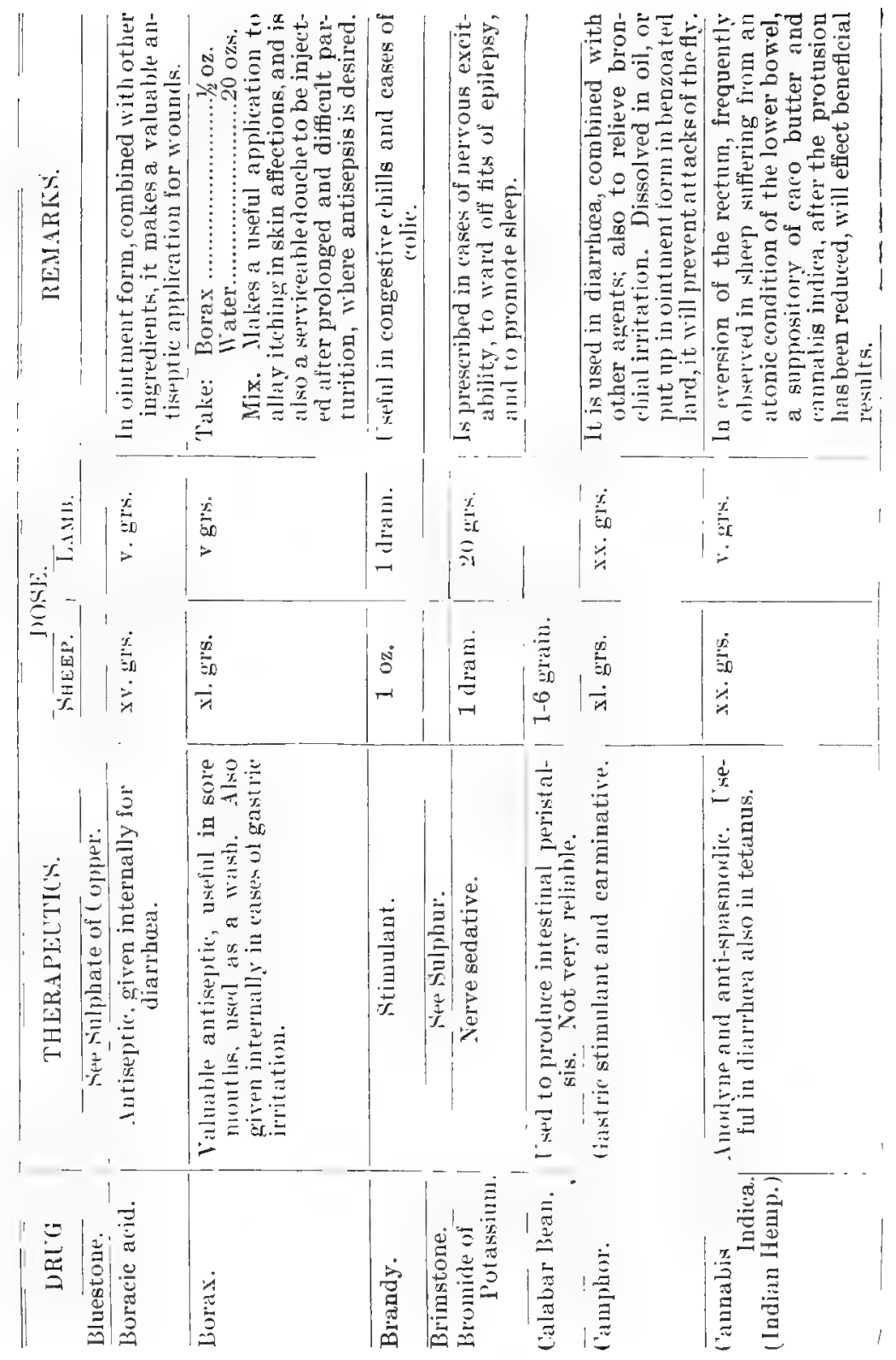




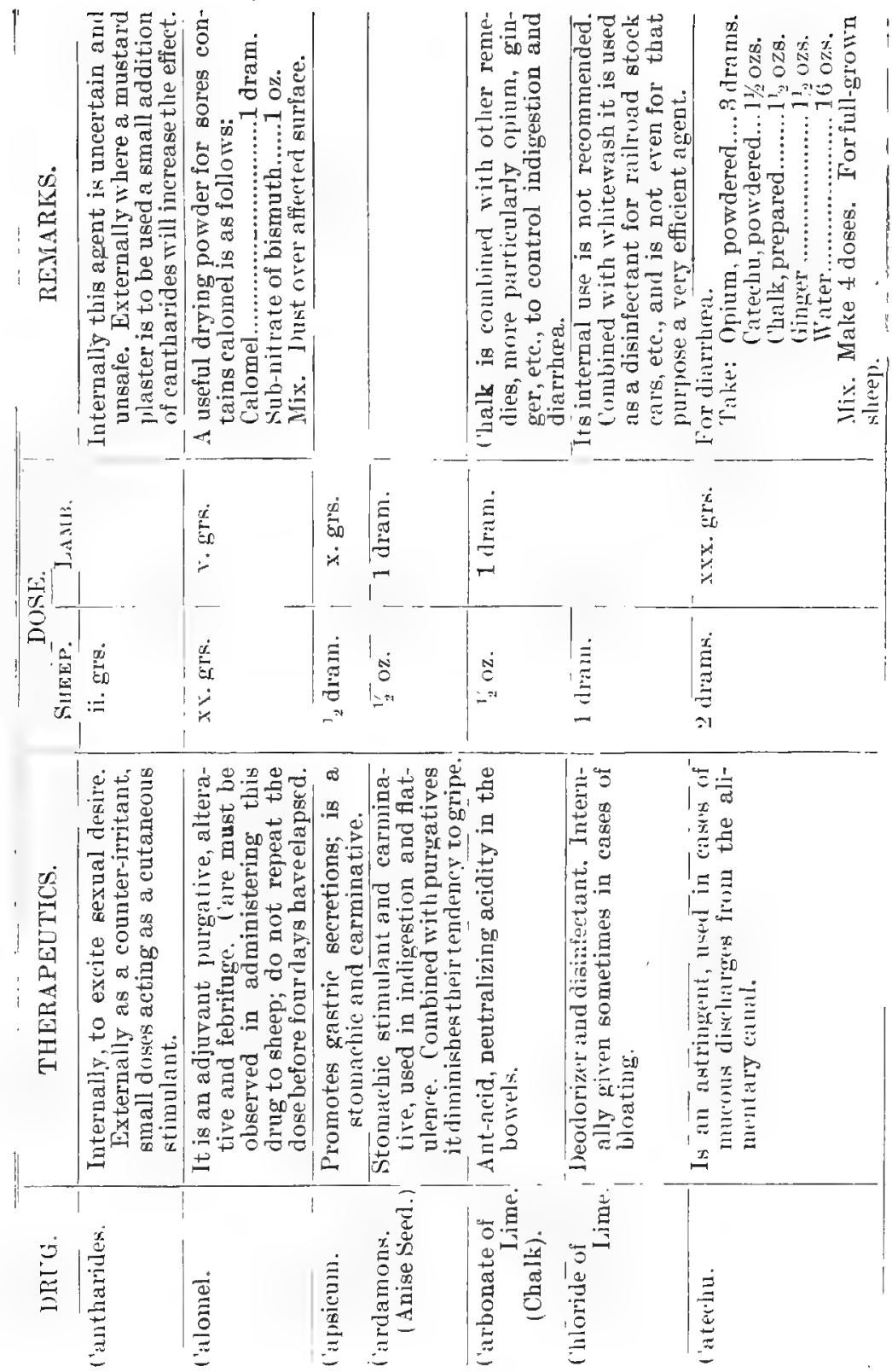


MEDICINAL AGENTS.

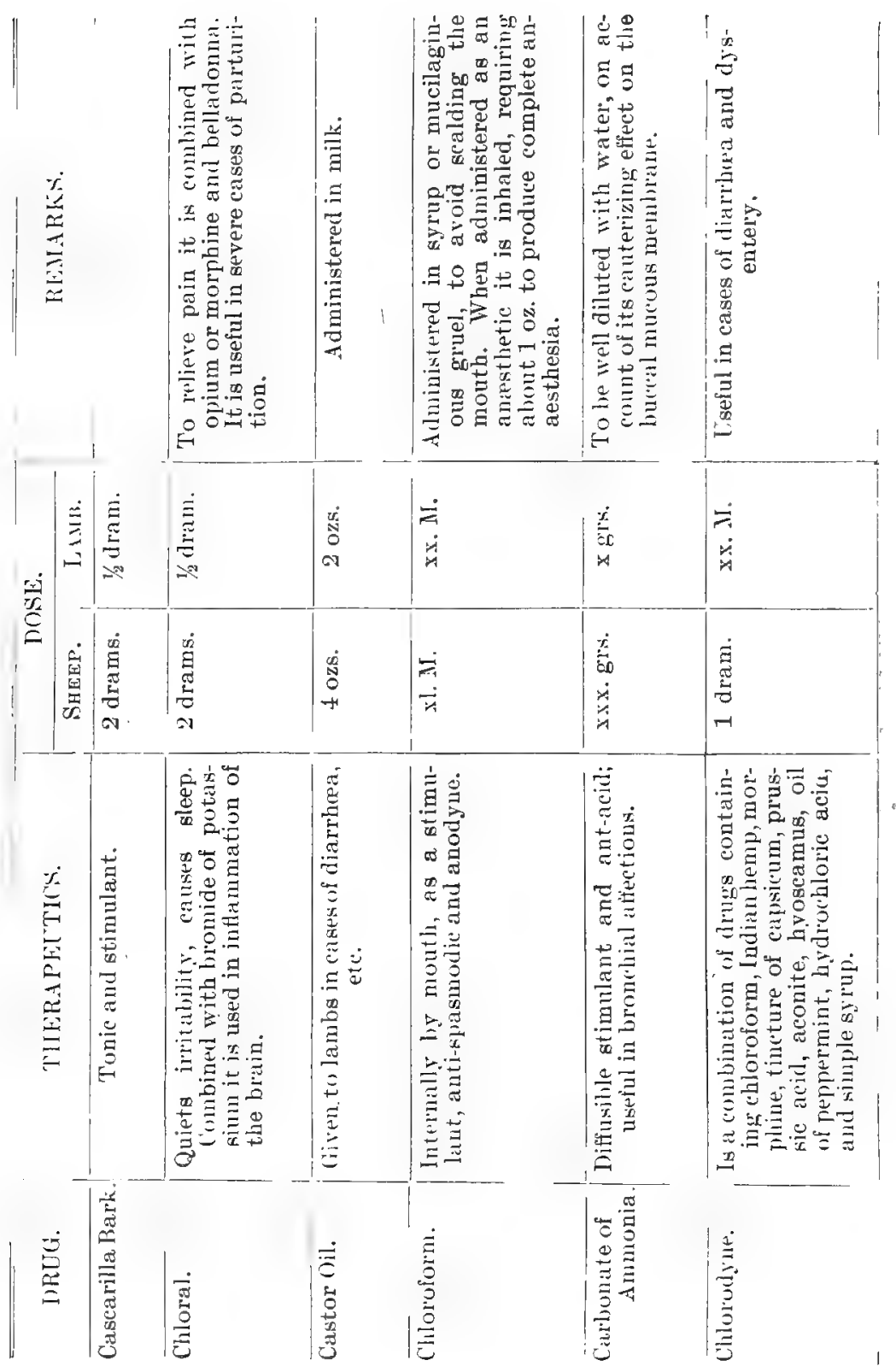




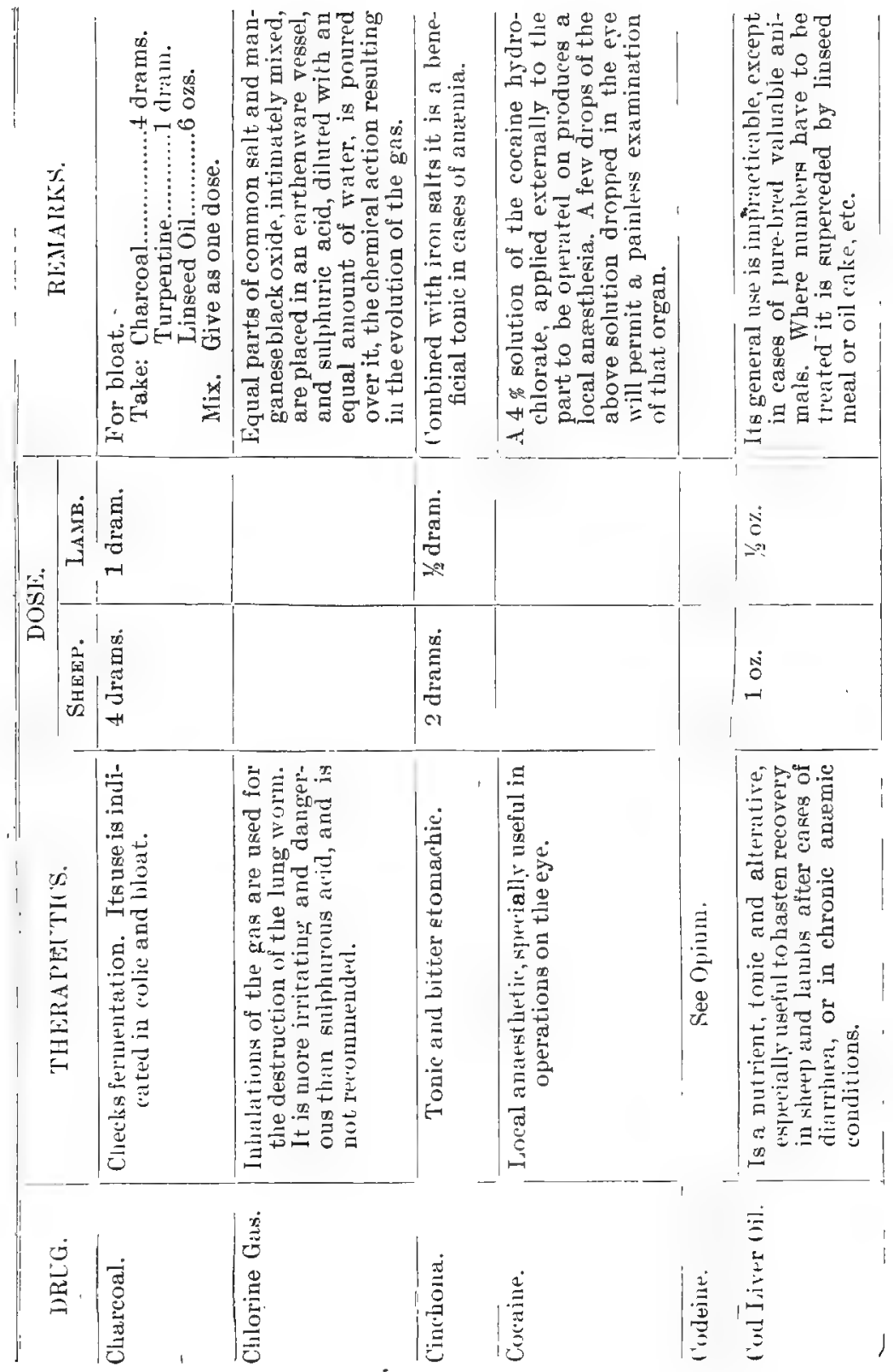




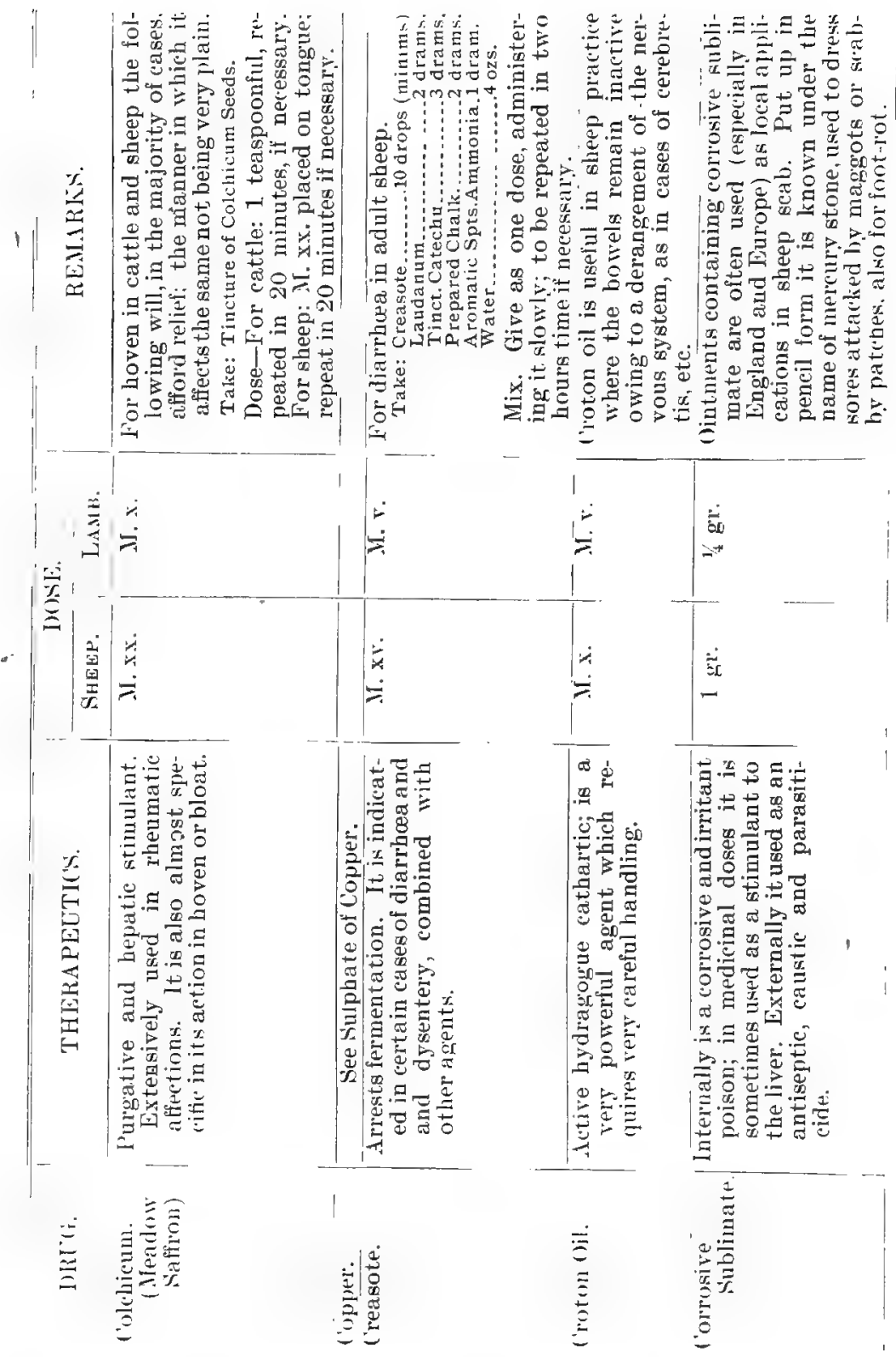




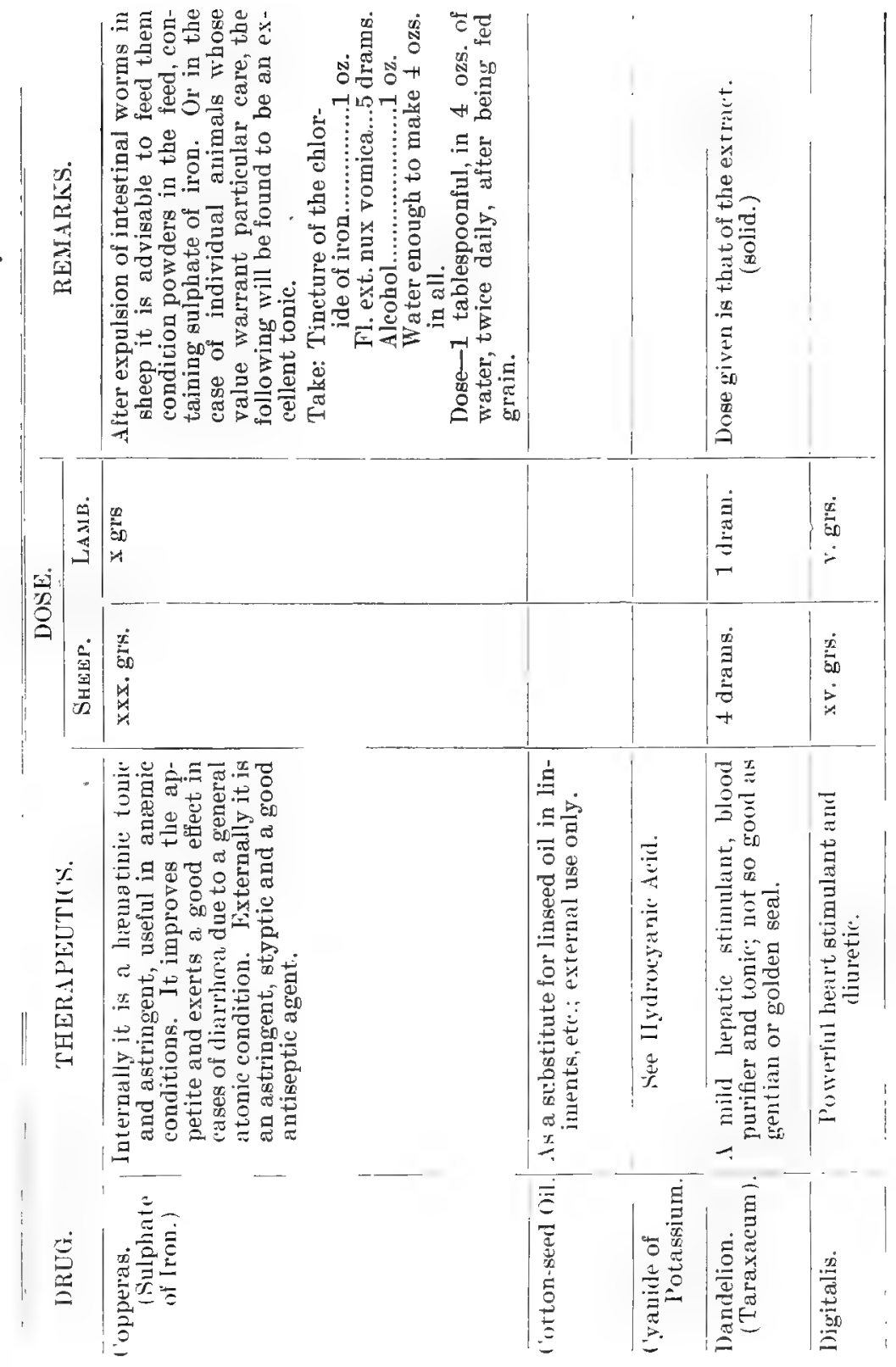




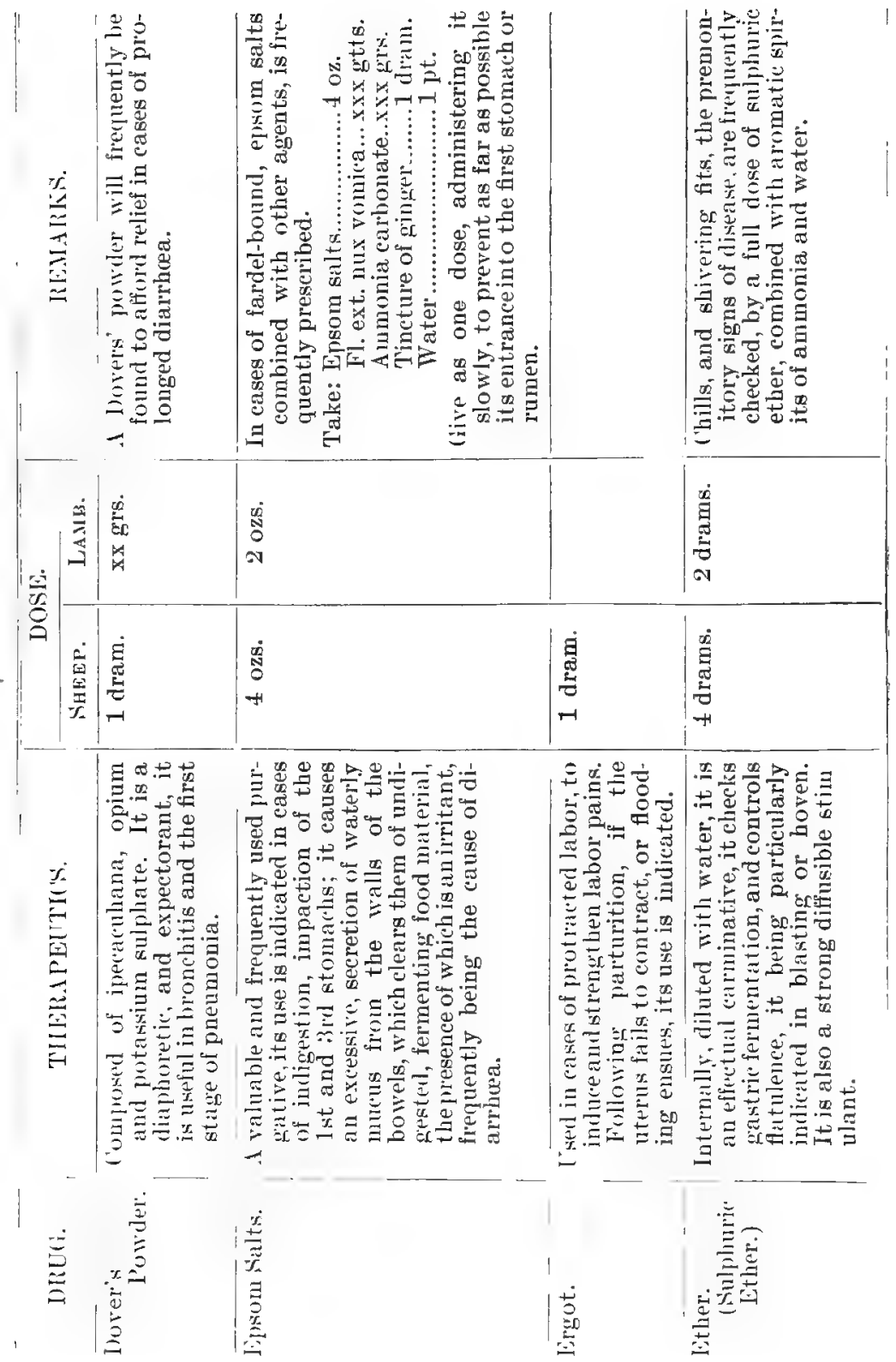




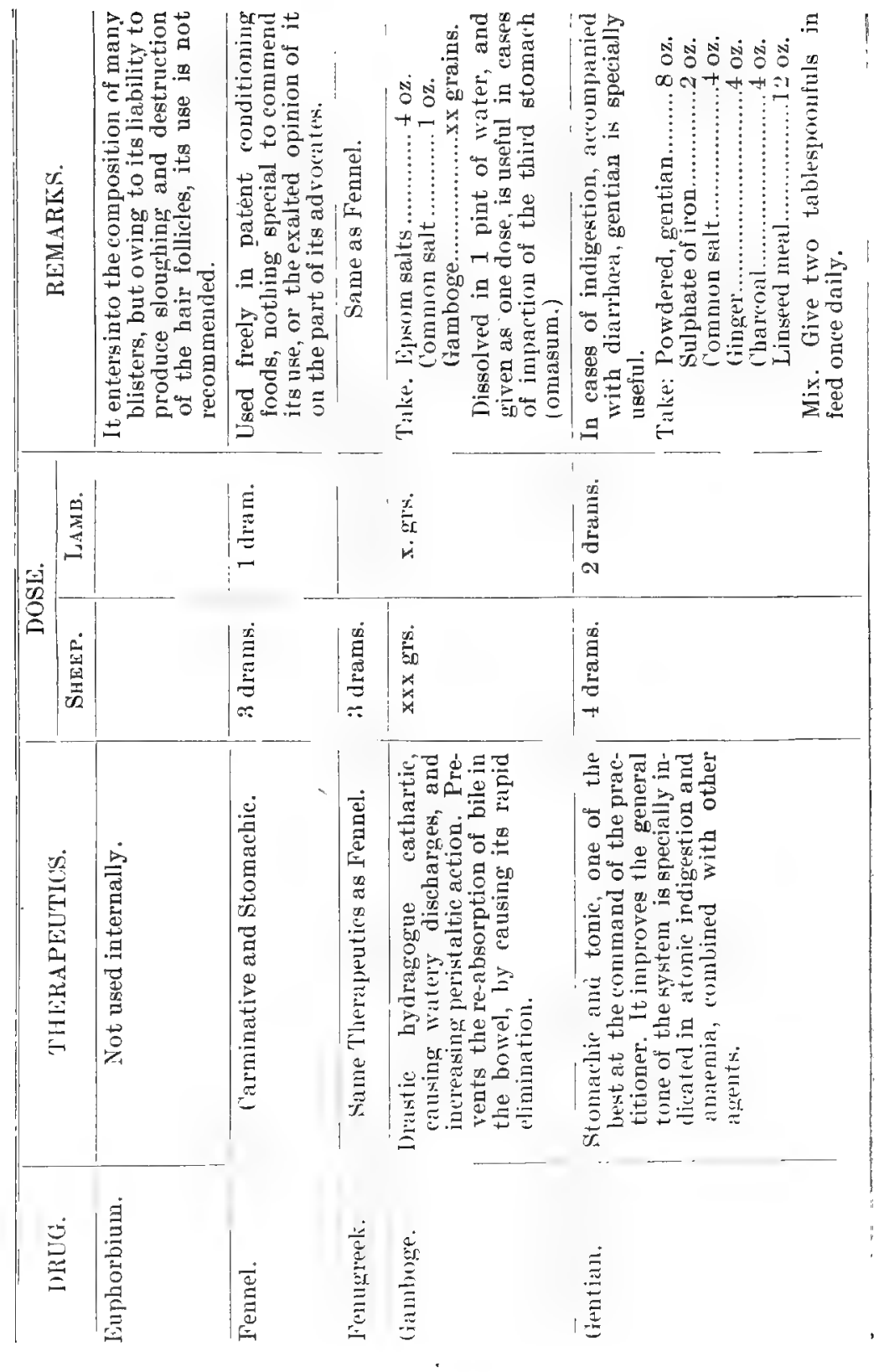




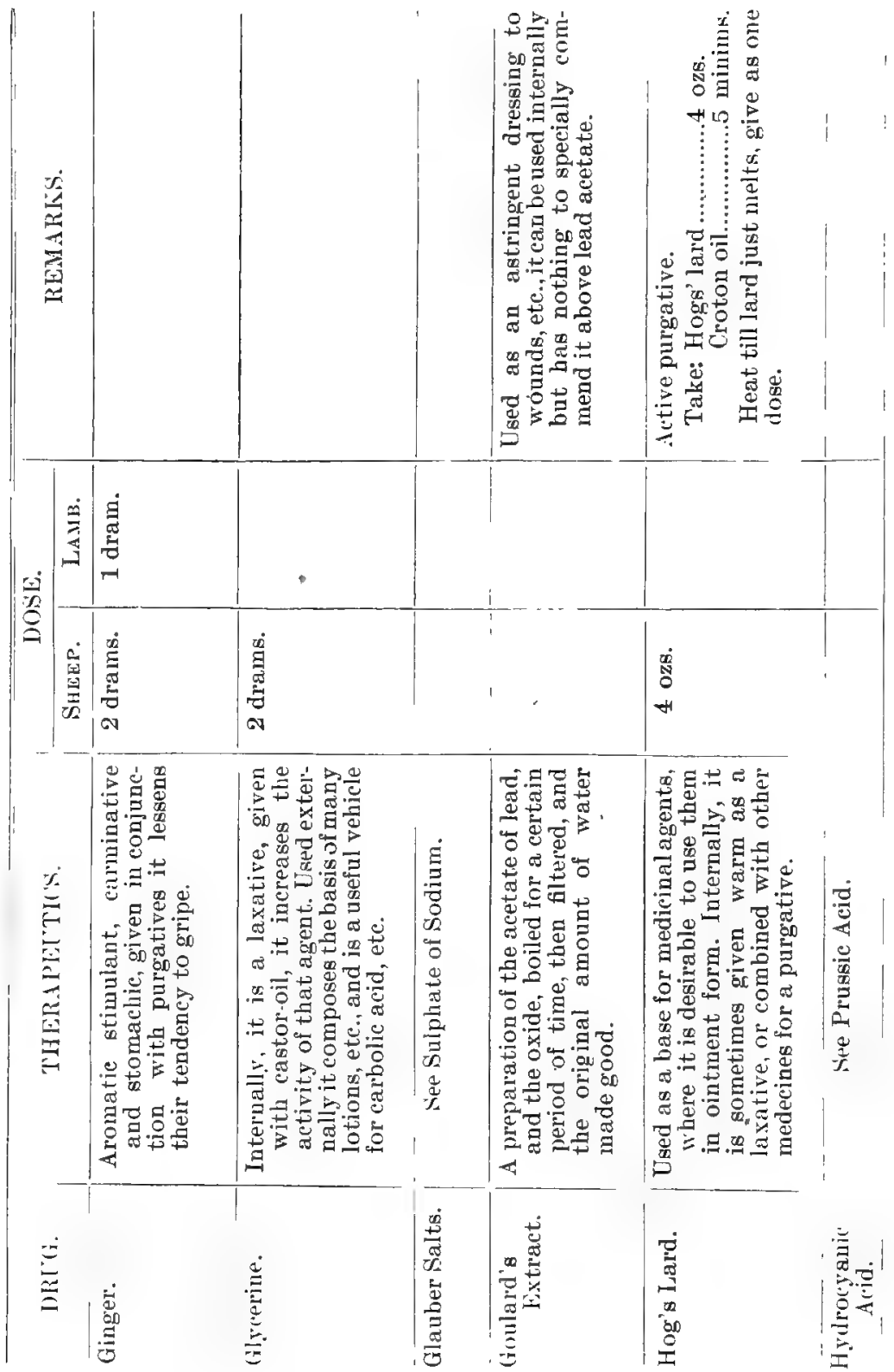




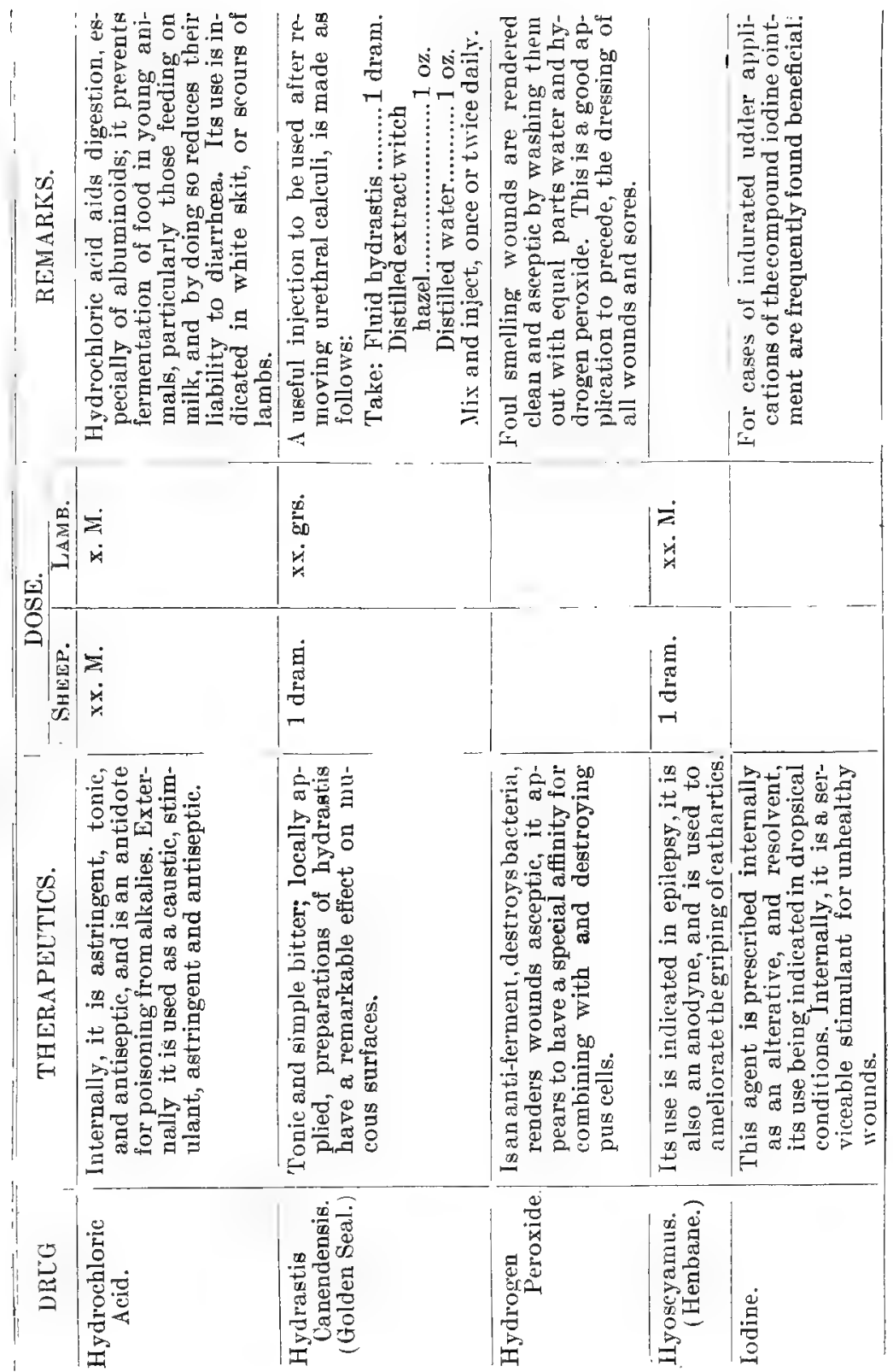




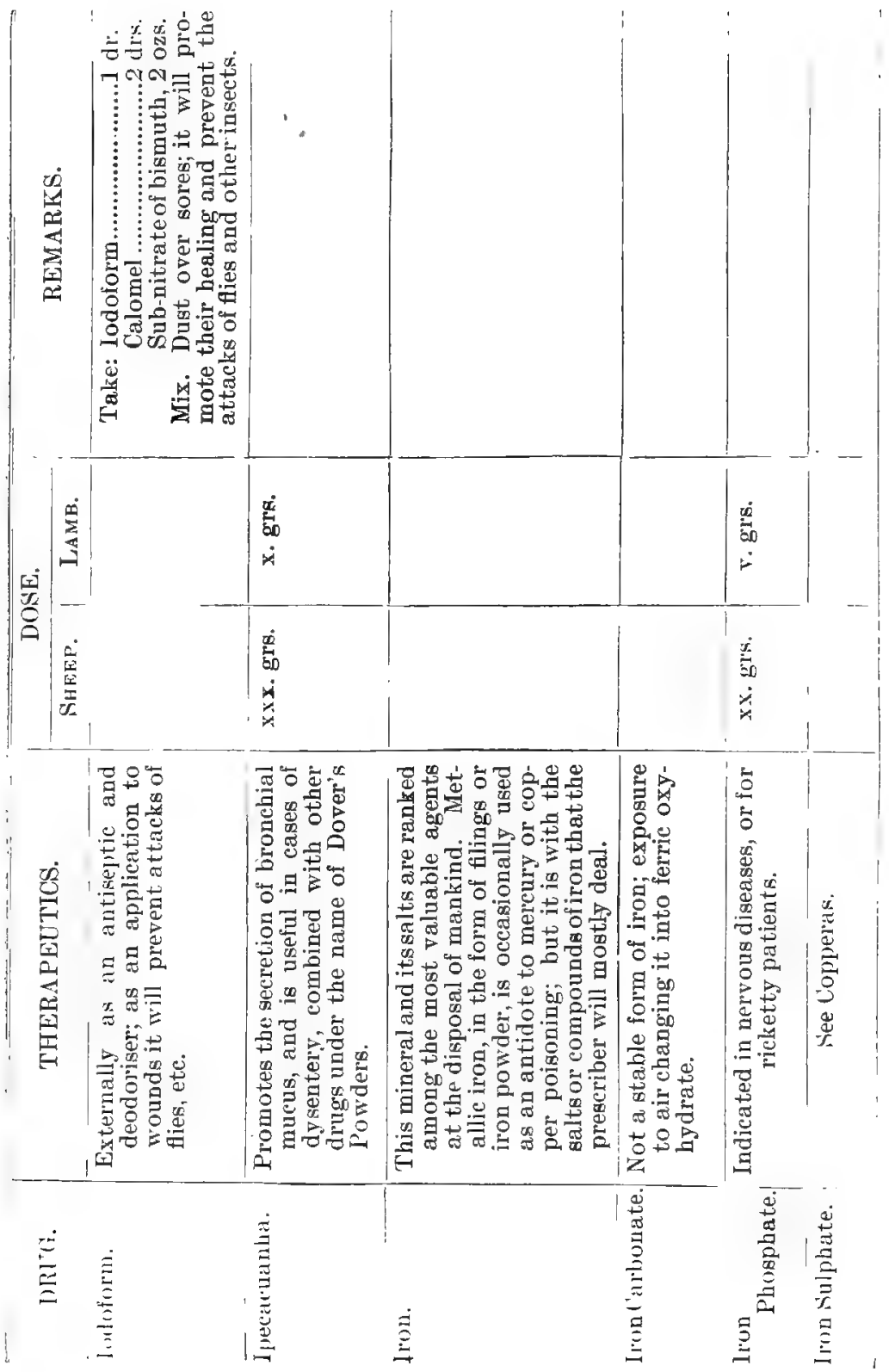




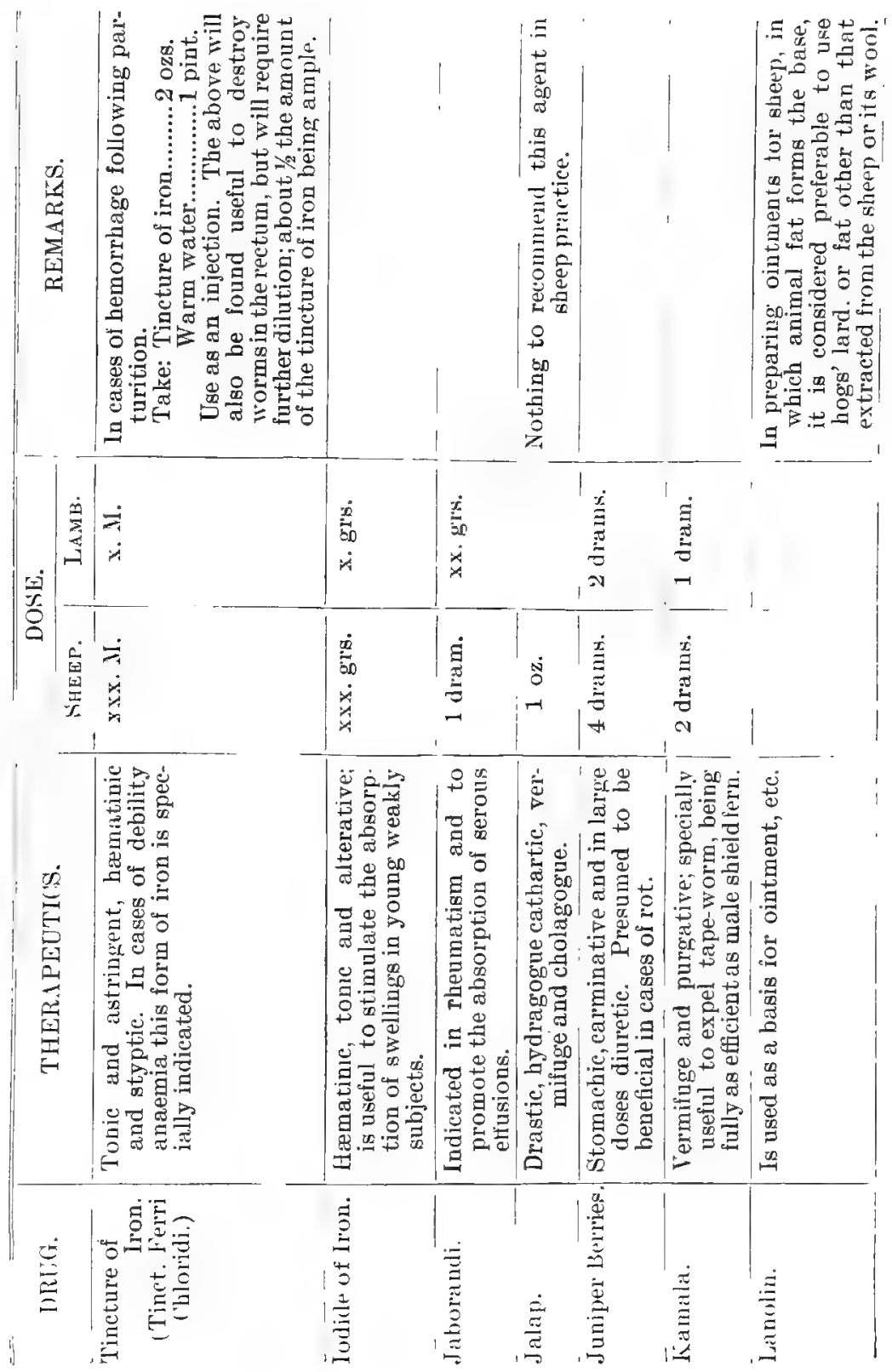




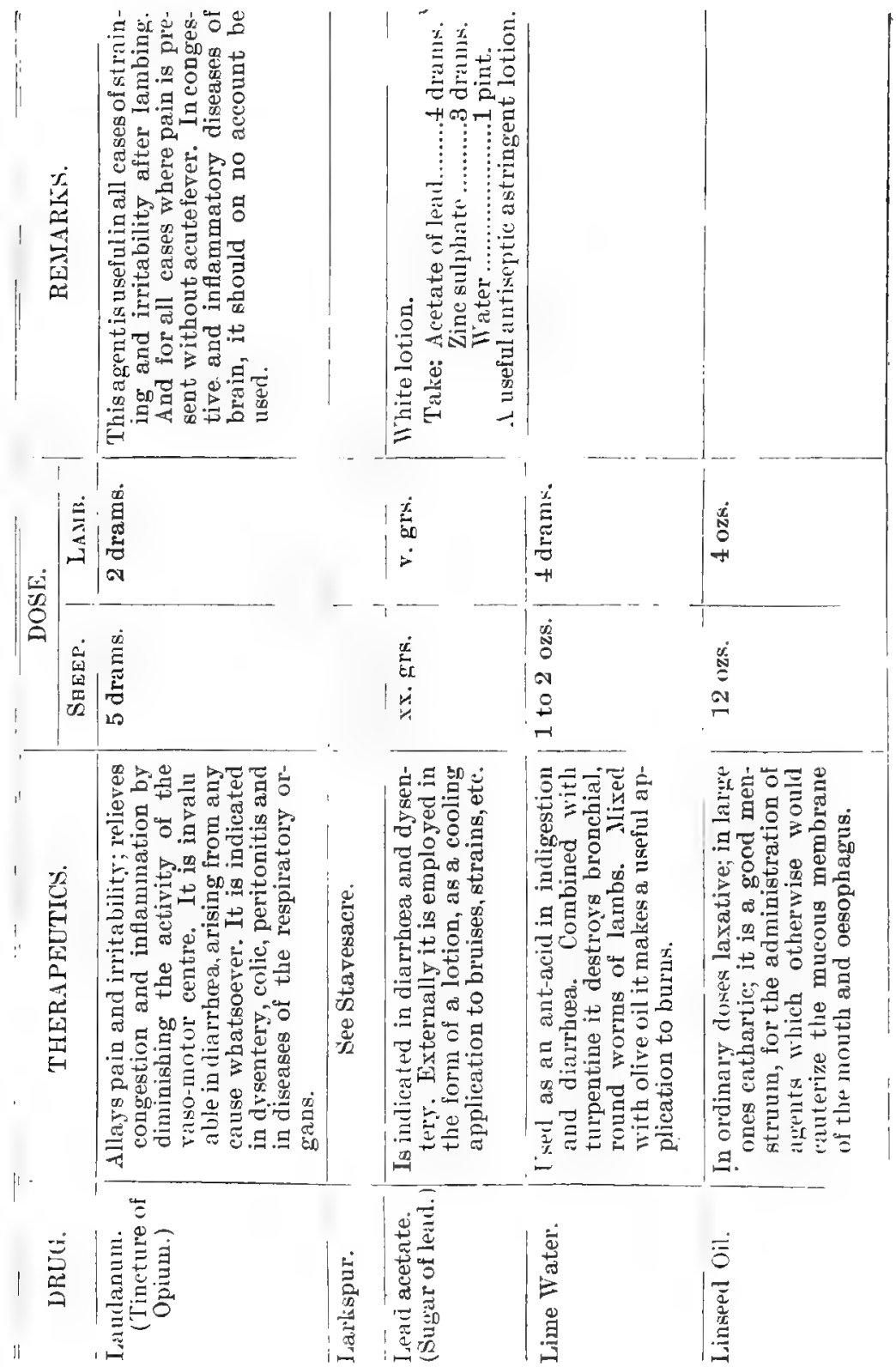




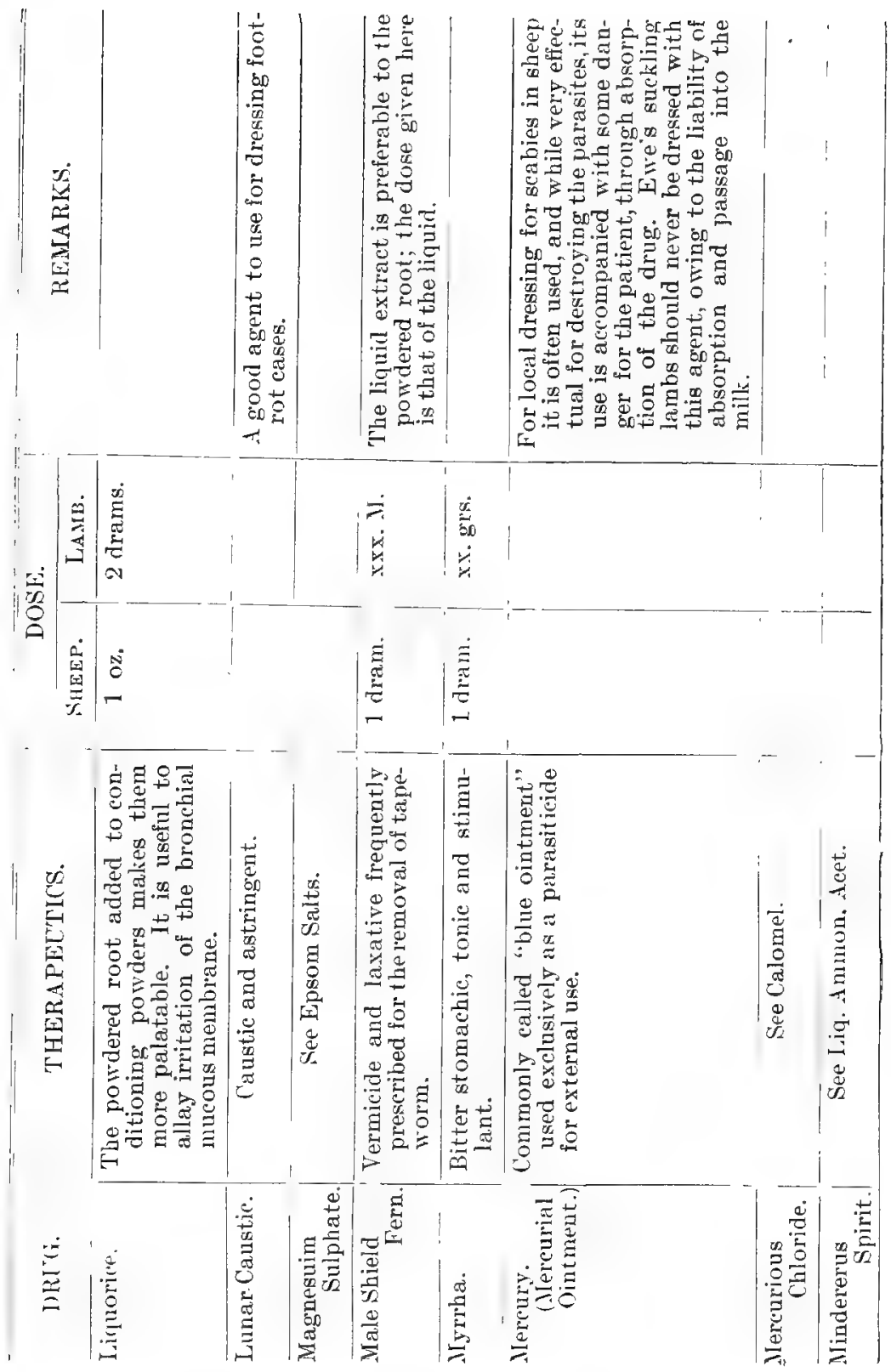




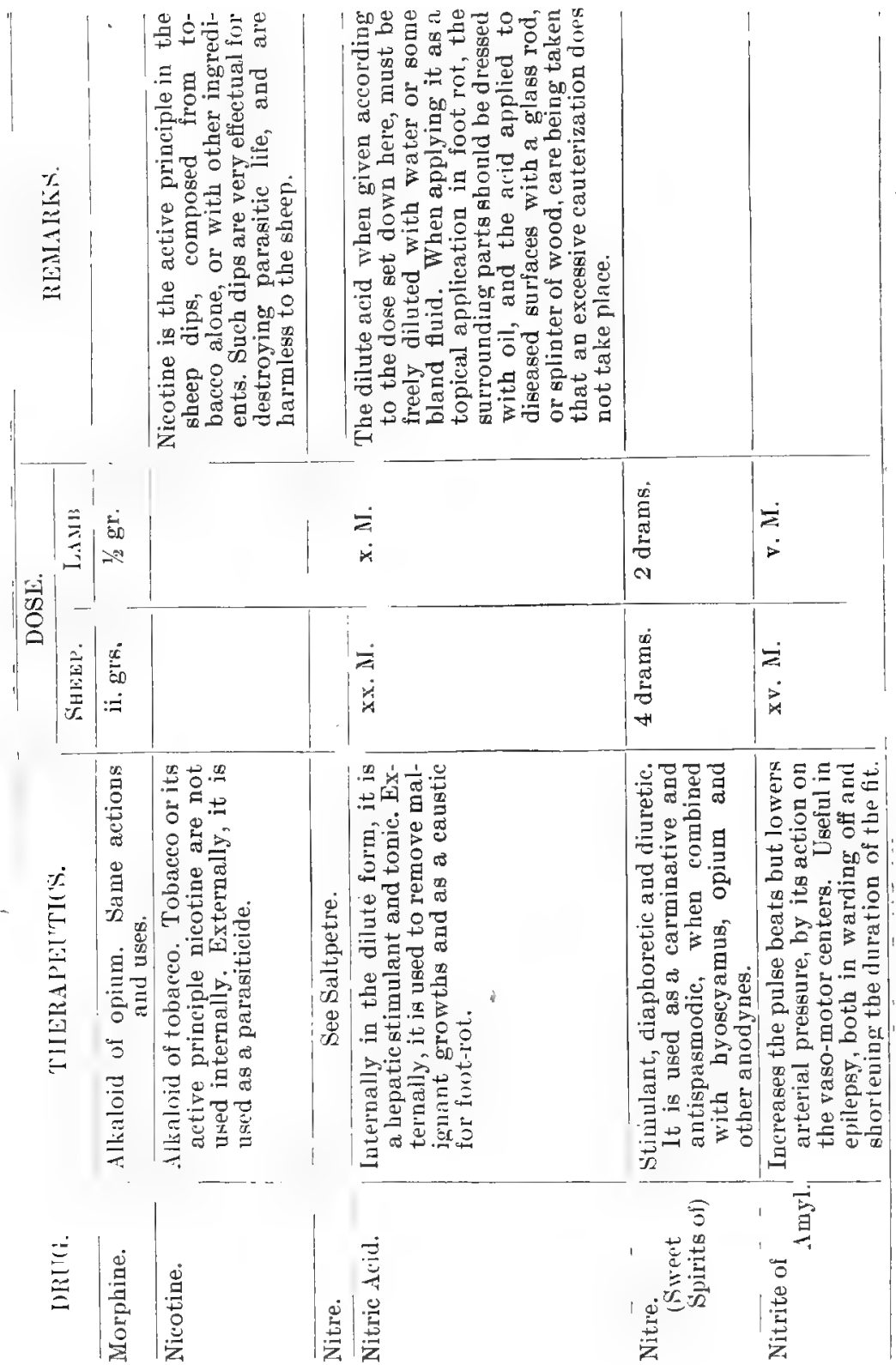




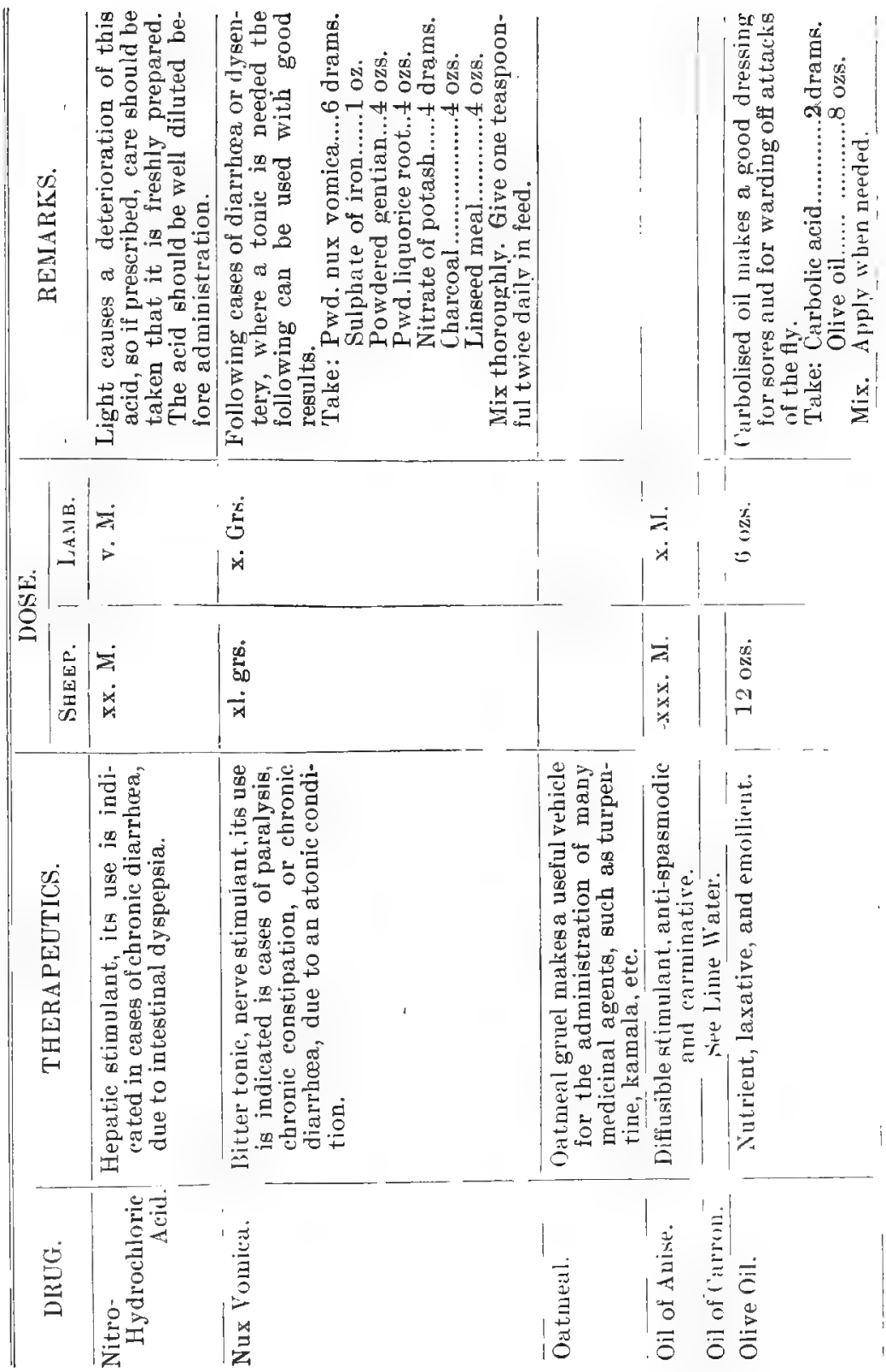




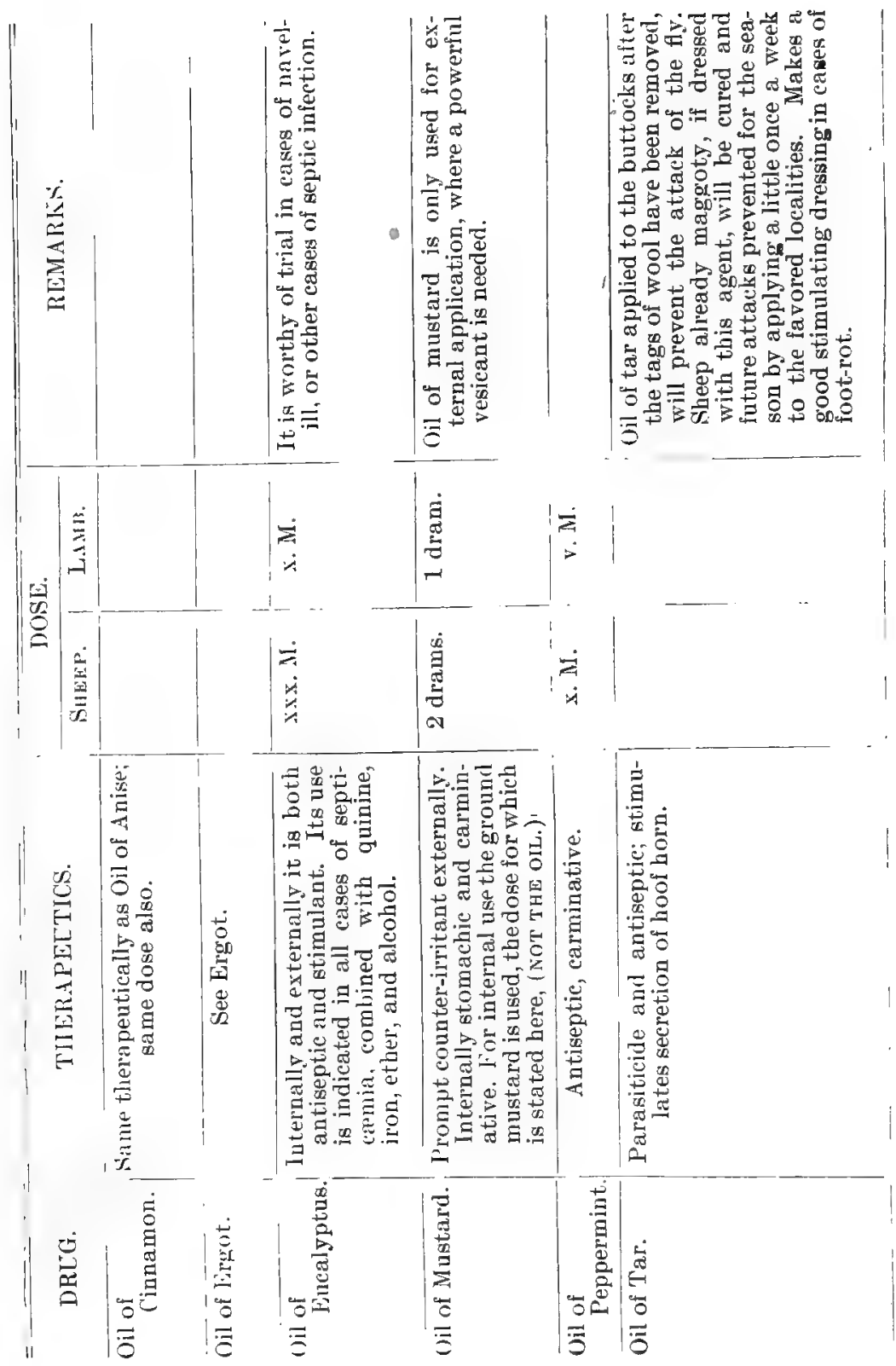




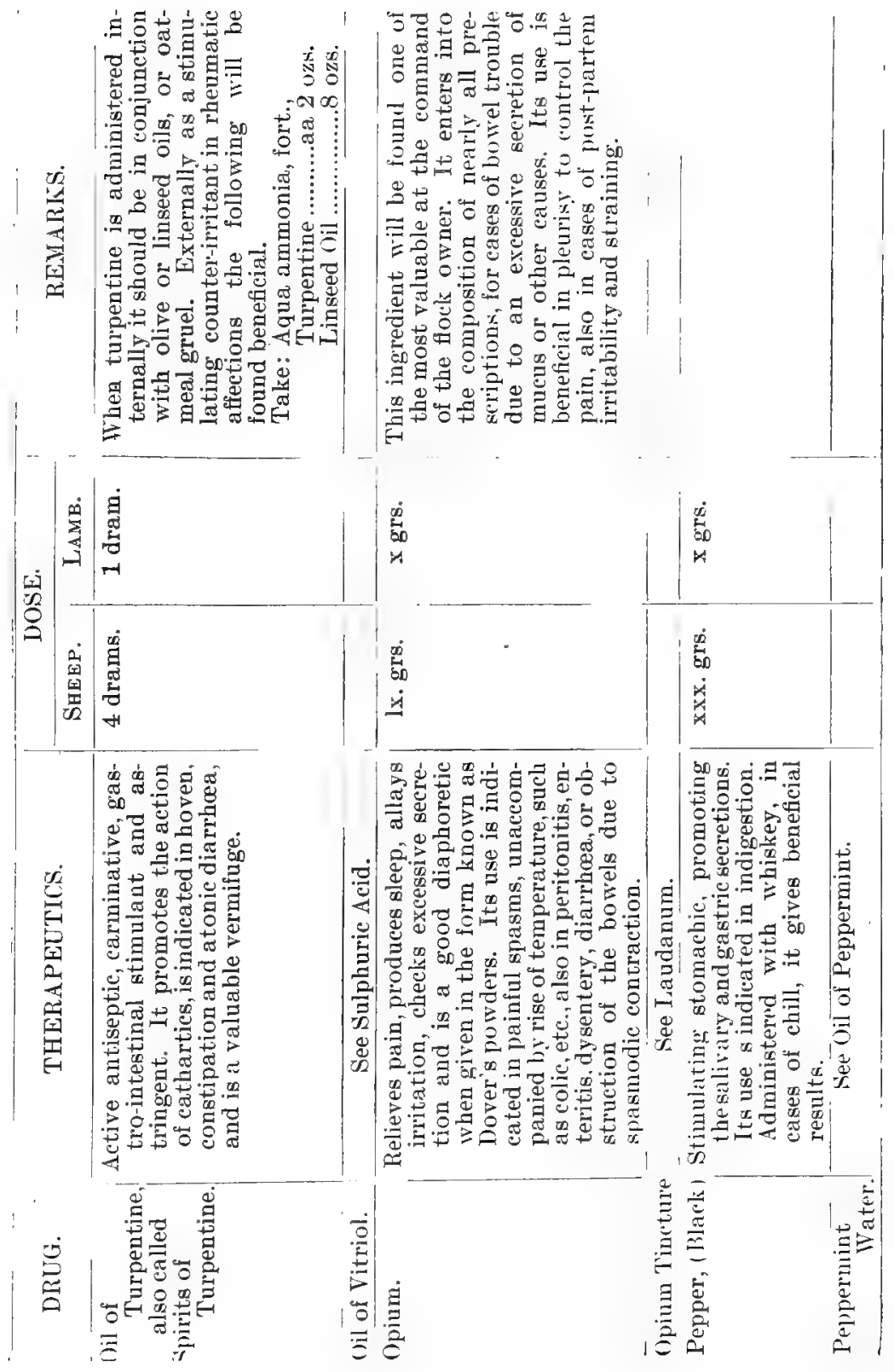




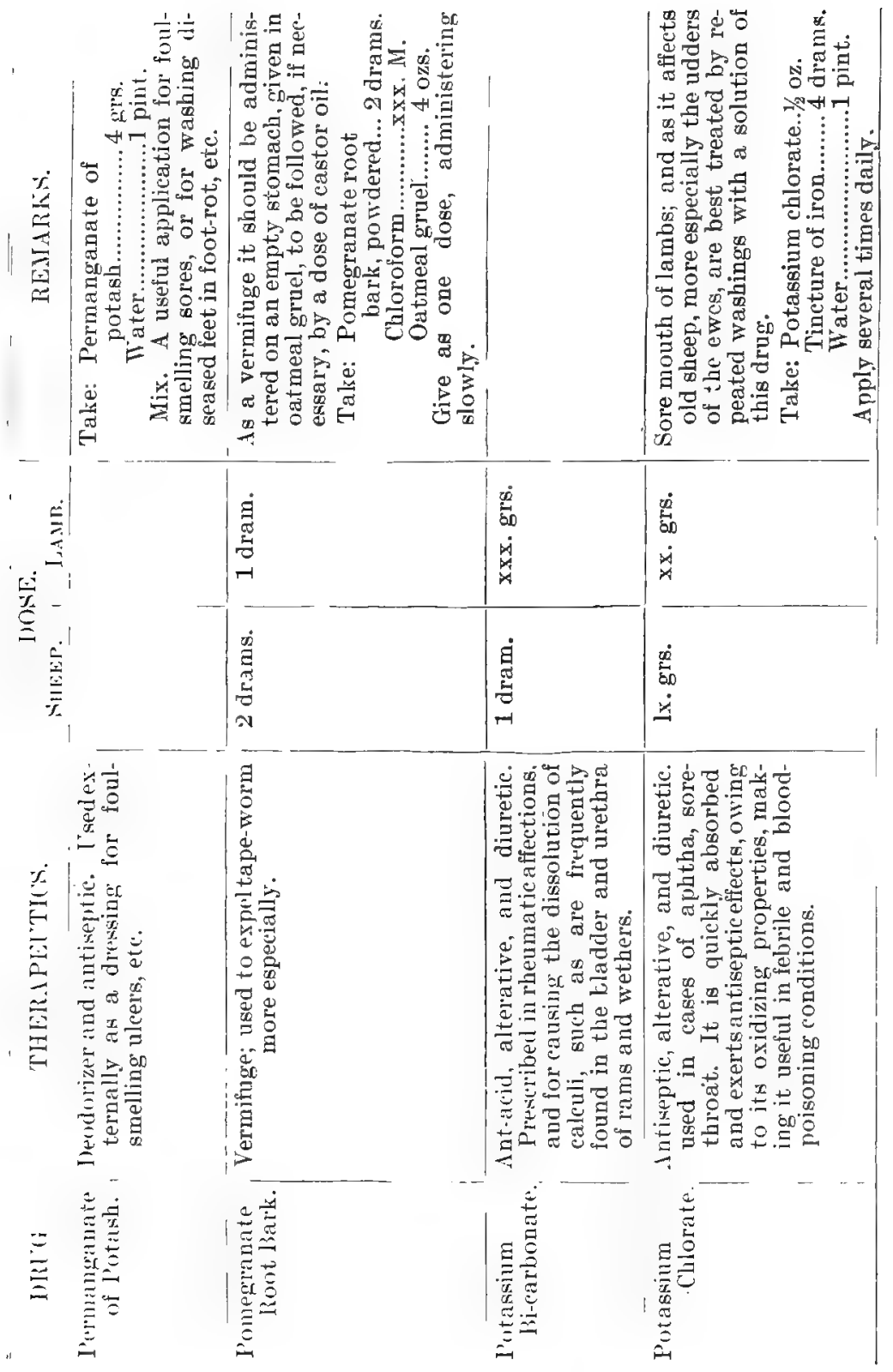




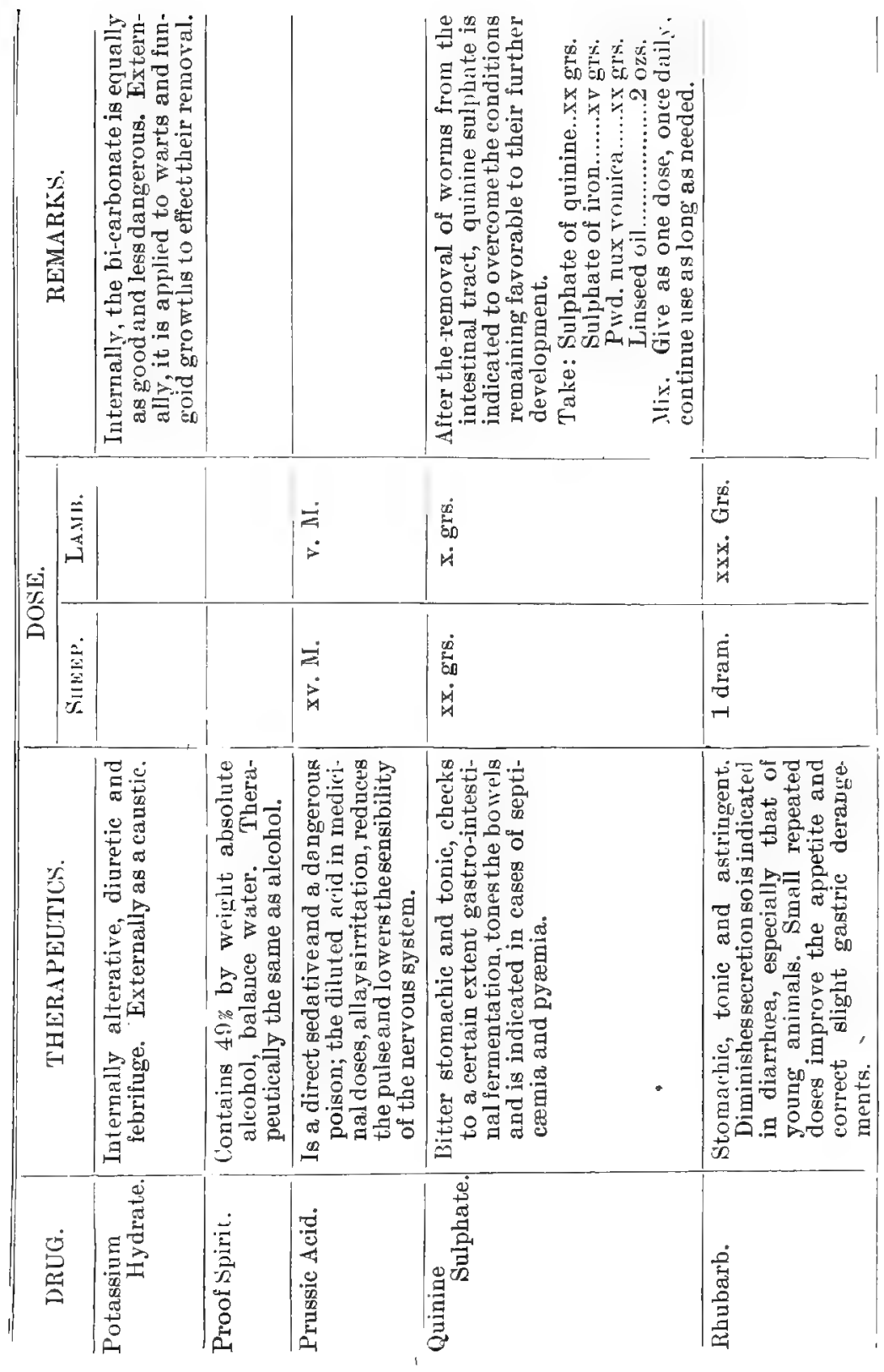



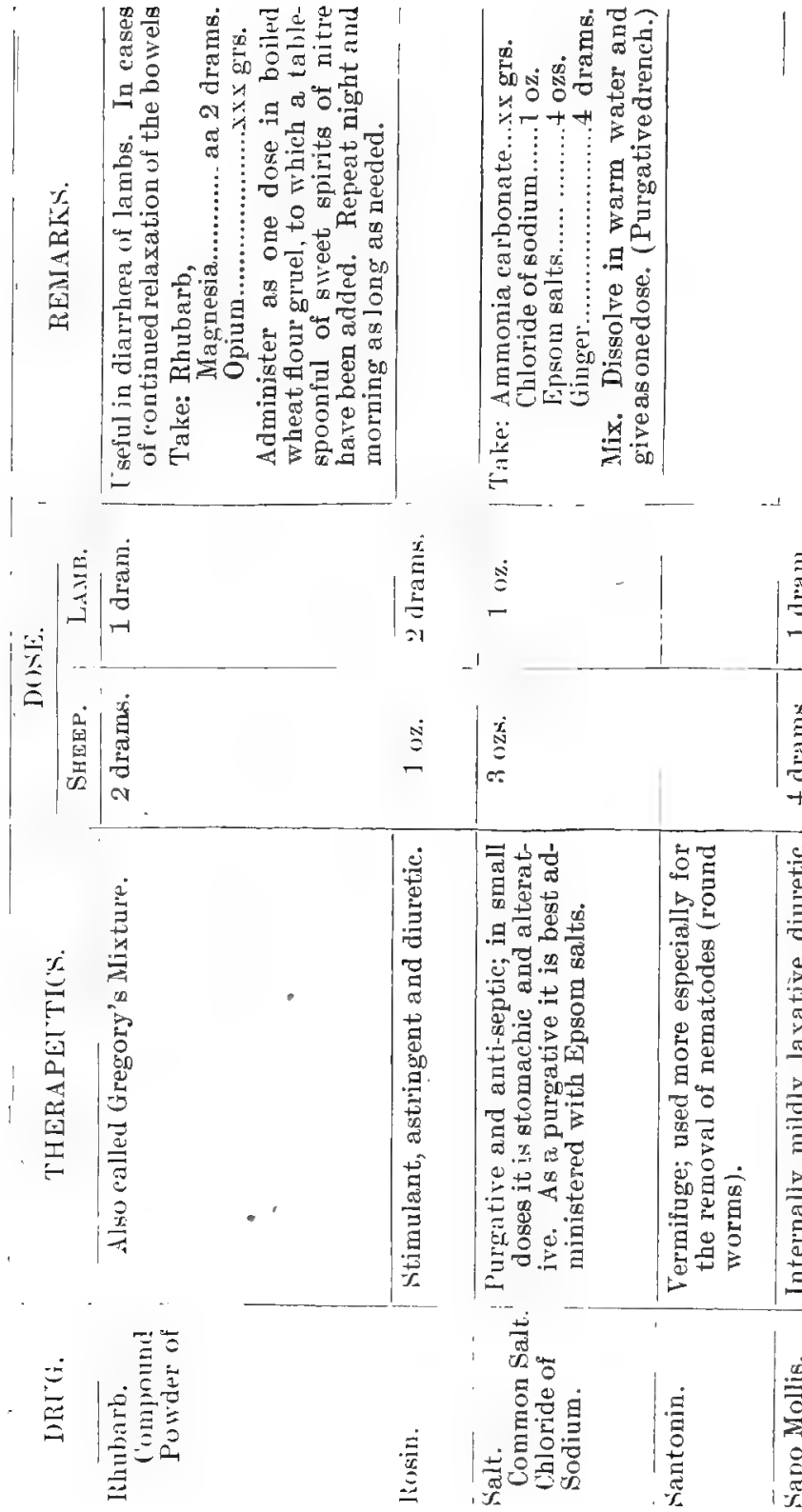


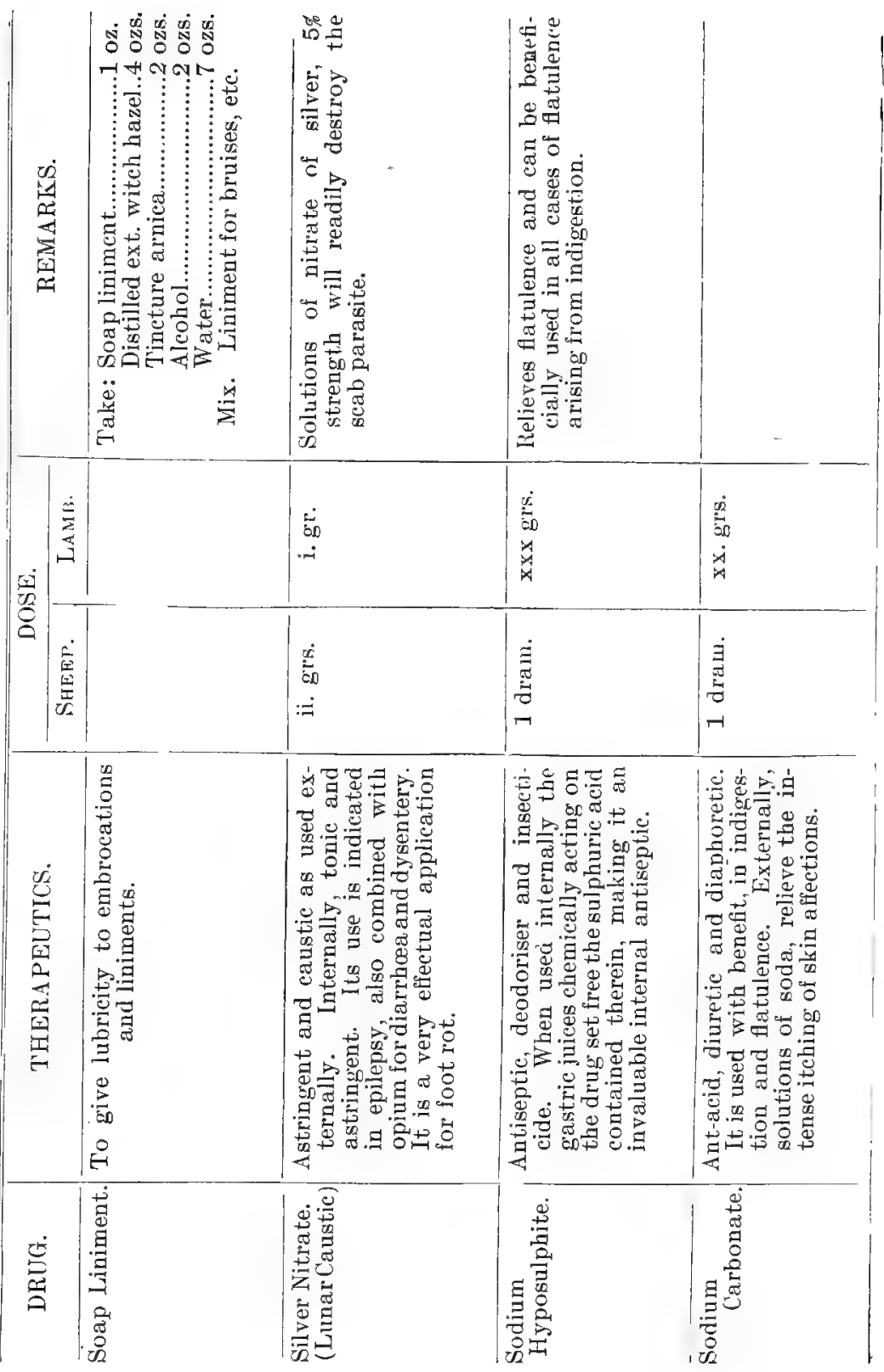




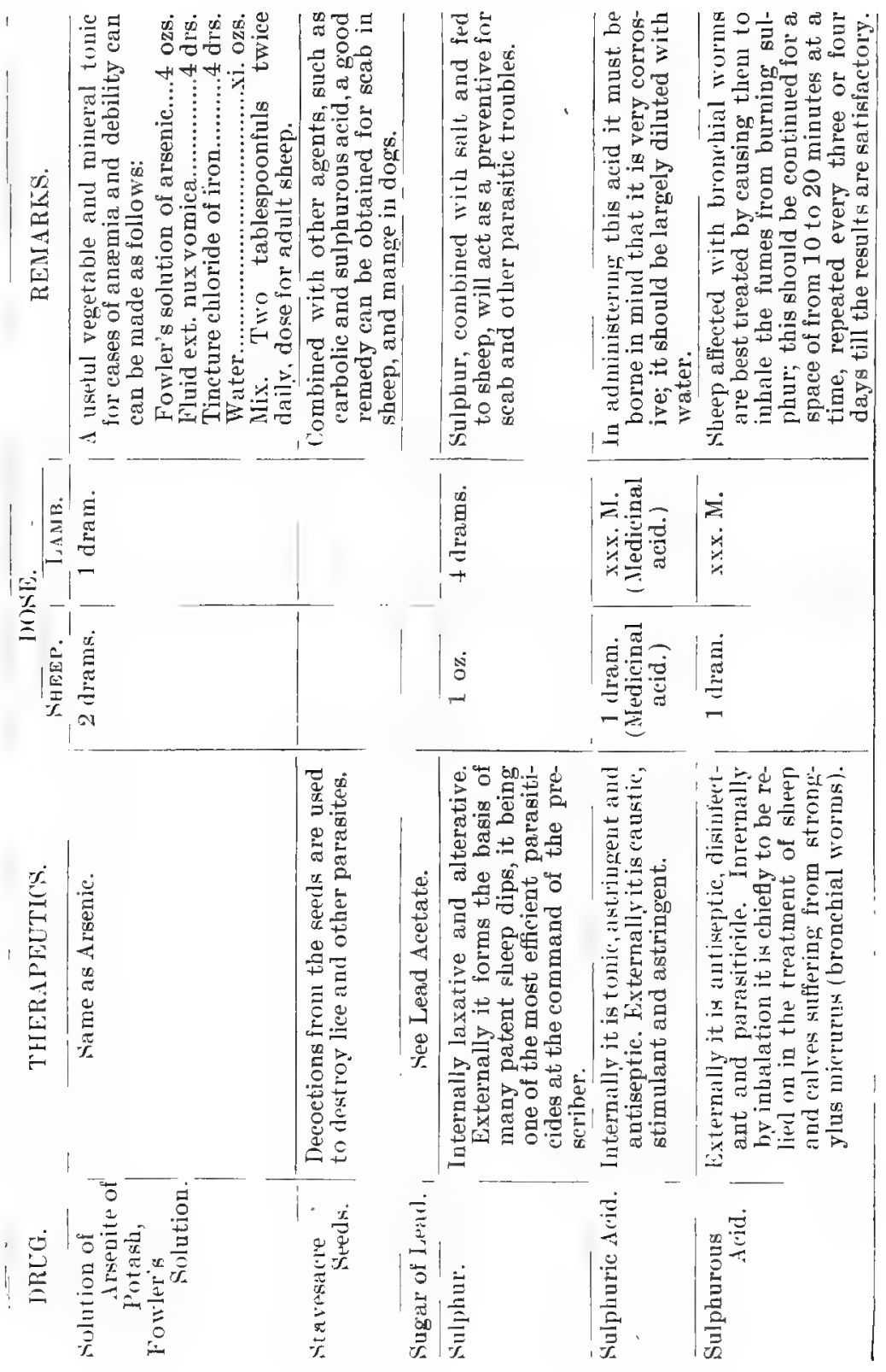




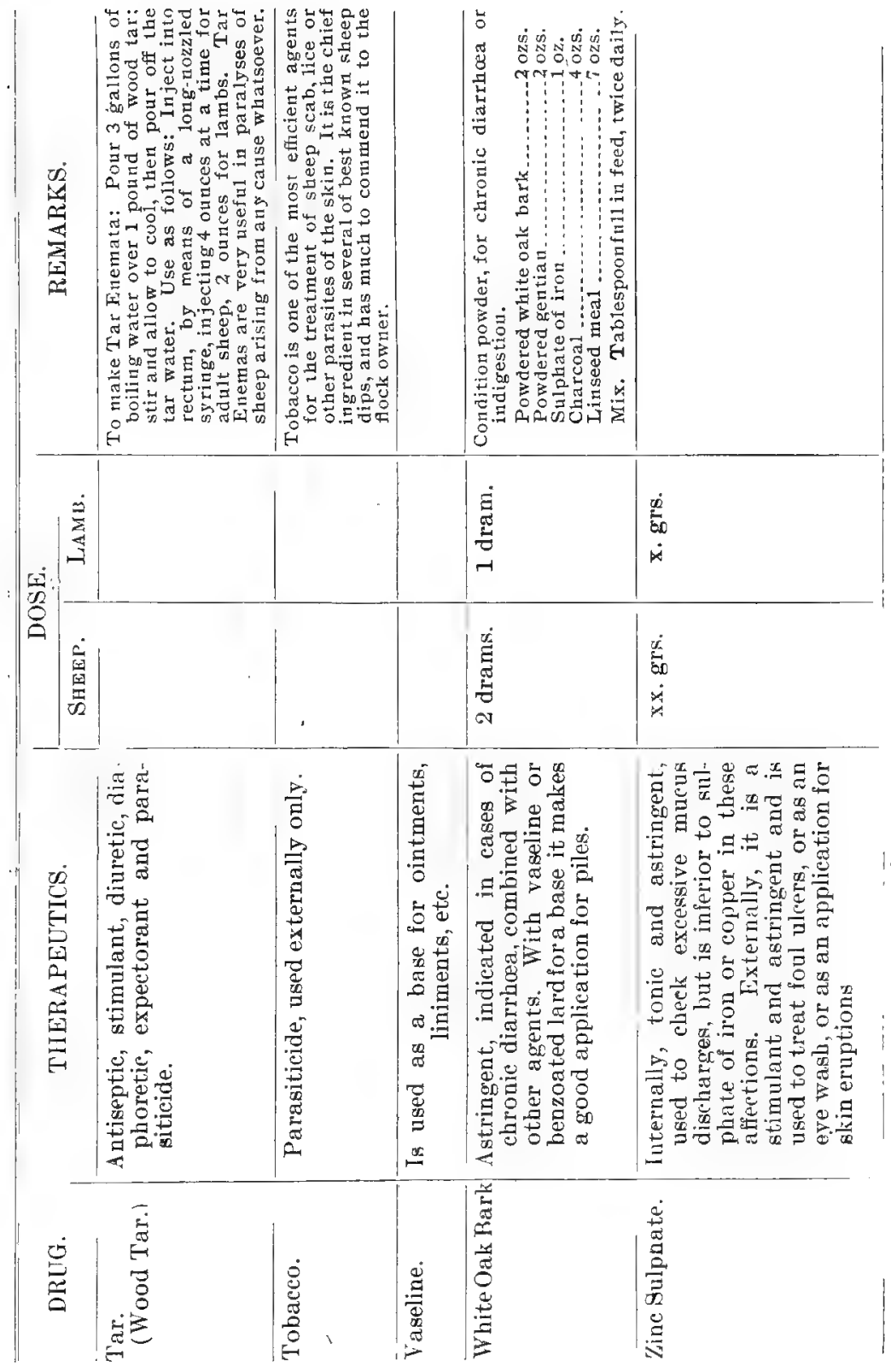




\section{CHAPTER XXI.}

\section{Inspection, Government and State.}

The inspection of live stock and meat products, starting with a srnall beginning some twenty years ago, has gradually risen to vast proportions, embracing not only the jnspection of live stock entering the United States, but exercising a rigid inspection of export animals and their products, a careful exarnination of inter-state shipments, and at the large market centers of the country, an unexcelled stock-yard inspection, where the diseased and crippled stock after being examined on arrival at the yards, are tagged by inspectors and killed under their personal supervision. When if unfit for human consumption the carcasses are immediately tanked. The results from the tankage being converted into fertilizers, axle grease, etc., permitting only the healthy to enter the channels of consumption. The Government inspection of sheep may be briefly stated as follows:

First. As regards their importations into the United States. On arriving at the port of entry, after complying with the customs regulations, they, if they should be importations from other countries than Canada, are placed in a suitable quarantine station, where they remain for a stated period of time (fifteen days) subject to daily inspections by the reterinary inspector in charge. Should they at the termination of that period prove to be in a healthy condition they are permitted shipment to their destination in the interior, and vice versa, should any evidences of disease appear among such animals while in quarantine they are immediately slaughtered and the carcasses destroyed or rendered in compliance with the regulations. Sheep imported from Canada, however, are admitted under special regulations common 
to both countries. They have to be accompanied with a certificate given by the official Canadian reterinarian of the district where they were bred in C'anada, stating that they have been personally inspected by himr and are free from any contagious and infectious affections, and that no contagious disease (execpting tuberculosis or actinomycosis) has existed in said district for the period of six months prior to said shipment. The clause relating to tubereulosis and actinomycosis, referring more particularly to cattle than sheep. The importer also in making his entry makes affidarit that said stock is imported for breeding or slaughtering purposen. Should they be for breeding and a certificate of registry accompany them showing that they are purebred and that their aneestors for two generations back are also registered, they then enter duty free, and are allowed to pass immediately to their destination. Sheep entering for immediate slaughter do not require a veterinary certificate, but only the affidavit of the importer. They are, however, submitted to a rigid examination by a reterinary inspector before being allowed access to the markets. The regulations given below being faithfully carried out lyy those having charge of the same, rirtually preclude the possibility of the introduction of diseased theep into the Uniterl State:

\title{
Regulations for the Inspection and Quarantine of Animals Imported from Canada into the anited States.
}

\author{
L.S. Department of Agriculture, \\ Office of the Secretary. \\ Tashington, D. C., January 23, 189\%.
}

In pursuance of sections 7,8 , and 10 of the act of Congress entitled "In act providing for the inspection of meats for exportation, and prohibiting the importation of adulterated articles of food or clink, and authorizing the President to make proclamation in certain cases, anc for other purposes," approred Angust 30, 1890, and 
of an act of Congress entitled "An act making appropriations for the Department of Agriculture for the fiscal year ending June 30 , $1897, "$ the following regulations, to take effect from and after February 1, 1897, are hereby prescribed for the inspection and quarantine of animals imported from Canada into the United States, and all order's and regulations or parts thereof inconsistent with these regulations are hereby revoked in so far as applies to inspection and quarantine of animals imported from Canada:

1. With the approval of the Secretary of the Treasury, the following-named ports along the border or boundary line between the United States and Canada have been designated as quarantine stations, and all animals imported from Canada into the Uniced States for which inspection is required by these regulations must be entered through these ports, viz: Vanceboro and Houlton, Maine; Beechers Falls, Island Pond, Newport, Richford, and St. Albans, Vermont; Rouses Point, Ogdensburg, Charlotte, Suspension Bridge, and Buffalo, New Iork; Port Huron and Detroit, Michigan; Duluth and St. Vincent, Minnesota; and Port Townsend, Washington.

2. The word "animals" when used in these regulations refers to and includes all or any of the following kinds: Horses, neat cattle, sheep, and other ruminants, and swine. The term "contagious diseases" when used in these regulations includes and applies to all or any of the following diseases: Glanders and farcy, maladie du coit, anthrax, contagious pleuro-pneumonia, Texas or splenetic fever, tuberculosis, actinomycosis, foot-and-mouth disease, rinderpest, sheep pox, foot-rot, sheep scab, hog cholera, swine plague, and erysipelas. Animals found affected with any one of these contagious diseases must be returned to Canada or killed without compensation.

3. All animals imported into the United States from Canada must be accompanied by an affidavit made by the owner or importer, declaring clearly the purpose for which said animals are imported, viz: whether for breeding purposes, for milk production, for work animals, for grazing, feeding, or slaughter, or whether they form part of settlers' effects, or whether they are horses entered for temporary stay, as provided in section 7 of these regulations. Said affidavit must be presented to the collector of customs at the port of entry, who will decide whether the animals are entitled to enter under these regulations, and who will notify the inspector of the Bureau of Animal Industry in all cases where these regulations require an inspection to be made.

4. All animals imported into the United States for breeding purposes, for milk production, for grazing or feeding, horses for work, 
and swine for slaughter must be inspected by an inspector of the Bureau of Animal Industry at the port of entry. All animals covered by this section except horses, and swine for slaughter, must be accompanied with a certificate signed by a Canadian official veterInarian, stating that no contagious disease, except tuberculosis and actinomycosis in cattle, affecting the species of animals imported, has existed in the district in which the animals have been kept for six months preceding the date of importation, excepting animals which are part of settlers' effects, or belonging to Indian tribes, which may be entered without certification or inspection. The owner or importer must present an affidarit that said certificate refers to the animal or animals imported. The certificate for cattle for breeding and for such milch cows must also show that they have been submitted to the tuberculin test and found free from tuberculosis, giving the date of testing, with the chart of reaction, and a description of the cattle, with age and markings, All animals imported for breeding purposes, milk production, grazing or feeding, when not accompanied by the required affidavits and certificates, must be detained in quarantine for one week, at the expense of the owner or importer, under the supervision of the inspector in charge. During this detention a rigid inspection will be made, and cattle for breeding or milk production will be tested with tuberculin. Animals found free from disease at the end of this period will be released. Cattle and sheep for grazing or feeding, if accompanied by the required affidavits and certificates, need not be unioaded for inspection, but all other animals covered by this section must be unloaded and carefully inspected.

5. All Canadian animals will be admitted at any port of the United States for transit in bond to any Canadian port without inspection.

6. Cattle and sheep in bond for export will be admitted without inspection at any of the ports named in section 1, in transit to and for export from Portland, Me, Boston, Mass, and New York, N. Y. Horses will be admitted in bond at any port of the United States without inspection for export from any port of the United States. All animals admitted for export will be subject to inspection at port of export.

7. Horses for temporary stay, whether for pleasure driving, teaming, exhibition, racing, or used in connection with stock raising or mining, cattle and sheep for slaughter, and animals belonging to Indian tribes or forming part of settlers' effects will be admitted through any port without inspection or certification.

8. The railroad cars used in the transportation of animals specified by these regulations must be thoroughly cleaned and disinfected 
before said animals are placed therein. All litter from previous shipments must be removed, and the car whitewashed with lime and carbolic acid, one pound of commercial carbolic acid to five gallons of line wash. C'nless this regulation is complied with Canadian animals will not be allowed entry into the United States, and animals from the United States will not be admitted into Canada. Shippers should see that cars are properly cleaned and disinfected before animals are loaded.

J. STERLING MORTON,

Secretary.

\title{
Regulations for the Inspection and Quarantine of Neat Cattle, Sbeep, and Other Ruminants, and Swine Imported into the anited States.
}

\author{
T. S. Department of Agriculture, \\ Office of the secretary. \\ Washington, D. C., February 11, 1895.
}

In pursuance of sections $\boldsymbol{r}, 8$ and 10 of the act of Congress entitled "In act providing for the inspection of meats for exportation, and prohibiting the importation of adulterated articles of food or drink, and authorizing the President to make proclamation in certain cases, and for other purposes," approved August 30, 1890, the following regulations are hereby prescribed for the inspection and quarantine of neat rattle, sheep, and other ruminants, and swine imported into the Lnited States, and all previous regulations prescribed for such inspection and quarantine are hereby rescinded:

1. With the approval of the Secretary of the Treasury, the following-named ports are hereby designated as quarantine stations, and all cattle, sheep, and other ruminants, and swine imported into the United States, must be entered through said ports, viz: On the Atlantic Seaboard, the ports of Boston, New York, and Baltimore; on the Pacific Seaboard, San Diego, Cal.; along the boundary between the United States and Mexico, Nogales, Ariz.; El Paso, Eagle Pass, and Laredo, Tex.; along the border or boundary line between the Inited States and British Columbia and Canada, through the custom ports of Tanceboro and Houlton, Me.; Richford, Newport, St. Albans, Island Pond, and Beecher Falls, Vt.; Ogdensburg, Rouses Point, Buffalo, Charlotte, and Suspension Bridge, N. Y.; Detroit and Port IIuron, Mich.; Minnesota, Minn., and Puget Sound, Wash

2. Ihe word "animals," when used in these regulations, refers to and includes all or any of the following kinds: Neat cattle, sheep, and 
other ruminants, and swine. The words "contagious diseases," when used in these regulations, includes and applies to all or any of the following diseases: Inthrax in cattle, sheep, goats, or swine; contagious pleuro-pneumonia in cattle; Texas or splenetic fever in cattle; tuberculosis in cattle; foot-and-mouth disease in cattle, sheep, goats, and swine; rinderpest in cattle and sheep; sheep pox, foot-rot, and scab in sheep; hog cholera, swine plague, and erysipelas in swinc.

3. All cattle, sheep, and other ruminants imported into the Uniterl States from any part of the world shall be accompanied with a eertificate from the local authority of the district in which said animals have been for one year next preceding the date of shipment, stating that no contagious pleuro-pneumonia,foot-ancl-mouth disease, or rinderpest has existed in said district for the past year. And all swine imported into the United States from any part of the world shall be accompanied with a similar certificate relating to the existence of foot-and-mouth disease, hog cholera, and erysipelas. All such animals shall also be accompanied with an affidavit by the owner from whom the importer has purchased them, stating that said animals have been in the district where purchased one year next preceding the date of sale, and that none of the above-mentioned diseases have existed among them, nor among any animals of the kind with which they come in contact, for one year last past, and that no inoculation has been practiced among said animals for the past two years. Also by an affidavit from the importer or his agent supervising the shipment, stating that they have not passed through any district infected with contagious diseases affecting said kind of animals; that they have not been exposed in any possible manner to the contagion of any of said contagious diseases, and that the animals, when not driven, have been shipped in clean and disinfected cars and vessels direct from the farm where purchased.

4 The foregoing certificate and affidavits must accompany sajd animals and be presented to the collector of customs at the port of entry, and by him delivered to the inspector of the Bureau of Inimal Industry stationed at said port, to allow them to be imported into the United States.

5. All neat cattle imported into the United States from any part of the world except Mexico, Central and South America, shall be subject to a quarantine of ninety days, counting from date of arrival at the quarantine station. All sheep and other ruminants, and swine, from any part of the world except North, Central, and South America, shall be subject to a quarantine of fifteen days, counting from date of arrival at the quarantine station.

6. Any person contemplating the importation of animals from any part of the world except North, Central, and South America, or of 
cattle from the Dominion of Canada, must first obtain from the Secretary of Agriculture two permits, one stating the number and kind of animals to be imported, the port and probable date of shipment, which will entitle them to clearance papers on presentation to the American consul at said port of shipment; the other, stating the port at which said animals are to be landed and quarantined, and the approximate date of their arrival, and this will assure the reception of the number and kind specified therein at the port and quarantine station named, at the date prescribed for their aurival, or at any time during three weeks immediately following, after which the jermit will be void. These permits shall in no case be arailable at any port other than the one mentioned therein. Permits must be in the name of the owner of, or agent for, any one lot of animals. Then more persons than one own a lot of animals for which permits hare been issued, a release from quarantine will be given each owner for the number and kind he may own, and this release will be a certificate of fulfillment of quarantine regulations. Permits will be issued to quarantine at such ports as the importer may elect. so far as facilities exist at such port, but in no case will permits for importation at any port be granted in excess of the accommodations of the Government quarantine station at such port. United States consuls shonld give clearance papers or certificates for animals from their districts intended for exportation to the United States only upon presentation of permits as above provided, with dates of probable arrival and destination corresponding with said permits. and in no case for a number in excess of that mentioned therein. When such shipments originate in the interior of a foreign country, these permits should be submitted to the consul of that district and through the forwarding agent to the consul at the port of embarkation.

7. Cattle and sheep from the Dominion of Canada for export from the United States may be entered at the ports of Island Pond and lieecher Falls, Vt., in bond for Portland, Me., for export from the latter port only, provided said animals are accompanied by the health certificate and affidavits required by section 3 , and provided, further. that suitable pens are furnished by the railroad companies at the ports of entry for their unloading and proper inspection.

8. All animals. imported into the United States shall be carefully inspected by an inspector of the Bureau of Animal Industry, and all animals found to be free from disease and not to have been exposed to any contagious disease, shall be admitted into the United States, subject to the provisions for quarantine as established in paragraph 5. Whenever any animal is'found to be affected with a contagious discase, or to have been exposed to said disease, said animal, and all ani- 
mals that have been in contact with or exposed to said animal, will be placed in quarantine, and the inspector quarantining the same shall report at once to the Chief of the Bureau of Animal Industry, who will direct whether or not saic animals quarantined shall be appraised ancl slaughtered, as provided by section \& of the act under which these regulations are made. $A l l$ animals quarantined by reason of disease or exposure to disease shall not be admitted to the established quarantine grounds, but shall be quarantined elsewhere at the expense of the importer, or dealt with in such manner as the Chief of the Burean of Animal Industry shall determine.

9. In case of imported animals proring to be infected, or to have been exposed to infection, such portions of the cargo or the vessel on which they have arrived as have been exposed to these animals or their emanations shall be subjected, under the direction of the inspector of the Bureau of Inimal Inclustry, to disinfection in such manner as may be considered by said inspector necessary before it can be landed

10. No litter, fodder, or other aliment, nor any ropes, straps, chains, girths, blankets, poles, buckets, or other things used for or about the snimals, and no manure shall be landed, excepting under such regulations as the inspector shall provide.

11. On moving animals from the ocean steamer to the quarantine grounds they shall not be unnecessarily passed orer any highways, but must be placed on the cars at the wharves or removed to the cars on a boat which is not used for conveying other animals. If such boat has carried animals within three months, it must be first cleaned and then disinfected under the supervision of the inspector, and after the conreyance of the imported animals the boat must be disinfected in the same manner before it may again be used for the conveyance of animals. When passage upon or across the public highways is unavoidable in the transportation of animals from the place of landing to the quarantine grounds, it must be under such careful supervision and restrictions as the inspector may in special cases direct.

12. The banks and chutes used for loading and unloading imported animals shall be reserved for such cattle, or shall be cleansed and disinfected as abore before being used for such imported cattle.

13. The railway ears used in the transportation of animals to the quarantine grounds shall be either cars reserved for this exclusive use or box cars not otherwise employed in the transportation of animals or their fresh products, and after each journey with animals to the quarantine grounds they shall be disinfected by thorough cleansing and disinfection under the direction of the inspector.

14. While animals are arriving at the quarantine stations, or lear- 
ing them, all quarantined stock in the yards adjoining the alleyways through which they must pass shall be rigidly confined to their sheds. Animals axriving by the same ship may be quarantined together in one yard and shed, but those coming on different ships shall in all cases be placed in separate yards.

15. The gates of all yards of quarantine stations shall be kept locked, except when cattle are entering or leaving quarantine.

16. The attendants on animals in particular yards are forbidden to enter other yards and buildings, unless such are occupied by stock of the same shipment with those under their special care. No dogs, cats, or other animals, except those necsssarily present, shall be allowed in the quarantine grounds.

17. The allotment of yards shall be under the direction of the inspector of the port, who shall keep a register of animals entered with description, name of owner, name of vessel in which imported, date of arrival and release, and other important particulars.

18. The inspector shall see that water is regularly furnished to the stock and the manure removed daily, and that the prescribed rules of the station are enforced.

19. Food and attendance must be provided by the owners of the stock quarantined. Employees of such owners shall keep the sheds and yards clean to the satisfaction of the inspector.

20. Smoking is strictly forbidden within any quarantine inclosure.

21. No visitor shall be admitted to the quarantine station without special written permission from the inspector. Butchers, cattle dealers and their employes are especially excluded.

22. No public sale shall be allowed within the quarantine grounds.

23. The inspector shall, in his daily rounds, as far as possible, take the temperature of each animal, commencing with the herds that have been longest in quarantine and ending with the most recent arrivals, and shall record such temperatures on lists kept for the purpose. In passing from one herd to another he shall invariably wash his thermometer and hands in a weak solution (1 to 100) of carbolic acid.

24. In case of the appearance of any disease that is diagnosed to be of a contagious nature, the inspector shall notify the Chief of the Bureau of Animal Industry, who shall visit the station personally or send an inspector, and on the confirmation of the diagnosis the herd shall be disposed of according to the gravity of the affection.

25. The yard and shed in which such disease shall have appeared shall be subject to a thorough disinfection. Litter and fodder shall be burned. Sheds, utensils and other appliances shall be disinfected 
as the inspector may direct. The vard, fence, and manure box shall be freely sprinkled with a strong solution of chloricle of lime. The flooring of the shed shall be lifted and the whole shall be left open to the air and unoccupied for three months.

26 . In case of the appearance of any contagious clisease the infected herd shall be rigidly confined to its sheds, where disinfectants shall be freely used, and the attendants shall be forbidden all intercourse with the attendants in other yards, and with persons outside the quarantine grounds.

J. STERLING MORTON,

Secretary.

The quarantine exacted from all sheep arriving from foreign countries excepting ('anada reduces the danger of admission of such disease as sheep-pox, rinde-pest, etc., to a minimum, and the proof of the pudding being in the eating, it is only sufficient to say that since such regulations have been in force no outbreaks in the United States have occurred among sheep which are traceable to the admission of foreign animals.

The same precautions are exercised in the shipments of sheep to foreign countries, notably England. All such animals have to be carefully examined by a Government official at the market where they are purchased. They are again inspected before being loaded on the ship for transportation abroad. Great care is taken that no animal showing the least sign of sicknes: is permitted to be shipped.

Sheep-scab is particularly guarded against. The sheep before shipment are submitted to a thorough dipping to insure their being free from this troullesome affection These regulations are necessary owing to the fact that complaints have been made against American sheep, claining that they have been responsible for outbreaks of contagious diseases in countries importing them, notably England, it having been asserted that scab frequently followed their entrance to that country. These complaints have so prejudiced the authorities there, that at the present time shipments of live stock are only permitted entry under the condition 
that they are slaughtered at the port where the entry is made. They are no longer allowed to be sold to the farmers for feeders or stockers. The only way this disadrantage can ever be overcome is by the rigid enforcement of all the regulations governing the transportation and handling of live stock at home, so that fureign countries will finally be forced to believe in the competency of the Imerican inspection and again permit their importations on the former more favorable terms.

The following are the United States regulations governing. the importation and exportation of sheep:

\section{Order and Regulations for the Inspection of Cattle and Sheep for Export.}

U. S. Department of Agriculture, Office of the Secretary.

Washington, D. C., October 20, 1890.

The following order and regulations are herehy made for the inspection of neat cattle and sheep for export from the United States to Great Britain and Ireland and the Continent of Furope, by virtue of the authority conferred upon me by Section 10 of the Act of Congress approved Iugust 30,1890 , entitled "An act providing for the inspection of meats for exportation, prohibiting the importation of adulterated articles of food or drink, and authorizing the President to make proclamation in certain cases, and for other purposes:"

1. The Chief of the Bureau of Animal Industry is hereby directed to cause careful veterinary inspection to be made of all neat cattle and sheep to be exported from the United States to Great Britain and Ireland and the Continent of Europe.

2. This inspection shall be made at any of the following named stock yards:-Kiansas City, Mo.; Chicago, Ill.; Buffalo, N. I.; Pittsburg, 1'a.; and at the following ports of export, viz:-Boston and Charlestown, Mass.; New York, N. Y.; Philadelphia, Pa.; Baltimore, Md., and Norfolk and Newport News, Ya. All cattle shipped from any of the aforesaid yards must be tagged before being shipped to the ports of export. Cattle arriving at ports of export from other parts of the United States will be tagged at said ports.

7. Export animals, whenever possible, shall be unloaded at the 
port of export from the cars in which they have been transported directly at the wharves from which they are to be shipped. They shall not be unnecessarily passed orer any highways or removed to cars or boats which are used for conveying other animals. Boats transporting said animals to the ocean steamer must be first cleansed and disinfected under the supervision of the Veterinary Inspector of the port, and the ocean steamer must, before receiving said animals, be thoroughly cleaned or disinfected in accordance with the dircetions of said Inspector. When passage upon or across the public highways is unavoidable in the transportation of animals from the cars to the boat, it must be under such careful supervision and restrictions as the Veterinary Inspector may, in special cases, direct.

8. Any cattle or sheep that are offered for shipment to Great Britain or Ireland, or the Continent of Europe, which have not been inspected and transported in accordance with this order and regulations, will not be allowed to be placed upon any vessel for exportation, as they will be deemed, under the law, to have been exposed to infection so as to be dangerous to other animals.

9. The supervision of the movement of cattle from cars and yards to the ocean steamer at the ports of export will be in charge of the Veterinary Inspector of the port. No ocean steamer will be allowed to receive more cattle or sheep than it can comfortably carry. Over-crowding will not be permitted.

10. The Veterinary Inspector at the port of export will notify the Collector of the Port of the various shipments of cattle or sheep that are entitled to clearance papers, and certificates of the inspection of said animals will be given to the consignors for transmission with the bills of lading.

J. M. RUSK, Secretary.

\title{
Order and Regulations for the Inspection of Cattle and Sheep for Export.
}

\author{
U. S. Department of Agriculture, \\ Office of the Secretary, \\ Washington, D. C., February 7, 1895.
}

The following order and regulations are hereby made for the inspection of neat cattle and sheep for export from the United States to Great Britain and Ireland and the Continent of Europe, by virtue of the authority conferred upon me by section 10 of the act of Congress approved August ?0, 1890, entitled "In act providing for an inspection 
of meats for exportation, prohibiting the importation of adulterated articles of food or drink, and authorizing the President to make proclamation in certain cases, and for other purposes":

1. The Chief of the Bureau of Inimal Industry is hereby directed to cause careful veterinary inspection to be made of all neat cattle and sheep to be exported from the United States to Great Britain and Ireland and the Continent of Europe.

2. This inspection will be made at any of the following naned stock yards:-Kansas City, Mo.; Chicago, Ill.; Buffalo, X. Y.; Pittsburg, Pa.; and at the following ports of export, viz:-Portland, Me.; Baltimore, Md,; Boston and Charlestown, Mass.; New York, $\mathrm{Y}$. I.: Philadelphia, Pa., and Norfolk and Newport News, Ta. 111 cattle shipped from any of the aforesaid yards must be tagged before being shipped to the ports of export. Cattle arriving at ports of export from other parts of the United States will be tagged at said ports.

3. After inspection at the aforesaid stock yards, all cattle found free from disease and shown not to have been exposed to the contagion of any disease, shall be tagged uncler the direction of the inspector in charge of the yards. After tagging, the cattle will be loaded into (leaned and disinfected cars, and shipped through from said yards, in said cars, to the port of export.

4. All animals shall be reinspected at the port of export. All railroad companies will be required to furnish clean and disinfected cars for the transportation of cattle and sheep for export, and the various stock yards located at the ports of export shall keep separate, clean, and disinfected yards for the reception of export animals only.

5. Shippers shall notify the inspectors in charge of the yards of intended shipments of cattle, and shall give to the said inspector the locality from which said animals have been brought, and the name of the feeder of said animals, and such other information as may be practicable for the identification of the place from which said animals have come.

6. The iuspector, after passing and tagging said cattle, shall notify the inspector in charge of the port of export of the inspection of said animals, giving him the tag numbers and the number and designation of the cars in which said animals are shipped.

7. lxport animals, whenever possible, shall be unloaded at the port of export from the cars in which they have been transported $\mathrm{d}$; rectly to the wharves from which they are to be shippect. They shall not be unnecessarily passed over any highwa,y or removed to cars or boats which are used for conveying other animals. Boats transporting said animals to the ocean stermer must be first cleansed and disin- 
fected under the supervision of the inspector of the port, and the ocean steamer must, before receiving said animals, be thoroughly cleansed or disinfected in accorlance with the directions of said inspector. When passage upon or across the public highway is unavoidable in the transportation of animals from the cars to the boat, it must be under such careful supervision and restrictions as the inspector may direct.

S. Any cattle or sheep that are offered for shipment to Great Britain or Ireland, or the Continent of Europe, which have not been inspected and transported in accordance with this order and regulations, or which having been inspected are adjudged to be infected, or to have been exposed to infection so as to be dangerous to other animals, shall not be allowed to be placed upon any vessel for exportation.

9. The supervision of the movement of eattle from cars and yards to the ocean steamer at the ports of export will be in charge of the inspector of the port. No ocean steamer will be allowed to receive more cattle or sheep than it can comfortably carry. Overcrowding will not be permitted.

10. The inspector at the port of export will notify the collector of the port of the various shipments of cattle or sheep that are entitled to clearance papers, and certificates of the inspection of said animals will be given to the consignors for transmission with the bills of lading.

\section{J. STERLING MORTON,} Secretary.

\section{[Hmendment to the Order dated february $7,1895$.}

U. S. Department of Agriculture, Office of the Secretary, Washington, D. C., Dec. 19, 1895.

It is hereby ordered that the Order and Regulations of February $\tau, 1895$, above mentioned, be and same are hereby amended as follows:

Section 2 is hereby amended by the addition of Port Royal, South Carolina; New Orleans, Louisiana, and Galveston, Texas, as ports of export.

And it is stipulated that transportation companies carrying cattle or sheep to Port Royal, S. C., for export shall establish at that point special stock yards for export eattle and sheep, and such stock yards shall be used for no other purpose.

The cattle exported from Port Royal, S. C., shall originate above the quarantine line established by the Department of Agriculture and 
shall not be unloaded south of said line prior to arrival at Port Royal. Cattle exported from New Orleans, La., and Galveston, Tex., shall originate south of said quarantine line, and no cattle from north of said quarantine line shall be exported from ports of New Orleans, La., or Galveston, Tex., except by special permit from the Chief of the Bureau of Animal Industry. All cattle and sheep exported from the three ports above mentioned shall be inspected, and the provisions of sections 4 and 5 of order of February 7, 1895, shall be applicable thereto, together with such other provisions of said order as may be deemed practicable by the Chief of the Bureau of Animal Industry.

The tagging of export animals at above ports shall be discretionary with the Chief of the Bureau of Animal Industry.

J. STERLING MORTON,

Secretary.

While a strict inspection is thus maintained on all sheep imported into or exported from this country, it must be acknowledged that the regulations governing inter-state shipments ret leave something to be desired.

For instance, the interpretation of the term "inter-state shipments" appears to be somewhat vague. Sheep designed for shipment for feeding or breeding purposes from any of the large stock-yards in the country which come under the care of Federal inspectors must be dipped before being allowed to leave the rards. This is a most excellent provision, and if rigidly enforced would materially assist in keeping under, if not entirely eradicating, the disease known as scab; but here arises a loop-hole through which advantage of this regulation can be taken. Sheep shipped to a stock-yards and held there for sale and which are sold at those yards and allowed to remain therein several days after such sale come under the State laws and are not subject to the restrictions of the inter-state regulations. These sheep can be shipped to any point in that State without dipping.

Now, it would be evident that if the infection from scab exists in the large stock-yards throughout the country as is claimed, these sheep would carry the infection to whaterer point 
within the State they were shipped, and not only that, but they would infect the car or cars used for their transportation, which on being used again in the inter-state trade for other sheep shipments, would be liable to cause outbreaks of the disease in different parts of the country; furthermore, sheep affected with scab in the State of New York, for instance, can be shipped to the New York Central stock-yards and from there, should the shipper so desire and unless the State authorities should see fit to intervene, can be shipped to any other point within that State, as in no sense would they come under the regulations governing inter-state shipments. From this it is evident that although the Federal inspectors may use due diligence and care in enforcing their regulations, sheep scab ean still be distributed over wide areas of country. The Western States appear to have thoroughly grasped this idea and are generally enforcing State legislation to cover the movements of diseased animals within their borders; and if every State in the Union would enact laws providing for the appointment of sheep inspectors who shall be assigned to certain districts within each State, and whose duty it should be immediately on the report of a contagious disease existing within his district, to investigate, and if the facts should justify him, quarantine said animals and said district in which the disease occurs, prohioiting their being removed from the farm or feeding lot until cured, it would be a speedy soIution of this difficulty. Their co-operation then with the Federal inspectors at the different stock-yards would render it virtually impossible for diseased animals to be transported throughout the country.

The inter-State Federal inspection of sheep is carried out with the object of preventing the spreading of contagious diseases, notably sheep-scab, from one State to another, but unhappily this disease has gotten such a firm bold now generally throughout the United States, especially where W'estern sheep 
are being fed, that the only method for the eradication of the pest is to place a rigid quarantine on diseased stock wherever they may be found. An instance can be quoted here to illustrate the desirability of some such proceeding. In 1896 , in a Western feeding district where considerably over 100,000 lambs are fed every year for the Eastern markets, principally Chicago, the majority of the flocks were affected with scab-in fact, all but one or two. These animals, while they were thoroughly dipped, were by no means in all cases cured, but were released from the State quarantine and shipped to Chicago, because, as it appeared, scabby sheep arriving there for immediate slaughter were passed by the authorities, and it would have been detrimental to the interests of the sheep-feeders of that State to have had their floclss held in quarantine while others were permitted access to the market. The mere fact that the transportation of animals suffering from such a disease would infect the railroad cars to the further danger and damage of other shippers does not appear to have entered into their calculations. They were not engaged then in protecting their neighbors' territory, and the result now is apparent. Whereas, the scab was mostly confined some years ago to certain sections of the country, notably the Western States and Territories, now we find it has been scattered broadcast; that clean sheep in feeding lots are the exception ard not the rule, the trouble having followed the lines of the railroads till it is unsafe to load absolutely healthy sheep on railroad cars and after shipment place them with a flock free of disease, as they carry with them the infection from the cars, which in a short time will cause outbreaks of scabies in the fock to which they have been admitted.

The following regulations refer to the inter-State transportations of sheep: 


\title{
Cransportation of Sheep Hffected with Scabies.
}

\author{
U. S. Department of Agriculture. \\ Office of the Secretary, \\ Washington, D. C., June 18, 1897.
}

To the Managers and Agents of Railroads and Transportation Companies of the United States, Stockmen and Others:

In accordance with Section 7 of the act of Congress approved May 29, 1884, entitled "An act for the establishment of a Bureau of Animal Industry, to prevent the exportation of diseased cattle, and to provide means for the suppression and extirpation of pleuro-pneumonia and other contagious diseases among domestic animals," and of the act of Congress approved April 23, 1897, making appropriation for the Department of Agriculture for the fiscal year ending June 30, 1898, you are hereby notified that the contagious disease known as sheep scab, or scabies of sheep, exists among sheep in the United States, and that it is a violation of the law to receive for transportation, or transport any stock affected with said disease from one State or Territory to another, or from any State into the District of Columbia, or from the District into any State. It is also a violation of the law for any person, company or corporation to deliver for such transportation to any railroad company, or master or owner of any boat or vessel, any sheep, knowing them to be affected with said disease; and it is also unlawful for any person, company or corporation to drive on foot or transport in private conveyance from one State or Territory to another, or from any State into the District of Columbia, or from the District into any State, any sheep, knowing them to be affected with said disease. All transportation companies and individuals shipping, driving or transporting sheep are requested to co-operate with this Department in enforcing the law for preventing the spread of the said disease. Inspectors of the Bureau of Animal Industry are directed to report all violations of this act which come to their attention.

In order to more effectually accomplish the object of the abore mentioned laws, it is hereby ordered that any railroad cars, boats or other vehicles, which have been used in the transportation of sheep affected with said disease, shall be immediately cleaned and disinfected by the owners or by the transportation companies in whose possession said cars or vehicles may be at any time the animals are unloaded by first removing all litter and manure which they con- 
tain, and then saturating the woodwork with a tive per cent. solution of crude carbolic acid in water. Inspectors of the Bureau of Animal Industry are directed to see that this order is carried into effect.

JAMES WILSON,

Secretary.

\section{State Inspection.}

Several of the Mestern States and also some of those of the Middle West have realized the necessity of controlling the passage of live stock across their borders, hence we find that the State of Colorado has built up an inspection bureau which has much to commend it. Starting out to prevent the promiscuous driving of Texas cattle into its territory, (they having been the cause of disastrous outbreaks of Texas fever among the stock with which they came in contact), laws were enacted which had for their especial meaning the prohibiting of sheep affected with scab from coming into the State. Unfortunately, however, the sheep-feeders found their source of supply endangered, as the sheep raised in the State were insufficient, or not such profitable feeders as those obtainable from New Mexico and Arizona, and their influence was sufficient to produce special rulings on the part of the Veterinary Sanitary Board by which they were permitted to continue the importations of lambs from infected districts on the payment of a tax per head of from one to two cents, which was termed an inspection fee, although it was virtually a payment for privilege, as an inspection would have prohibited their importation altogether. These sheep or lambs then were shipped direct to the feeding districts and placed on the farms of the feeders, where they were considered to be in quarantine, the feeder being supposed to use due precaution by means of dipping, etc., to clean them up. This could only be a perfunctory proceeding at the best; just sufficient to keep the disease under control but never entirely eradicating it; and when fit for sale the stock was shipped direct to one or the other of the great markets. 
This process was responsible for the scattering of the infection over wide portions of territory. Far better would it have been if some method could have been found to compel a thorongh cleaning of the flocks of New Mexico, compelling ev(ry shcep) leaving the Territory for other States to be dipped before being loaded on the cars. Then if they had been dipped thoroughly again on arrival at their destination, the disease would have been under control, and the danger of transmitting infection reduced to a minimum. We-believe lately better methods are being taken to guard against these conditions, and that a supervision of railroad cars and their thorough disinfection is being taken in hand, which is sure to produce beneficial results. Dr. Charles Gresswell, State Veterinary Surgeon and Secretary of the Colorado State Veterinary Sanitary Board, writes concerning inspection as follows:

"I am strongly in favor and alway" have been of rigorous inspection regulations, mainly with the object of protecting owners of improved stock, who, of course, suffer the most from negligence of owners of less valuable animals. It is a noted fact that scab does more injury in direct proportion to improvement of breed and artificial handling. The owner of the wild Mexican sheep suffers but little in comparison to the owner of well-brecl Shropshires or other pure-breeds. The same idea holds good with cattle, so the whole question resolves itself into one of rigorons inspection or no inspection whatever. With no inspection at all herds of sheep and cattle will gradually become more or less immune to contagious diseases which affect them, although with a great loss in the process. Animals raised by artificial selection and under our present domesticated conditions have little or no power to resist disease, and the ravages of disease among them are always very expensive. Therefore modified inspection is apt to make people think they are secure. They go in for the improved conditions, and then suffer from imperfectly executed inspection 
laws. If there were no inspection laws, they might learn to take care themselres, or not go into the business of improved stock at all. Therefore, I repeat, inspection laws if once instituted should be carried out rigorously in spite of the temporary hardships they may and do at times cause, and the execution of such matters should be kept absolutels free from politics of ererr kind."

We publish here the rules and regulations governing the entry and disposition of sheep arriving in the State of Colorado from outside States and Territories:

\section{State of Colorado Sheep Quarantine.}

Denver, Col., May 4, 1897.

From and after this date and until further notice, the following regulations will govern the admission of sheep from the States of Washington, Oregon, Montana, Idaho, Wyoming, California, Nevada, T $^{\top}$ tah and Texas, and the Territories of Arizona, New Mexico and Oklahoma, and the Republic of Mexico, into the State of Colorado.

First. Mll sheep intended to be driven or shipped into or through this State from the above scheduled States and Territories must be inspected by the State Veterinary Sanitary Board or by its duly authorized deputies before being allowed to enter said State, and due notice must be given of such intention to the Secretary at the Capitol Building, Denver, Colorado, or to one of the authorized inspectors of this Board, except: Sheep from the above scheduled districts may enter Colorado without inspection or a bill of health, by rail, provided they do not unload in the State except in quarantine pens for the purpose of feeding and watering and for a period not exceeding twenty-four hours.

Second. No sheep, except as provided for above. will be allowed to be driven or shipped across the State line unless accompanied by a Bill of Health granted hy the State Veterinary Sanitary Board, or by its duly authorized deputies, certifying that such sheep are wholly free from disease, and have not come in contact with any diseased sheep during the preceding sixty days, or unless accompanied by a Special Permit, which will be granted only on the following conditions:

That sheep so introduced shall be dipped to the satisfaction and under the supervision of this Board, or its duly authorized inspectors. 
at Denver, Pueblo, La Junta or at such other point as mar be designated by said Board, before such sheep shall be permitted to reload, or be driven to any point from the point of nnloading, and said sheep, if introduced under such Special Permit shall be held in quarantine by said Board until the above prorisions of inspection and dipping are fully complied with.

Third. To defray the expenses of inspection and the necessary supervision, a fee of one cent per head will be charged before a Bill of Health is issued, and a fee of one and one-half cent per head before a Special Permit is issued. The latter fee will include the costs of re. lease hereafter granted upon the fulfilment of the terms of the Permit.

Fourth. The cars used to transport all sheep coming into this State under Special Permit, as provided for above, and the pens in which they are unloaded, must be disinfected in the following manner: (a) Remove all litter and manure. This litter may be disinfected by mixing it with lime, or saturating it with a five per cent. solution of carbolic acid, or if not disinfected it may be stored where no sheep can come in contact with it. (b) Saturate the walls and floors of cars, fencing, troughs and chutes, or pens with a solution made by dissolving four ounces of chloride of lime in one gallon of water, or disinfect the cars with a jet of steam under a pressure of not less than fifty pounds to the square inch.

Inspectors will be stationed at the following points:

P. J. Towner, E. Las Tagas, New Mexico.

H. G. Ballard, Thompsons, Utah.

J. A. Slayton, Carr, Colorado.

J. H. Fleming, Folsom, New Mexico.

and at other points of dipping within the State of Colorado.

The penalty for infringement, or an attempt to infringe upon the provisions of this order, is a fine of not less than $\$ 100.00$ nor more than $\$ 5,000$, or imprisonment for not less than three months nor more than two years, or both.

THE STATE VETERINARY SANTTARY BOARD OF COLORADO.

CHAS. GRESSTELL, Secretary.

E. J. TEMPLE, President.

The rules and regulations of the various Western States and Territories governing the transportation or driving of sheep across their borders are, with few modifications and changes, a counterpart of the above, so further reference to them will be un- 
neeresily. Suffice to say that inspection is as yet in its infancy. The more the intelligent farmers see of its benefits, the more desirous are they to clain the protection afforded them by the enforcement of the law, and it is safe to predict that the next few years will see a marked diminution in the spread of contagious affections, and a great anount of capital thereby sared to the producer. 


\section{Index.}

H

Page.

Abdomen ...........

Abortion ...........

343

Abomasum ........

Abscess ............

Acari .............

Acetanelide ........

Acetic Acid ........

Actinomycosis .....

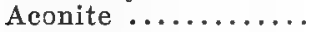

Adipose tissue .....

After-pains ........

Age, how to tell...

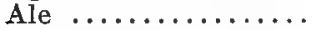

Alcohol ............

Alexander, Dr. A S...

Alimentary canal ...

Alfalfa ...........

Aloes .............

Alteratives ........

Alum .............

Amaurosis ........

Ammonia Liniment. .

Amniotic fluid......

Anaemia ...........

Anaesthetics .......

Anal opening ......

Analysis food-stuffs.

Anatomy, the ......

Anise-seed .........

121

298

240-241

354

354

281

354

95

330

113

355

354

189

116

90

355

350

355

304

162

324

285

351

132

89

94

359

Ant-acids .........

351

Anterior maxillary..

101

Anthrax fever ......

262

Anthelmintics ......

351

Anodynes ..........

351

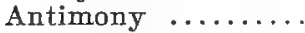

356

Antiseptics ........

Antispasmodics .....

Aphtha ...........

Apoplexy .........

Apothecaries meas-

Arachnoid space.....

Areca nut ..........

Argali $\ldots \ldots \ldots \ldots \ldots$

Arnica ...........

Arsenic ............

Arsenical sheep dips.

Page.

248

Arteries ...........

Asafoetida ........

Asphixia ......... 339

Astringents ....... $\quad 350$.

Atlas, the ......... 100

Auditory nerves .... 101, 108

B

Bacillus anthracis ..

263

Bacillus tetani ......

278

Bacillus tuberculosis.

261

Ball, E. N., Sec. Merino Association ..

Bakewell, Mr.......

Barley, food value ..

Belladonna .........

356

Benzoated lard ..... 357

Benzine .......... 224

Benzoin ......... 357

Bismuth .......... 357

Bile, the ......... 129 .

Bile, functions of.... 130

Bistournage ....... 292

Black oils ......... 357

Black leg........... 267

Black leg, vaccination against ......

Bladder, the ........

269.

Blasting ............

Bleeding ...........

Bleeding from cheek vein .............

Bleeding from jugular vein .........

146,328

Bleeding from saphena vein.......

Bleeding from umbilicus ...........

Blinds, the ... .....

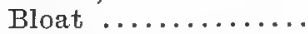

339.

304

Blood, the .........

173

Blood analysis .....

Blood, circulation of.

Blood diseases ......

Bloodlessness ...... 
Bloody flux ........

Page.

Boncs, the ..........

Bones of the head..

Bones of the body..

102

Bones of the fore extremities .......

Bones of the hind extremities ......

Boracic acid ........

Borborygmus ......

Brain, the .........

Broad ligament.....

Bronchocele ........

Bruises ...........

\section{C}

Cachexia ..........

Caecum, the .......

Calabar bean.......

Calcis, the ........

Calculi ............

Calculi, renal ......

103

106

358

180

96,107

135

301

297

Calculi, urethral ....

Calomel ............

Camphor ..........

Cannabis Indica ....

Cantharides ........

Capillaries .........

Capsicum ..........

Carbo-hydrates .....

Carbolic acid ........

Carbolic dips ......

Carbonate of ammonia ...........

Carbonate of lime..

Carbon ............

Carbonic acid gas....

Carcass weights.....

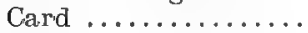

Carding ...........

Cardamons .........

Carminatives ........

Cartilage ...........

Cartilaginous tissue..

Castor oil...........

Cascarilla bark.....

Castration .........

Ca.tarrh ...........

Cathartics .........

Catechu ...........

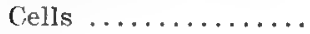

Page.

309

232

Cercaria ............

151

Cerebritis ..........

Cerebellum ........

Cerebrum ..........

Cervical vertebrae...

Cervix uteri.........

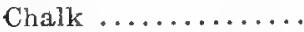

Charbon ...........

Charcoal ...........

Cheeks, the........

Ohest, the..........

Cheviot sheep.......

Chlorine gas.........

Chloral ............

Chloroform ........

Chlorodyne .........

Chloride of lime.....

Chokered ..........

Choking ...........

Chorioptes ovis......

Cholagogues .......

Chyme, the.........

Chyle .............

Cinchona ..........

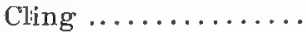

Cloudy wool.........

Cocaine ...........

Coccyx, the........

Codeine ...........

Cod-liver oil..........

Coenurus cerebralis.

Coffin bone.........

Colchicum .........

Colic .............

Colon, the...........

Common scab.......

Combing ...........

Congential hernia...

Conjunctiva, the....

Connective tissue....

Constipation .......

Consumption .......

Convulsions .........

Cooper, M. A., Sec.

Dorset Association.

100,107

100,107

102

134

185

262

361

114

96

70

361

360

360

360

359

228,286

171

234

352

121

97

361

187

79

361

102

361

361

201

104

362

181

127

236, 239

77

133

303

95

189

272

153

Copperas .... 303

303

Corn, value for food..

Corn, silage.........

Cornea, capacity of.. 305

362 
Page.

Cotswold sheep.....

Cotswold sheep, deseription of.......

Cotton-seed oil.......

Covered operation...

Cracked teats.......169, 308, 337

Cranial cavity......

Cranial nerves.......

108

Creosote ...........

Crepitus ..........

Cross-breeding ......

Croton oil..........

Cumberland disease.

Cyanide of potassium

Cyanosis ...........

Cystic tumors.......

\section{D}

Dandelion .........

Daniells, H. A., Sec. National Lincoln Association .....

Delaine Merino......

Delaine Merino, origin of...........

Delaine Merino, scale of points.........

Dentition ...........

Decussation .........

Dental pad.........

Dermatodectes ovis. .

Diaphoretics .......

Diaphragm, the.....

Diaphragmatichernia

Diarrhoea .........

Diarrhoea of lambs..

Digitalis ..........

Dipping ...........

Dipping plant.......

Diseases, definition of

Diseases, a nithracoid..

Diseases of brain....

Diseases of digestive system.........

Diseases of eye.....

Diseases of liver.....

Diseases, parasitic...

Diseases due to external parasites...

Diserases of the respiratory organs...
362

295

$=37$

362

263

363

342

300

363

29

69

70

113

108

112,117

234

352

117

179

183

184

363

248

250

142

263

151

168

302

192

201

234

160
Diseases of the urinary system........

Diseases of the new$1 \mathrm{y}$-born ..........

Diseases, incidental to parturition.....

Distoma hepaticum..

Diuretics ...........

Docking ..........

Dorset horned sheep.

Dorset sheep, first importations ......

Downrights, the....

Dover's powder.....

Drasties ..........

Dropsy ...........

Dropsy, abdominal...

Druce, Mr..........

Drying up.........

Drying wool........

Duodenum, the.....

Dunn's tonic drench.

Dura mater.........

Dysentery ..........

$\epsilon$

Early lambs........

Ectozor .......... 201

Eczema ........... 307

Eczema epizootica... 270

Ejaculatory ducts... 134

Eliman, Mr........ 37

Embryotomy ....... 327

Emphysema infectuosum ............ 267

Enemata.......... 381

Encephalitis ........ 151

Enteritis ........... 182

Entozoa ........... 201

Enzootic diseases.... $\quad 145$

Epithelial cells...... 94

Epiglottis, the...... 117

Epilepsy ......... 153

Epsom salts....... 146, 364

Ergot . ........ 364

Erysipelas ........ 280

Erythema ......... 308

Ethmoid bone....... 101

Ether.................. 364

Euphorbium ....... 365

Eustachian tubes.... 115

Eversion of rectum.. 191 
Ewes, conceive best..

Examine for scab.... Examination of export sheep........

Examination of import sheep........

Exeretion, an.......

Extensor muscles...

\section{$f$}

Fallopian tubes.....

Fardel bound........

Fasciola hepaticum. .

Feeding ...........

Feeding lambs, ration for..........

Feeding tables......

Feeding tables, value of ..............

Feeding tables, Wolff's

Felting .............

Felty wool .........

Femur, the..........

Fennell ............

Fenugreek ........

Fibrous tissue......

Fish oil............

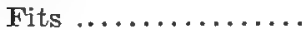

Flooding ............

Fly, the............

Foetus, the.........

Food and increase...

Foot and mouth disease ................

Foot-rot .........104, 145, 310

Foramen ...........

Fowler's solution....

Fractures ..........

Frenzy, the.........

Frontal bones........

Fungus haematodes..

\section{6}

Gad-fly ............

Gall-bladder .......

Gamboge ...........

Ganglion ............

Garget ...........

Gasoline ...........

Gastric julice........

-Gentian ...........
Page.

141

240

392,396

383-386

130

110

134

176

231

84

90

89,90

90

89

76

79

106

365

365

95

260

153

328

259

135

91

270

102

380

295

151

99,101

305

207

130

365

109

335

224

121

365

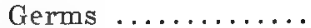

Germ ovum.........

Gestation, period of.

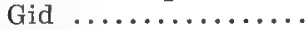

Ginger ...........

Glass eye..........

Glauber salts.......

Glycerine .........

Goitre .............

Goulard's extract...

Granulation, healing by ..............

Grass staggers.....

Great head.........

Green skit..........

Gresswell, Dr. Chas..

Gullet, the........

Gutta serena........

万

Haematosepsis .....

Hampshire Down....

Hampshire Down, the old ............

Hampshire Down, the new .............

Hampshire D o w n, first importations..

Hampshire Down, standard of excellence .............

Hay, food value of...

Head scab..........

Healing by first intention .........

Healing by granulation .............

Health, definition of.

Heart, the.........

Heels, the..........

Hemorrhoids ........

Hemp ...........

Hepatic artery.....

Hepatitis ...........

Herdwick sheep....

Hernia ............

Hernia, congenital...

Hernia, d i a p h r a gmatic ...........

Hernia, umbilical... .

Hermaphroditic parasites ...........
Page.

261

133

135,323

201

366

304

146,366

366

115,301

366

296

176

263

185

401

117

304

267

45

45

47

47

49-50

238

296

297

142

96

105

191

79

129

192

72

179

133

179

180

232 
Hogg, the Ettrick shepherd .........

Hog's lard...........

Hoose .............

Honeycomb, the....

Hoven ............

Hock joint, the......

Humerus, the.......

Husk ..............

Humphrey, Mr......

Hydrastis canendensis .............

Hydrocephalus ......

Hydrochloric acid...

Hydrocyanic acid....

Hydrogen ..........

Hydrogen peroxide..

Hydrophobia ........

Hydrothorax .......

Hypnotics ........

Hyoscyamus .......

I

Icterus $\ldots \ldots \ldots \ldots$.

Ileum, the.........

Ilio caecal valve.....

Impaction of rumen.

Impaction of omasum

Impaction fourth stomach of lambs..

Imperforate anus....

Impetigo Labialis... .

Imports from Canada

Imports other countries ............

In-breeding ........

Incontinence of urine Infectious abortion..

Infectious aphtha....

Page.

Inferior maxillary...

Influenza ..........

Inflammation of blad-

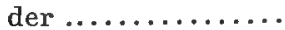

I $\mathrm{n}$ fl a m mation of bowels ...........

I $\mathrm{n}$ fl a m m tion of

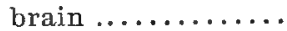

Inflam ation of bronchial tubes....

Infla $\mathrm{mmation}$ of liver ............ 160

Inflam mation of

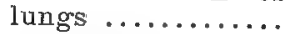

I $\mathrm{n} f \mathrm{a} \mathrm{m} \mathrm{m}$ a tion of inter-digital canal.

I $\mathrm{n}$ fl a $\mathrm{m} \mathrm{m}$ a tion of kidneys ..........

In fl a m mation of pleura ..........

I $\mathrm{n}$ fl am mation of vagina ..........

Infla $m$ mation of womb ...............

Inflammation umbilical cord..........

Inspection ..........

Inspection, Federal. .

Inspection, State....

Interdigital canal... .

inter-State sheep inspection ..........

Inter-ungulate sinus.

Intestines, length of.

Intestinal obstructions .............

Intus-susception ....

Inversion of womb. .

Inversion of vagina..

Involuntary muscle tissue ...........

Page.

164

106,321

196

166

331

332

339

38 ,

$382-400$

400-404

105

399

105

126

178

180

329

330

Iodine ............

Iodoform .......... 368

Ipecacuanha . . . . . $\quad 368$

Iron ............ 368

Iron carbonate...... $\quad 368$

Iron iodide......... 369

Iron phosphate..... $\quad 368$

Iron sulphate....... 368

Iron tincture....... $\quad 369$

Ischiatic spines...... 106

3

Jaborandi ...........

369

Jalap ............ 369

Jaundice .......... 193

Jejunum ......... 127

182

151

163

192

Jugular vein........

Jugular vein, bleed-

Kamala ........... 
Kentish long-wooled sheep .......... Kidneys, the........ Kidneys, inflammation of structure.

\section{I.}

Labor pains........

Lachrymal bones...

Lachrymal duct.....

Lacteals ...........

Llama ............

Laminal tissue......

Laminitis ..........

Laminitis parturient.

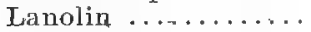

Larkspur .........

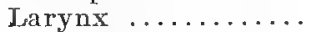

Laryngitis ........

Lashing ............

Laudanum .........

Laxatives ..........

Lead acetate........

Leicester sheep......

Leicester sheep, the old ..............

Leicester sheep, the new ............

Leicester sheep, Border ..........

Leicester sheep, fleece ............

Lice .............

Ligaments ........

Lime water.........

Lime and sulphurdip

Lincoln sheep.......

Lincoln sheep, the

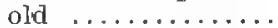

Lincoln sheep, the new ...........

Lincoln sheep, scale of points.........

Linseed oil..........

Linseed meal.......

Lips, the..........

Liquid measure.....

Liquor amnii.......

Liquorice .........

Litmus paper.......

Liver, the..........

Tiver, functions of.
. Page.

115,117

162

292

370

351

370
Liver, inflanmation of .............

Liver flukes..........

Lobules of liver.....

Loek-jaw ..........

Loodiana disease....

Lombriz ...........

Long-wooled breeds.

Long bones.........

Loss of cud..........

Louping-ill .........

Iucellia marcellaria.

Lungs, the.........

\section{M}

Madness ..........

Mad staggers.......

Maggots ..........

Magnesium sulphate.

Malar bones........

Male shield fern.....

Malignant pustule...

Malignant parturien't fever ............

Mamm'itis ........

Mianyplies, the......

Marrow, the........

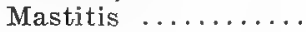

Mating ...........

Measure, solid......

Measure, liquid......

Medical agents.......

Medical treatment in general ..........

Medulla oblongata...

Meconium, the......

Melophagus ovinus..

Membrana nictitans.

Mercurious chloride.

Mercury ...........

Merino ............

Merino, first importations ...........

Merino, American...

Merino, Spanish.....

Merino, Delaine.....

Merino, Dickinson...

Merino wool fibres...

Mesentery, the.....

Mesentery, glands of

Page.

192

$2 \div 5$

129

148,278

262

222

23

98

174

155

259

96

275

155

260

371

101

370

262

333

335

121

98

335

136

353

353

350,381

348,349

100,107

341

255

2.) 303

371

371

Metacarpus ........ 103

Metastasis ......... 
Page.

Metritis .........

Mexican lambs......

Middle-wooled sheep.

Midiriff, the.........

Milz-brand .........

Mindererus spirit....

Molar teeth.........

Monge, M..........

Monstrosities ......

Morphine ..........

Mountain breed.s....

Mouth, the........

Mouth, broken.......

Mucus rales........

Muscles, the........

Muscular tissue.....

Muscles, contraction

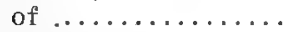

Musmon, the.......

Mutton fat........

Mutton, analysis of. .

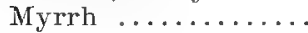

\section{$\mathbf{N}$}

Nasal bones........

Nasal cavity........

Nasal catarrh.......

Navel-ill ..........

Nephritis .........

Nerves ............

Nervous tissue.....

Nicotine ..........

Nippers, the........

Nitrite of amyl.....

Nitric acid.........

Nitrogen .........

Nitre, sweet spirts of

Nitro hydrochloric acid ............

Nocard, M..........

Nodular disease.....

Non-contagious diseases ...........

Nux vomica.........

0

Oatmeal ..........

Oats, as food.......

Obliteration of os uteri ...........

Obstruction of gullet

Occipital bone.......
279,332

$84-85$

23

118

262

371

113

76

327

372

70

114

113,140

164

110

95

95

19

87

87

356

101

101

160

339

196

96,108

95

372

113

372

372

87

372

373

169

224

$307-322$

373

373

90

325

171

100
Oesophagostoma columbianum .......

Oesophagus ........

Oesophageal canal...

Oestrum, period of..

Oestrus ovis........

Oil of anise.........

Ojl of carron........

Oil of einnamon.....

Oil of ergot.........

Oil of eucalyptus....

Oil of mustard.....

Oil of olive.........

Oil of peppermint...

Oil of $\operatorname{tar} . . . . . . . .$.

Oil of turpentine....

Oil of vitriol.........

Olfactory nerves.....

Omasum, the.......

Omasum, impaction of .............

Opacity of the cornea

Operative surgery....

Opium tincture.....

Ophthalmia, simple..

Ophthalmia proper. .

Optic nerves........

Os hyoides..........

Os pedis............

Ovaries, the........

Ovaries, castration of

Oxfordshire Down...

Oxfordshire Down, origin of.........

Oxfordshire Down, early importations.

Oxygen ............

P

Palate bones.........

Palsy, the..........

Pancreas ...........

Pancreas, its uses...

Pancreatic juice....

Paralysis ..........

Paralysis, peripheral

Paralysis, simple...

Paralysis, transverse

Parasites .........

Parasites, internal...

Parasites of the skin
Page.

$192, \quad 2 \div 4$

117

118

135

207

373

373

374

374

374

374

373

374

374

375

375

101,108

121

176

305

290-302

375

303

304

108.

115

104

134

294

50

50.

52

88

101

157

130

131

131

150

150

157

150

145

201

234 
Parasitic diseases of the brain.........

Parasitic gastric catarrh ...........

Parasitic ibronchitis,

Parasitic diarrhoea..

Parasitic nasal catarrh ...........

Parietal bones, the..

Paronchyia interdigitalis ..........

Parotid glands.......

Parturient laminitis.

Parturition .........

Parturition, diseases incidental to.....

Parturition, malpresentations .....

Parturition, normal.

Parturition, prolonged ............

Pastern joint.......

Pasteur, M., method of vaccination for anthrax ..........

Patella, the........

Pelvis, the.........

Penis, the..........

Pepper ...........

Peppermint ........

Pepsin .............

Pericardium .......

Peritoneum, the....

Peritonitis .........

Periosteum, the....

Permanganate of potash ..............

Persian sheep......

Petrous temporal bone ..............

Peyers patches......

Pharynx ..........

Physiological action of drugs..........

Pia mater..........

Picklock, the.......

Pictate of Potash....

Piles ..............

Pinding ..........

Pining ............

Placental papillae...

Plethoric diseases...
Page.

207

100

310

114

338

323

323

326

323

324

104

263

106

106

134

375

375

122

97

97,120

191

98

376

115,117

350

107

77

223

191

188

289

331

145
Pleura, the........

Pleurisy ...........

Pneumogastric nerve

Pneumonia ........

Poked ..............

Pomgranate root bark ............

Portal vein..........

Page.

97

166

108

164

286

376

129

328

hage ............

Potassium bi-carbonate .............

Potassium chlorate..

Potassium hydrate.

Prehensile organs...

Prime, the..........

Probang, the.......

Prolapsus of the rectum .............

Prolapsus uteri.....

Prolapsus vaginae...

Prominent breeds of sheep ...........

Proportion of parts..

Protein ............

Proof spirit.........

Prurigo ............

Prussic acid........

Psoroptes communis.

Ptomaines .........

Pulse, the..........

Pulse beats..........

Pumpkin seeds......

Purgatives .........

Pylorus, the.......

375

367

377

114

77

172

191

329

330

23

91

88

377

309

354,377

234

261

147

147

224

145,352

122,127

\section{Q}

Quarantine regulations ............

Quarantine, import sheep ...........

Quarantine, sh e e p affected with contagious diseases...

Quarter-ill .........

Quicklime ..........

Quinine sulphate...

R

Rabies ........... Rabies, in the $\operatorname{dog} . .$. Radius, the........
383

386

399

267

319

377

148,275

277

103 
Rambouillet, the...

Rambouillet Association ............

Rambouillet, e a r l y importations ......

Rambouillet, origin of

Rectum, the........

Red-clover, value of.

Rediae ............

Red water...........

Renal basin.........

Renal calculi.......

Regulations for inter-state shipments

Retention of foetal membranes ......

Retention of meconium .............

Retention of urine...

Reticulum, the.....

Rheumatism .......

Rheumatism acute...

Rheumatism chronic.

Rhubarb ..........

Rhubarb, compound powder of........

Ribs, the...........

Rigidity of os uteri..

Rock salt...........

Rocky mounta i n sheep ...........

Romney Marsh sheep

Romney, first importations of........

Rosin ............

Rot, the...........

Rot, prevention of...

Rumen, the........

Rumen, impaction of

Rumination ........

Rumenotomy .......

Rupture ..........

Ruta-baga .........

\section{S}

Sacrum, the.......

Saliva, the.........

Salivary glands.....

Saliva, its uses.....

Salmon, Dr. D. E....

Salt .............

Sanguineous Ascites.

Page.

66

68

68

68

127

89

232

283

132

197

399

328

341

197

120

287

288

288

377

378

102

325

85,214

19

33

35

378

226

232

118

175

123

176

179

89

107

114

114

115

224

145,378

283

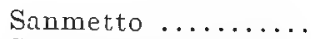

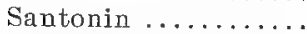

Sapo Mollis..........

Sarcoptes ovis......

Searing, the cord....

Secretion, definition of $\ldots \ldots \ldots \ldots$.

Scab, the..........

Scab infection......

Scab mites..........

Seab, multiplication

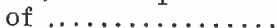

Seapula, the.......

Scrotum, the.......

Scrotal hernia.......

Secretion, a........

Selection ...........

Semen, the.........

Sesamoids ........

Shearing ..........

Sheep ............

Sheep, number in U. S.............

Sheep, how to catch.

Sheep pox..........

Sheep tick.........

Short-wooled sheep..

Shropshire breed....

Shropshire, origin of

Shropshire, points of excellence .......

Shropshire, early importations .......

Shropshire Sheep Association

Silver nitrate.......

Simple ophthalmia..

Skeleton, the.......

Skin dryness........

Snots, the..........

Snuffles, the........

Soap liniment.......

Sodium carbonate...

Sodium hyposulphite

Sore mouth, contagious in lambs..

Sore-throat .......

Soft palate.........

Southdown sheep....

Southdown early history ...........
Page.

200

378

378

234

292

130

234

243

238-242

236

103

133

133,293

130

140

133

104

148

19

22

144

273

255

23, 59

41

41

43-45

43

43

379

303

95,97

342

211

160

379

379

379

169

162

115

35

37-39 
tis

Page.

Southdown Associat-

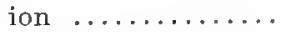

Southdiown, seale of

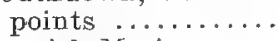

Spanish Mrerino......

Spanish wool........

Spaying ............

Special nerves......

Specific diseases.....

Spermatic cord......

Sphenoid bone.......

Spinal cord........99, 102, 107

Spinal vertebrae....

Splenie apoplexy....

Spleen in anthrax...

Sporocyst ..........

Sprains ...........

Squamous temporal..

Starch ............

State, inspection of sheep ...........

Statistics, wool.....

Stavesacre seed.....

Steno's duct.........

Stifle joint.........

Sitomach ..........

Stomach round worms ...........

Stomatitis ........

Strains ............

Streptococeus erysipelatis ...........

Stricture ..........

Stripy wool.........

Strongylus contortus

Strongylus filaria....

Strongylus rufescens

Struma ............

Sturdy .............

Subcorneus $m$ embrane ...........

Sublingual glands...

Submaxillary glands.

Suffolk sheep.......

Suffolk standard of excellence ........

Suffolk Association. .

Sussex sheep........

Sugar of lead.......

Sulphate of iron....

Sulphur ...........

Sulphuric acid......

Sulpthurous acid....

Page.

Super-purgation ....

109

\section{c}

Tables ............

Tables, wool imports

Tables, Wolff's.......

Taenia coenurus.....

Taenia expansa.....

'Tagging ...........

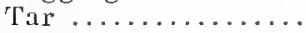

Tar, oil of.........

Taraxacum .......

Teeth, the.........

Teeth, incisors......

Teeth, molars........

Teeswaters, the.....

Temperature, how to take ...........

Temporal bones....

Tendons ............

'Testicles, the.......

Testicles, castration of ................

Tetanus ............

Therapeutic action of drugs..........

Thoracic duct......

Thorter-ill .........

Thymus, the.......

Thyroid bodies.....

Tibia, the.........

Tissue ............

Tissue, kinds of.....

Tobacco ...........

Tobacco sheep dip...

Tonies ............

Tongue, index in dis-

Treatment of individuals ..........

Treatment, a whole flock ............ 
Tremblings, the....

Trephining ........

Trocar, the.........

Tuberculosis .......

Tumors ...........

"Thmors, treatment of

Tunica vaginalis....

Turnsick .........

Turnips ...........

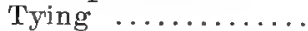

Typhus ..........

\section{a}

Ulna, the..........

Umbilical cord.......

Umbilical hernia.... .

Umbilical cord, inflammation of....

Umbilical hemorrhage ...........

Uraemic poisoning...

Urea .............

Ureters ..........

Urethra ..........

Urine .............

Uterus, the........

Uterus, amputation of .............

$\vartheta$

Vaccination anthrax.

Vaccination blackleg.

Vagina, the........

Vaginitis ..........

Variola ovina.......

Vas deferens........

Vaseline ...........

Veins .............

Vermes ............

Vermiform appendage .............

Vermifuges ........

Vermicides .........

Vesiculae seminales.

Villi, the..........

Vinquish ........

Voluntary muscle tissue ............

Volvulus ...........

Vulva, the.........

\section{वa}

Water on the brain. .
Page.

155

210

172,174

272

299

300

293

201

89

$2(1)$

263

103

339

180

339

339

198

132, 196

132

132

131-132

134

330

266

269

135

331

273

133

381

96

201

134,199

352

352

133

97,127

289

135

154
Watery wool.......

Webb, Jonas........

Wheat-bran, for food

White oak bark.....

White skit.........

Wild-fire ............

Wing, Jos. E........

Wiring ...........

Wolff's tables:......

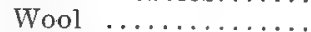

Wool balls..........

Wool closure of fleece

Wool curl...........

Wool, growth of.....

Wool fibres.........

Wool fibres, serrations of..........

Page.

is

$8 \%$

89

3५1

1 irt

$: 81$

221

101,206

89

(1)

178

77

77

75

65

Wool, fine.......... $\quad 76$

Wool, fineness...... 77

Wool, superfine...... 77

Wool, hemp........ 79

Wool, short........ 77

Wool, cloudy.......

Wool, long........ 77

Wool, broad-topped.. $\quad 80$

Wool break......... 80

Wool, watery........ 78

Wool, stripy........ 78

Wool thickness...... 77

Wool, felty........ 79

Wool, toppy........ 79

Wool, stapler....... 77

Wool, strength of fibre ...........

Wool imports........ 83

Wool-sorters' disease 262

Womb, the........ 134

Wound, .......... 296

Wounds contused.... 297

Wound's of the eye.. 305

Wounds incised...... 296

Wounds lacerated.... $\quad 297$

Wounds punctured. . 296

\section{$\nabla$}

Yolk of fleece....... 76

Youatt ........... 76

$z$

Zine sulphate.......

Zygomatic areh..... 



\section{SHEEP BREEDERS'}

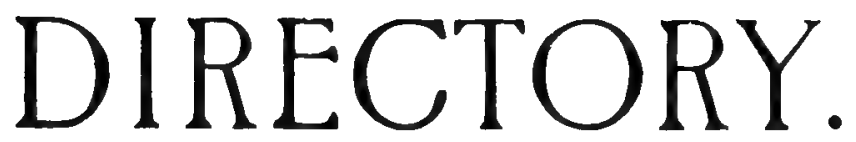

CONTAINING A LIST OF THE

PROMINENT

\section{SHEEP BREEDERS' ASSOCIATIONS}

OF THE UNITED STATES AND

CANADA.

ALSO

NAMES AND POST OFFICE ADDRESSES OF BREEDERS OF PURE-BRED SHEEP OF THE BEST KNOWN BREEDS OF NORTH AMERICA.

1899. 


\section{Sheep Breeders' Associations of the United States and Canada.}

\section{Che American Leicester Breederg' Hssociation.}

President.

D. C. GRAHAM, Cameron, Ill.

Vice-President.

A. W. SMrTH, Maple Lodge, Ont.

Secretary-Treasurer.

A. J. TEMPLE, Cameron, III.

Directors.

John Felly, Shakespeare, Ont.

John Walton, Calkinsville, Mich.

J. W. Wurphy, Cass City, Mich.

James E. Gaunt, Lucknow, Ont.

J. M. Garclhouse, Highfield, Ont.

James Snell, Clinton, Ont.

C. E. Wood, Freeman, Ont.

Honorary Vice-Presidents.

W. A. McCoy, Mercer, Pa.

A. Whilelaw, Guelph, Ont.

John Marshall, Cass City, Mich.

George Richardson, Benedict, Neb.

A. I. Wingate, lron, Ill.

S. P. Goudey, Yarmouth, N. S.

William Clark, North Wiltshire, P. E. I.

J. W. McKinney, Salem, Oregon.

\section{Fmerican Cotsroold Record.}

President,

JOHN C. SNELL, Snelgrove, Ont.

rice President.

J. HAL WOODFORD, Paris, Ky.

Secretary and Treasurer.

GEO. HARDING \& SOx, Waukesha, Wis.

Board of Directors.

R. C. WATT, Xenia, Ohio.

JOHN C. SNELL.

J. HAL WOODFORD.

GEO. HARDTNG.

F. W. HARDING. 


\title{
Hmerican Cotswold Record-Continued.
}

Vice Presidents.

Eastern Ontario-- Tanes Russell, Richmond Hill.

Western Ontario-David McCrae, Guelph.

California-Chas. McDairmaid, San Jacinto.

Colorado-T. H. Oreutt, Rocky Ford.

Illinois-Thos. Clark, Beecher.

Indiana-J. B. Herkless, Carthage.

Iowa-S. Bennington, Volga.

Kansas-s. G. McCandless, Cottonwood Falls.

Kentucky-Abram Renick. Sycamore.

Naine-Oscar Shirley, Houltion.

Michigan-W. R. Montgomery, Jr., Millsdale.

Minnesota-R. C. Judson, St. Paul.

Montana-F. K. Parkhurst, Ekalaka.

Missouri-Hopson Glascock, Rensselaer.

North Dakota-W. C. Heron, Harvey.

South Dakota-Fred Wilson, Conde.

New Tork-John Chick, Attica.

Ohio-W. J. Cherry, Xenia.

Oregon-James Withycombe, Corvallis.

Pennsylvania-S. V. MrDowell, Fredonia.

Utah-Jas. B. Ririe, Weber.

West Virginia-James J. Idleman, Mt. Storm.

Wisconsin-N. M. Jewell, Mineral Point.

\section{National Lincoln Hssociation.}

\author{
President.
}

BERT SMITH, Charlotte, Mich.

Secretary-Treasurer.

H. A. DANIELLS, Elva, Mich.

Tice-Presidents.

William Oliver, Ontario.

E. P. Oliver, Michigan.

J. W. Ganes, Wisconsin.

Col. C. C. Rice, Illinois.

Col. H. Z. Leonard, Indiana.

H. C. Coburn, South Dakota.

F. G. Bovyer, P. E. Island.

C. H. Marshall, Vermont.

H. H. Cleaver, Missouri.

W. W. Steed, Utah.

S. W. Beal. Michigan.

Directors.

G. E. Port, Michigan.

Graham Walker, Ontario.

M. L. Wasson, Michigan.

James Z. Mott, Michigan.

Pedigree Committee.

Capt. T. E. Robson. Robert Knight. Wm. Shier. 


\section{American Southdown Breeders' Hssociation.}

\section{President.}

J. H. PICKRELL, Springfield, Ill.

Secretary.

JNO. G. SPRINGER, Springfield, III.

Treasurer.

D. W. SMITH, Springfield, Ill.

Board of Directors.

Geo. McKerrow, Sussex, Wis.

L. M. Crothers, Crothers, Pa.

J. H. Warren, Hoosick Falls, N. Y.

Jerome A. Leland, Springfield, Ill

S. E. Prather. Springfield, Ill.

C. M. Clay, White Hall, Ky.

John Jackson, Abingdon, Ont., Can.

J. D. Pancoast, Moorestown, N. J.

F. J. Tompkins, Girard, Mich.

\section{American Shropshire Association.}

President.

Hon. JOHN DRYDEN, Toronto, Canada.

First Vice-President.

Prof. W. C. LATTA, LaFayette, Indiana.

Secretary-Tireasurer.

MORTIMER LEVERING, LaFayette, Indiana.

Executive Committee.

H. H. Clough, Ohio, George Allen, Ill.,

Dr. G. H. Davison, N. Y.,

T. A. Bixby, Mich.,

Committee on Pedigrees.

$\begin{array}{cccc}\text { term expires, Nov. } & 1899 \\ \text { ". } & \text { " } & \text { " } & 1899 \\ \text { " } & \text { " } & & 1900 \\ & & & 1900\end{array}$

S. H. Todd, Ohio,

J. C. Payne, Wis.,

$\begin{array}{cccc}\text { term expires, } & \text { Nov. } & 1899 \\ \text { "6 } & \text { "6 } & 1899 \\ \text { " } & \text { " } & \text { " } & 1900 \\ & & & \end{array}$

H. W. Mumford, Mich.,

J. N. Greenshields, Que.,

Vice-Presidents.

British Columbia-E. A. Kipp, Chilliwack.

Manitoba-J. A. S. Macmillan, Brandon.

Northwest Territory--O. P. Skrine, Grenfell.

Nova Scotia-Darid Logan, Pictou.

Ontario-W. H. Beattie, Wilton Grove.

P. E. T.-Donald Ferguson, Charlottetown.

Quebec-W. C. Edwards, Montreal.

Arizona-Joseph Baum, Phoenix.

Arkansas-R, C. Walton, Rogers. 


\section{American Shropshire Association-Continued.}

California-J. H. Glide, Jr., Sacremento.

Colorado-J. D. Stannard, Fort Collins.

Connecticut-D. B. Wilson, Waterbury.

Georgia-T. P. Branch, Augusta.

Illinois-George Allen, Allerton.

Indiana-F. C. Yeiser, Avilla.

Iowa-L. M. Hartley, Salem.

Kansas-Elwood Rush, Shaw.

Kentucky-J. M. Garrett, Fort Garrett.

Long Island-E. R. Ladew, Glen Cove.

Maine-Bert Hilton, Anson.

Maryland-C. H. Tilghman, Tunis Mills.

Massachusetts-Frank P. Bennett, Boston.

Michigan-L. S. Dunham, Concord.

Minnesota-W. J. Poynton, Rochester.

Mississippi-T. H. Harrod, Newton.

Missouri-W. R. Turner, Shelbyville.

Nebraska--C. H. Ballinger, Lexington.

N. H.-H. W. Keyer, North Haverhill.

New Jersey-R. Stuyvesant, Allamuchy.

New Mexico-C. W. Riggs, Albuquerque.

New York-James Hilton, New Scotland.

North Carolina-J. S. Carr, Durham.

North Dakota-R. T. Kingman, Hillsboro.

Ohio-S. F. Streetor, Painesville.

Oregon-L. F. Mascher, Silverton.

Pennsylvania-J. A. Woodworth, Sayre.

Rhode Island-F. S. Ballou, Slatersville.

S. Dakota-F. W. Goodrich, Farmingdale.

Tenn.-James Calloway, Four Mile Branch.

Vermont-Albert Bresee, Hubbardton.

Virginia-Mr. Thompson, Swoope.

West Virginia-T. L. Hayes, Mannington.

Wisconsin-Prof. J. A. Craig, Rice Lake.

Wyoming-W. R. Carlin, Medicine Bow.

\section{Fampshire Down Breeders' Association.}

President.

IRA J. HILLER, West Bay City, Mich.

Vice-Presidents.

J. W. GANES, Reeseville, Wis.

J. G. MASSEY, Rawlins, Wyo.

P. W. ARTZ, New Carlisle, Ohio.

E. M. BENHA.r, Hopewell Center, N. Y.

Secretary and Treasurer.

JOHN I. GORDON, Nercer, Pa.

Anditors.

JOSEPH JUNKIN, Mercer, Pa.

J. H. ALIISON, Mercer, $\mathrm{Pa}$. 


\section{American Oxford Down Sheep Record Hssociation.}

President.

GEO. MekElRolv, Sussex, Wisconsin.

First Vice-President.

H. J. DeGARMO, Highland, Michigan.

Secretary and Treasurer.

W. A. SH.\FOR, Middletown, Ohio.

Vice-Presidents.

Trilliam Duval, Alliance, 0 .

J. H. Iylor, Gunpowder, Ky.

Edmund Orgill, Bonds, Tenn.

A. Bordwell, Fargo, N. Y.

F. C. Biddle, Chadds Ford, Pa.

D. Williams, Pleasant Valley, W. Va.

L. N. Olmsted, Muir, Mich.

J. R. Cunningham, Antioch. Ind.

James Tolton, Walkerton, Ont., Can.

M. G. Okey, Millersville, Ill.

L..D. Hill, Hingham, Wis.

William M. Liggett, Benson, Minn.

Eli Kelly, Fairfield, Ia.

R. H. Sampson, Rocheport, Mo.

E. Cook, Wilmont, South Dakota.

F. C. Goldsborough, Easton, Md.

Charles W. Hilton, Anson, Me.

F. E. Simpson, Saxonville, Mass.

Robert Jones, Fort Steele, Wyo.

E. S. Dunlap, Truro, N. S.

\section{Dorget Бorn Sheep Breeders' Hssociation of Hmerica.}

President.

HON. JOHN A. MeGILLIVRAY, Toronto, Canada.

Vice-President.

HENRY PALMER, Avondale, Pa.

Secretary ard Treasurer.

M. A. COOPER.

Executive Committee.

Wm. E. Kimsey, Angola, Ind.

Wm. L. MrCleary, Washington, Pu.

Samuel Briggs, Cleveland, Ohio.

E. O. Denton, Somerset, N. Y.

L. S. Gillet, Verona, Md. 
Dorset Dorn Sheep Breeders' Association of America-Continued.

Vice-Presidents.

Canada-A. 'T. Button.

New York-J. L. Buell.

Indiana-A. H. Omstead.

P'ennsylvania-D. Strickler.

Michigan-Lewis Love.

Connecticut-J. B. Palmer.

Ohio-S. C. Priest.

Nebraska-H. D. Watson.

Tisconsin-Hugh H. Price.

Illinois-John J. Gates.

lientucky-James B. Finnell.

Marvland-Gallaway Cheston.

Nassachusetts-Alfred Birnie.

Missouri-A. M. Teller.

Delaware-George IT. Bush.

New Jersey-R. Stuyvesant.

North Carolina-J. S. Carr.

Vermont-James C. Colgate.

Virginia-Prof. D. O. Nourse.

Ontario-M. N. Empey.

Minnesota-Giles Hayward.

Oregon-Fichard Scott.

Maine-H. B. Whitman.

Tennessee-James J. AcClaskey.

\section{Continental Dorset Club.}

Secretary.

J. E. WING.

The Improved Black-Cop Merino Sheep Breeders'

Hssociation of America.

President.

L. L. MARSH.

Vice-President.

L. J. WILSON.

Corresponding Secretary.

o. M. ROBERTSON.

Secretary and Treasurer.

L. M. CROTHERS. 


\section{Hmerican Rambouillet Sheep Breeders' Hssociation.}

President.

J. E. WEBB, Webb, Ind.

Vice-President.

C. L. HALLADAY, Sebewa, Mich.

Secretary and Treasurer.

E. V. BURNHAM, Woodstock, Ohio.

\section{National Delaine Merino Sheep Breederg' Hssociation.}

President.

JAMES McCLELLAND.

Corresponding Secretary.

J. H. HAMILTON.

Treasurer.

R. W. CROTHERS.

Recording Secretary.

C. C. JOHNSON.

\section{Che Michigan Merino Sheep Breederg' Hssociation.}

President.

A. A. WOOD, Saline.

Vice-President,

H. R. DEWEY, Grand Blanc.

Secretary.

E. N. BALL, Hamburg.

Treasurer.

THOS. VAN GIESON, Clinton.

Directors.

L. W. Barnes, Byron.

P. Voorhies, Jr., Pontiac.

William Ball, Hamburg.

F. L. Corbin, Lansing.

C. E. Lockwood, Washington, Mich.

Committee of Pedigrees.

D. P. Dewey, Grand Blanc.

W. E. Boyden. Delhi Mills.

E. W. Hardy, Howell. 


\section{National Cheviot Sheep Society.}

President.

PROF. C. S. PLUMB, LaFayette, Ind.

First Vice-President.

P. P. NOEL, Rockville, Ind.

Vice-Presidents for States.

T. N. CLRRY, Hartwick, N. Y.

U. S. MILLER, Pulaski, Iowa.

H. C. DAVIIISON, Elbridge, Tenn.

C. H. MARSHALL, Vergennes, Vt.

Secretary.

HOWARD H. KEIM, Ladoga, Ind.

Treasurer.

ISAAC LLOYD, Russellville, Ind.

Artist.

I. A. WEBSTER, Whiting, Vt.

Executive Committee.

The President and Secretary ex-officio.

P. P. Noel,

Hon. D. W. Heagy.

R. L. Ainslie.

Isaac Lloyd.

William Curry.

W. S.'Crodian.

\section{Sheep Breeders' Directory.}

\section{Breeders of Ireicester Sheep.}

Archer, A. E............................Warwick, Ont.

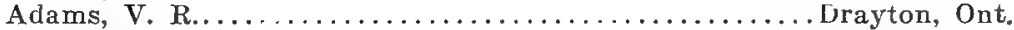

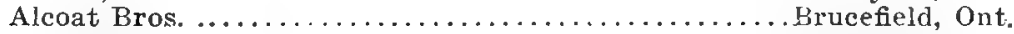

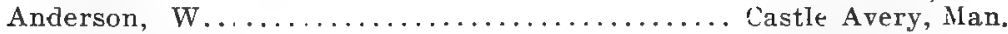

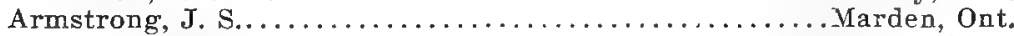

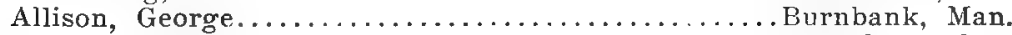

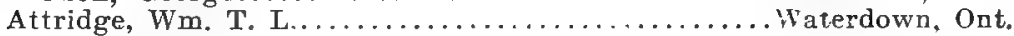

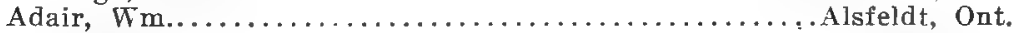

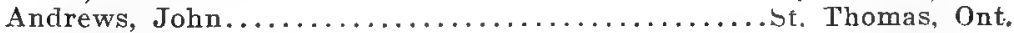

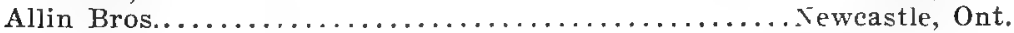

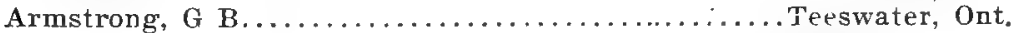

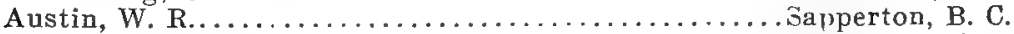

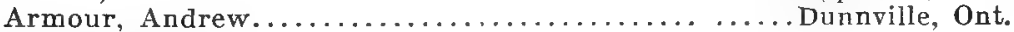

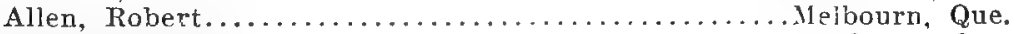

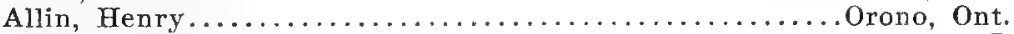

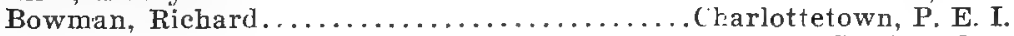

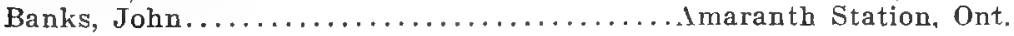




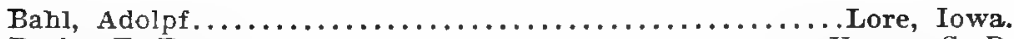

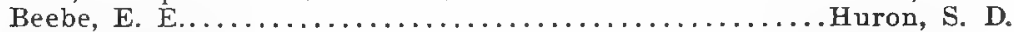

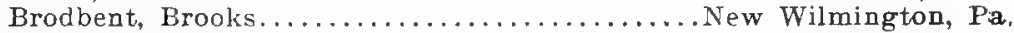

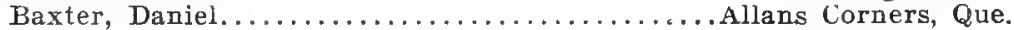

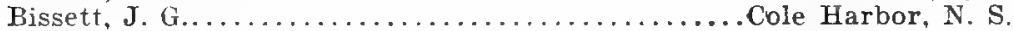

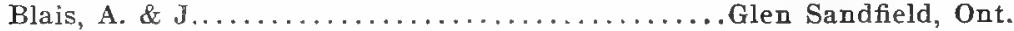

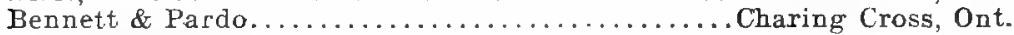

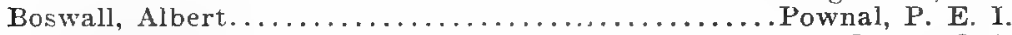

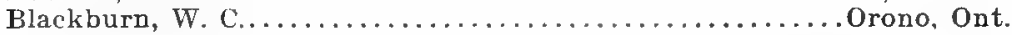

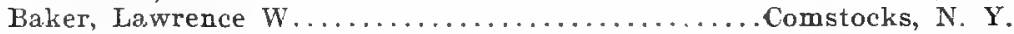

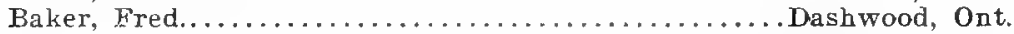

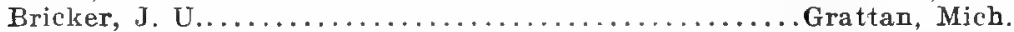

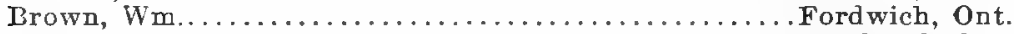

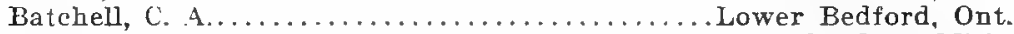

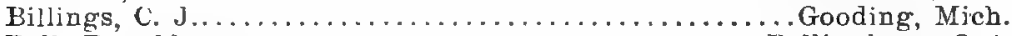

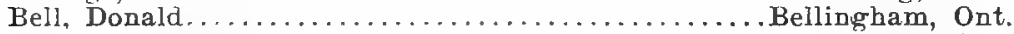

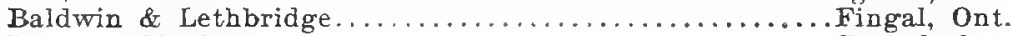

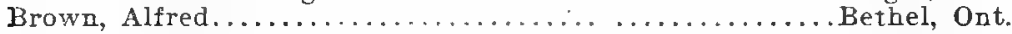

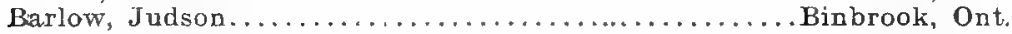

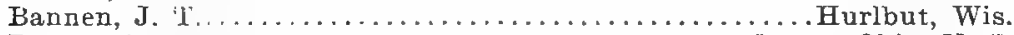

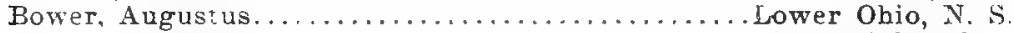

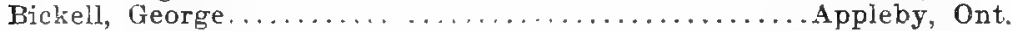

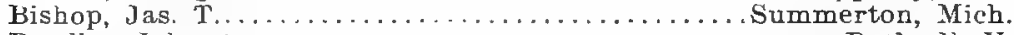

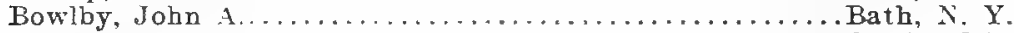

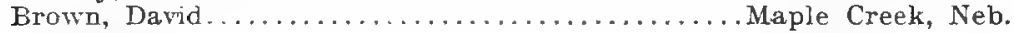

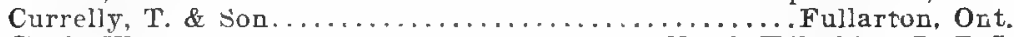

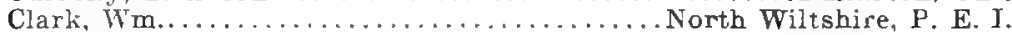

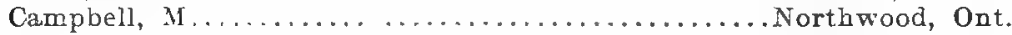

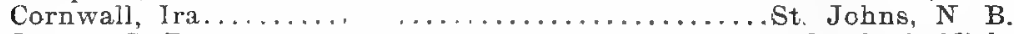

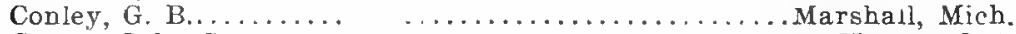

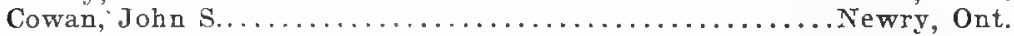

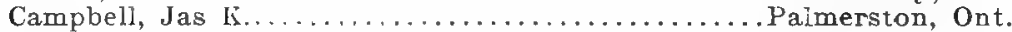

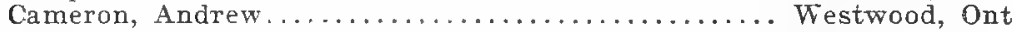

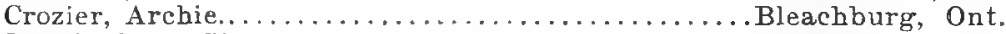

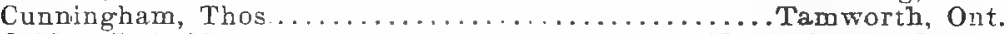
Calder, J. A. M........................ North Glanford, Ont.

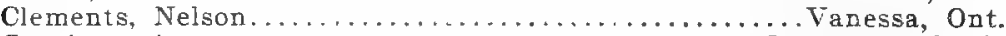

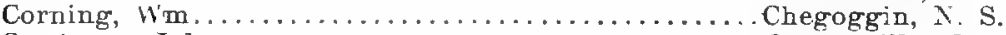

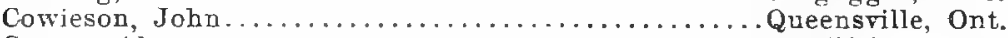

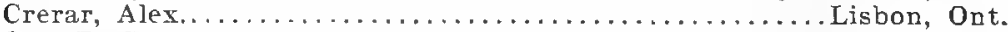

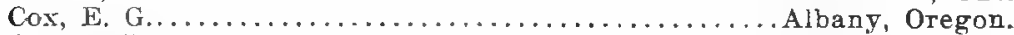

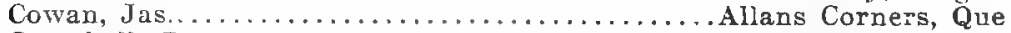

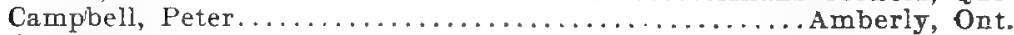

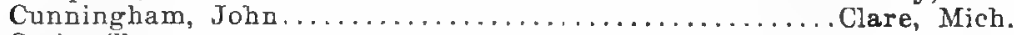

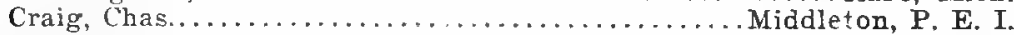

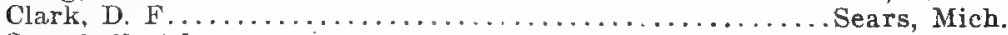

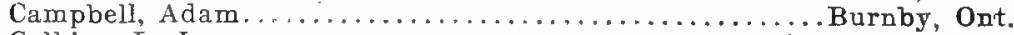

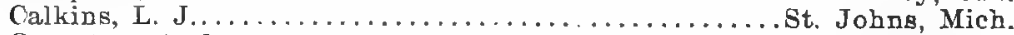

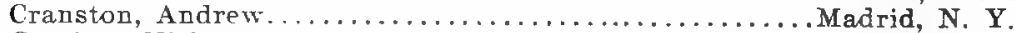

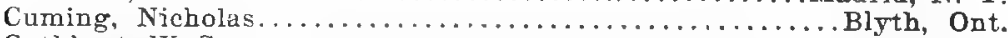

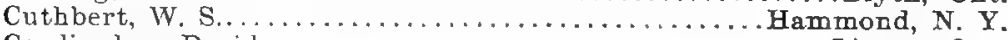

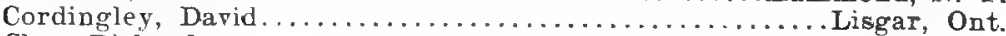

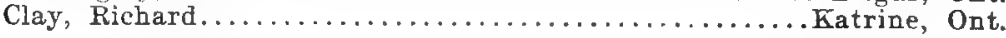


Dwyer, Jas.

. Skerry, N. Y.

Doherty, A. F.

Clare, Mich.

Doelly, John... Cass City, Mich.

Deschenes, M. Fraserville, Que.

Donkin, Thos. \& Sons Riverview, Ont.

Davison Bros. Harriston, Ont.

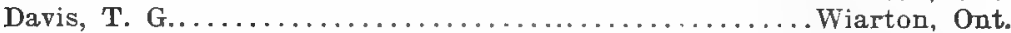

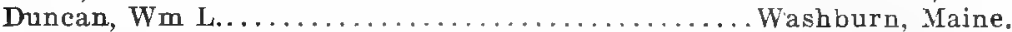

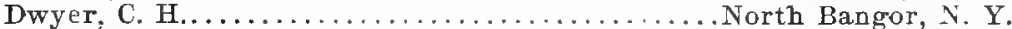

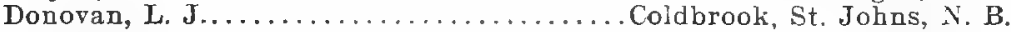
Donaldson, S. S. Lbly, Mich.

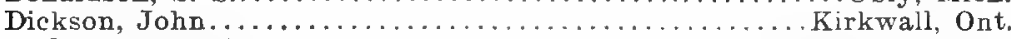

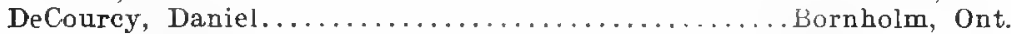

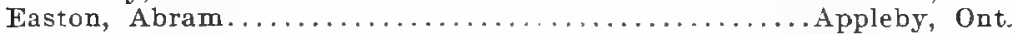

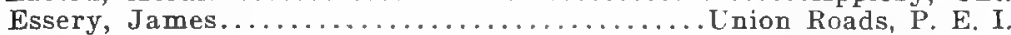

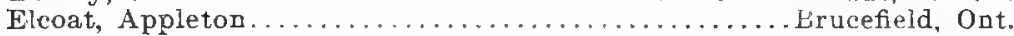

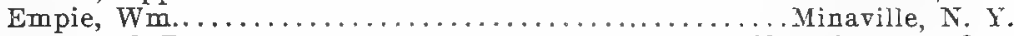

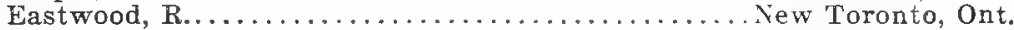

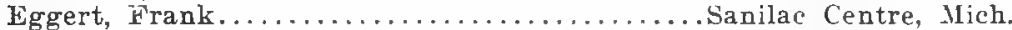

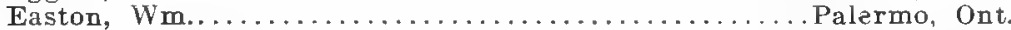

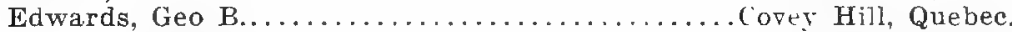

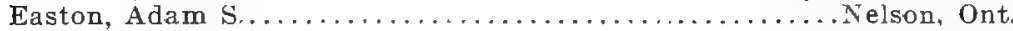

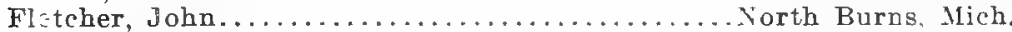

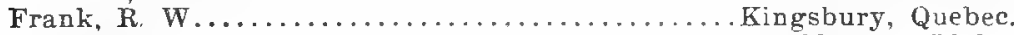

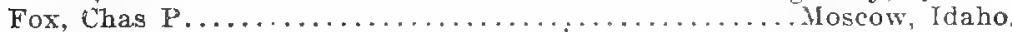

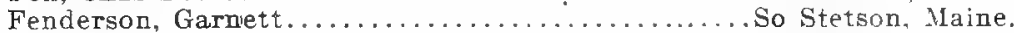

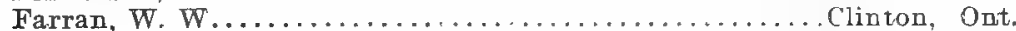

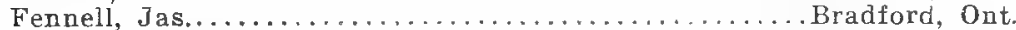

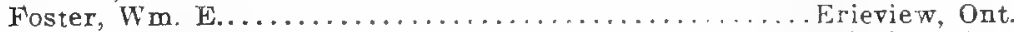

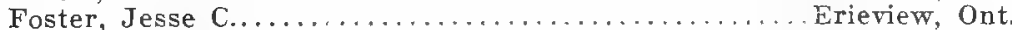

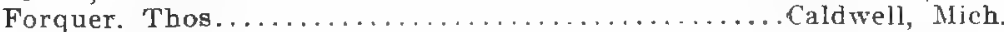

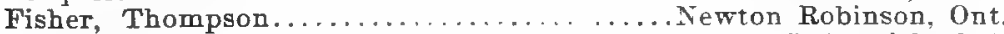

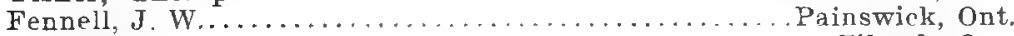

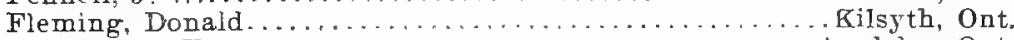

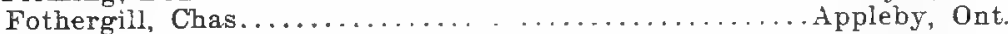

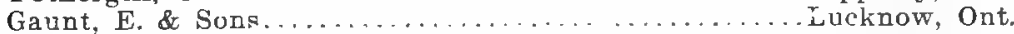

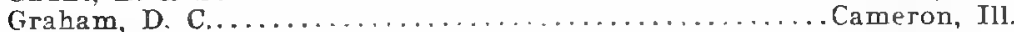

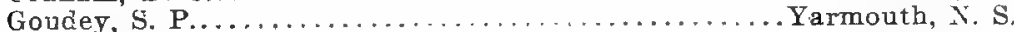

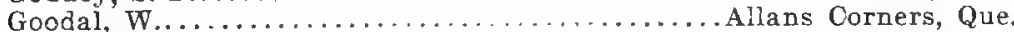

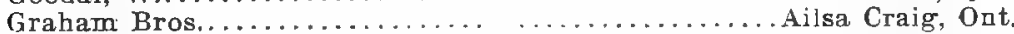

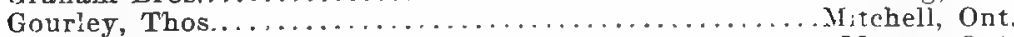

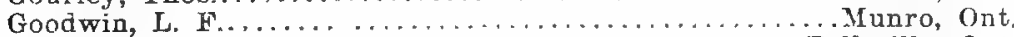

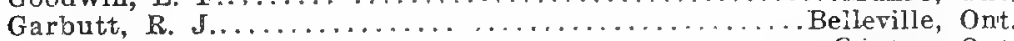

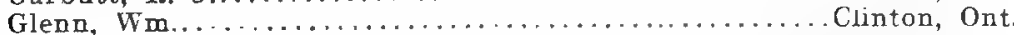

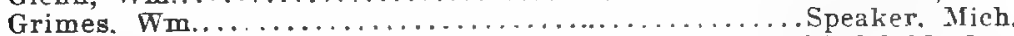

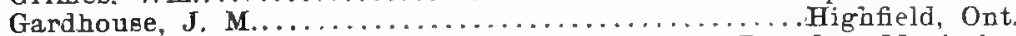

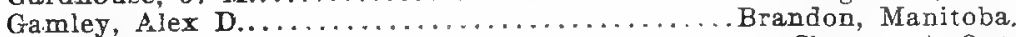

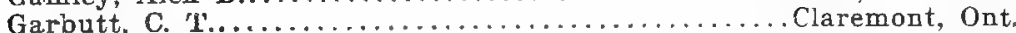

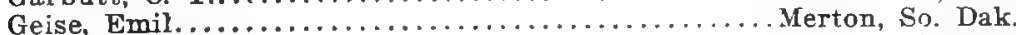

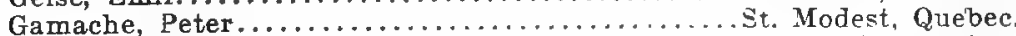

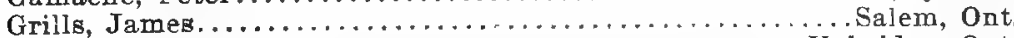

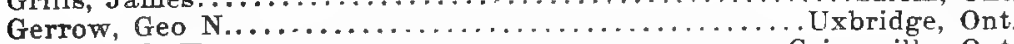

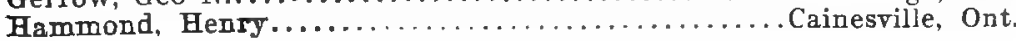




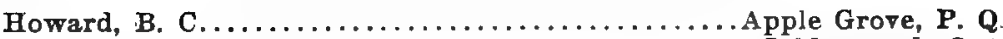

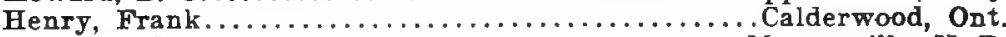

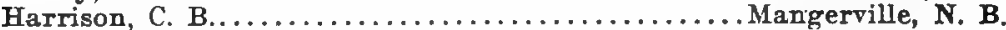

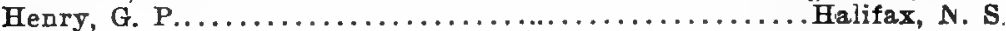

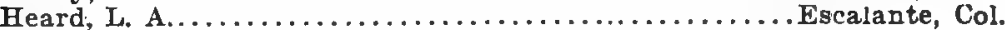

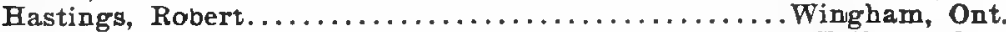

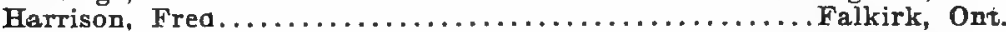

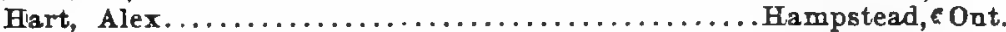

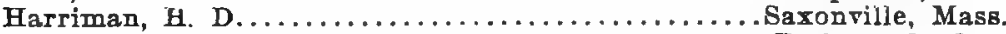

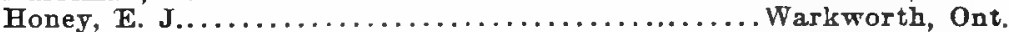

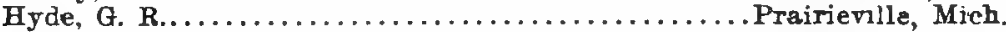

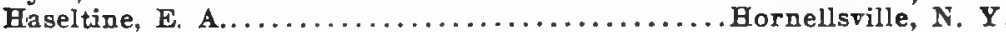

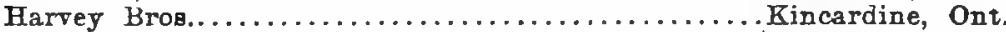

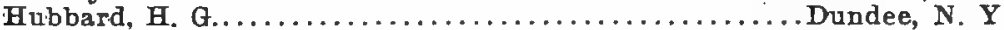
Hill, D. W..............................................

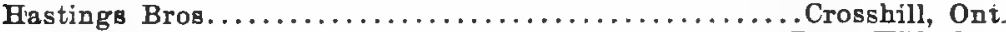

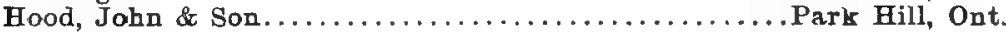

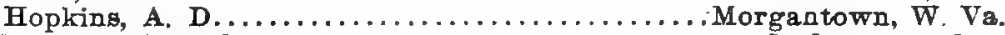

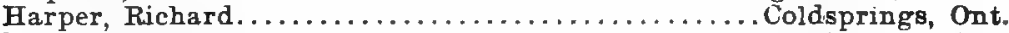
Hastie, Alex

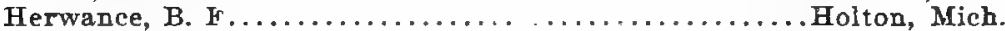

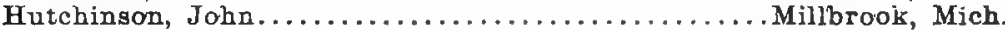

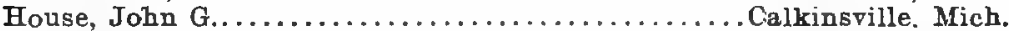

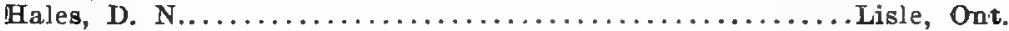

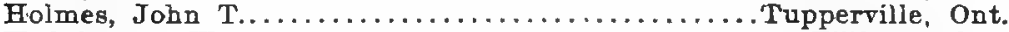

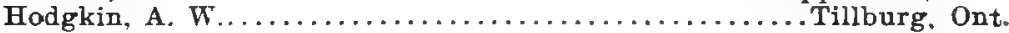
Hammer, George. . . . . . . . . . . . . . . . . . . . Reed City. Mich.

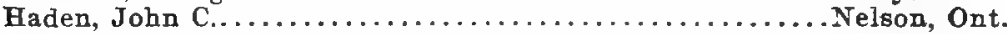

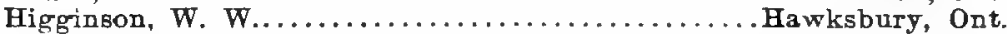

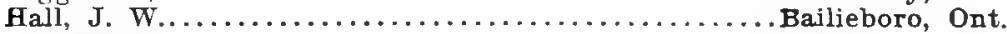

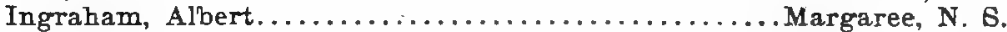

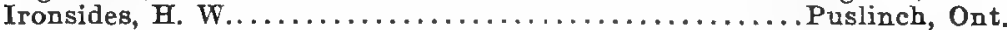

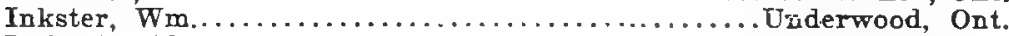

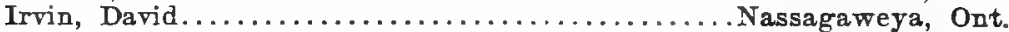

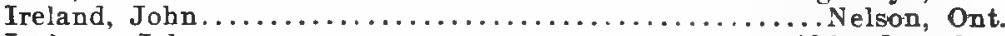

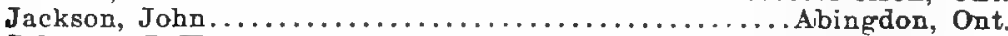

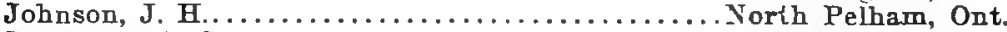

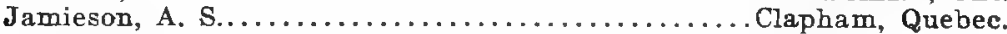

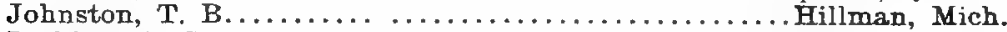

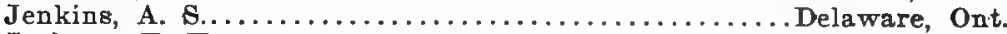

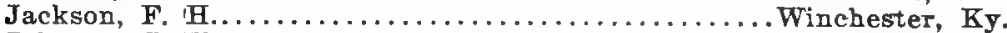

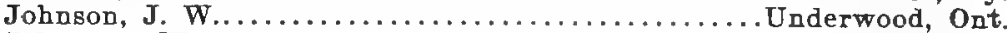

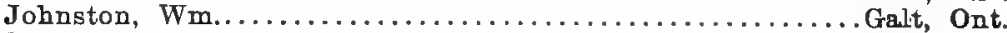

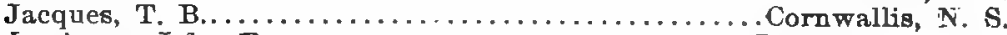

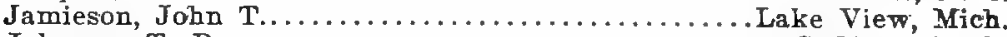

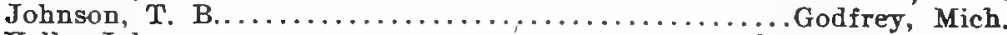

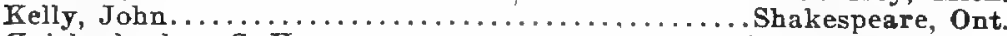

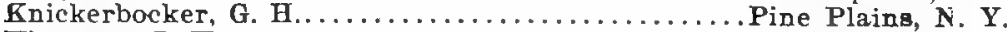

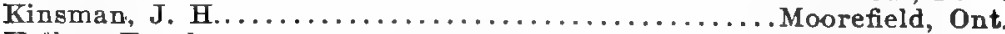

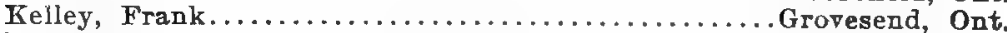

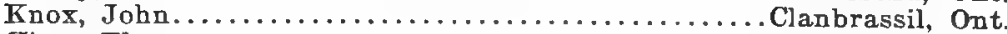
King, Thomas.................................... Mich.

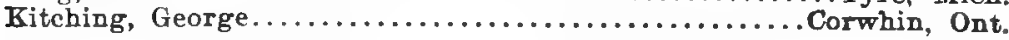


Lawrence, Chas.

Laidlaw, John.

Collingwood, Ont.

Lewis, A. M.

Wilton Grove, Ont.

Ladd, Wm. . Cairo, Mich.

Lee, $T$.

Portland, Oregon.

Login, D

Highgate, Ont.

Lee, J. L. .Picton, N. S.

Lane, Henry.

Ironside, Oregon.

Logan. John.

Mt. Mellick, P. E. I

Laycock, Fred.

Laur, Frank...

- Watford, Ont.

Longhead, Jos.

Gladwin, Mich.

Lawson, George.

.Millerton, Ont.

Lyon \& Son, C. H.

Lion's Head, Ont.

Metler, Peter Laskay, Ont.

Murphy, J. W Gageville, Ohio

Martin, R. G.

Torth .Pelham, Ont.

Miller, Robert.

. Cass City, Mich.

Morley, Wm.

Marysville, Ont.

Murray, Jas.

Brougnam, Ont.

Moodie, Andrew

Glenmorris, Ont.

Marshall, John . Perth, Ont.

Mason, C. K . Cass City, Mich.

Martín, L. V Horneilsville, N. Y.

Mullin

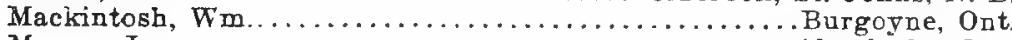

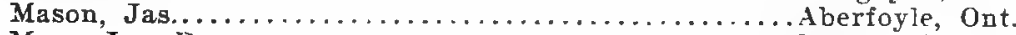

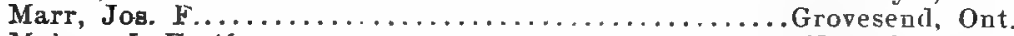

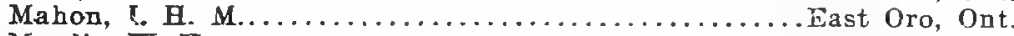

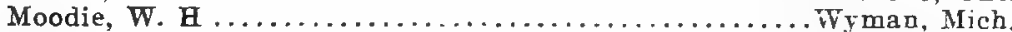

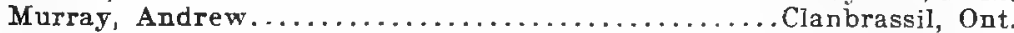

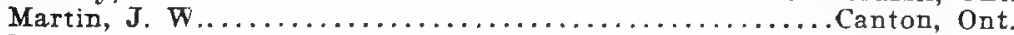

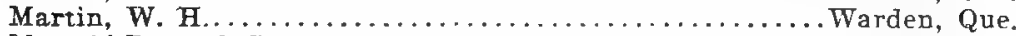

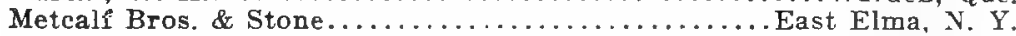

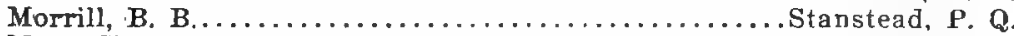

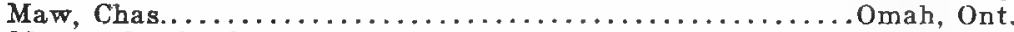

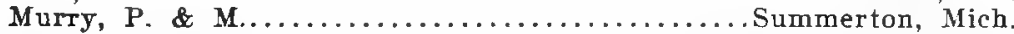

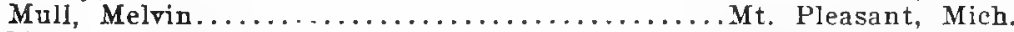

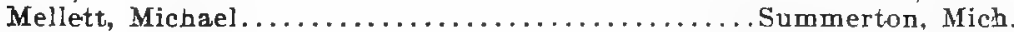

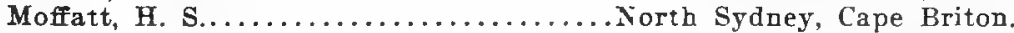

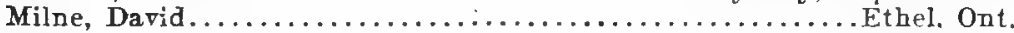

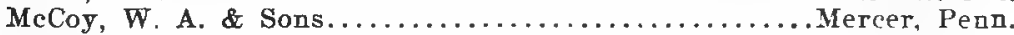

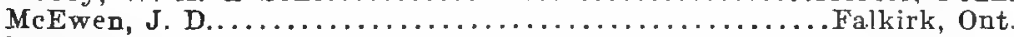

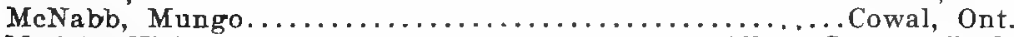

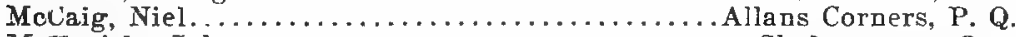

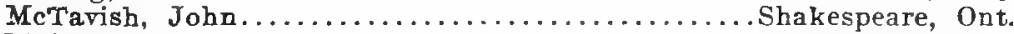

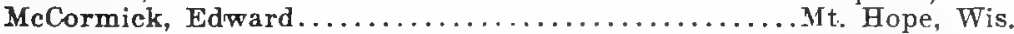

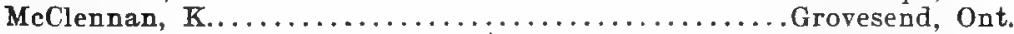

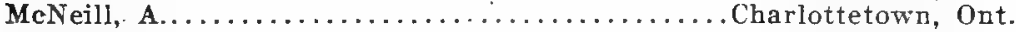

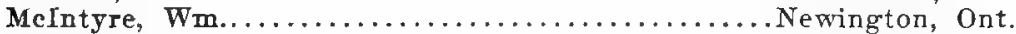

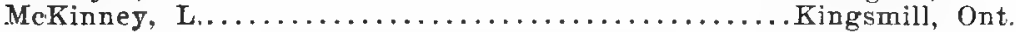

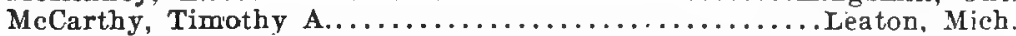

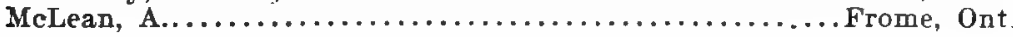




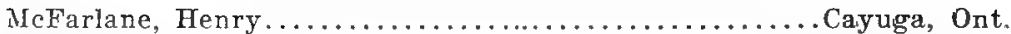

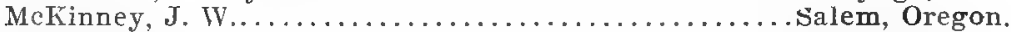

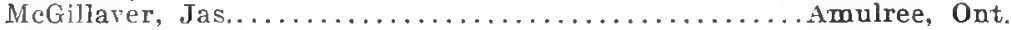

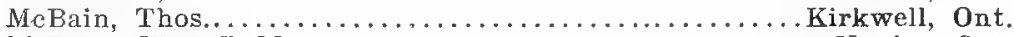

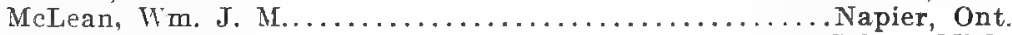

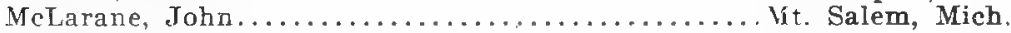

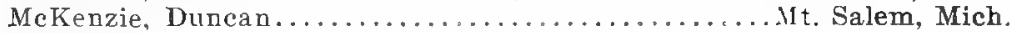

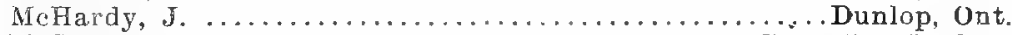

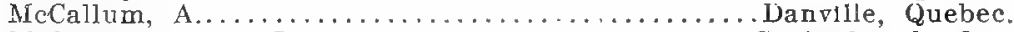

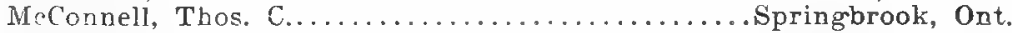

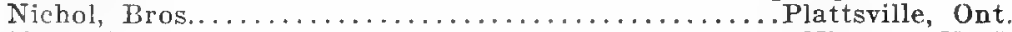

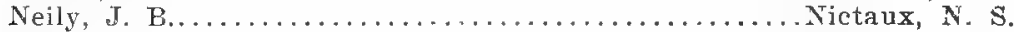

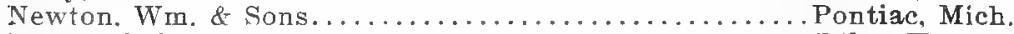

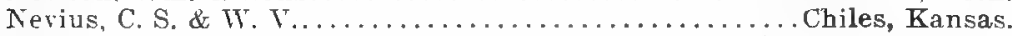

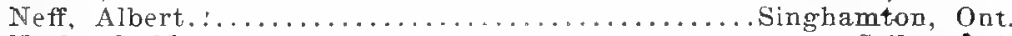

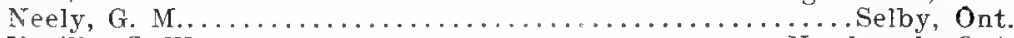

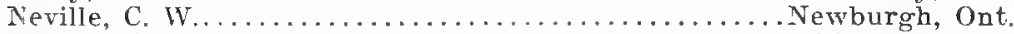

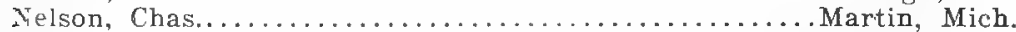

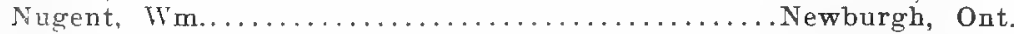

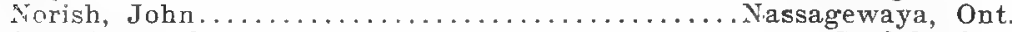

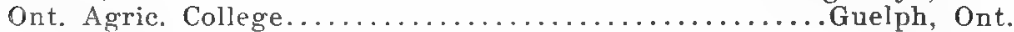

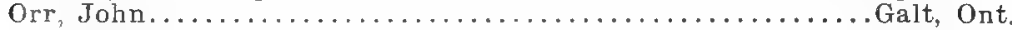

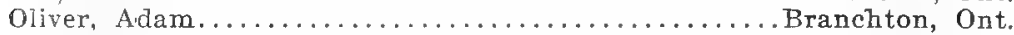

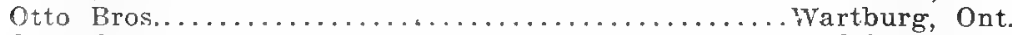

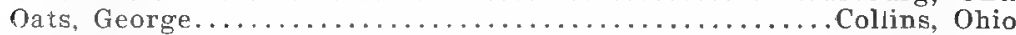

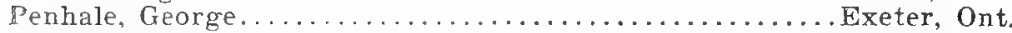

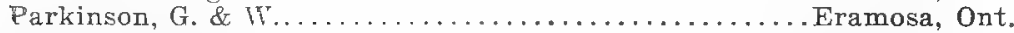

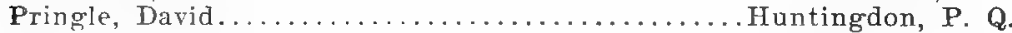

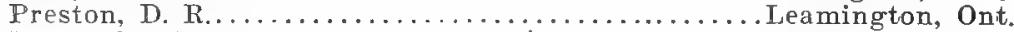

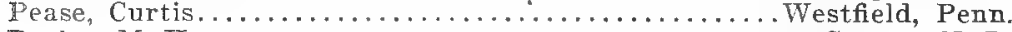

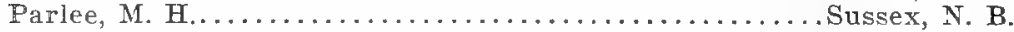

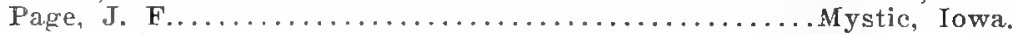

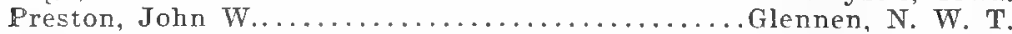

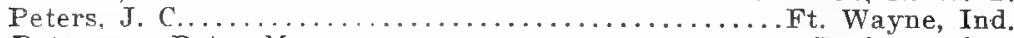

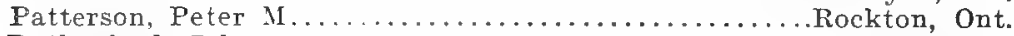

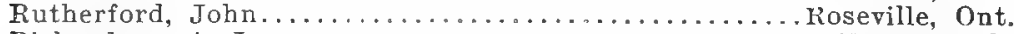

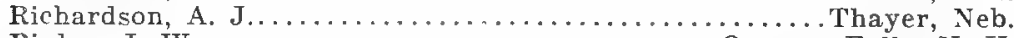

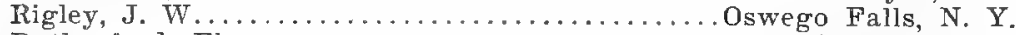

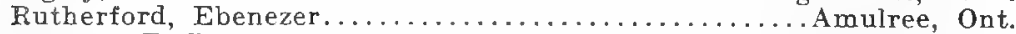

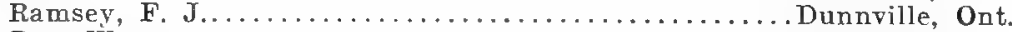

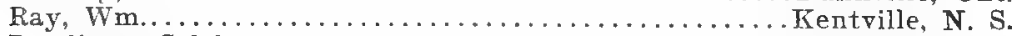

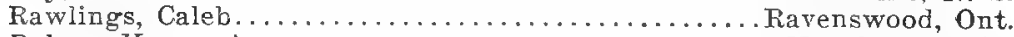

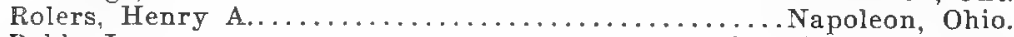

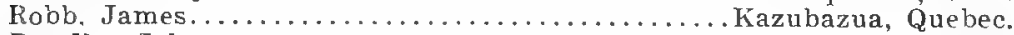

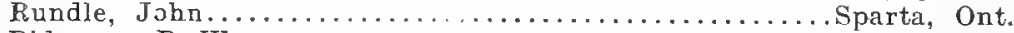

Ridenour, D. W............................. Johns, Mich.

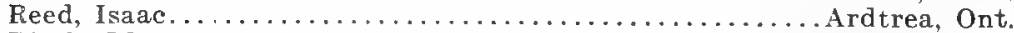

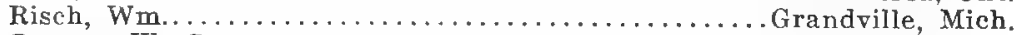

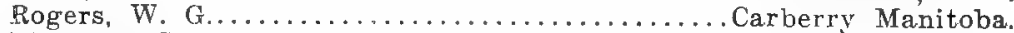

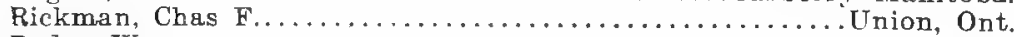

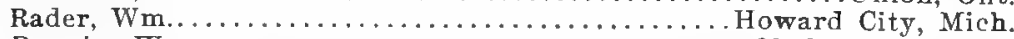

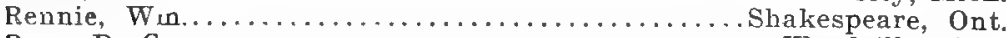

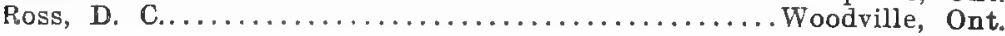




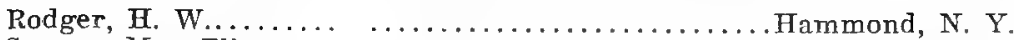

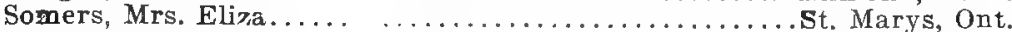

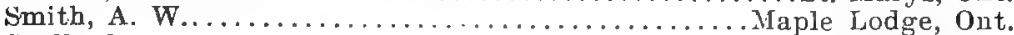

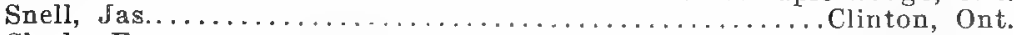

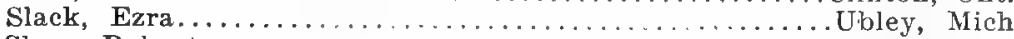

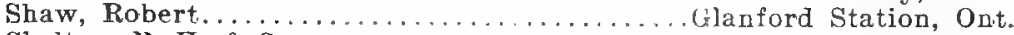

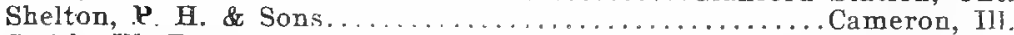

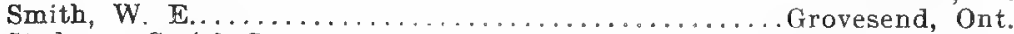

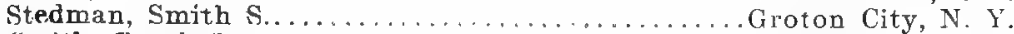

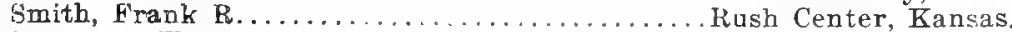

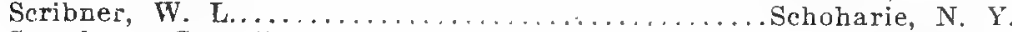

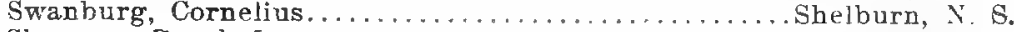

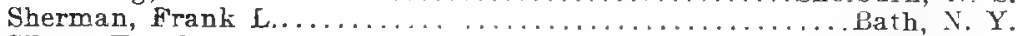

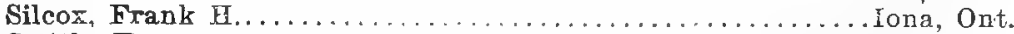

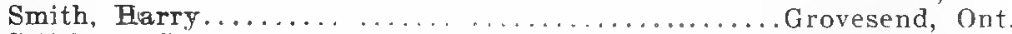

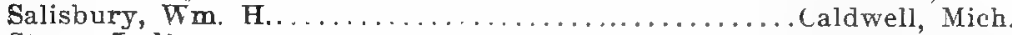

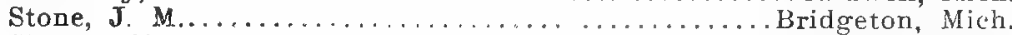

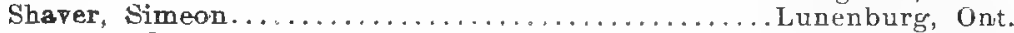

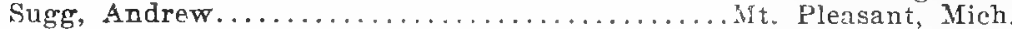

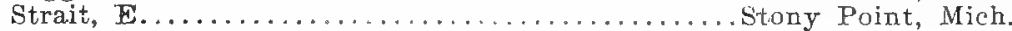

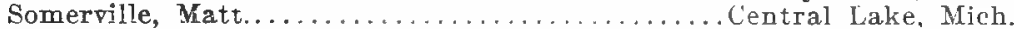

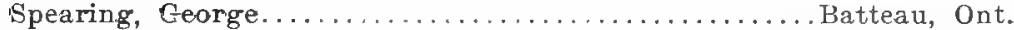

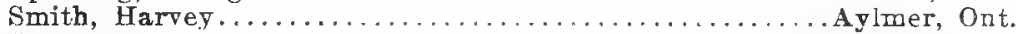

Stuyvesant, R..........................llamuchy, N. J.

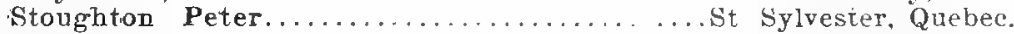

Stewart, Thos........................... Wye Bridge, Ont.

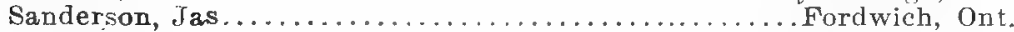

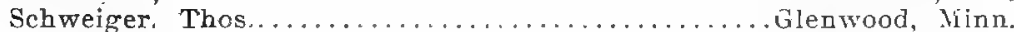

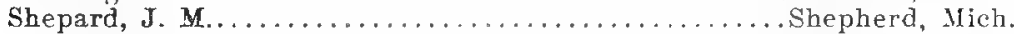

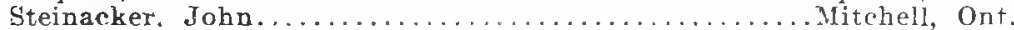

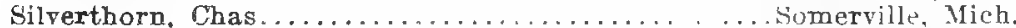

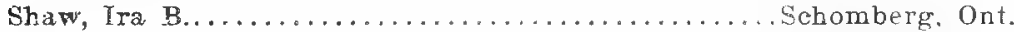

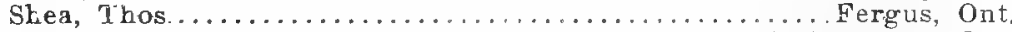

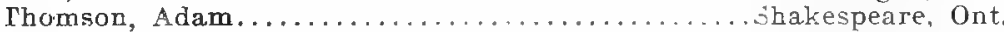

Thompson, F. A.......................... Newcastle, Pa.

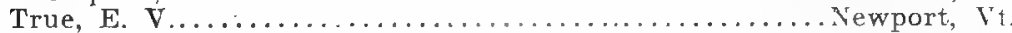

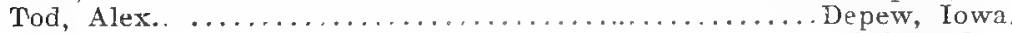

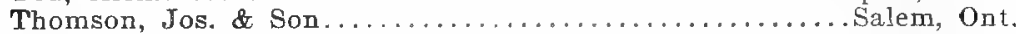

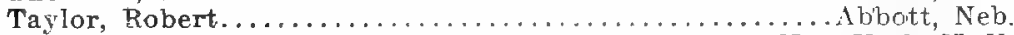

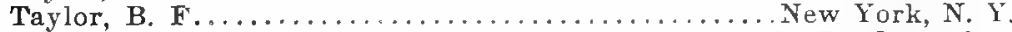

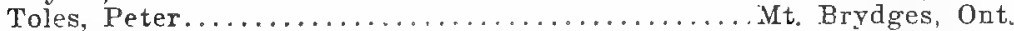

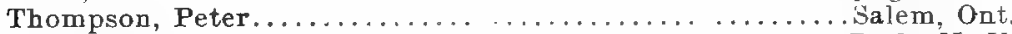

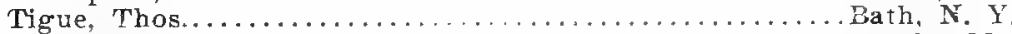

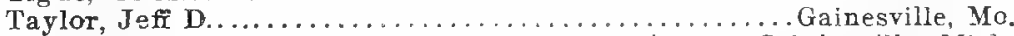

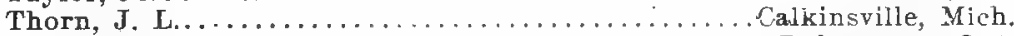

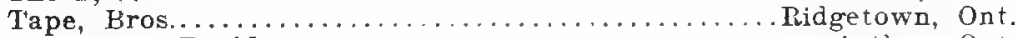

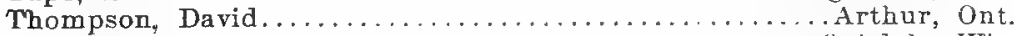

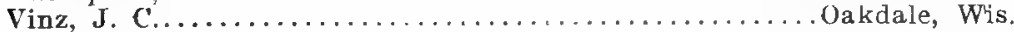

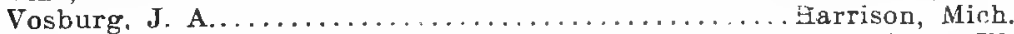

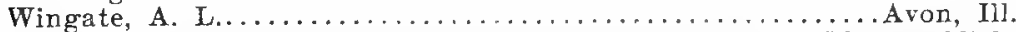

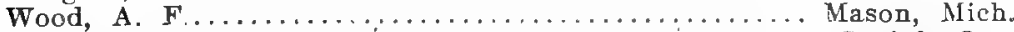

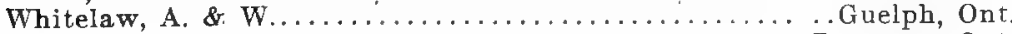

Wood, C. \& E............................. Freeman, Ont. 


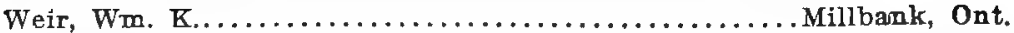

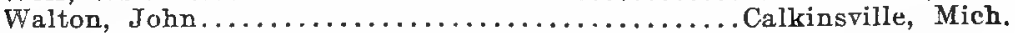

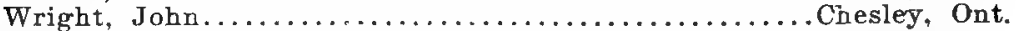

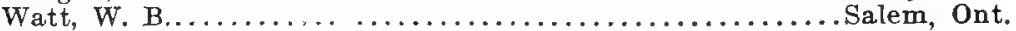

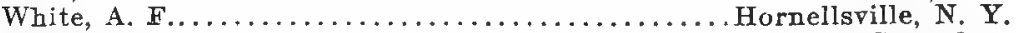

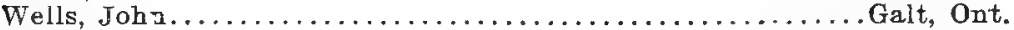

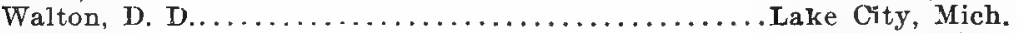

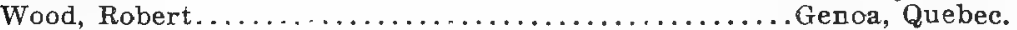

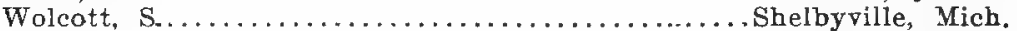

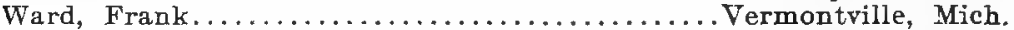

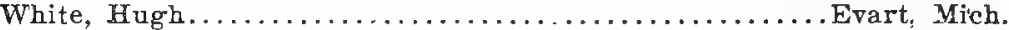

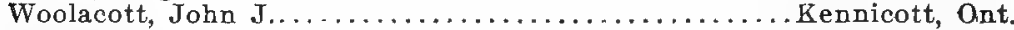

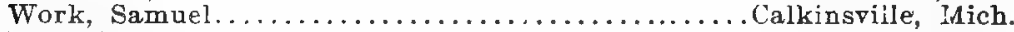

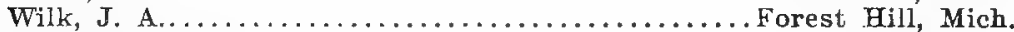

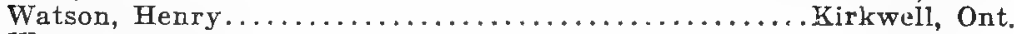

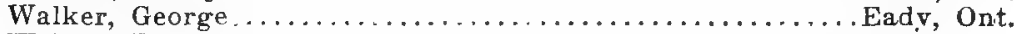

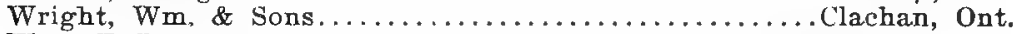

West, F. B..............................ferferson, Oregon.

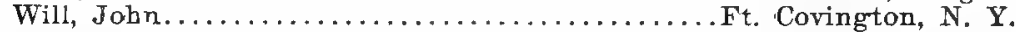

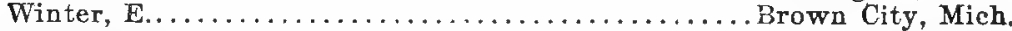

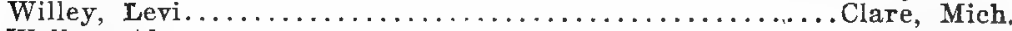

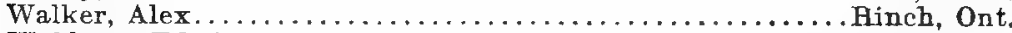

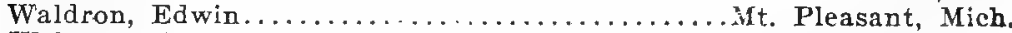

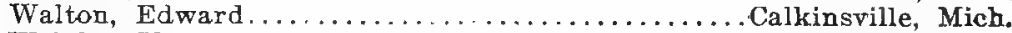

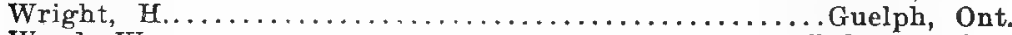

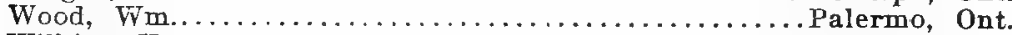

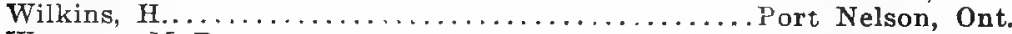

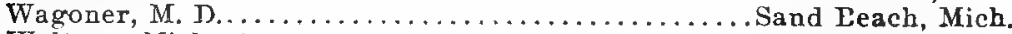

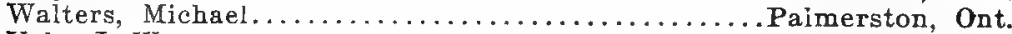

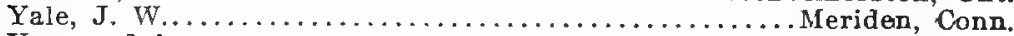

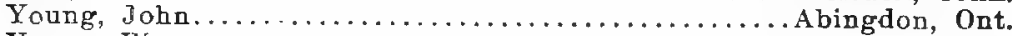

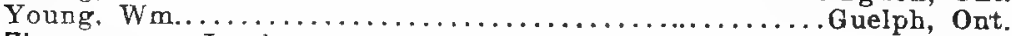

Zimmerman, Jacob..................................

\section{Breeders of American Cotswold Sheep.}

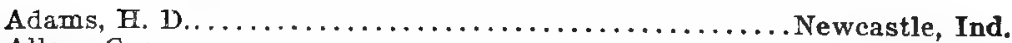

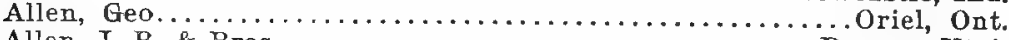

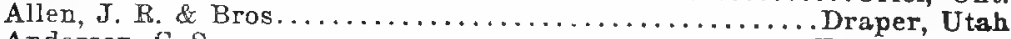

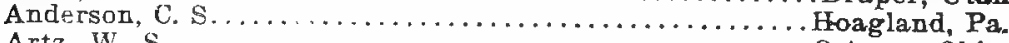

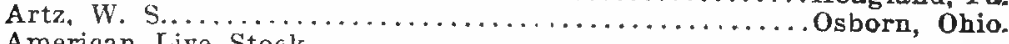

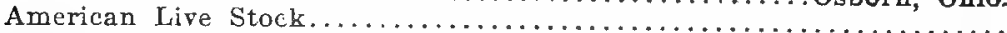

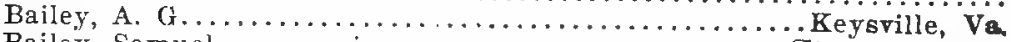
Bailey, Samuel............................. Uttoxeter, Ont.

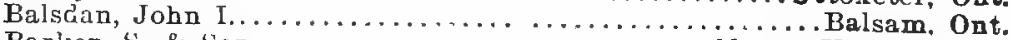

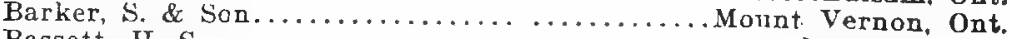

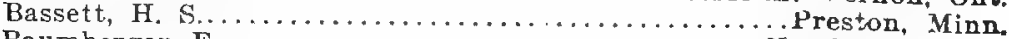

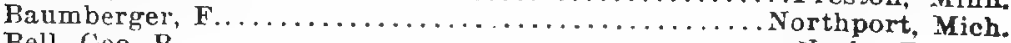

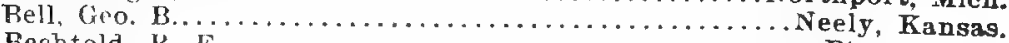

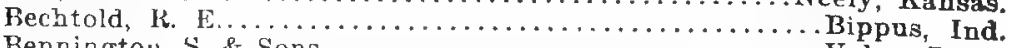

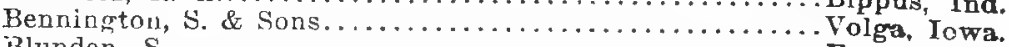

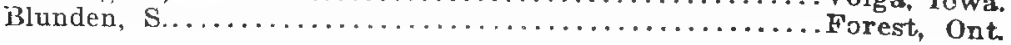


Bonnycastle, F. \& Son..................... Campbellford, Ontario.

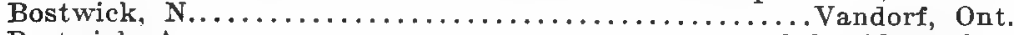

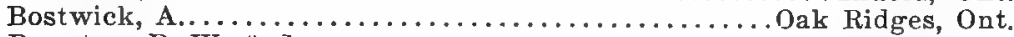
Boynton, P. W. \& Son............................................ Ont.

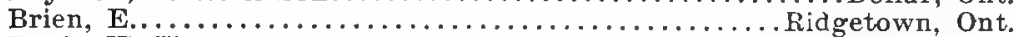

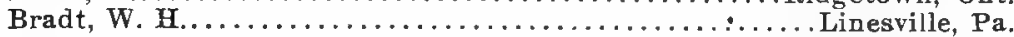

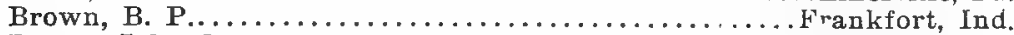
Brown John $L . . \ldots \ldots \ldots \ldots \ldots \ldots \ldots \ldots \ldots \ldots \ldots$. Uxbridge, Unt.

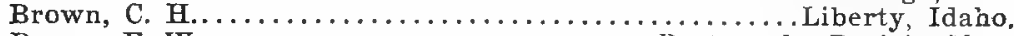

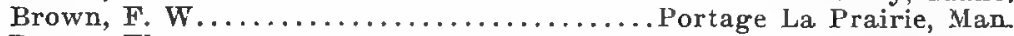

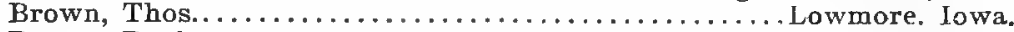

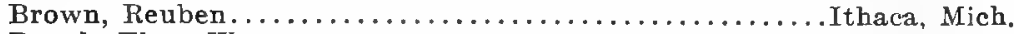

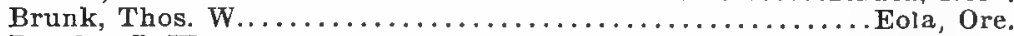

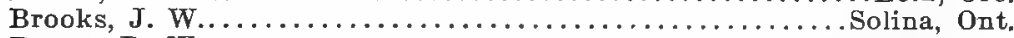

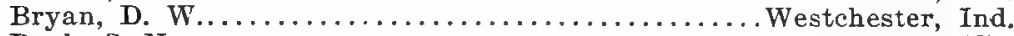
Buck, S. N............................... Appleton, Wis.

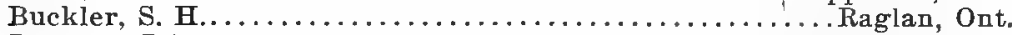

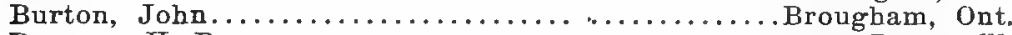

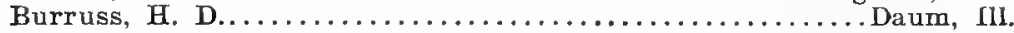
Campbell, E. \& Son.......................... Pittsfield, Ohio.

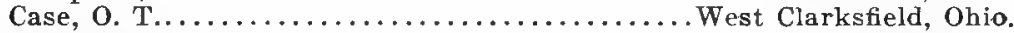

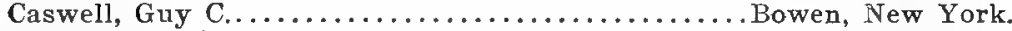
Chapman, F. M...................................... Ondley,

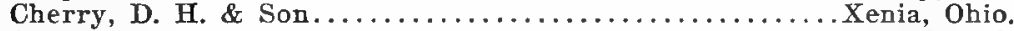
Cheesman, John............................... Chick, John....................................... N. Y.

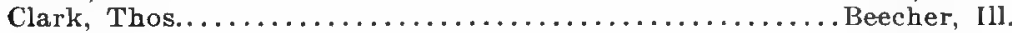

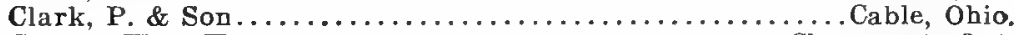

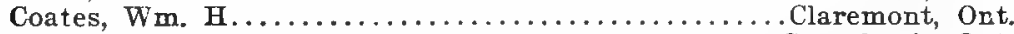

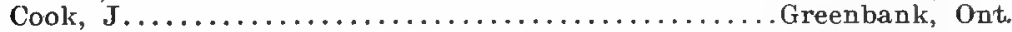

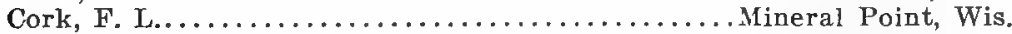

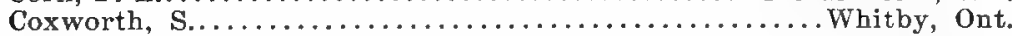
Current, Freeman................................... Nation, Iowa.

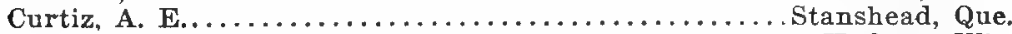

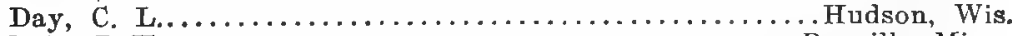

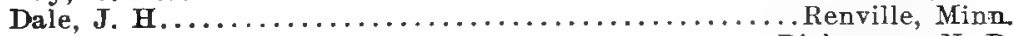

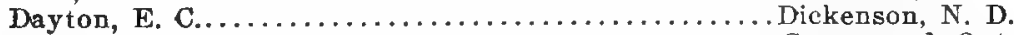

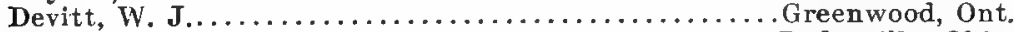

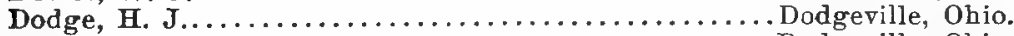

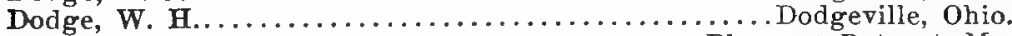

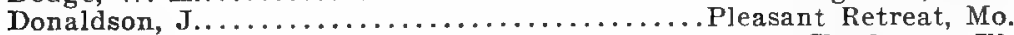

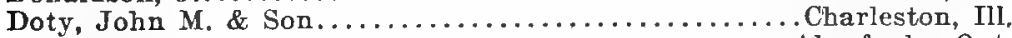

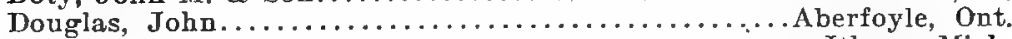

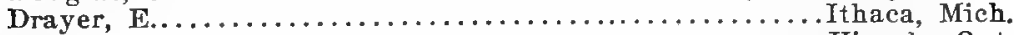

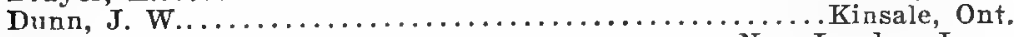

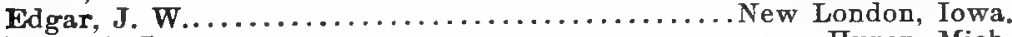

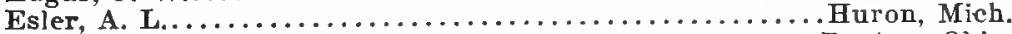

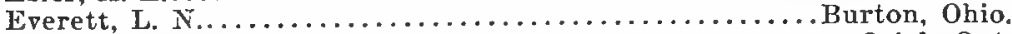

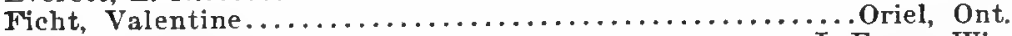
Fisher, George B..............................Farge, Wis.

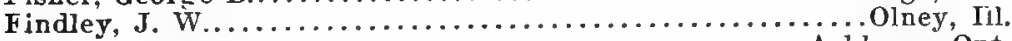

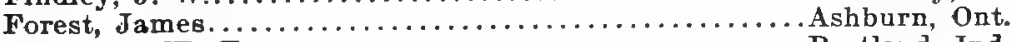

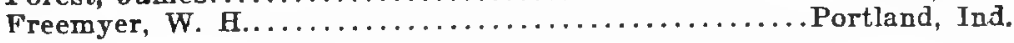




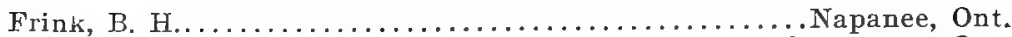

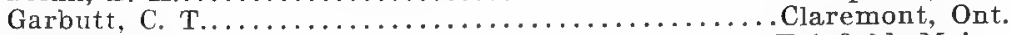

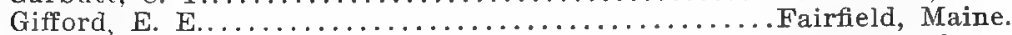

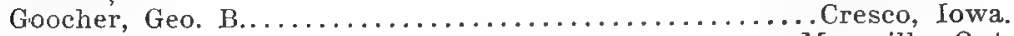

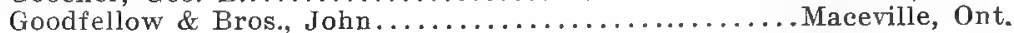

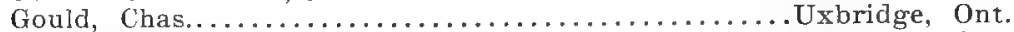

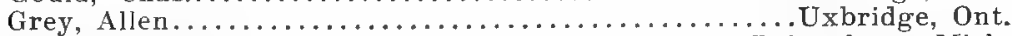

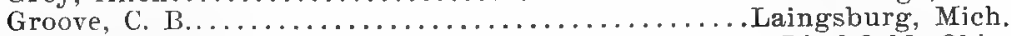

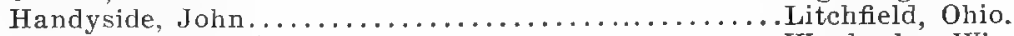

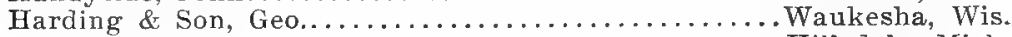

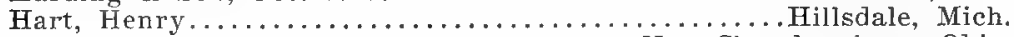

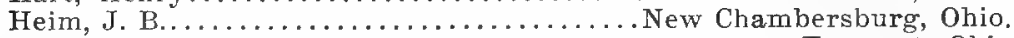

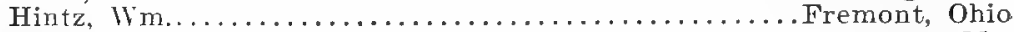

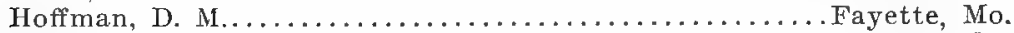
Hogan \& Sons, James.....................Waunakee, Wis.

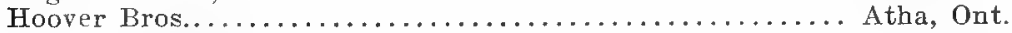

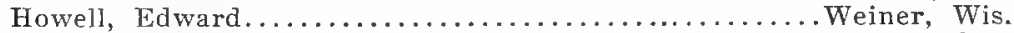

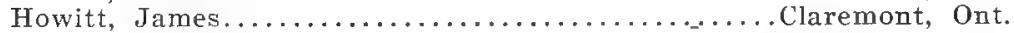

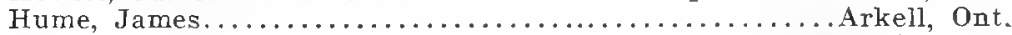

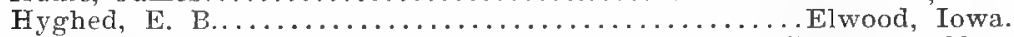

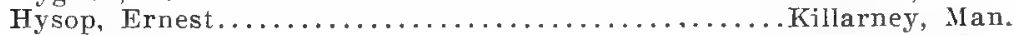

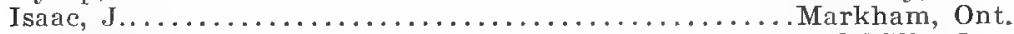

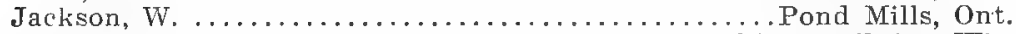

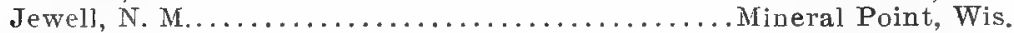

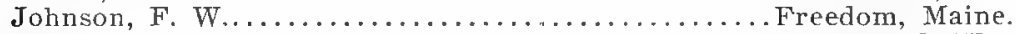

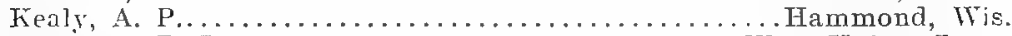

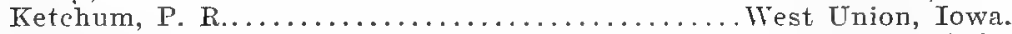

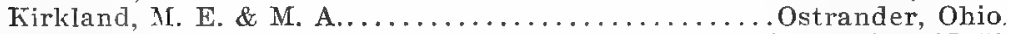

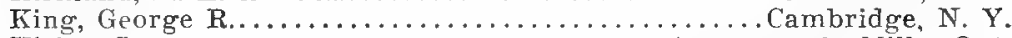

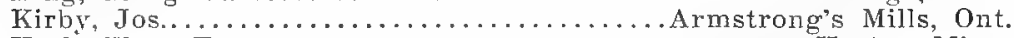

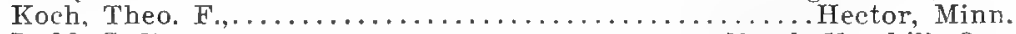

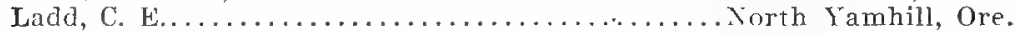
Laidlaw, Wm. G.......................Wilton Grove, Ont.

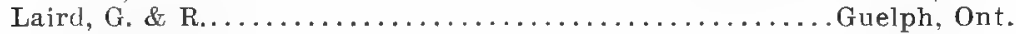

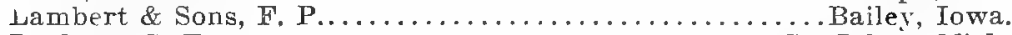

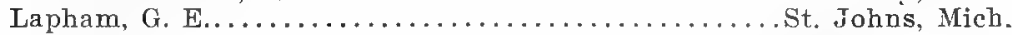

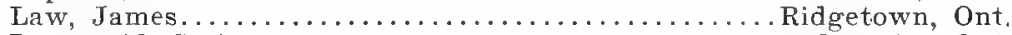

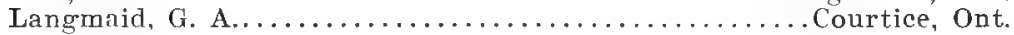

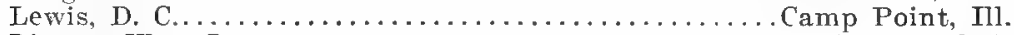

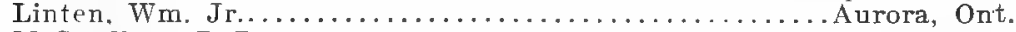

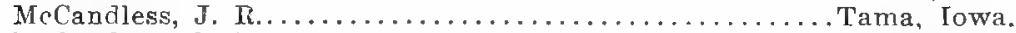

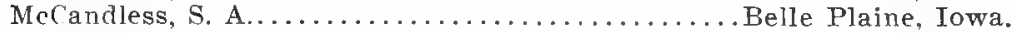

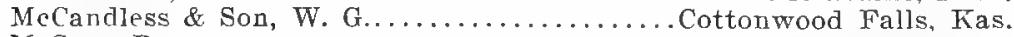

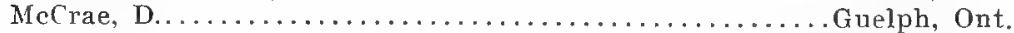

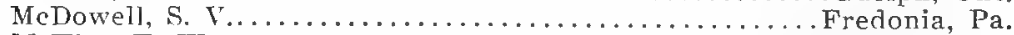

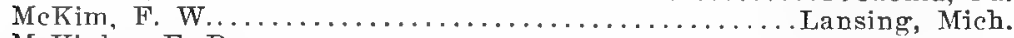

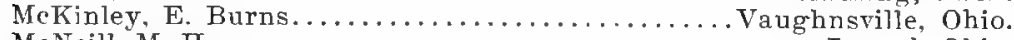

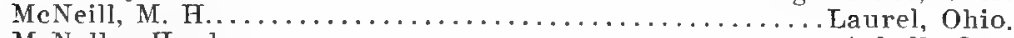

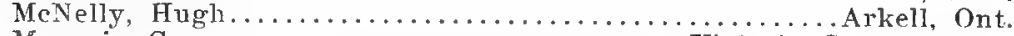

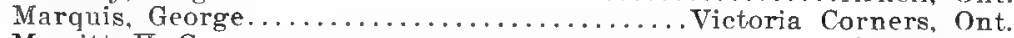

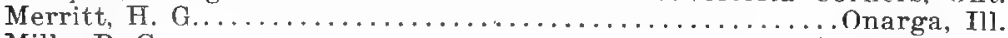

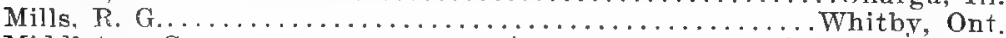

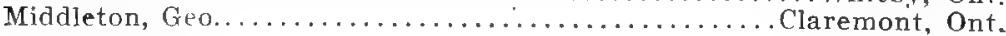




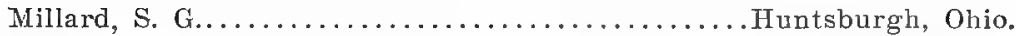

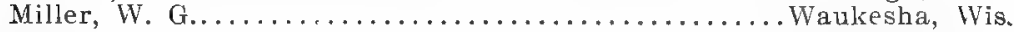

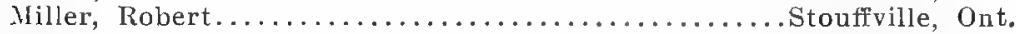

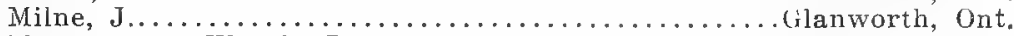

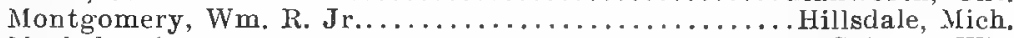

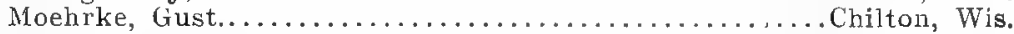

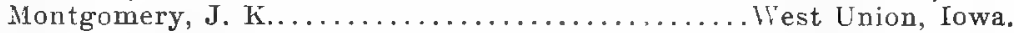

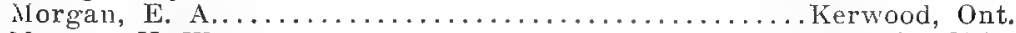

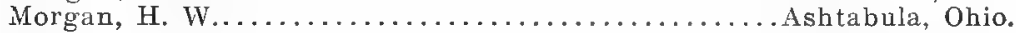

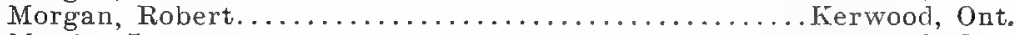

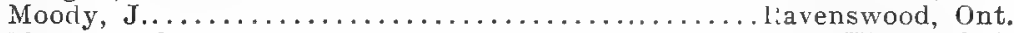

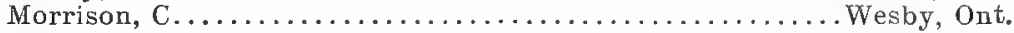

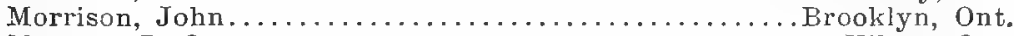

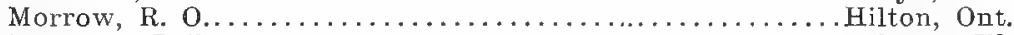

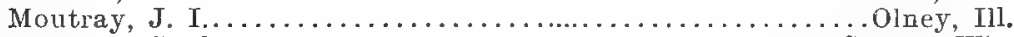

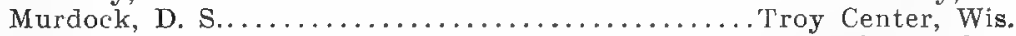

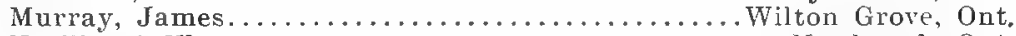

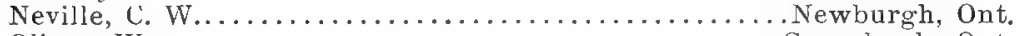

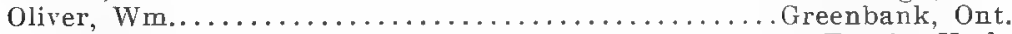

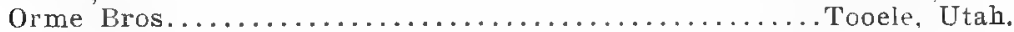

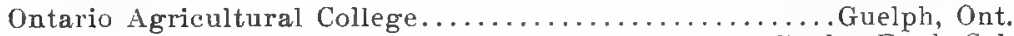

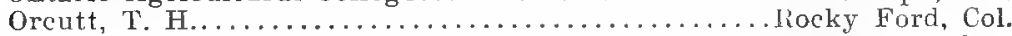

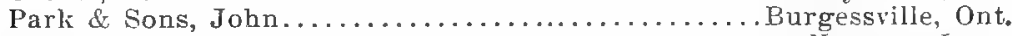

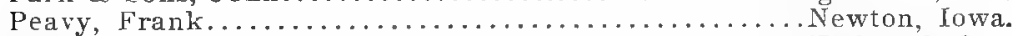

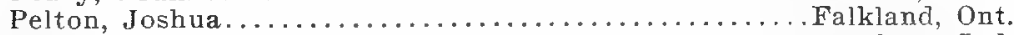

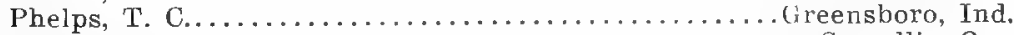

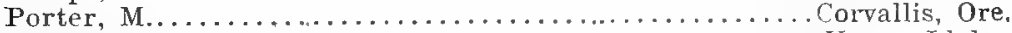

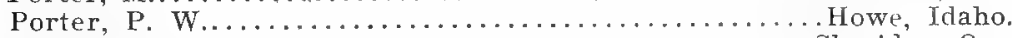

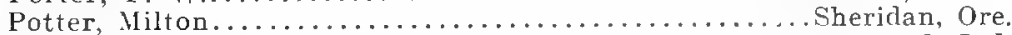

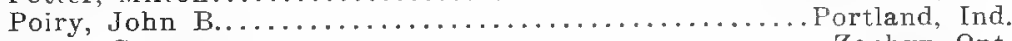

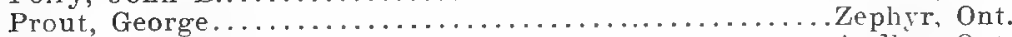

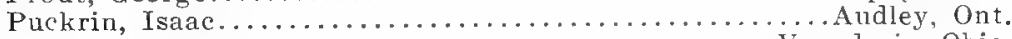

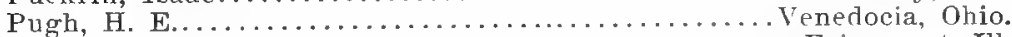

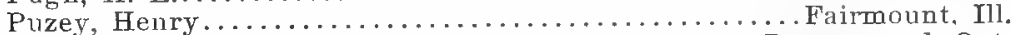

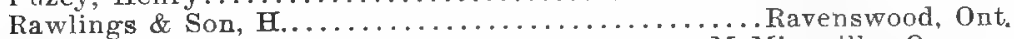

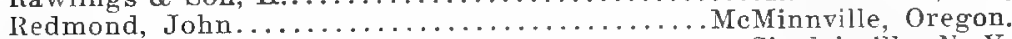

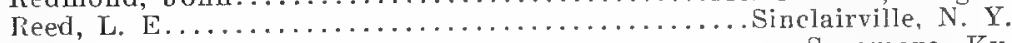

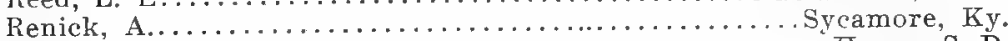

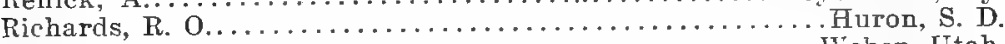

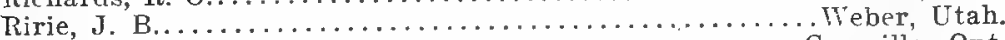

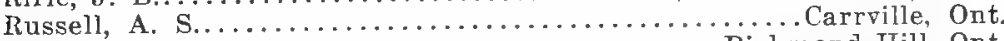

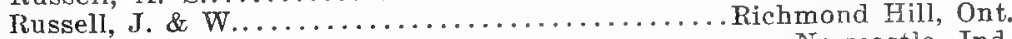

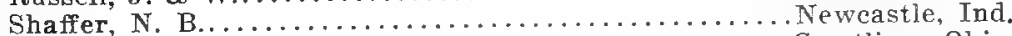

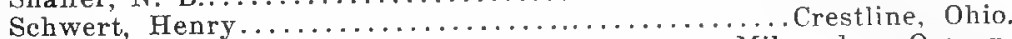

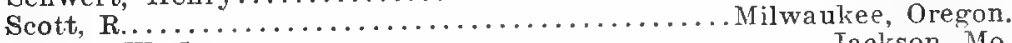

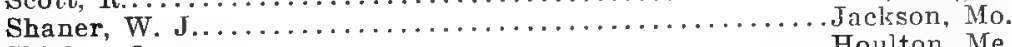

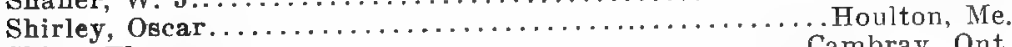

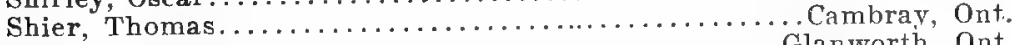

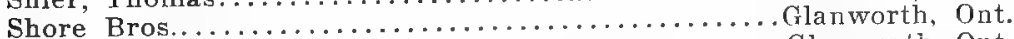

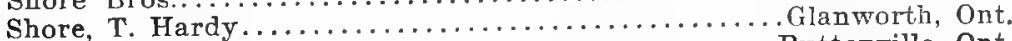

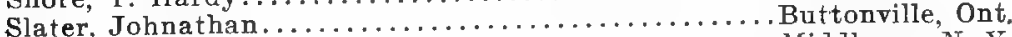

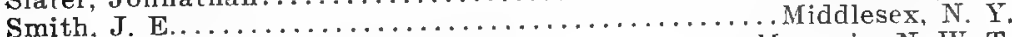

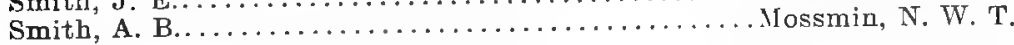




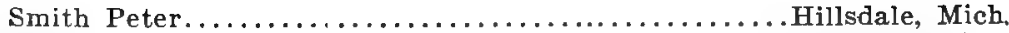

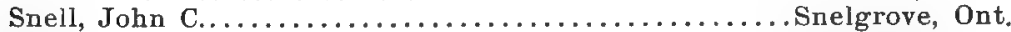

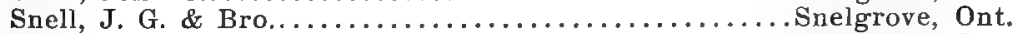

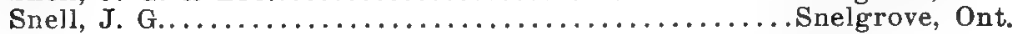

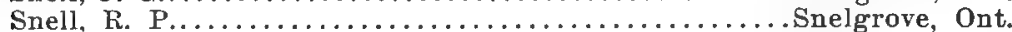

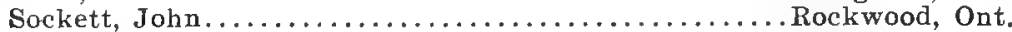

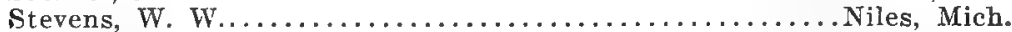

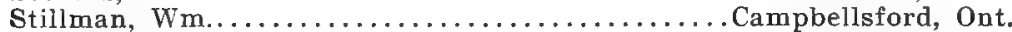

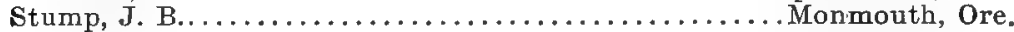

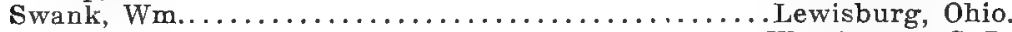

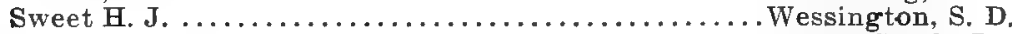

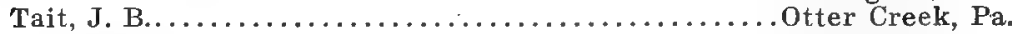

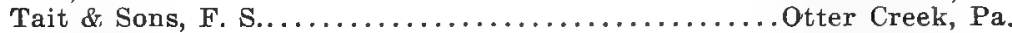

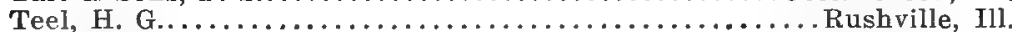

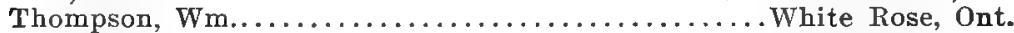

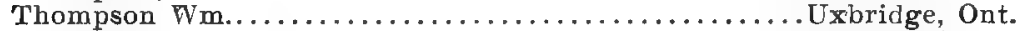

Thompson John........................ Uxhridge; Ont.

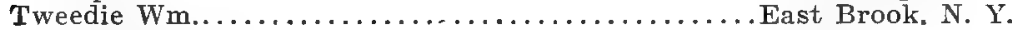

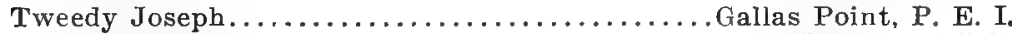

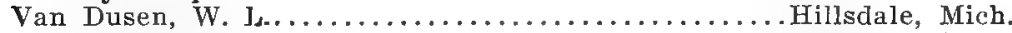

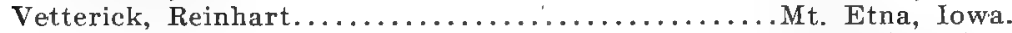

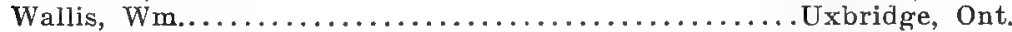

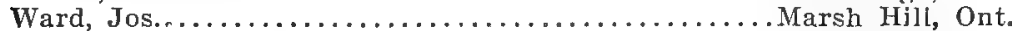

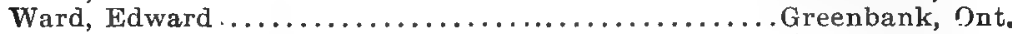

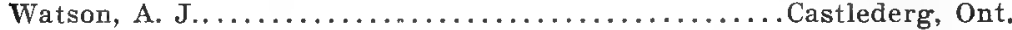

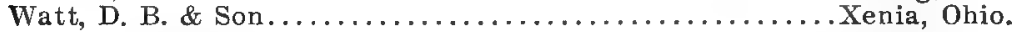

Watt, D. B. \& R. C........................... Xenia, Ohio.

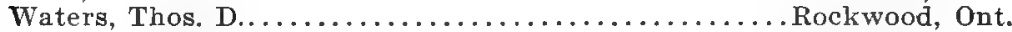

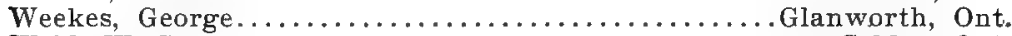

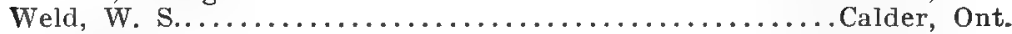

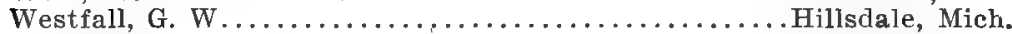

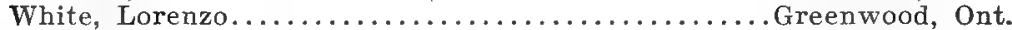

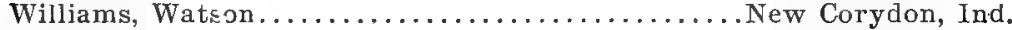

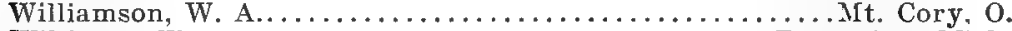

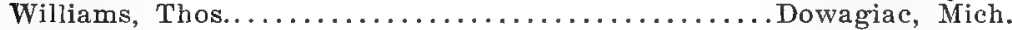

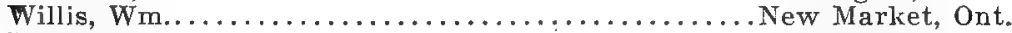

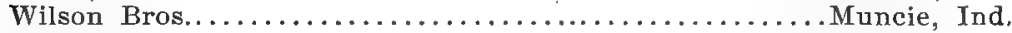

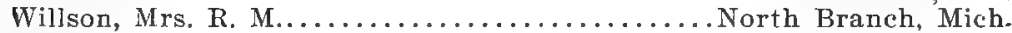

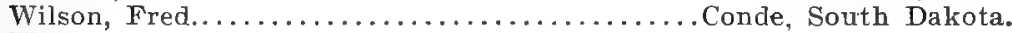

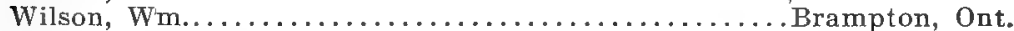

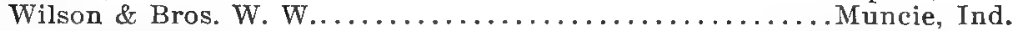

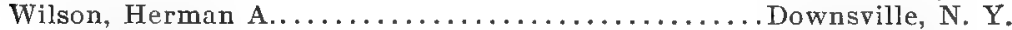

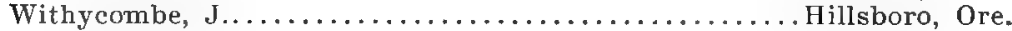

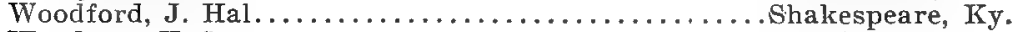

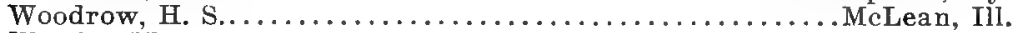

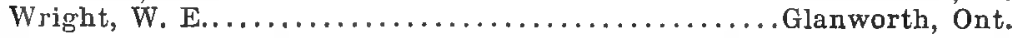

\section{Breeders of Lincoln Sheep.}

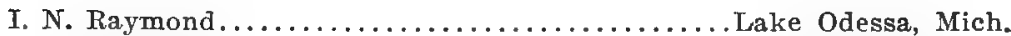

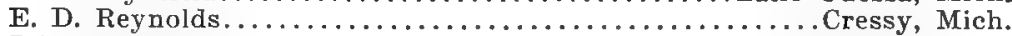

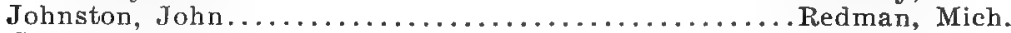

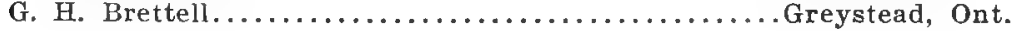


Thomas Fraleigh

Arva, Ont. .

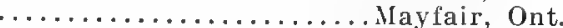

T. E .

.

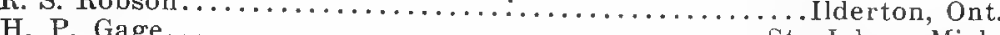

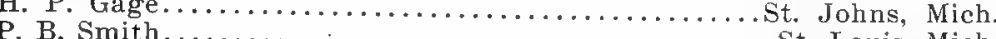

Wm. T .

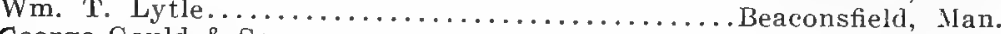
George Gould \& Son......................... Rutherford, Ont. W. N. Wakeman ......................................

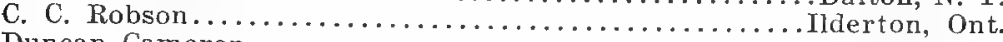
Duncan Cameron................................ Ivan, Ont.

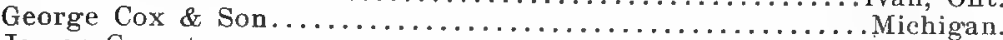

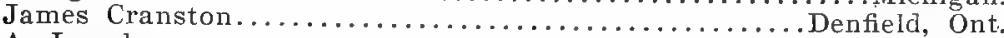
A. Longley ........................................ Ontario

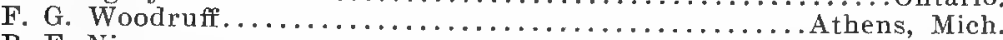

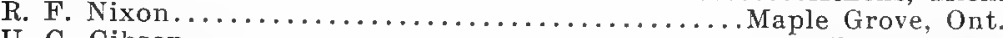
U. G. Gibson........................................ Wis. W. W. Crittenden................................. Mich.

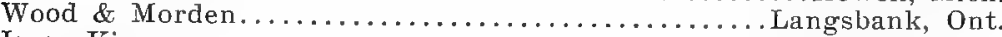

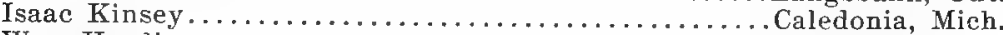

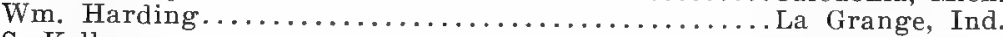

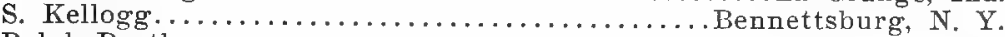
Ralph Brothers......................................

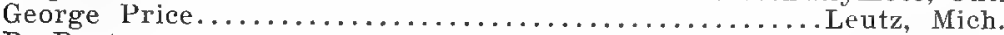

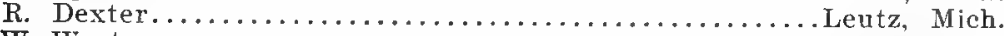

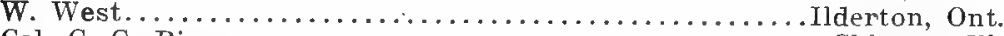

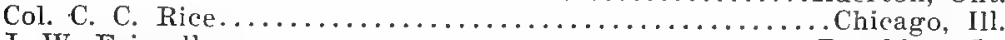
J. W. Frizzell............................................ Ia. Lowry Austin................................

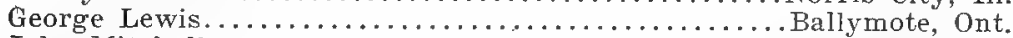

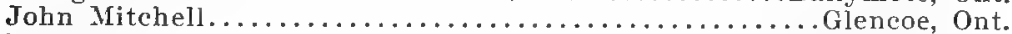

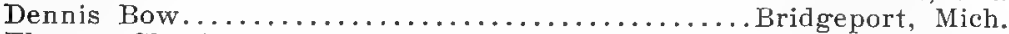

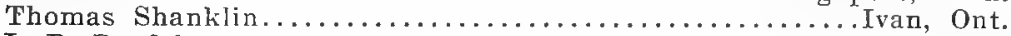
L. D. Bradshaw................................ Mid, Mich.

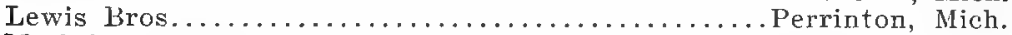

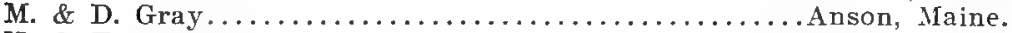
Noah Tompkins.......................... Fostoria, Mich. Fred C. Tompkins............................ Fostoria, Mich.

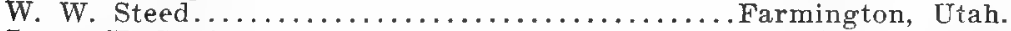

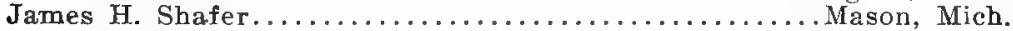

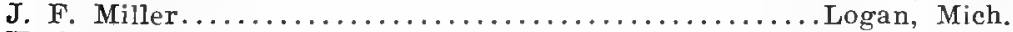

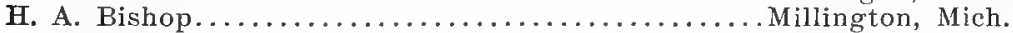

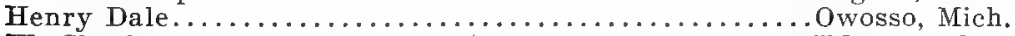

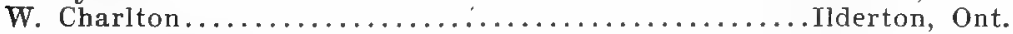

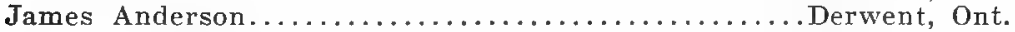

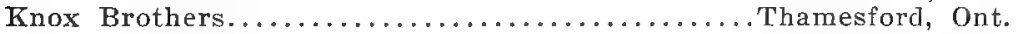
R. Little \& Son..............................Ilderton, Ont.

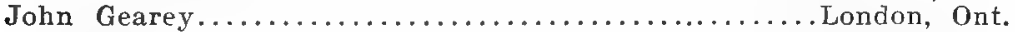

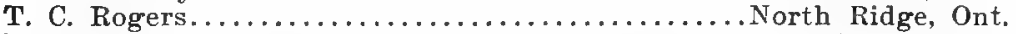

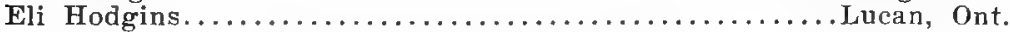

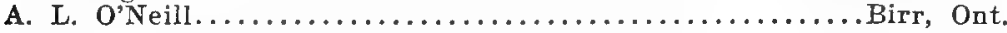


Frank Hicks. . Centralia, Ont.

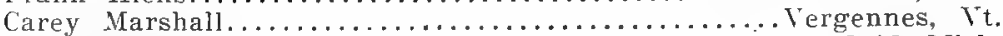

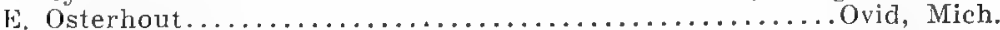

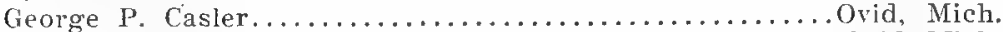

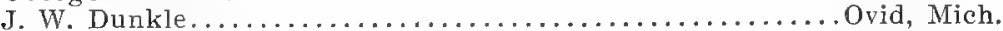

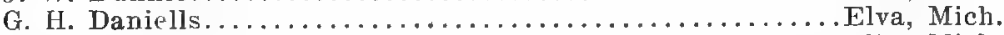

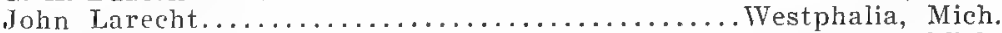

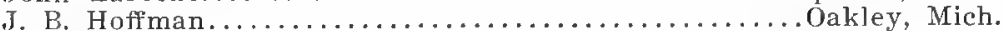

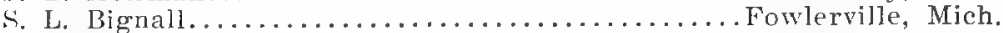

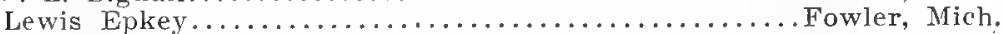

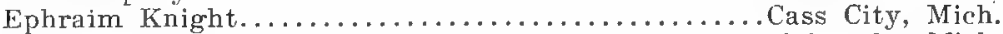

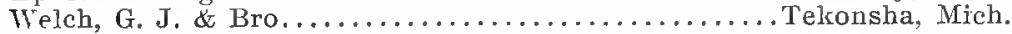

\section{Breeders of Southdown Sheep.}

Aitken, George............................Woodstock, Vt.

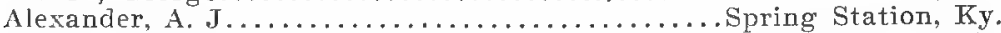

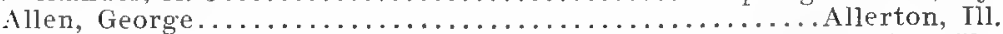

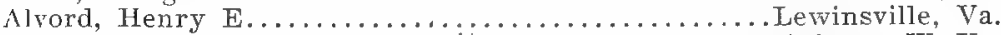

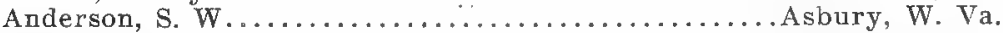

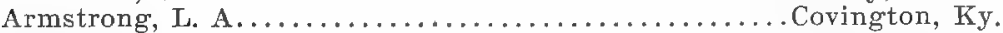

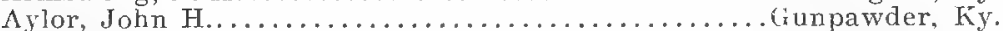
Bailey, C. I................................Winthrop, Me.

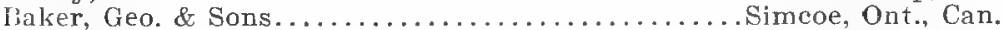

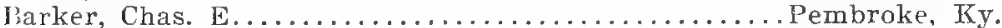
Barrett, $\mathbf{F}$. W. Mrs.........................Wadsworth, X. Y.

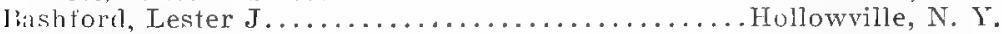

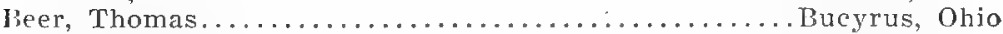

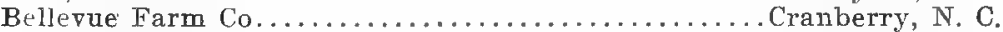

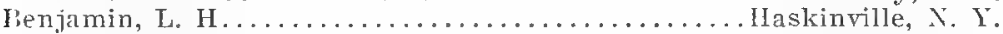

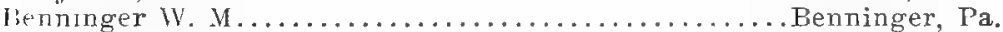
Rickford, Lewis J.................... Dixmont Centre, Me. Tirllings, Frederick....................... Woodstock, Vt.

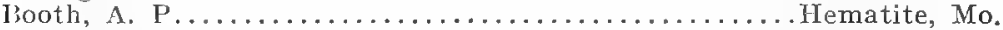

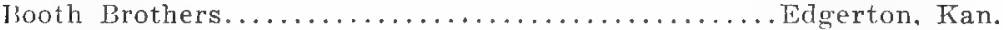
Boutelle, Geo. K......................Waterville, Me.

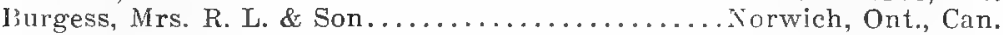

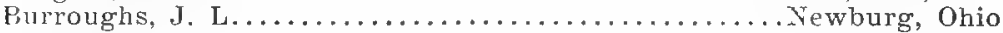

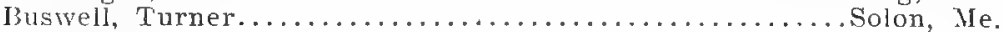

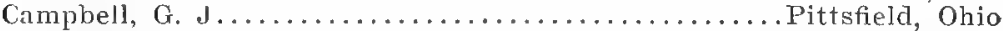

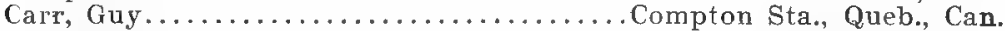

Cass \& Burns.......................... . . . . . . . . . . . . . . Chapman, Wm. J...................... ['nion Hill, N. Y.

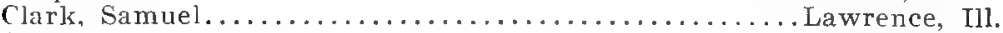

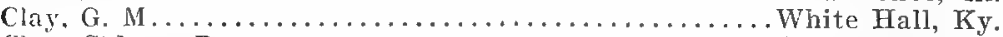

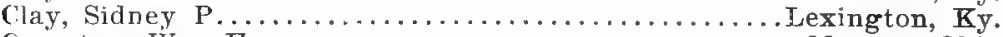

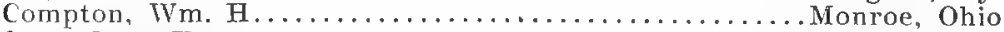
Cope, Jesse K.......................West Chester, Pa.

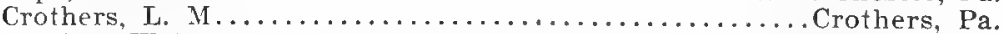

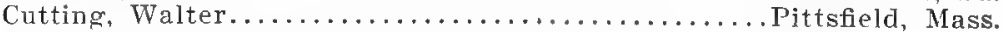

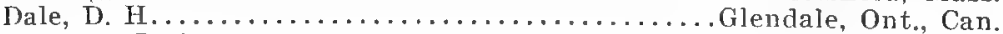
Donnan, J. $\Lambda \ldots \ldots \ldots \ldots \ldots \ldots \ldots \ldots \ldots \ldots \ldots \ldots \ldots \ldots \ldots \ldots$ Wadsworth, $\mathrm{N}$. $\mathrm{Y}$. 
Donoho, W. T

Elmerville, Tenn.

Douglas, T. C. Galt, Ont., Can.

Dunkin, John. Bridgeport, W. Va.

Eiselstein, Geo. Pomeroy, 0 .

Estill, W. W. Lexington, Ky.

Evans, D. W.

Venedocia, Ohio

Fargason, J. T.

Memphis, Tenn.

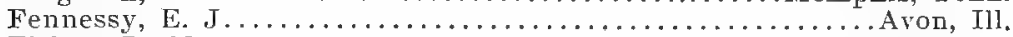

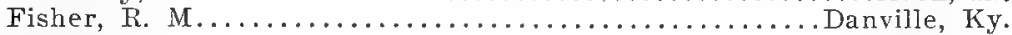

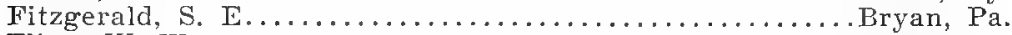

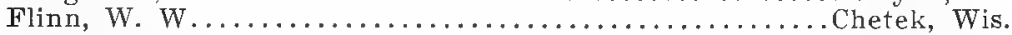

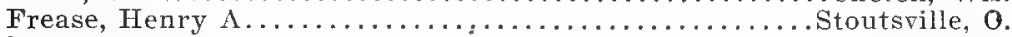

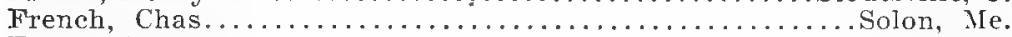

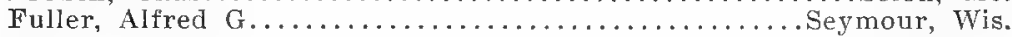

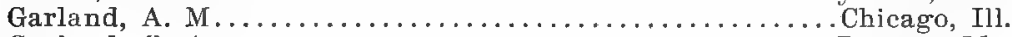

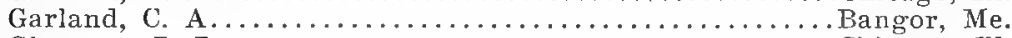

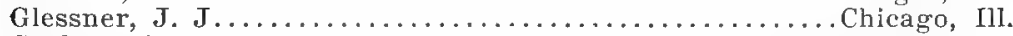

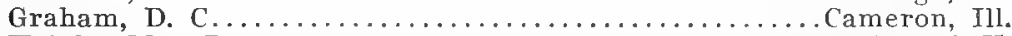

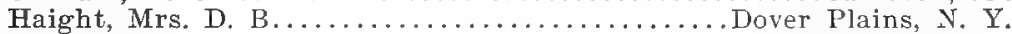

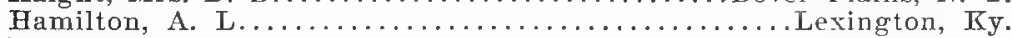

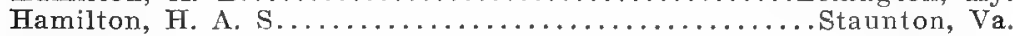

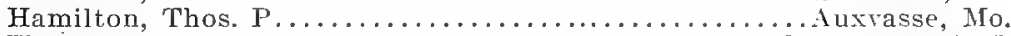

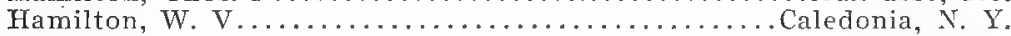

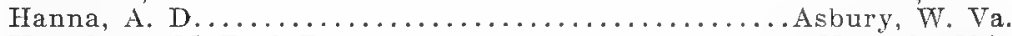

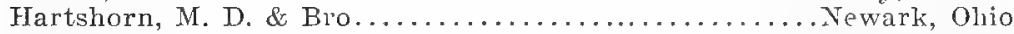

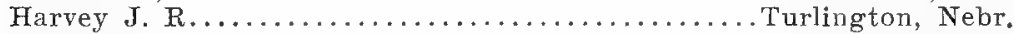

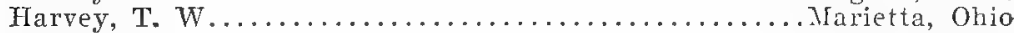

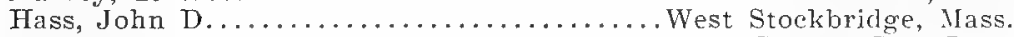

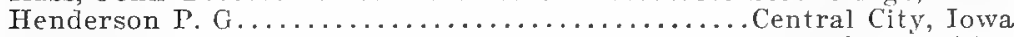

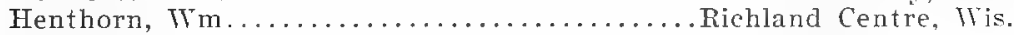

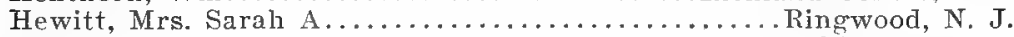

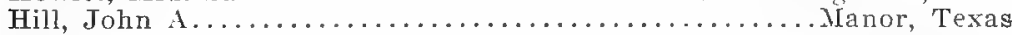

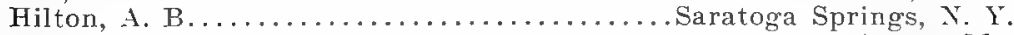

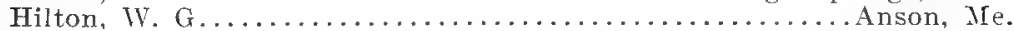

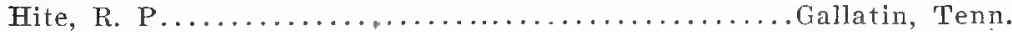

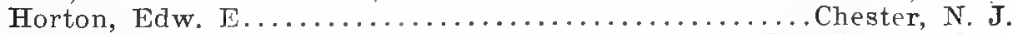

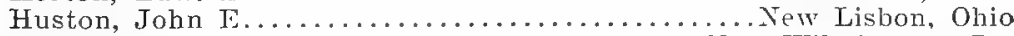

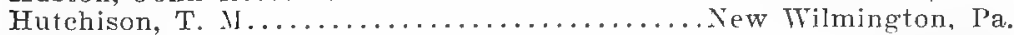

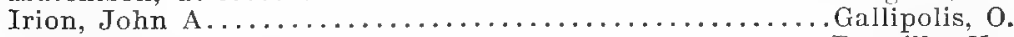

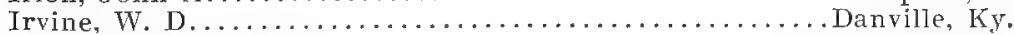

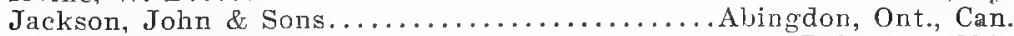

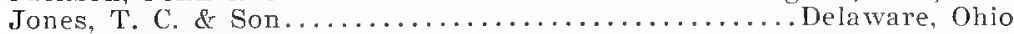

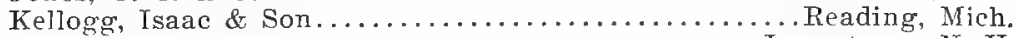

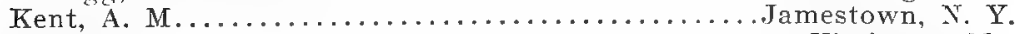

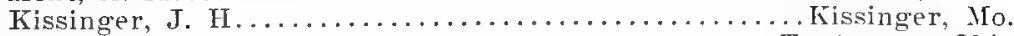

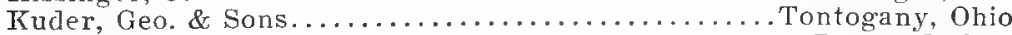

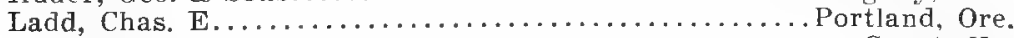

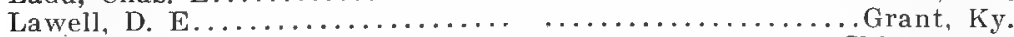

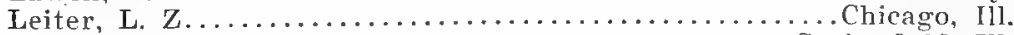

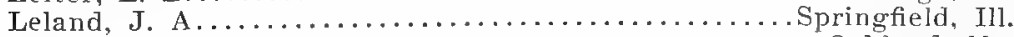

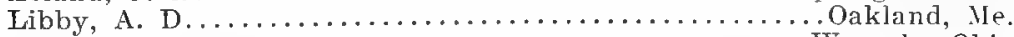

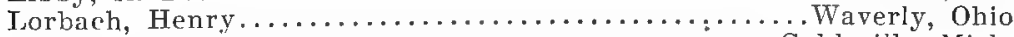

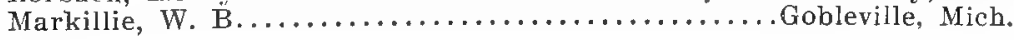


Marsh, Robt. \& Sons....................Richmond Hill, Ont., Can.

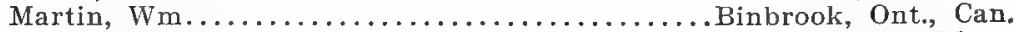

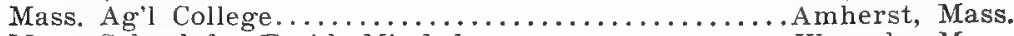

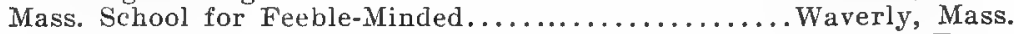

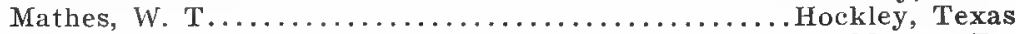

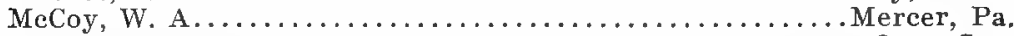

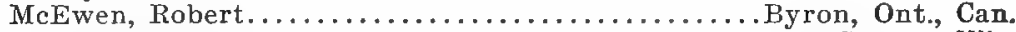

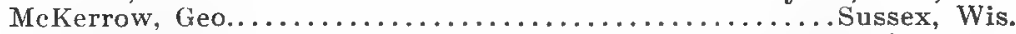

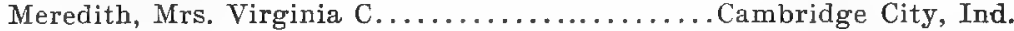

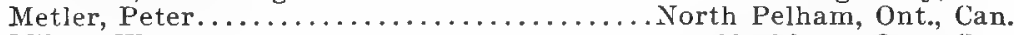

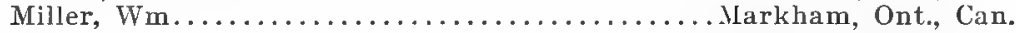

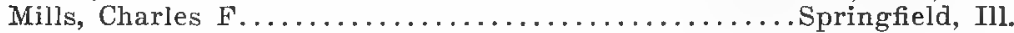

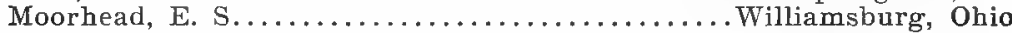

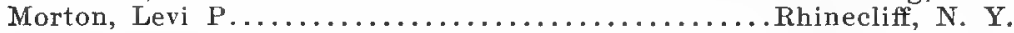

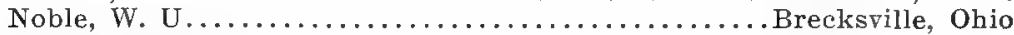

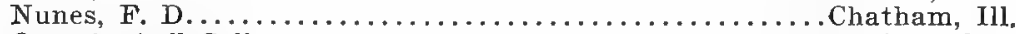

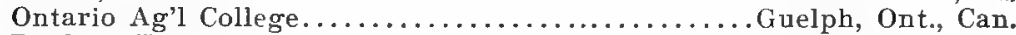

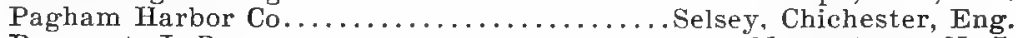

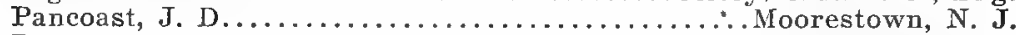

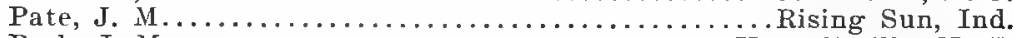

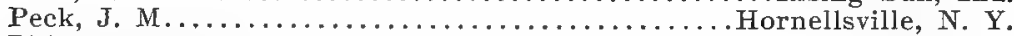

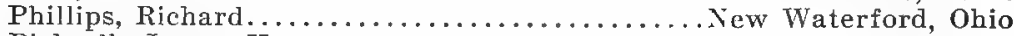

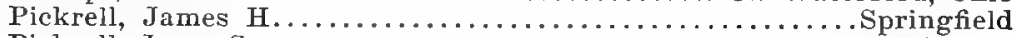

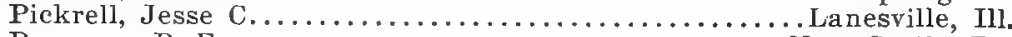

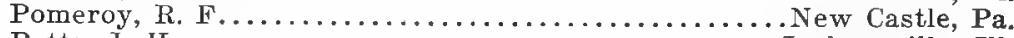

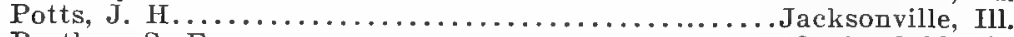

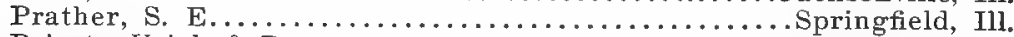

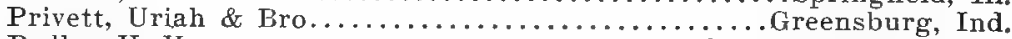

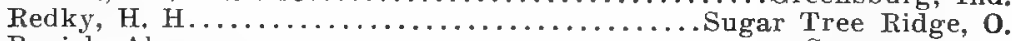

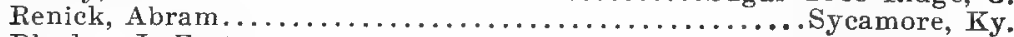

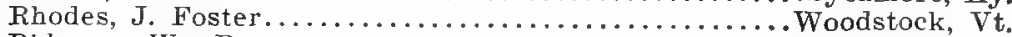

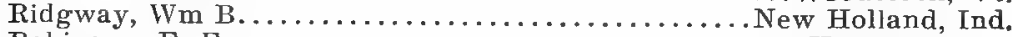

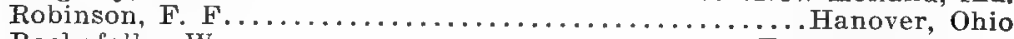

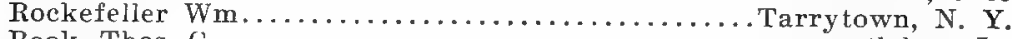

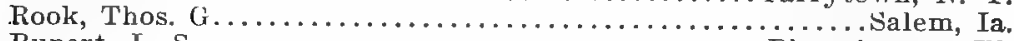

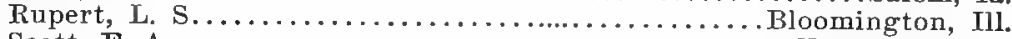

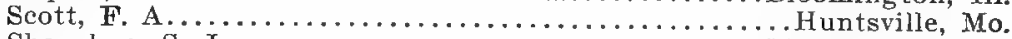

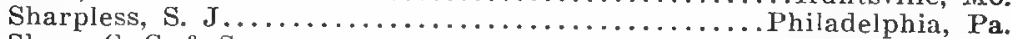

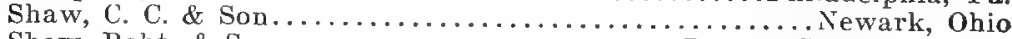

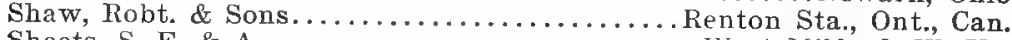

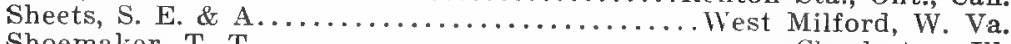

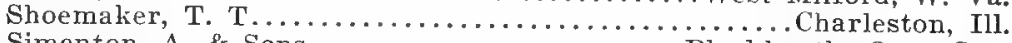

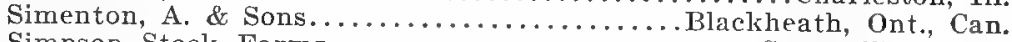

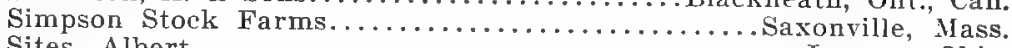

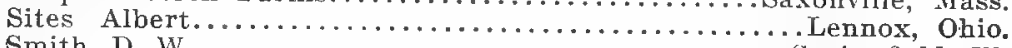

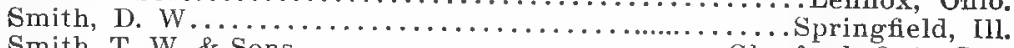

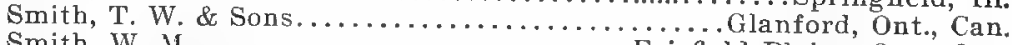

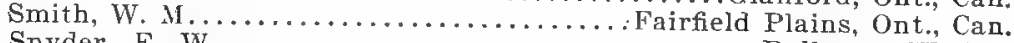

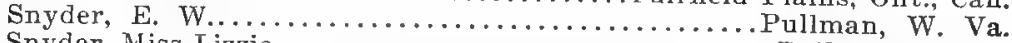

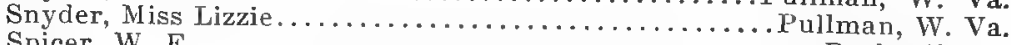

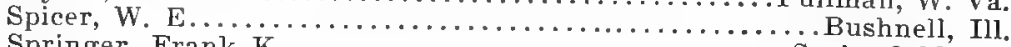

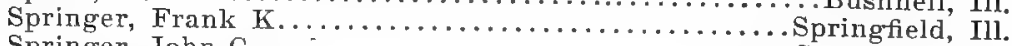

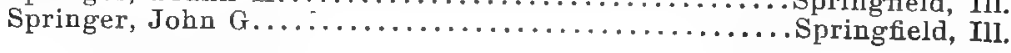


Stuckey, Chas. J.

Mechanicsburg, Ohio

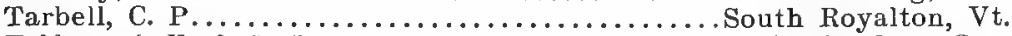
Telfer, W. E. \& G. L...........................Paris, Ont., Can.

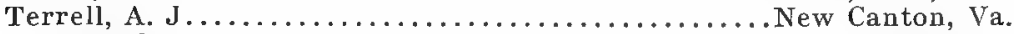

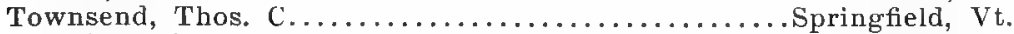

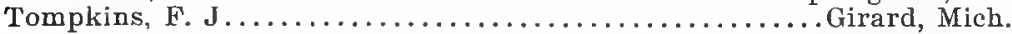

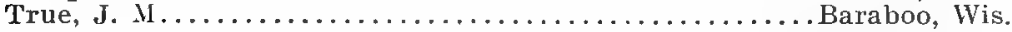

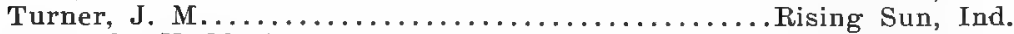

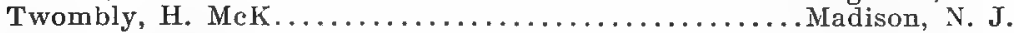
Warren, John Hobart...................... Hoosick Falls, N. Y.

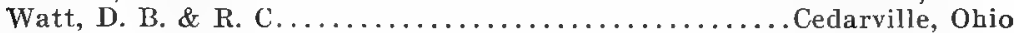

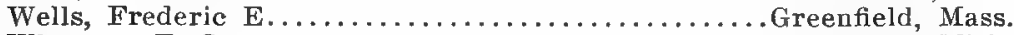

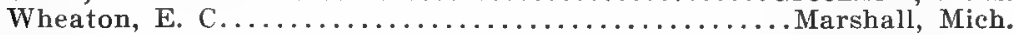

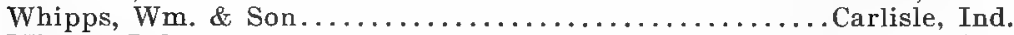

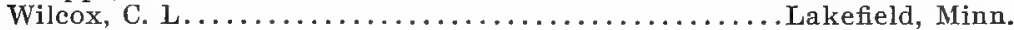

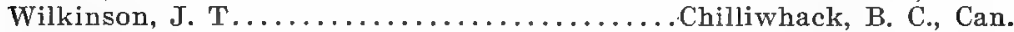

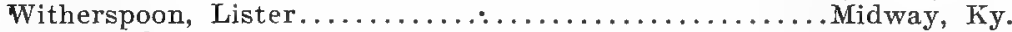

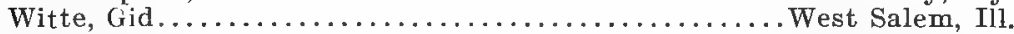
Wood, Mrs. W. A...................................... Smithfield, Pa.

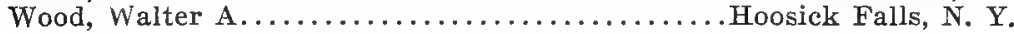

\section{Breeders of Shropshire Sheep.}

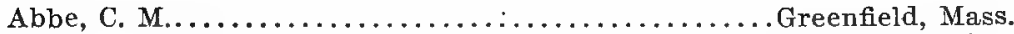

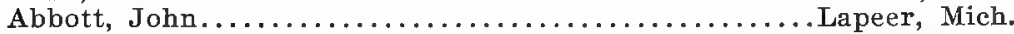

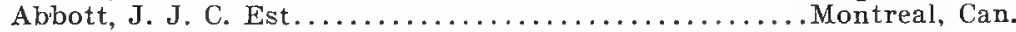

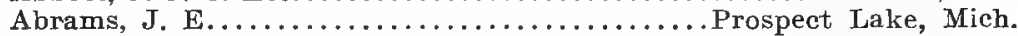

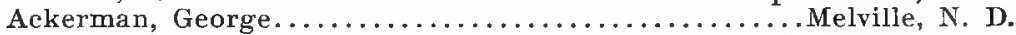

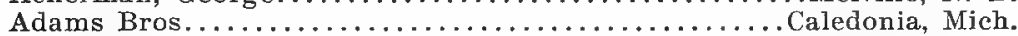
Adams, Clark E.......................................

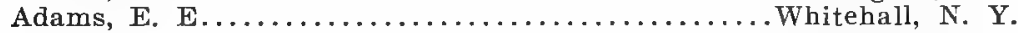

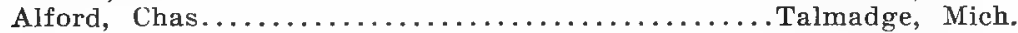

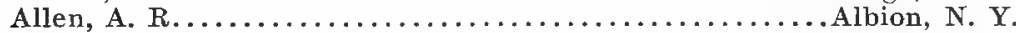

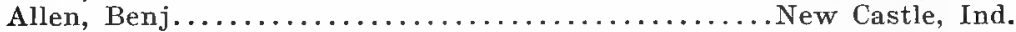
Allen, George \& Son ................................

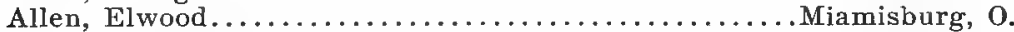

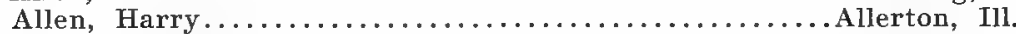

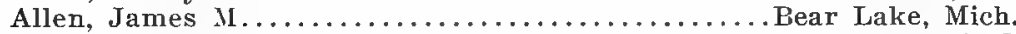

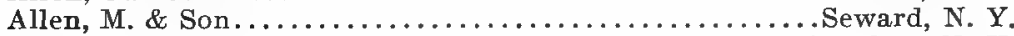

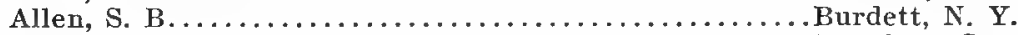

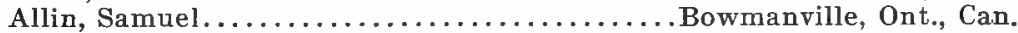

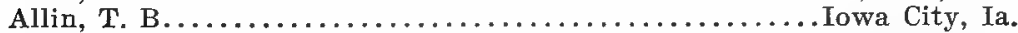

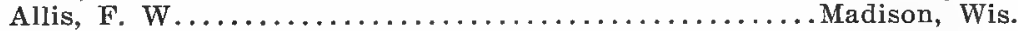

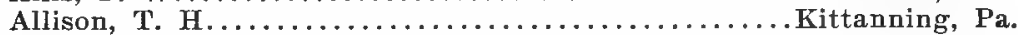

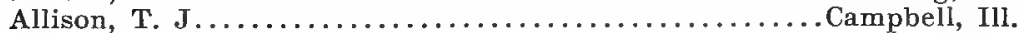

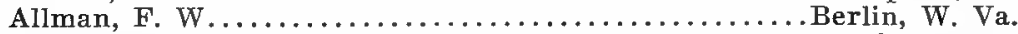

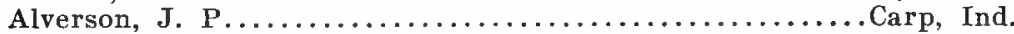

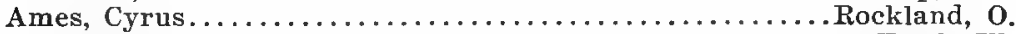
Ames, Mrs. L. V. S........................................ Ill.

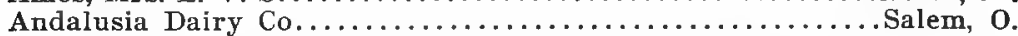

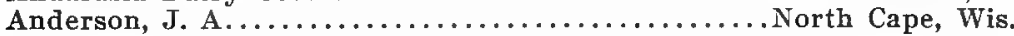

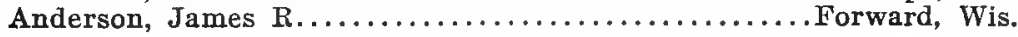




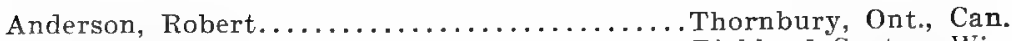

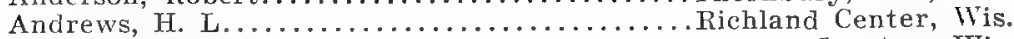

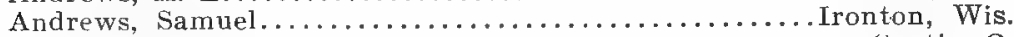

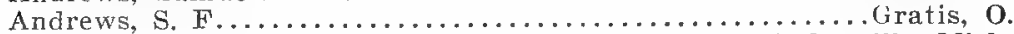

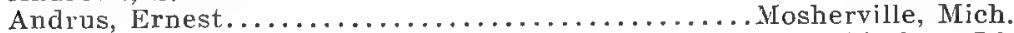

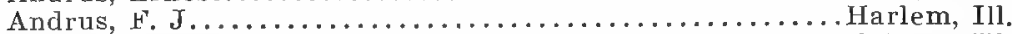

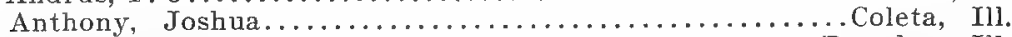

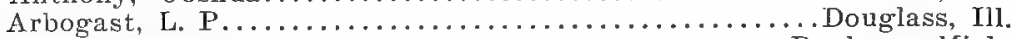

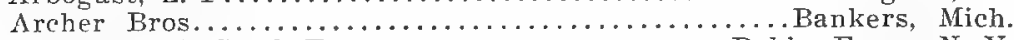

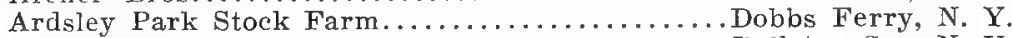

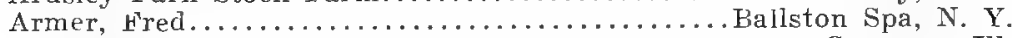

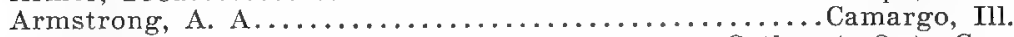

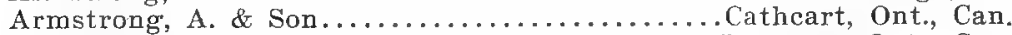

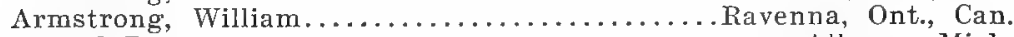

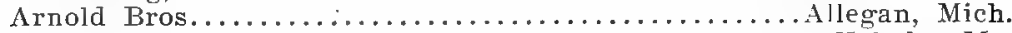

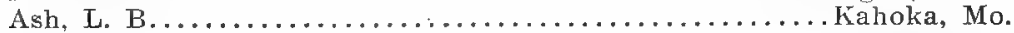

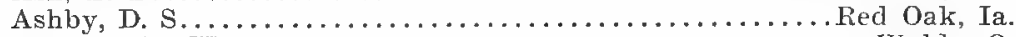

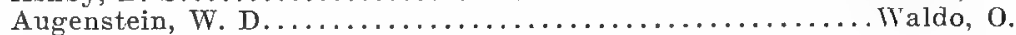

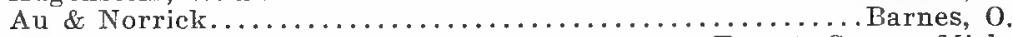

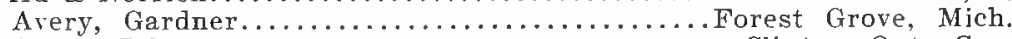

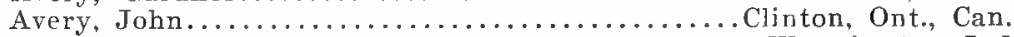

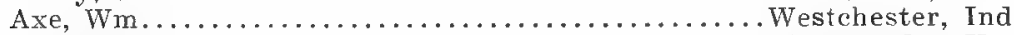

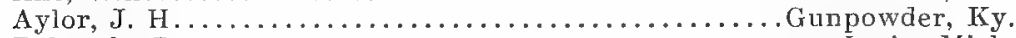

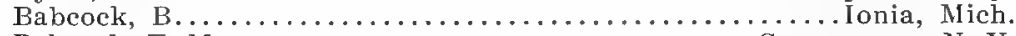

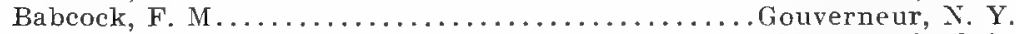

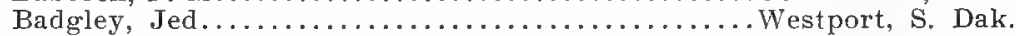

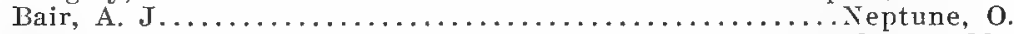

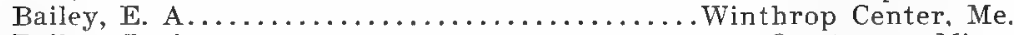

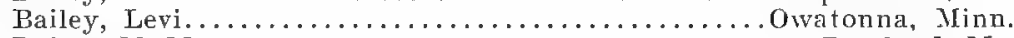

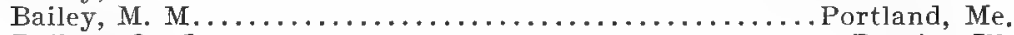

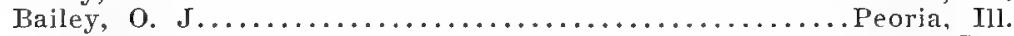

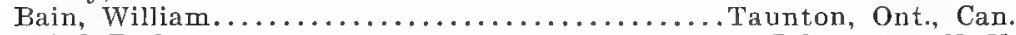

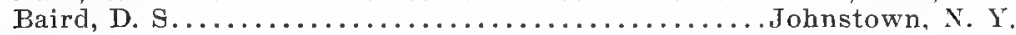

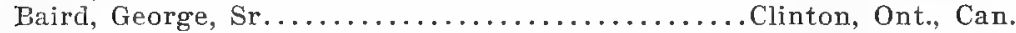

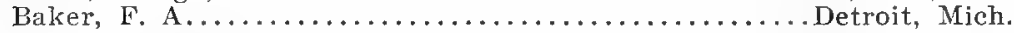

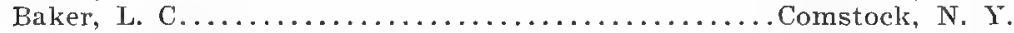

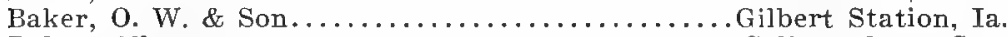

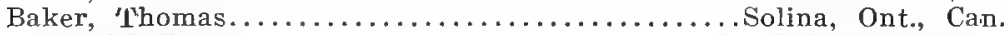

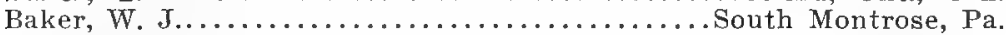

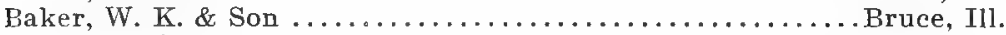

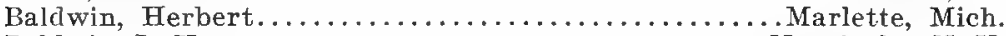

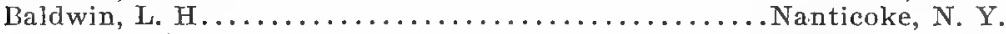

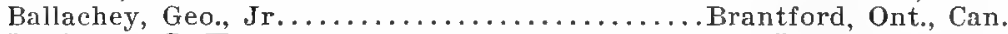

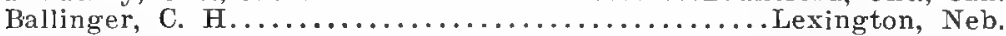

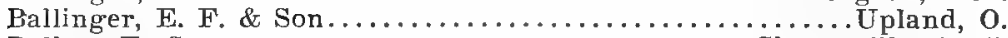

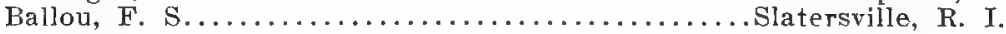

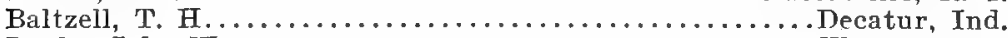

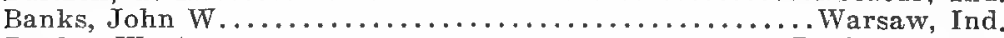

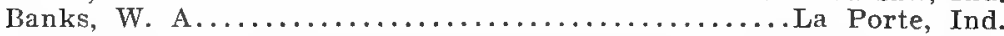

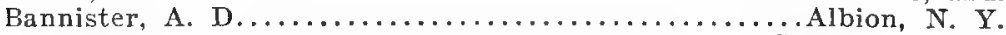

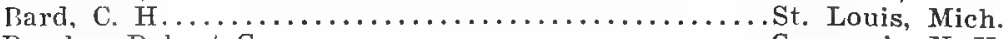

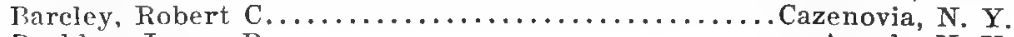
Barkley, James B....................................... 


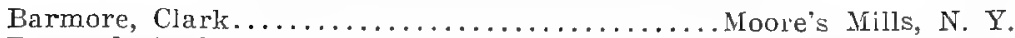

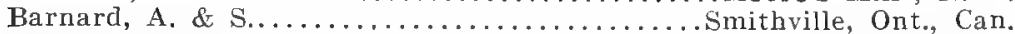

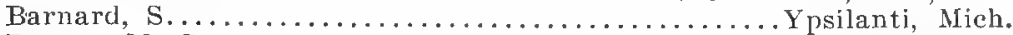

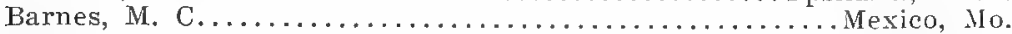

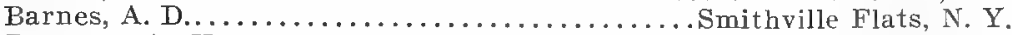

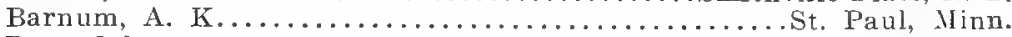

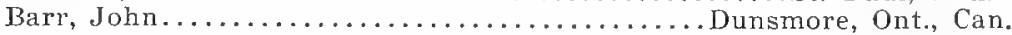

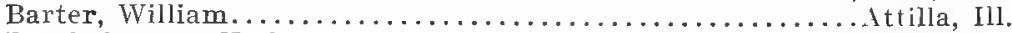

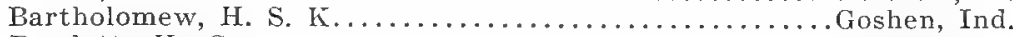

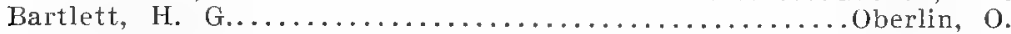

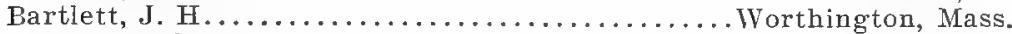

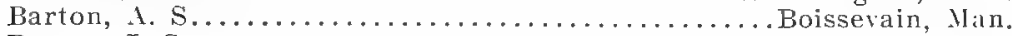

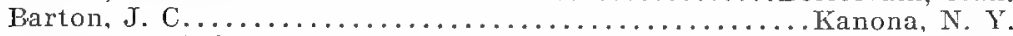

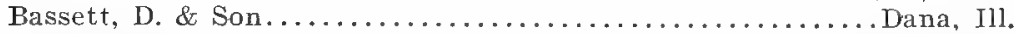

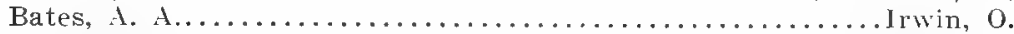

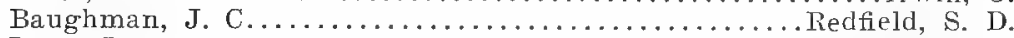

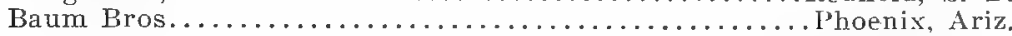

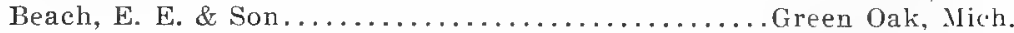

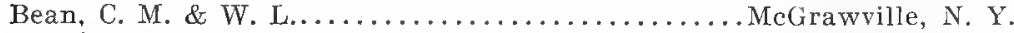

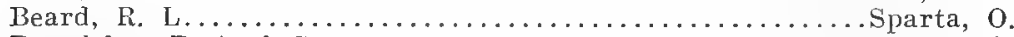

Beardsley, P. A. \& Son..................... A est Andover. 0.

Beattie, William H................Wilton Grove, Ont., Can.

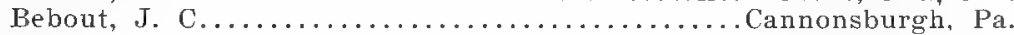

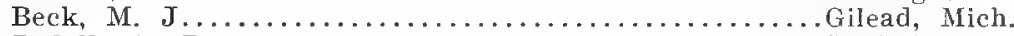

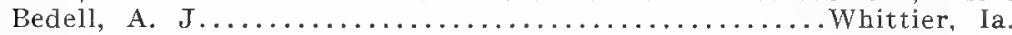

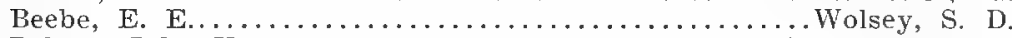

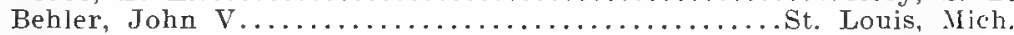

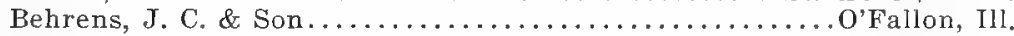

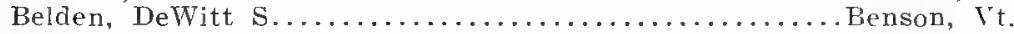

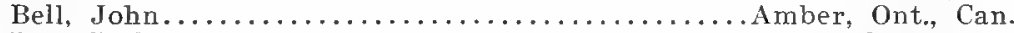

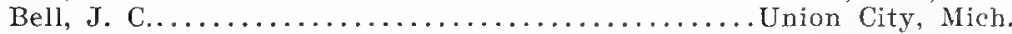

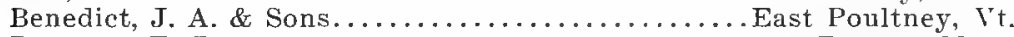

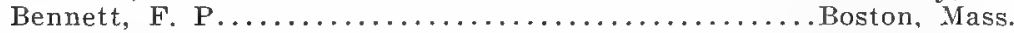

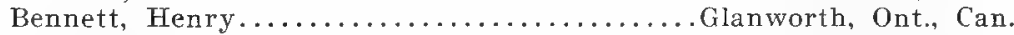

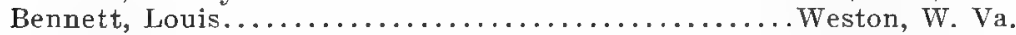

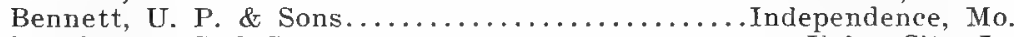

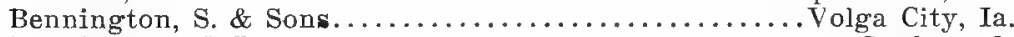

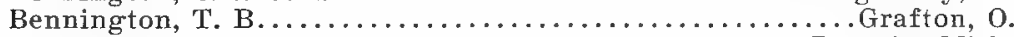

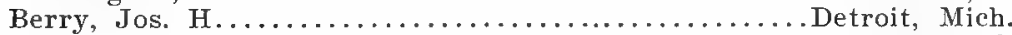

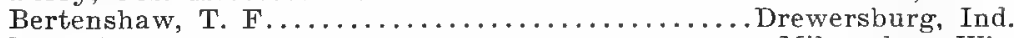

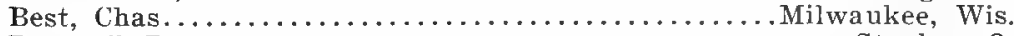

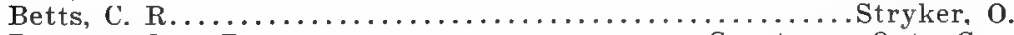

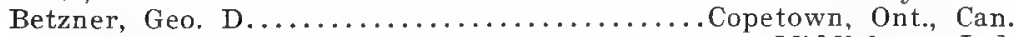

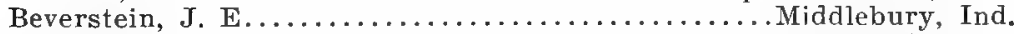

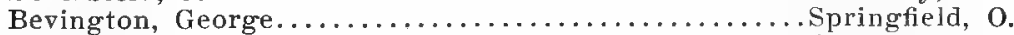

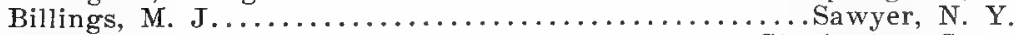

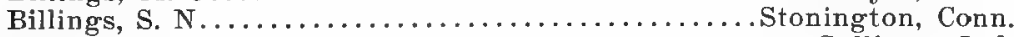

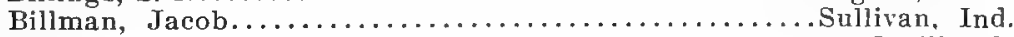

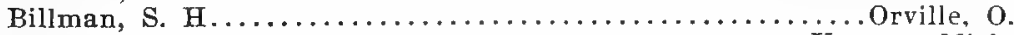

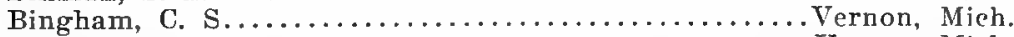

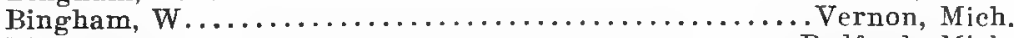

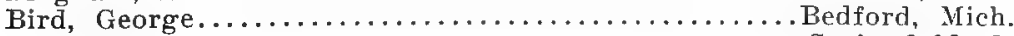

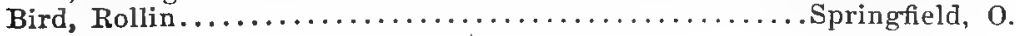


Birnie, Frank........................... Unadilla, Mich.

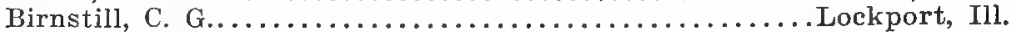

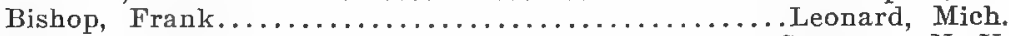

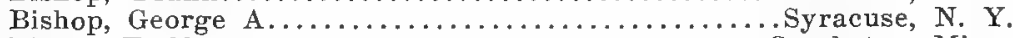

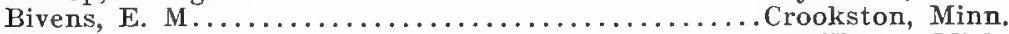

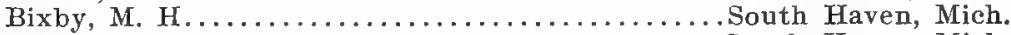

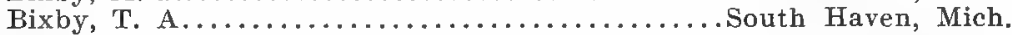

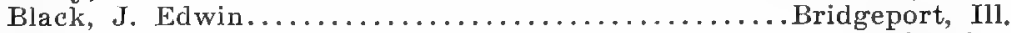

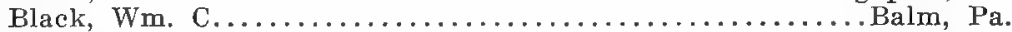

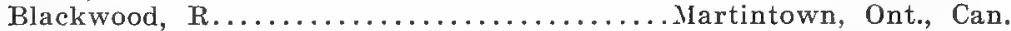
Blaine, S. E. \& C. H...................... Dutton, Mich.

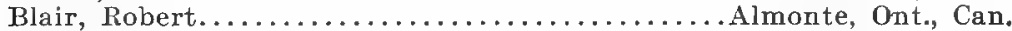

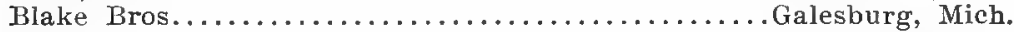

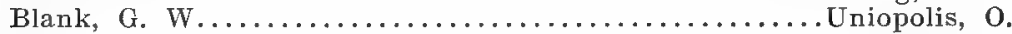

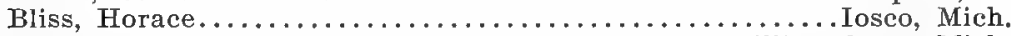

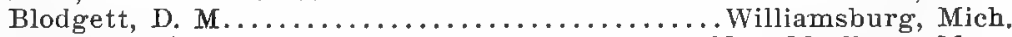

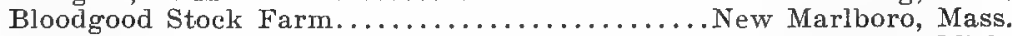

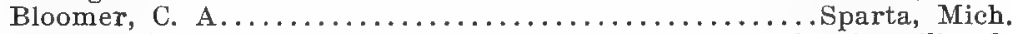

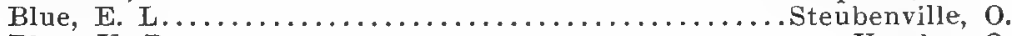

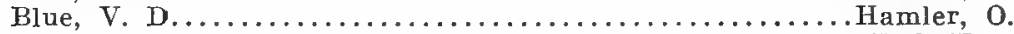

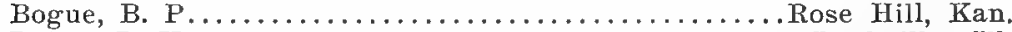

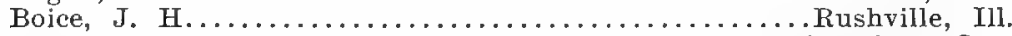
Bole, James........................Woodville, Ont., Can.

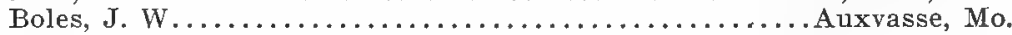

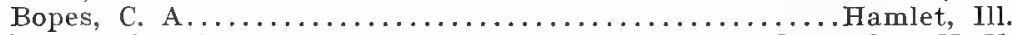

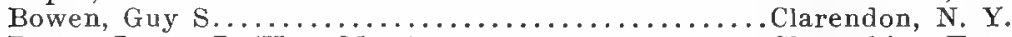

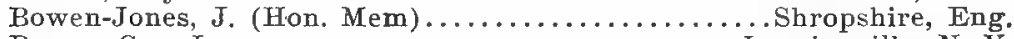

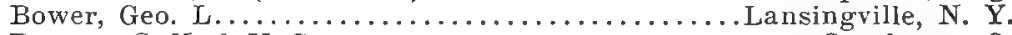

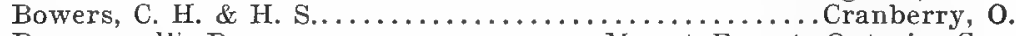

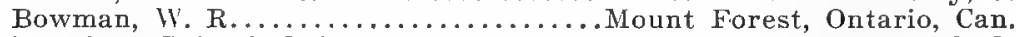

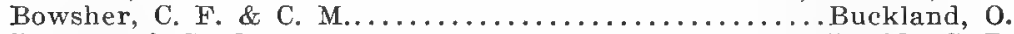

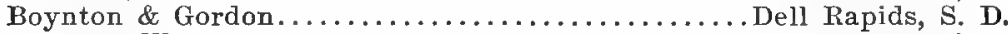

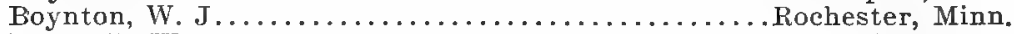

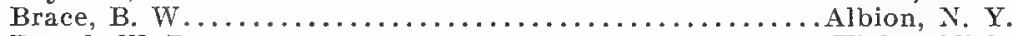

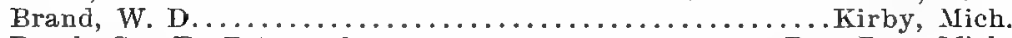

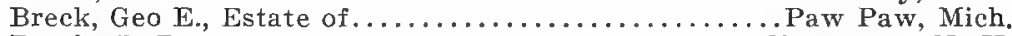

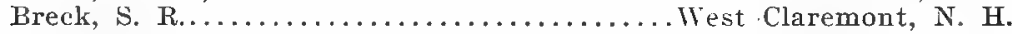

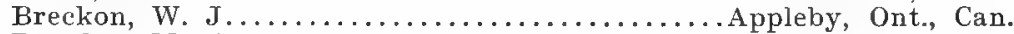

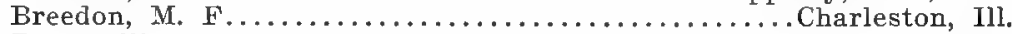

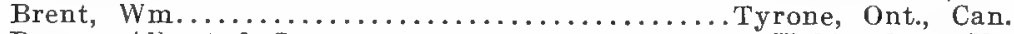

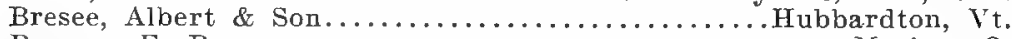

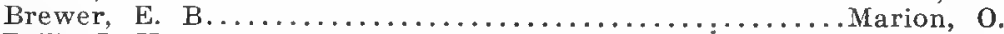

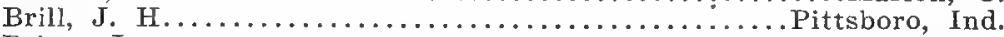

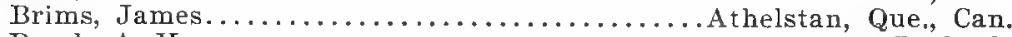

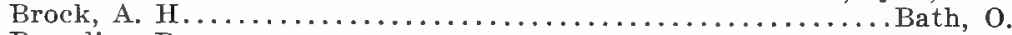

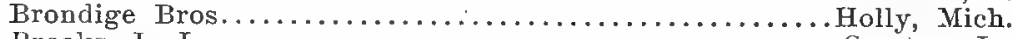

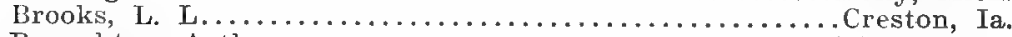

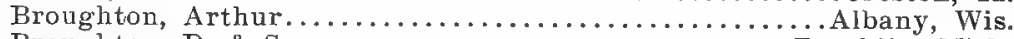

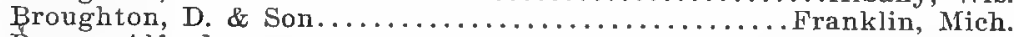

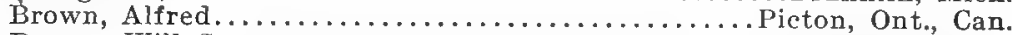

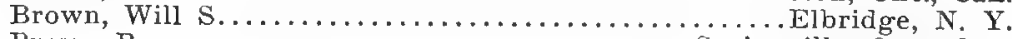

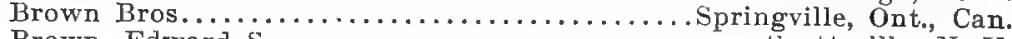
Brown, Edward $\mathrm{S} . \ldots \ldots \ldots \ldots \ldots \ldots \ldots \ldots \ldots \ldots$. Scottsville, $N$. $Y$. 
Brown, H. F

Brown, Wm. F. S

Minneapolis, Minn.

Brownlee, Hugh A. .Portland, Me. Brubaker, Geo.

Bruce \& Kerr.
Bruce, William. Shawville, Que., Can. West Millgrove, $\mathbf{0}$.

Mctennan Ont

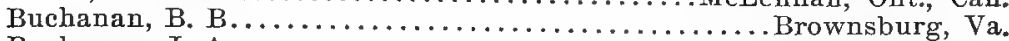

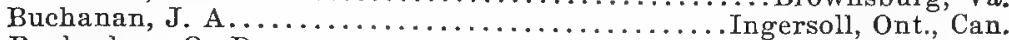

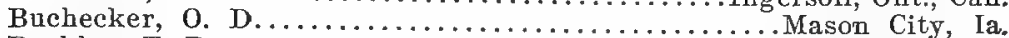

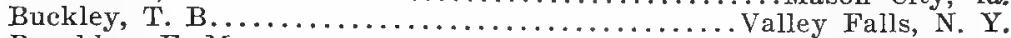

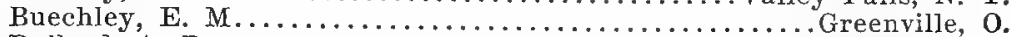

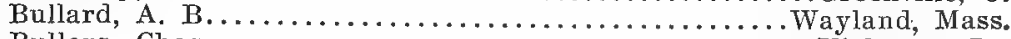

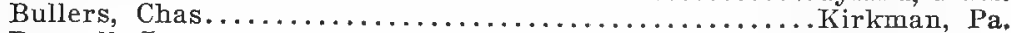

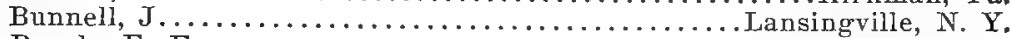

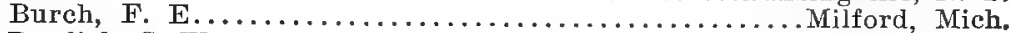

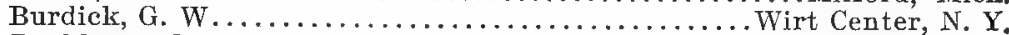

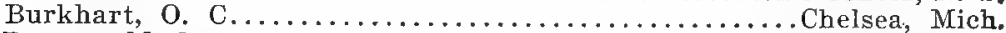

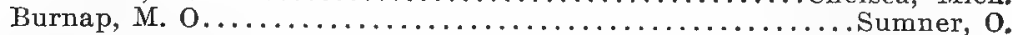

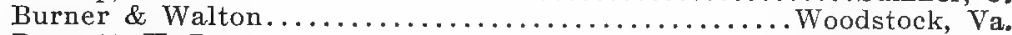

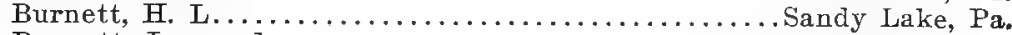

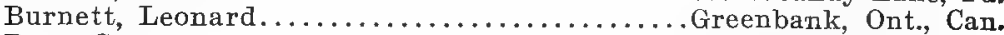

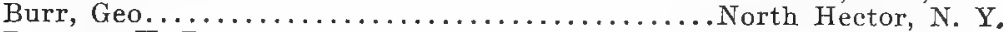

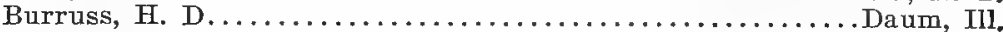

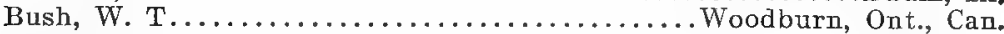

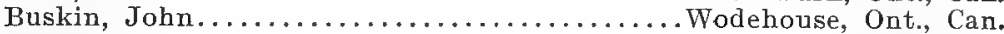

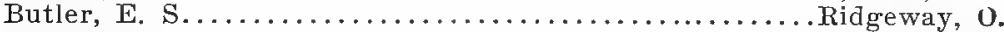

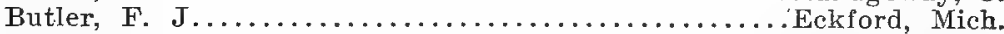

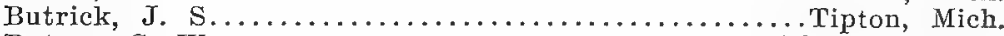

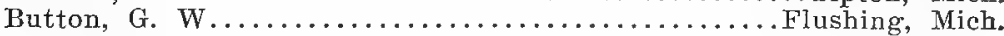

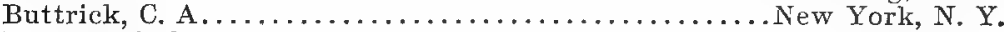

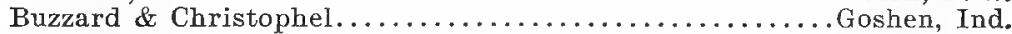

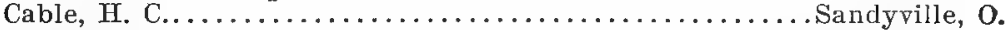

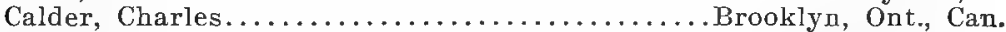

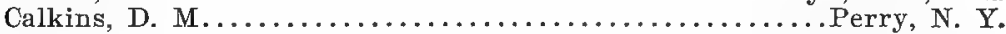

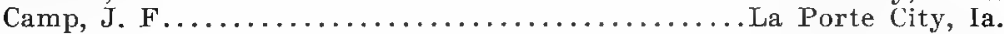

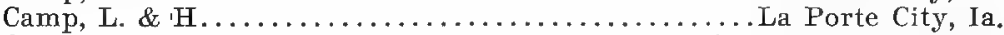

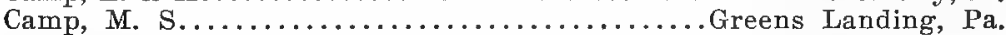

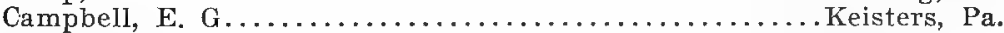
Campbell, John, Jr...................Woodville, Ont., Can.

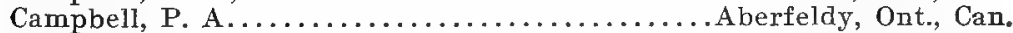

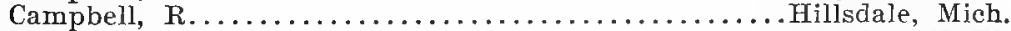

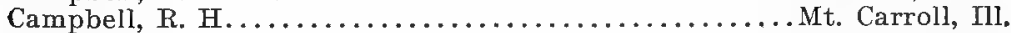

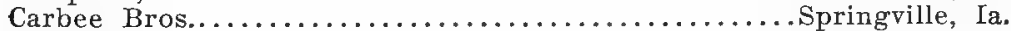

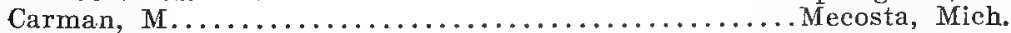

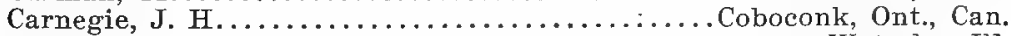

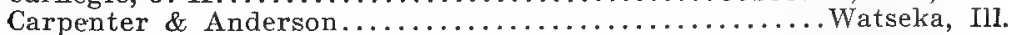

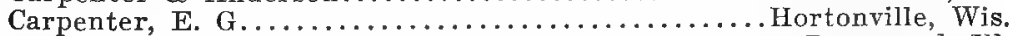

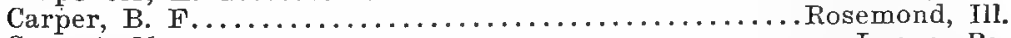

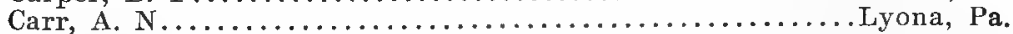

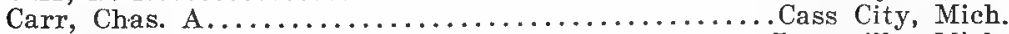

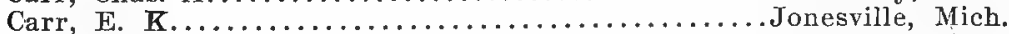

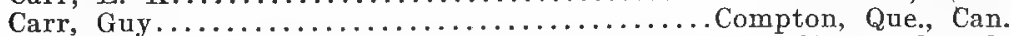

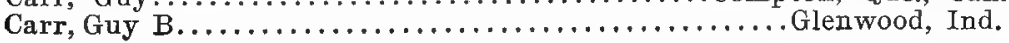


Carr, J. H. .Unionville, Ia.

Carr, J. S. Durham, N. C.

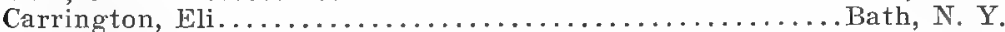

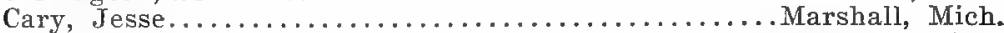

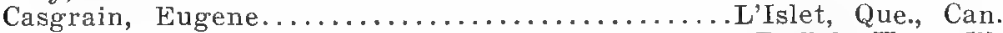

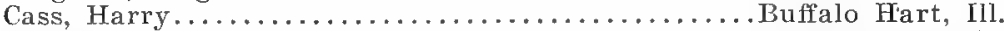

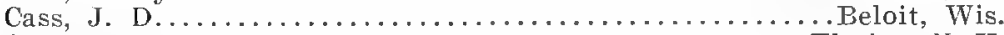

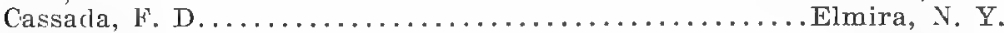

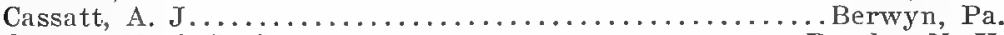

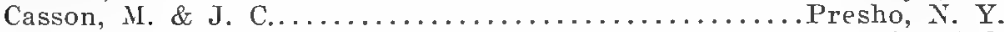

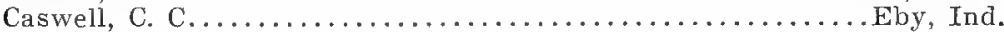

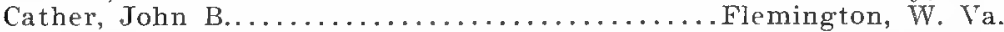

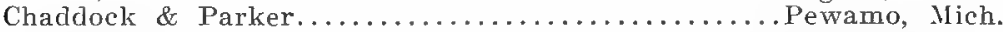

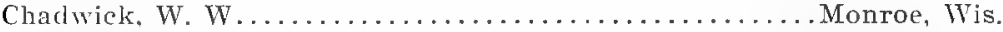

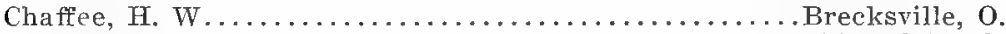

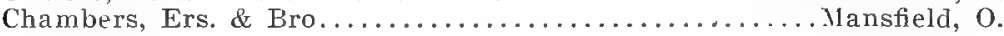

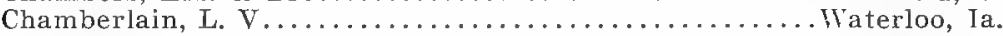

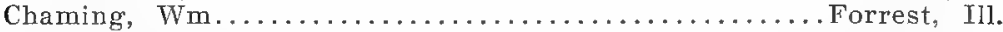

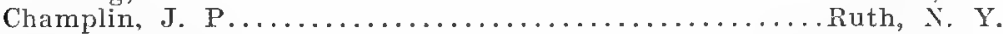

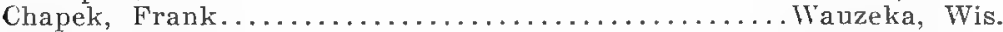

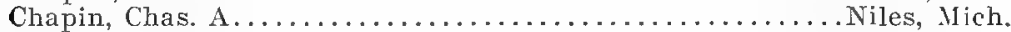

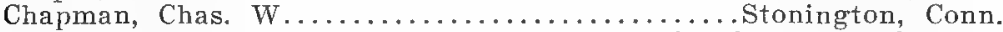

Chapman, D. L. \& A. B................. South Rockwood, Mich.

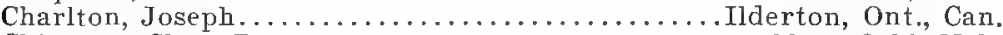

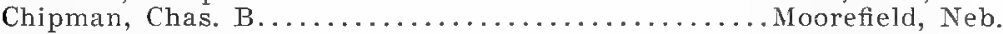

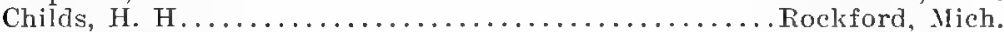

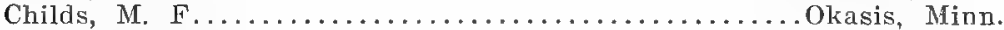

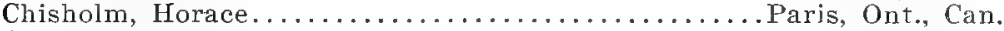

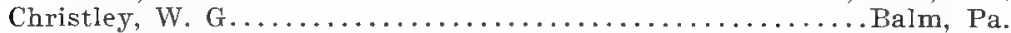

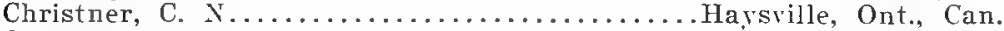

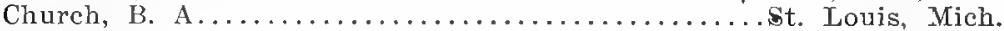

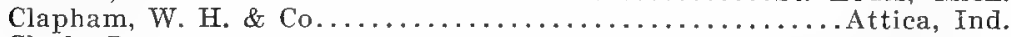

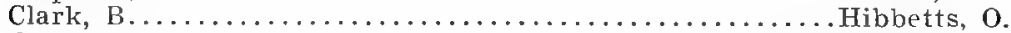

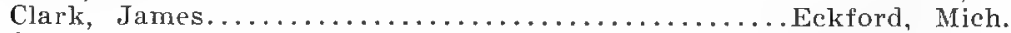

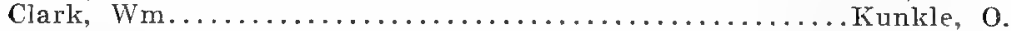

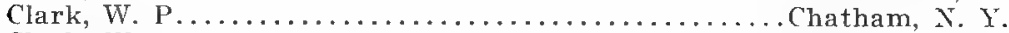

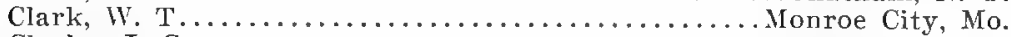

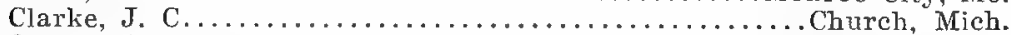

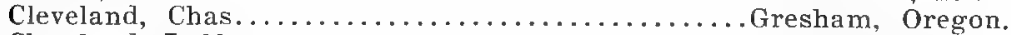

Cleveland, J. $11 \ldots \ldots \ldots \ldots \ldots \ldots \ldots \ldots \ldots \ldots \ldots \ldots \ldots \ldots \ldots \ldots \ldots \ldots \ldots$ Union, Mich.

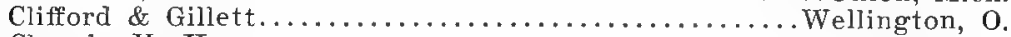

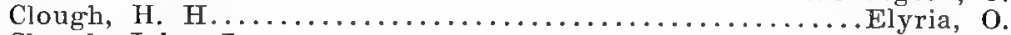

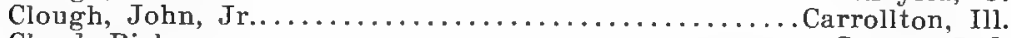

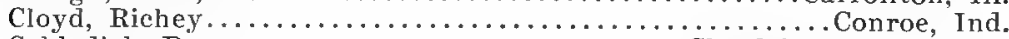

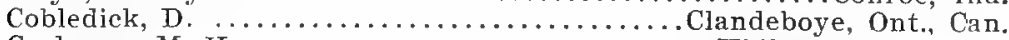

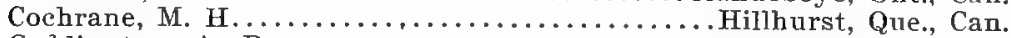

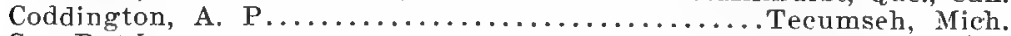

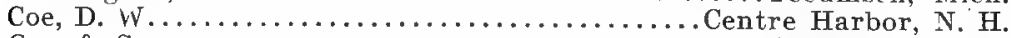

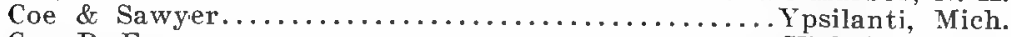

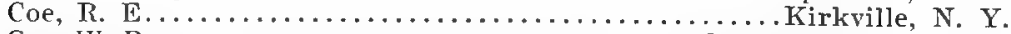

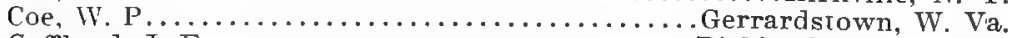

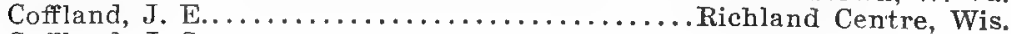

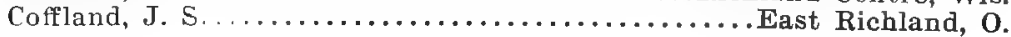


Cole, A. H

Cole, Ogden.

Savona, N. Y.

Cole, Oscar.

Addison, Mich.

Cole, T. J. T.

Aurora, Ill.

.... Ty rone, Ont., Can.

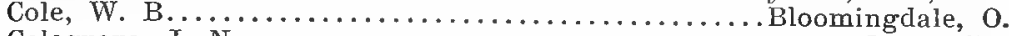

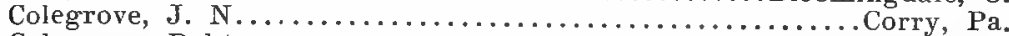

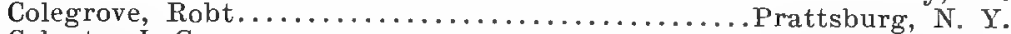

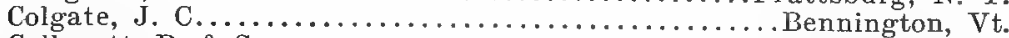

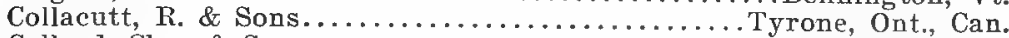

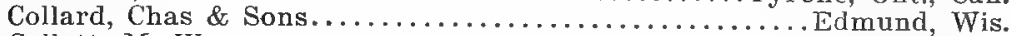

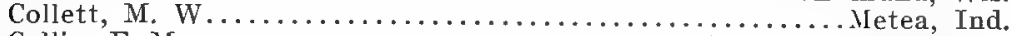

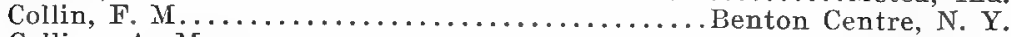

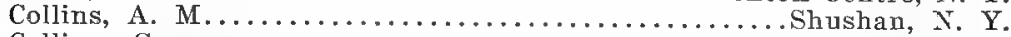

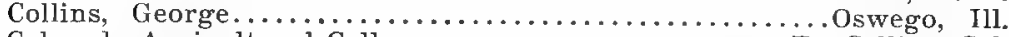

Colorado Agricultural College................... Collins, Col.

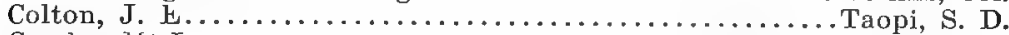

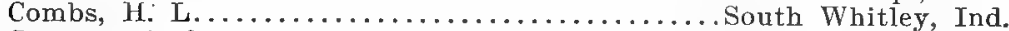

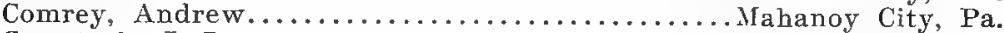

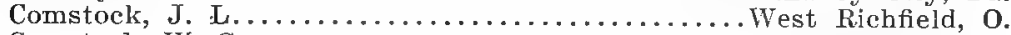

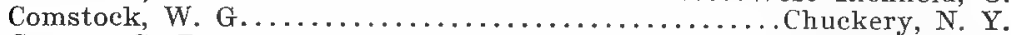

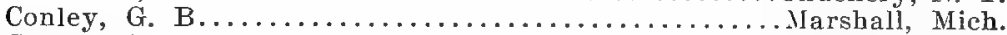

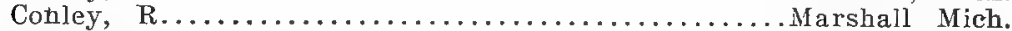

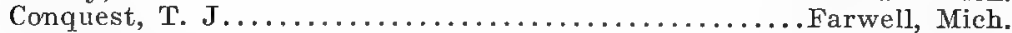

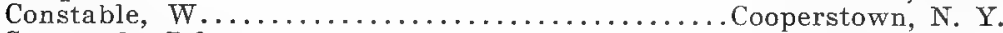

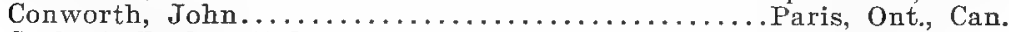

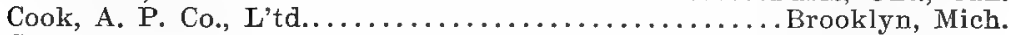

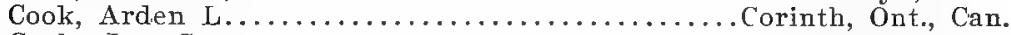

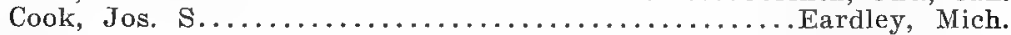

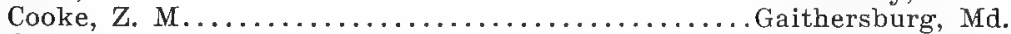

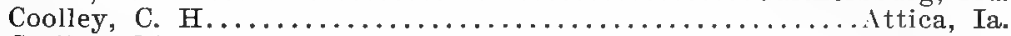

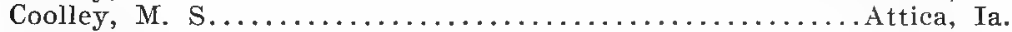

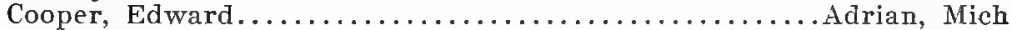

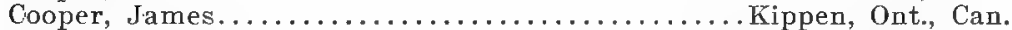

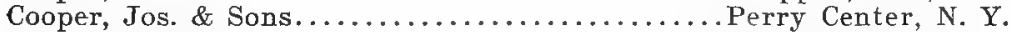

Cooper, William..................................

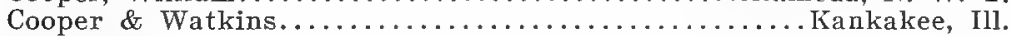

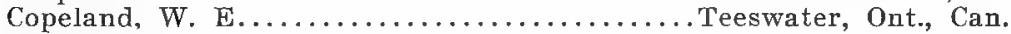

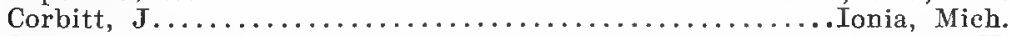

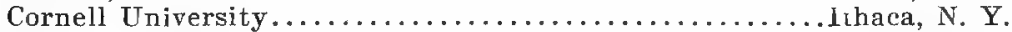

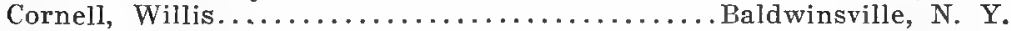

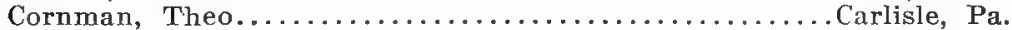

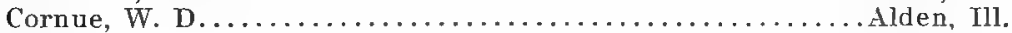

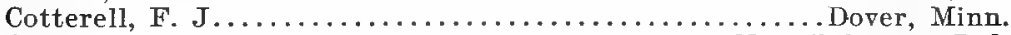

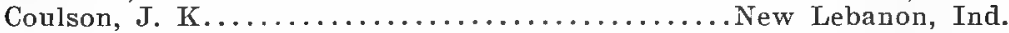

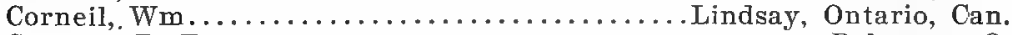

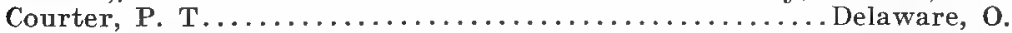

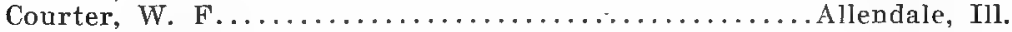

Covert, H. B...................................... Y.

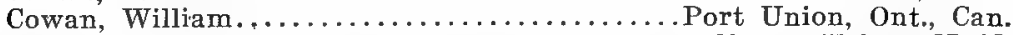

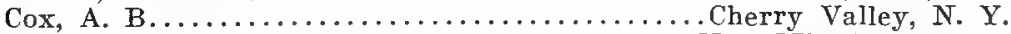

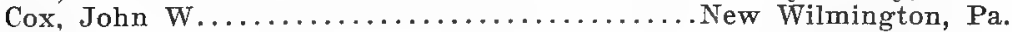

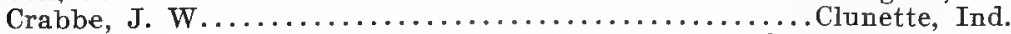

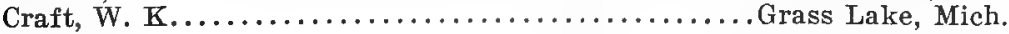




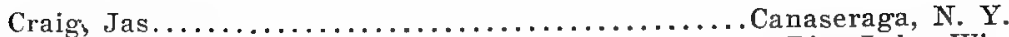

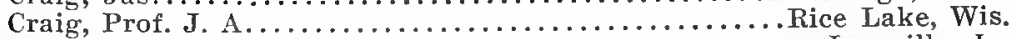

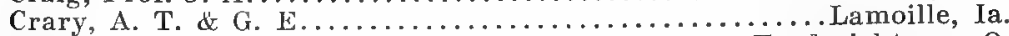

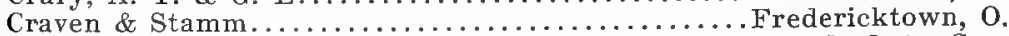

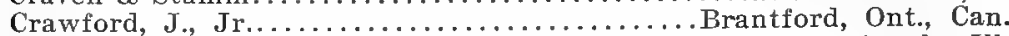

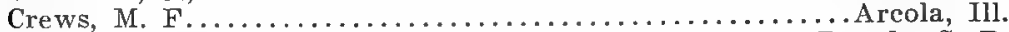

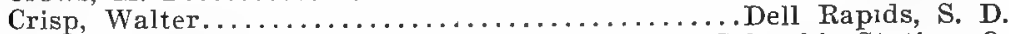

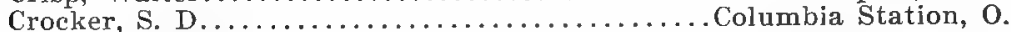

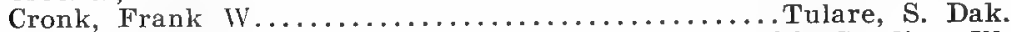

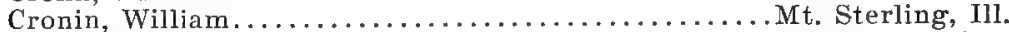

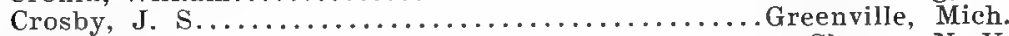

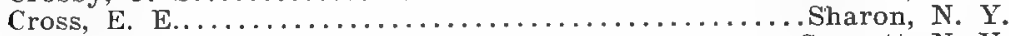

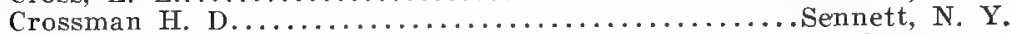

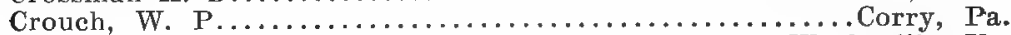

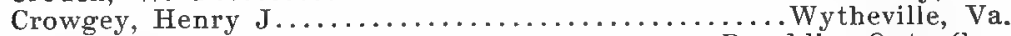

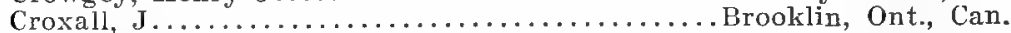

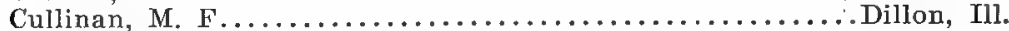

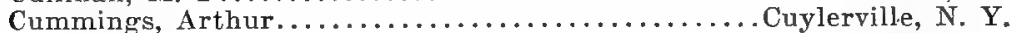

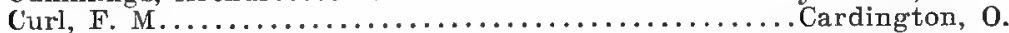

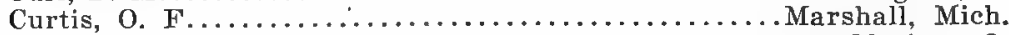

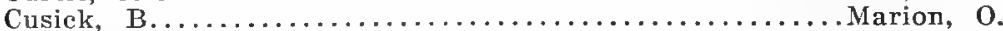

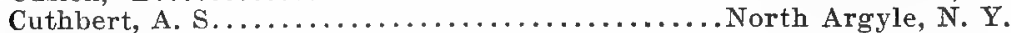

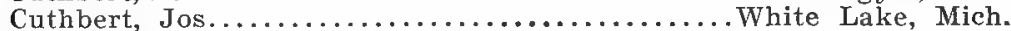

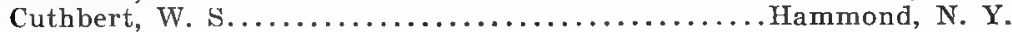

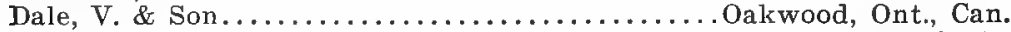

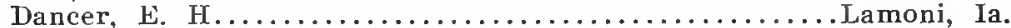

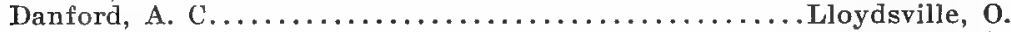

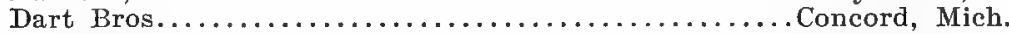

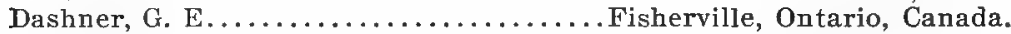

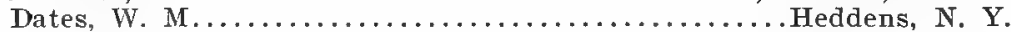
Davidson, J. N. \& Son......................Whitesville, Ind.

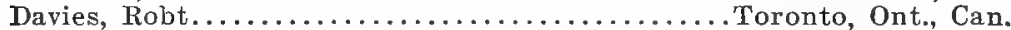

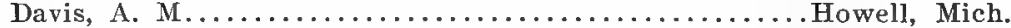

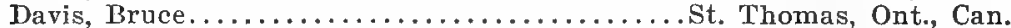

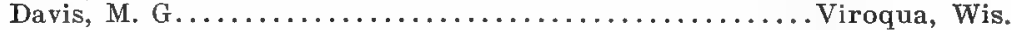

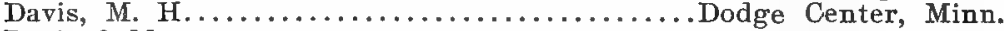

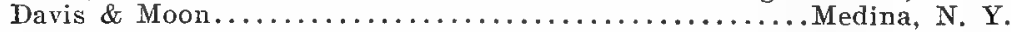

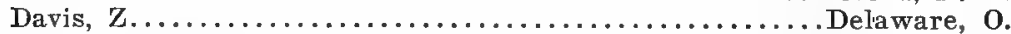

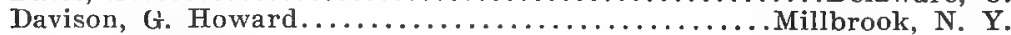

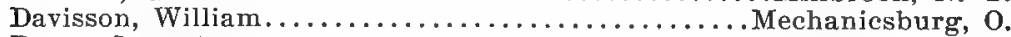

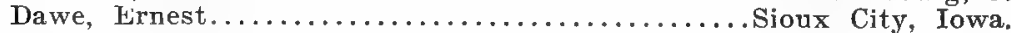

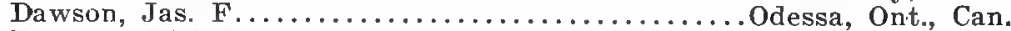

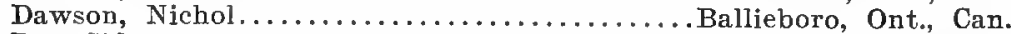

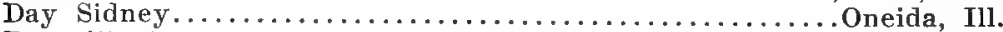

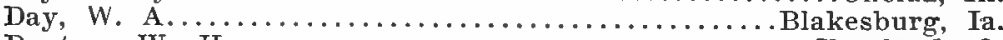

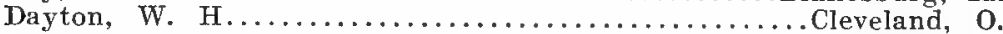

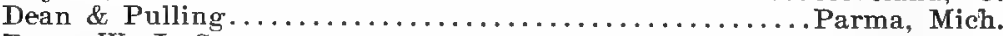

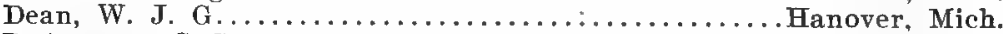

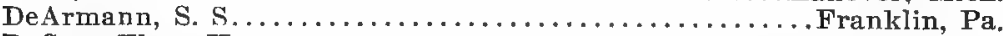

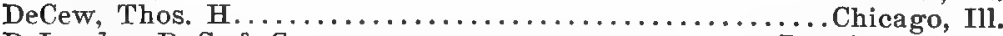

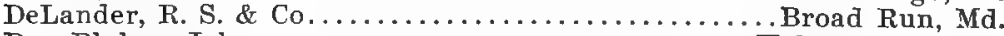

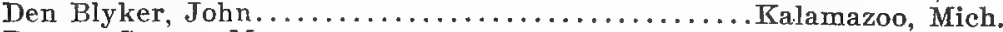
Denny, George M....................... Harveysburg, 0 . 
DeRight, S. H.......................................... Y.

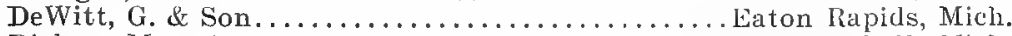

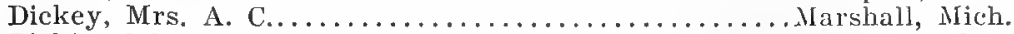

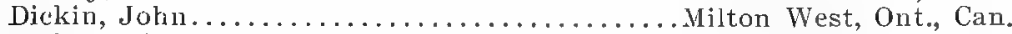

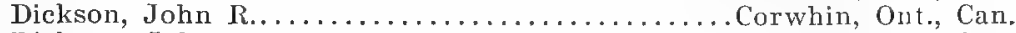

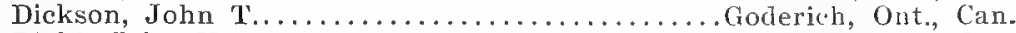

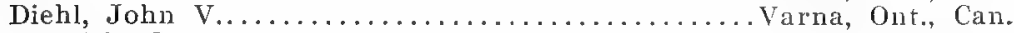

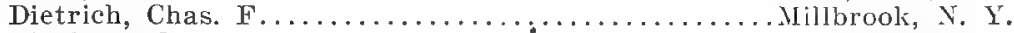

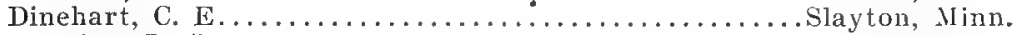

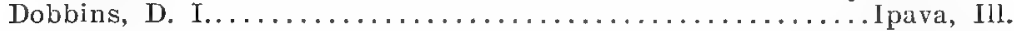

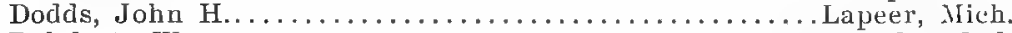

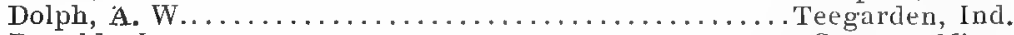

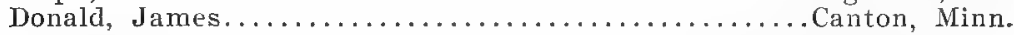

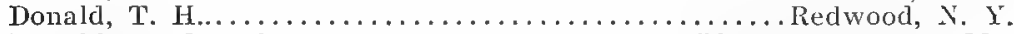

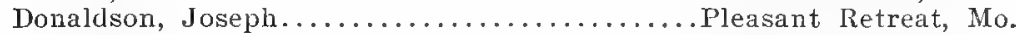

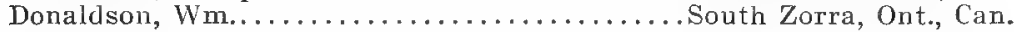

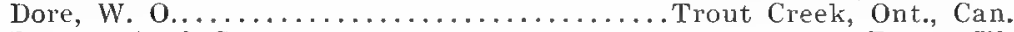

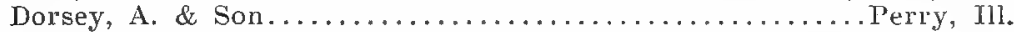

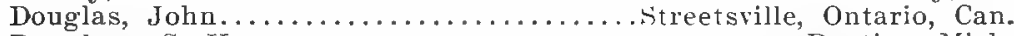

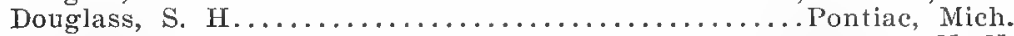

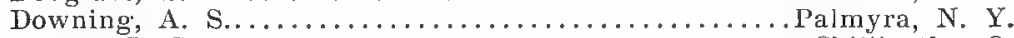

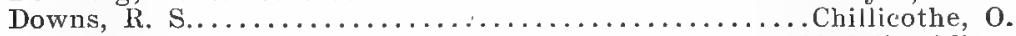

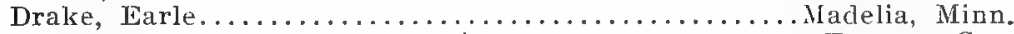

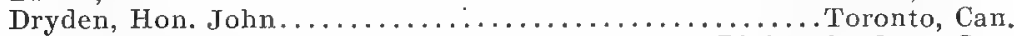

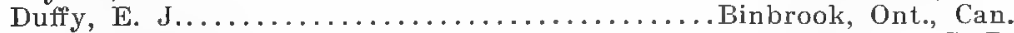

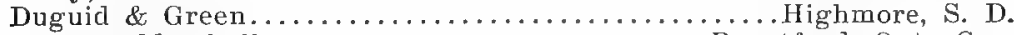

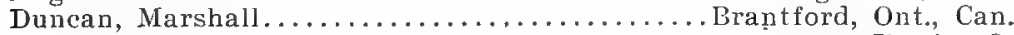

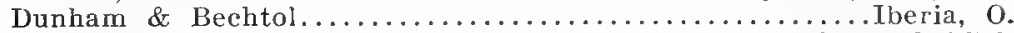

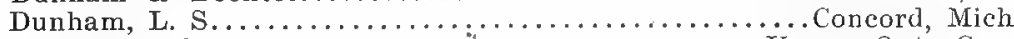

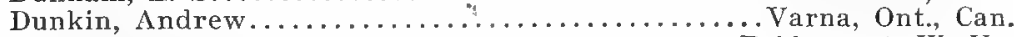

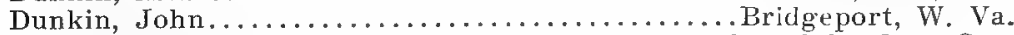

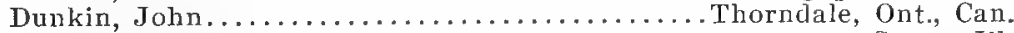

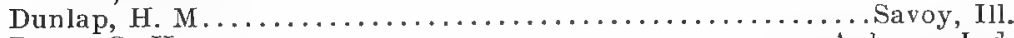

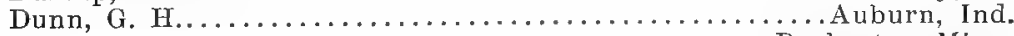

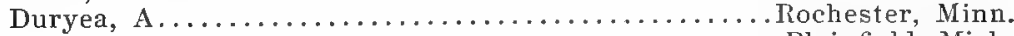

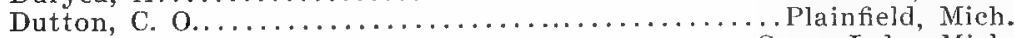

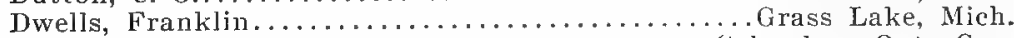

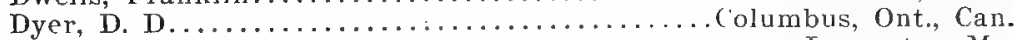

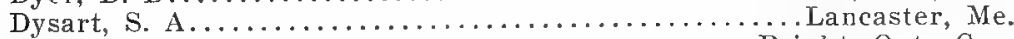

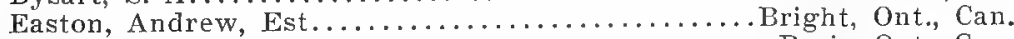

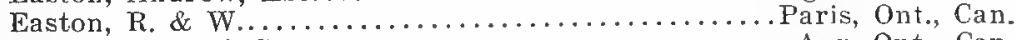

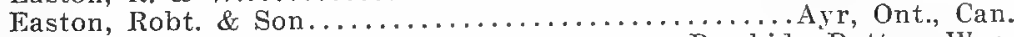

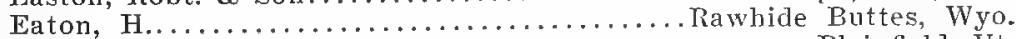

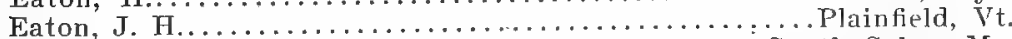

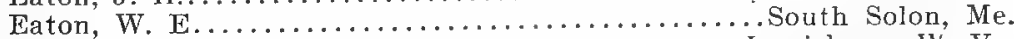

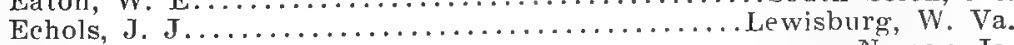

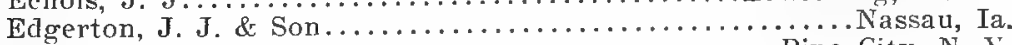

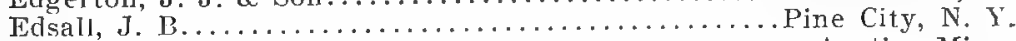

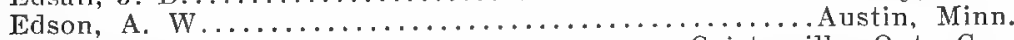

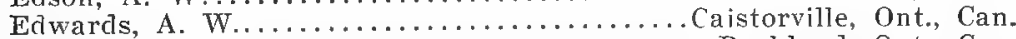

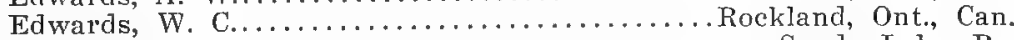

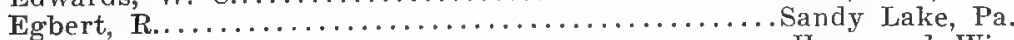

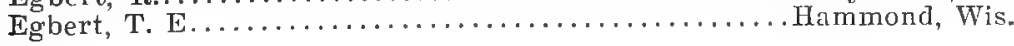




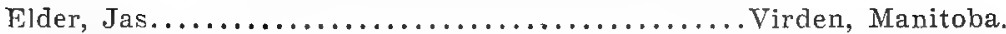

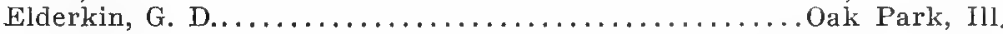

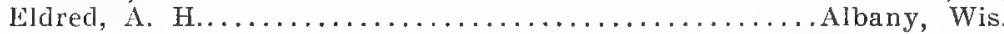

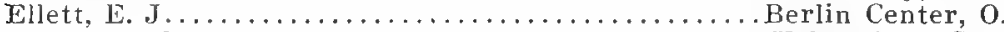

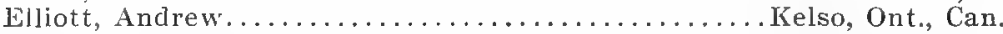

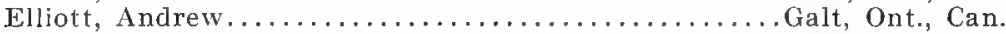

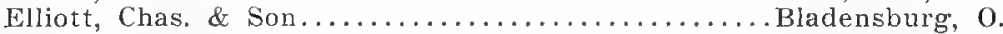

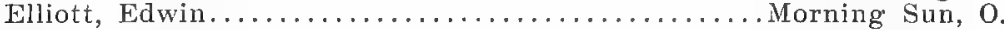

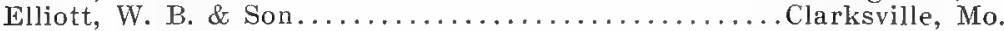

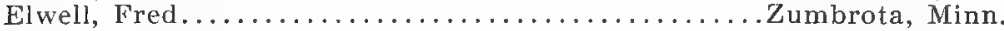

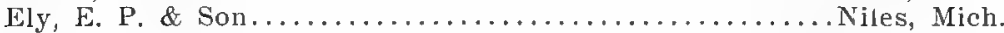

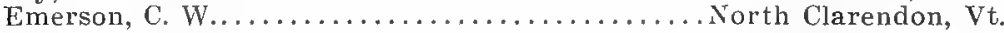

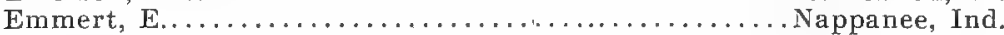

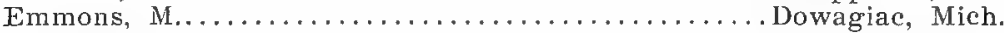

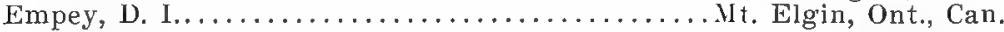

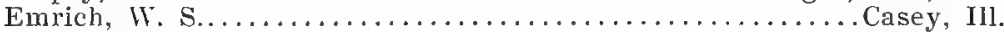

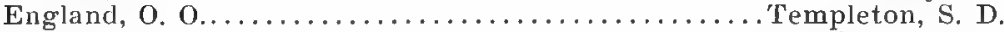

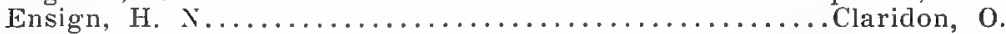

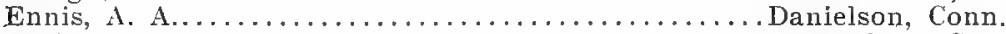

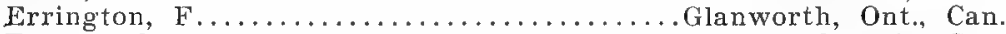

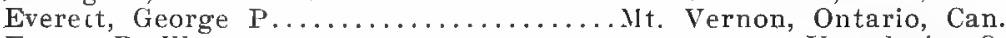

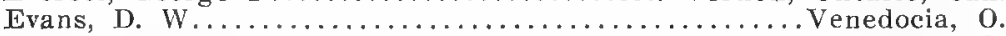

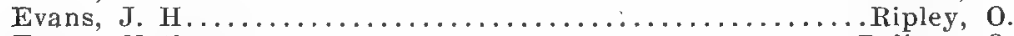

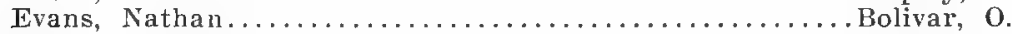

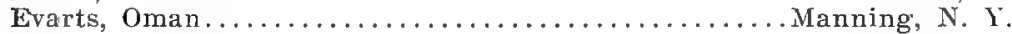

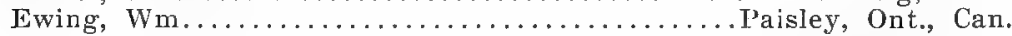

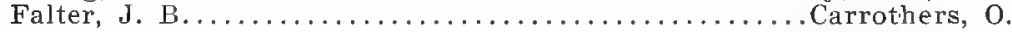

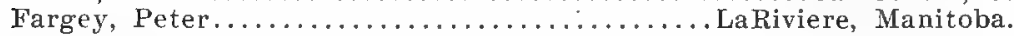

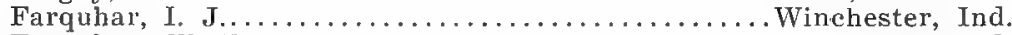

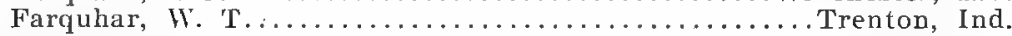

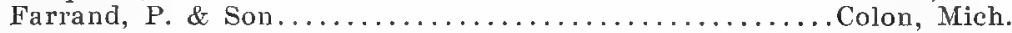

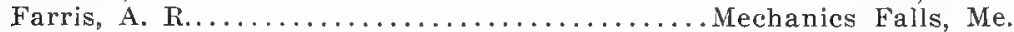

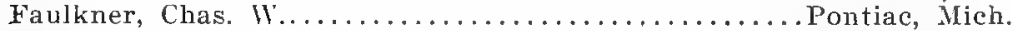

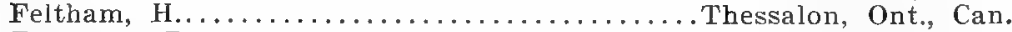

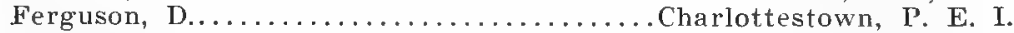

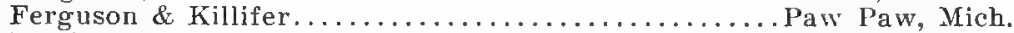

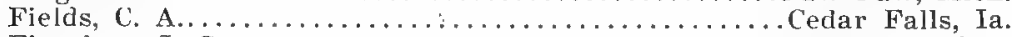

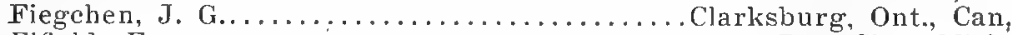

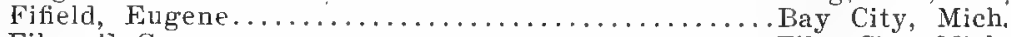

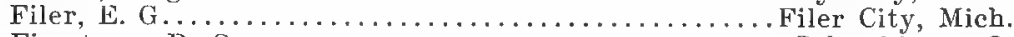

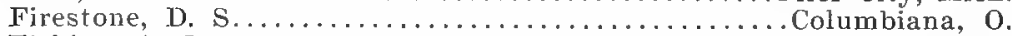

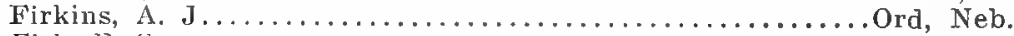

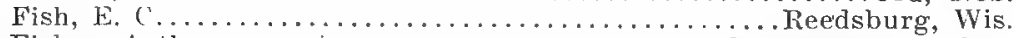

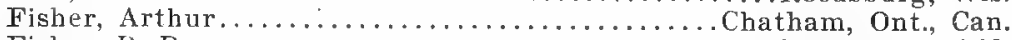

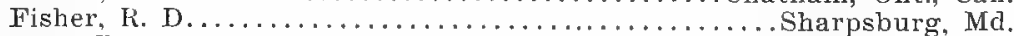

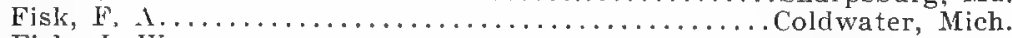

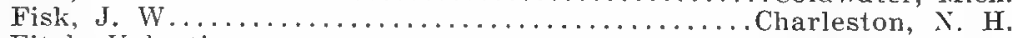

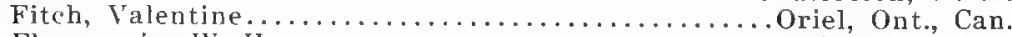

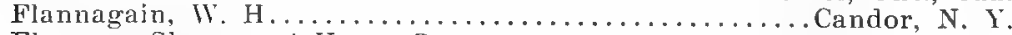

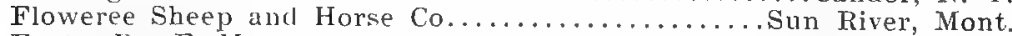

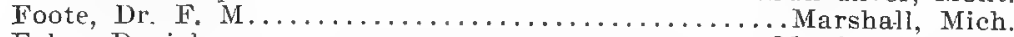

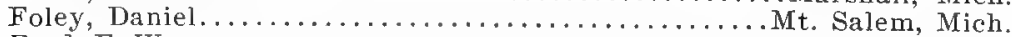

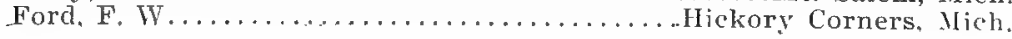


Ford \& Stratton.

Hickory Corners, Mich

Forester, Edward. . Gormley, Ont., Can.

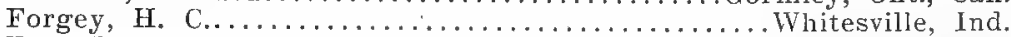

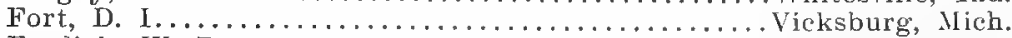

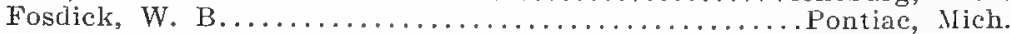

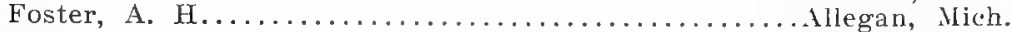
Foster, J. E. \& Son....................... Prairie.Home, Ill.

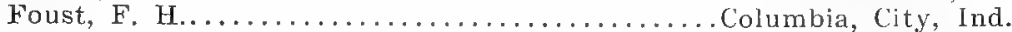
Fowler, H. A. Heart Prairie, Wis. Fowler, John. Warsaw, O. Fox, A. O Oregon, Wis. Fox, J. A.

Fox, Philip. Raymilton, Pa.

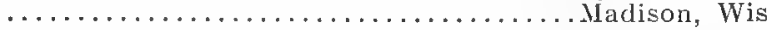

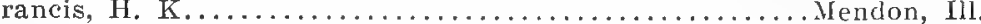

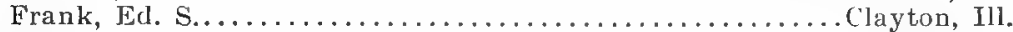

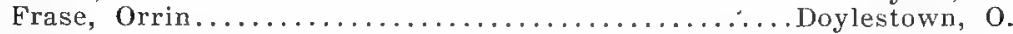

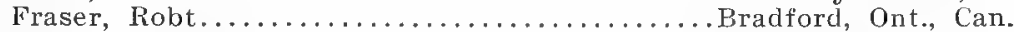

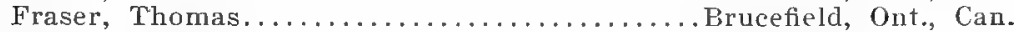

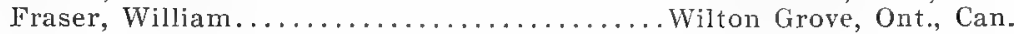

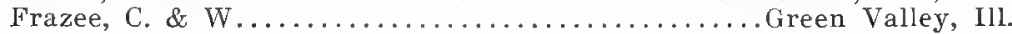

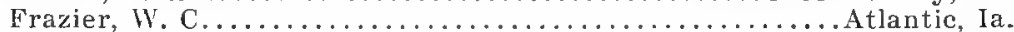

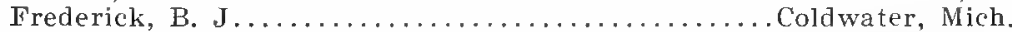

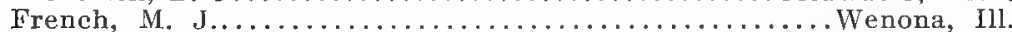

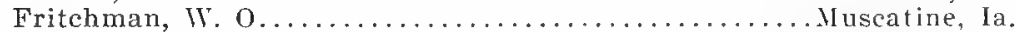

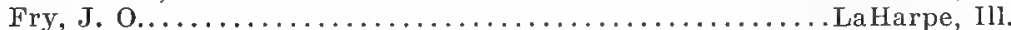

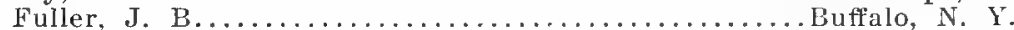

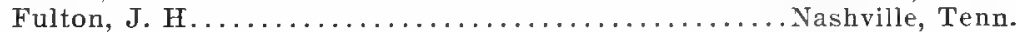

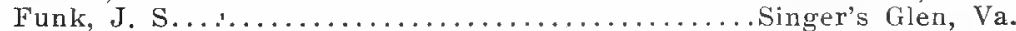

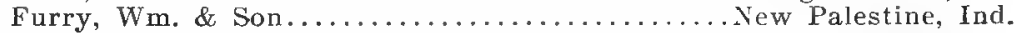

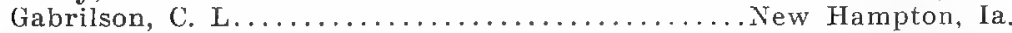

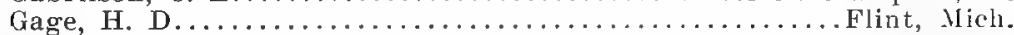

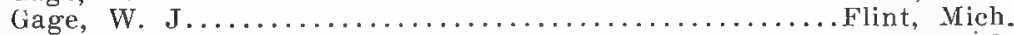

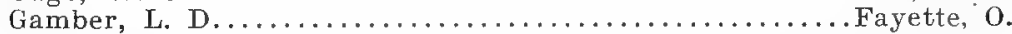

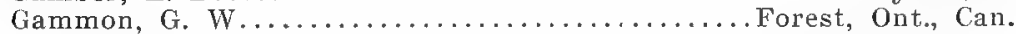

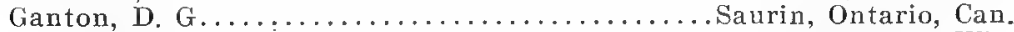

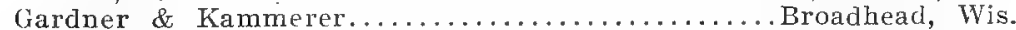

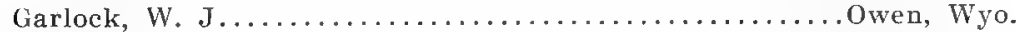

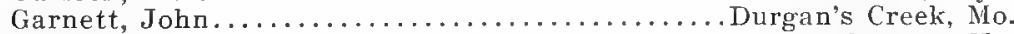

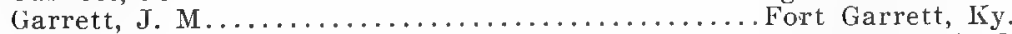

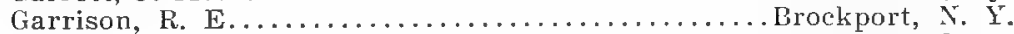

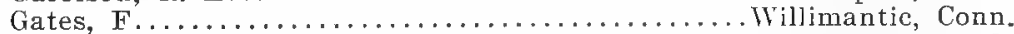

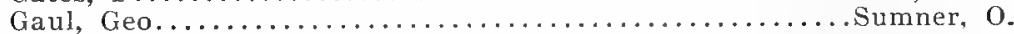

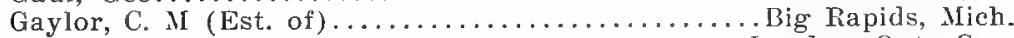

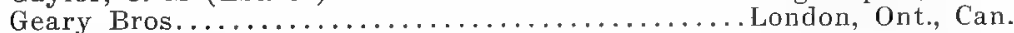

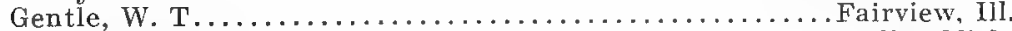

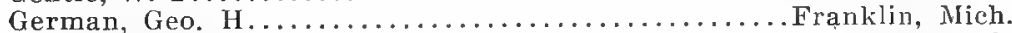

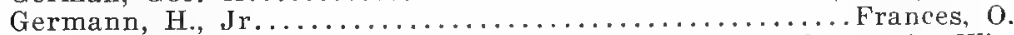

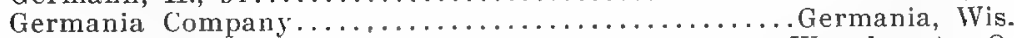

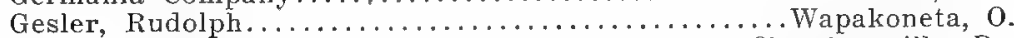

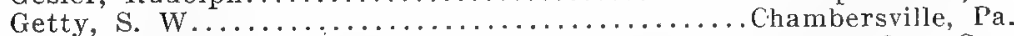

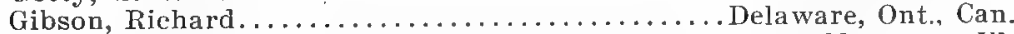

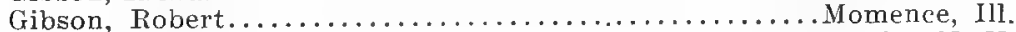

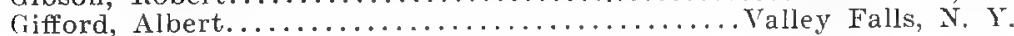




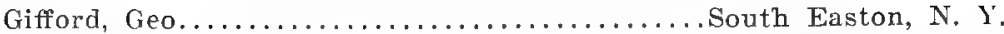

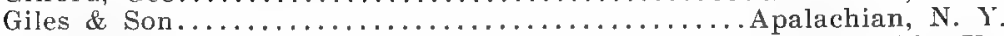

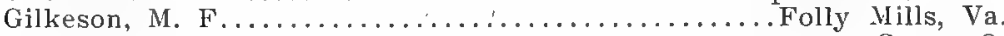

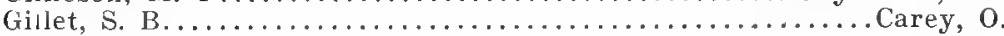

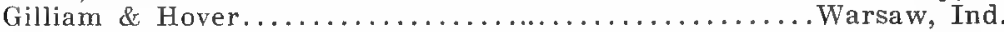

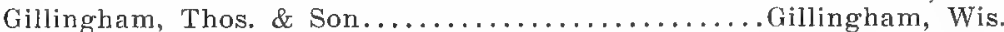

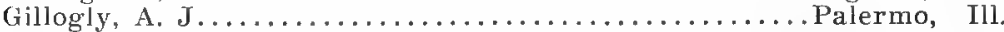

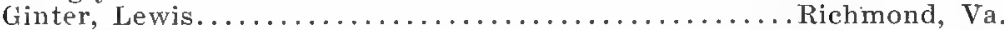

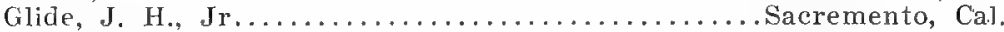

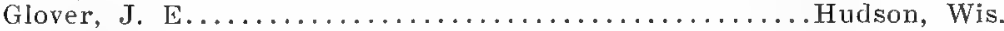

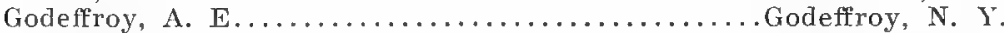

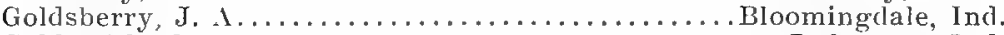

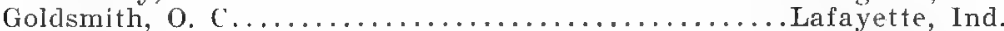
Gonyeau, F. F......................West Milton, Vt.

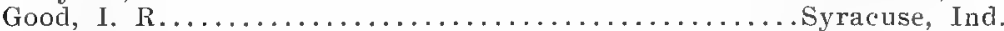

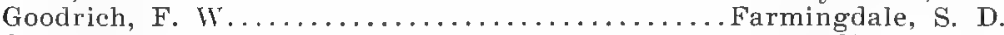

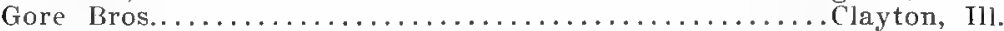

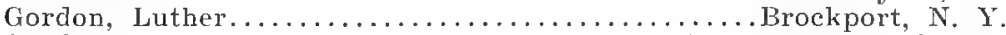

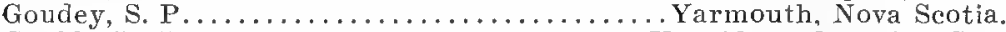

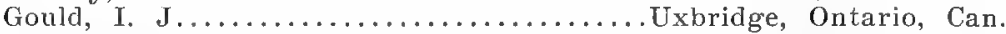

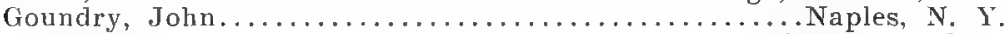

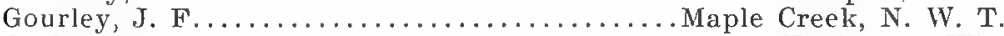

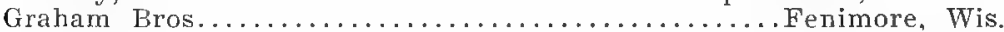

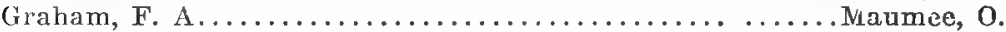
Graham \& Williamson.....................West Milgrove, 0.

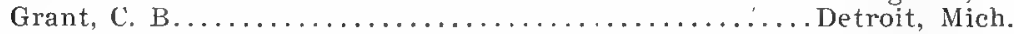

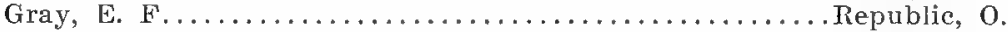

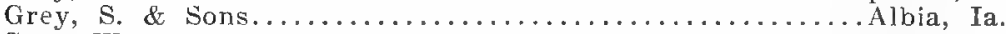

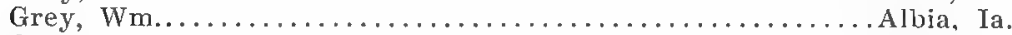

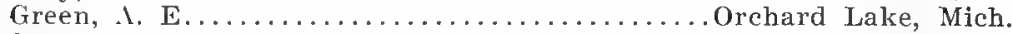

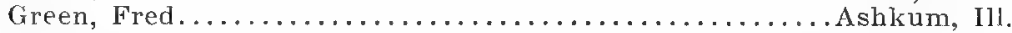

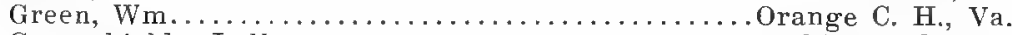

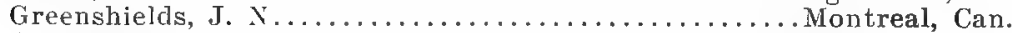

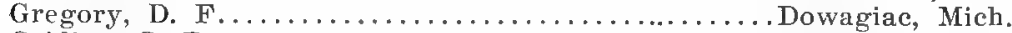

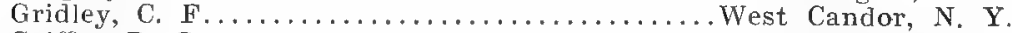

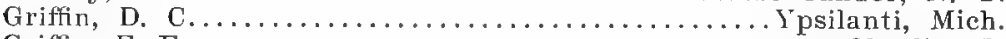

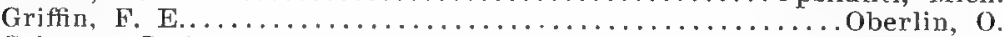

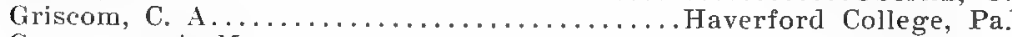

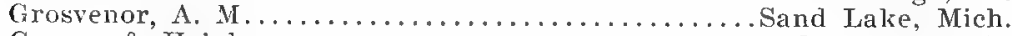

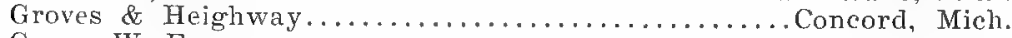

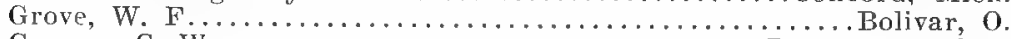

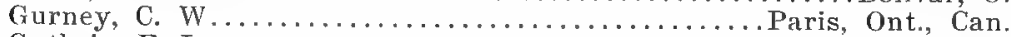

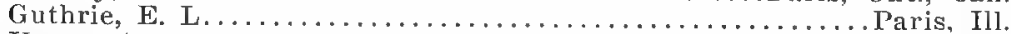

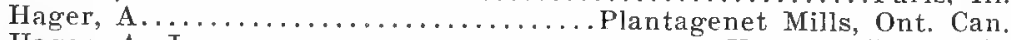

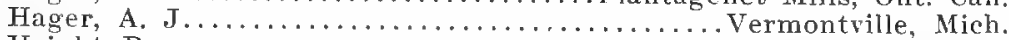

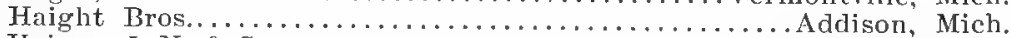

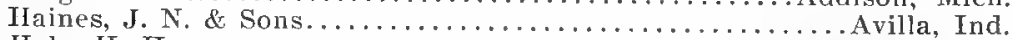

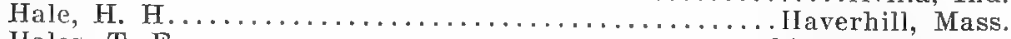

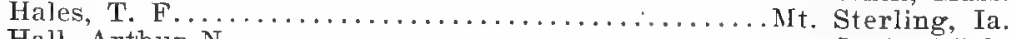

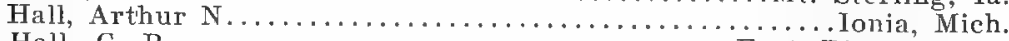

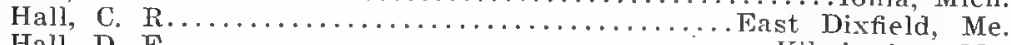

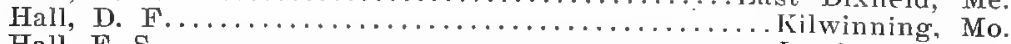

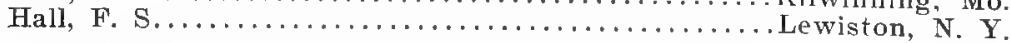


Hall, H. H

Hall, Thomas B

Fredonia, X. Y.

Hallenbeck, D. H

Sacremento, Cal.

Hamlin, Chester $\mathbf{P}$

Seward, N. Y.

Hamilton, H. A. S.

Temple, Me.

Hammond, G. H., Jr

Staunton, Va.

Hamrich, J. R. M.

Detroit, Mich.

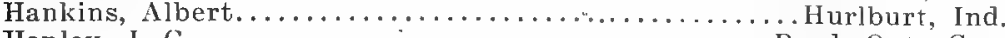

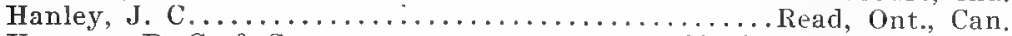

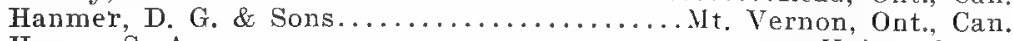

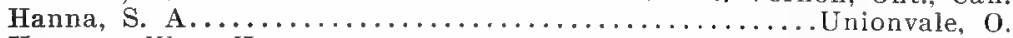

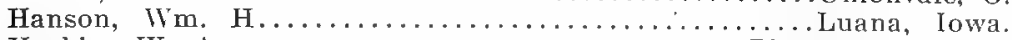

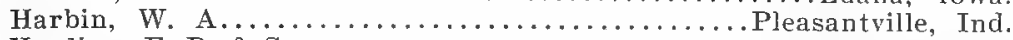

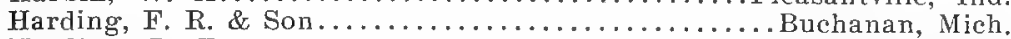

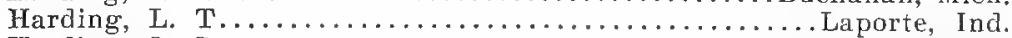

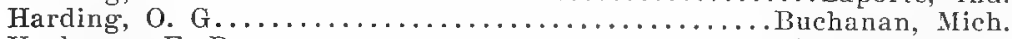

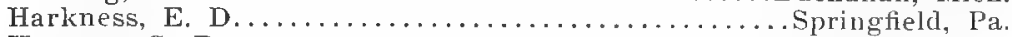

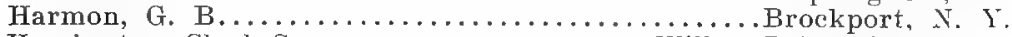

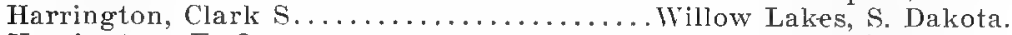

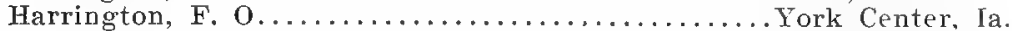

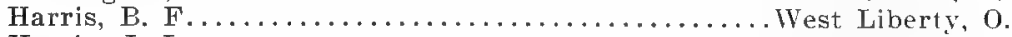

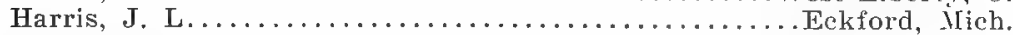

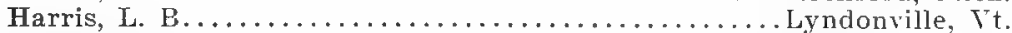

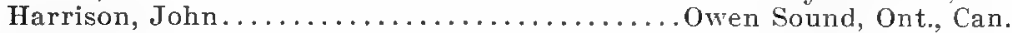

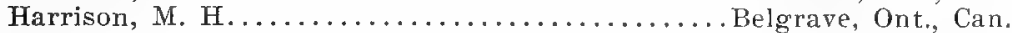

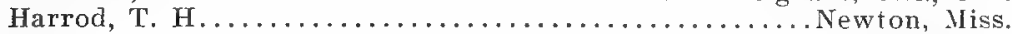

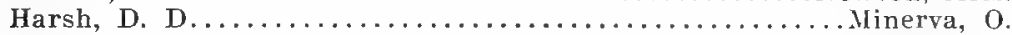

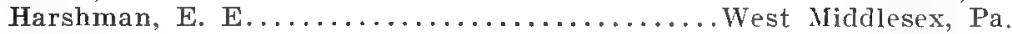

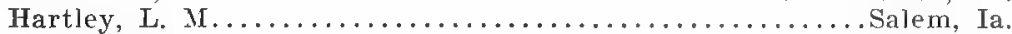

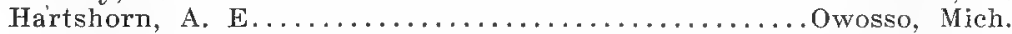

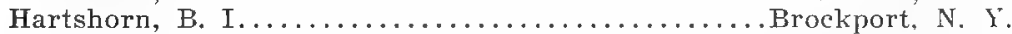

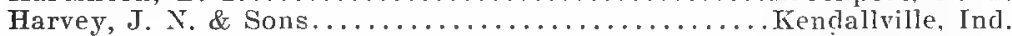

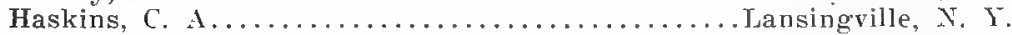

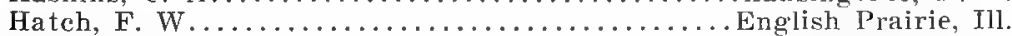

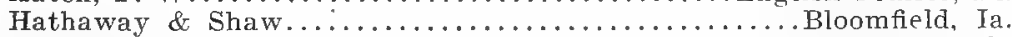

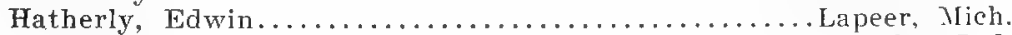

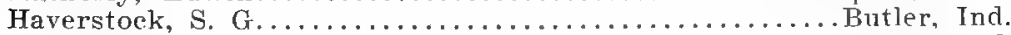

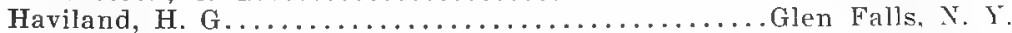

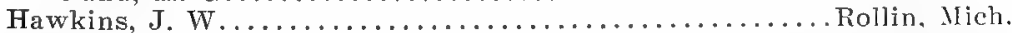

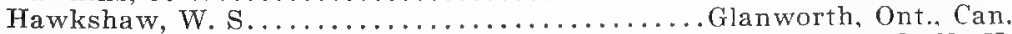

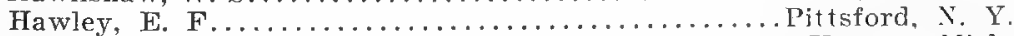

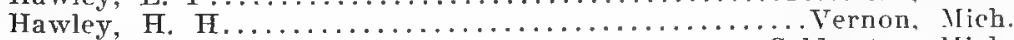

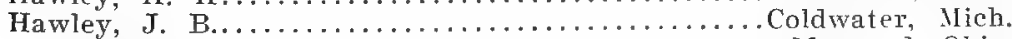

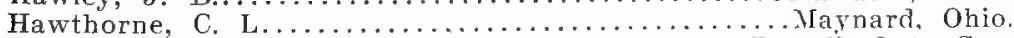

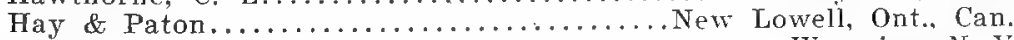

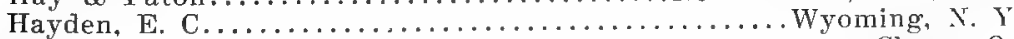

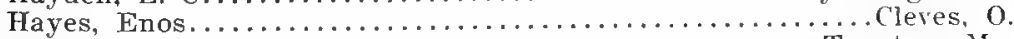

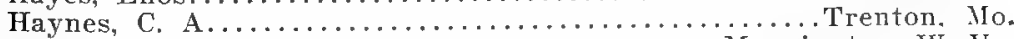

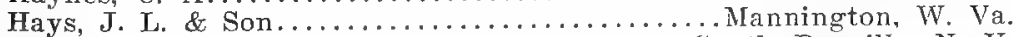

Healey, $W . W \ldots \ldots \ldots \ldots \ldots \ldots \ldots \ldots \ldots \ldots \ldots$. . . . . . . . . . .

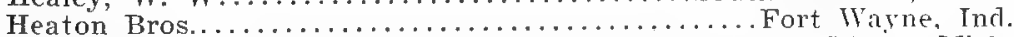

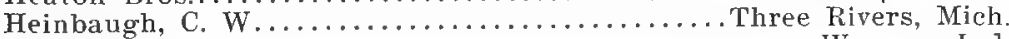

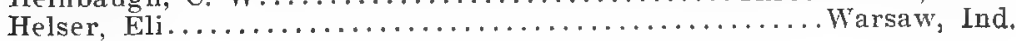




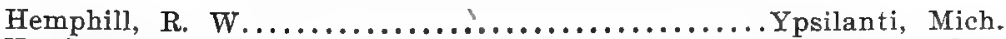

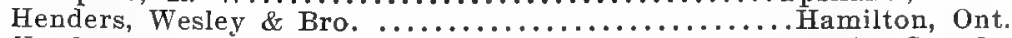

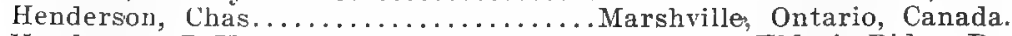

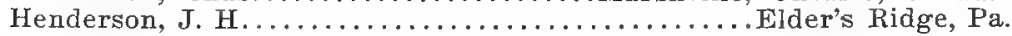

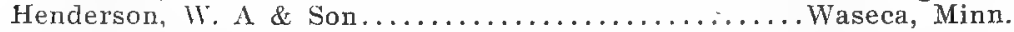

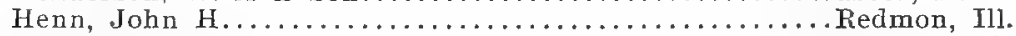

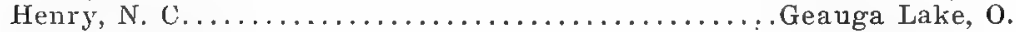

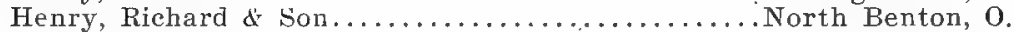

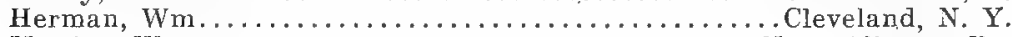

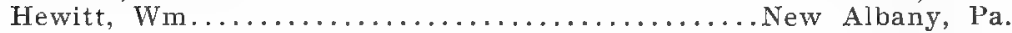

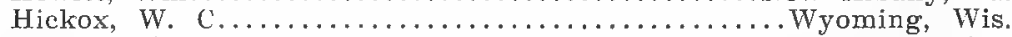

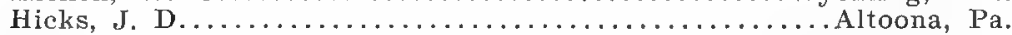

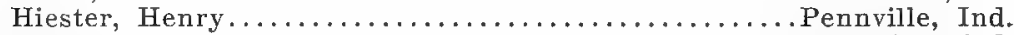

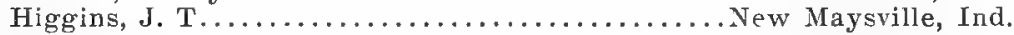

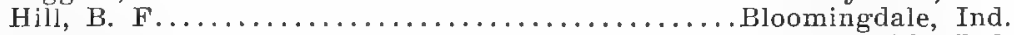

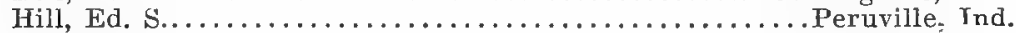

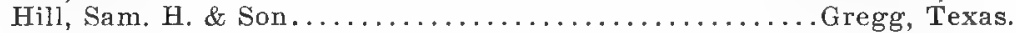

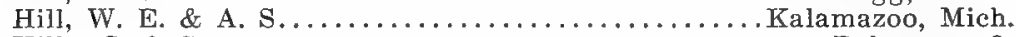

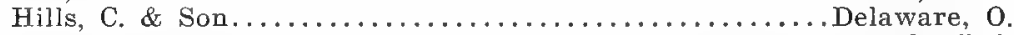

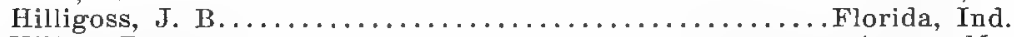

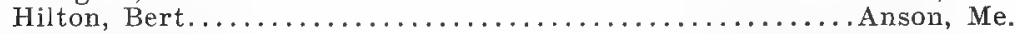

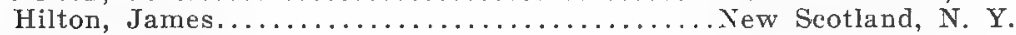

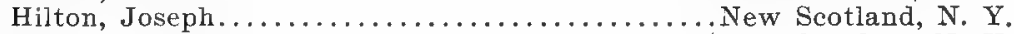

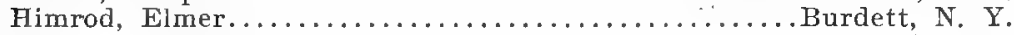

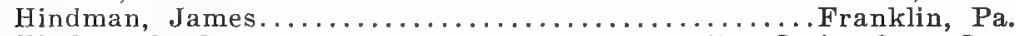

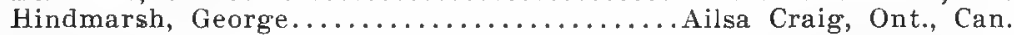

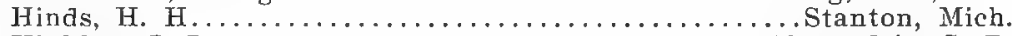

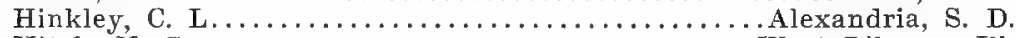

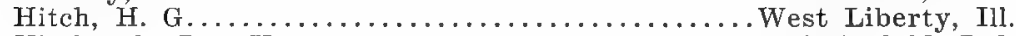

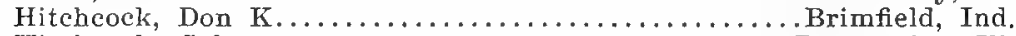

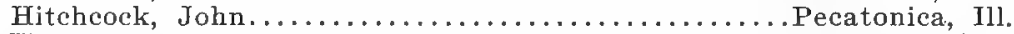

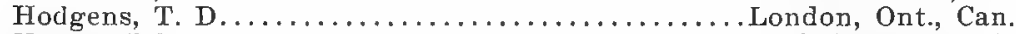

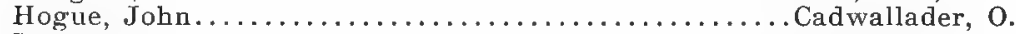

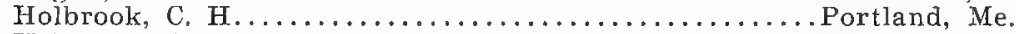

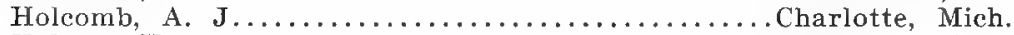

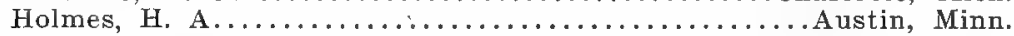

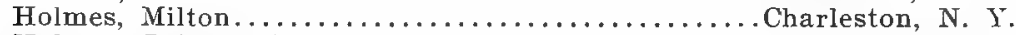

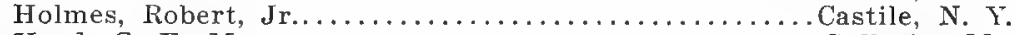

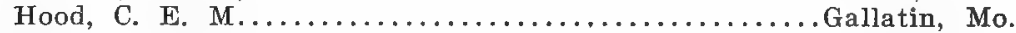

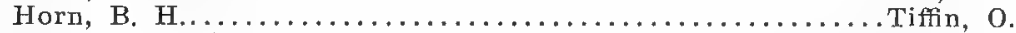

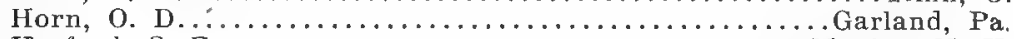

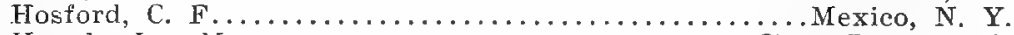

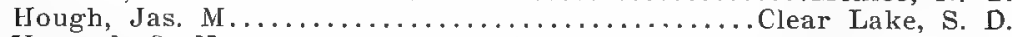

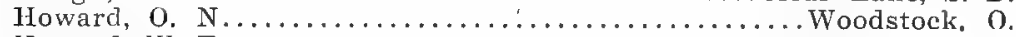

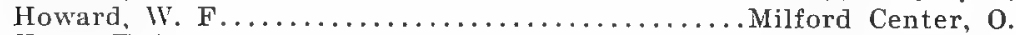

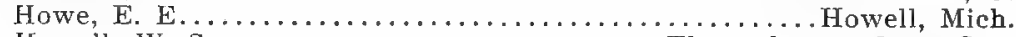

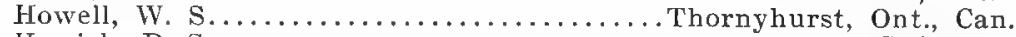

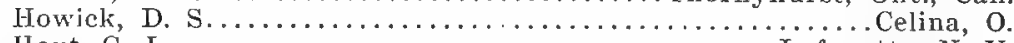

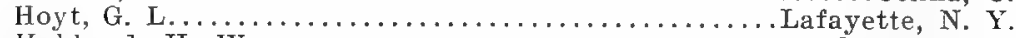

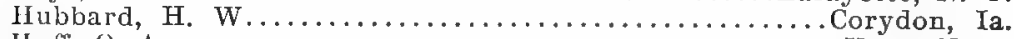

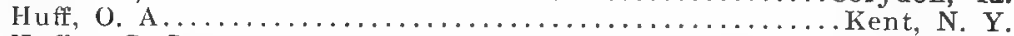

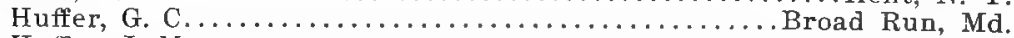

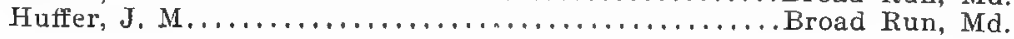




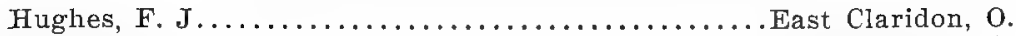

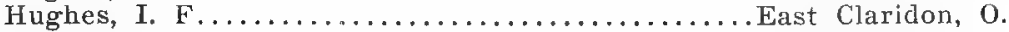

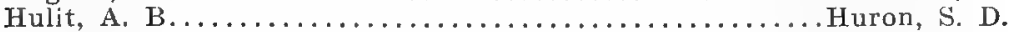

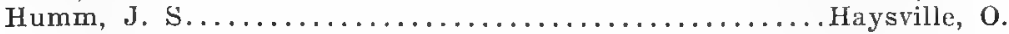

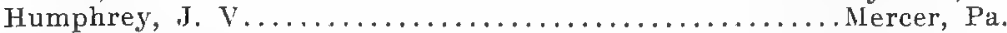

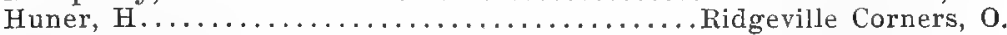

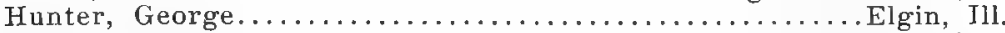

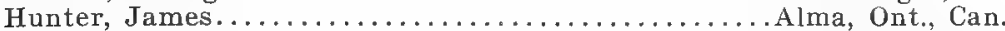

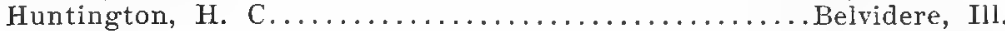

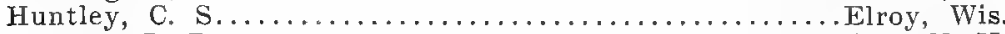

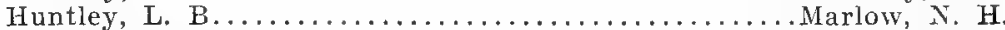

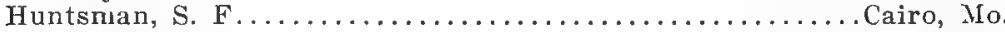

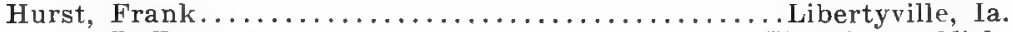

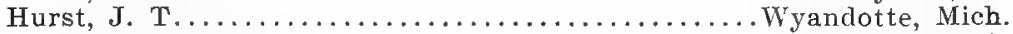

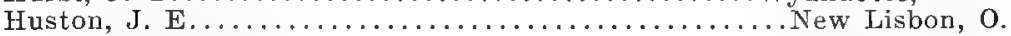

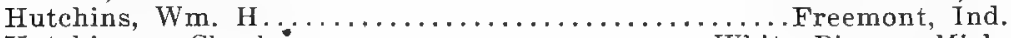
Hutchinson, Charles...................White Pigeon, Mich.

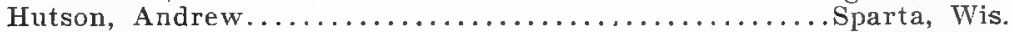

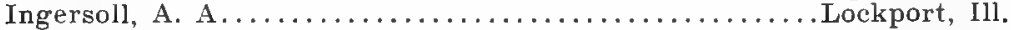

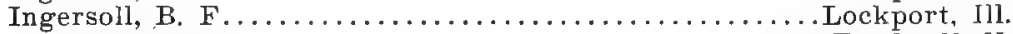

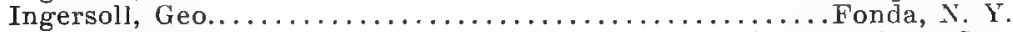

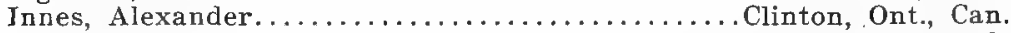

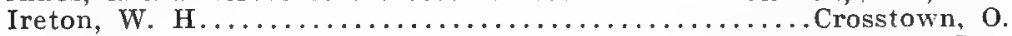

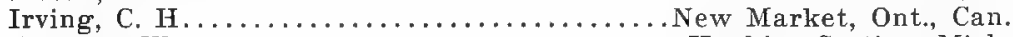

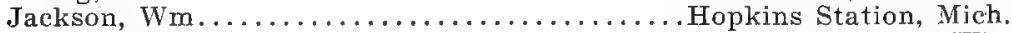

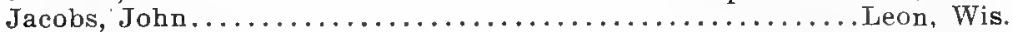

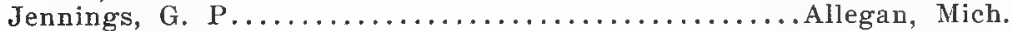

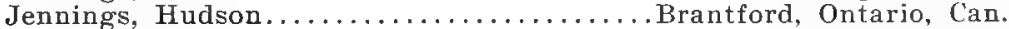

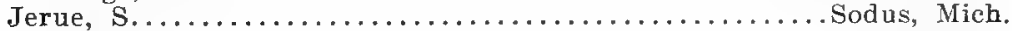

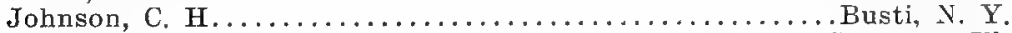

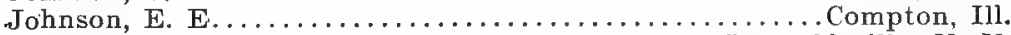

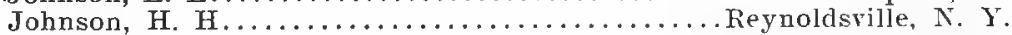

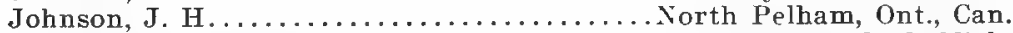

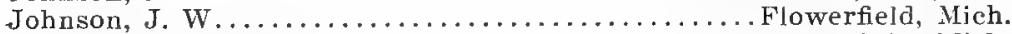

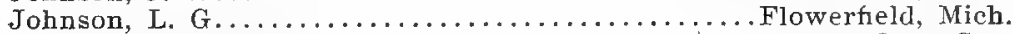

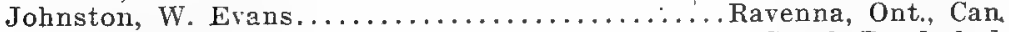

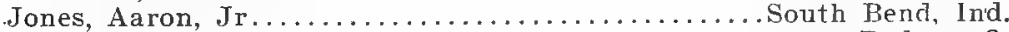

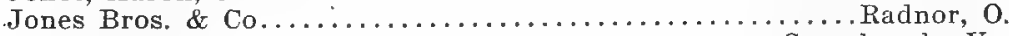

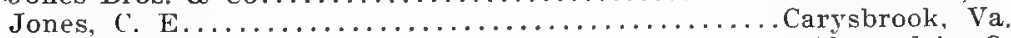

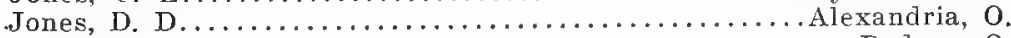

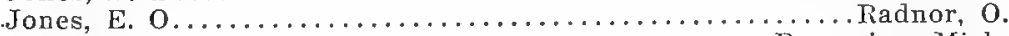

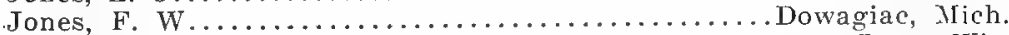

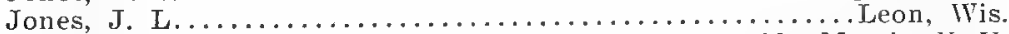

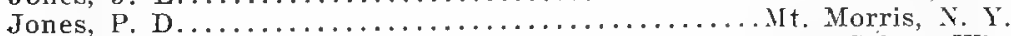

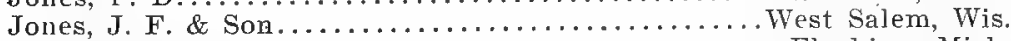

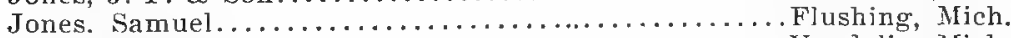

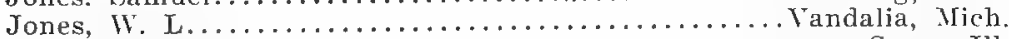

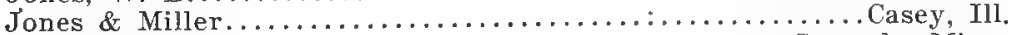

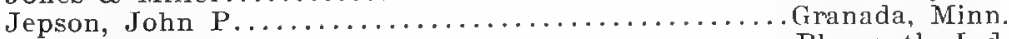

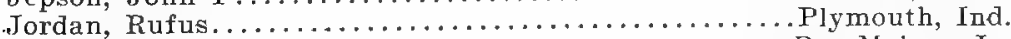

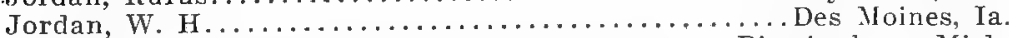

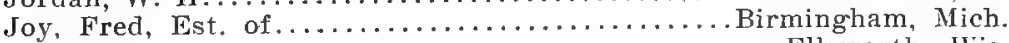

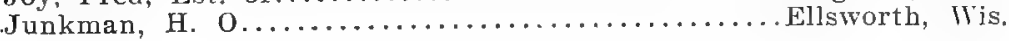


Kane, Alfred.

Goshen, Ind.

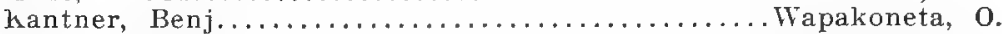

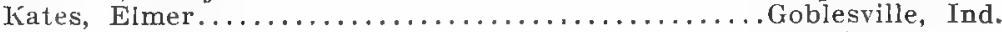

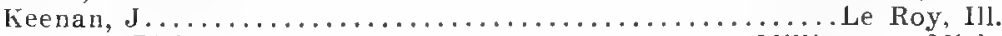

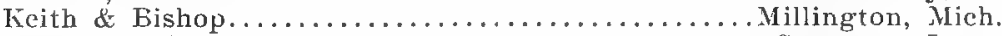

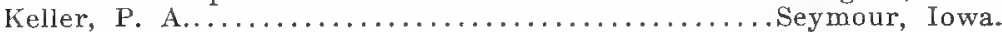

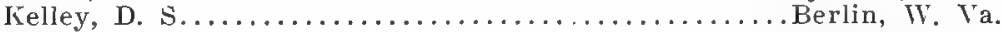

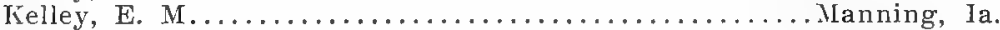

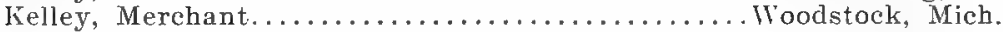

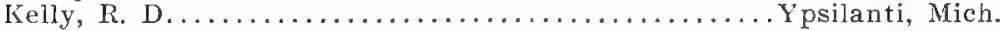

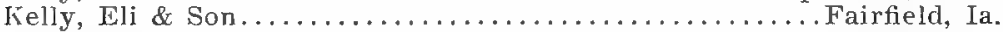

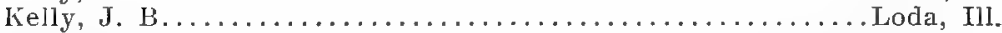

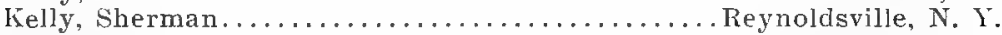

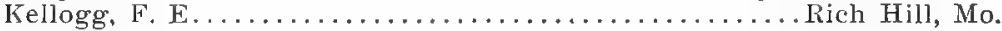

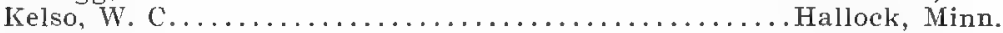

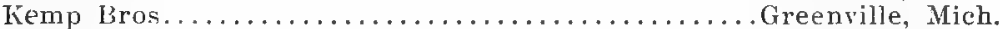

Kempley, J. H. \& C. H....................Packwaukee, Wis.

Kendrick, J. K........................... Denver, Col.

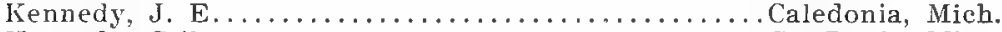

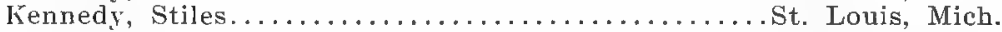

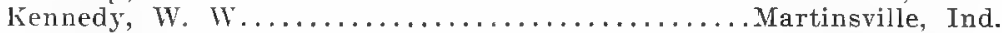

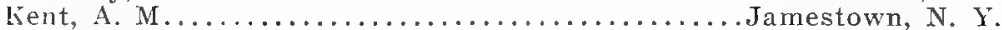

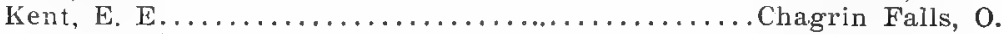

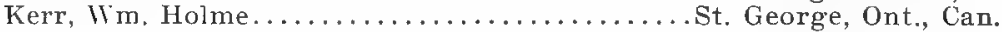

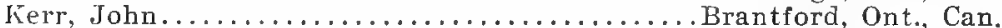

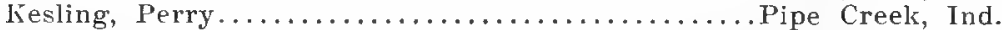

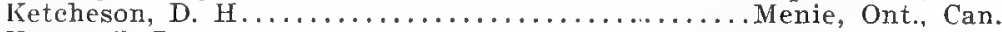

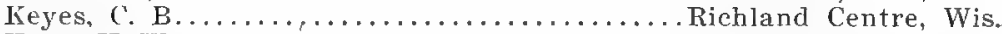

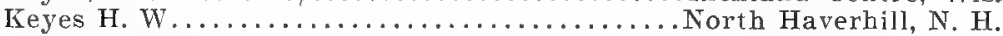

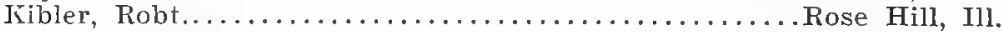

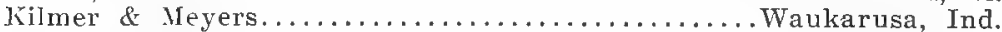

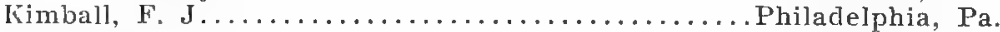

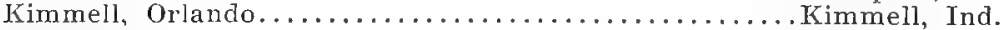

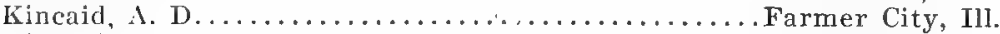

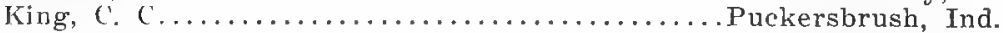

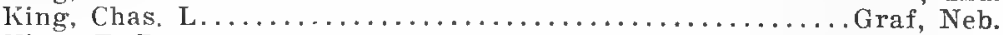

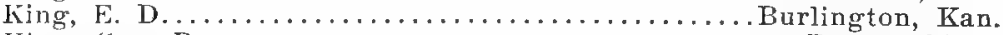

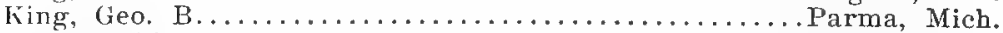

King, T. H....................... Trumansburgh, N. Y.

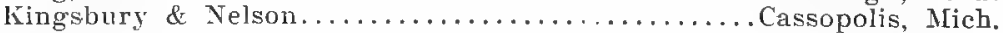

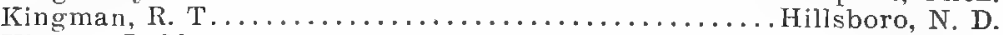

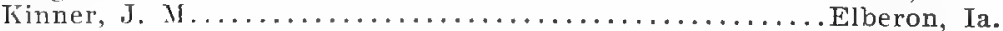

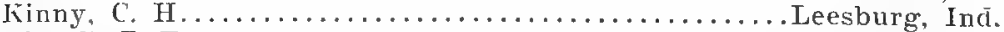

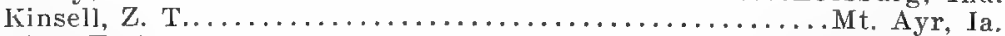

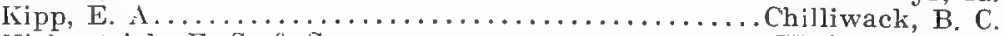

Kirkpatrick, E. S. \& Son...................Wellsville, Kan.

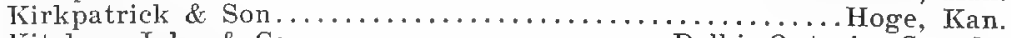

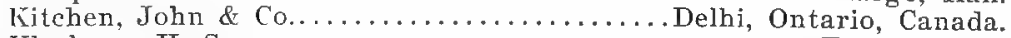

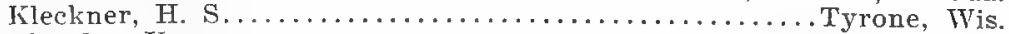

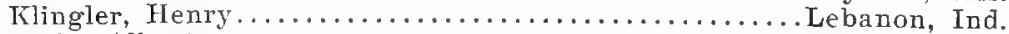

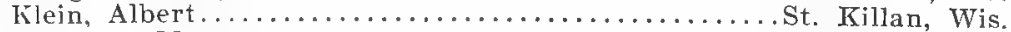

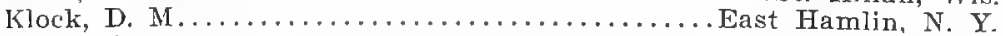

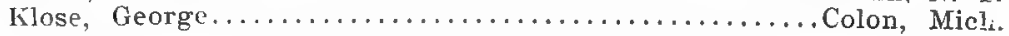


Kneeland, Barney.

Knox, J. K.

St. Johns, Wich.

Koogle, O

Palmer, Mass.

.................... Ohio City, o.

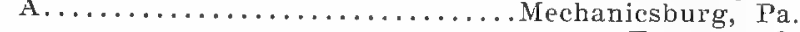

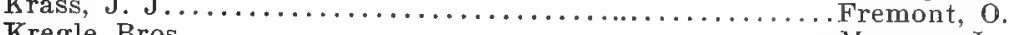

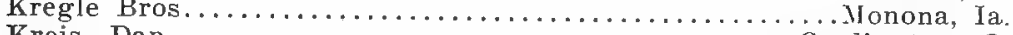

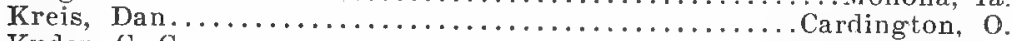

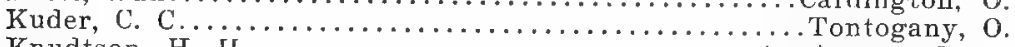

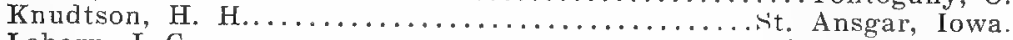

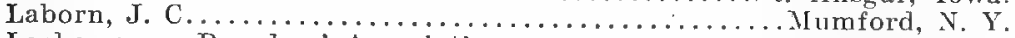

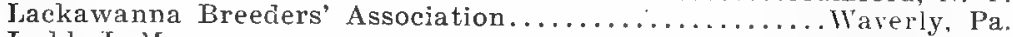

Ladd, J. M.

Ladew, E. R .

LaGrange, C. C.

Lamb, T. R. .

Lambkin, F. E. \& C

Iampman, J. C

Lander, John.

Landman, Paul.

Lanehart, Albert.

Lantz, J, F.

Isaraway, $\mathrm{H}$

Larrabee, Chas., Jr.

Lasher, G. V. \& Sons.

Late, W. H. .

Latham, F. H

Lathrop, G. W

Latson, E. E.

Latta, Prof. W. C.

Law, T. A.

Iawrence, Chas.

Lawrence, Chas.

Jawrence, H. H

I.awrence, Jas.

Jawrence \& Crosby.

Lay, Jacob.

Laylin, T. C

Leach, John

Lean, John.

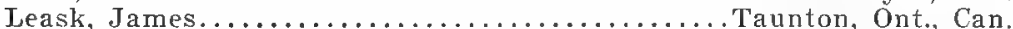

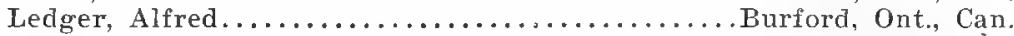

Lee, O. W.

Leland, E. E.

Lemen, Clare.

Leonard, H. J

Leonard, Mrs. S. A

Leonard, S. F.

Lesh, D. W.

Juessiter, John.

Levens, C. W

Levering, Richmond M.

Jevering, Mortimer...

Lewis, B. R.
Gilen Cove, L. I.

. Slingerland, N. Y.

Carlos City, Ind. Lowell, Mich. Hastings, Mich. Taunton, Ont., Can. Scotland, S. D. ..Butler, 0. Altoona, Pa. . Emery, Mich. Windham, Conn. Rutland, $\mathrm{O}$. Bridgeport, W. Va. ........ Corwith, Ia. Oxford Junction, Ia. W...... Howell, Mich. West LaFayette, Ind. Astor, W. I'a. Collingwood, Ont., Can. Danville, Wis. Columbia City, Ind. Groton, Mass. Barrington, N. Y. . Wayne, Wis. Norwalk, 0 . Burlington, Wis. Palmyra, Wis. Painesville, $O$. .Emery, Mich. .Hamburg, Mich. .......Peloit, Wis. ........Roann, Ind. . Washington, Minn. . Markle, Ind. . Cole, Mich. . LaFayette, Ind. LaFayette, Ind. . Salem Center. Ind. Albert Lea, Minn. 


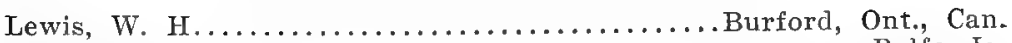

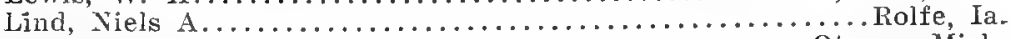

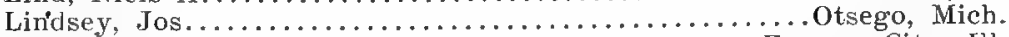

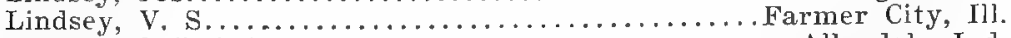

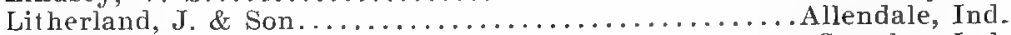

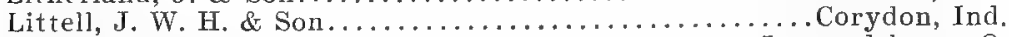

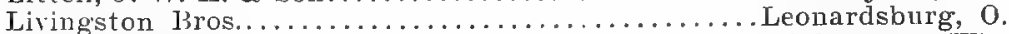

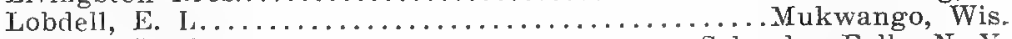

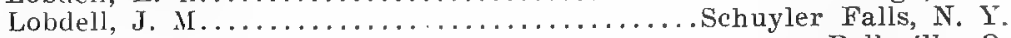

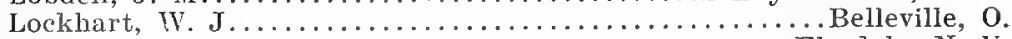

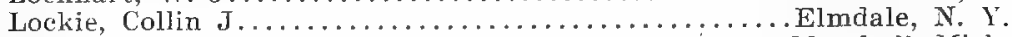

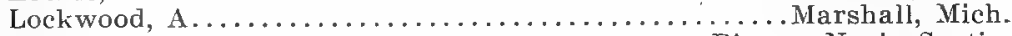

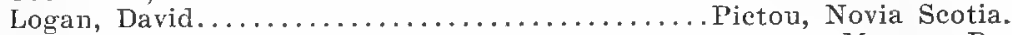

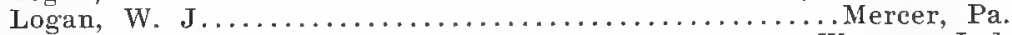

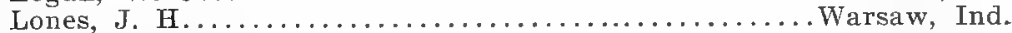

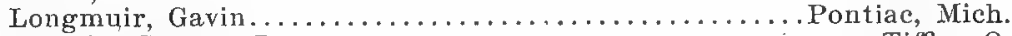

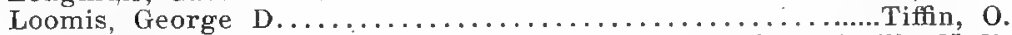

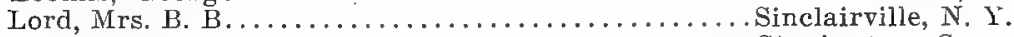

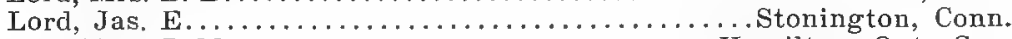

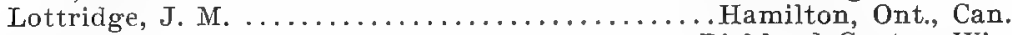

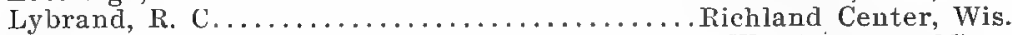

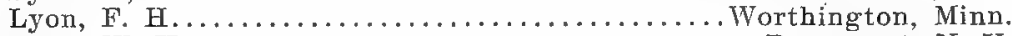

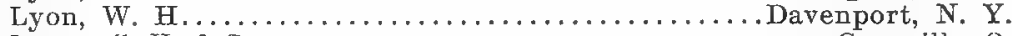

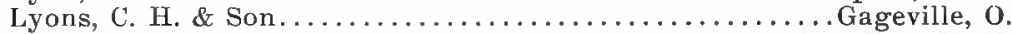

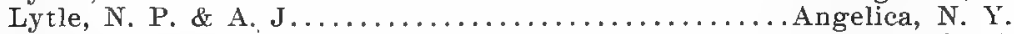
MacDermaid, J...................Kansas City, Mo. (Hon. Mem.)

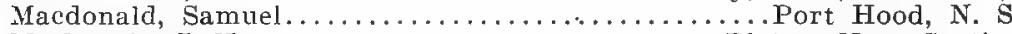

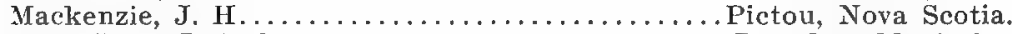

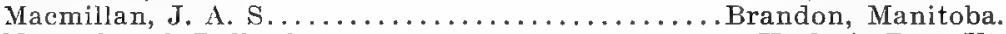

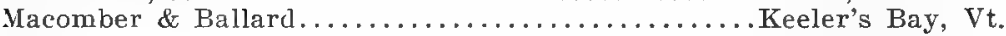

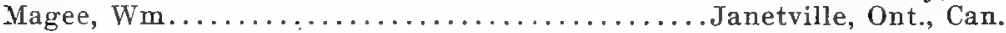

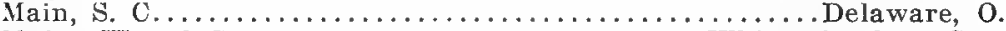
Major, Wm. \& Son...................Whitevale, Ont., Can.

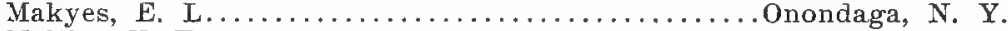

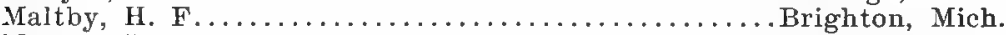

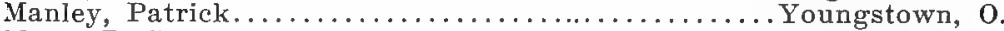

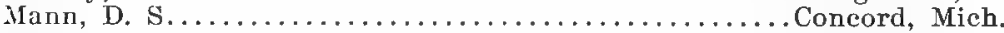

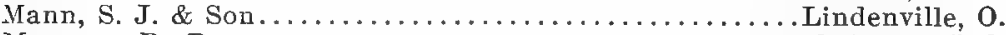

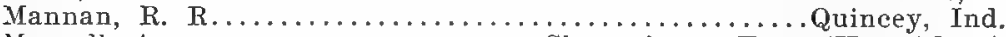

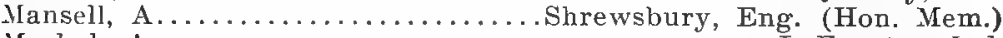

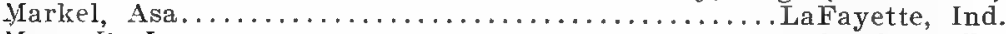

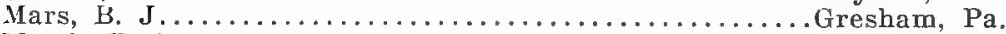

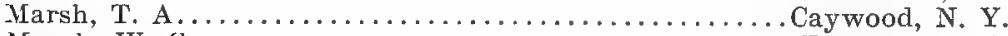

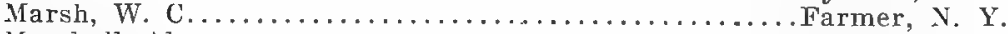

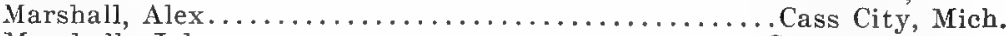

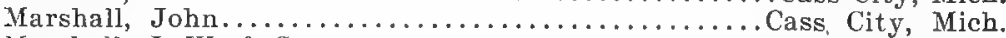

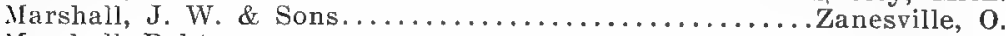

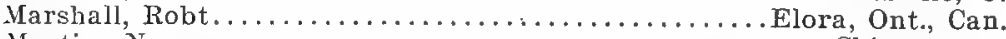

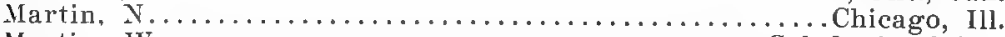

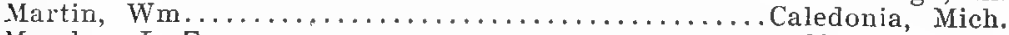

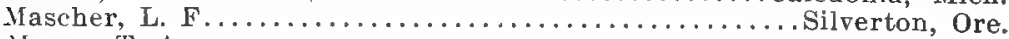

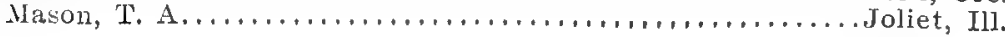


Mason, Mrs. W. B. Marshall, Mich.

Mathers, S. \& Sons Belleville, N. Y.

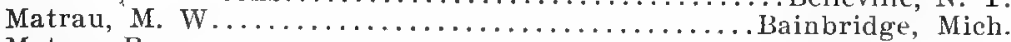

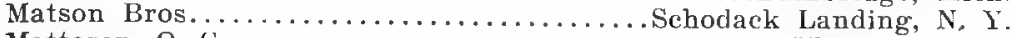

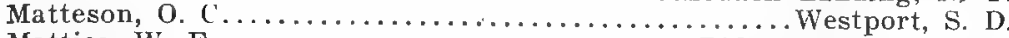

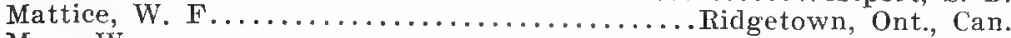

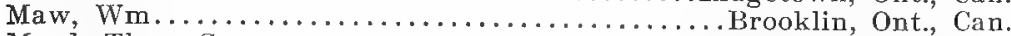

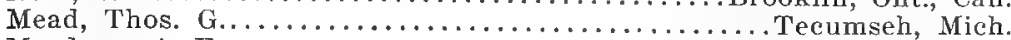
Meadows, A. E............................ Hope, Ont., Can.

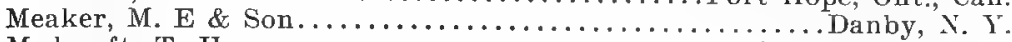

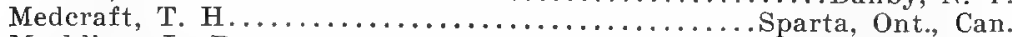

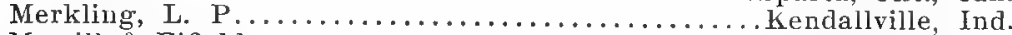

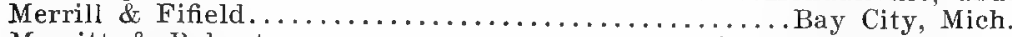

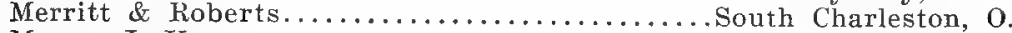

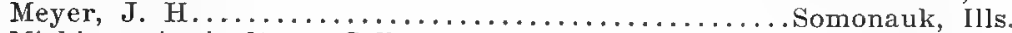

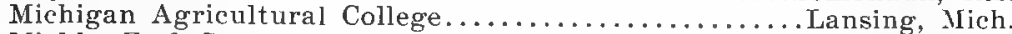

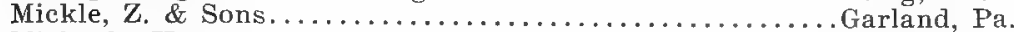

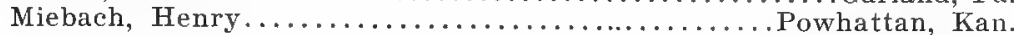

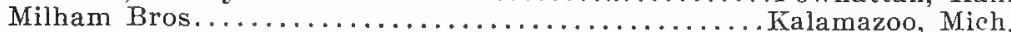

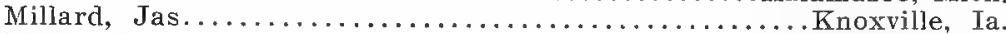

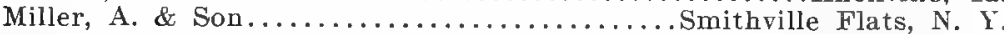

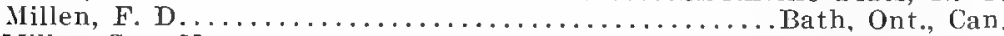

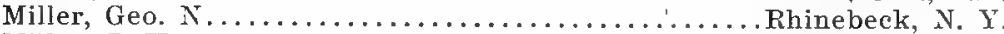

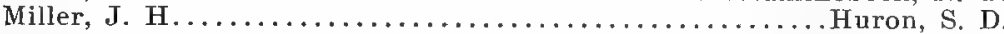

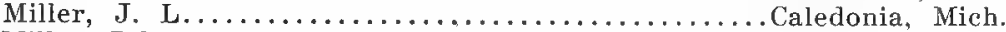

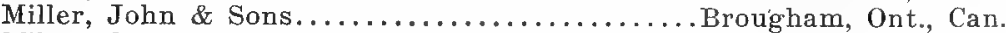

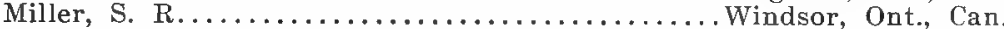

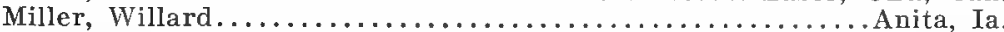

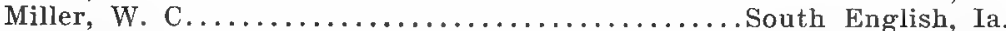

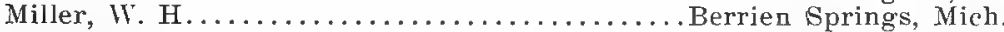

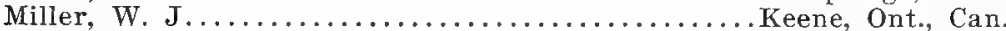

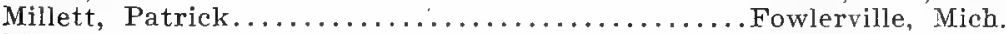

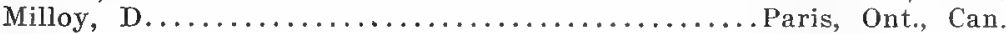

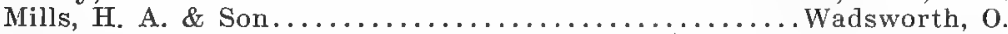

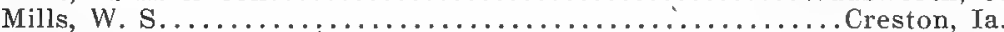

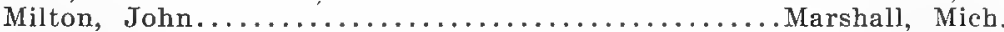

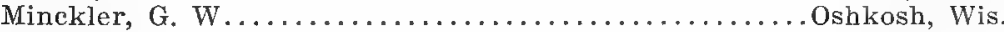
Mitchell, E B.............................. Danvers, Ill.

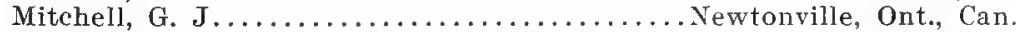

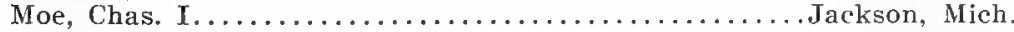

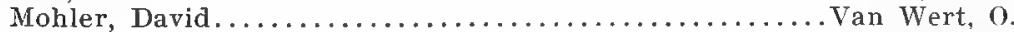

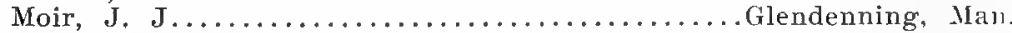

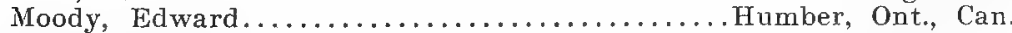

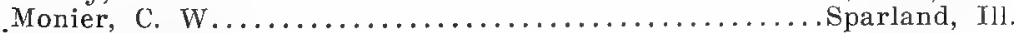

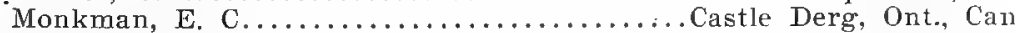

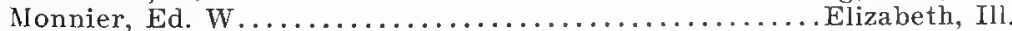

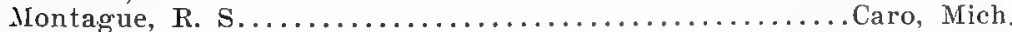

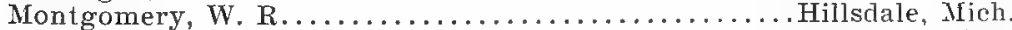

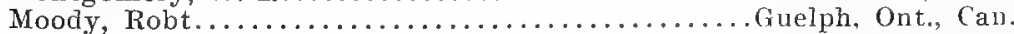

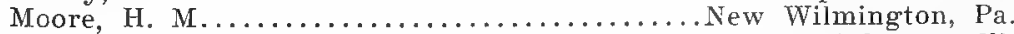

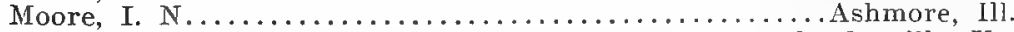

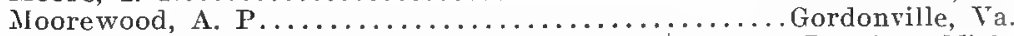

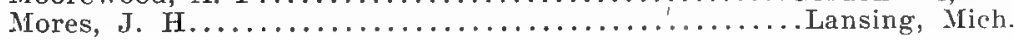




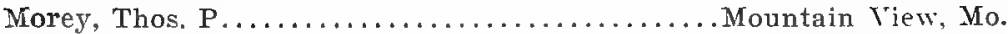

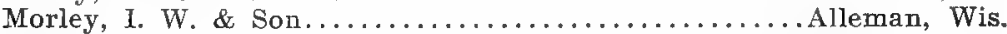

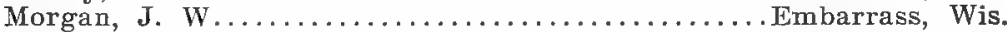

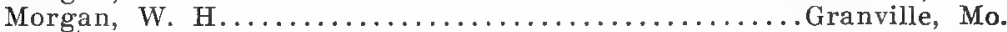

Morris, J. H. \& Son........................Warrenton, Ill.

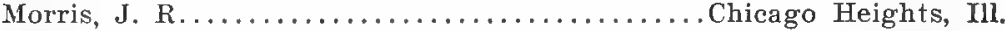

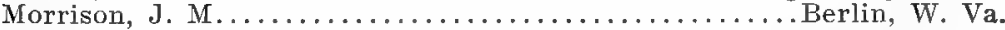

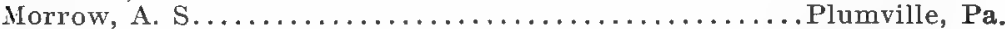

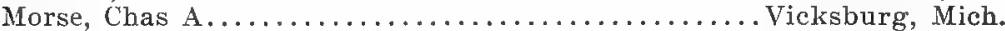

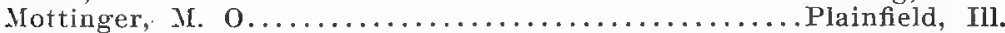

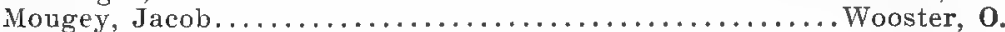

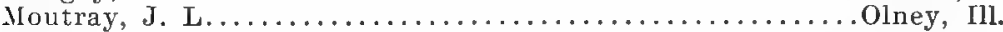

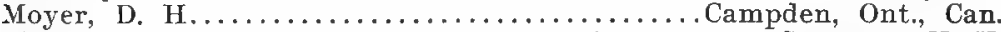

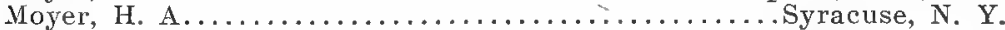

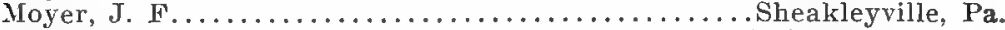

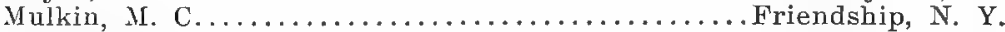

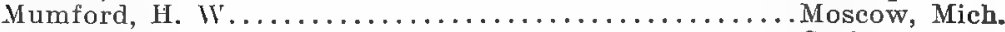

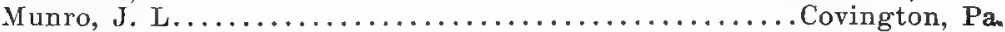

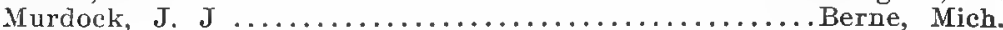

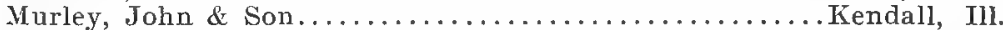

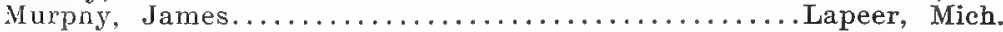

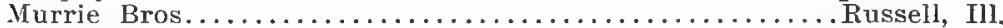

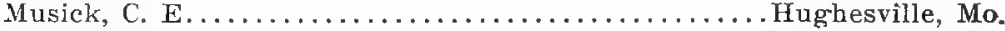

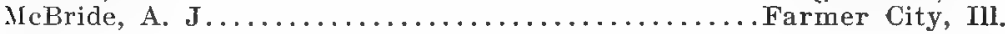

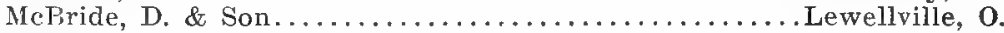

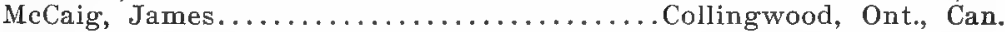

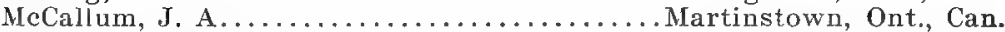

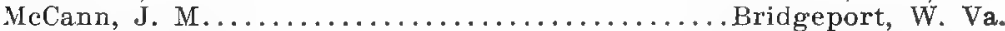

McCannell, Wm. A....................Washington: Vt.

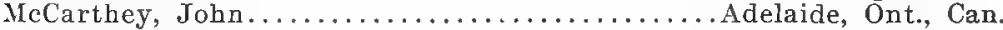

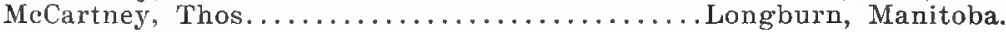

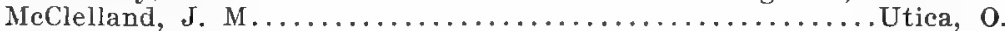

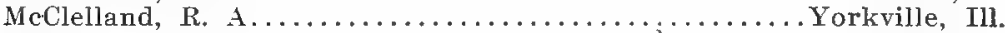

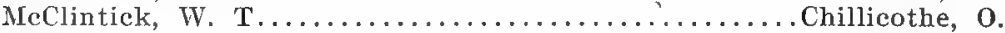

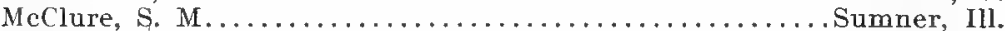

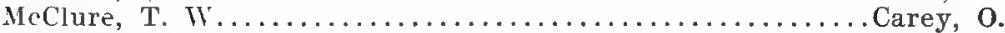

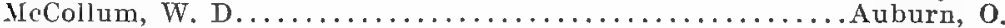

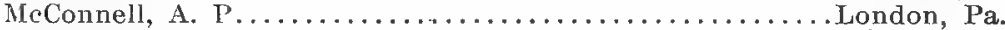

MeCormick, L. H. \& R. H............Chicago and Lake Forest, Ill.

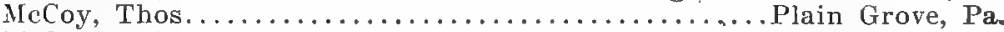

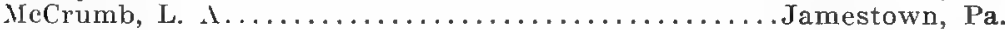

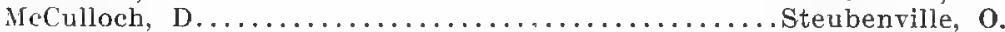

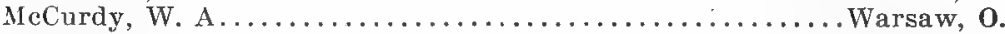

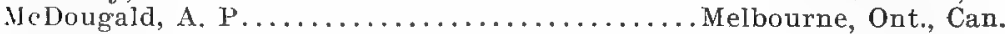

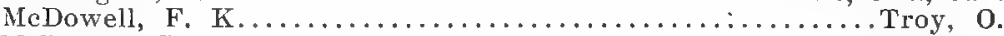

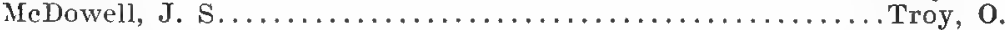

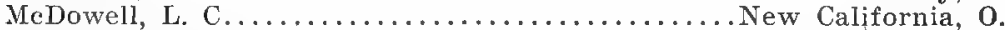

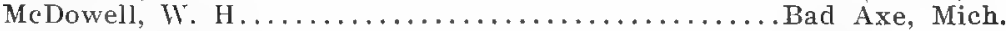

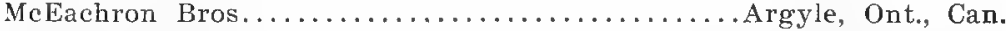

McEachron, R.......................Williamsburg, Ta.

MeEachron, W.......................Williamsburg, Ia.

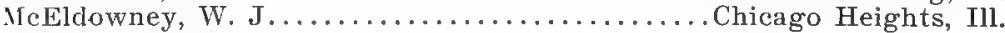

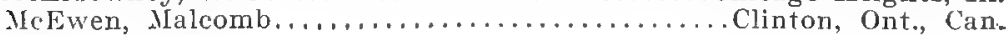




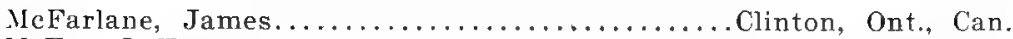

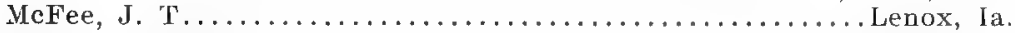

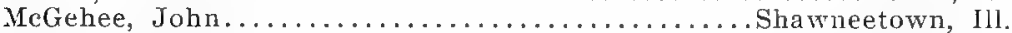
MeGinness, W. H........................Winterset, Ia.

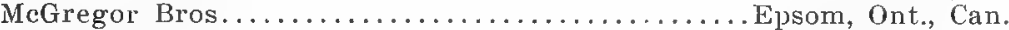

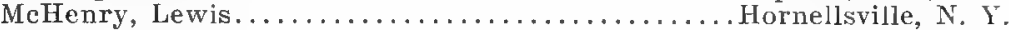

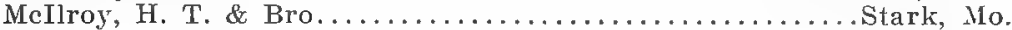

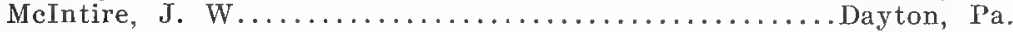
McIntosh, J. 1. \& Son..................Ravenswood, W. Va.

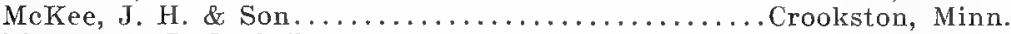

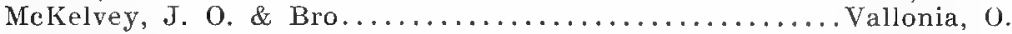

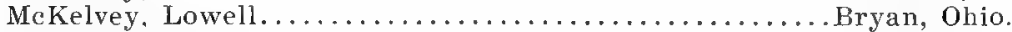

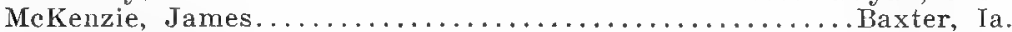

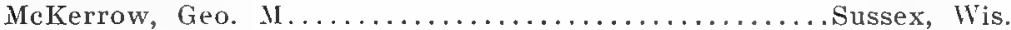

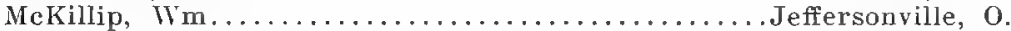

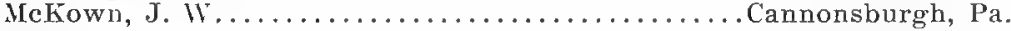

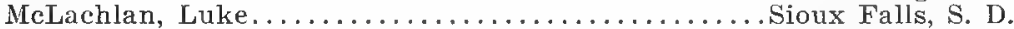

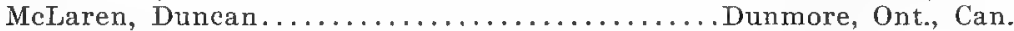

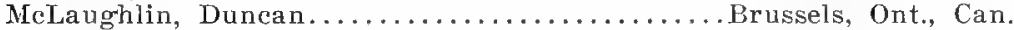

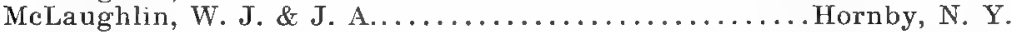

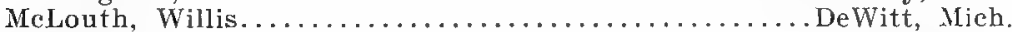

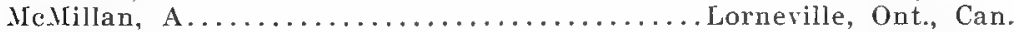

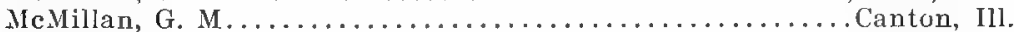

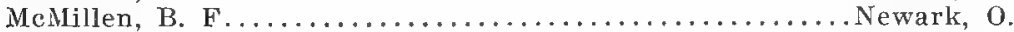

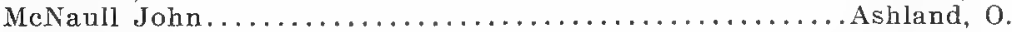

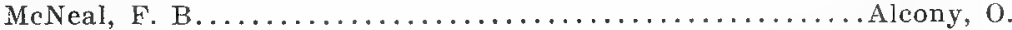

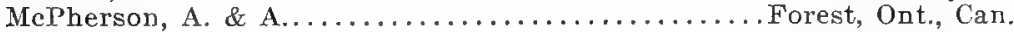

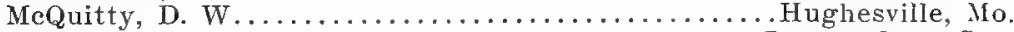

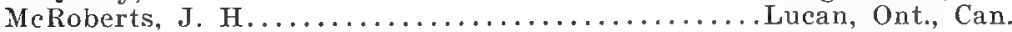

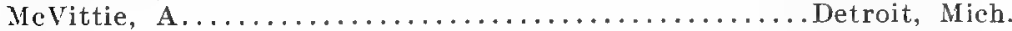

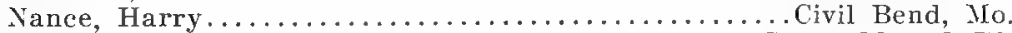

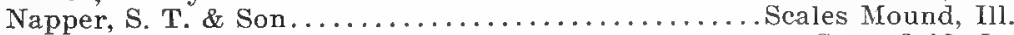

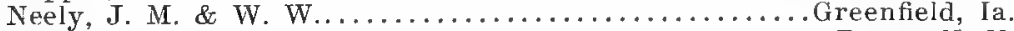

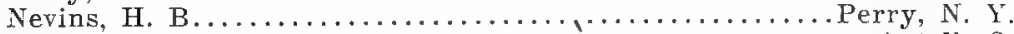

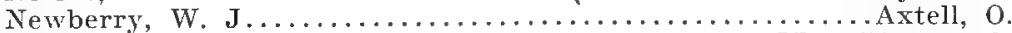
Tewell, John \& Sons.....................West Liberty, 0.

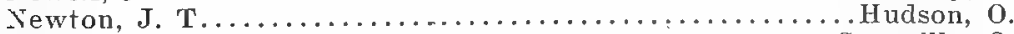

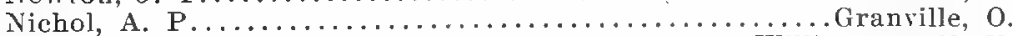
Nichols, G. M......................Williamson, $\mathrm{N} . \mathrm{Y}$.

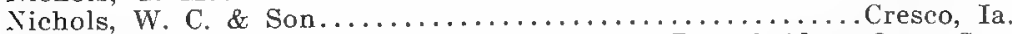

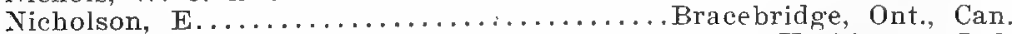

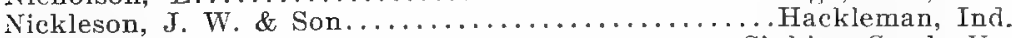

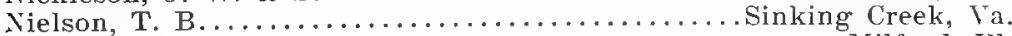

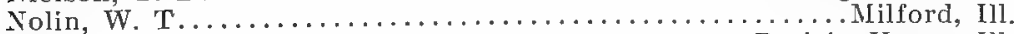

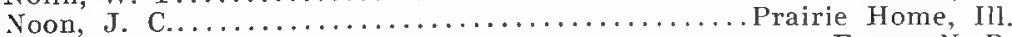

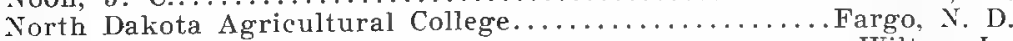

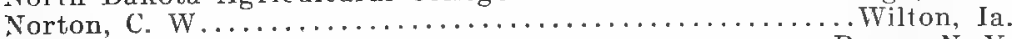

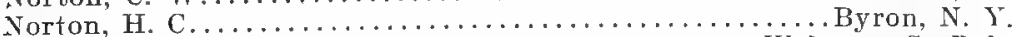

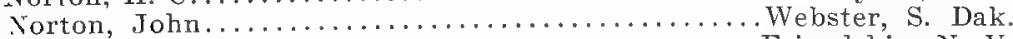

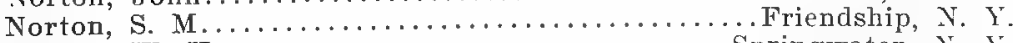

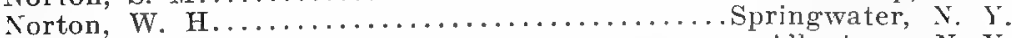

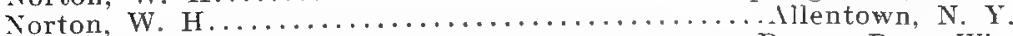

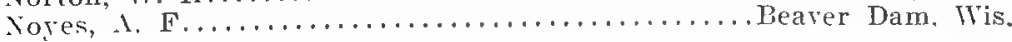




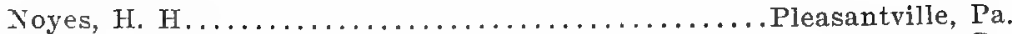

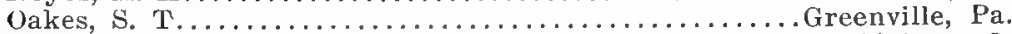

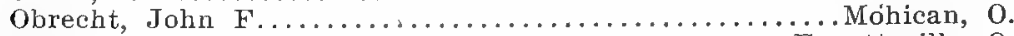

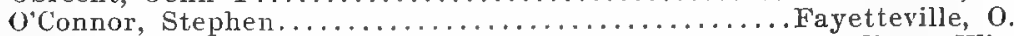

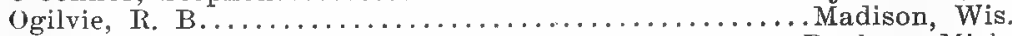

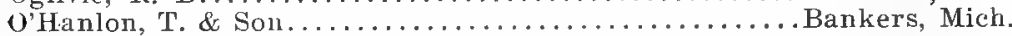

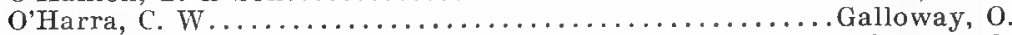

Ohio Agricultural Experiment Station................Wooster, O.

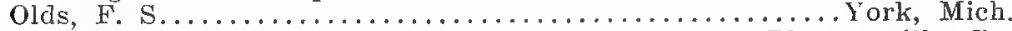

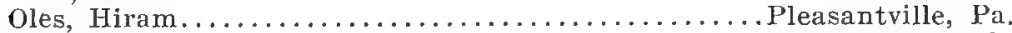

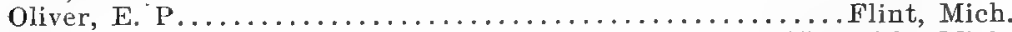

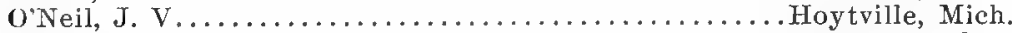

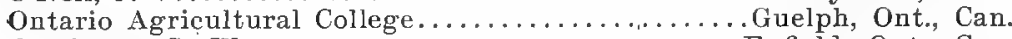

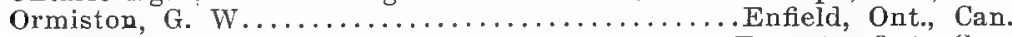

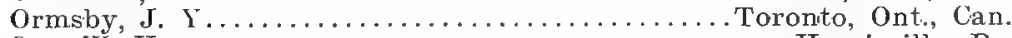

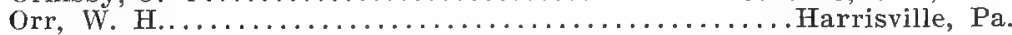

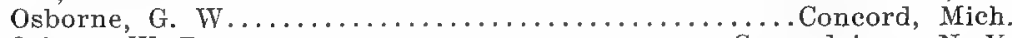

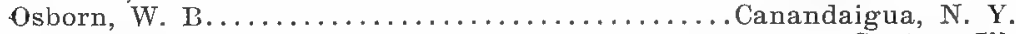

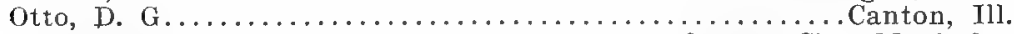

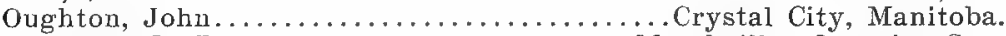

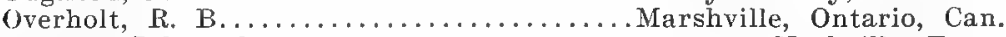

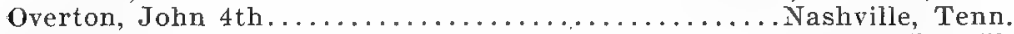

Owen, A. A. \& Bro....................... Bunker Hill, Ill.

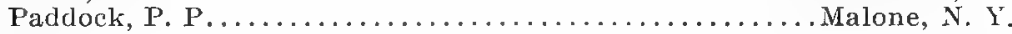

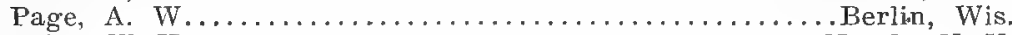

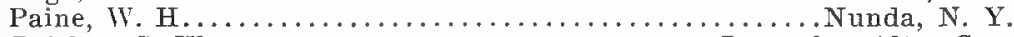

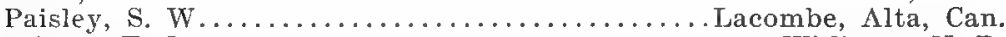

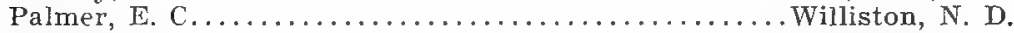

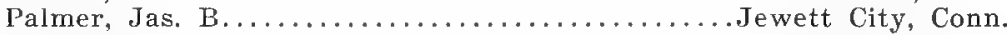

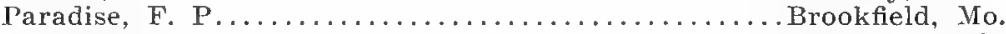

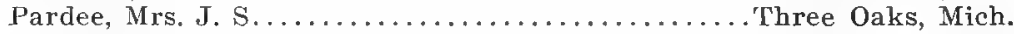

Parish, D. . . . . . . . . . . . . . . . . . . . . .

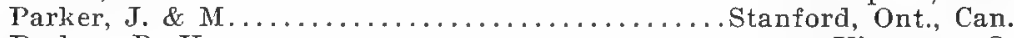

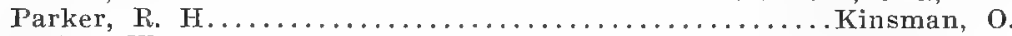

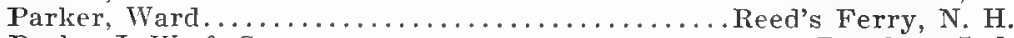

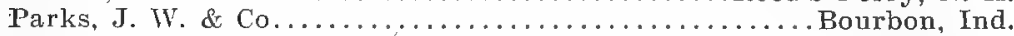

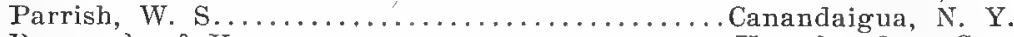

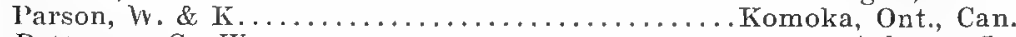

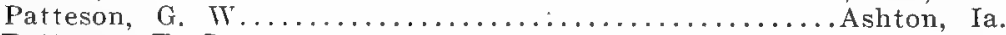

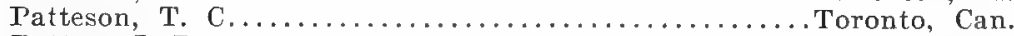

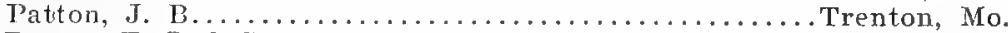

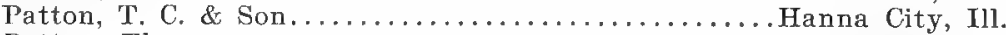

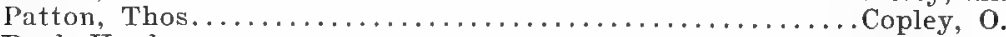

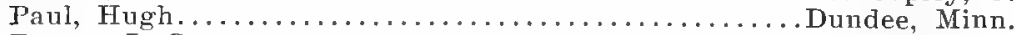

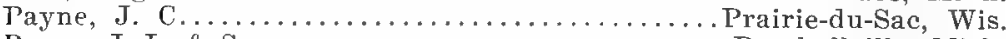

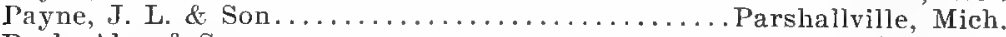

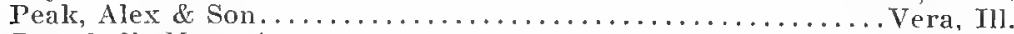

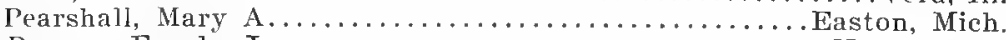

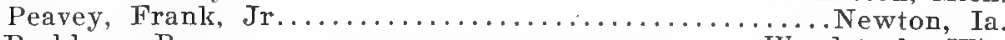

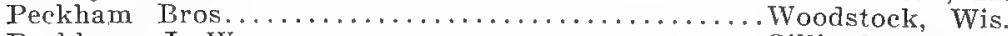

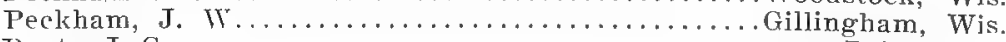

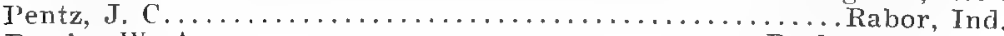

Perrin, W. A.................................................... 
Perry, E. R....................... Vorth Charleston, X. I1.

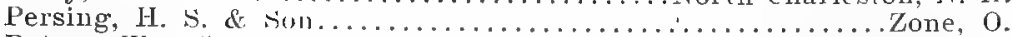

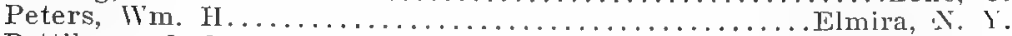

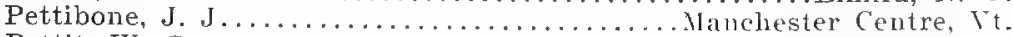

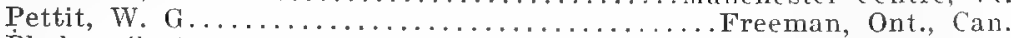

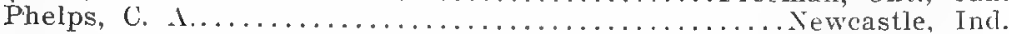

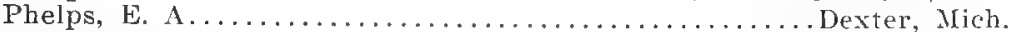

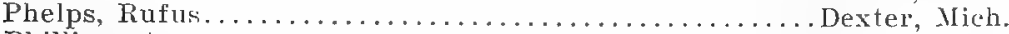

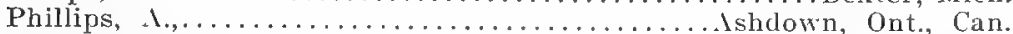

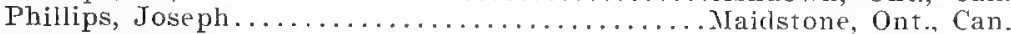

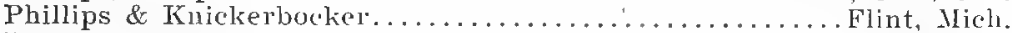

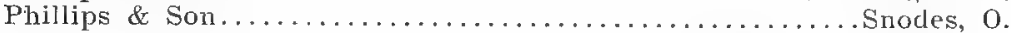

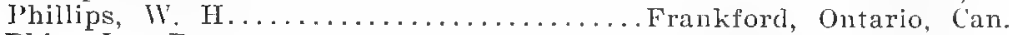

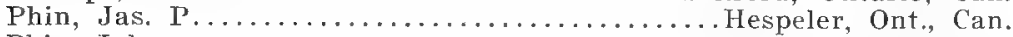

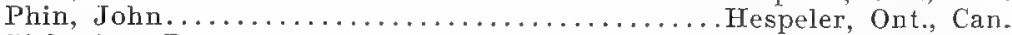

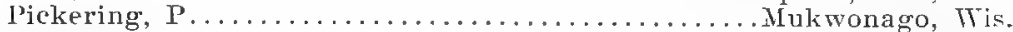

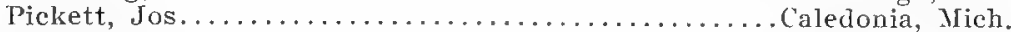

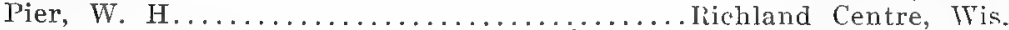

Pierce, Irving \& Sons................. L'nion City, Mich.

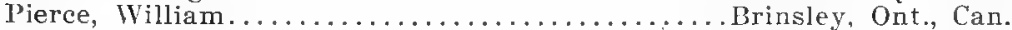

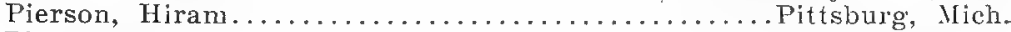

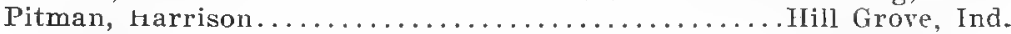

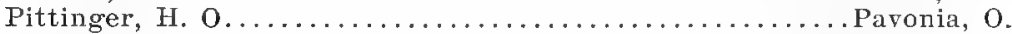

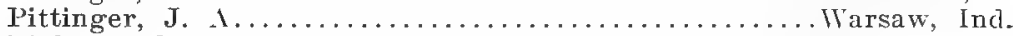

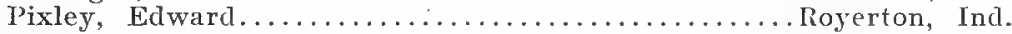

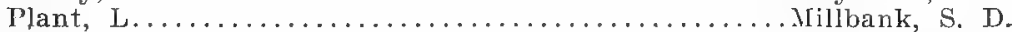

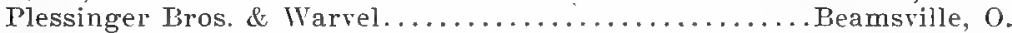

J'lumly, J. L..............................Waubeek, Ta.

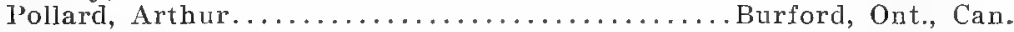

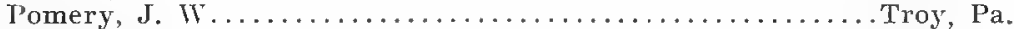

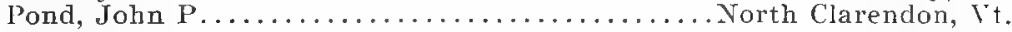

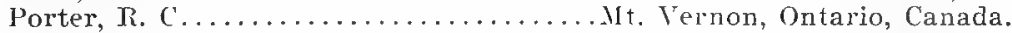

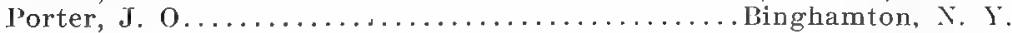

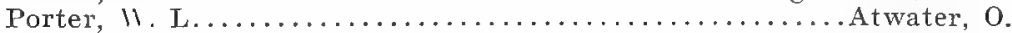

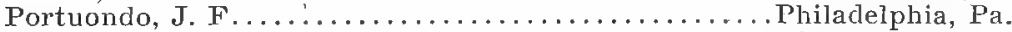

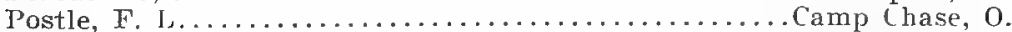

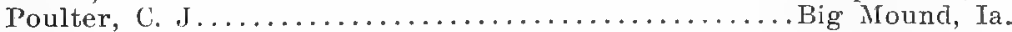

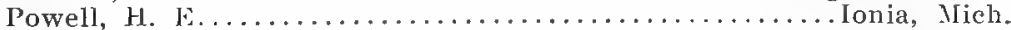

Powell, John............................ Whabash, 0.

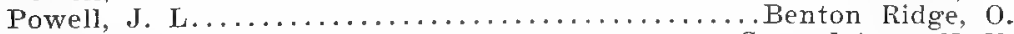

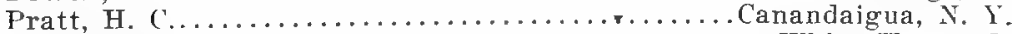

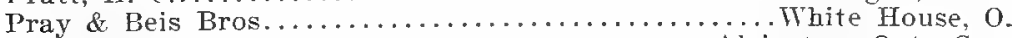

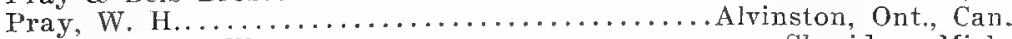

Prestel, John $11 . \ldots \ldots \ldots \ldots \ldots \ldots \ldots \ldots \ldots \ldots \ldots \ldots . \ldots \ldots$ Sheridan, Mich.

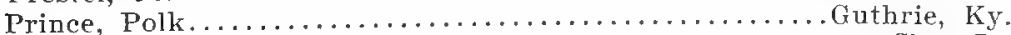

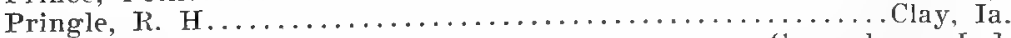

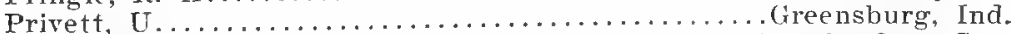

Pugh, Thos. \& Son...................Whitevale, Ont., Can.

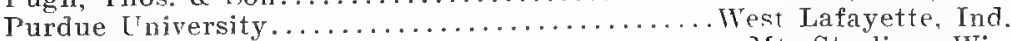

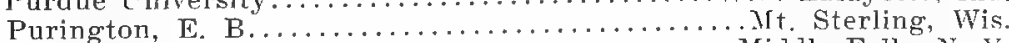

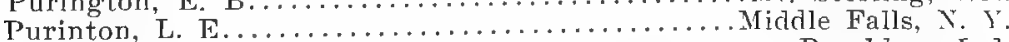

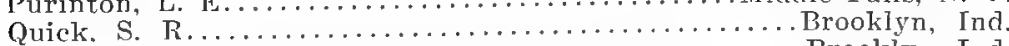

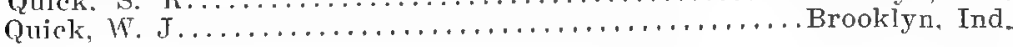


Raccoon Farm Association

Bellowsville, Pa.

Rager, Jacob.

Williams C'enter, 0.

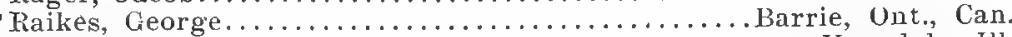

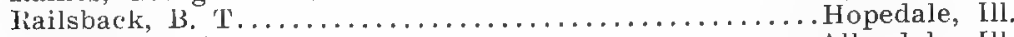

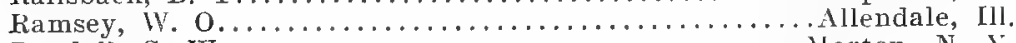

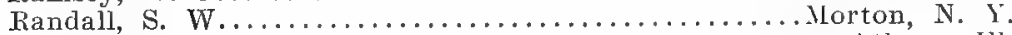

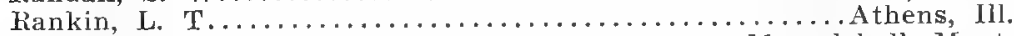

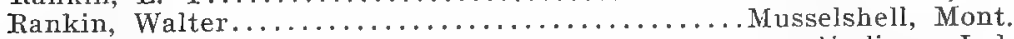

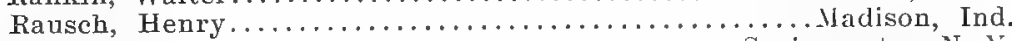

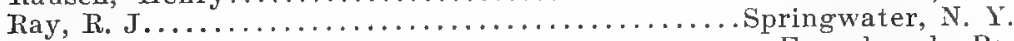

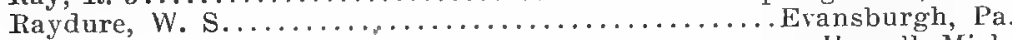

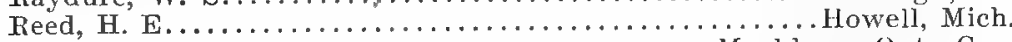

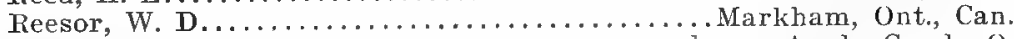

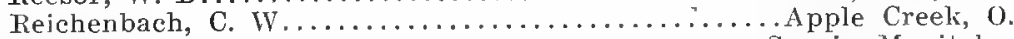

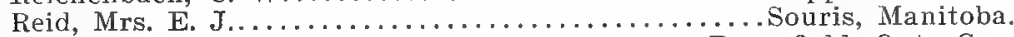

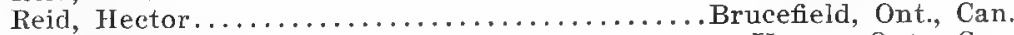

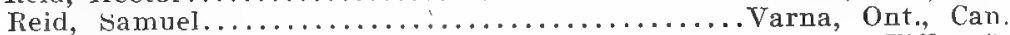

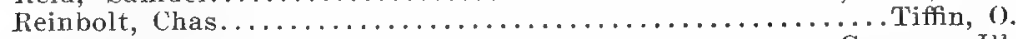

Remington, W. $1 \ldots \ldots \ldots \ldots \ldots \ldots \ldots \ldots \ldots \ldots \ldots \ldots$ Geneseo, Ill.

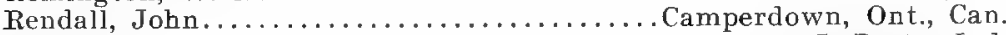

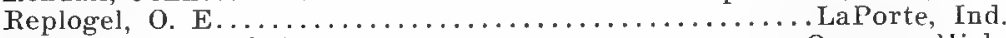

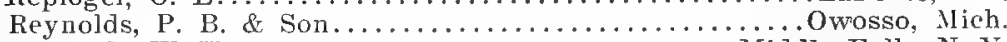

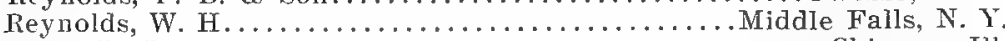

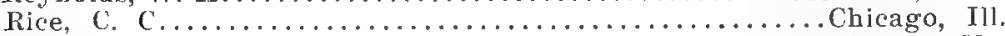

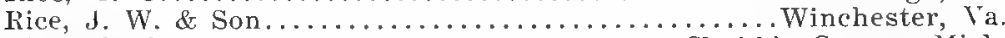

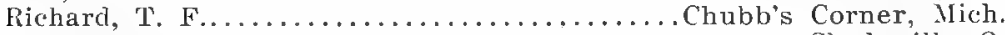

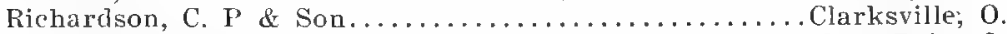

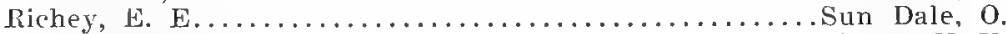

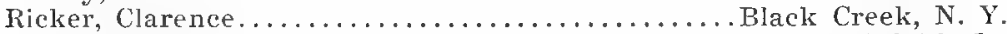

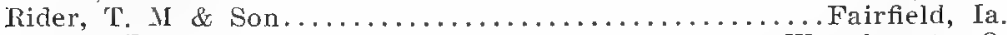

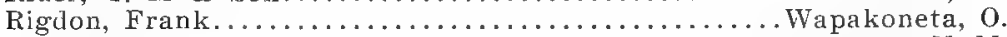

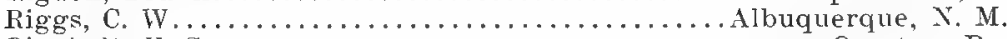

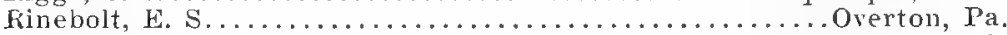

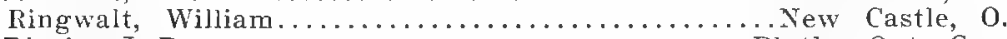

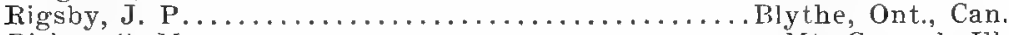

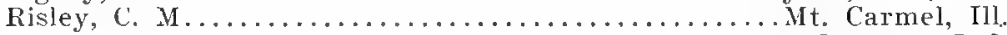

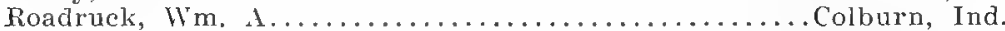

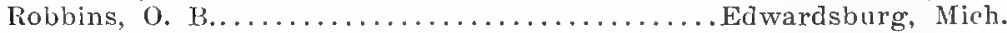

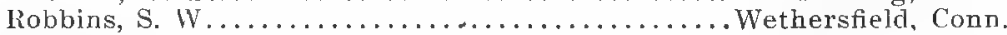

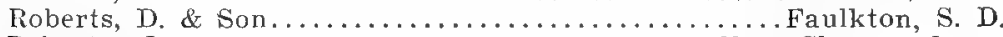

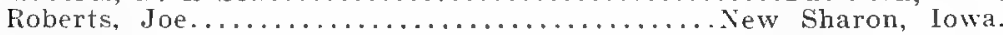

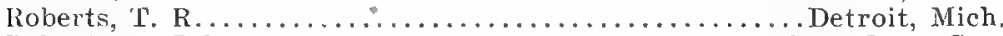

Robertson, John....................Wyoming, Ont., Can.

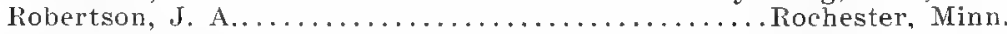

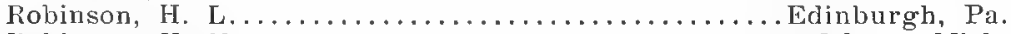

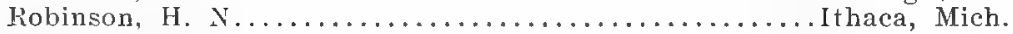

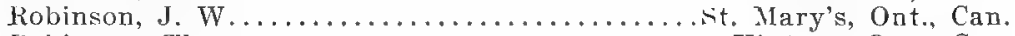

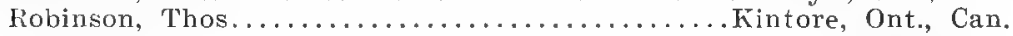

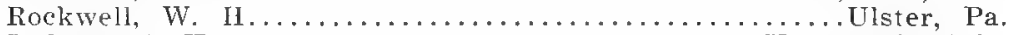

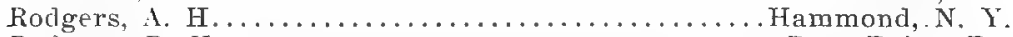

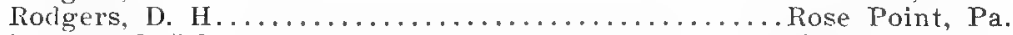

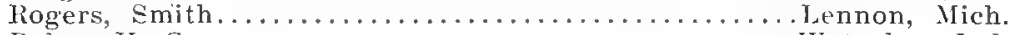

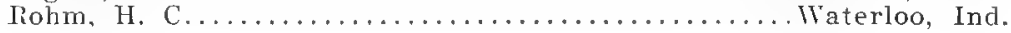


Rolason, H.

Howell, Mich.

Roller, A. J...

Elgin, $O$.

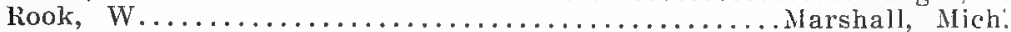

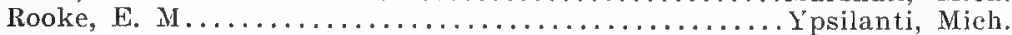

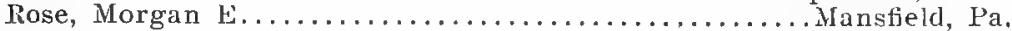

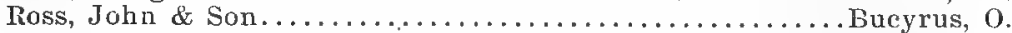

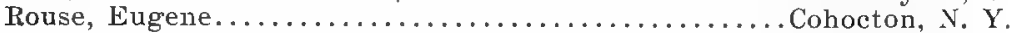

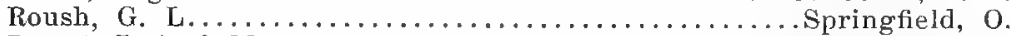

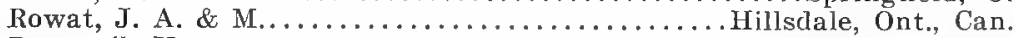

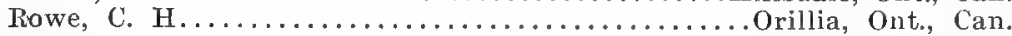

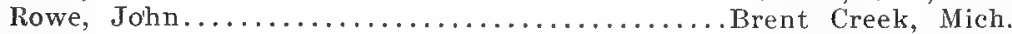

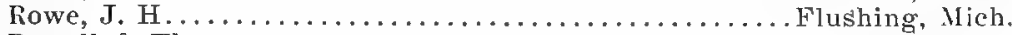

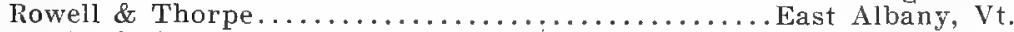

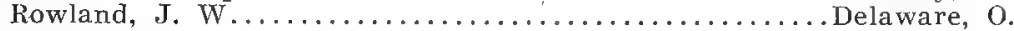

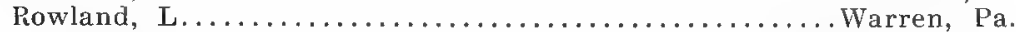

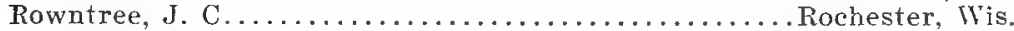

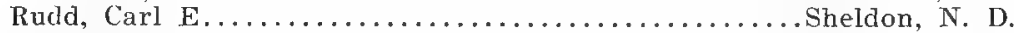

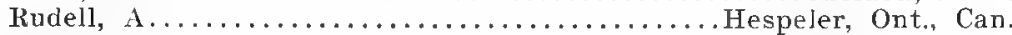

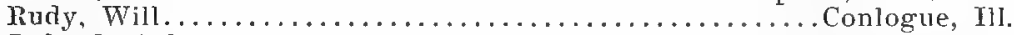

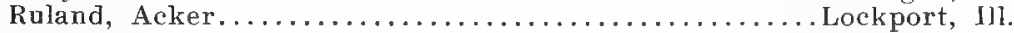

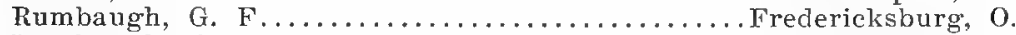

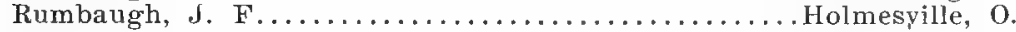

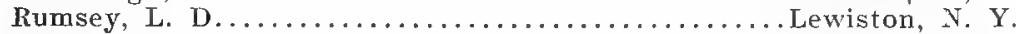

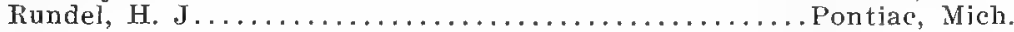

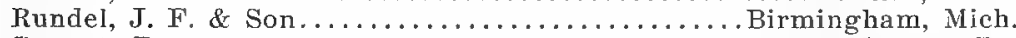

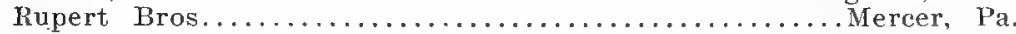

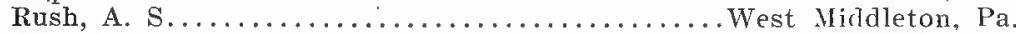

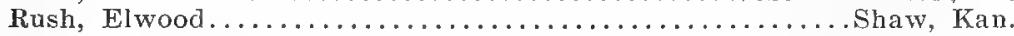

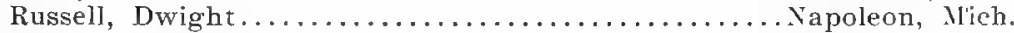

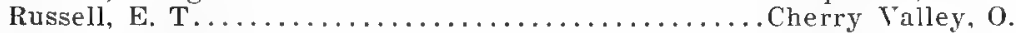

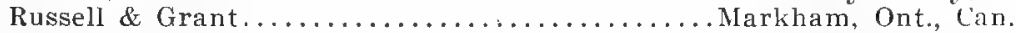

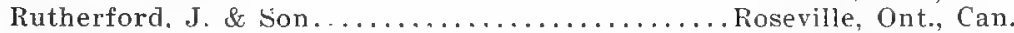

Rutherford, W. L. \& W...................Waddington, $Y . Y$.

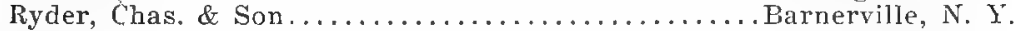

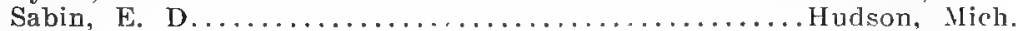

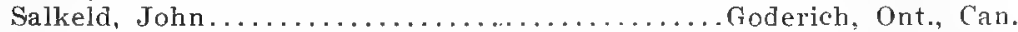

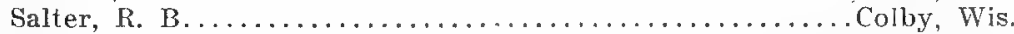

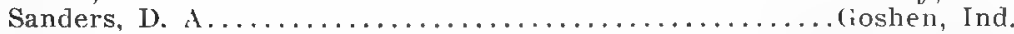

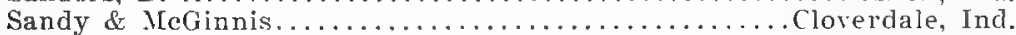

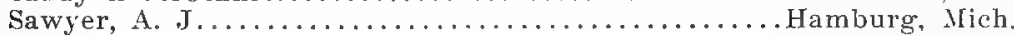

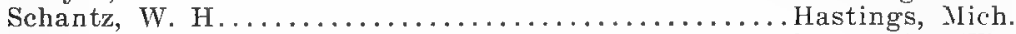

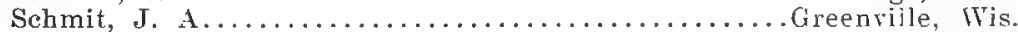

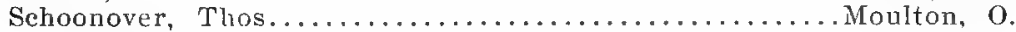

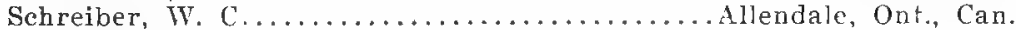

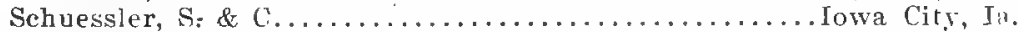

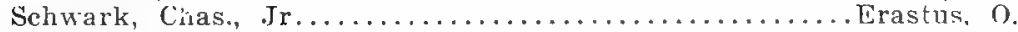

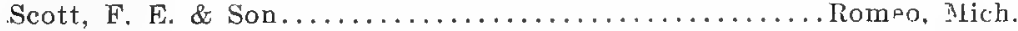

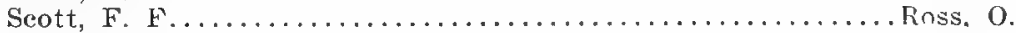

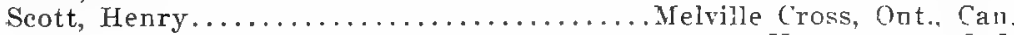

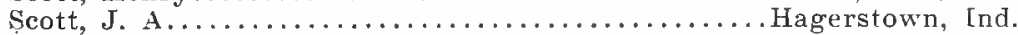

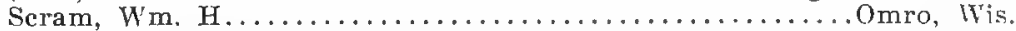

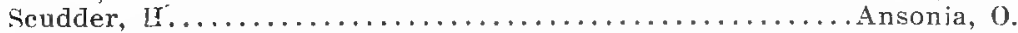

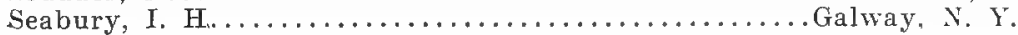




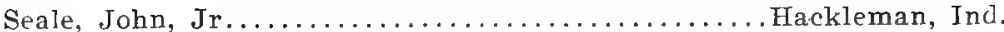

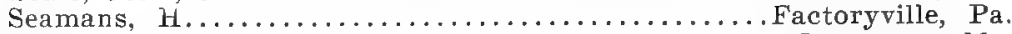

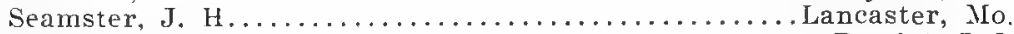

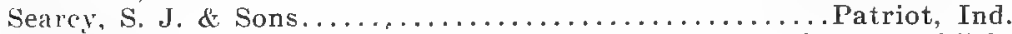

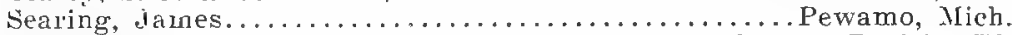

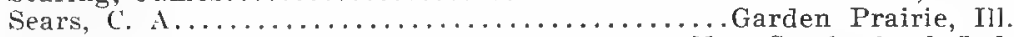

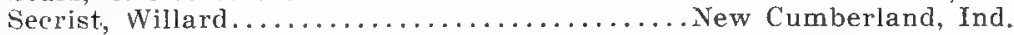

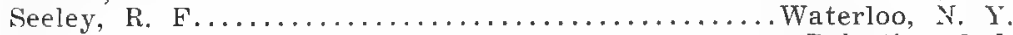

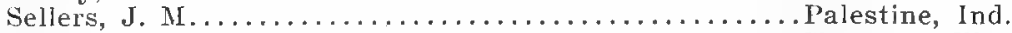

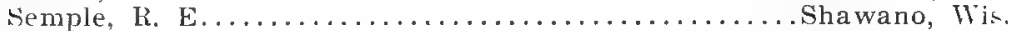

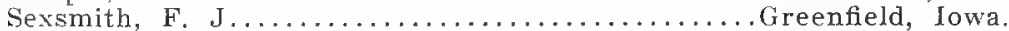

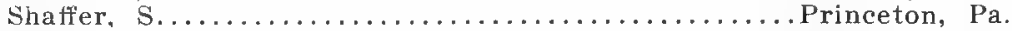

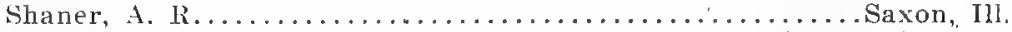

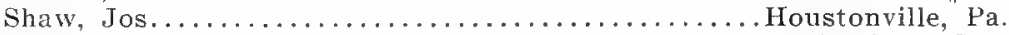

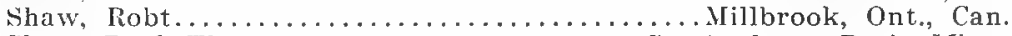

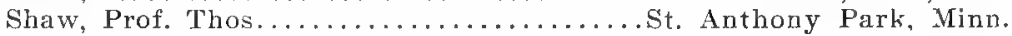

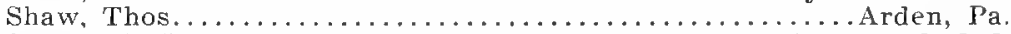

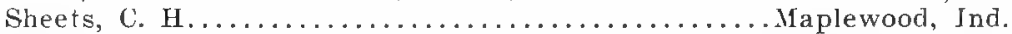

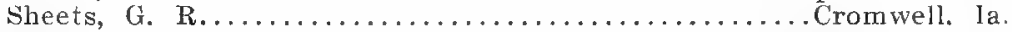

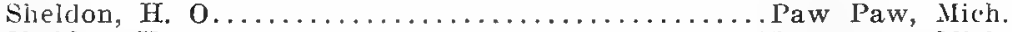

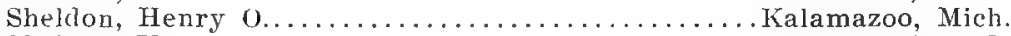

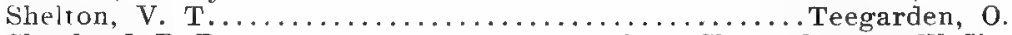

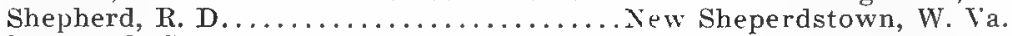

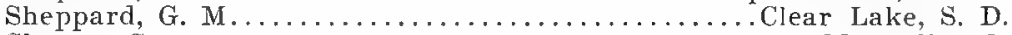

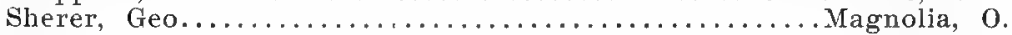
Sherman, Frank T................................

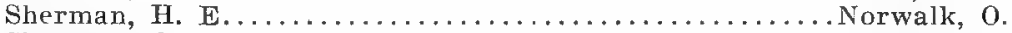

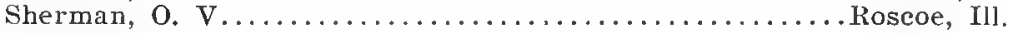
Sherman \& Roeper.......................Wyoming, N. Y.

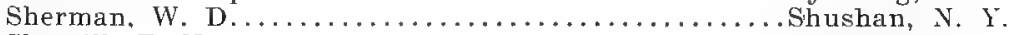

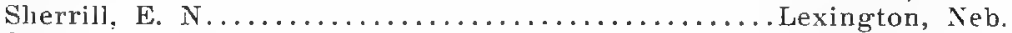

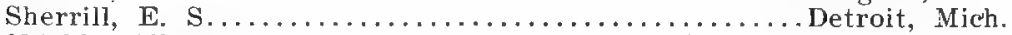

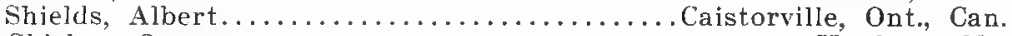

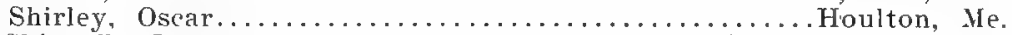

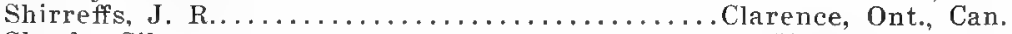

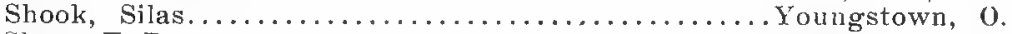
Shore, F. R.......................White Oak, Ont., Can.

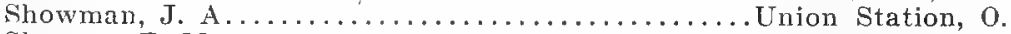

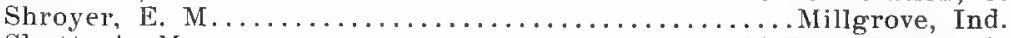

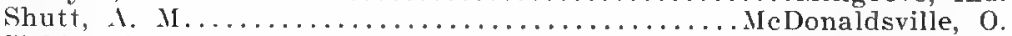

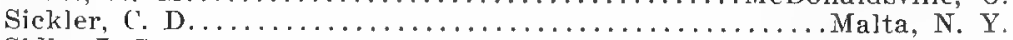

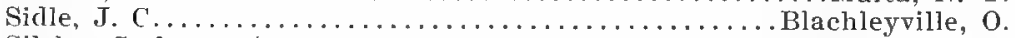

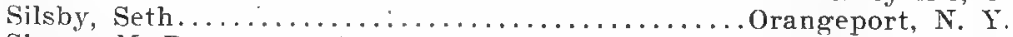

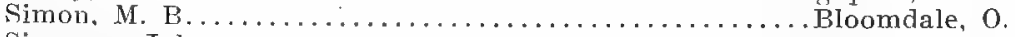

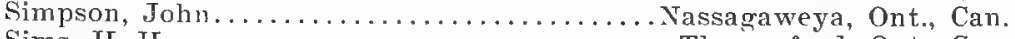

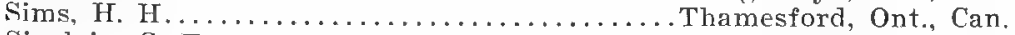

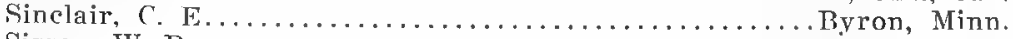

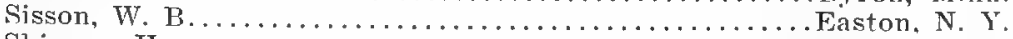

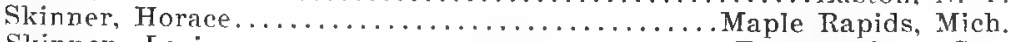

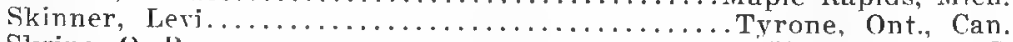
Skrine, (o. 1 . . . . . . . . . . . .

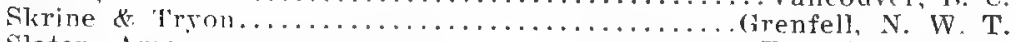
Siater. Imos. West Andover, 0 . 
Slater, P. F

Hinckley, Ill. Sloan, D. H. Ashland, $O$.

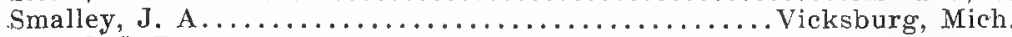

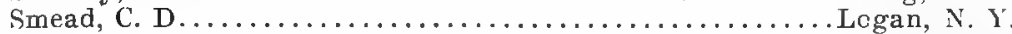

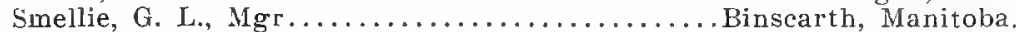

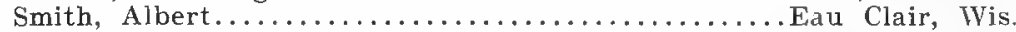

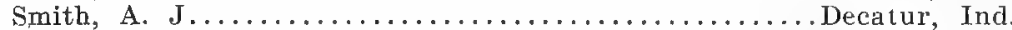

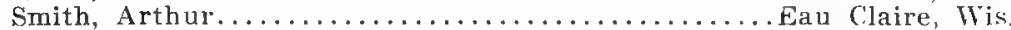

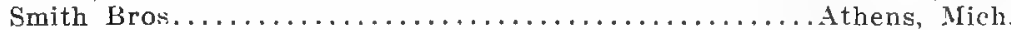

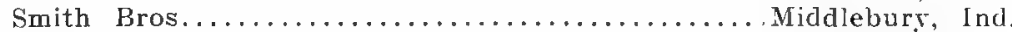

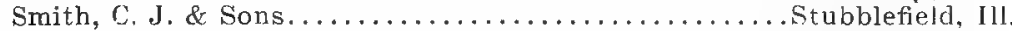

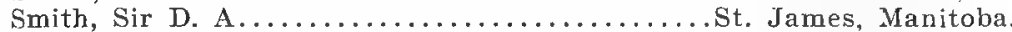

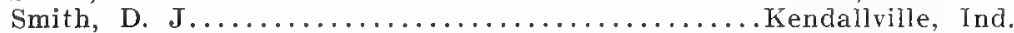

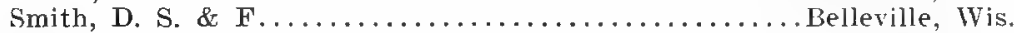

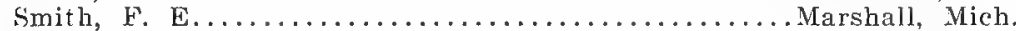

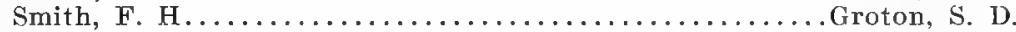

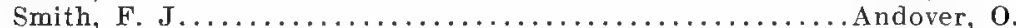

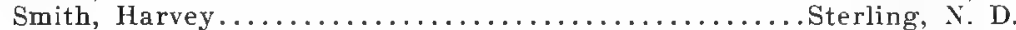

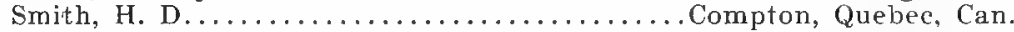

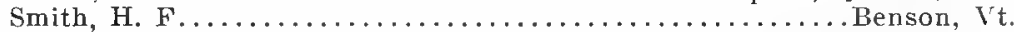

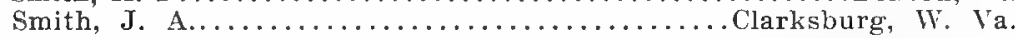
Smith, J. J. \& Son......................West Branch, Ia.

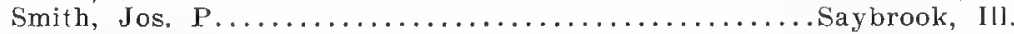

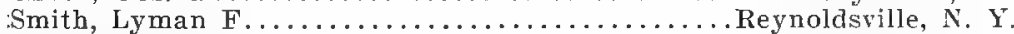

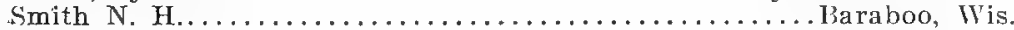

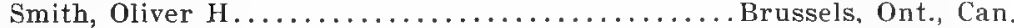

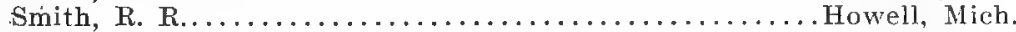

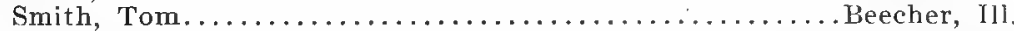

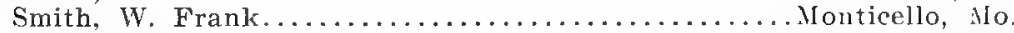

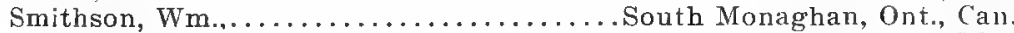

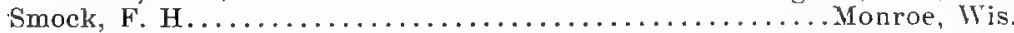

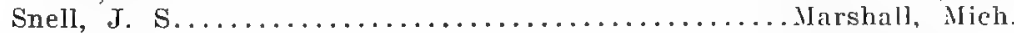

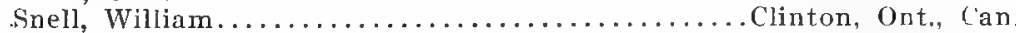

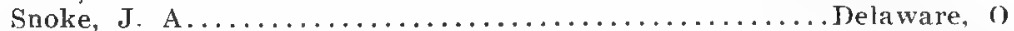

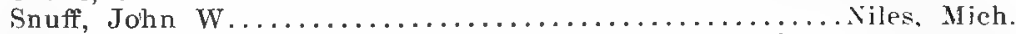

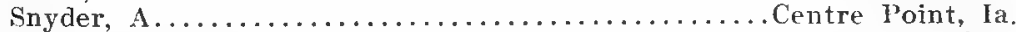
Snyder, Jos. B......................Waterloo, Ont., Can.

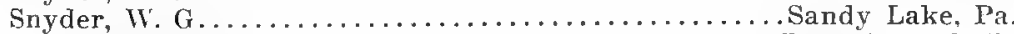

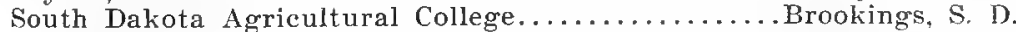

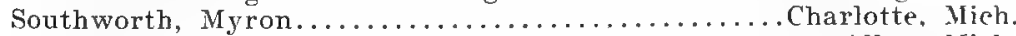

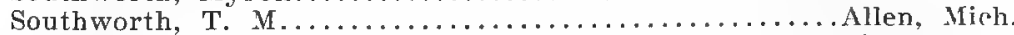

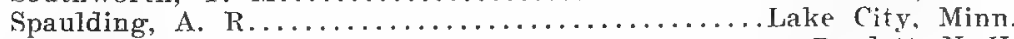

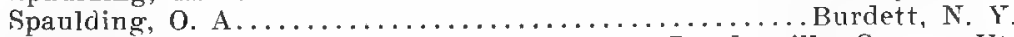

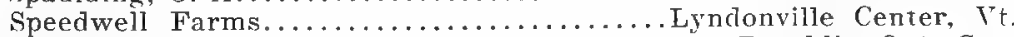

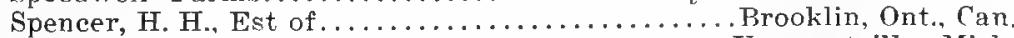

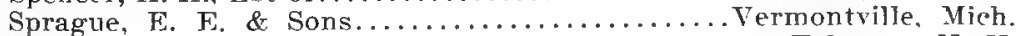

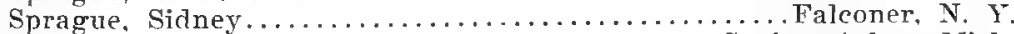

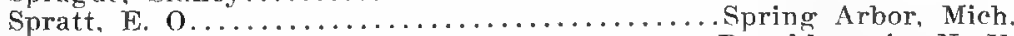

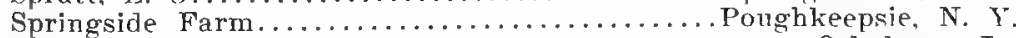

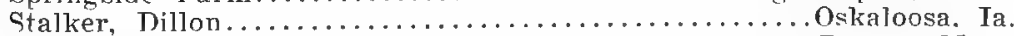

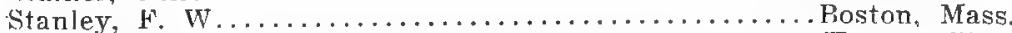

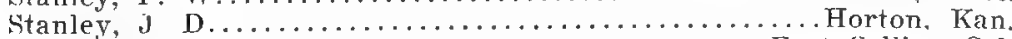

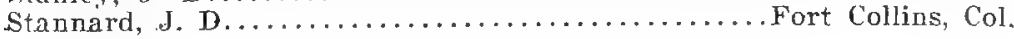


Sitaples, li...

Lifford, Ont., Can. starin, J. $H$.

Stemmons, T. J

.Fultonville, N, Y.

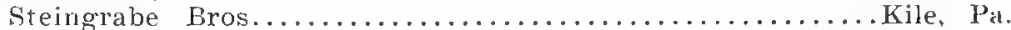

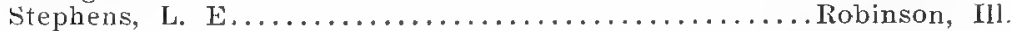

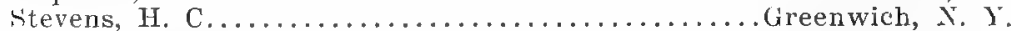

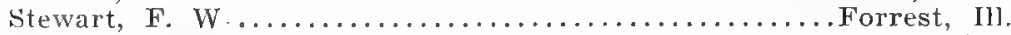

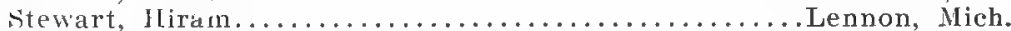

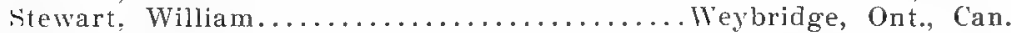

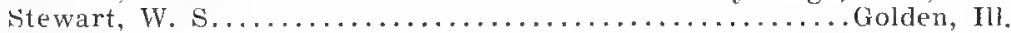

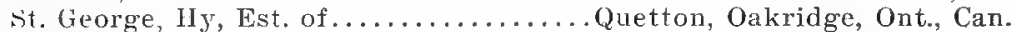

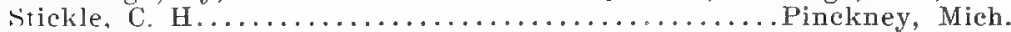

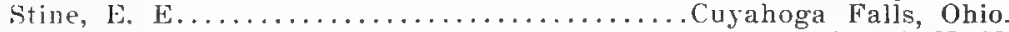

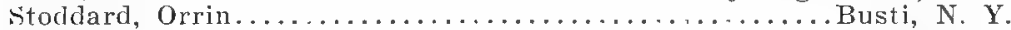

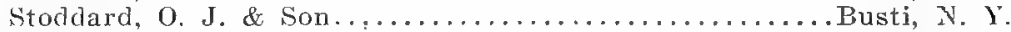

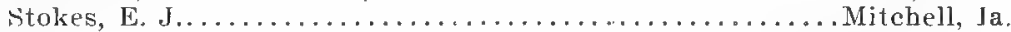

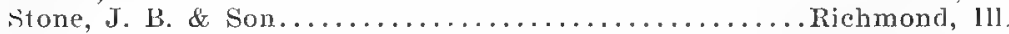

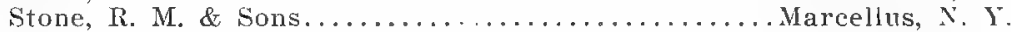

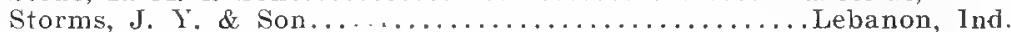

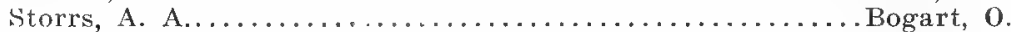

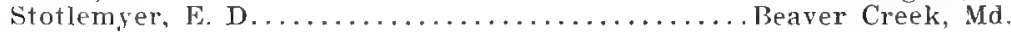

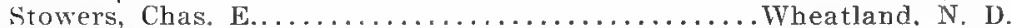

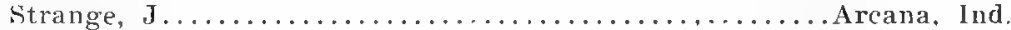

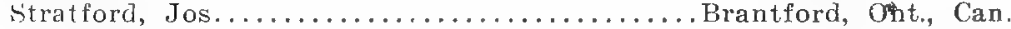

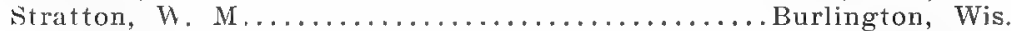

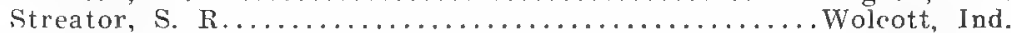

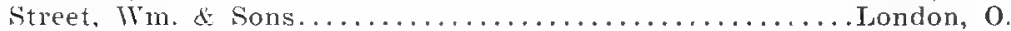

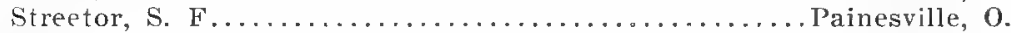

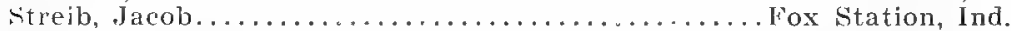

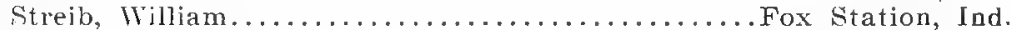

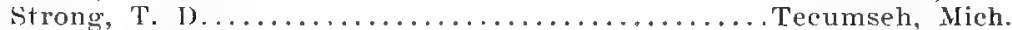

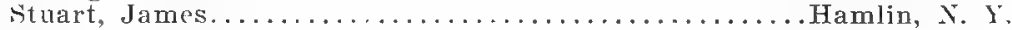

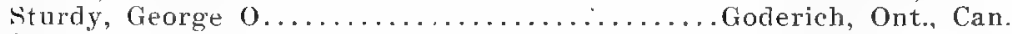

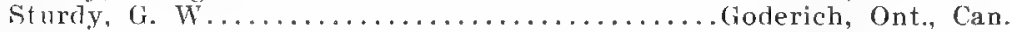

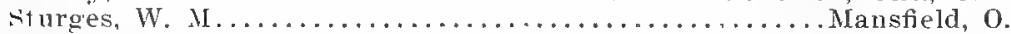

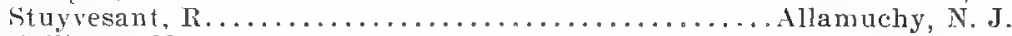

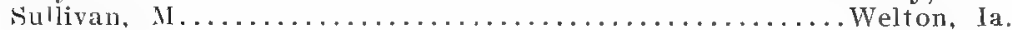

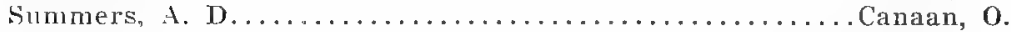
Sutherland, I. W................................

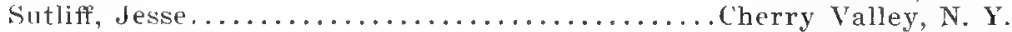

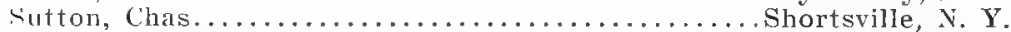

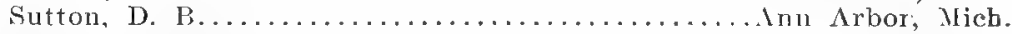

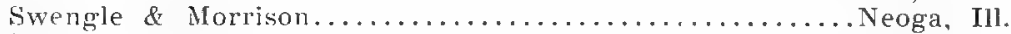

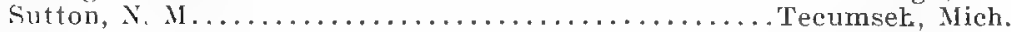

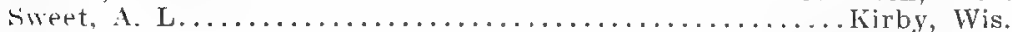
Swartz, I. H......................Waukesha, Wis.

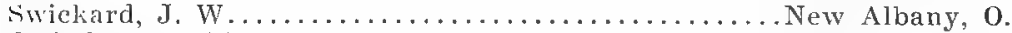

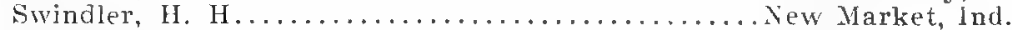

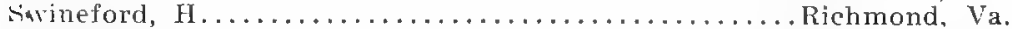

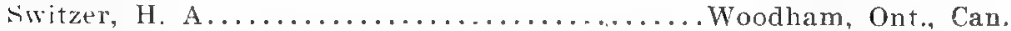

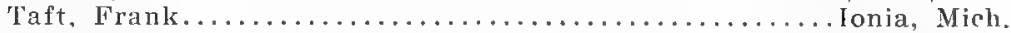
Tainter,

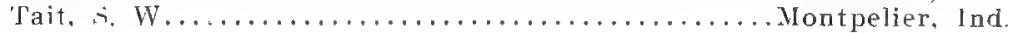


'Talcott. G. I3.

.Owego, N. Y.

'Talcott, J. B.

Rome, N. Y.

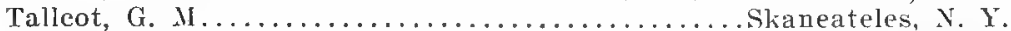

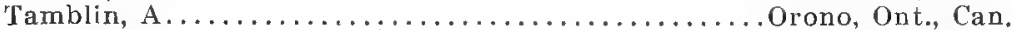

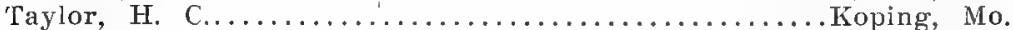

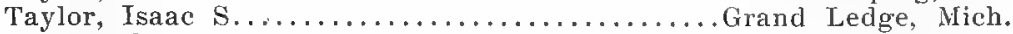

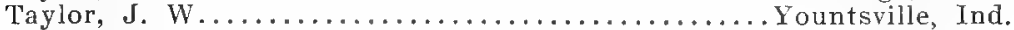

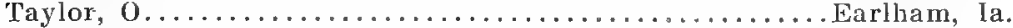

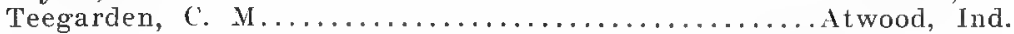

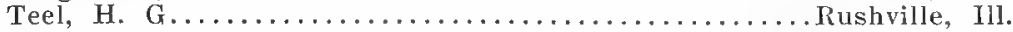

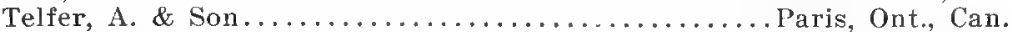

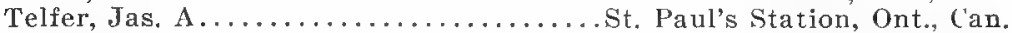

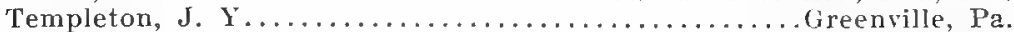

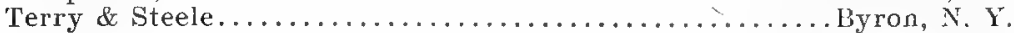

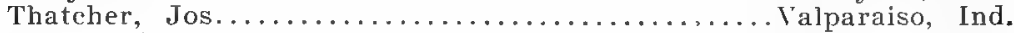

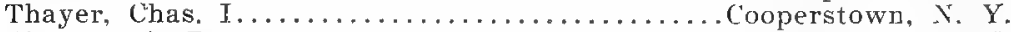

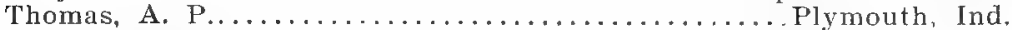

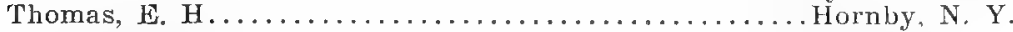

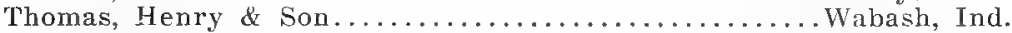

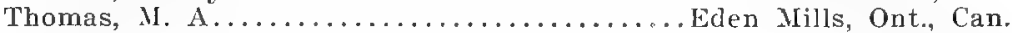

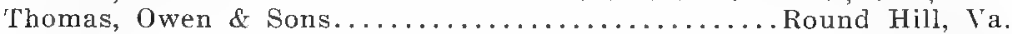

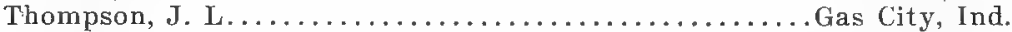

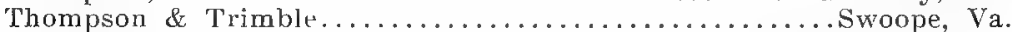

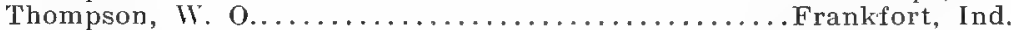

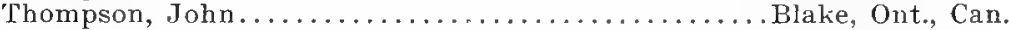

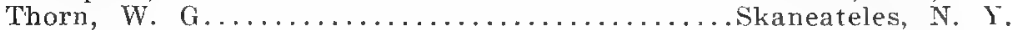

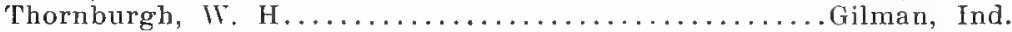

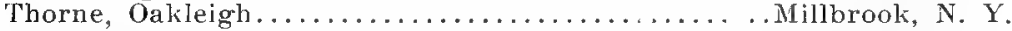

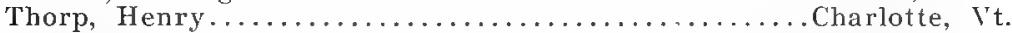

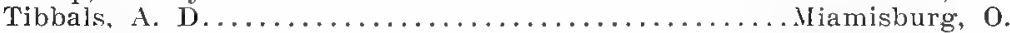

Tilden, ... J...........................West Lebanon, N. Y.

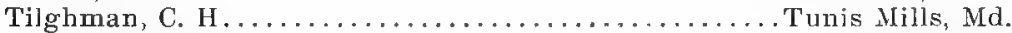

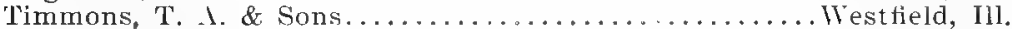

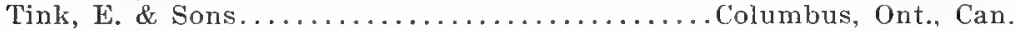

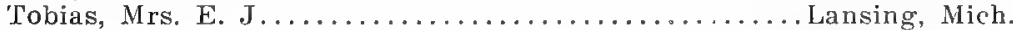

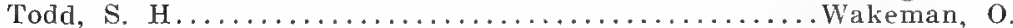

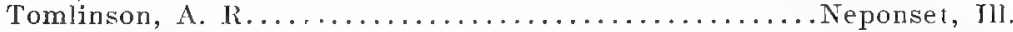

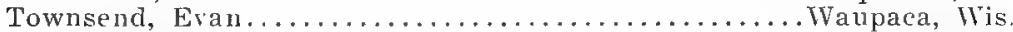

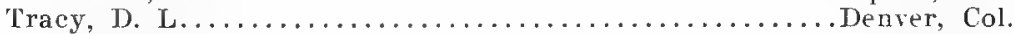

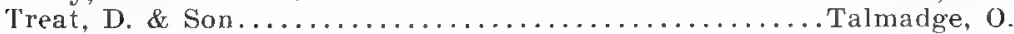

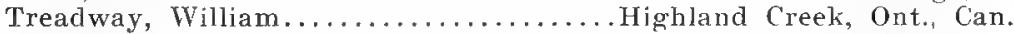

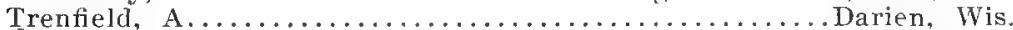

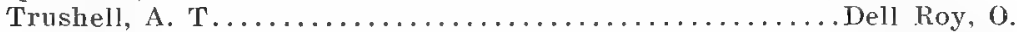

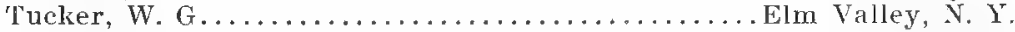

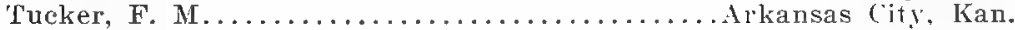

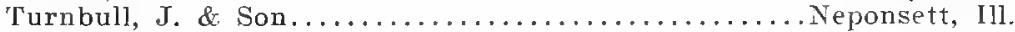

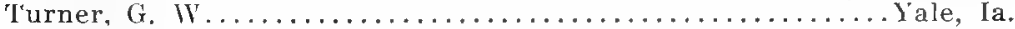

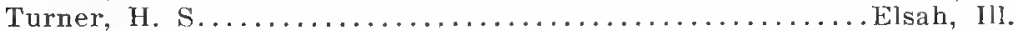

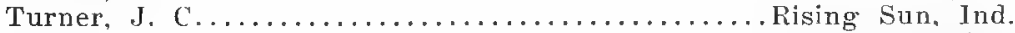

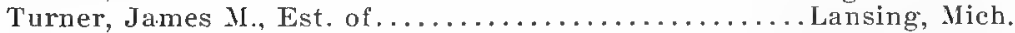

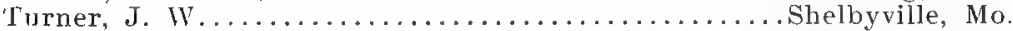

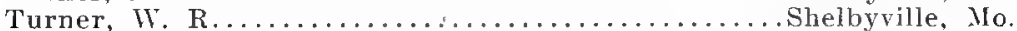

Tuttle, chas. $\mathrm{x} \ldots \ldots \ldots \ldots \ldots \ldots \ldots \ldots \ldots \ldots \ldots \ldots \ldots$ Itomellswille, $\mathrm{N} . \mathrm{Y}$. 


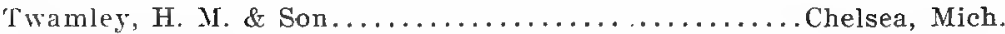

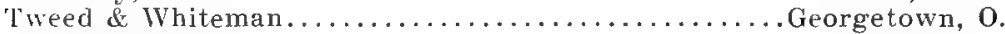

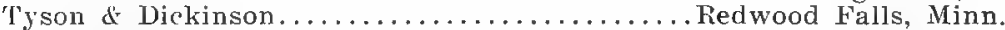

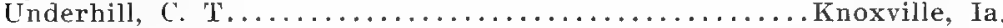

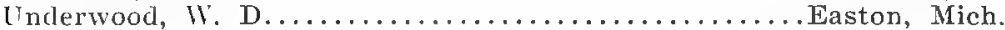

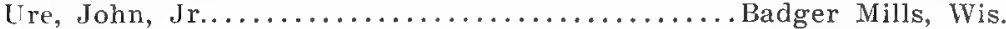

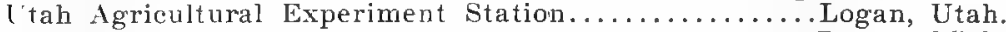

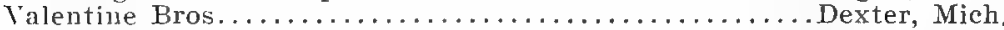

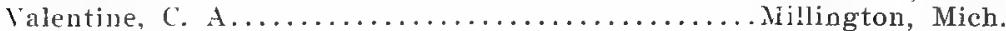

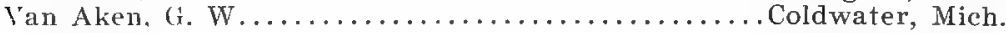

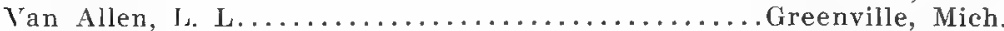

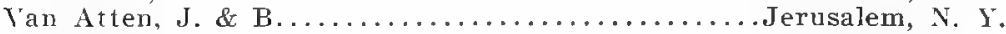

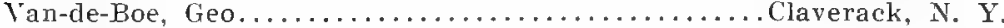

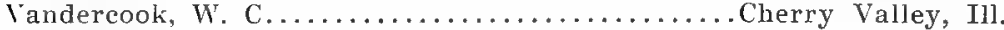

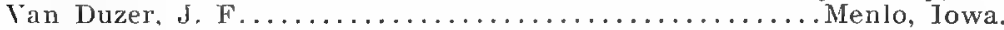

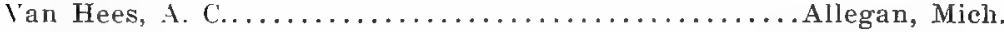

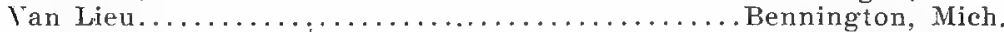

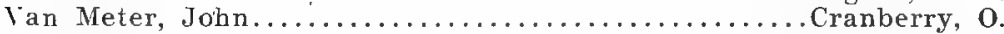

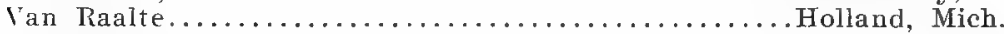

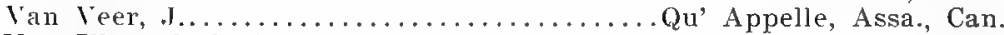

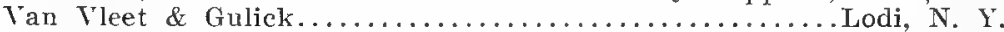

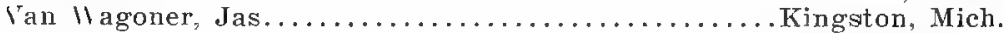

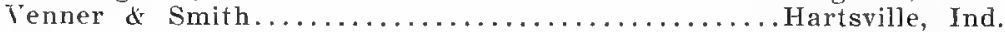

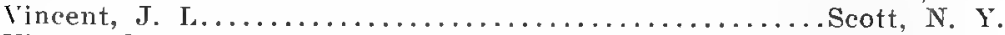

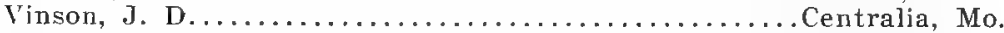

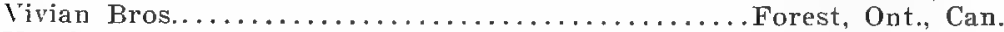

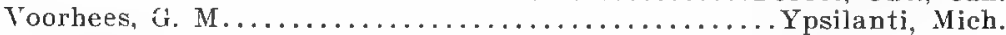

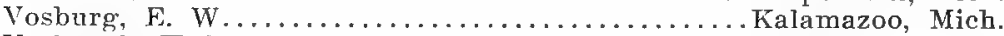

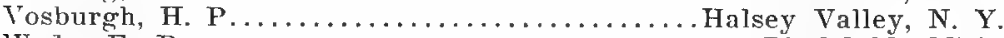

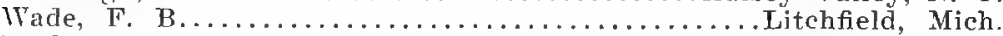

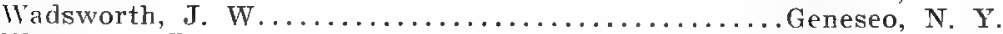

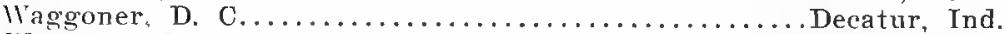

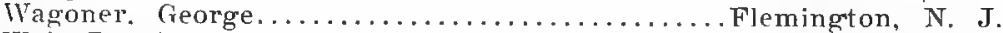

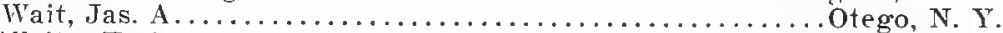

Waite, H. \& Son........................West Valley, N. Y.

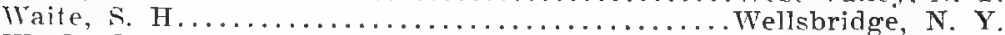

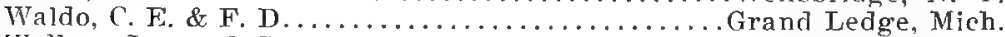

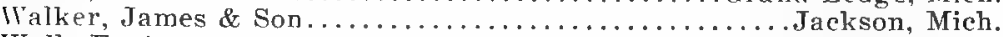

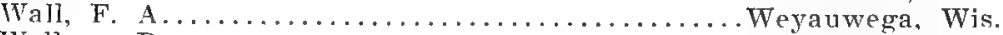

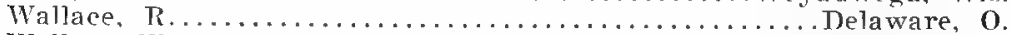

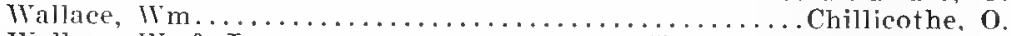

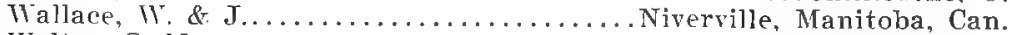

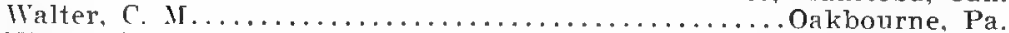

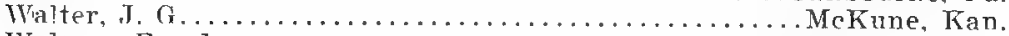

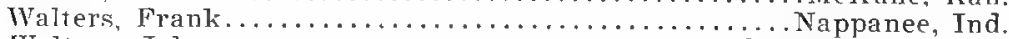

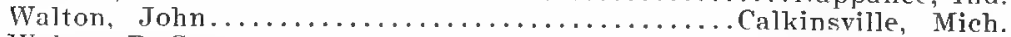

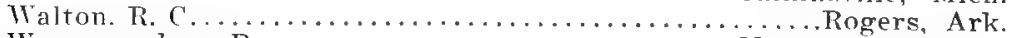

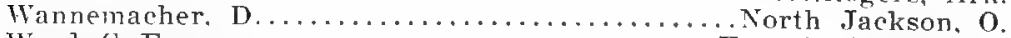

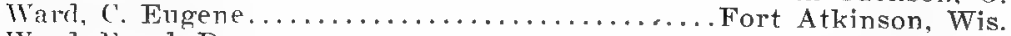

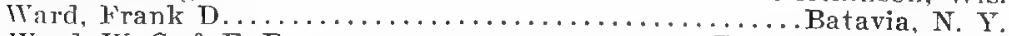

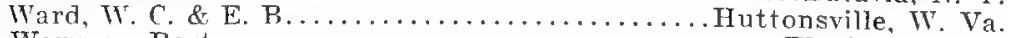

Warner, Bert........................tysian, Minn.

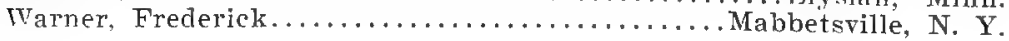




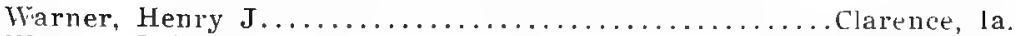

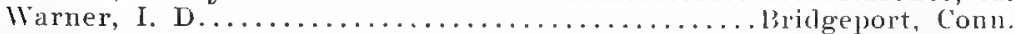

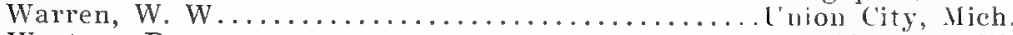

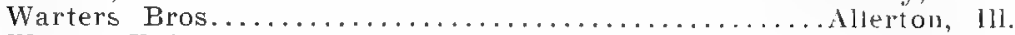

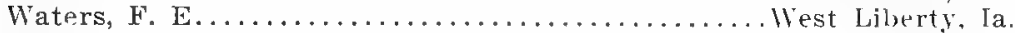

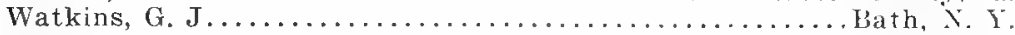

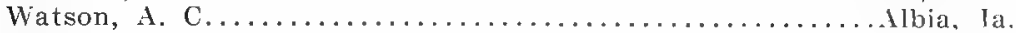

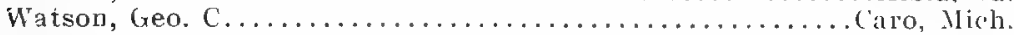

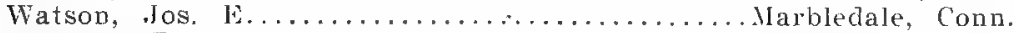

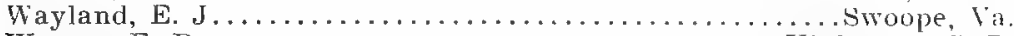

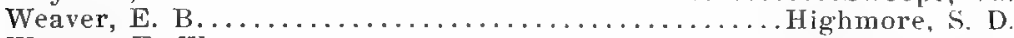

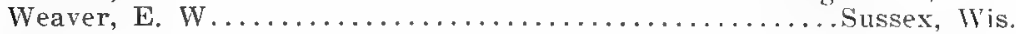

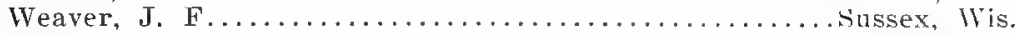

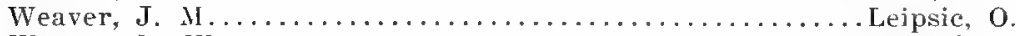

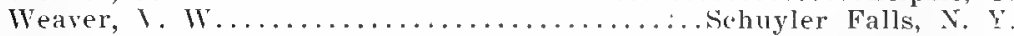

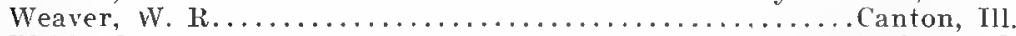

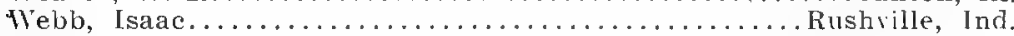

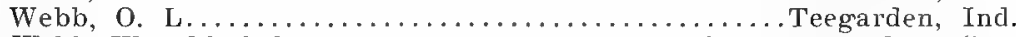

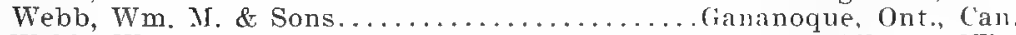

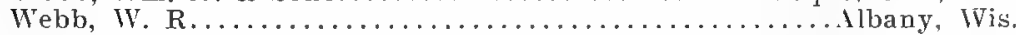

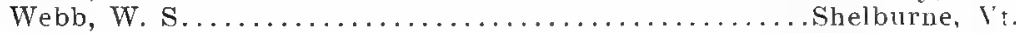

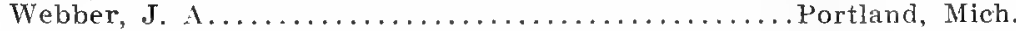

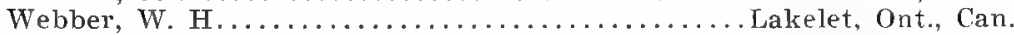

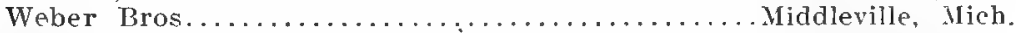

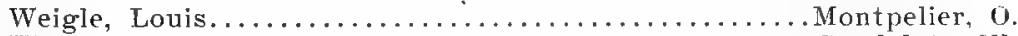

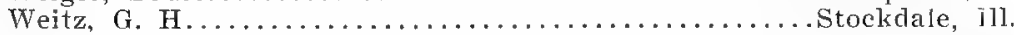

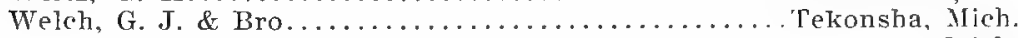

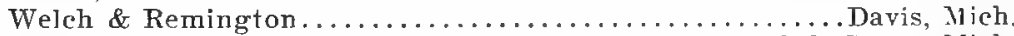

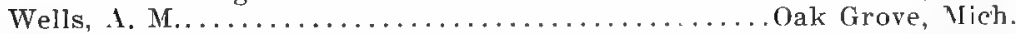

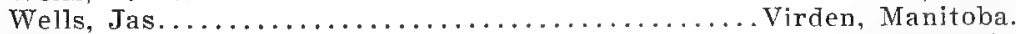

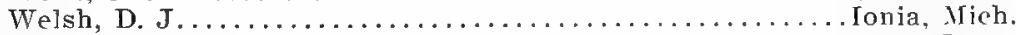

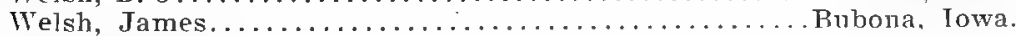

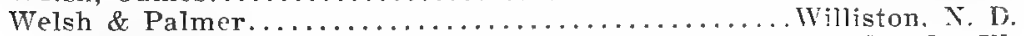

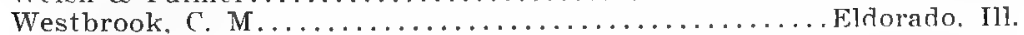

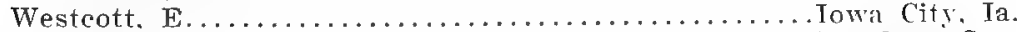

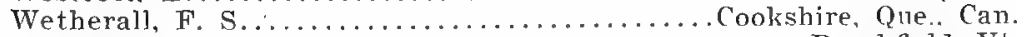

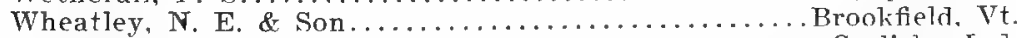

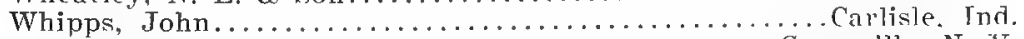

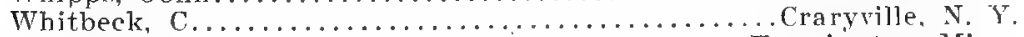

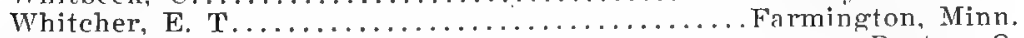

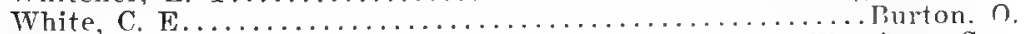

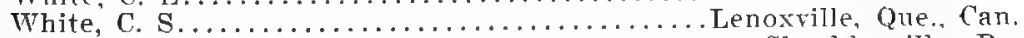

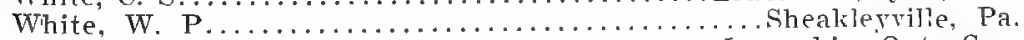

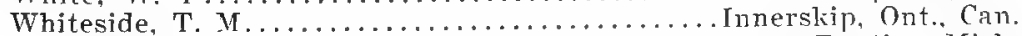

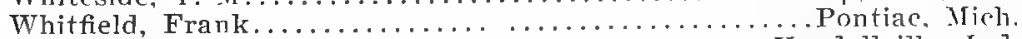

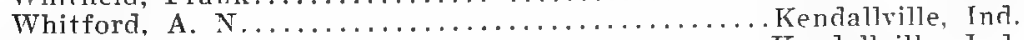

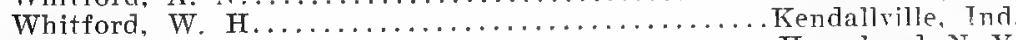

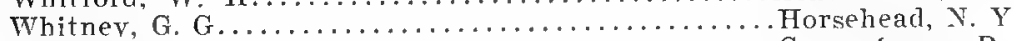

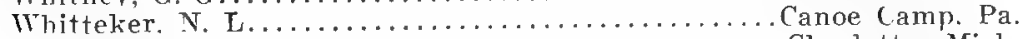

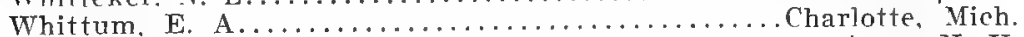

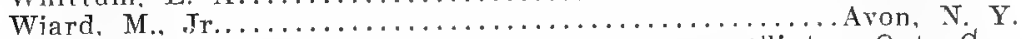

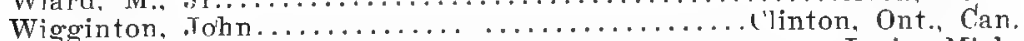

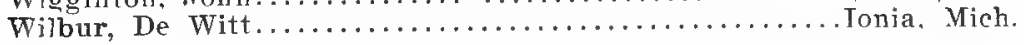


Wilcox, 1. W. \& J. P..................... Bridgport, Vt.

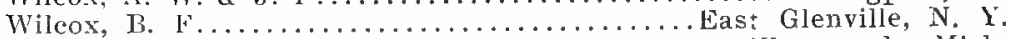

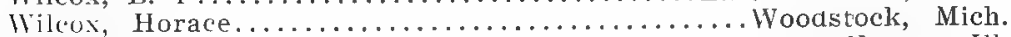

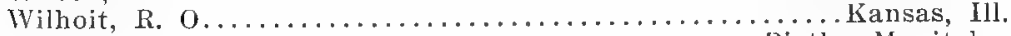

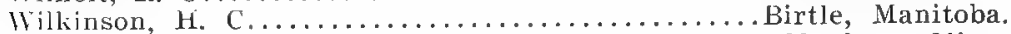

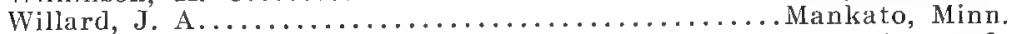

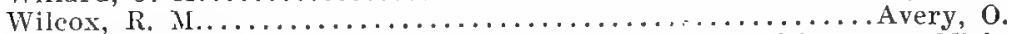

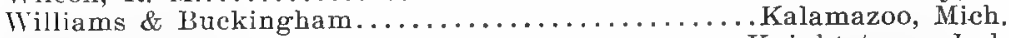

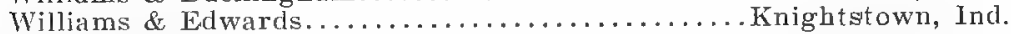

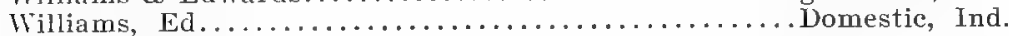
Williams, Henry $(\ldots \ldots \ldots \ldots \ldots \ldots \ldots \ldots \ldots \ldots$. . . . . . . . . . . . . . .

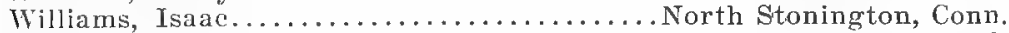

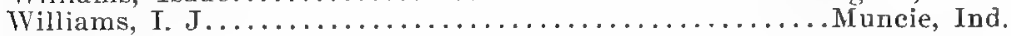

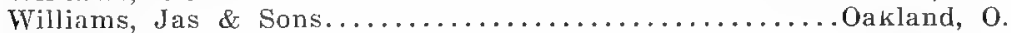
Williams,

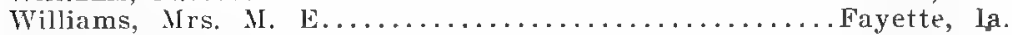

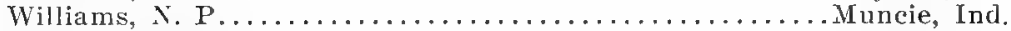

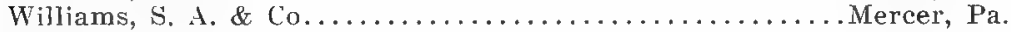

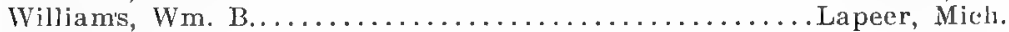

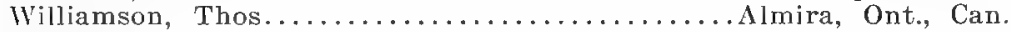

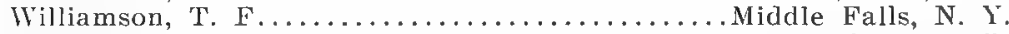

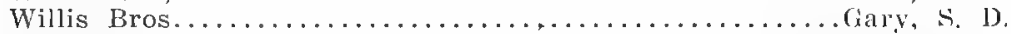

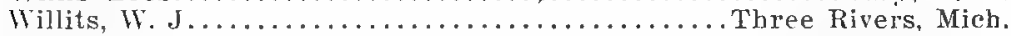

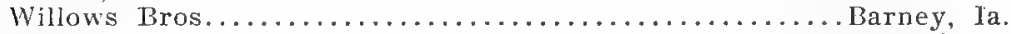

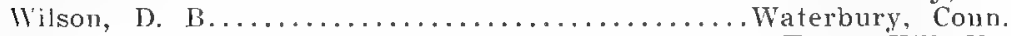

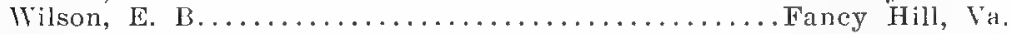

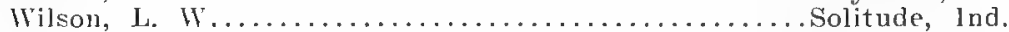

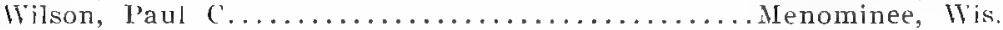

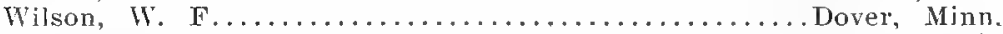

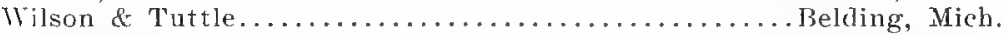

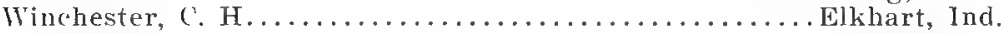

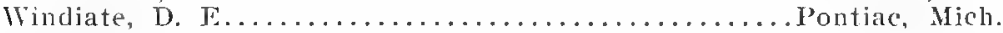

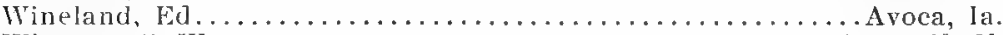

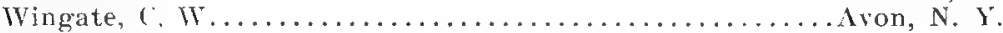

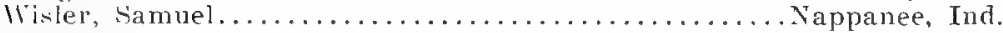

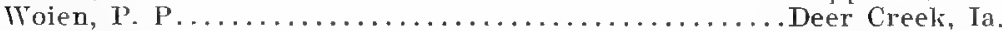

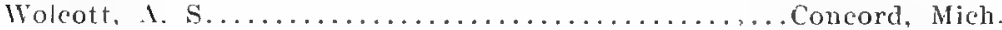

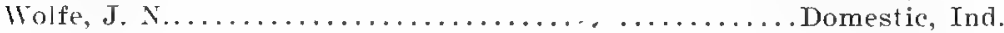

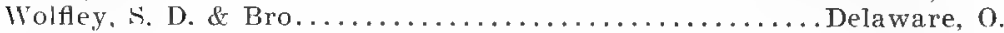

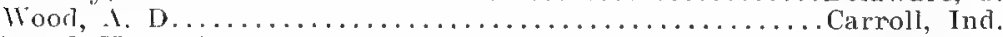

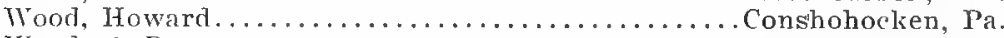

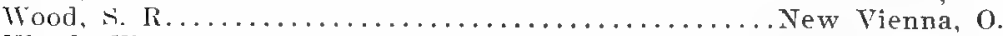

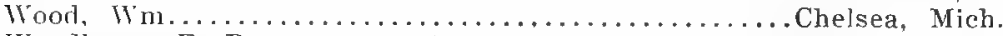

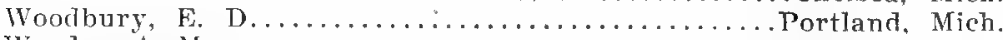

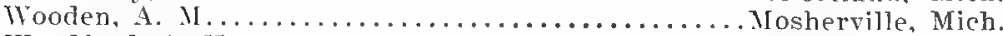

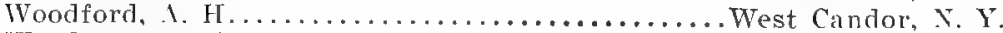

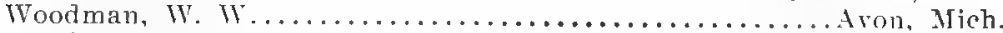

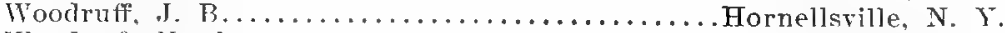

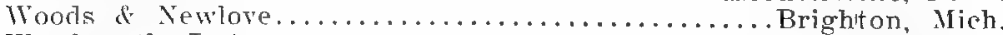

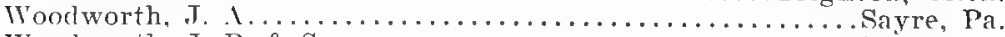

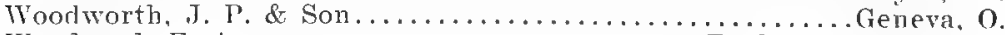

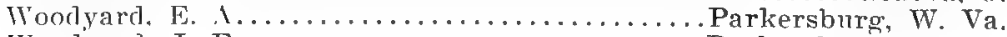

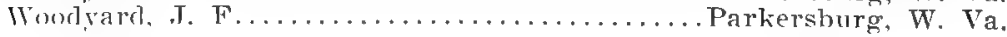


Woodard, W.

Work \& Collins.

Bloomer, Wis.

Workman, S. 1

Bardolph, Ill.

Wormer, E. F. Knob Noster, Mo.

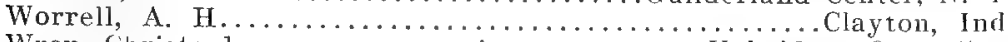
Center, N. Y.

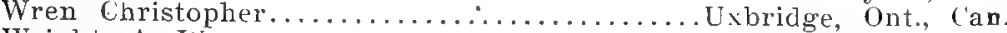

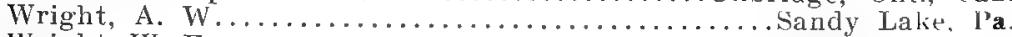

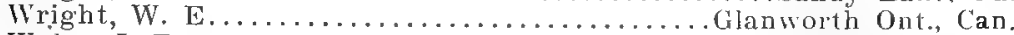

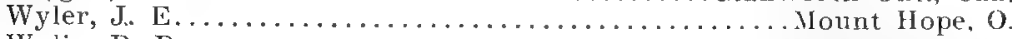

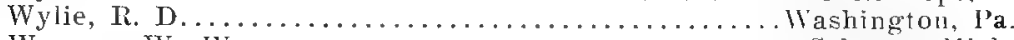

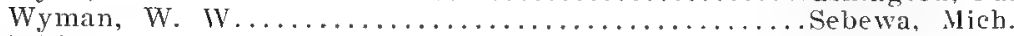

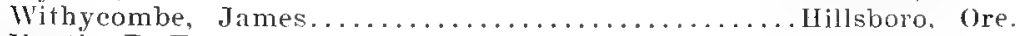

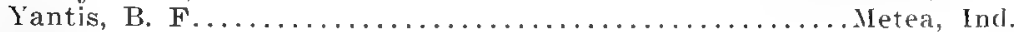

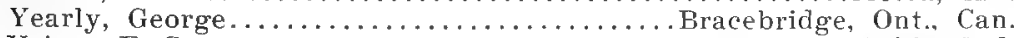

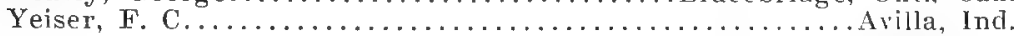

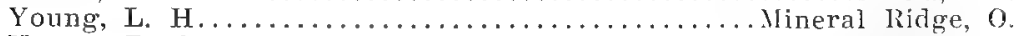

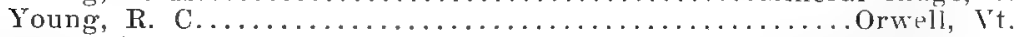

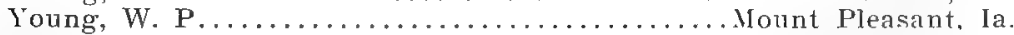

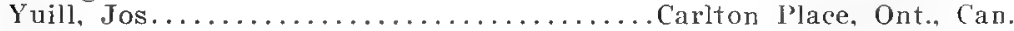

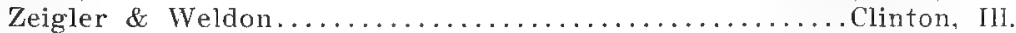

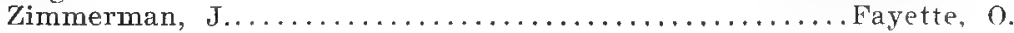

\section{Breeders of Fampshire Down Sheep.}

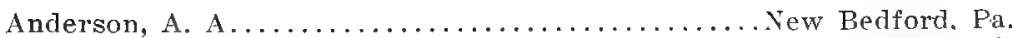

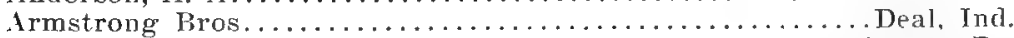

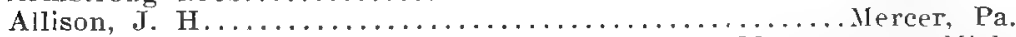

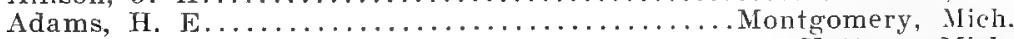

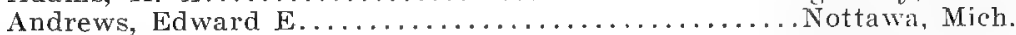

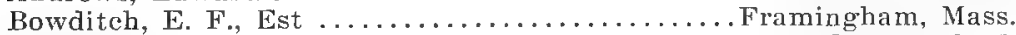

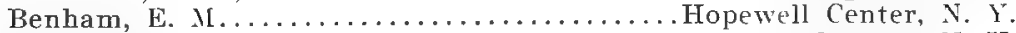

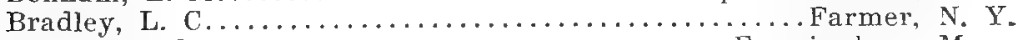

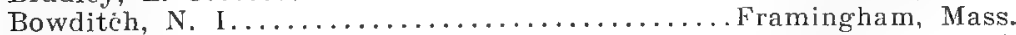

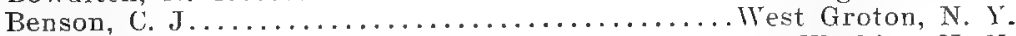

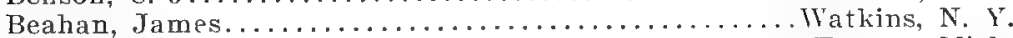

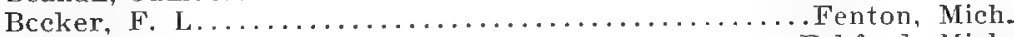

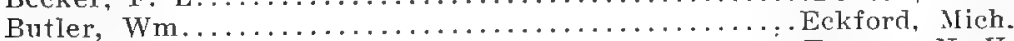

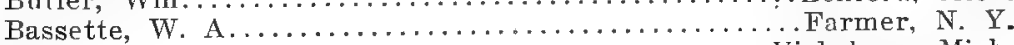

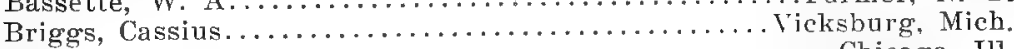

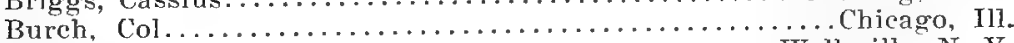

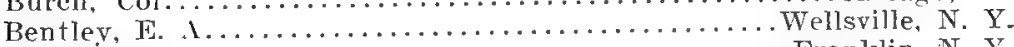

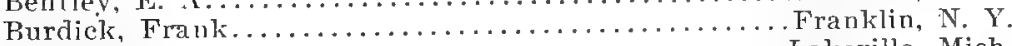

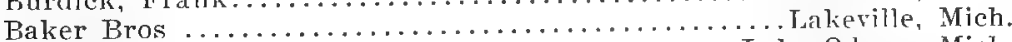

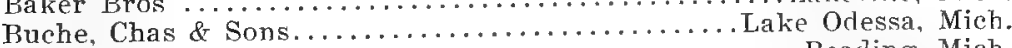

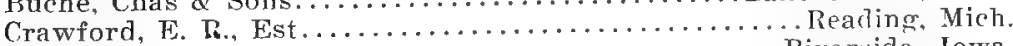

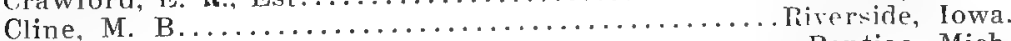

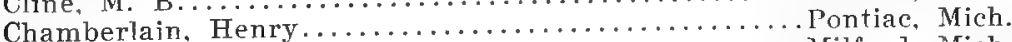

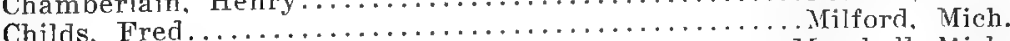

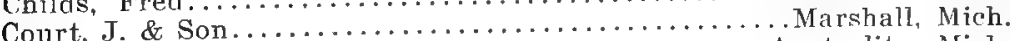

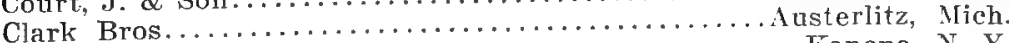

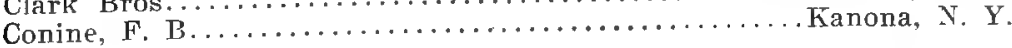


Corbett, Herman.

Farmington, Me.

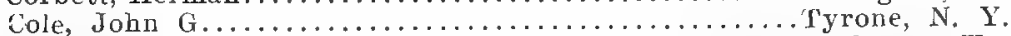
Chilton, Hon. W. $\mathrm{T} \ldots \ldots \ldots \ldots \ldots \ldots \ldots \ldots \ldots \ldots \ldots \ldots \ldots \ldots \ldots \ldots$ Campbellsburg, $\mathrm{K}_{\mathrm{y}}$.

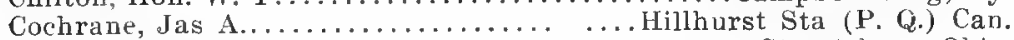

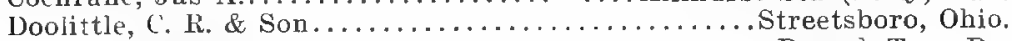

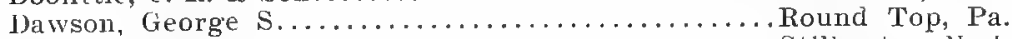

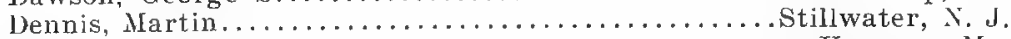

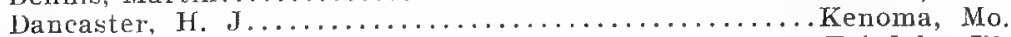

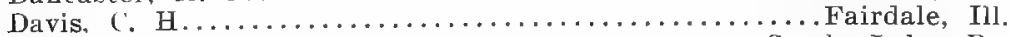

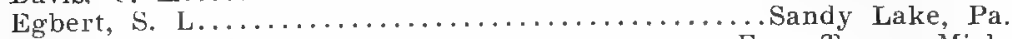

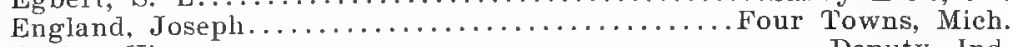

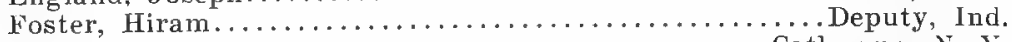

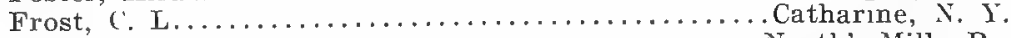

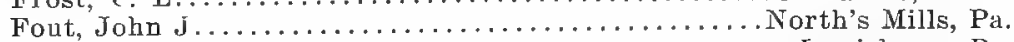

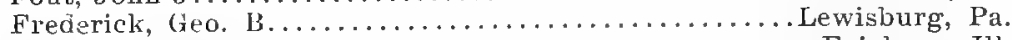

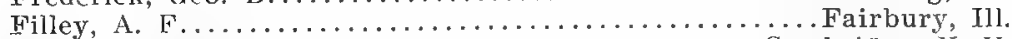

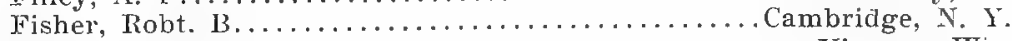

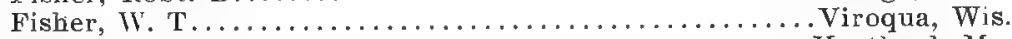

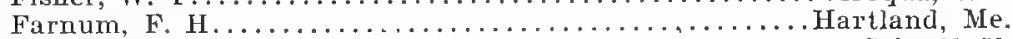

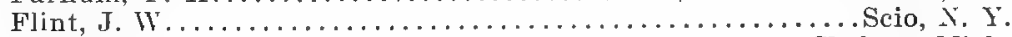

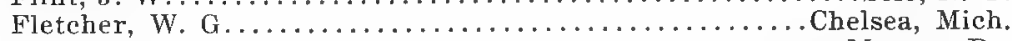

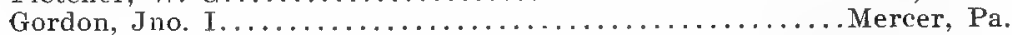

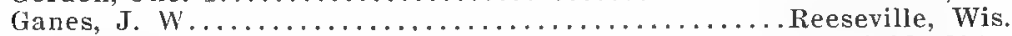

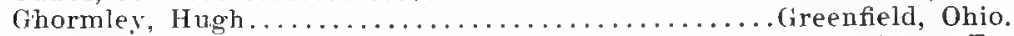

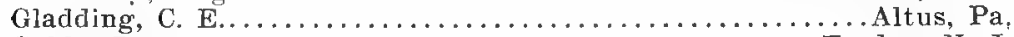

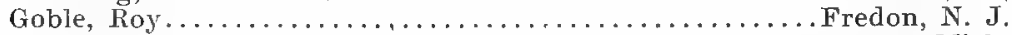

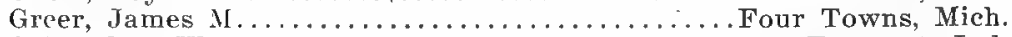

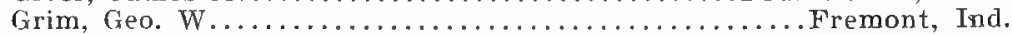

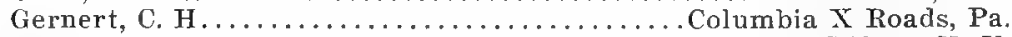

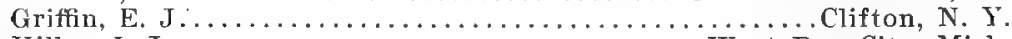

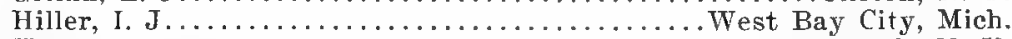

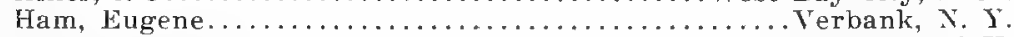

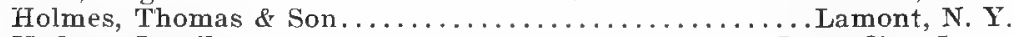

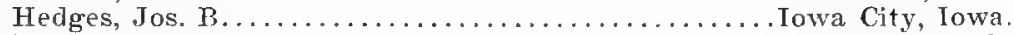

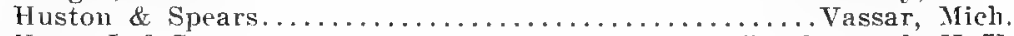
Hoag, J. \& Son...................... Tomhannock, $\mathrm{N}$. Y.

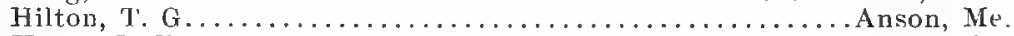

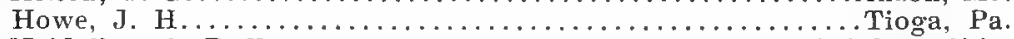

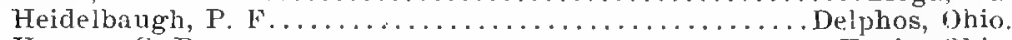

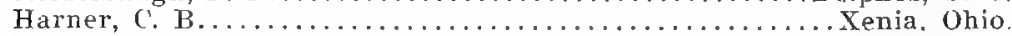

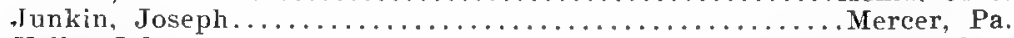

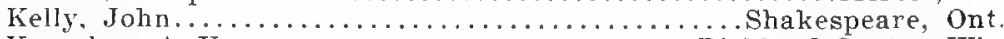
Krouskop, $\mathbf{1}, \mathrm{H}, \ldots \ldots \ldots \ldots \ldots \ldots \ldots \ldots \ldots$ Richland Center, Wis.

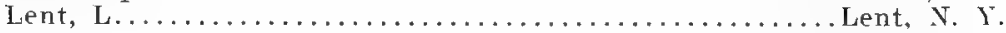

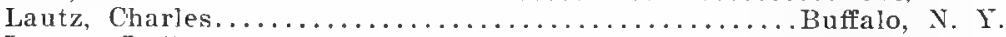

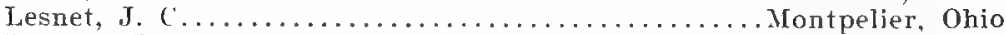

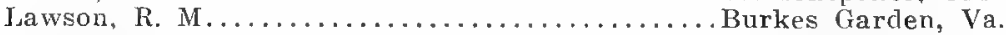

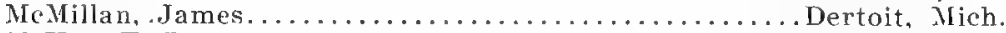

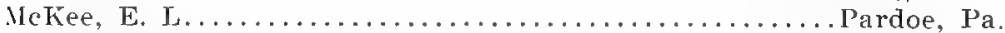

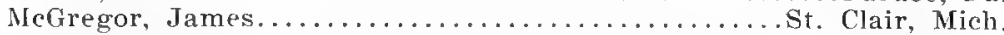

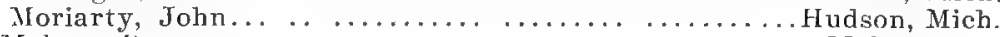

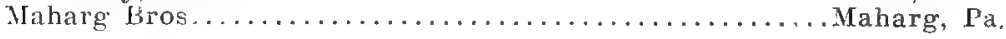


Mead, H. D.

Busti, N. Y.

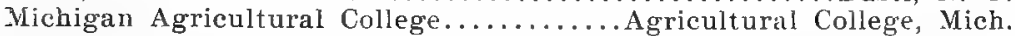

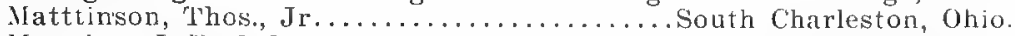

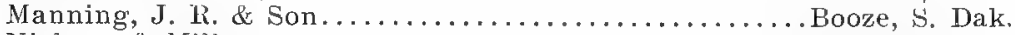

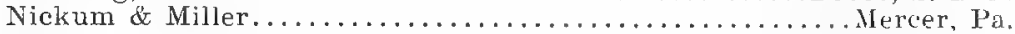
Niver, Charles W....................West Copake, $X$. $Y$.

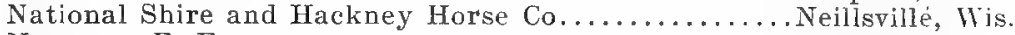

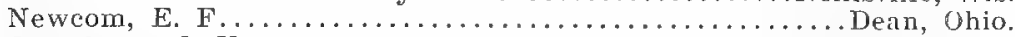

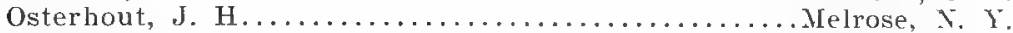

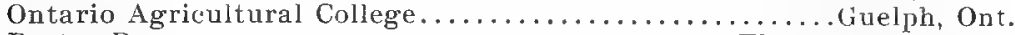

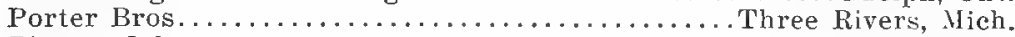

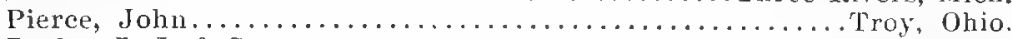

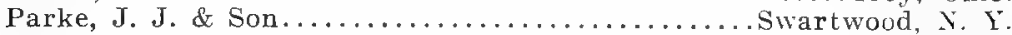

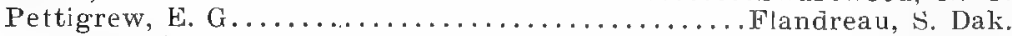

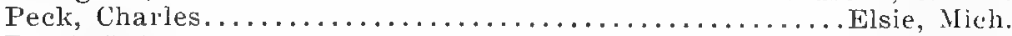

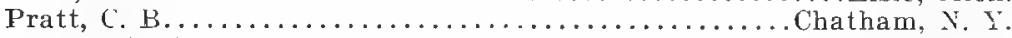

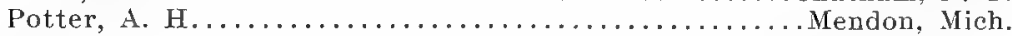

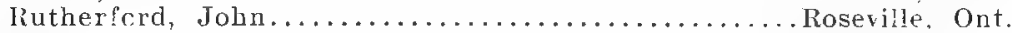

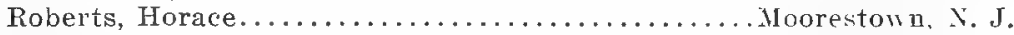

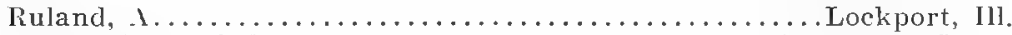

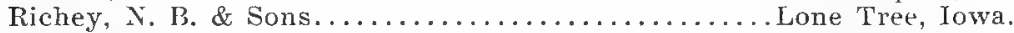

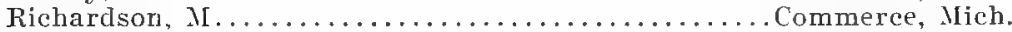

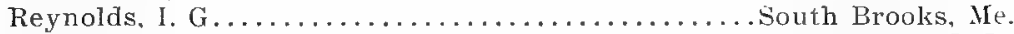

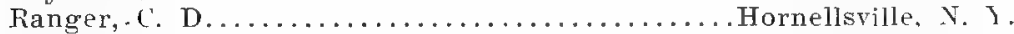

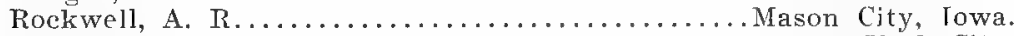

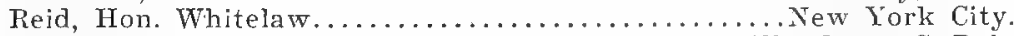

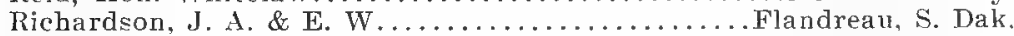

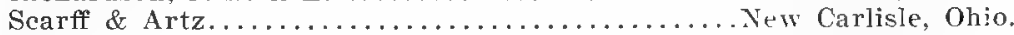

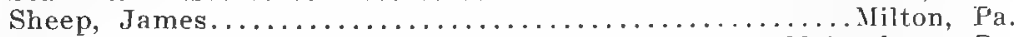

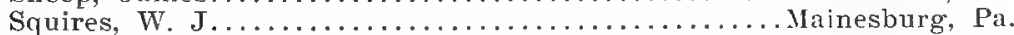

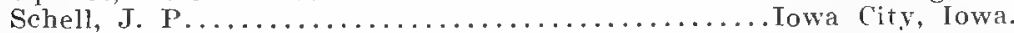

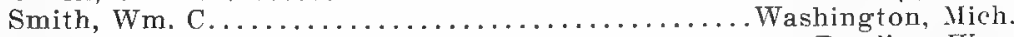

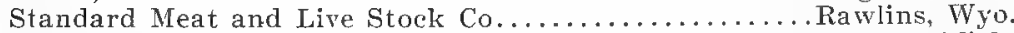

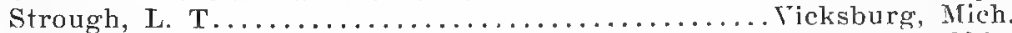

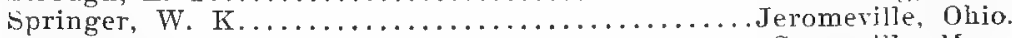

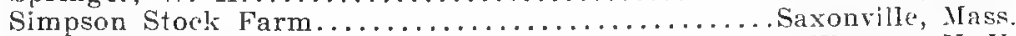

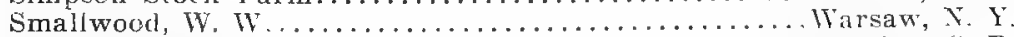

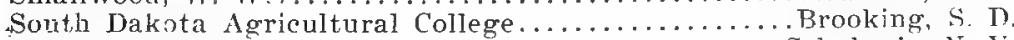

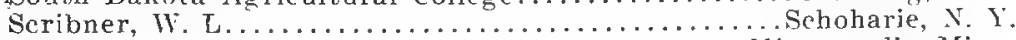

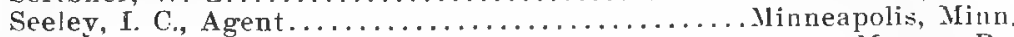

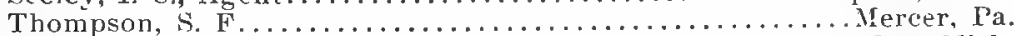

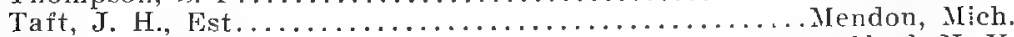

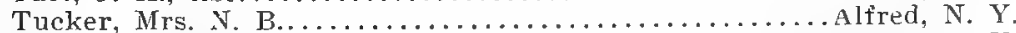

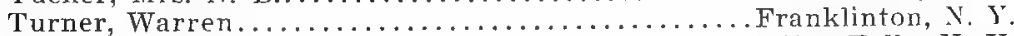

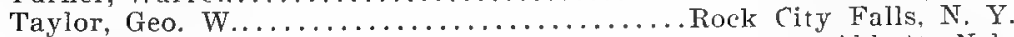

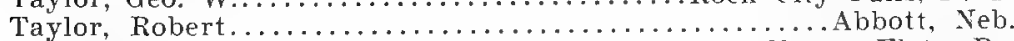

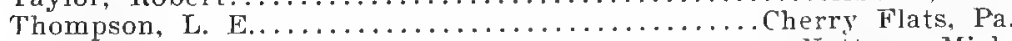

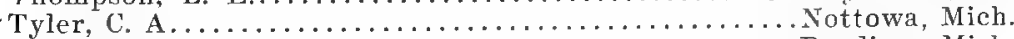

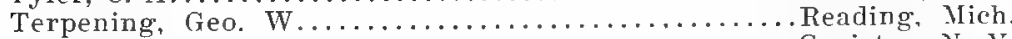

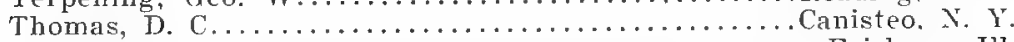

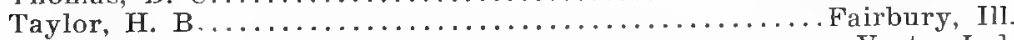

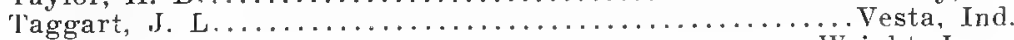

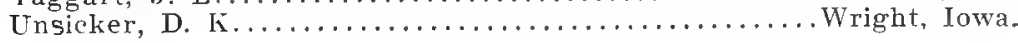




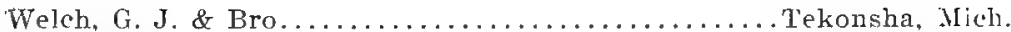
Tood, James................................... Kísco, N. Y.

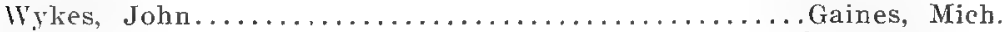
Woodward \& Jaques................Wright's Corners, $Y$. Y.

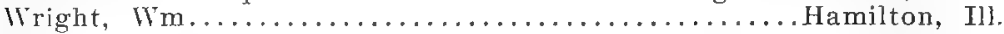

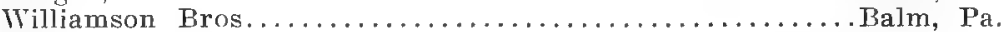

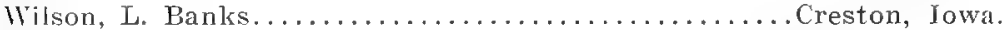

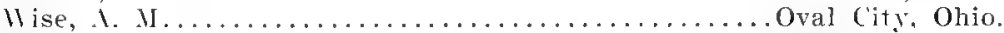

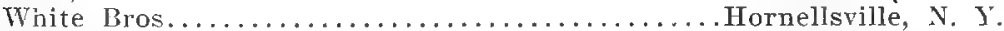

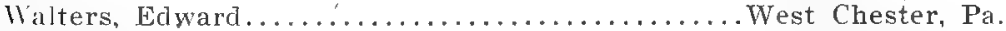

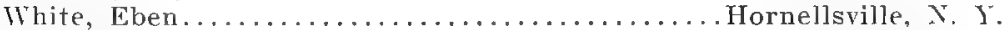

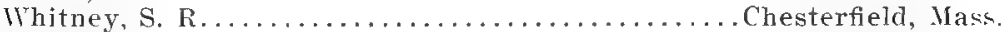

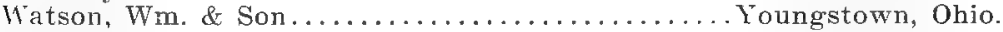

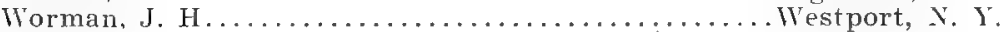

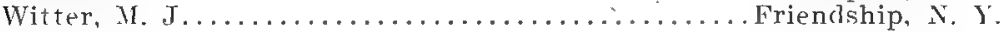

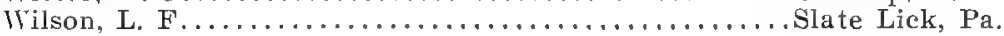

\section{Breeders of Oxford Down Sheep.}

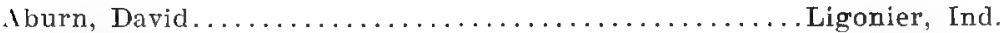

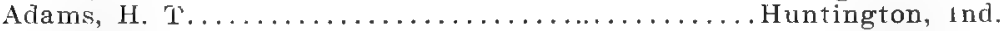

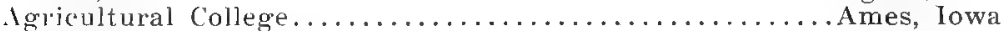

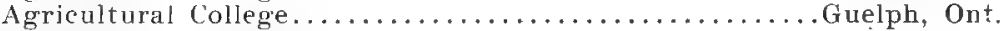

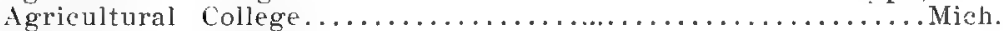

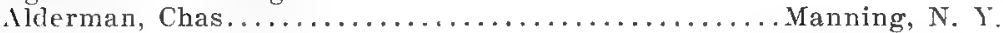

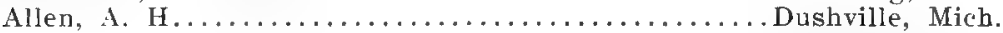

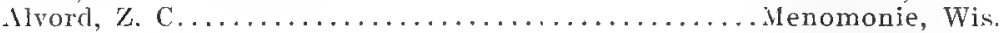

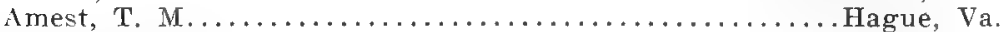

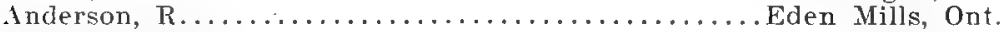

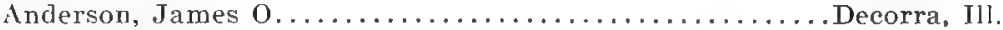

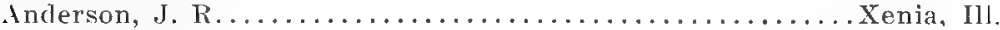

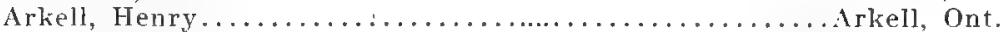

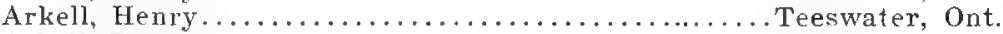

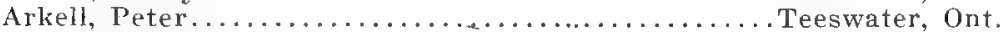

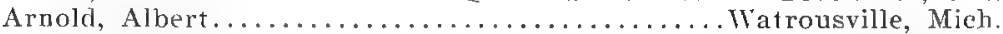

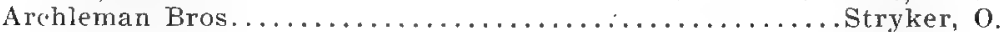

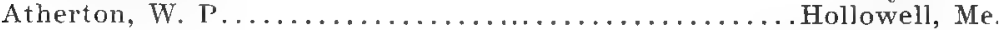

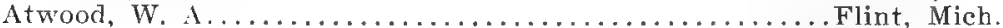

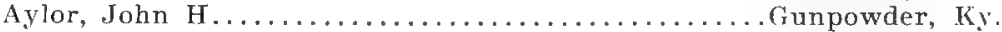

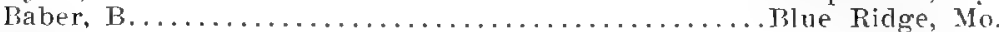

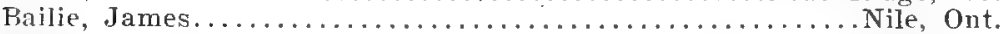

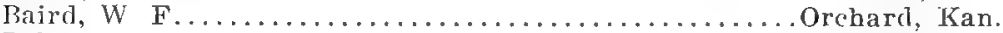

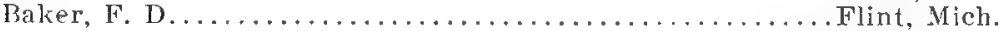

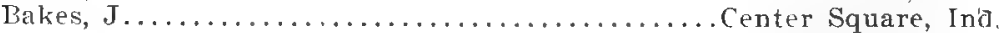

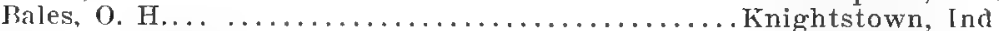

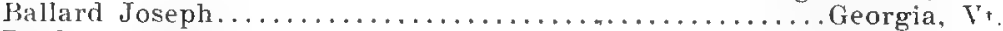

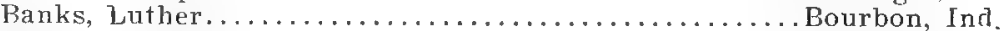

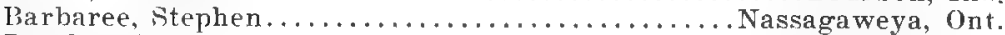

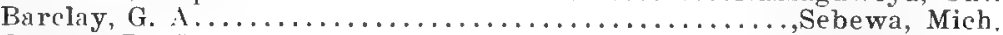

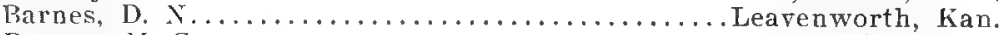

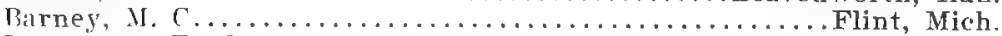

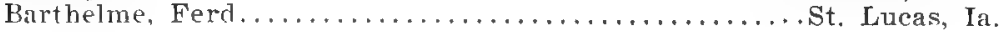


Rates, John

Moltke, Ont.

Bates, W. C.

Parsippany, $X$.

Beach, Faton.

Cleveland. $\mathrm{X}$. I.

Bean, Abraham

Bright, Ont.

Beard, Edward.

... Montpelier, 0

lieattie, W. $\mathrm{H}$. . .

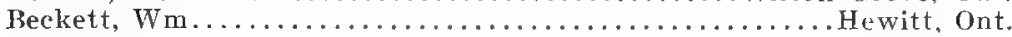

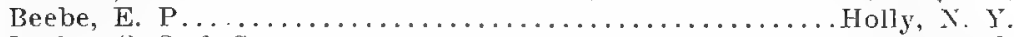

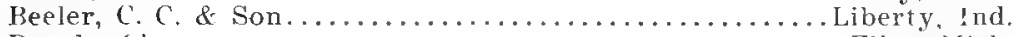

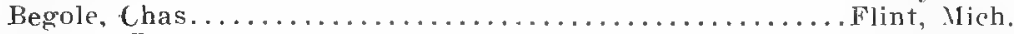

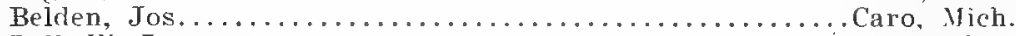

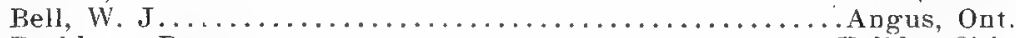

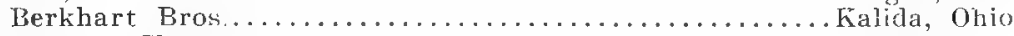

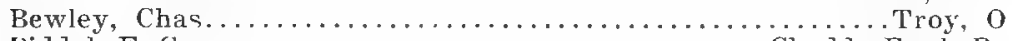

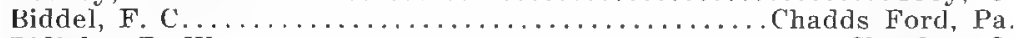

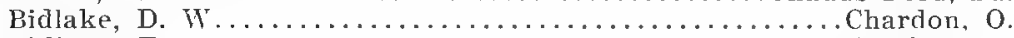

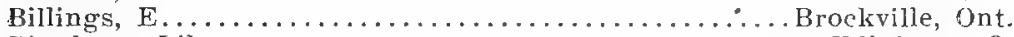

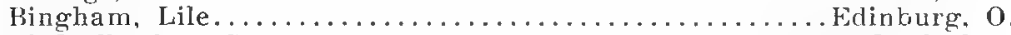

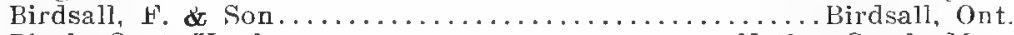

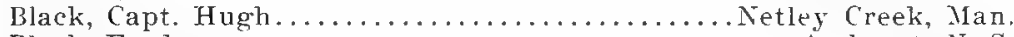

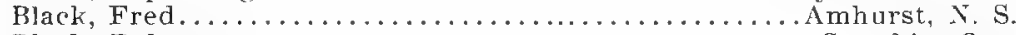

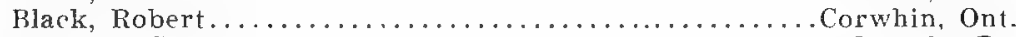

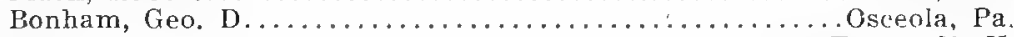

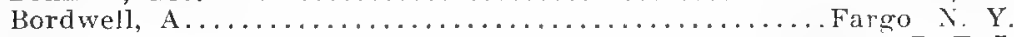

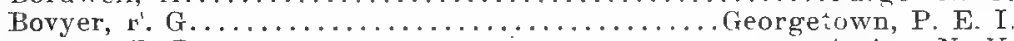

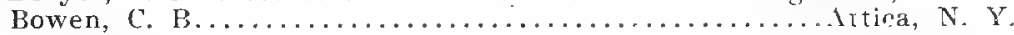

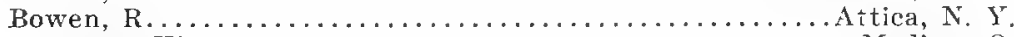

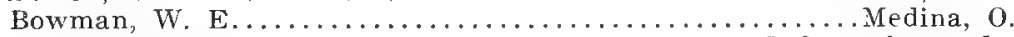

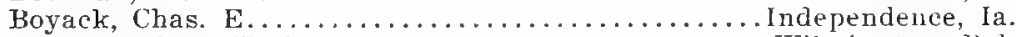

Bradford, Mrs. E. G......................Wilmington, Del.

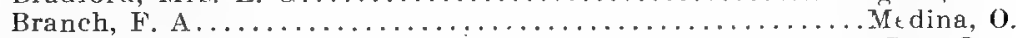

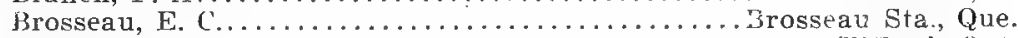

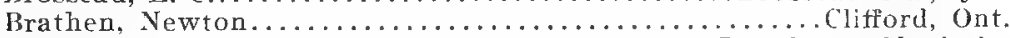

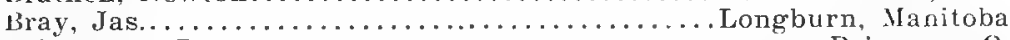

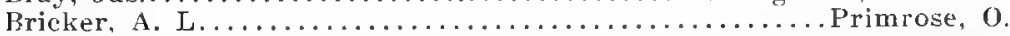

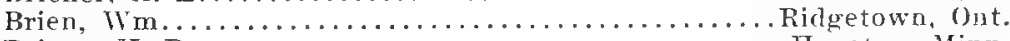

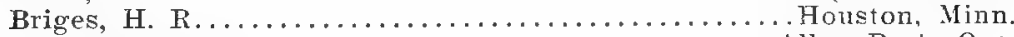

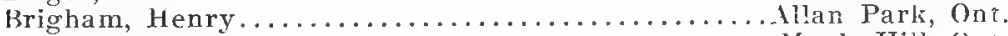

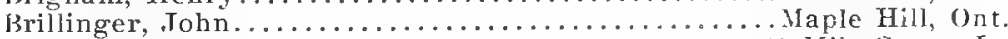

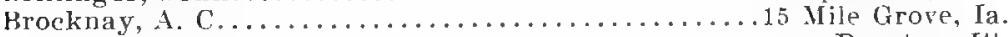

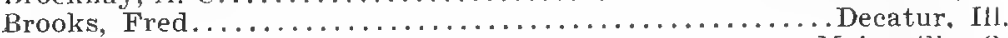

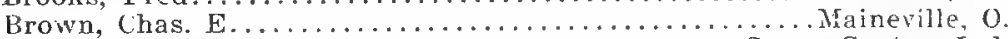

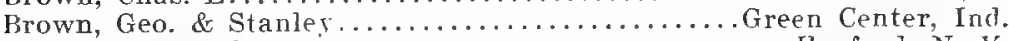

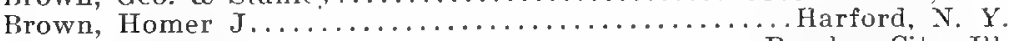

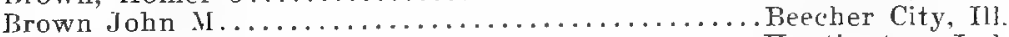

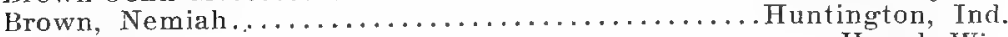

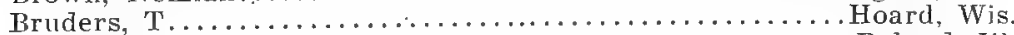

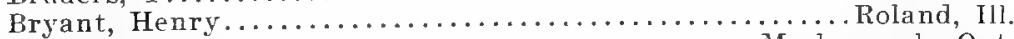

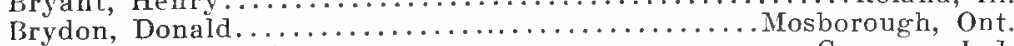

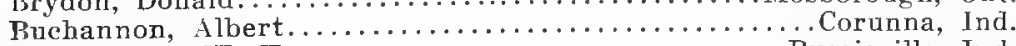

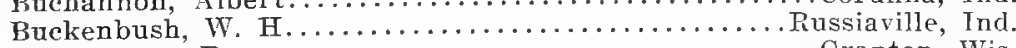

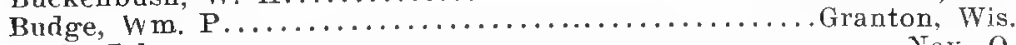

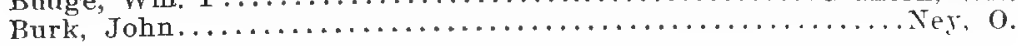


Burrington, John R

Grand Blane, Mich.

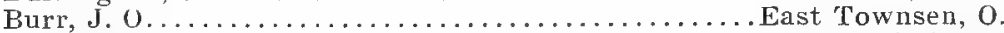

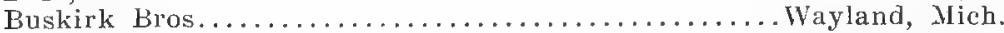

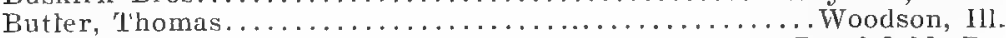

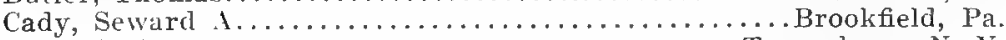

Cady, s. $1 \ldots \ldots \ldots \ldots \ldots \ldots \ldots \ldots \ldots \ldots \ldots \ldots \ldots \ldots$ Troopsburg, N. I.

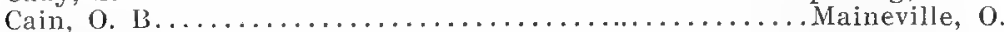

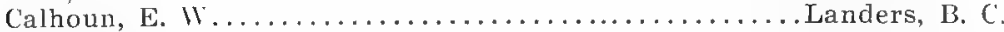

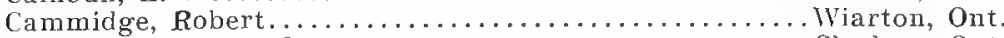

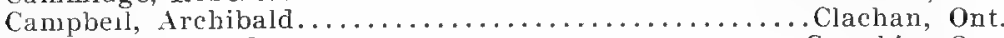

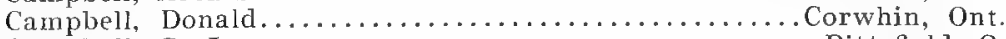

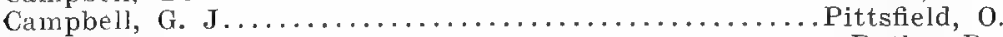

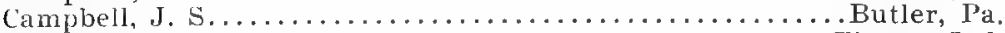

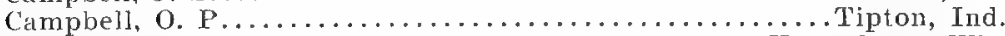

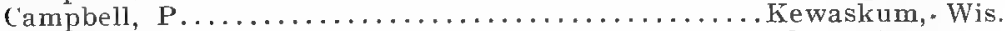

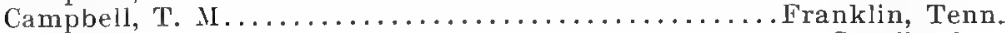

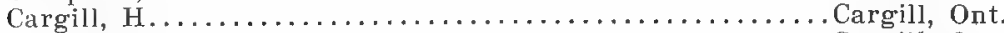

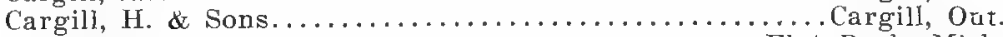

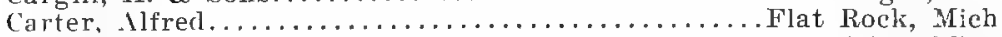

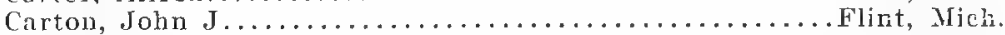

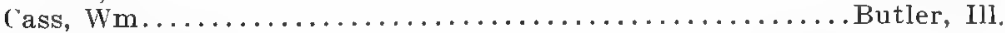

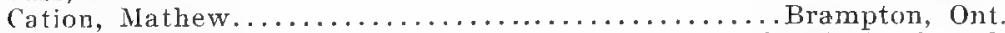

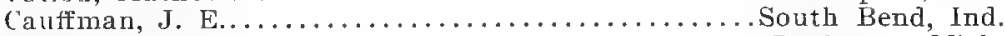

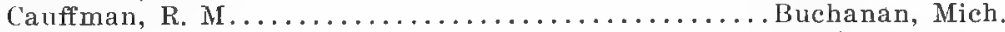

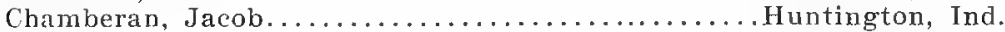

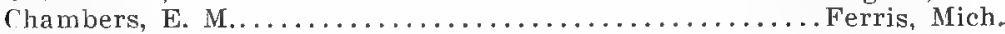

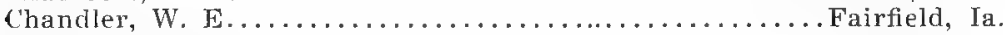

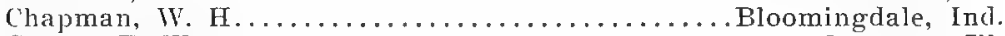

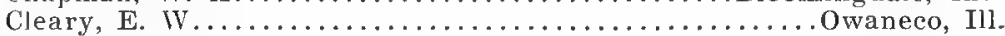

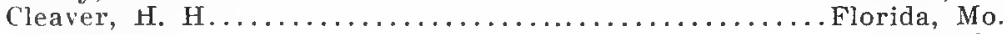

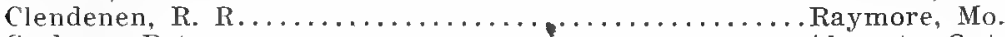

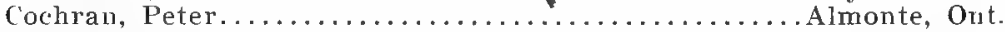

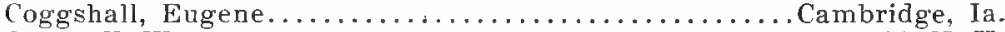

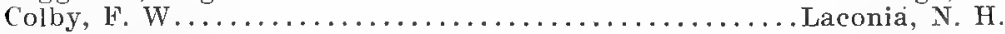

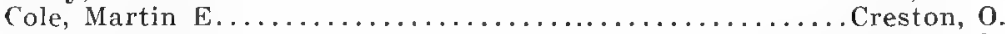

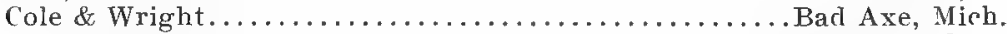

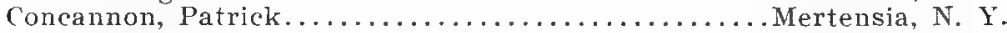

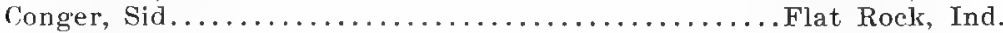

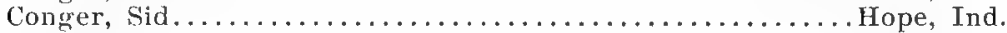

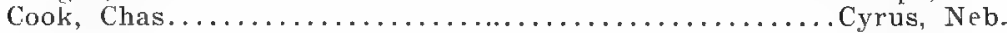

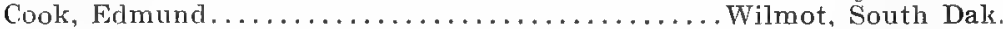

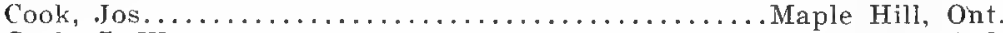

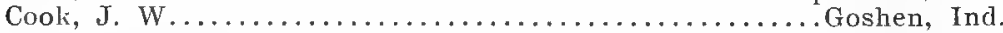

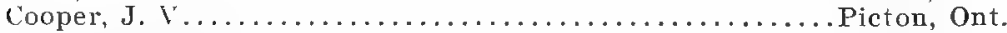

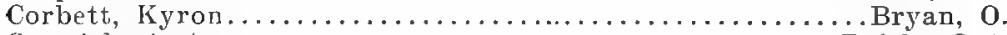

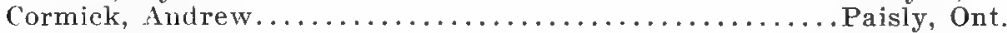

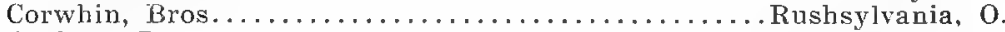

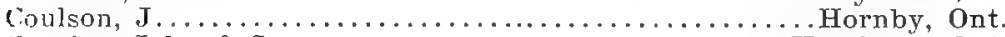

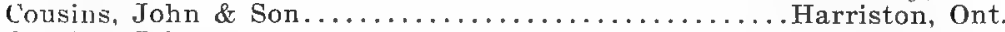

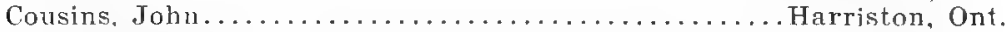

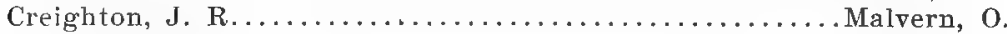

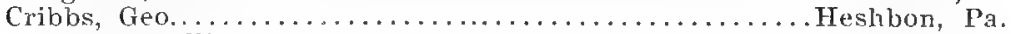

Croue, John W....................West Lebanon, Ind. 
Cunningham, Wm. \& Son.

(untioch, Ind

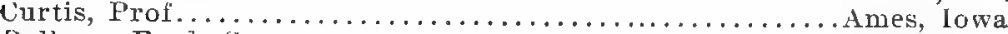

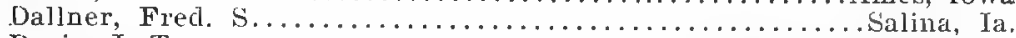

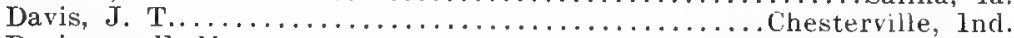

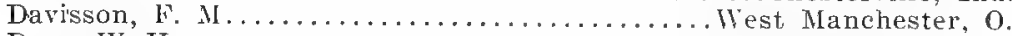

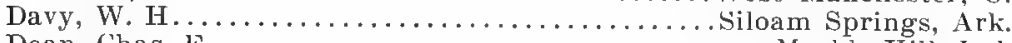

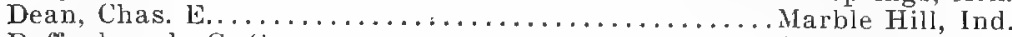

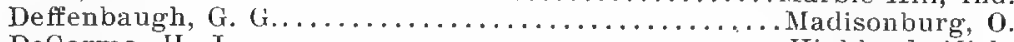

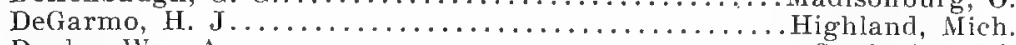

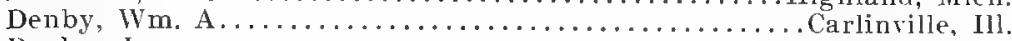

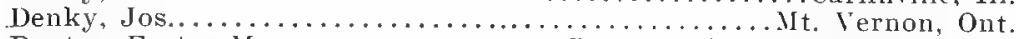

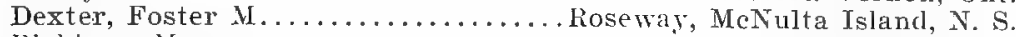

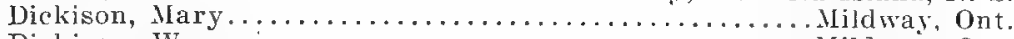

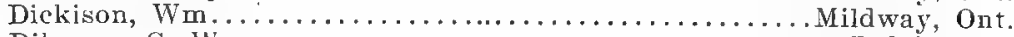

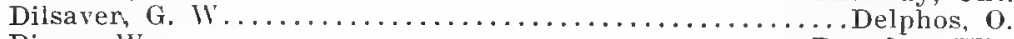

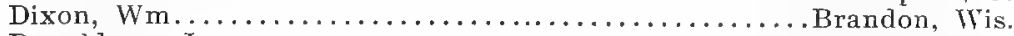

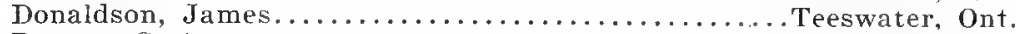

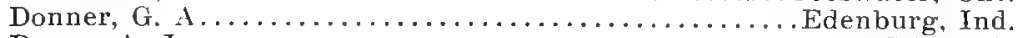

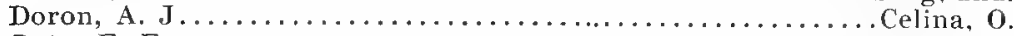

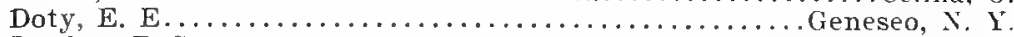

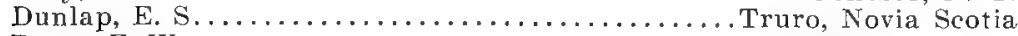

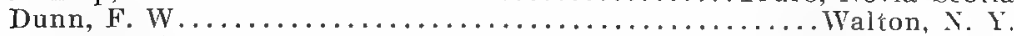

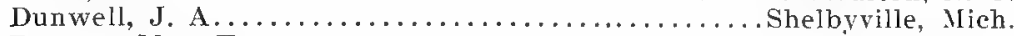

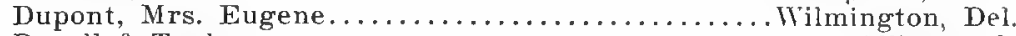

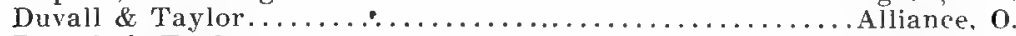

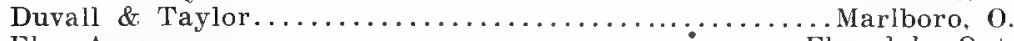

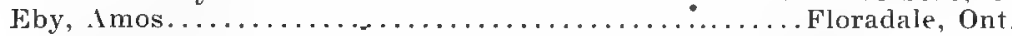

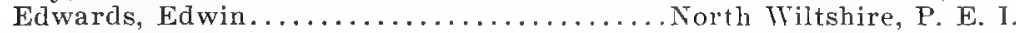

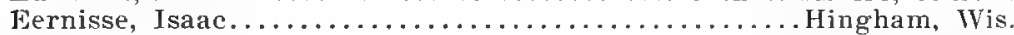

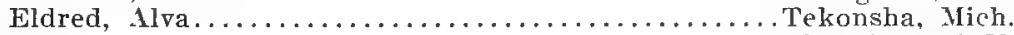

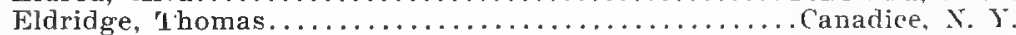

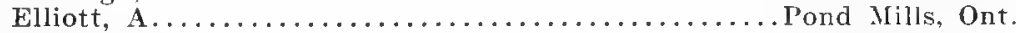

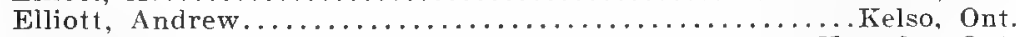

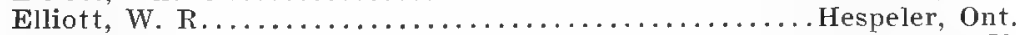

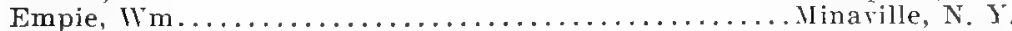

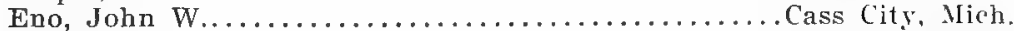

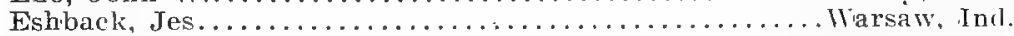

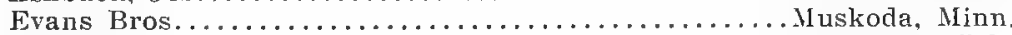

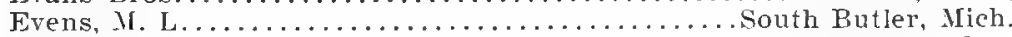

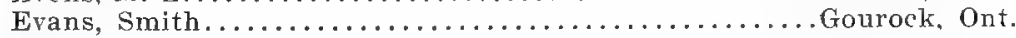

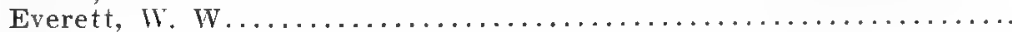

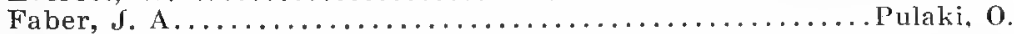

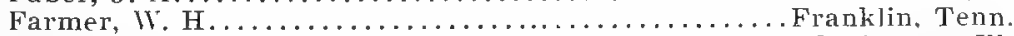

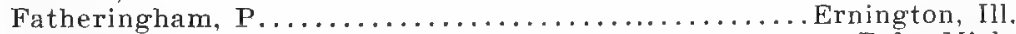

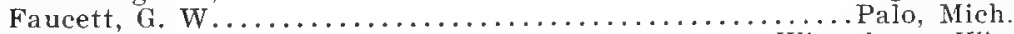

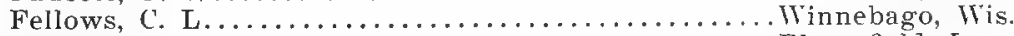

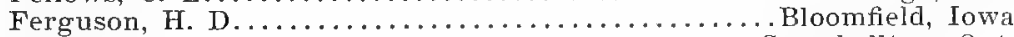

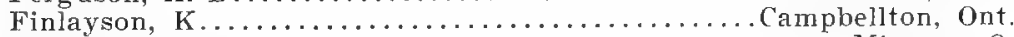

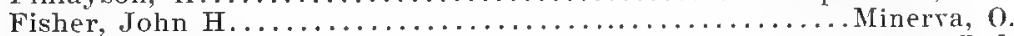

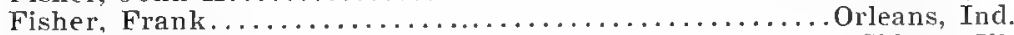

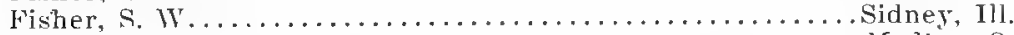

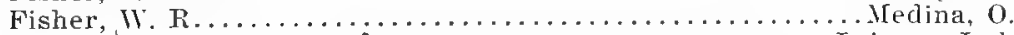

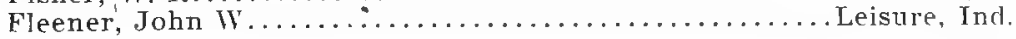




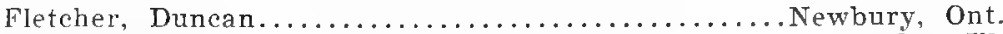

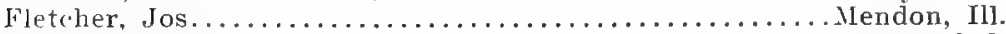

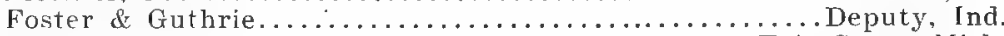

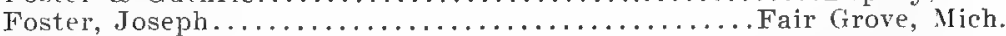

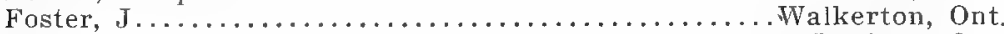

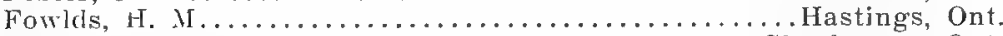

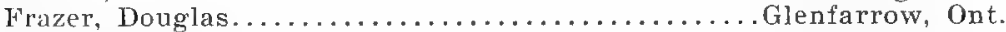

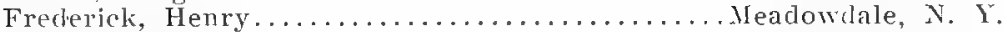

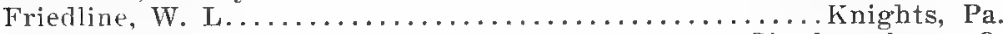

Fry, S. .1 . . . . . . . . . . . . . . . . . . . . .

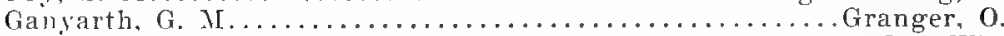

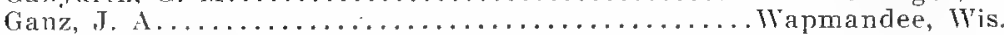

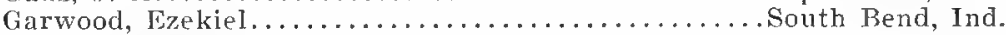

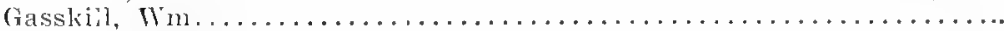

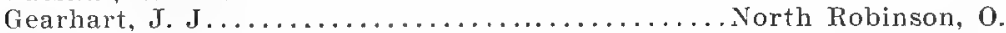

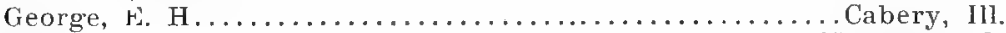

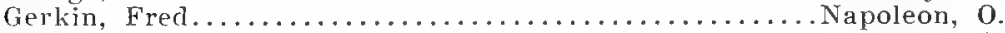

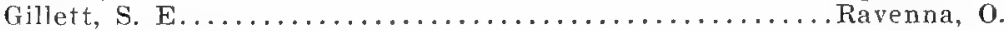

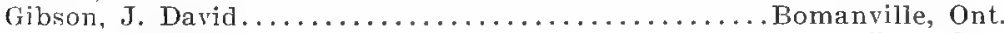

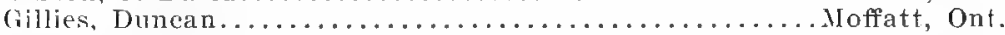

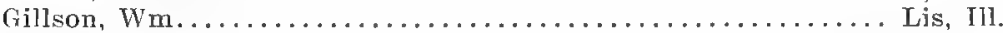

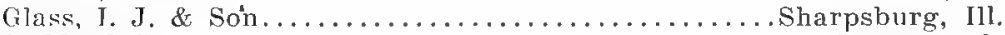

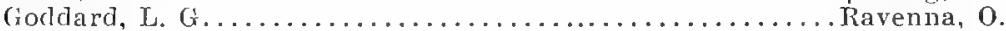

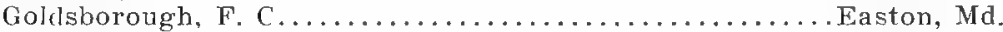

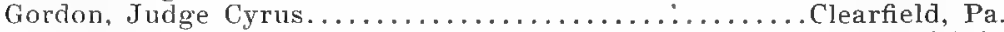

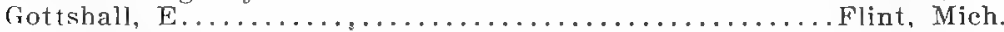

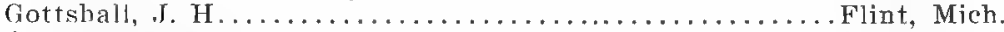

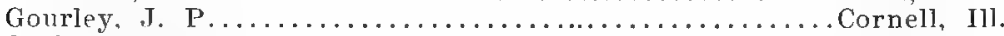

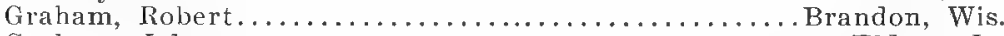

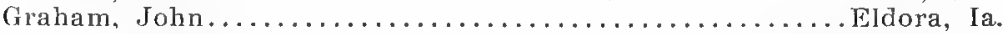

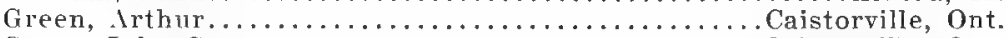

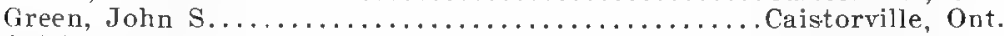

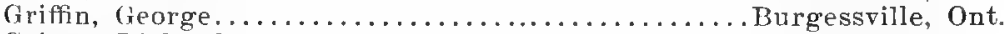

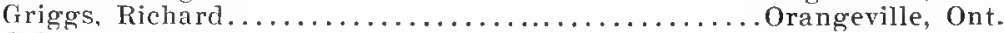

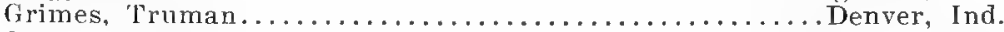

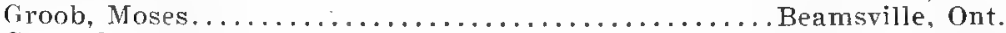

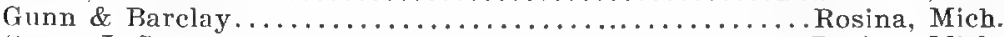

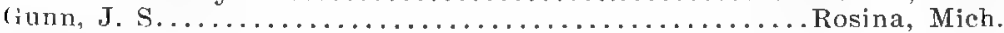

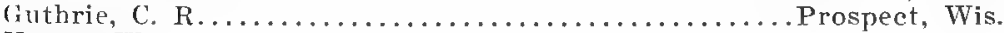

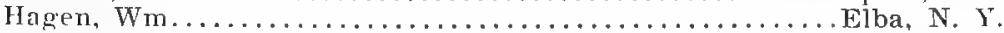

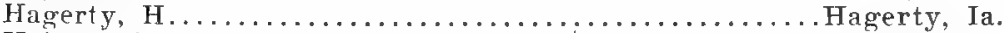

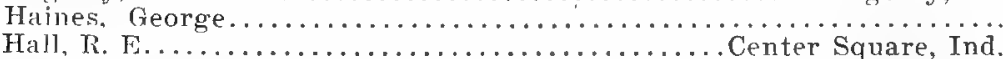

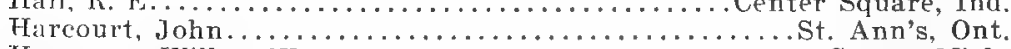

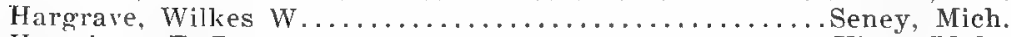

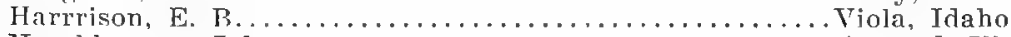

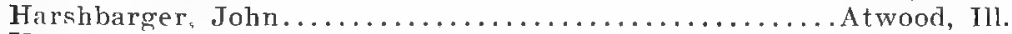

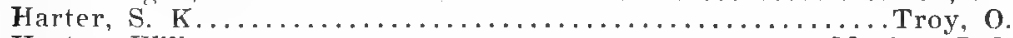

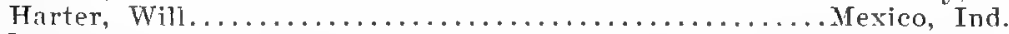

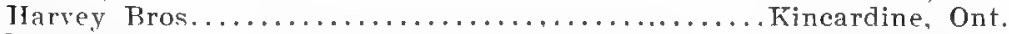

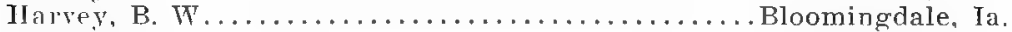

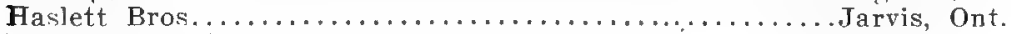

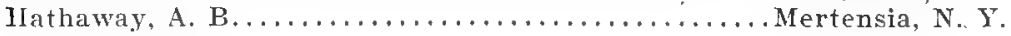


Henry, John.

Montpelier, 0 .

Henson, Ven

Huntington, Ind.

Hesskett Bros Fulton, $\mathrm{O}$.

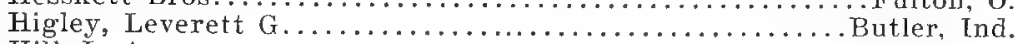

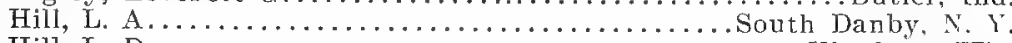

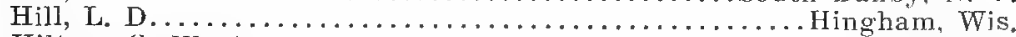

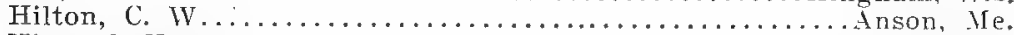

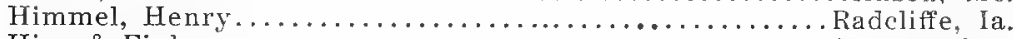

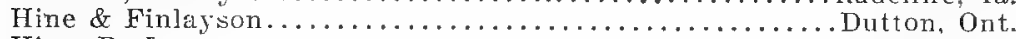

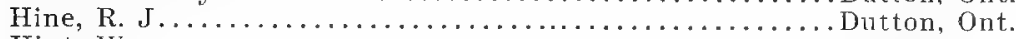

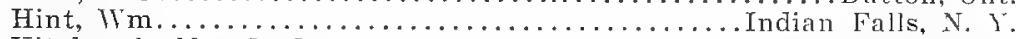

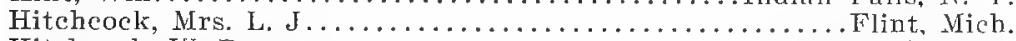

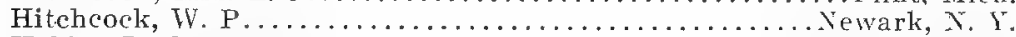
Hobbs, D. C. \& Sons. Hollingsworth, H. S Hobbs, Ind.

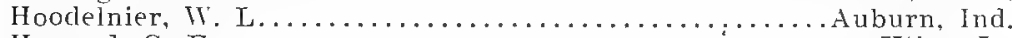

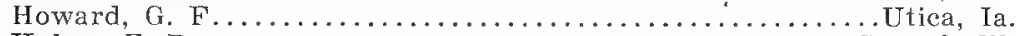

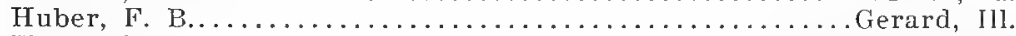

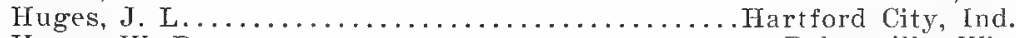

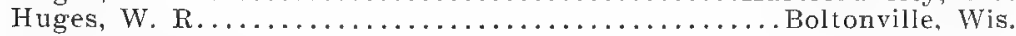

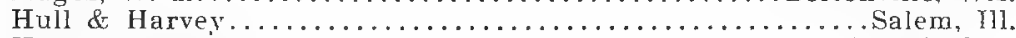
Hume, David. . Arkell, Ont.

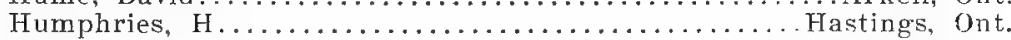

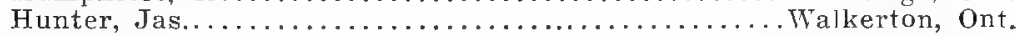

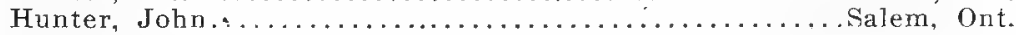

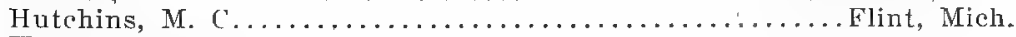
Huxford, John.

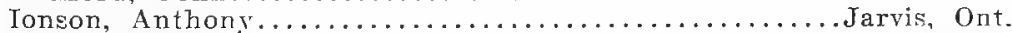

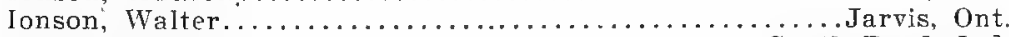

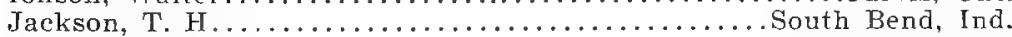

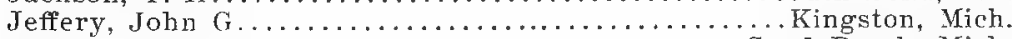

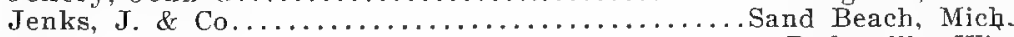

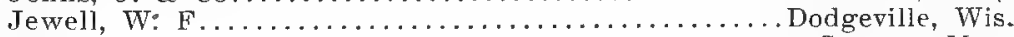

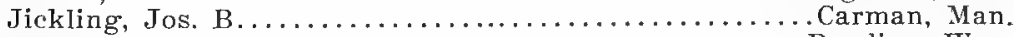

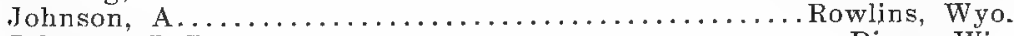

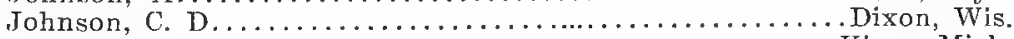

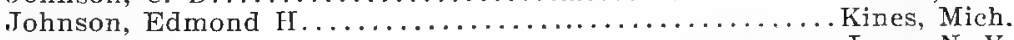

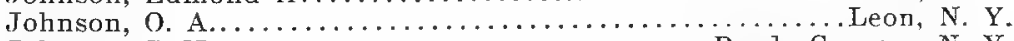

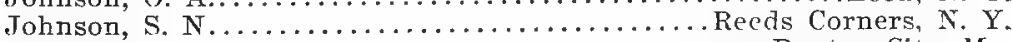

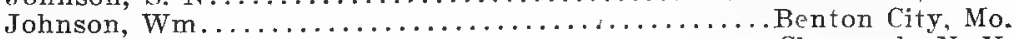

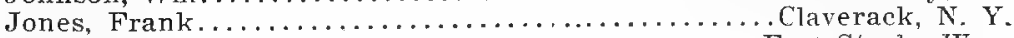

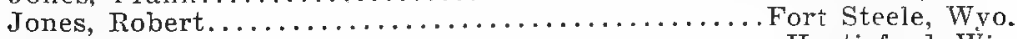

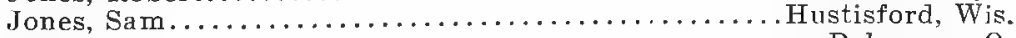

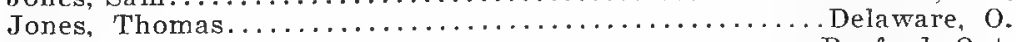

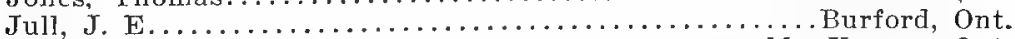

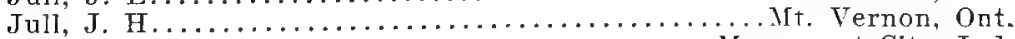

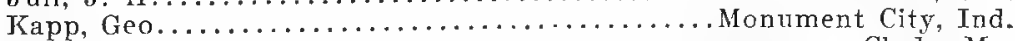

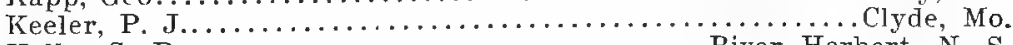

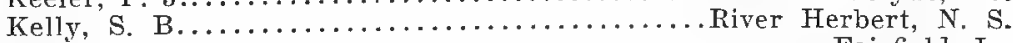

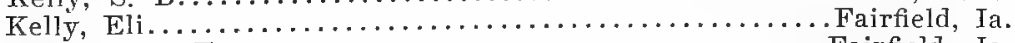

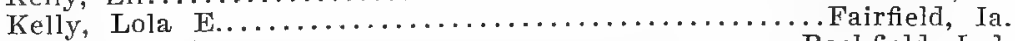

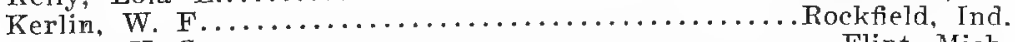

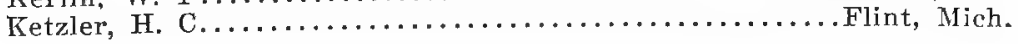




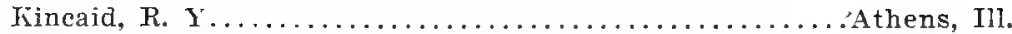

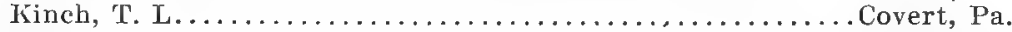

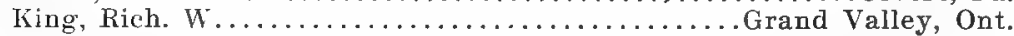

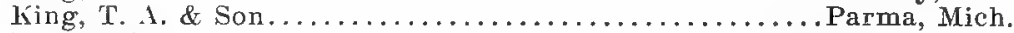

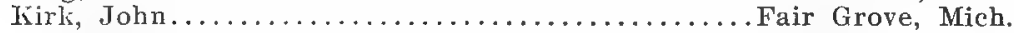

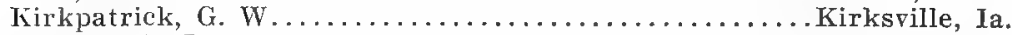

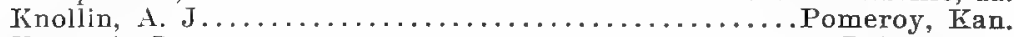

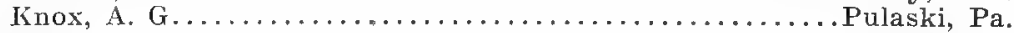

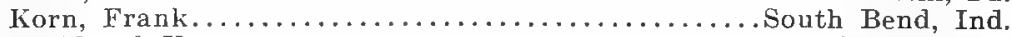

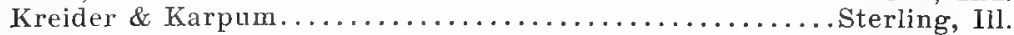

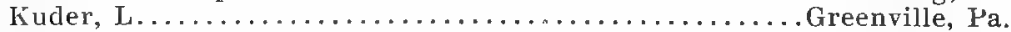

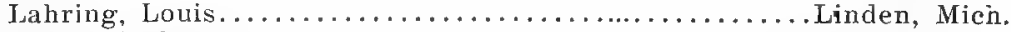

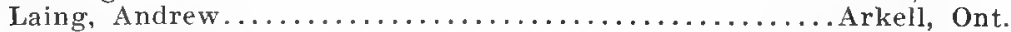

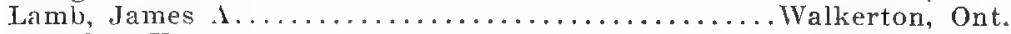

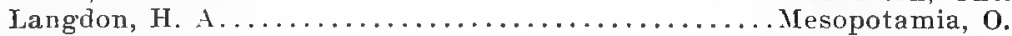

Large," (i. ( . . ............................ Taylorville, Ill.

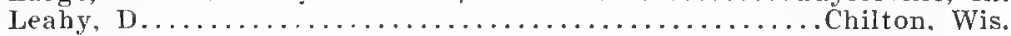

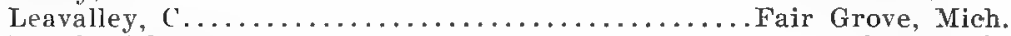

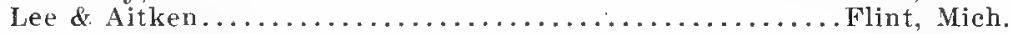

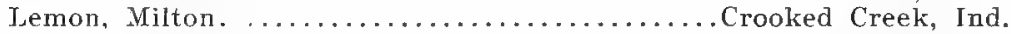

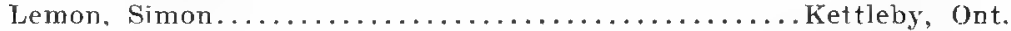

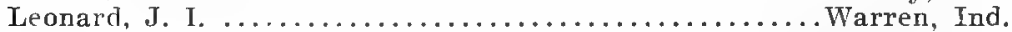

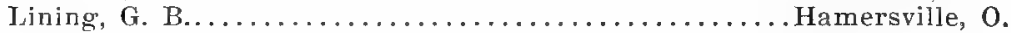

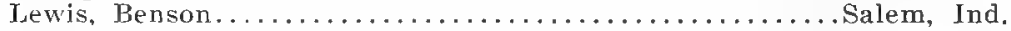

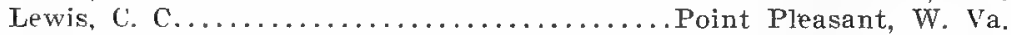

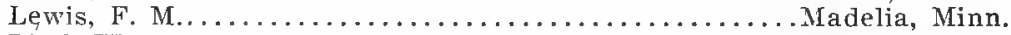

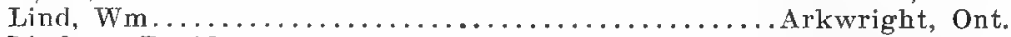

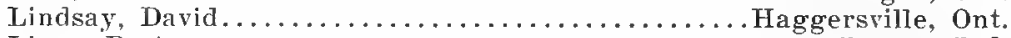

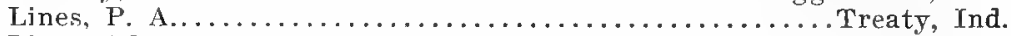

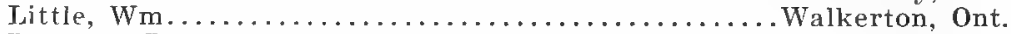

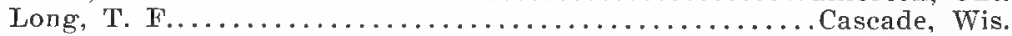

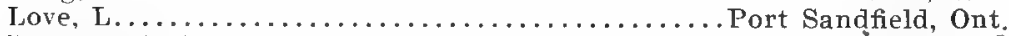

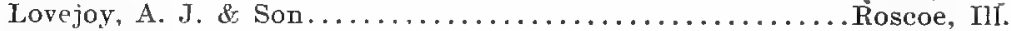

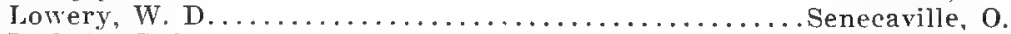

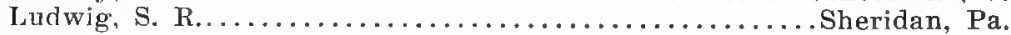

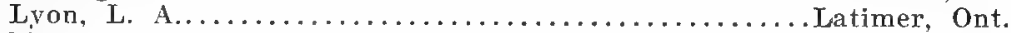

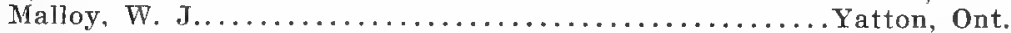

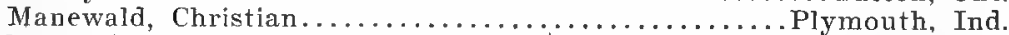

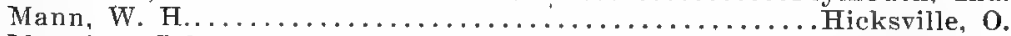

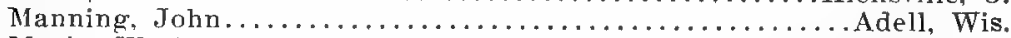

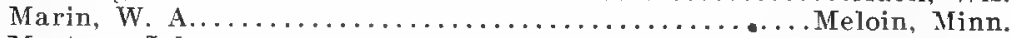

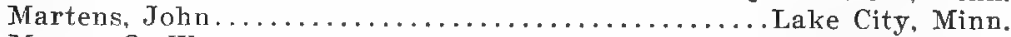

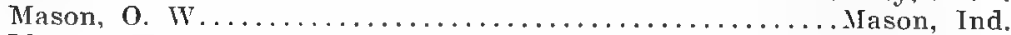

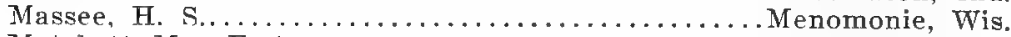

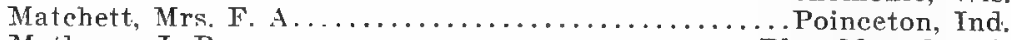

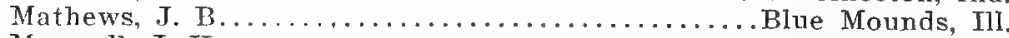

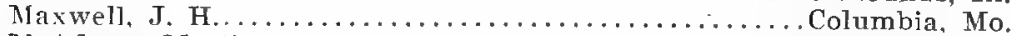

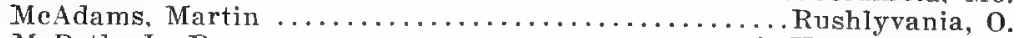

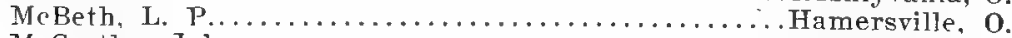

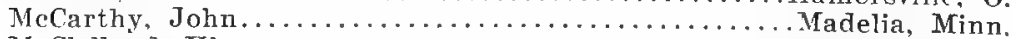

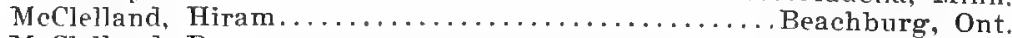

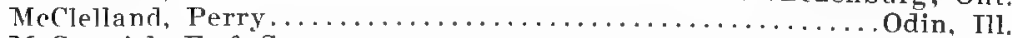

MeCormick, E. \& Sons......................... Hope, Wis. 
MeCracken, F. S

Kerrmoor, Pa. MeCracken, J. B. Muskegon, Mich. MeDonald, A. W St. Mary's, Ont. MeDonald, John Millbrook, N. S.

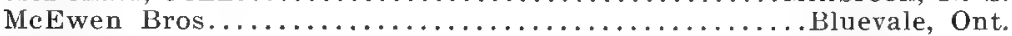

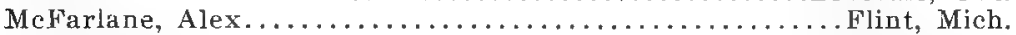

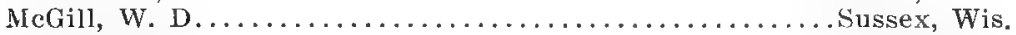

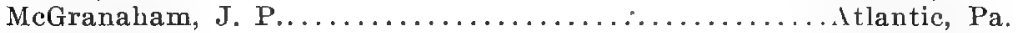
McIntosh, J. B..........................Windsor, 0.

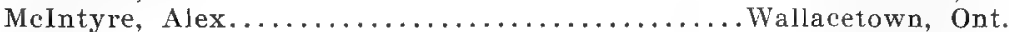

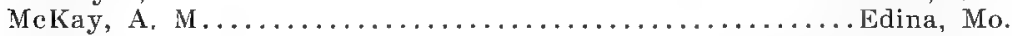

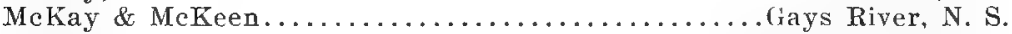

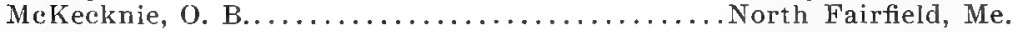

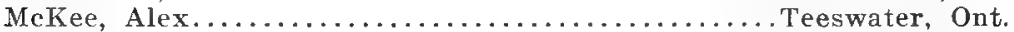

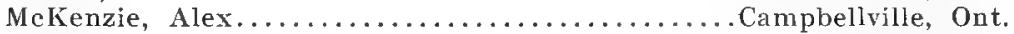

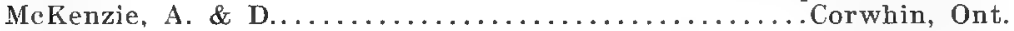

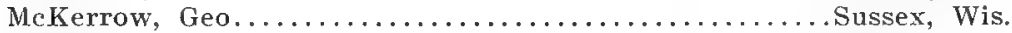

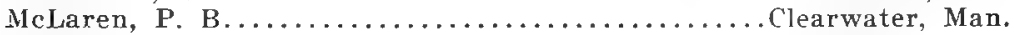

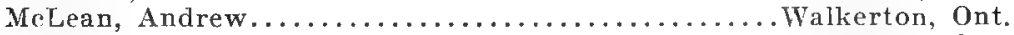

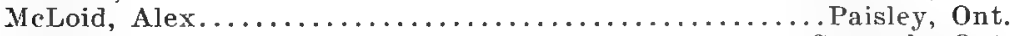

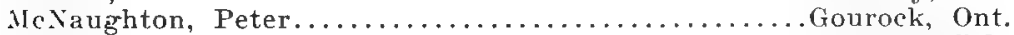

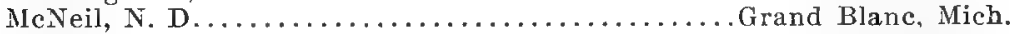

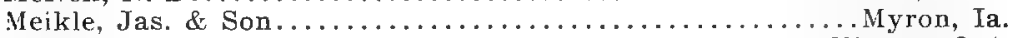

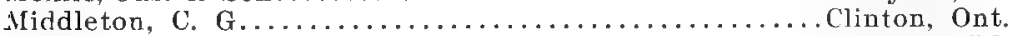

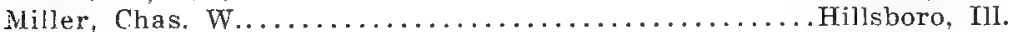

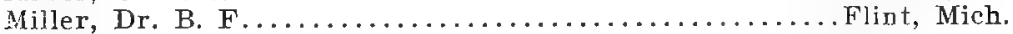

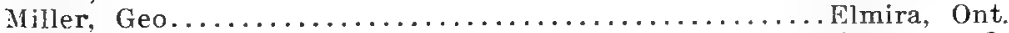

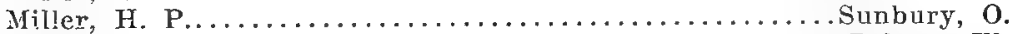
Miller, $\bar{\jmath} . \mathrm{W}$. Palmer, Ill. Miller, W. I Mexico, Ind.

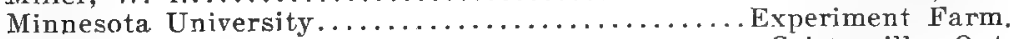

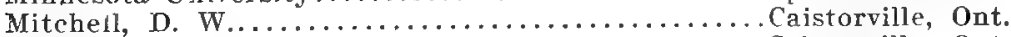

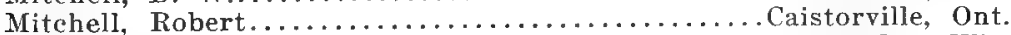

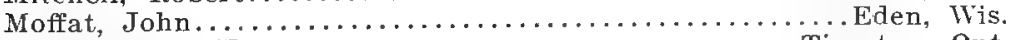

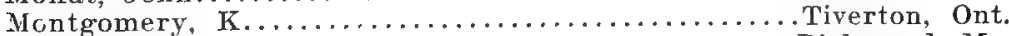

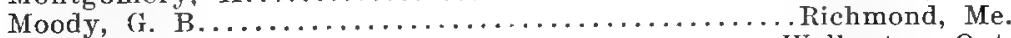

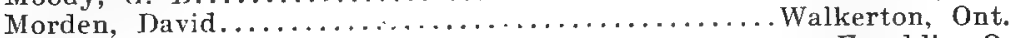

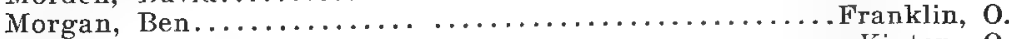

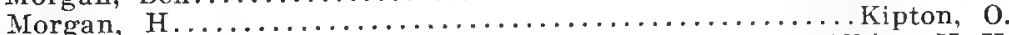

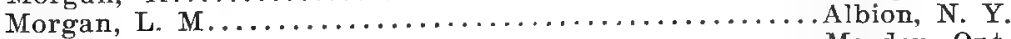

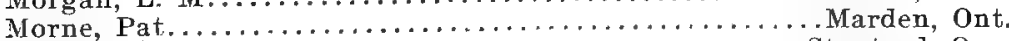

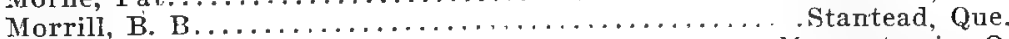

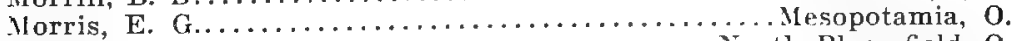

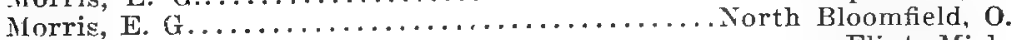

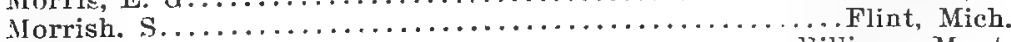

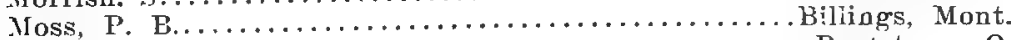

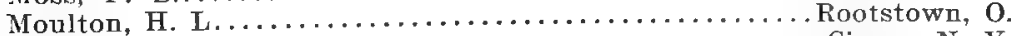

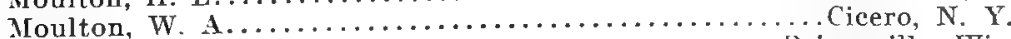
Mowers, J. I

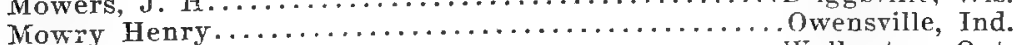

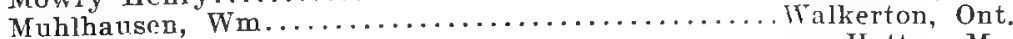

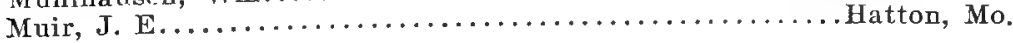


Murplyy, Chris. Sanilac Center, Mich. Murphy, J. W. Cass City, Mich.

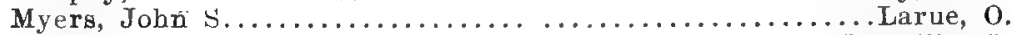

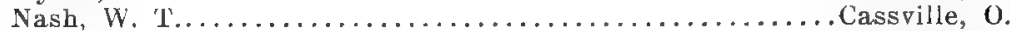

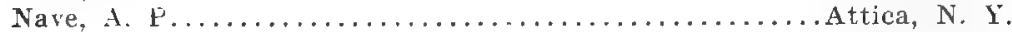

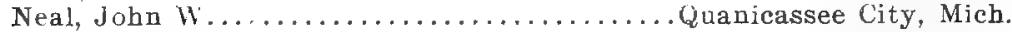

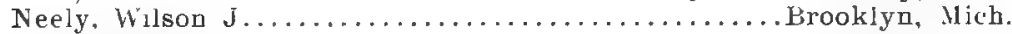

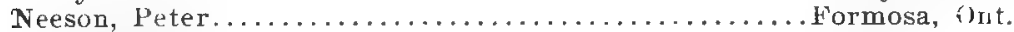

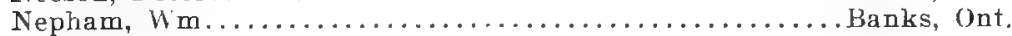

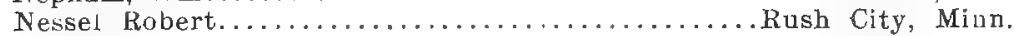

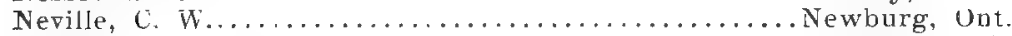

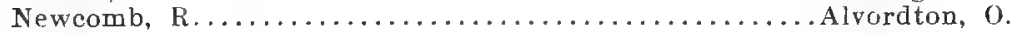

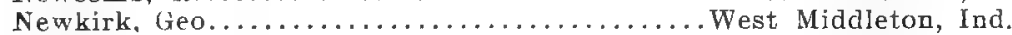

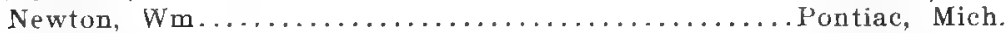

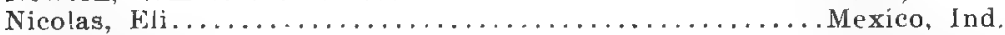

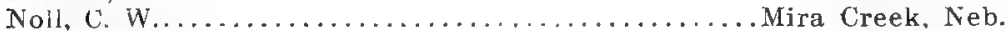

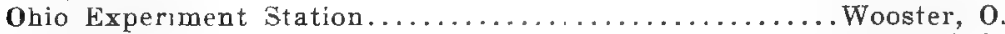

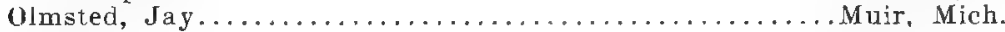

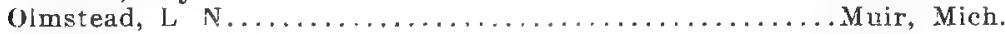

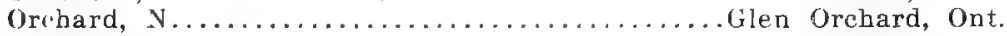

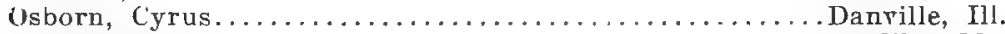

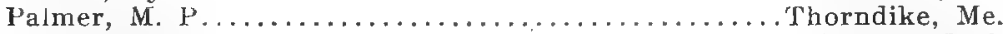

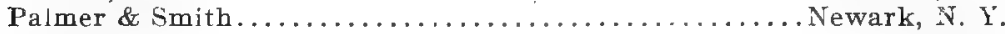

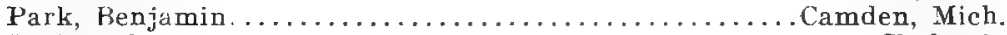

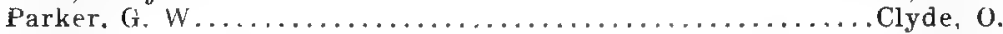

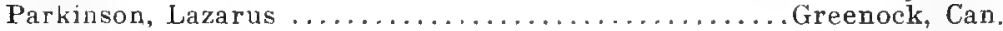

Parnell, R. M...........................Wyevale, Ont.

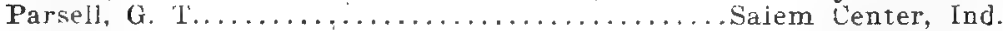

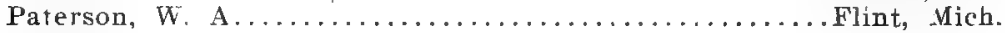

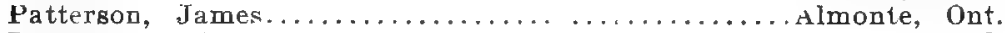

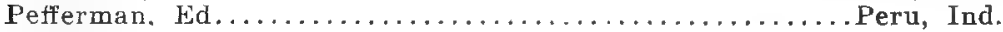

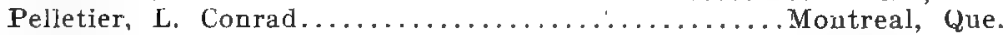

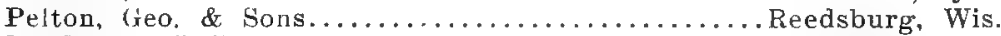

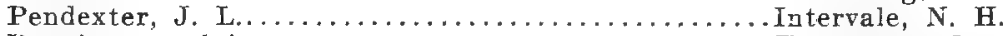

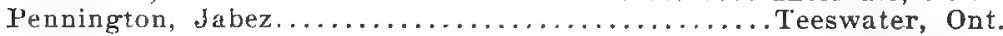

Perry, H. R. \& Son......................llington, Mich.

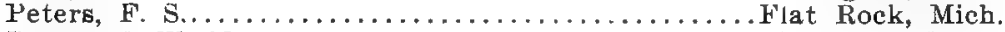

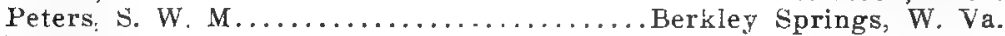

Petty Rufus

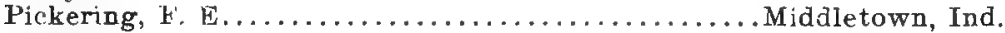

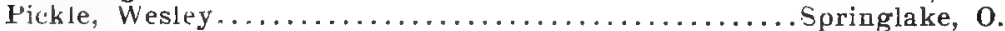

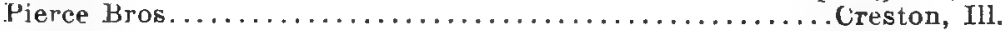

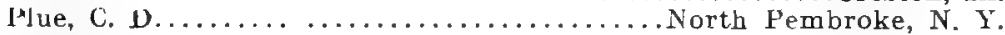

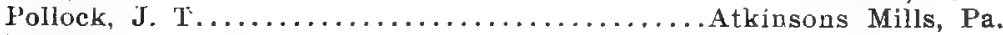

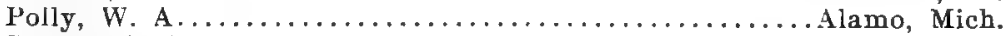

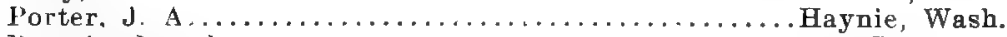

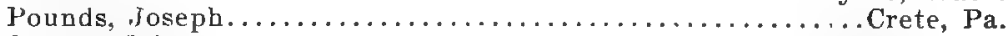

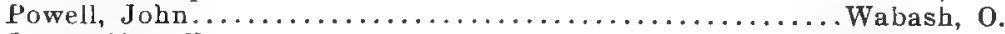

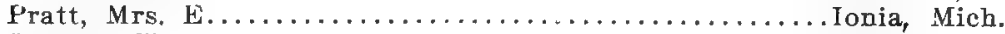

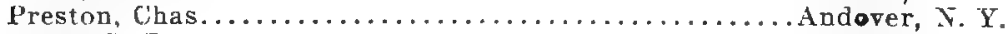

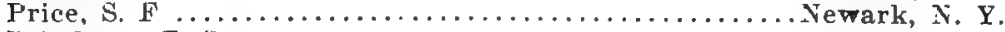

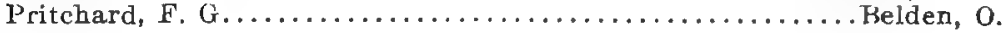


Privett, Uriah \& Co.

Greensburg, Ind.

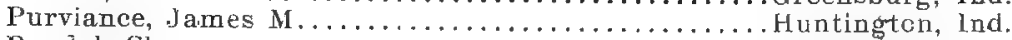

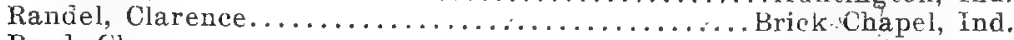

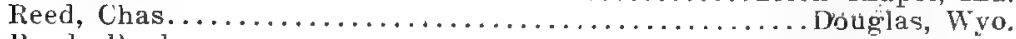

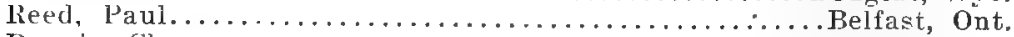

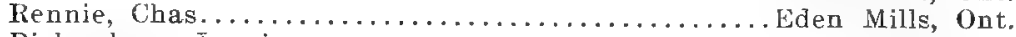

Richardson, Jennie.................... Indianapolis, Ind.

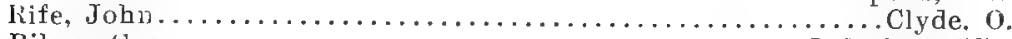

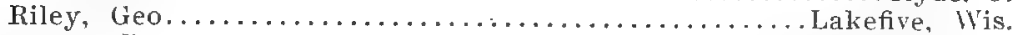

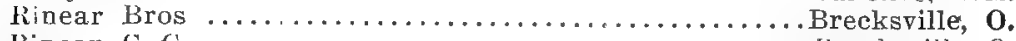

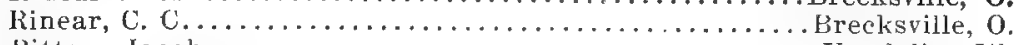

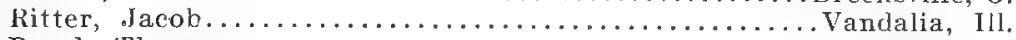

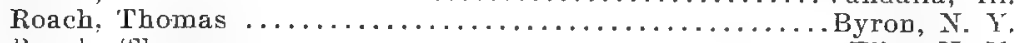

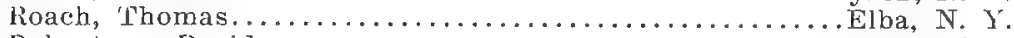

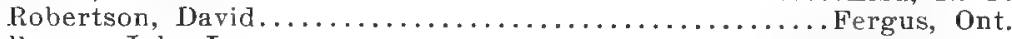

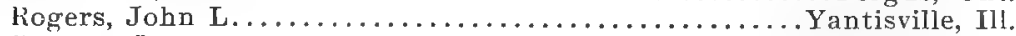

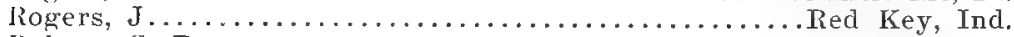

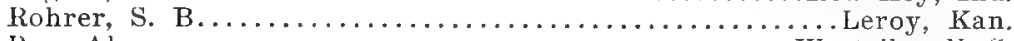

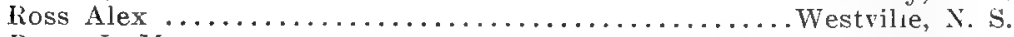

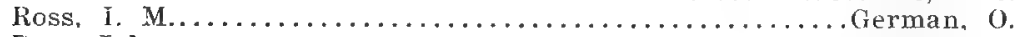

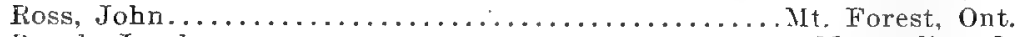

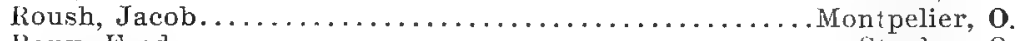

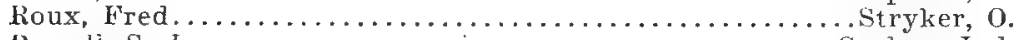

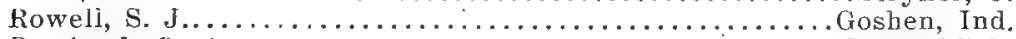

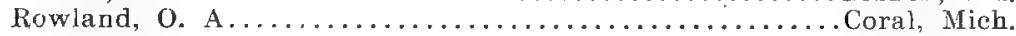

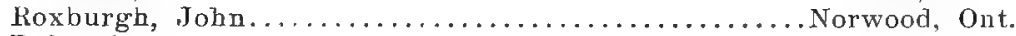

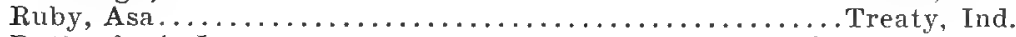

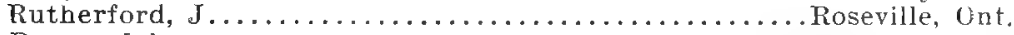

Ryan, John.

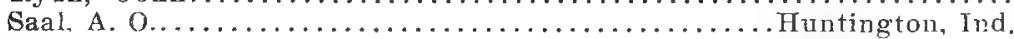

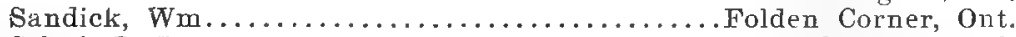

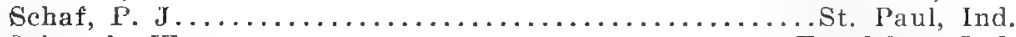

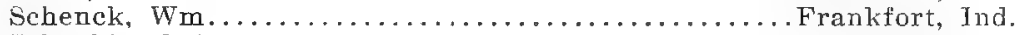

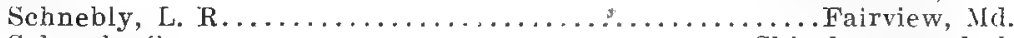

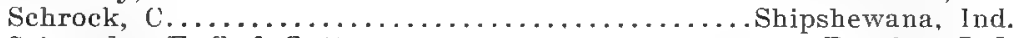
Schroeder, F. C. \& C. C........................Bourbor, Ind.

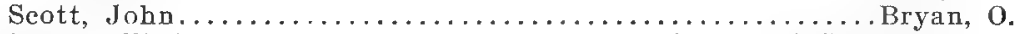

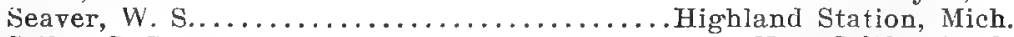

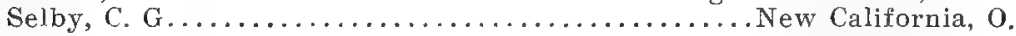

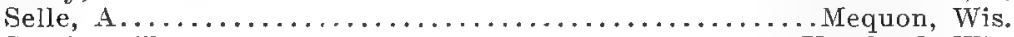

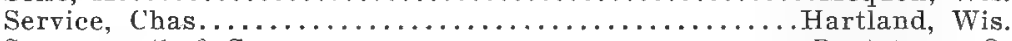

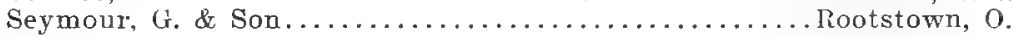

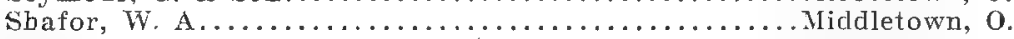

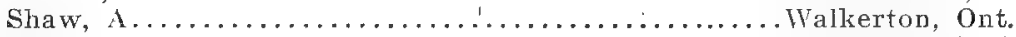

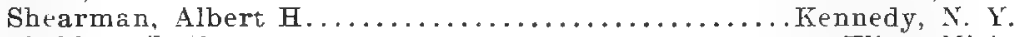

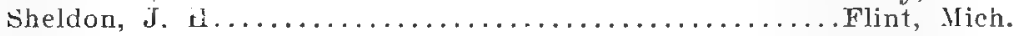

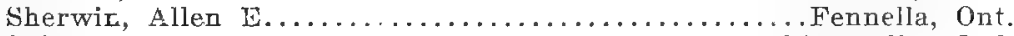

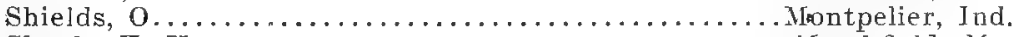

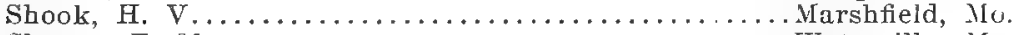

Shores, F. I . . . . . . . . . . . . . . . . . . . Waterville, Me.

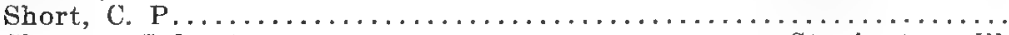

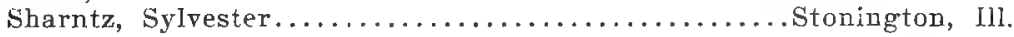


Simpson Stock Farm

Saxonville, Mass,

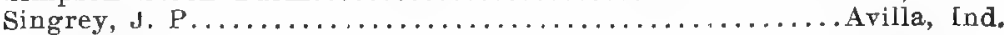

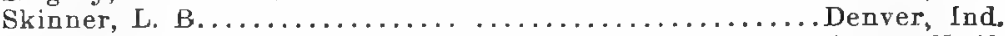

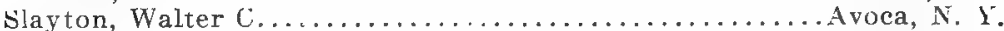

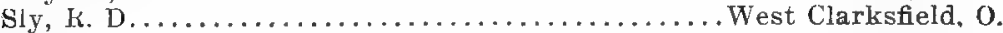

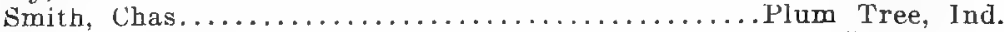

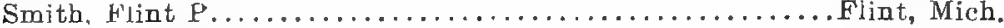

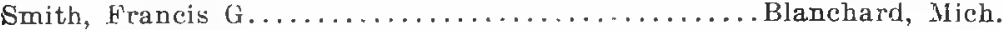

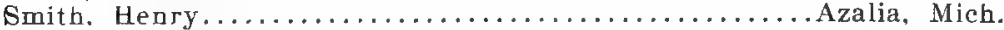

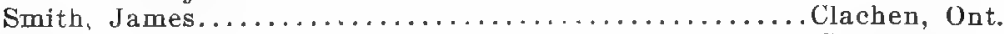

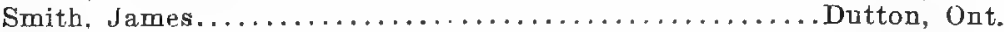
Smith, L. W. B........................................ I

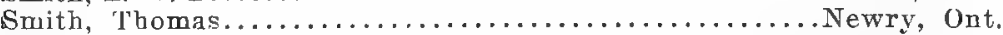

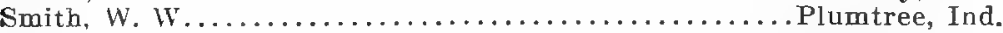

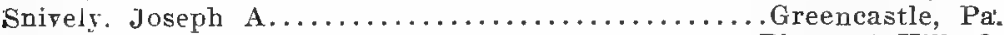

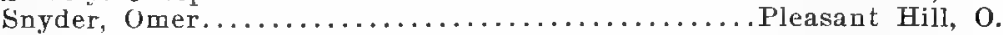

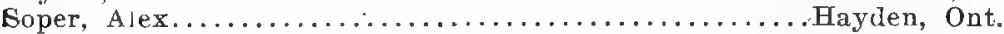

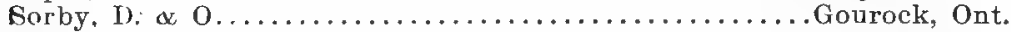

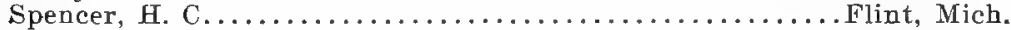

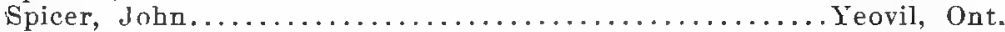

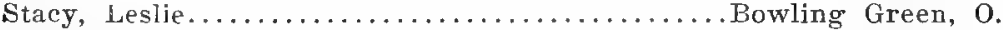

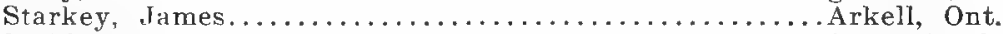

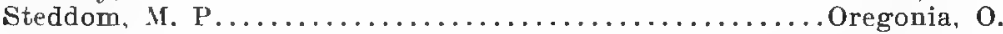

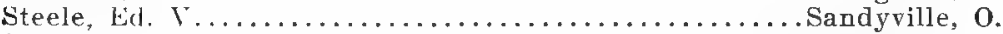

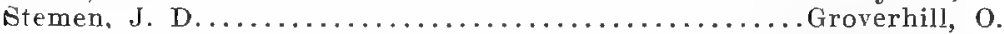

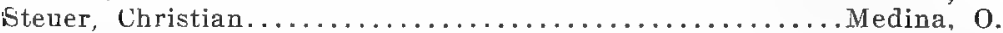

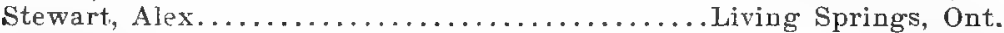

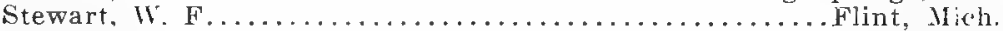

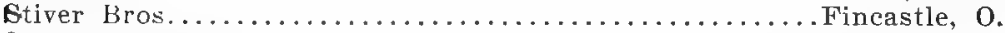

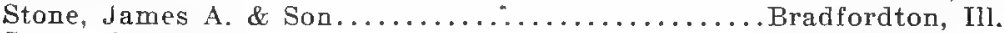

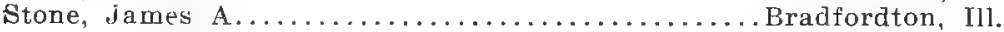

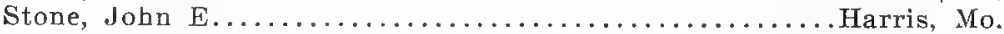

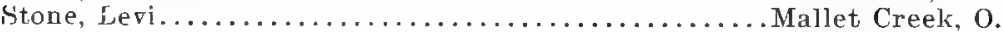

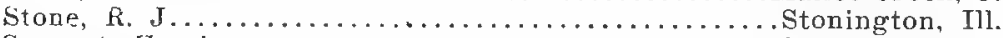

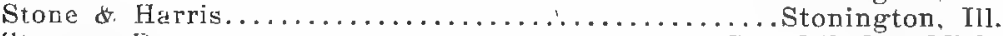

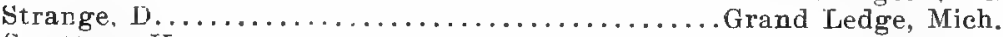

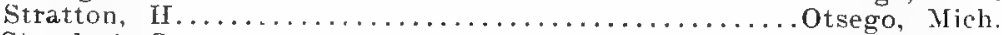

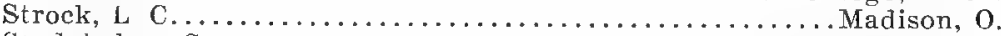

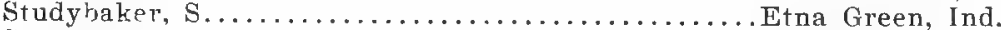

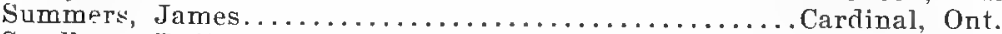

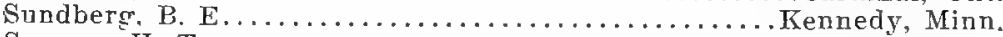

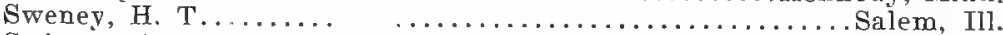

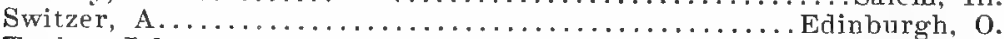

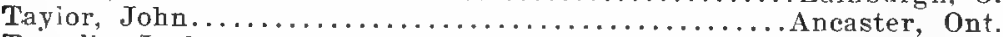

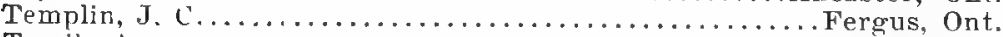

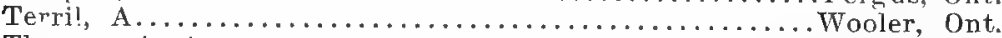

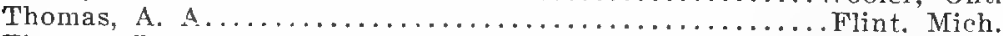

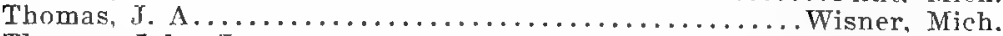

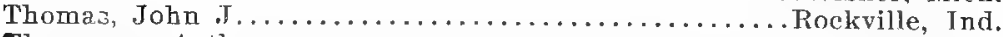

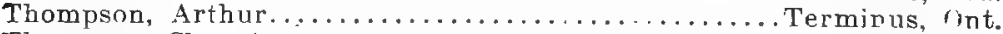

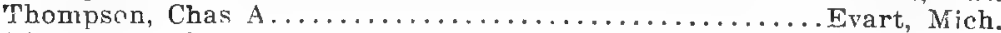

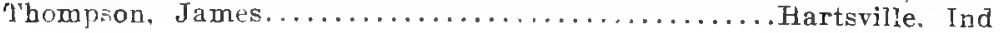


Thompson, J. M

Tibbitts, G. A...
Todd. Theodore.

Berlin, Ia.

Warsaw, Ind.

Todd, S. R.

Tolton, S. \& A

Warsaw, Ind.

Tolton, Jas. L

Hillview, Man.

Tolton, Jas.

Towner, R, R

Walkerton, Oni.

Tucker, Mellville.

Walkerton, Ont.

Turner, E.

Trexler, Jackson.

Walkerton, Ont.

I'ripp, H. F.

Trout, S..

Tubbs, Edward R.

Lucern, Ind.

T'urner, J. M. \& Bro.

Burford, Ont.

Turner, T. E

Wheeler, Il].

Turner, Wm Millers, N. 1 .

Van Der Volgen, A

Osceola, $\mathrm{Pa}$

Vanosdol, John.

Volner, Jacob.

Lebanon, Ind.

Wade, C.

Wadsworth, Wm

Wahl, Philip.

. Kirklin, Ind.

Waid, Geo.

Shelbyville, Mo.

Waldo, Alex

Newton, Ind.

Walker, Chas.

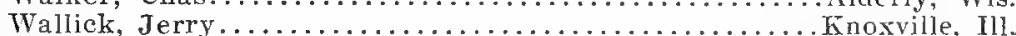

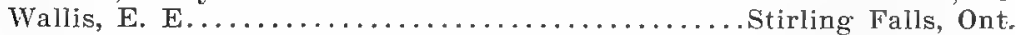

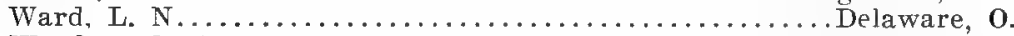

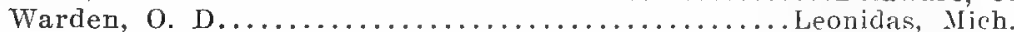

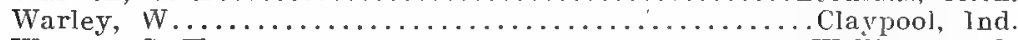

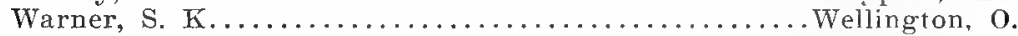

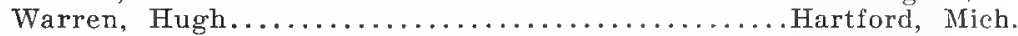

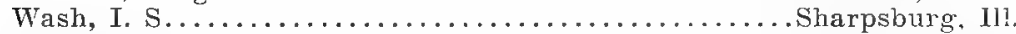

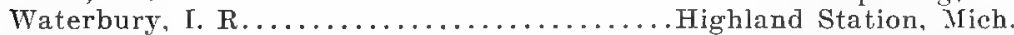

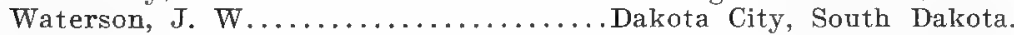

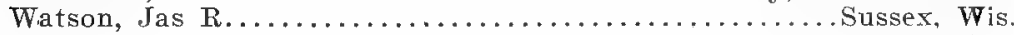

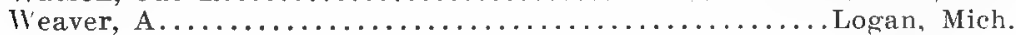

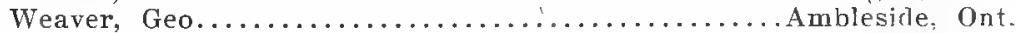

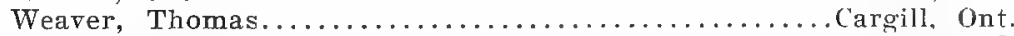

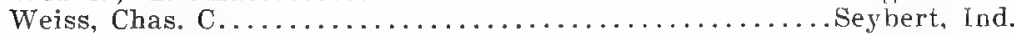

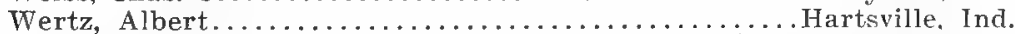

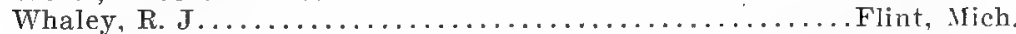

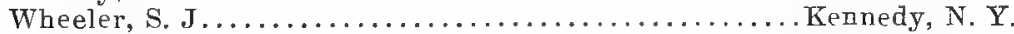

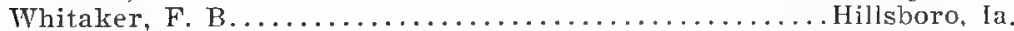

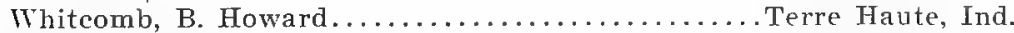

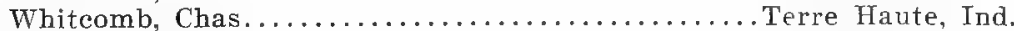

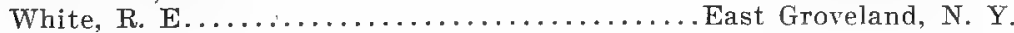

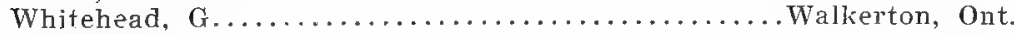

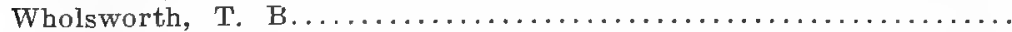

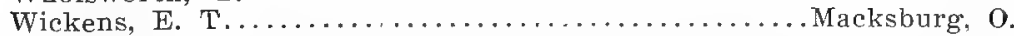

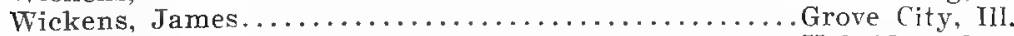

Widdefield, J. W......................... Uxbridge, Ont. 


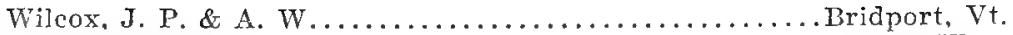

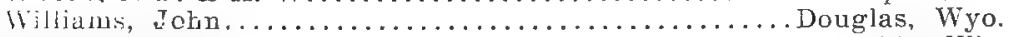

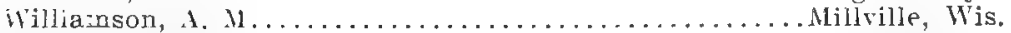

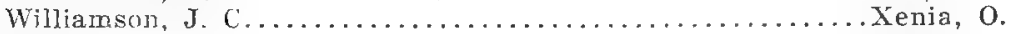

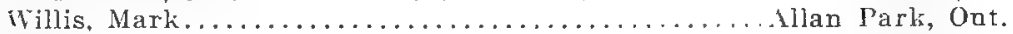

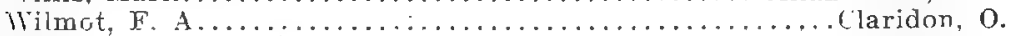

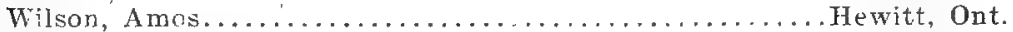

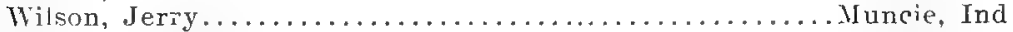

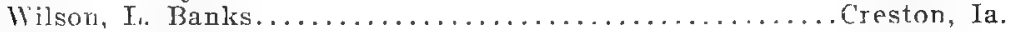

Wilson, L.

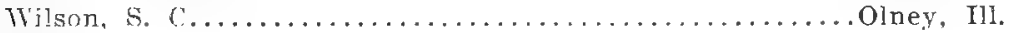

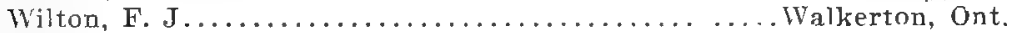

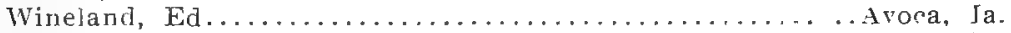

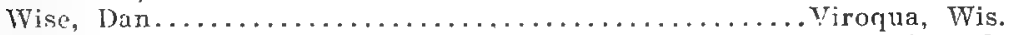

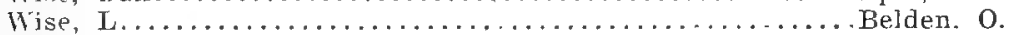

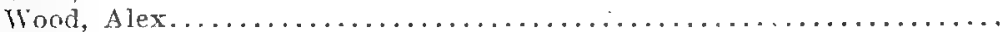

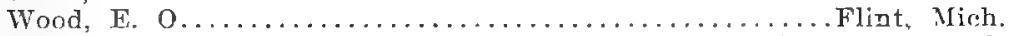

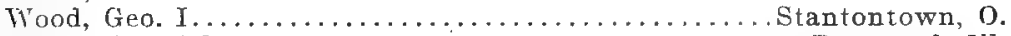

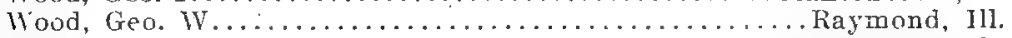

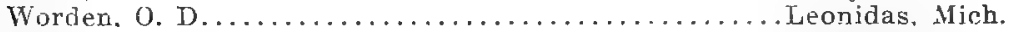

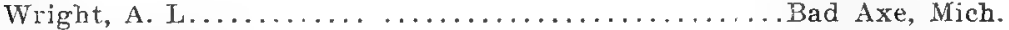

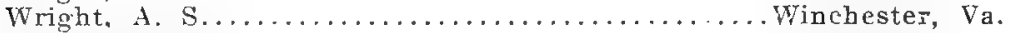

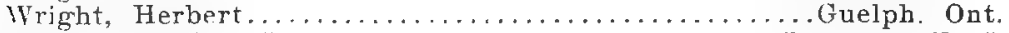

Wright, M. M. \& Snns..........................msons, $N$. Y.

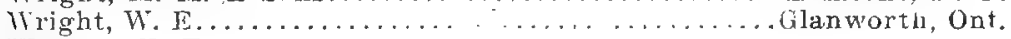

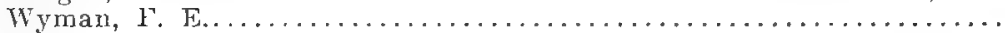

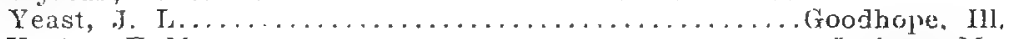

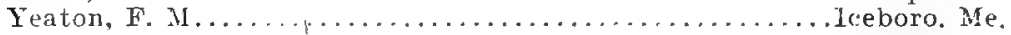

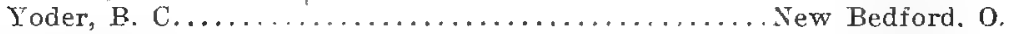

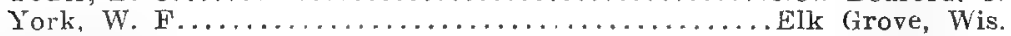

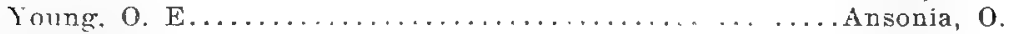

Young. O. E.......................... Union City, Ind.

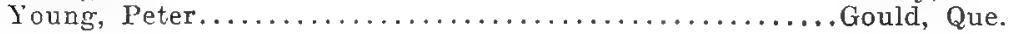

\section{Breeders of Dorset Sheep.}

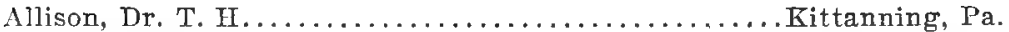

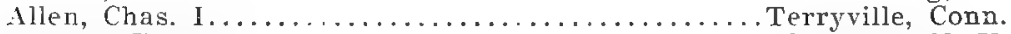

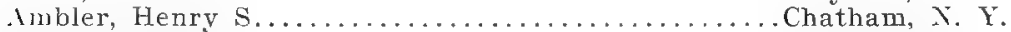

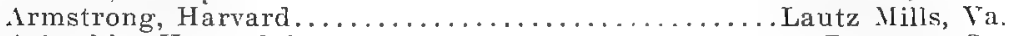

Arbuckle, Howard $1 . \ldots \ldots \ldots \ldots \ldots \ldots \ldots . \ldots \ldots$ Decatur, Ga.

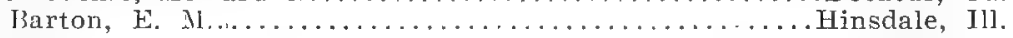

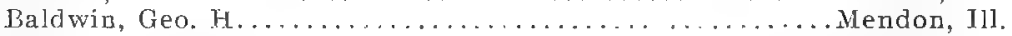

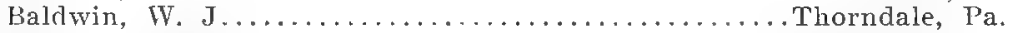

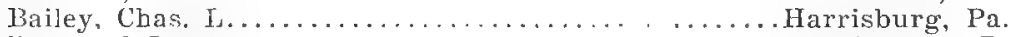

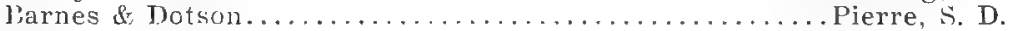
Barnett, Oliver.........................

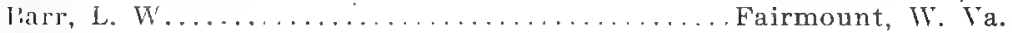

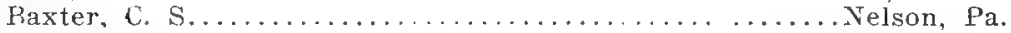

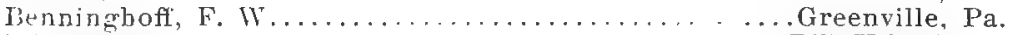

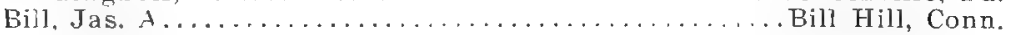

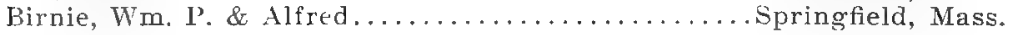


Blair, Joseph A.

Blessing, H. J...

.80 Broadway, New York City.

Blowen, J, D. Jeffersonville, $\mathrm{O}$.

Brisben, John î.

. Barnesville, $\mathrm{O}$.

Briggs, Samuel.

Madison, Ind.

Booth, J. B....

48 Cedar Ave., Cleveland. 0.

Bowditeh, F. F

Lindleys Mills, I’a.

Buchanan, J. L. \& Son.

Buell, J.

Wramingham, Mass.

Burkey, M. H

Hickory, Pa.

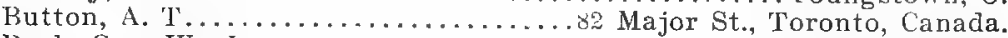

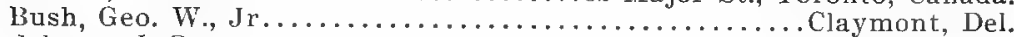

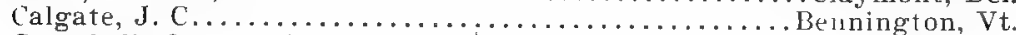

Campbell, George $J \ldots \ldots \ldots \ldots \ldots \ldots \ldots \ldots \ldots \ldots$. . . . . . . . . . . . . .

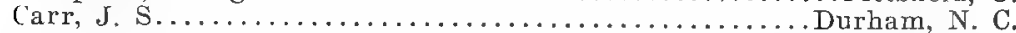

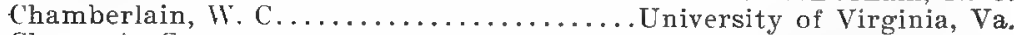

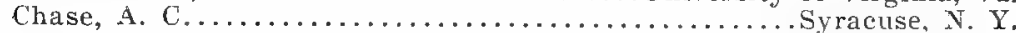

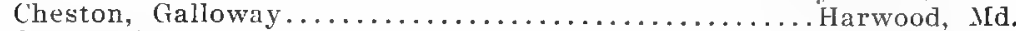

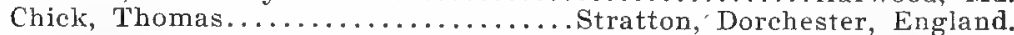

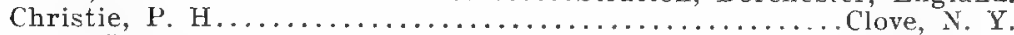

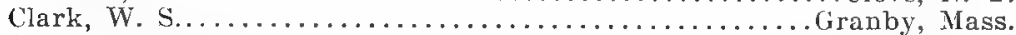

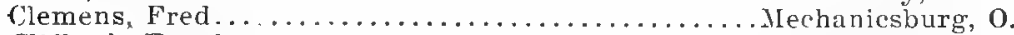

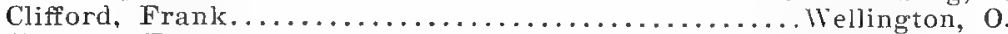

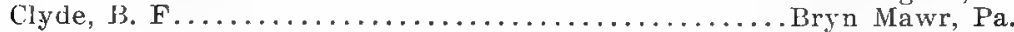

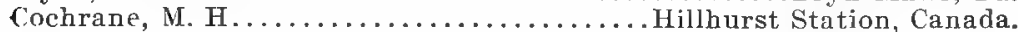

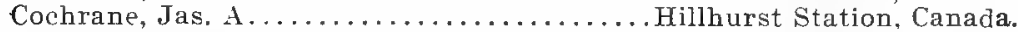

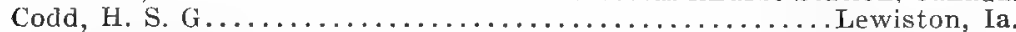

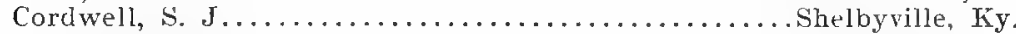

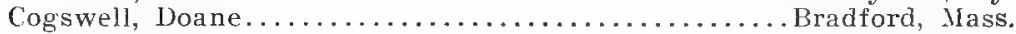

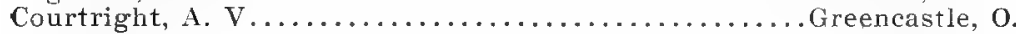

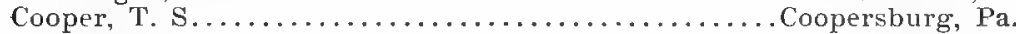

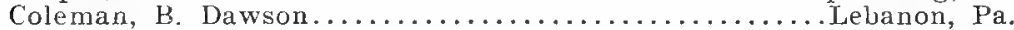

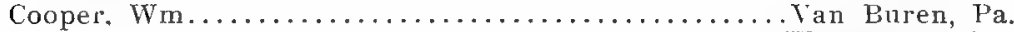

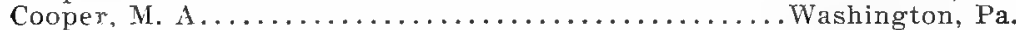

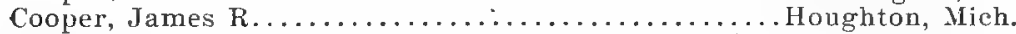

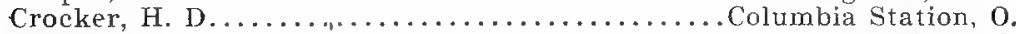

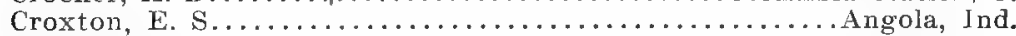

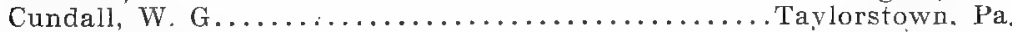

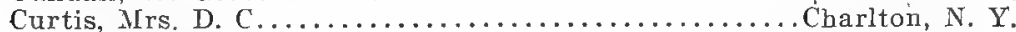

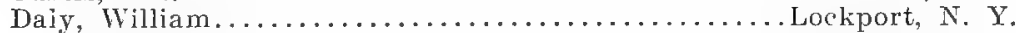

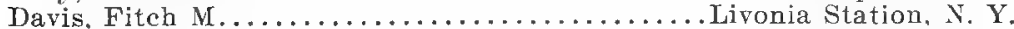

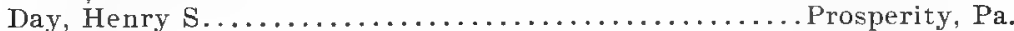

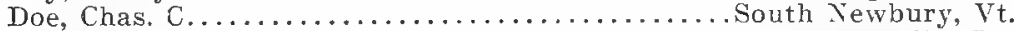

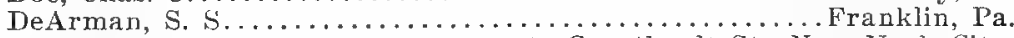

Dodge, Arthur M.............15 Courtlandt St., New York City.

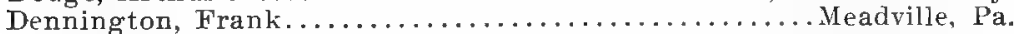

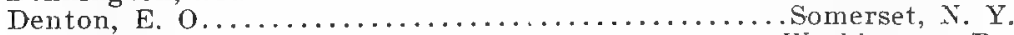

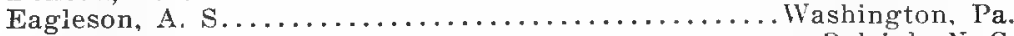

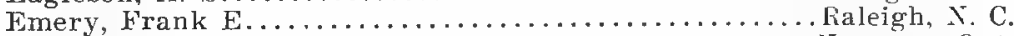

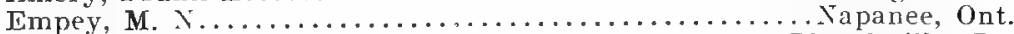

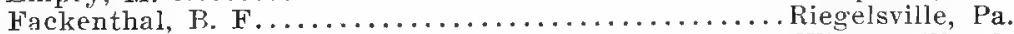

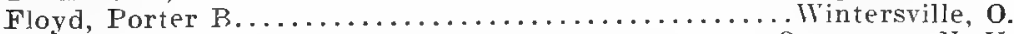

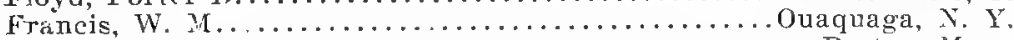

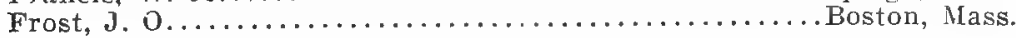


Finnell, James I:

Fletcher, H. E. Georgetown, Ky.

Earle, hichard 1

Minneapolis, Minn.

Fletcher Bros.

Centreville, Md.

Ensor, Fred.

315 Third Ave., North Minneapolis.

Gates, John J. \& Co....................... Yorkville, Ill.

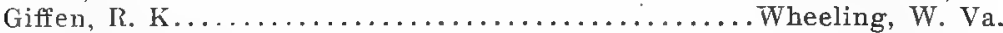

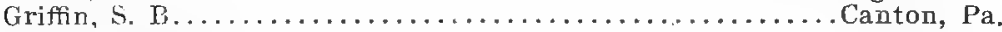

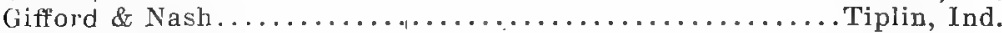

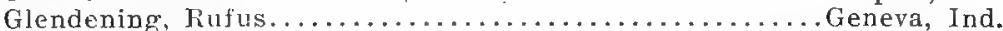

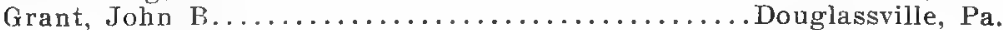

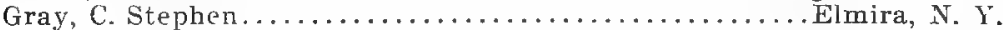

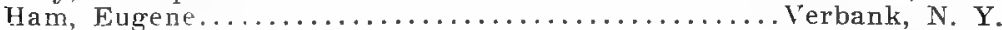

Ham, J. M...................Washingtown Hollow, N. Y.

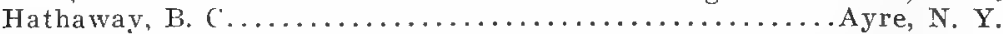

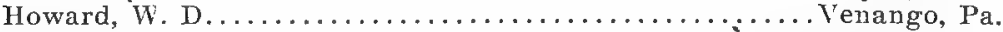

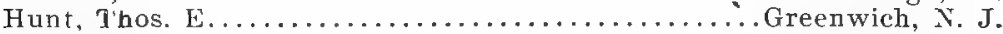

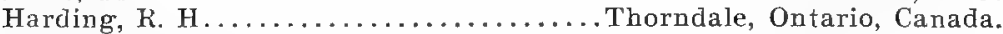

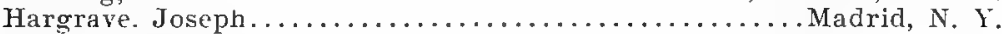

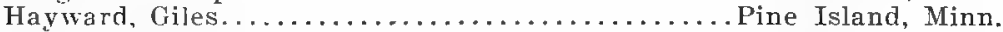
Hunter, John......................Wyoming, Ont., Canada.

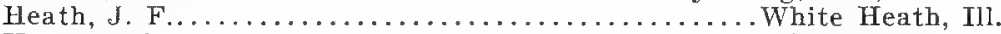
Hector. Thos. W............... Springfield-on-the-Credit, Canada.

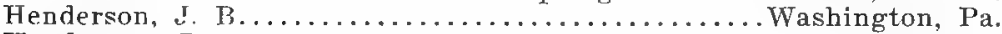
Henderson, J. L......................Washington, $\mathrm{Pa}$.

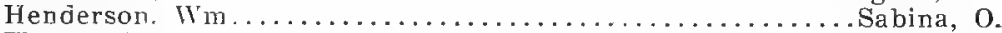

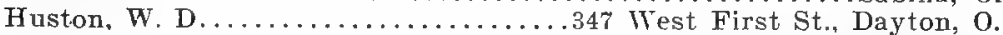

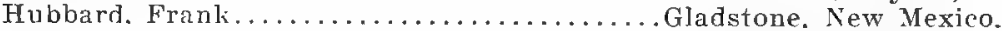
Humbert, J. I................... University of Virginia, Va.

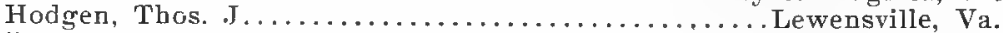

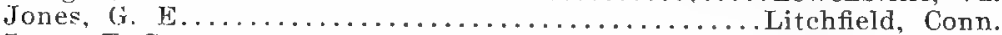

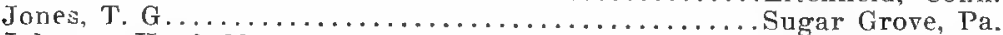

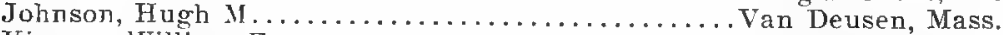

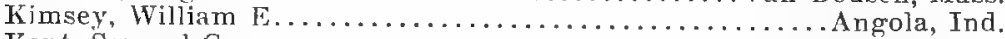

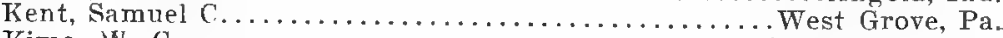

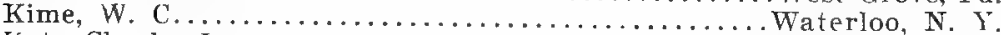

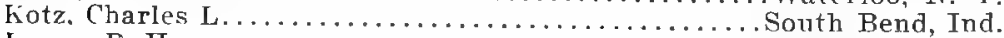

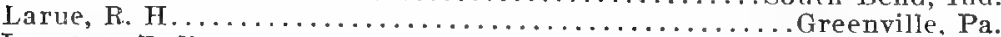

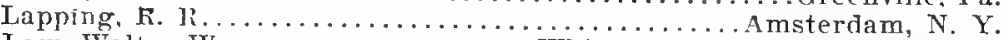
Law, Walter $W \ldots \ldots \ldots \ldots \ldots \ldots \ldots \ldots \ldots$ Whitsons $P . . .$. .. Sing Sing, N. Y. Leigh. Geo. \& Co............................................... Tll.

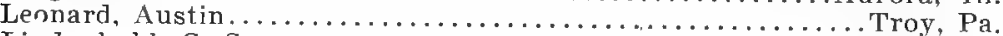

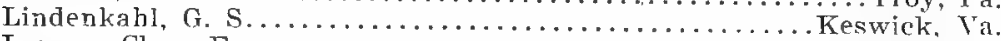

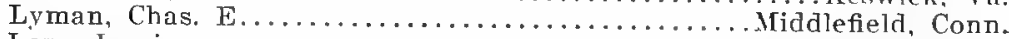

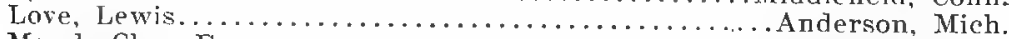

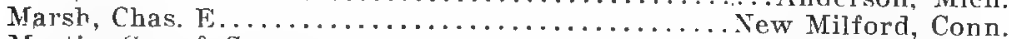

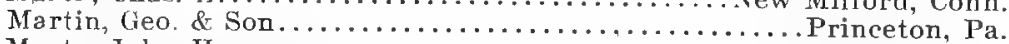

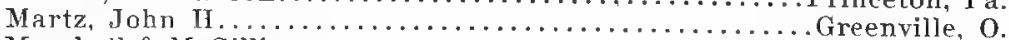

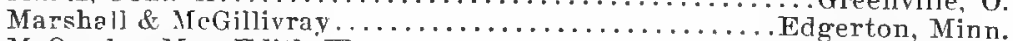
McCarthy, Mrs. Edith $W \ldots \ldots \ldots \ldots \ldots \ldots \ldots \ldots \ldots \ldots \ldots . . . \ldots$. . . . . . . . . . . . . . .

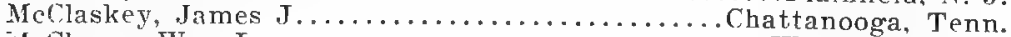

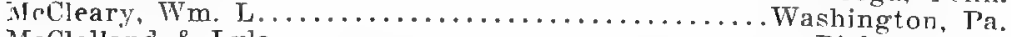

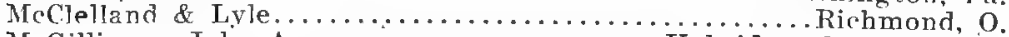

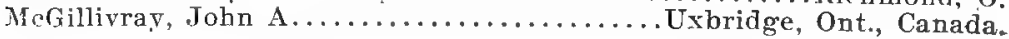


MeHarg, John W.

MeKay, E. V. D

Albany, N. Y.

Miller, H. P........

Geneva, N. Y.

.

Noure

Nourse, Prof. D. O............... va. Agl College, Blacksburg, Va.

Orendoff, Misses L. L. \& M. A............... Hopedale, Tazewell Co., Ill.

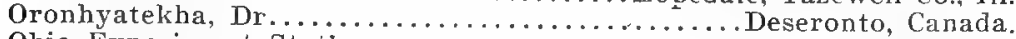

Ohio Experiment Station............................ Wooster, 0.

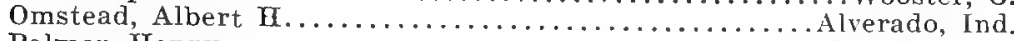

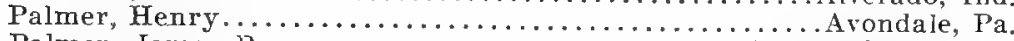

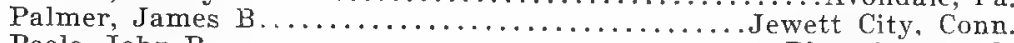

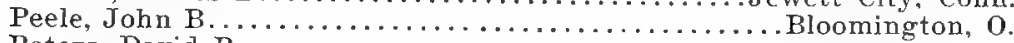

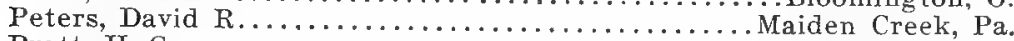

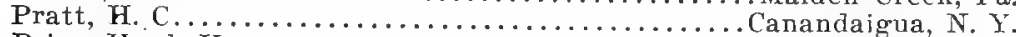

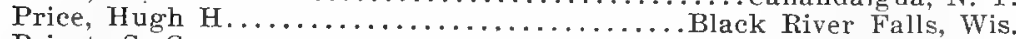

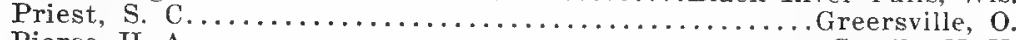

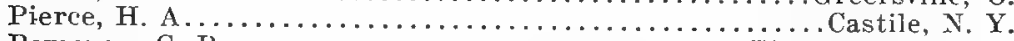

Pomeroy, C. B....................................

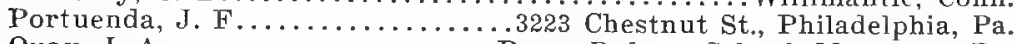

Quay, J. A......................... Reform School, Morganza, Pa.

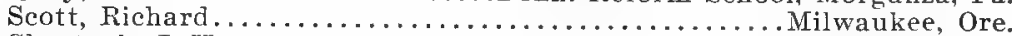

Shattuck, J. H...................26th and Parade Sts., Erie, Pa.

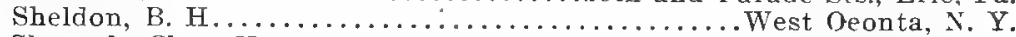

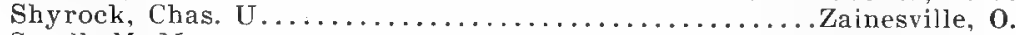

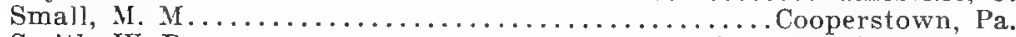

Smith, W. D.................. 197 and 199 Adams St., Chicago, Ill.

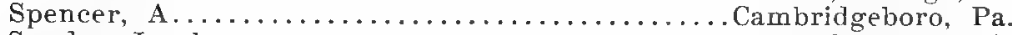

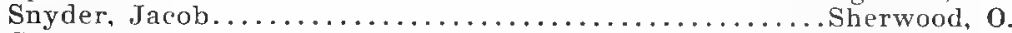

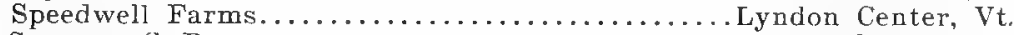

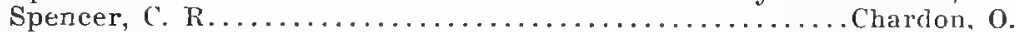

Spooner, M. L................................ Centre, N. Y.

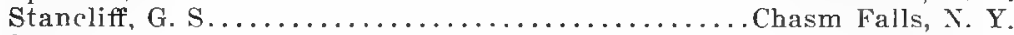

Starin, John H......................................

Strickler, D................................. York, Pa.

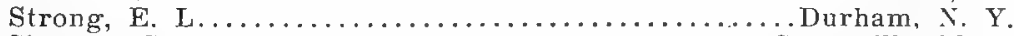

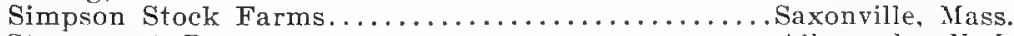

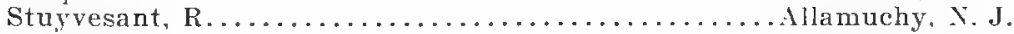

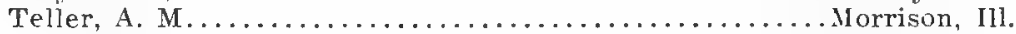

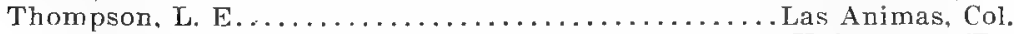

Threlkeld, V. H. \& J. P....................... Uniontown, Ky.

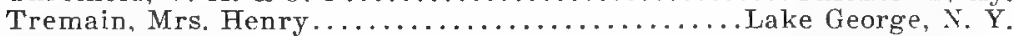

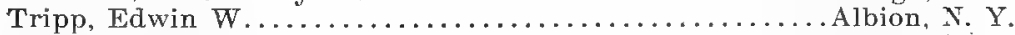

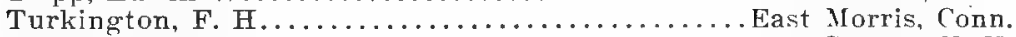

Van Valkenburgh, J. D., Jr............................

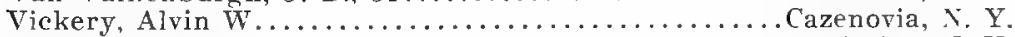

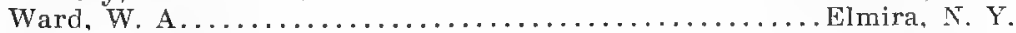

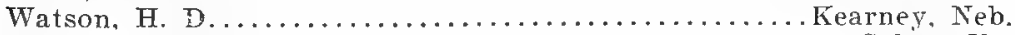

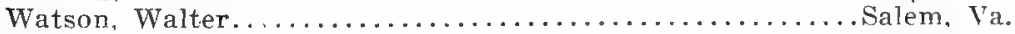

Wayman, Warrick $T^{\prime} \ldots \ldots \ldots \ldots \ldots \ldots \ldots \ldots \ldots \ldots \ldots$ Wheeling, W. - Va.

Wayman, W. P. \& Son..................Box 11, Wheeling, W. Va.

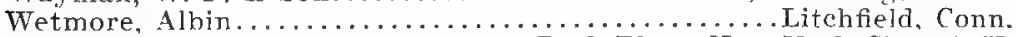

Westeott, R. E................19 Park Place, New York City, N. Y.

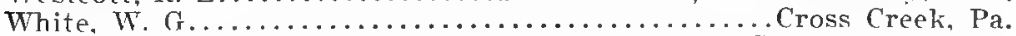

Whitman, H. H. \& H. B....................... South Turner. Me. 


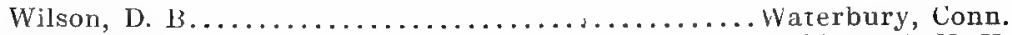

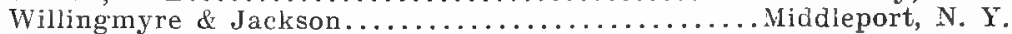

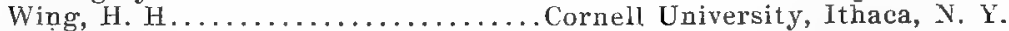

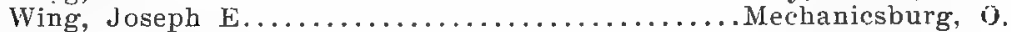

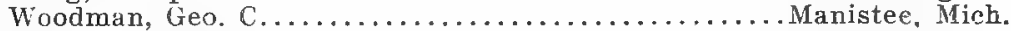

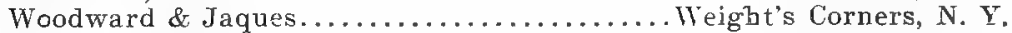

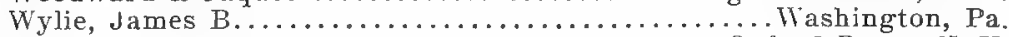

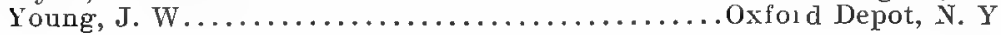

\section{Breeders of Improped Black Cop Merino Sheep.}

L. I. Harsh...................... Union City, Michigan.

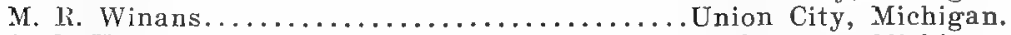

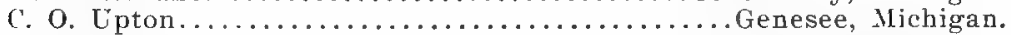

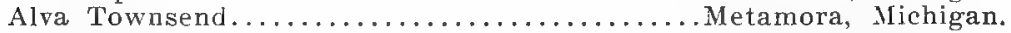

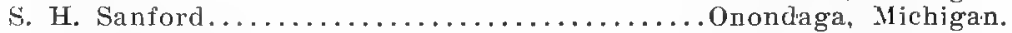

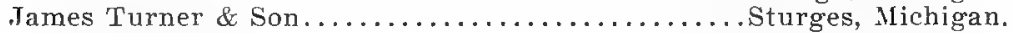

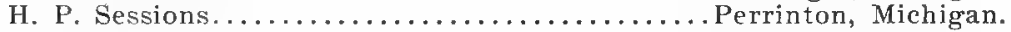

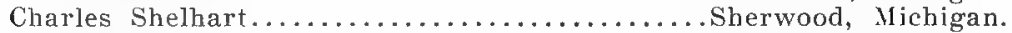

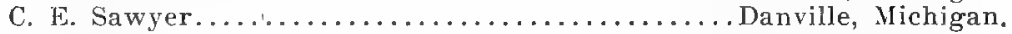

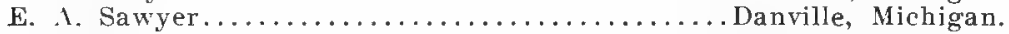

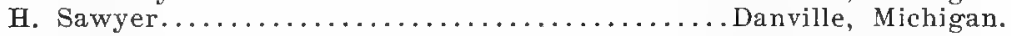

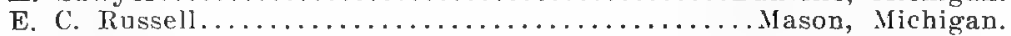

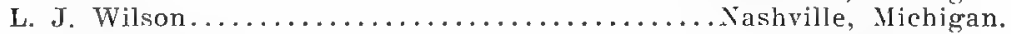

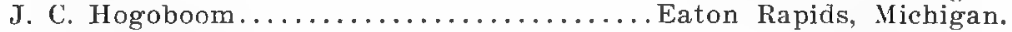

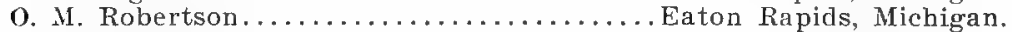

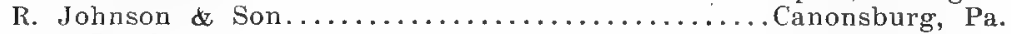

Geo. Black.........................Washington, Pa.

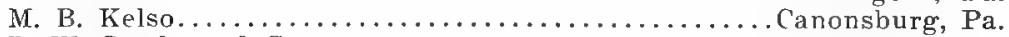

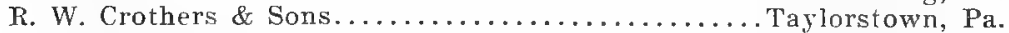

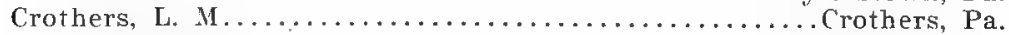

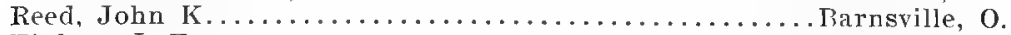

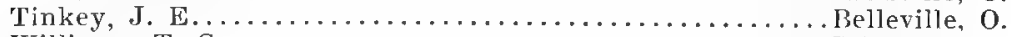

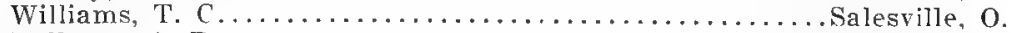

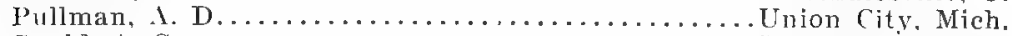

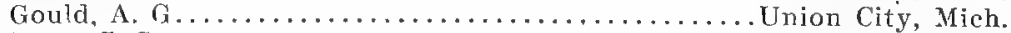

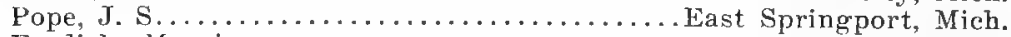

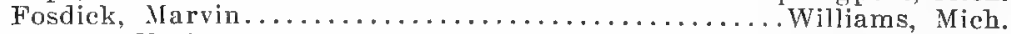

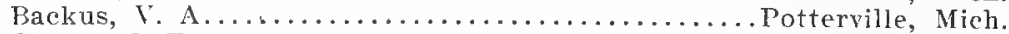

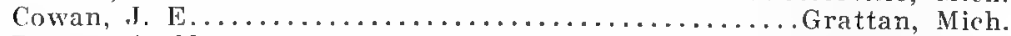

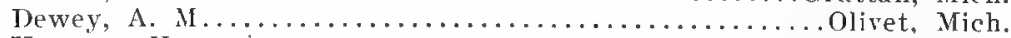

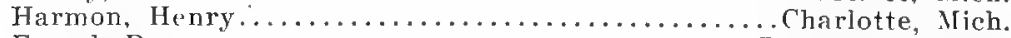

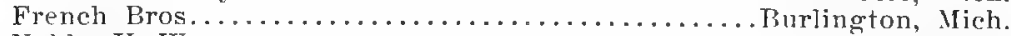

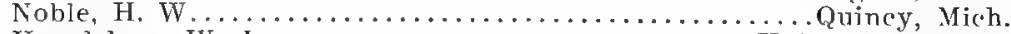

Hagelshaw, W. J..................... Union City, Mich.

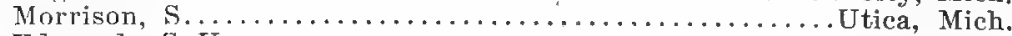

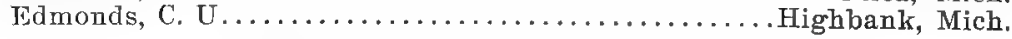

\section{Breeders of Rambouillet Sheep.}

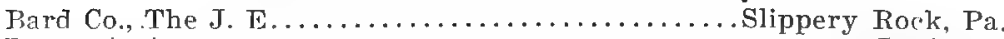

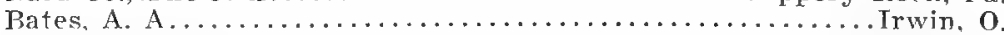

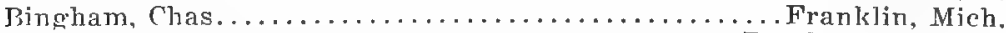

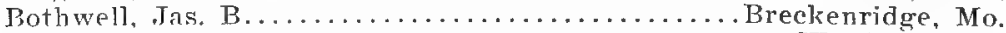

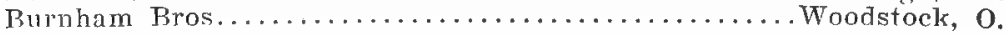


Burnham, W. 1.........................Woodstock, 0 .

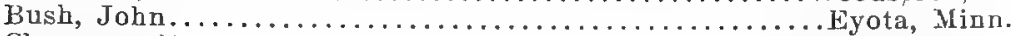

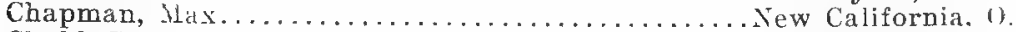

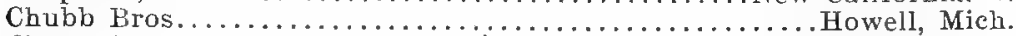

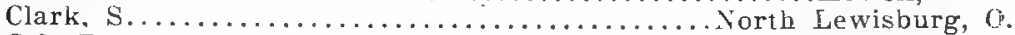

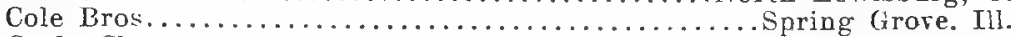

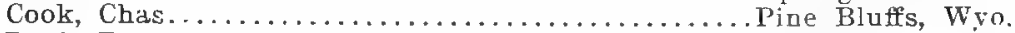

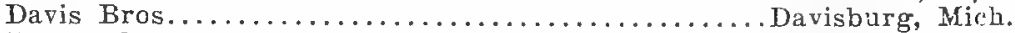

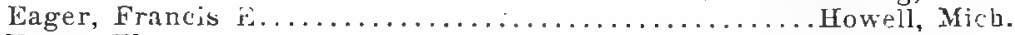

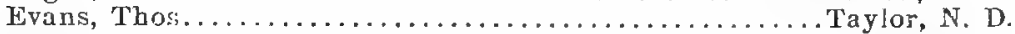

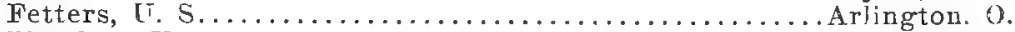

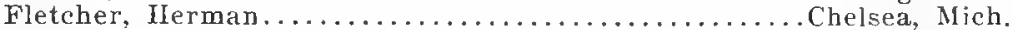

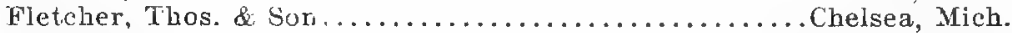

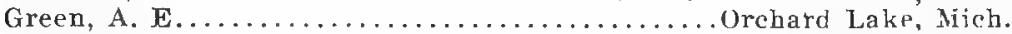

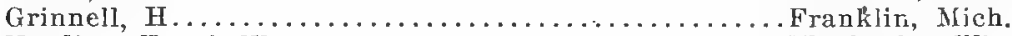

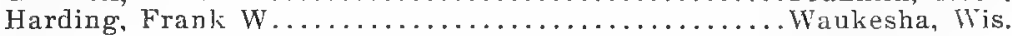

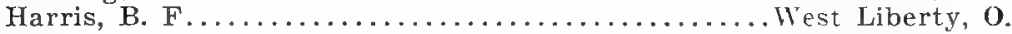

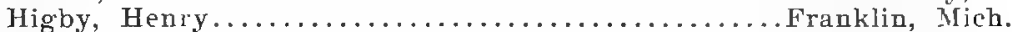

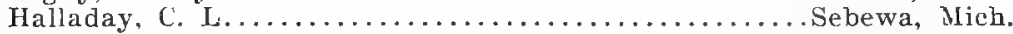

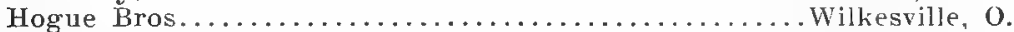

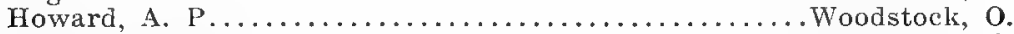

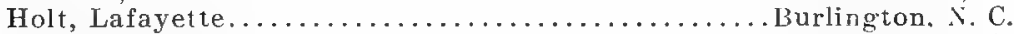

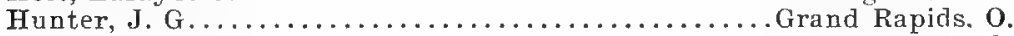

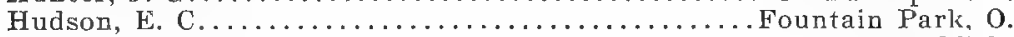

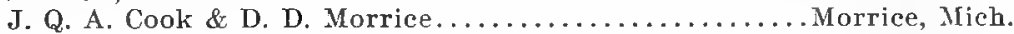

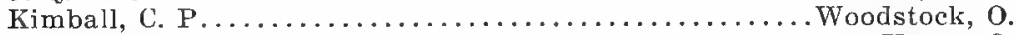

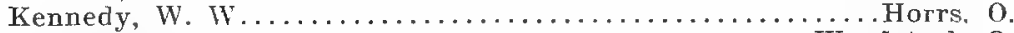

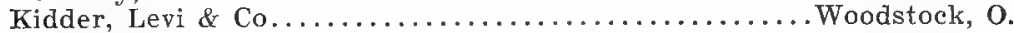

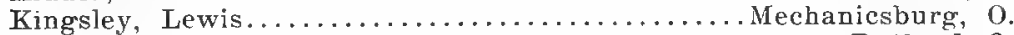

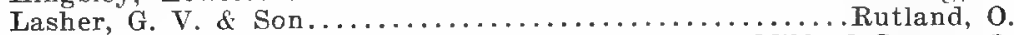

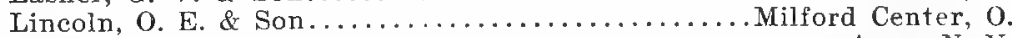

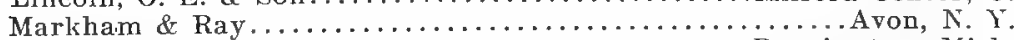

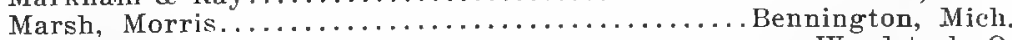

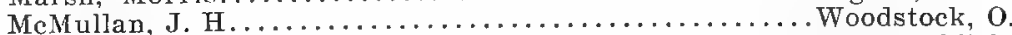

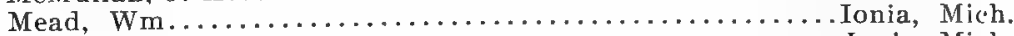

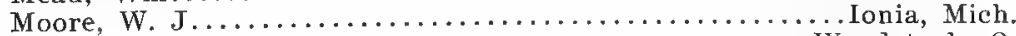

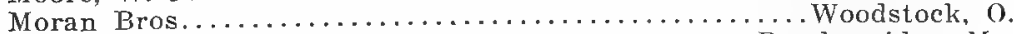

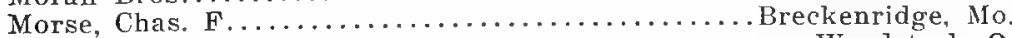

Moulton, R. C. \& Co.........................Woodstock, O.

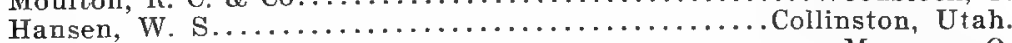

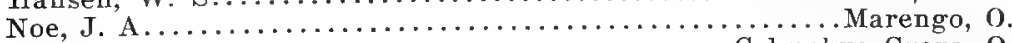

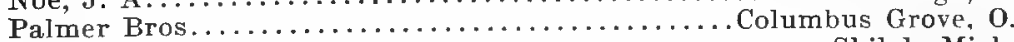

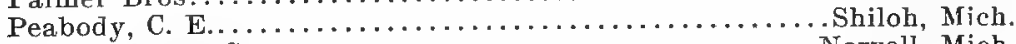

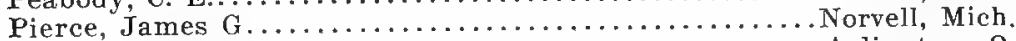

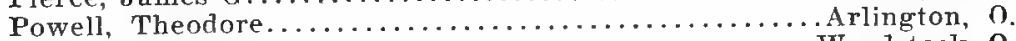

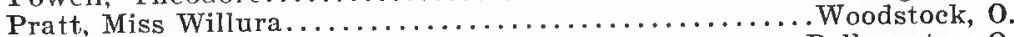

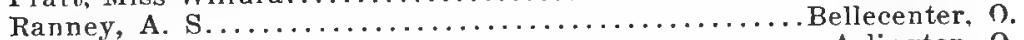

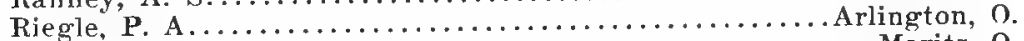

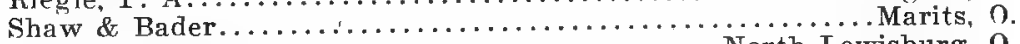

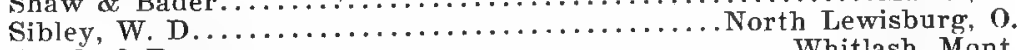

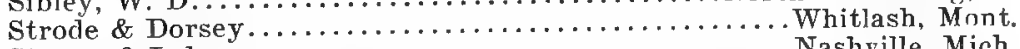

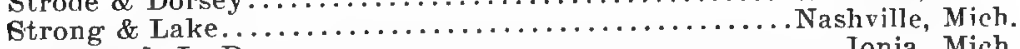

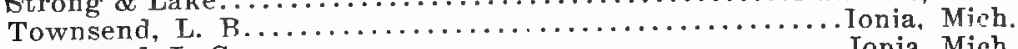

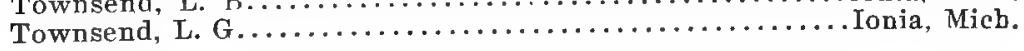




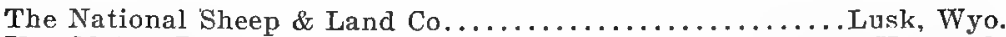

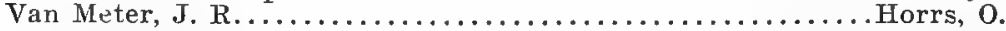

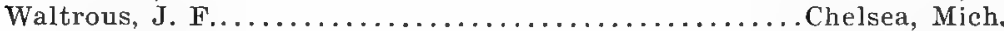

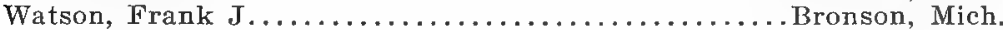

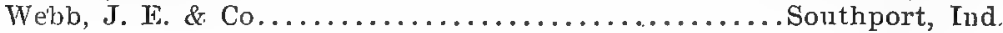

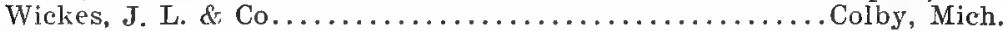

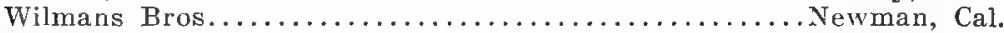

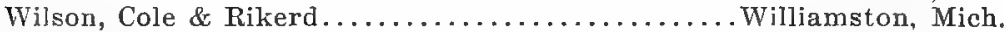
Wickham, P. B...........................

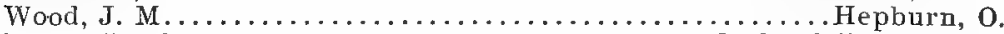

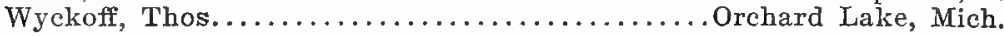

\section{Breeders of Delaine Merino Sheep}

Beall, James \& Bro........... Independence, Washington County, Pa.

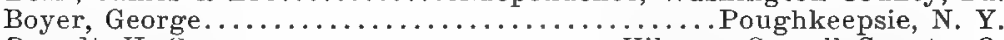

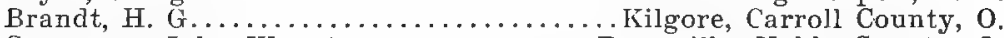

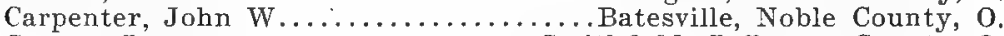
Carson, James........................................ Jefferson County, 0 . Crothers, R. W............. Taylorstown, Washington County, Pa.

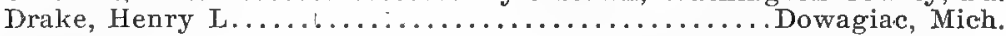

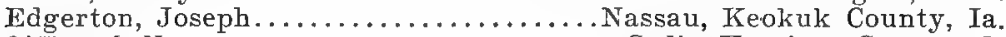

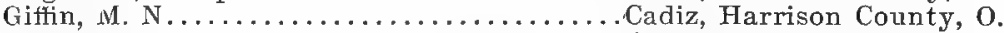

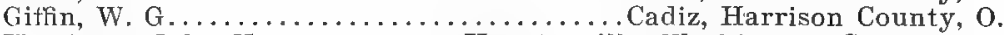
Hamilton, John H..........Houstonville, Washington County, Pa. Hamilton, R. D.............Houstonville, Washington County, Pa.

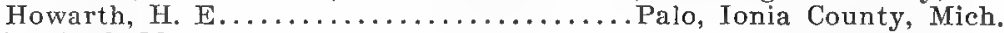

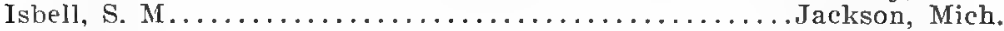
Johnson, J. B. \& Sons.......... Canonsburg, Washington County, Pa.

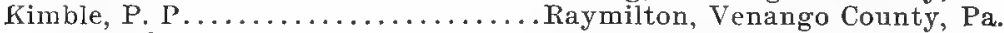
Long, W. C...................... Urbana, Champaign County, 0.

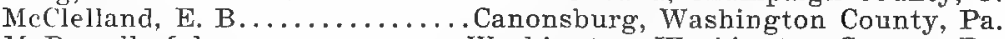
McDowell, Sohn............Washington, Washington County, Pa. MeNary, James S............ Canonsburg, Washington County, Pa.

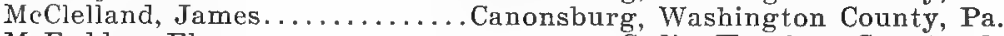

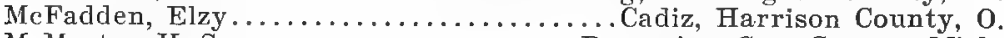
MeMaster, H. S.................. Dowagiac, Cass County, Mich. McNary, John C.......................................

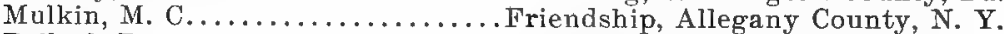

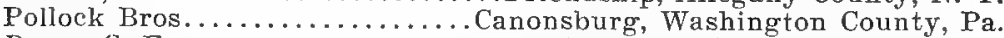

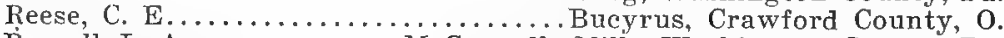
Russell, L. A................................ Shepherd Bros................ New Concord, Muskingum County, 0.

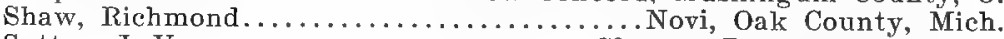
Sutton, J. $V \ldots \ldots \ldots \ldots \ldots \ldots \ldots \ldots \ldots \ldots \ldots$. . . . . . . .

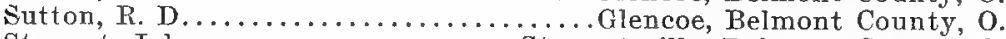

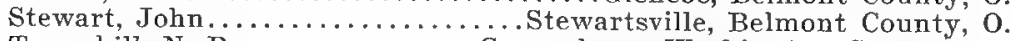

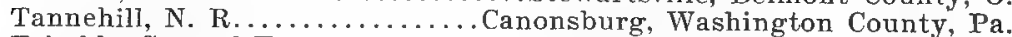

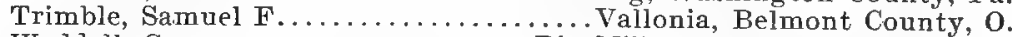

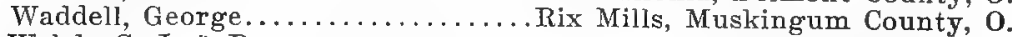

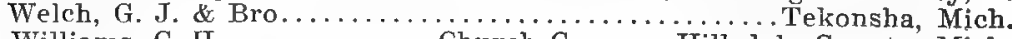
Williams, C. H............. Church Corners, Hillsdale County, Mich. Wylie, Robert \& Son..........Washington, Washington County, Pa. 


\section{Breeders of Merino Sheep.}

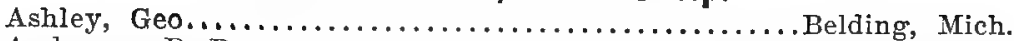

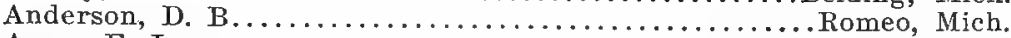

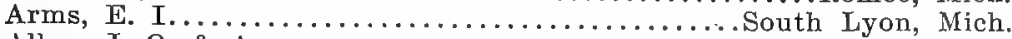

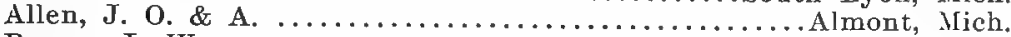

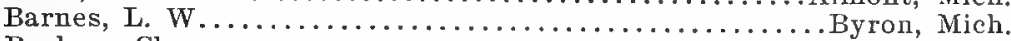

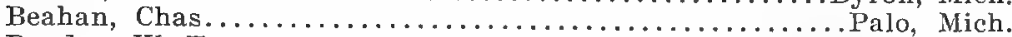

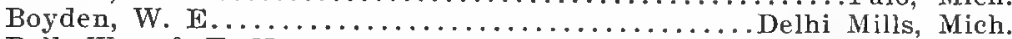

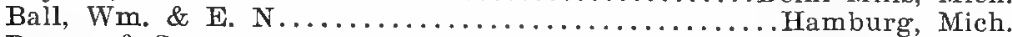

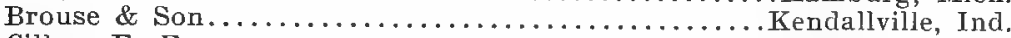

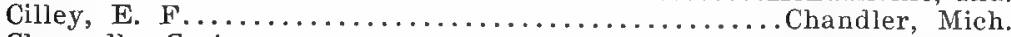

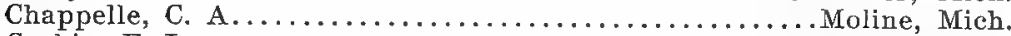

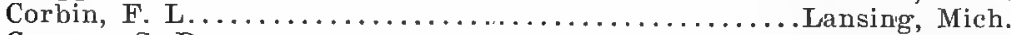

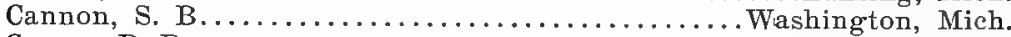

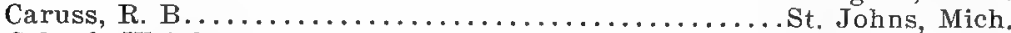

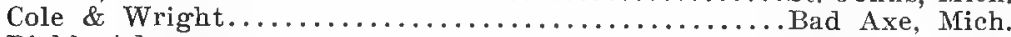

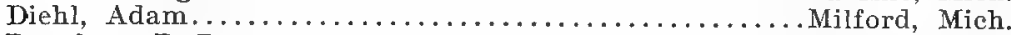

Donelson, P. D.......................... Swartz Creek, Mich.

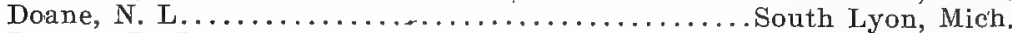

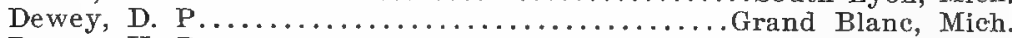

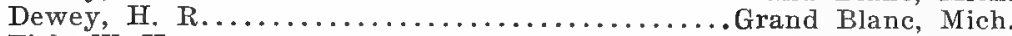

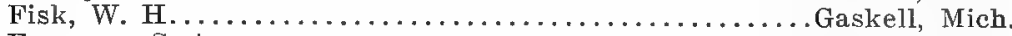

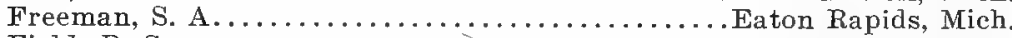

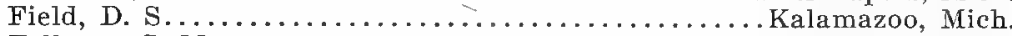

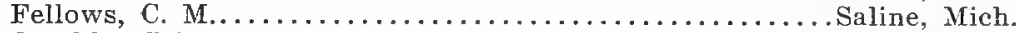

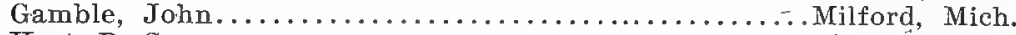

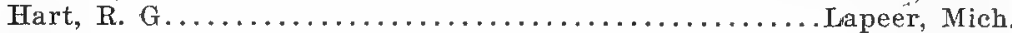
Hady E. J. \& E. W....................................

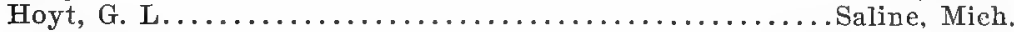

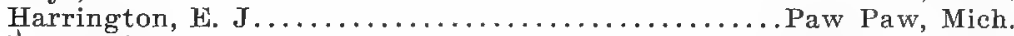

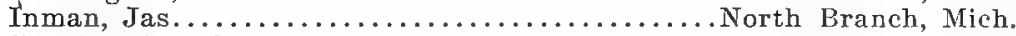

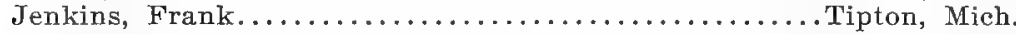

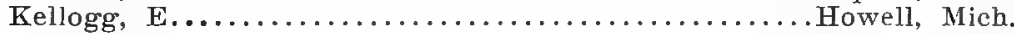
Lockwood, C. E.........................Washington, Mich. Lovell, E. T...............................max, Mich. Moon, M. C......................................

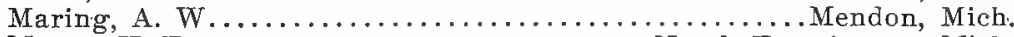
Moore, H. E. ........................... McCousey, J. F........................ Union City, Mich.

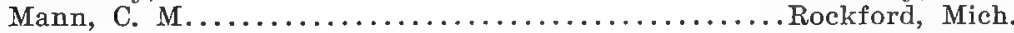

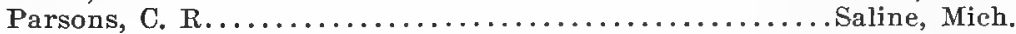

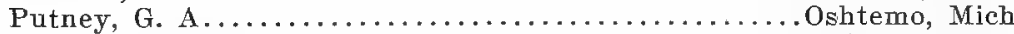
Pearce, Perry.................................... Creek, Mich. Parman, John.............................tehburg, Mich.

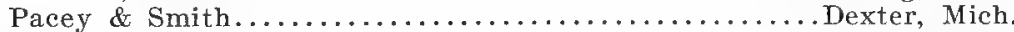
Quackenbush, T. V......................... Plymouth, Mich. Rich, J. T................................. Miba, M.

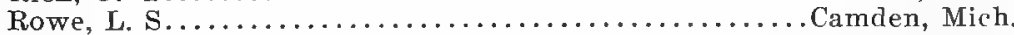

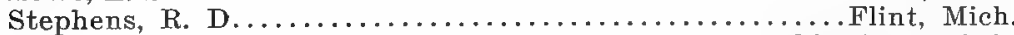

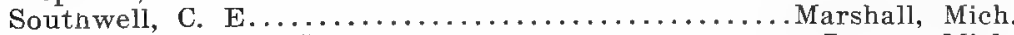
Stickney, W. W. \& Sons.........................Lapeer, Mich.

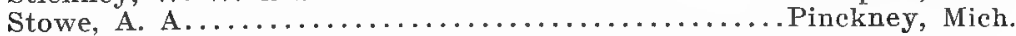
Southworth, T. M............................... 


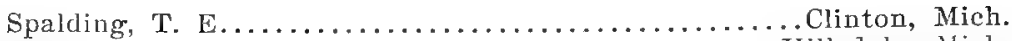

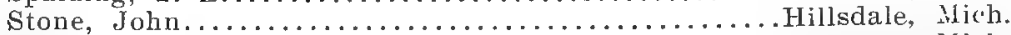

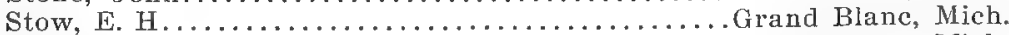

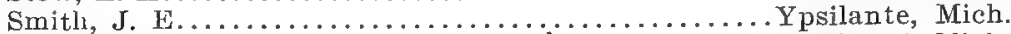

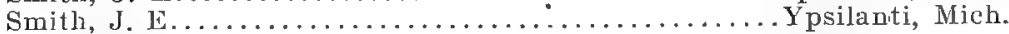

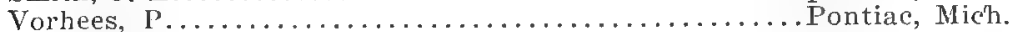

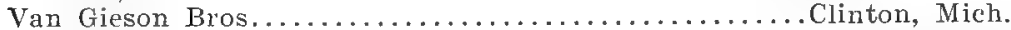

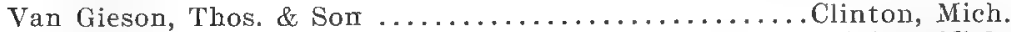

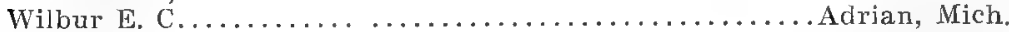

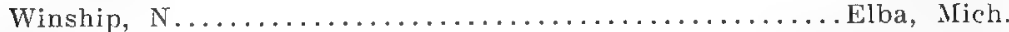

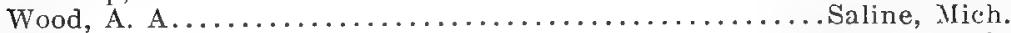

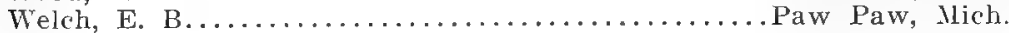

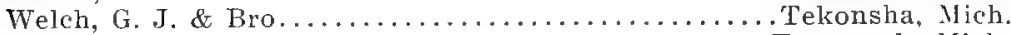

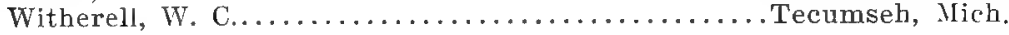

\section{Breeders of Cheviot Sheep.}

INDIAN

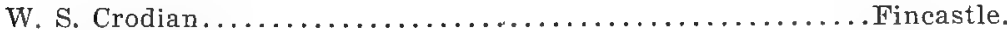

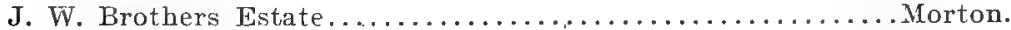

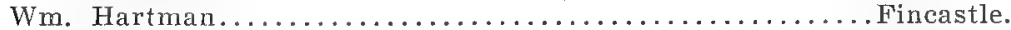

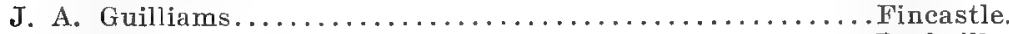

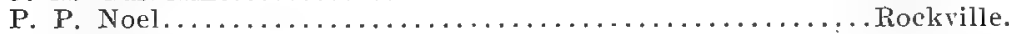

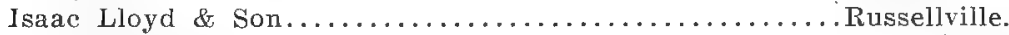

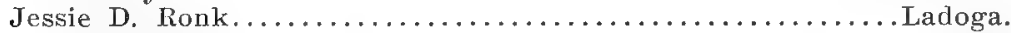

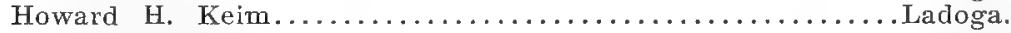

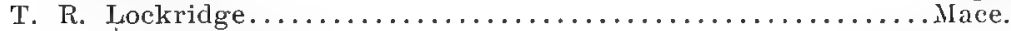

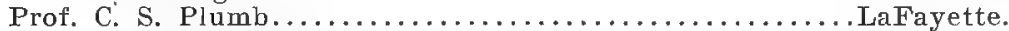

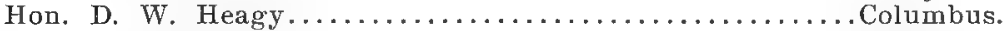

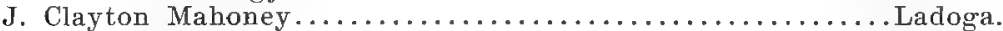

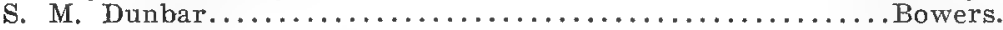

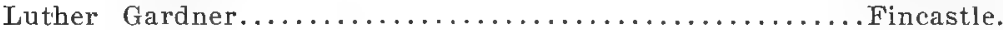

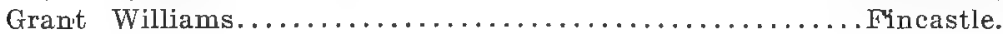

NEW YORK.

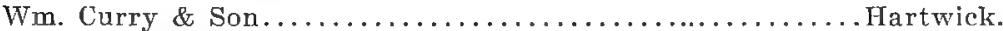

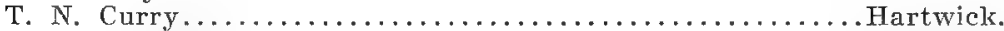

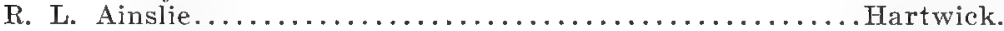

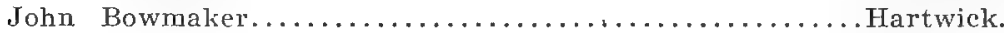

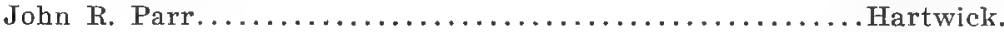

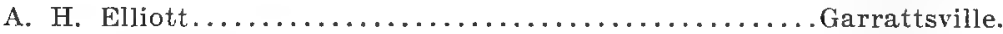

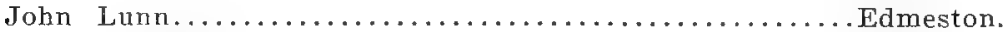

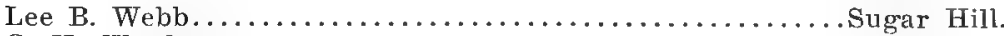

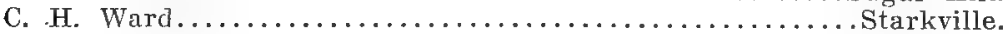

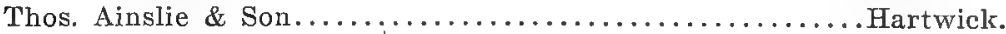

IOWA.

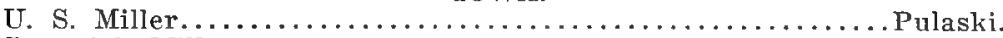

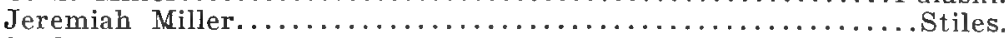

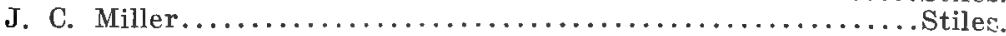

\section{VERMON'T}

L. A. Webster

Whiting.

C. H. Marshall

TENNESSEE

H. C. Davidson . Elbridge. 


\section{THE}
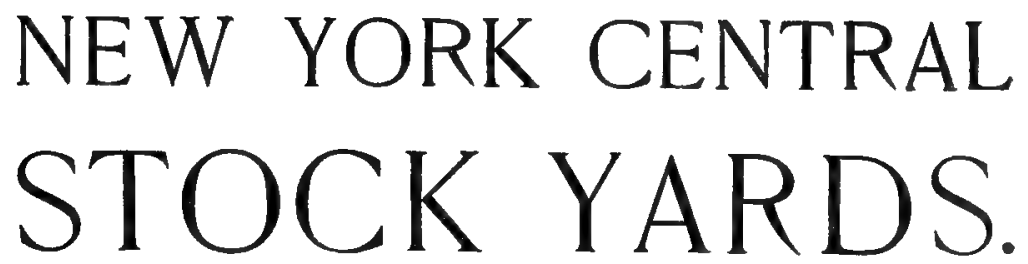

Located at East Buffalo, N: Y.

THE

CENTER AND DISTRIBUTING POINT

OF THE GREAT RAILROADS OF THE

\section{COUNTRY.}

CONTAINS:

Cattle Yards, Capacity 10,000 Head.

Sheep Barns, Largest in the World, Capacity 35.000 Head. Hog Yards, Capacity 35,000 Head.

....Fairbank's Suspension Stock Scales are used Exclusively.

YEARLY RECEIPTS:

Cattle . . . . 42,991 Cars, 859,820 Head. Hogs . . . 26,123 Cars, 3,657,220 Head.

Sheep . . . . 13,352 Cars, 2,670,400 Head.

Stock handled by responsible and experienced Commission firms. Buyers from New York, Boston, Jersey City, Pennsylvania and all New England points are located here.

THE LARGEST AND BEST APPOINTED SHEEP-DIPPING PLANT IN THE UNITED STATES HAS JUST BEEN COMPLETED AND IS NOW IN USE AT THESE YARDS.

For Information Address. LEONARD B. CROCKER, Supt., 


\section{Standard Oil of Tar.}

(DISINFECTAN'T.)

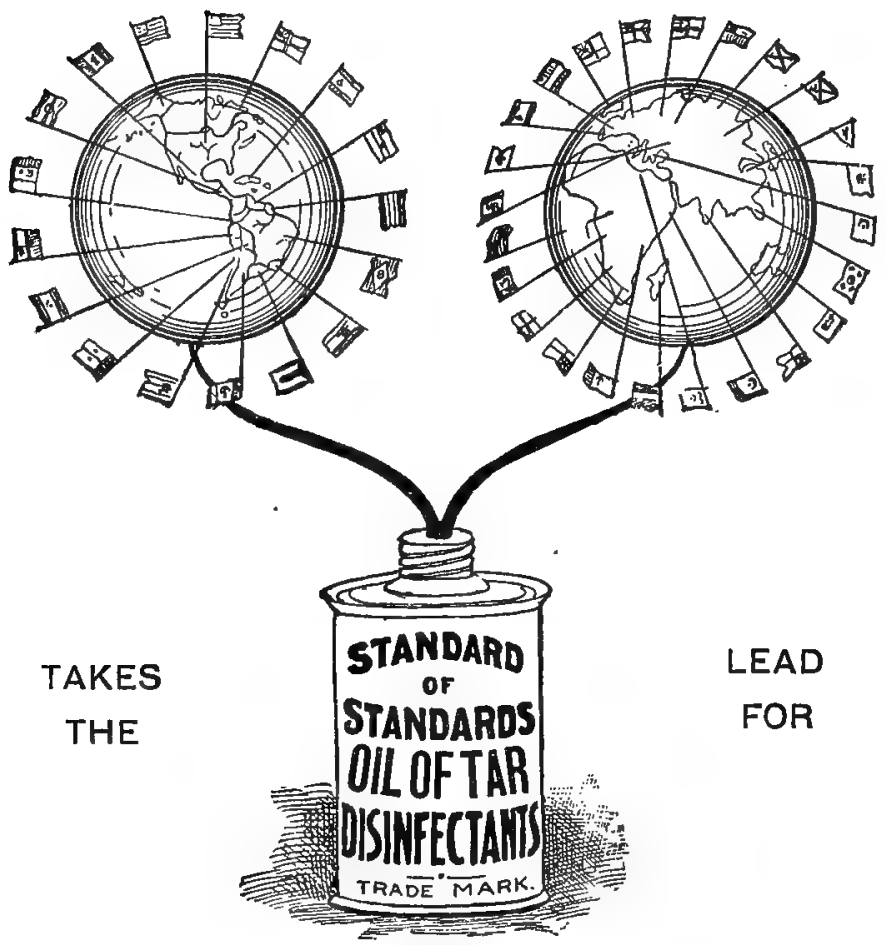

Be sure this trade mark is on every package. None genuiue without it.

\section{ALL. HOUSEHOLD USES. Dairymen, Stock Dealers, Kennels.}

"Preventalives" arenow preferred to Drugs in the treatment of the Diseases of Animals, as in those of human beings. The best "Preventatives" are Disinfectants and Antiseptics. A Disinfectant and Vermicide that is exteusively used in Europe and in this country, is STANDARD OL, OF TAR.

Factories:-CAMBRIDGe, ENG. Cleveland, 0., U. S. A. TORONTO, CAN. MANUFACTURED BY Standard Disinfectant Co., 22050 Long Street. Cleveland, o.

The Pioueer manufacturers of Disinfectants in the United States and Canada. Send for free Sample Secure Agency for Your District. 
ESTARLISHED 1876.

\section{DUNNNING G STEVENS,}
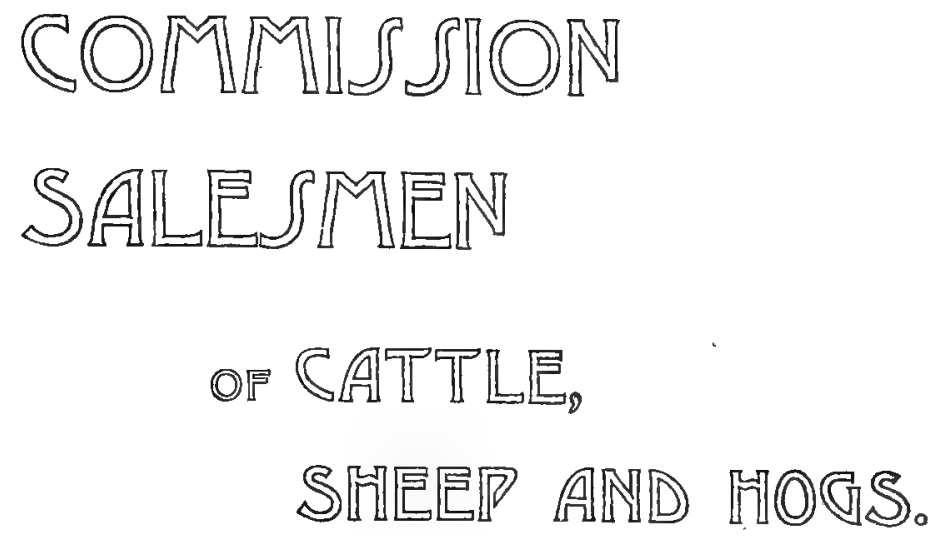

ROOM $\mathbb{1}$

LIVE STOCR EXCHANGE, ERST BUFFRL, N. Y.

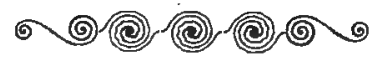

M. DUNNING, Sheep Salesman.

J. STEVENS, Cattle Salesman.

DOC. CHRISTIE, Cattle Salesman,

GEO. DONALDSON, Cattle Salesman,

GEO. TOMPKINS, Hog Salesman,

FRED. STEVENS, Calf Salesman, JOHN SMITH, Cow Salesman. 
The Lincoln raxed heep Dip.

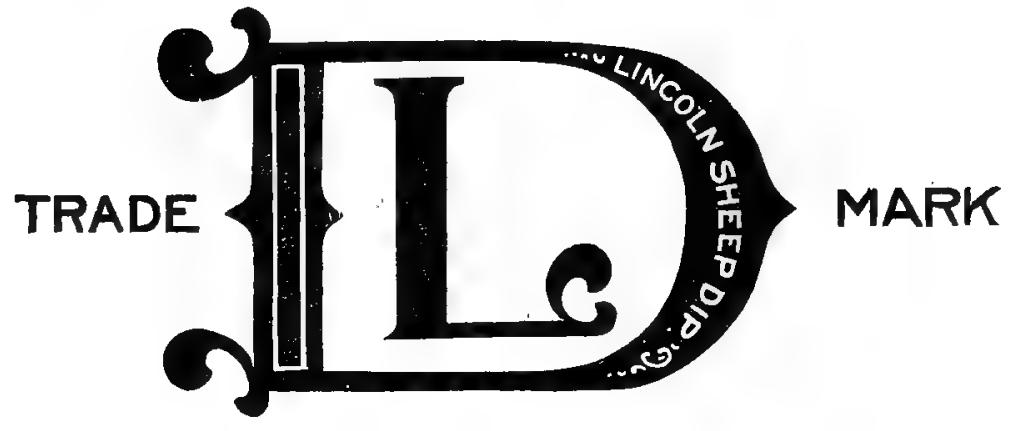

Contains :

Nicotine, Sulphur, Ċresylic Acid, Creasote.

Its Qualities :

Efficiency, Strength, Simplicity, Perfection.

COMPLIES WITH

THE GOVERNMENT REQUIREMENTS.

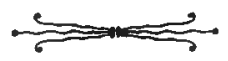

... MANUFACTURED EY ...

\section{TheLineoln She€p Dip Co.}

General Office, 855 Ellicott Square Bullding,

BUFFALO, N. Y. 

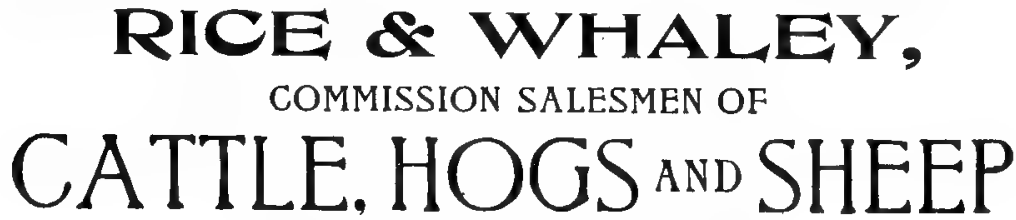

Office, Room 10, Live Stock Exchange Building,

EAST BUFFALO, N. Y.

Communications by nail or telegraph promptly attended to. Ship Stock in your own name to our care, References: Buffalo Commercial Bank, Citizen's Bank, Buffalo

\section{Kill the Cicks, Lice, Scab, Foot=Rot, Paper Skin}

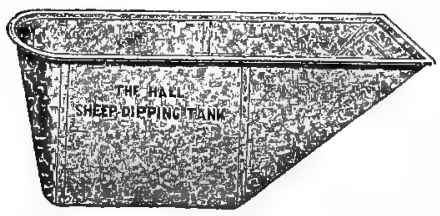

and all forms of Foot and Skin Diseases by Dipping your Sheep.

\section{HALL'S NEW DIPPING TANK}

Is the best and most convenient means of dipping sheep. Made of best galvanized steel. Can't leak, rust or rot. Holds 200 gallons of dip. Special inducements to prompt buyers. Circulars and prices free on application.

HALL STEEL TANK Co., 72 N. Ashland Ave., Chicago, III.

\section{CHEAP GRAZING LANDS!}

You can get rolling lands, with rich sandy loam soil and a clay subsoil well drained, pure living water, within two to fourmiles from the

"SOO" RAILWAY IN CHIPPAWA COUNTY, WISCONSIN,

For Only \$3.00 to $\$ 5.00$ per Acre.

This is a natural grass region. Clover, timotby and blue grass grow naturally, and cannot be excelled in quality or quantity by any region. These lands will produce as large crops of grain and vegetables as any lands in Iowa or Illinois, and are bound to enhance iu value rapidly. All the natural advantages for successful sheep-raising and dairying obtain here. A healthful climate, pure water, good drainage, rich soli, a natural grass and clover region, and nearness to nurkets. Send for a descriptive map to

D. W. Casseday, Land Agent, "Soo" Ry., Minneapolis, Minn.

\section{"AN IDEAL DIP."}

\section{OANOLINE SHEEP DIP.}

It is absolutely Non-Poisonods and Is PERFECTLY SAFE to use upon all animals. It will not stain or injure the wool or bair in ANY WAY. .

For Scab, 'Jicks, Lice, Fleas, Foot-rot, Flies, Tape-worm, and Grub in the Head it has no equa1. It never fails in any case where used as directerl, and may be used in winter or summer, hrord or soft, hot or cold water. The important falty matter it contains feeds the wool, and is so blended in the Dip that it is readily absorbed.

SA MPLF gallon sent, express paid, on receipt of $\$ 1.50$. On1y one gallon to each person. Agents wanted.

Manufactured only by THE CANNON MFG. CO., St. Louis, Mo., U. s. A. 

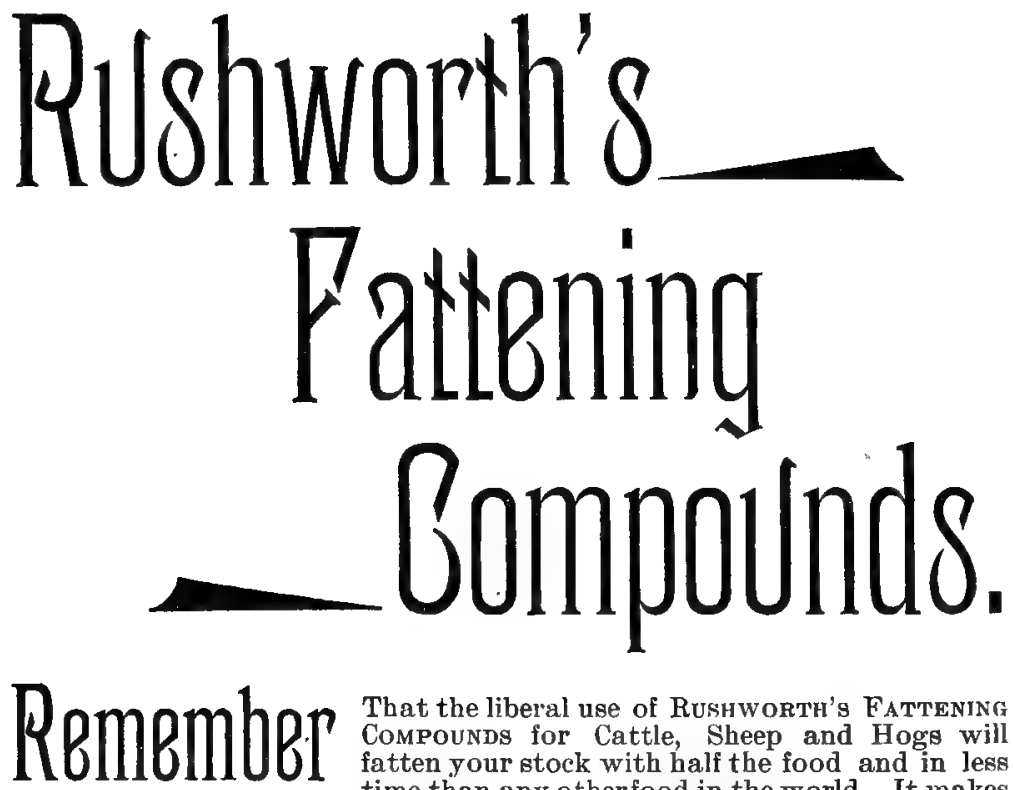

That the liberal use of Rushworth's Fattening Compounds for Cattle, Sheep and Hogs will fatten your stock with half the food and in less time than any other food in the world. It makes rich red blood, and puts all organs in perfect working order. It assists in removing all poisonous elements from the system. Aids digestion, and hastens the expulsion of worms so commonly found infesting live stock.

\section{Prom the First Months Use}

A great improvement will be apparent to the stock feeder. To prevent sickness they excell all other so-called foods. Not containing poisonous ingredients, their benefits are not trans= itory but lasting. GUARD AGAINST SUBSTITUTES.

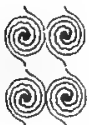

Caktle will Thriue on Less Pood, Make more Flesh, Cows Produce more Milk on a Diet in which these Foods are Used.

Unlike the majority of these preparations, no expense is spared in their manufacture. Demand from your dealer RUshworth's FATTENING CoMPounDs. So guard against loss and dissatisfaction.

Address for Full Particulars,

\section{The Union Stock Food Company,}

857 Ellicott Square, BUFFALO, N. Y. 
ESTABLISHED 1865.

\section{SWOPE, HUGHES, WALTZ \& BENSTEAD, Commission Salesmen, Cattle, Fogs and Sheep.}

ROOM 4, LIVE STOCK EXCHANGE, EAST BUfFALO, N. Y.

Also FARMERS' AND DROVERS' STOCK YARDS, CLEVELAND, 0.

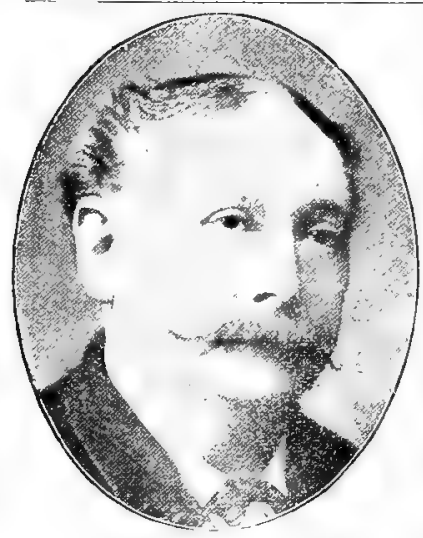

M. I. CRANDALL.

o. צ. PIRDY.

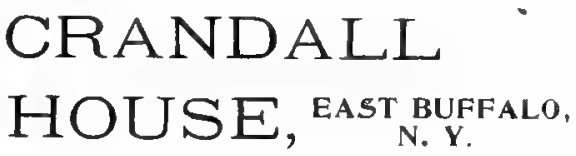

This widely-known and populat hotel is cen. trally and most cunveniently located for reaching all parts of the city. Is adjacent to the Lire Stock and Hotse Stock Yards.

Has been recently refitted and refurnisbed throughout and is second to no hotel in the city. for thoroughis heated and comfortabie ruoms, th. courteous attention paid to guests, and

SUPERIOR TABLE SERVICE.

RATES, \$1.5O PER DAY.
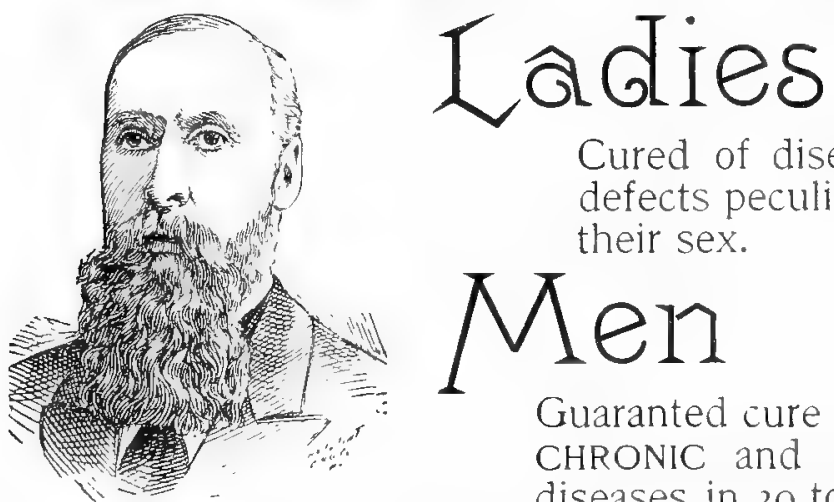

Cured of diseases and defects peculiar to their sex.

Men

Guaranted cure for

CHRONIC and BLOOL

diseases in 30 to go days.

CALL OR WRITE FOR SYMPTOM BLANK.

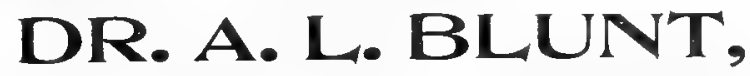

356 STATE STREET,

CHICAGO, ILL. 


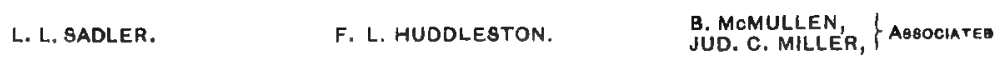

\section{SAdler, Huddleston \& Co.,}

Successors to J, F. SADLER \& CO.

\section{Commission Merchants \\ FOR THE \\ SALE OF \\ Cattle, Fogs and Sheep.}

NEW YORK CENTRAL STOCK YARDS.

RoOM 2, EXंchange BuILDING.

EAST BufFalo, N. Y.

Each Department in Charge of First=class Salesmen.

All correspondence promptly answered, and market reports furnished on application. Our motto, "Strong Market Price and Prompt Returns." References-

Peoples Bank of Buffalo, Bradstreet's or Dunn's Commercial Agencies.

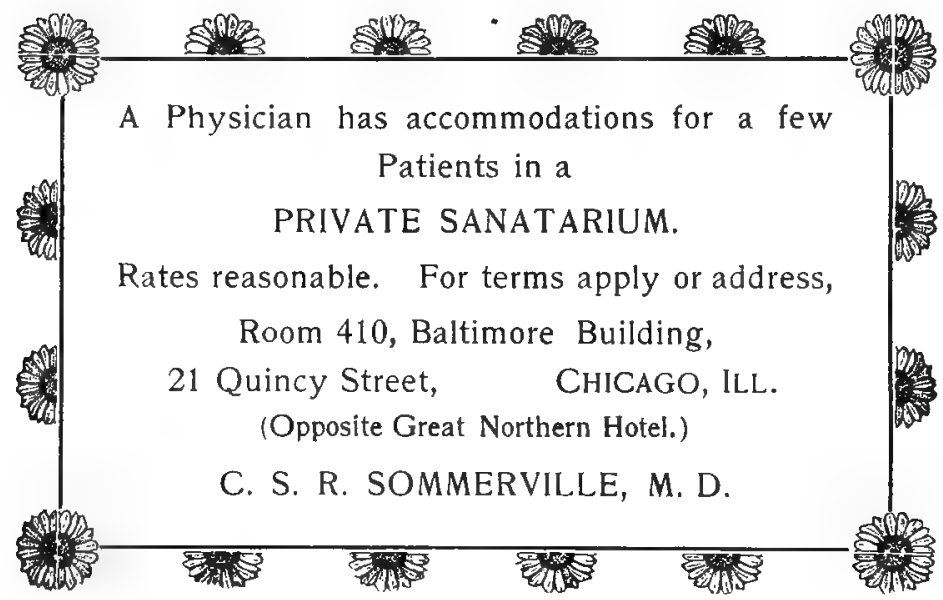




\title{
"Black Leaf" Sheep Dip.
}

CURES SCAB, KILLS TICKS, IMPROVES WOOL.

\section{PRICF. 5 Gallon Cans, $\$ 0.85$ per Gallon. \\ Gallon Cans, $\$ 1.00$ per Gallon.}

FF. O. B. Louisville, or any R. R. point in the U. S. East of Missouri River.)

If there is no Agent in your town, order direct from the factory.

\section{LOUISVILLE SPIRIT-CURED TOBACCO CO., LOUISVILLE, KY.}

E. S. NUTE, Hog Dept.

JNo. E. PELlien, Asst.

J. I. BEMENT, Sheep Dept.

C. E. FISHER, Asst.

L. E. LIN Coun, Cattle Dept.

A. S. BLUE, Cow Dept.

Nute, Bement \& Lincoln

Commission Merchants

For the Sale of

Cattle, Hogs and Sheep

New York Central Stock Yards,

East Buffalo, N. Y

OFFICE, ROOM 3 ,

LIVR STOCK EICHANGE BLDG.

Ship Stock in your own name to

onrcare. Reference, Citizens'

Bank of Buffalo.

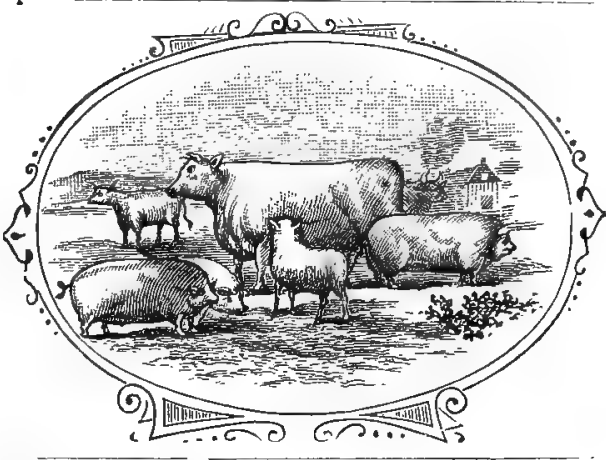

A. H. FOSTER,

BREEDER OF

ALLEGAN, MICH.,

\section{Shropshire Sheep

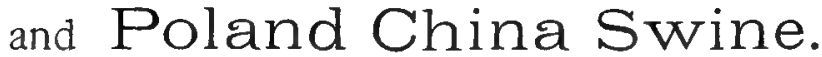

Grower of Pedigree Farm Seeds of all Kinds.

Correspondence Solicited and Enquiries Promptly Answered.

\section{LANGDON \& GEFFS,}

\section{$\mathrm{C}^{\substack{\text { ommission } \\ \text { Dealers in }}}$ Sheep, Hogs and Cattle.}

\author{
RoOM 17 Exchange BLDG., EAST BUfFALO, N. Y.
}

Sheep Department-FOSTER GEFFS, Salesman; W. C. HEINOLD, Assistant.

Hog Department-GEORGE W LANGDON, Salesman; FR ANK SEIBERT, Assistant. Cattle Department-ALBERT SEAMAN and J. B. GIBSON, Salesmen.

Office-0. D. WALKER.

Liberal advances made on shipment of live stock. Market quotations freely fur nished, and correspondence solicited. Prompt and personal attention given to all con. signments.

Referetuces-Citizens Bank of Buffalo; National City Bauk, New York; Bradsteet's or Dunn's Commercial Agencies. 

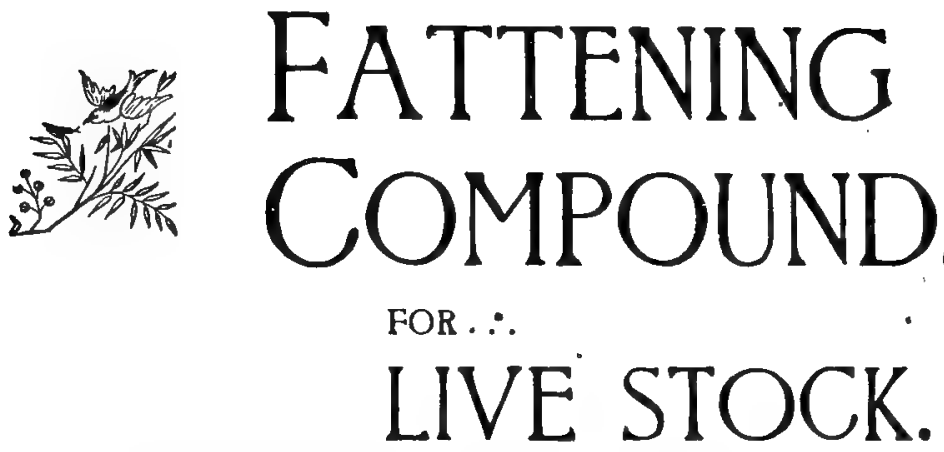

$\boldsymbol{L} \mathrm{LL}$ intelligent stock men realize that to obtain success in feeding live stock for the market everything depends on the rapidity with which the animals are fattened. The sooner they are ready for the market, the greater the profit for the feeder. This being a fact requiring no demonstration, it behooves the stock feeder to use every means in his power to accomplish the desired result. Conjoined with regularity in feeding, supplying the best of grains and purest water, other requisites are necessary, such as a concentrated stimulating tonic food, and

\section{THE QUESTION IS WHERE CAN THIS BE OBTAINED?} THE ANSWER TO THE QUESTION IS SIMPLE

uSE RUSHWORTH'S

\section{FATTENING COMPOUNDS.}

FOR CATTLE.

FOR SHEEP.

FOR HOGS.

These valuable preparations, used in accordance with the printed direcons will fatten your stock in half the time necessary to fatten by ordinary methods of feeding.

One Thorough Trial of these Goods will Convince You of the Truth of the Above Statement.

\section{Write for particularg and pamphlets to
The Union Stock Fod}

AGENTS WANTED IN EVERY TOWNSHIP. 


\section{DOTY \& WATKINS,}

\section{F. WATKIN, DODE MEEKS, \} Proprietors. \\ Live Stock Commission Salesmen,}

\section{Live Stock Exchange,}

\section{East Buffalo, N. Y.}

We do a strictly commission business for the handling of Cattle, Hogs and Sheep and have practical, sober, experienced salesmen in each department, aud guarantee all sales at full market price.

We respectfully solicit your consignnents, and are fully prepared in every way to handle your business satisfactorily.

DOTY \& WATKINS.

MARKET QUOTATIONS furnished promptly on application by Mail or Wire.

BILL ALL STOCK in your own name to care of DOTY \& WATKINS.

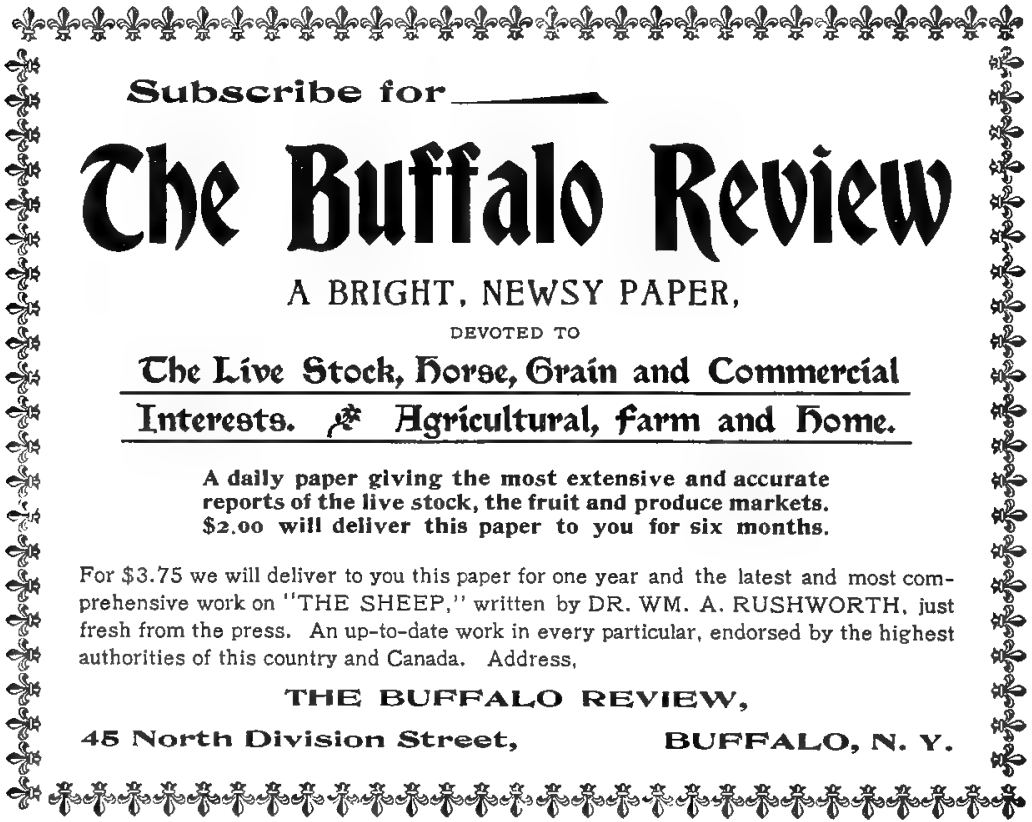



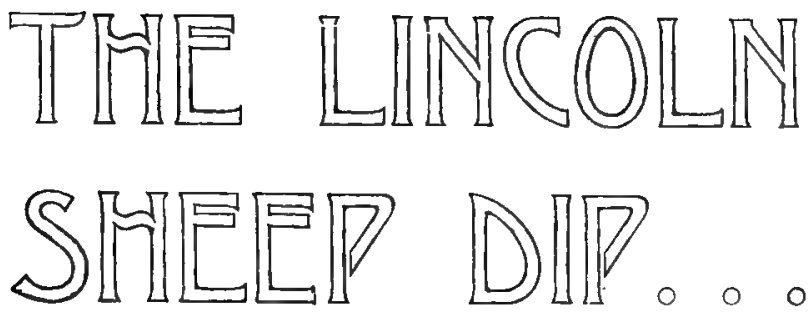

周 RRERARION

NONAPOISONOUS.

ABSOLNTERY RRLARLE。

EAST TO MANDLE, PROROTING TIRE GRONTH OFTHE

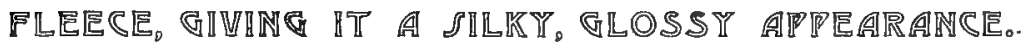

$$
\text { ()(ด) }
$$

WIIT IT Kills ticks, maggots, lice. Destroys the scab 败吹L DO。 mite, curing the disease without in any manner affecting the health of the sheep. Farmers cannot afford to be without a supply, as it cleanses the skin of all animals to which it is applied, destroying cattle lice, hog lice, chicken lice, and all similar parasites of the skin.

\section{THIS PREPARATION HAS BEEN THOROUGHLY TRIED AND FOUND EFFICIENT IN ALL SECTIONS OF THE COUNTRY.}

Send for testimonials and literature. Agents wanted in every township. Liberal inducements given. Write for terms and particulars. Sold in 1,2,5 and 10 gallon cans; also in barreis and half barrels. Cost per single gallon, $\$ 1.50$.

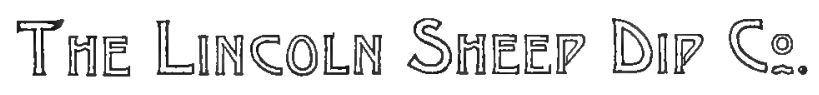

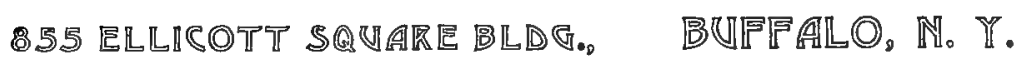
Michigan Agent, A. W. MASON, CONCORD, MICH. 


\section{Ceotimonials for Lineoln Sheep Dip.}

DR. W. B. WASHBURN, Veterinary Surgeon and Dentist, TIFEIN, O., Marsh 23d, 1899.

Lincoln Sheep Dip Co, Buffalo, N. Y.

Dear Sir:-Sometime ago I received a sample of your Disinfectant Fluid and Lincoln Sheep Dip, the results of the use of which I have been observing very carefully.

The bunch of scabby lambs I wrote you sometime ago about came out 0 . K. The farmer said he never saw Dip do the work so nicely, and he had used most all kinds. He said all the other Dips he had used usually put a few sheep off their feed for a day or two, but in the case of this bunch a few were affected so bad that they were off their feed before dipping, but that right after dipping they all ate their supper and continued to feed well from then on.

He thinks there is nothing like it. I have been using the Dip and Disinfectant on various cases of skin disorder and find that it is all that is claimed for it.

Yours truly, W. B. WASHBURN.

MONROE, UTAH, May 7th, 1899.

Lincoln Sheep Dip Co., Buffalo, N. Y.

Received the ten-gallon can of Dip, gave it to the sheep men in gallon and one-half gallon lots with good results.

Yours truly,

AMMON HUNT.

MECHANICSBURG, O., Dec. 12th, 1898.

Iincoln Sheep Dip Co., Buffalo, N. Y.

Please find enclosed check for $\$ 4.75$. I have given your Dip a test trial side of the Black Leaf Dip which I have used and sold for about ten years. I am so far well satisfied with the results.

Yours respectfully,

E. R. BOULTON.

GRASS LAKE, MICH., Jan. 3d, 1899.

Lincoln Sheep Dip Co., Buffalo, N. Y.

Enclosed find Postoffice Order for $\$ 4.50$; have been waiting for results; it does the business and is $0 . \mathrm{K}$. Respectfully yours,

G. C. McGEE.

To Whom It May Concern:

BUFFALO, N. Y., July 30th, 1899.

I have used the Lincoln Sheep Dip, and take pleasure in testifying as to its merits; it has given me every satisfaction, and is as efficient a preparation for curing the scab as I have ever come across.

Signed, JOHN BENSTEAD.

BUFFALO, N. Y., July 25th, 1898.

Lincoln Sheep Dip Co., Buffalo, N. Y.

Geritlemen:-I bought of J. W. Baley of your Company one gallon of the Lincoln Dip to use on a bunch of calves which were covered with lice to such an extent that they were poor in flesh. I used it at the strength of 1 to 100; it did excellent work, killing all the lice. The calves are now healthy and in good condition.

J. SEEGER. 
Live Stock Exchange Bldg., E. BUFFALO, N. Y., July 6th, 1898.

To Whom It May Concern:

I can recommend the Lincoln Sheep Dip as the best preparation for the purpose of curing the scab that I have ever come across. I saw it tried on a bunch of scabby sheep, and watched the effect. After having been dipped twice they were entirely cured, and the fleece was left in a perfect condition; it seems to do better work than the Black Diamond Dip that I used last year.

CHAS. C. EIRICK,

Sheep Salesman for Eirick Bros.

Live Stock Exchange Bldg., E. BUFFALO, N. Y., July 9th, 1898. To Whom It May Concern:

In the latter part of May, this year, there was consigned to the firm of Doty \& Watkins, 150 head of sheep coming from Ohio, part of which were very badly affected with scab. Thirty head were condemned by the Government Inspectors, twenty of which were bought by Mr. Baley of the Lincoln Sheep Dip Company, and placed in quarantine for treatment with that Company's preparation known as the Lincoln Sheep Dip.

These sheep were very badly affected with the disease; they were dipped twice, an interval of ten days between the dipping, and were entirely cured, so that they were permitted to go on the market for sale.

I understand from the parties in charge of the sheep, that they fed them all the corn they could eat, and kept them close penned to make the disease all the harder to cure, to give the dip a thorough test.

The twenty head when sold to Mr. Baley weighed 1,500 pounds, and when sold by him four weeks later, they weighed 1,551 pounds, a gain of two and one-half pounds apiece, which, when it is taken into consideration that they were twice dipped, is a remarkable gain. It gives me pleasure to endorse this preparation.

DOTY \& WATKINS,

Per W. F. Howard.

Live Stock Exchange Bldg., E. BUFFALO, N. Y., July 2d, 1898. Lincoln Sheep Dip Co., Buffalo, N. Y.

Gentlemen:-I saw the sheep which were bought by $\mathbf{M r}$. Baley of your Company some weeks ago, and your preparation did excellent work; all the sheep were entirely cured, and the fleece was left in perfect condition.

Having seen the sheep prior to their being dipped, and observing their very scabby condition, I will say that your preparation did better work than any sheep dip I have seen used. I can cheerfully recommend it to anyone who wants a sheep dip.

Yours very truly,

BERNARD McMULLEN, Sheep Salesman for Sadler \& Co.

To whom it may concern:-

I have used the Lincoln Sheep Dip and it has afforded me perfect satisfaction. It does the work and leaves the fleece in a nice white, silky condition. I take pleasure in recommending it to all sheep feeders and breediers.

(Signed)

A. J. ABBOTT, Perry, N. $\mathbf{Y}$. 


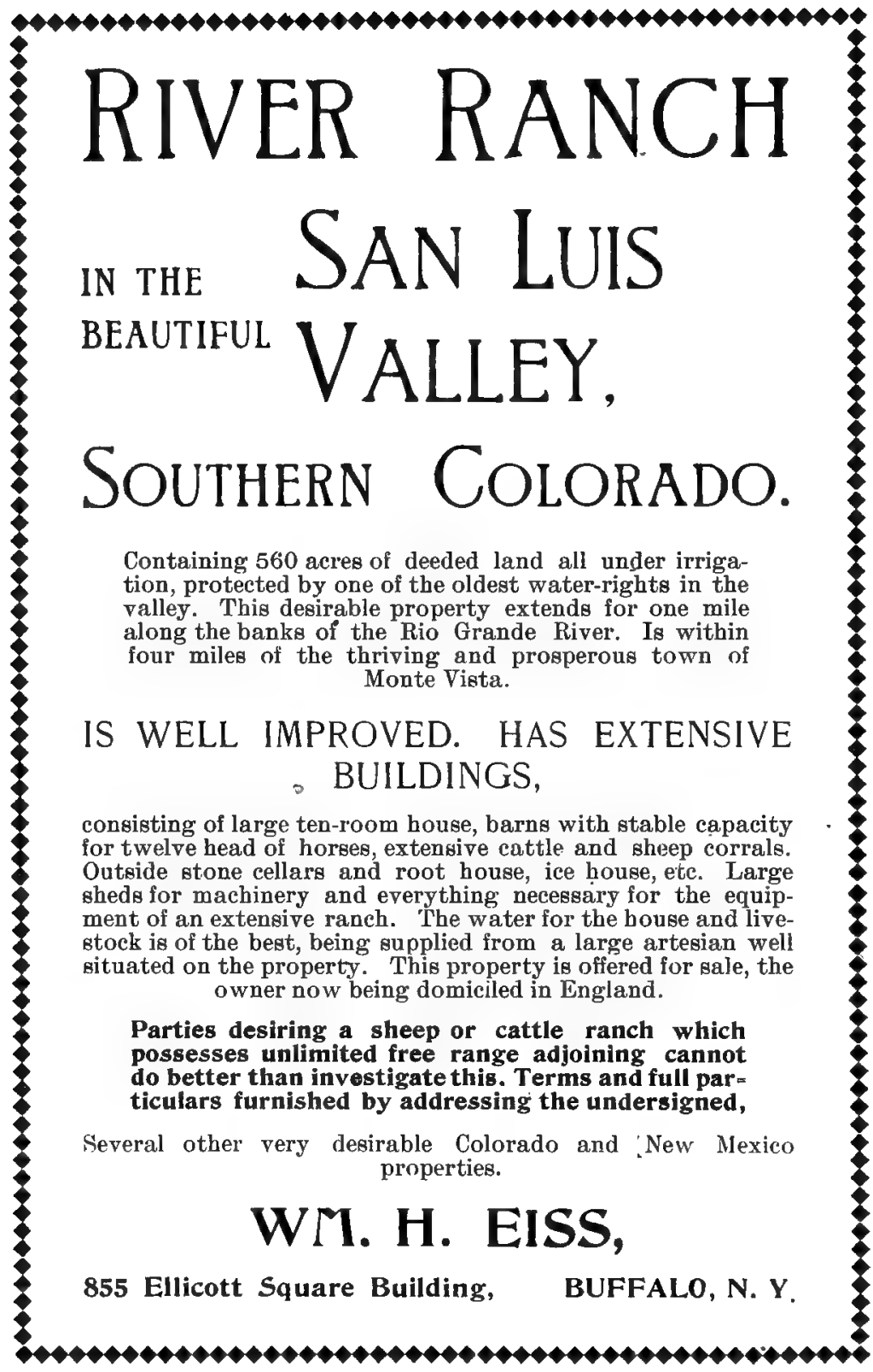









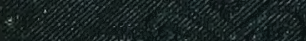

2007 .

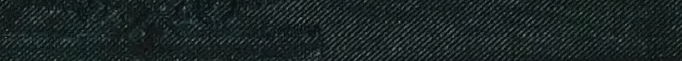

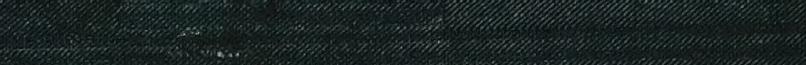

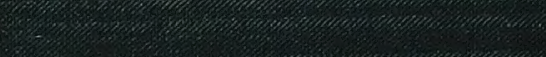

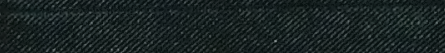

